\title{
UC-NRLF
}

IIIIIIIIII

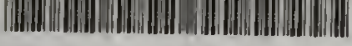

C $\begin{array}{lll}3 & 037 & 418\end{array}$

\section{THE REGIONS OF THE}

HUMAN BODY

OSTEOLOGY

ARTHROLOGY

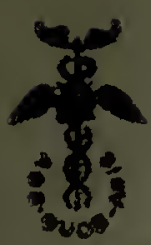




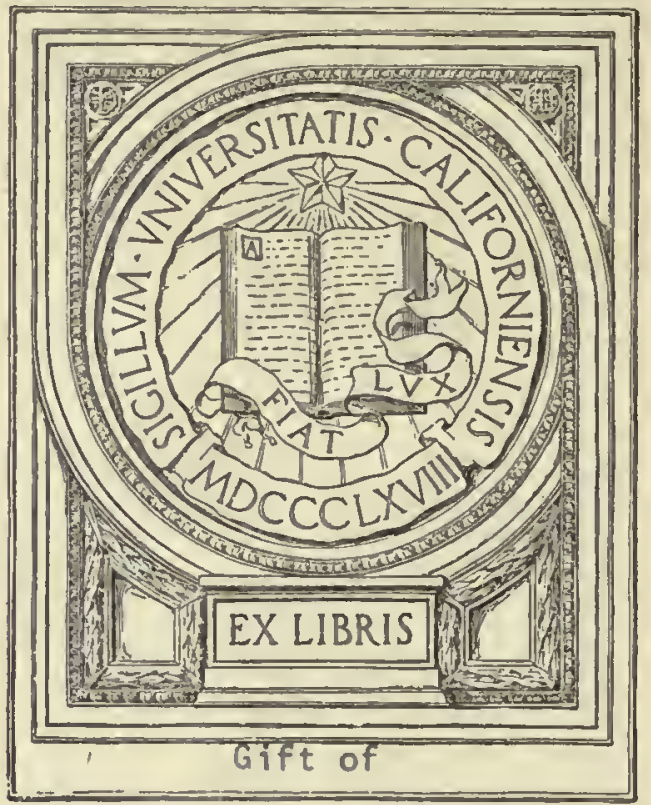

St. Francis Hospital Medical Library La Crosse. Wisc. 
DRS CAITLISL WUNDE AEN \& SIIIDDAL.

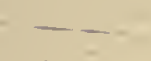


Digitized by the Internet Archive in 2007 with funding from Microsoft Corporation 


\section{A N A T L A S}

A

\section{HUMAN ANATOMY}

FOR STUDENTS AND PHYSICIANS

BY

\section{CARL TOLDT, M.D.}

ASSISTED BY

PROFESSOR ALOIS DALLA ROSA, M.D.

Adapted to Englisb ano American anto Futernational Terminology

BY

M. EDEN PAUL, M.D. BRUX., M.R.C.S., L.R.C.P.

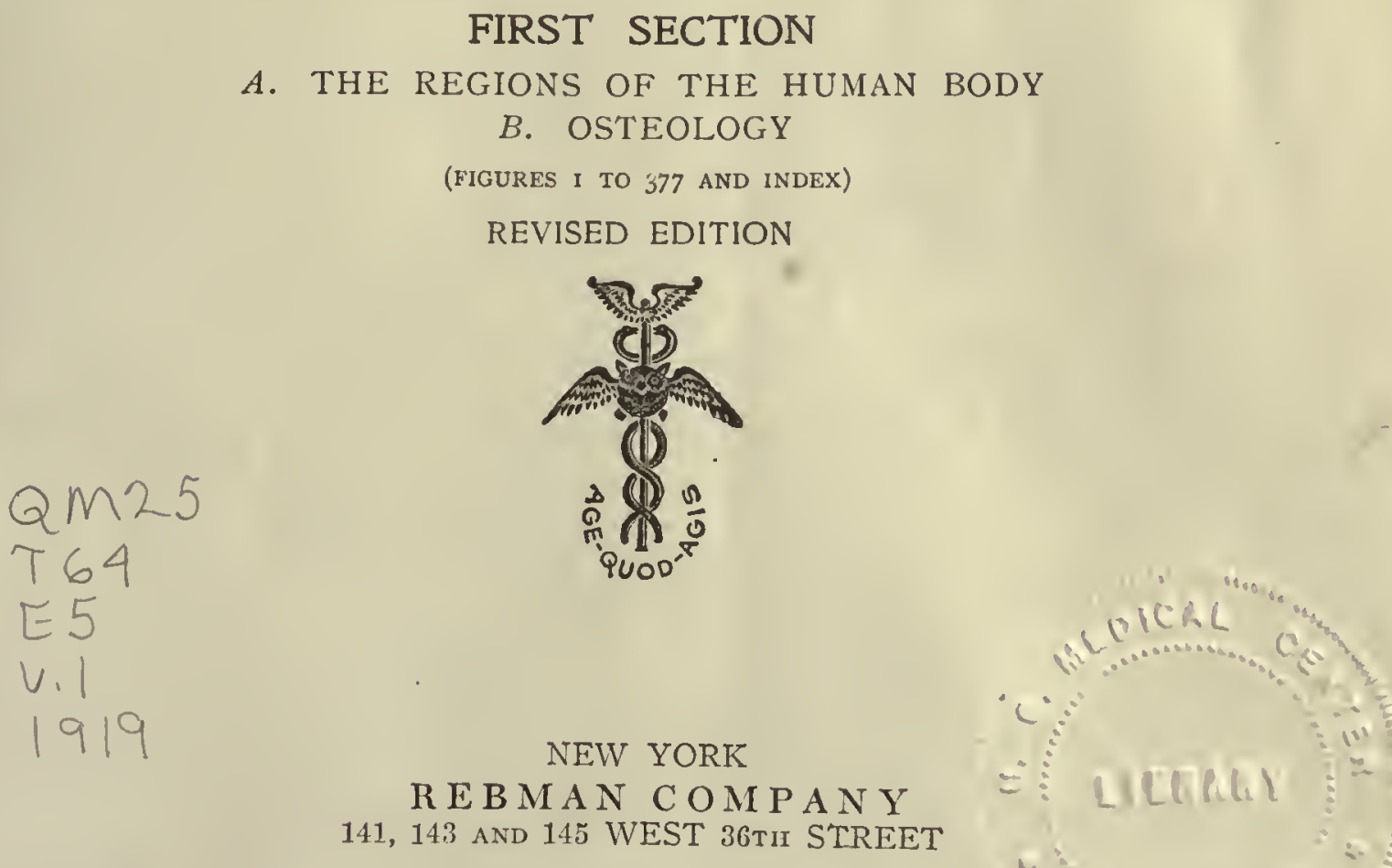


Copyright, 1919, by REBMAN COMPANY

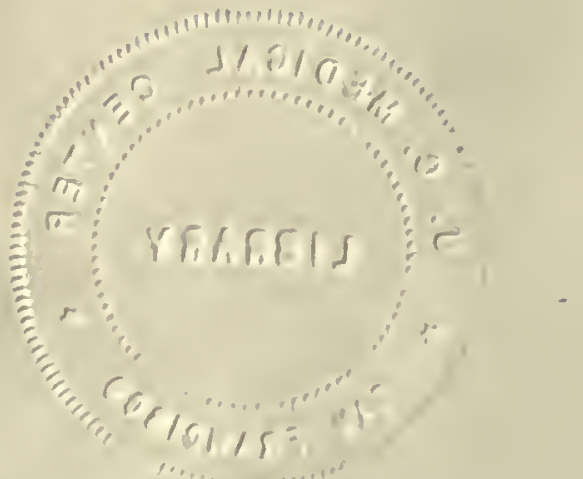




\section{TRANSLATOR'S PREFACE}

THE science of human anatomy is purely descriptive in its methods, the field it covers is not very extensive, and its boundaries are sharply limited; it is, therefore, one of the few sciences in which something closely verging on finality and completeness has been attained. Even, however, if no new anatomical data are likely to be forthcoming, there is yet scope for originality in the method of presentation of those data of which the science now consists; and originality of this kind Professor Toldt's "Atlas of Human Anatomy" exhibits in a high degree. In the many admirable manuals of human anatomy now extant in English, the illustrations, even when numerous, as they are often, and when good, as they are occasionally, form a mere supplement-usually a very imperfect supplement-to the text. Atlases of anatomy, and useful atlases, also exist in English, but all are quite fragmentary. Some, like the well-known and valuable, but somewhat antiquated, "lllustrations of Dissections," consist of a series of pictures of selected regions carefully prepared on the cadaver: these are models for the imitation of the student in his own dissecting work, but are not of much value for private study. Others, like Bellamy's English edition of Braune's atlas of frozen sections of the human body, present a small number of anatomical facts from a striking and unfamiliar point of view. But among English works, an accurate pictorial representation of all the data of human anatomy, carefully drawn to scale from actual specimens, and arranged suitably for systematic study, has hitherto been lacking.

Whilst a true knowledge of anatomy, a knowledge that will through life supply the needs of the physician and the s'rrgeon in their practical work, can be obtained only in the dissecting-room, the student's labours with scalpel and forceps must be preceded and supplemented by systematic private study. Now, for this purpose, the textual descriptive treatise is rict alone sufficient; or, if sufficient, it is so at an excessive expenditure of time and labour. Both in his work preparatory to dissection and in his revision of his anatomical knowledge subsequent to dissection, the energy of the student will be enormously economized if he has at hand a graphic representation of every structure named and described in his systematic treatise. An increased use of the visual or graphic method, both in the acquirement and in the revivification of knowledge, is a feature of the age in all educational departments; but this English translation of Professor Toldt's work is, as far as the English-speaking races are concerned, the first adequate application of the method to the study of human anatomy.

In speaking of the finality and completeness of anatomical science, one exception must be made, and this exception relates to anatomical terminology, which, though nearly completed, has not yet attained finality. Had there been a universal anatomical nomenclature-a nomenclature, that is, adopted by, or even fully intelligible to, anatomists of all nationalities - an English edition of this work would have been superfluous. Anatomy, however, like all other sciences, has suffered from the dispersion of tongues that ensued on the R.enascence, when the good and the evil of mediævalism became inextricably confounded, and were cast away together, and the inestimable gift of a language common to the learned of all lands was lost for ever. The German-speaking peoples have a fairly complete and fairly pure Latin anatomical nomenclature, needing, however, to be eked out here and there by the vernacular; whilst in England, as in France, a strange and bastard dialect, half Latin and half vernacular, has come into use. Uncouth jargon as it is, being current and familiar, it is not likely in England and America ever to be replaced by the more consistent terminology in use in the anatomical schools of Germany and Austria; 1 have, however, in this English edition of the "Atlas of Anatomy" retained the terminology of the original side by side with the English translation, distinguishing between the two by a difference of type.

In some cases, in the nomenclature used by the author, terms are met with which have no counterpart in English anatomical terminology : either because the author regards as normal a structure which English anatomists regard as a variety; or, and far more commonly, because the structure in question, though normal, is unimportant, and English anatomists have therefore neglected to name it. Sometimes, in such cases, 1 have given a literal English translation of the Latin name used by the author; sometimes, however, a periphrasis has been required to explain what the structure is, or to account for the absence of an English name, and this periphrasis, when lengthy, has been printed as a foot-note. In all such cases, an asterisk is prefixed both to the Latin name and to its English equivalent, to indicate to the reader that there is something unusual in the terms employed.

1 must further point out that in a few instances the author's nomenclature actually conflicts with that commonly used in England, so that the literal translation of the author's name for a certain structure is applied in England to a structure totally different. For instance, what the author calls canalis pierygopalatinus is in England called the posterior palatine or palatomaxillary canal, whilc the perygopalatine canal of English anatomists is called by the author canalis pharyngeus. But for this warning, beginners might imagine such divergencies to be due to carelessness on the part of the translator or to errors of the press.

A further difficulty has arisen from the fact that English anatomical nomenclature is itself not yet finally settled, nor even wholly consistent. Not merely is the same structure often known by several names; but, which is worse, the same 


\section{TRANSLATOR'S PREFACE}

name is sometimes applied to two different structures Reform is therefore needed, but it is not the part of a translator to undertake it, and 1 have perforce been content to follow the authorities. Wy teading autnorty has been the tenth edition of Quain's "Eiements of Anatomy," but I have also had Macalister"s "Text-bonk ot Human Anatomy" in constant requisition. From these works I have, when more than one name is used to denote any structure, taken all those in common use, the order in which the alternative names have been printed showing most often the relative frequency of employment; in a few cases, however, where a name less commonly used has appeared to me distinctly preferable for any reason to an alternative name more commonly used, $I$ t tve given the less usual but preferable name the precedence. To this small extent only have I been influenced by my own views in the matter of anatomical terminology; and, with the exception of those names which for the reason already furnished are preceded by an asterisk, all the terms in the English nomenclature are in use by one or more of the leading English authorities.

As regards the terminology employed in the United States of America, the contributions of the scientific investigators of that country to anatomy have, owing to tue early perfection of this branch of study, becn far less extensive than in the case of the other sciences ancillary to medicine; and the science of anatomy was for the most part taken bodily over, text-books, terminology, and all complete. A few differences, however, exist, and 1 have therefore collated nuy manuscript with that useful little work, Young's "Synopsis of Human Anatomy," and any divergent terms in use in America only have been inserted in my translation, and distinguished by the addition of the letters "U.S."

A considerable number of the references to the figures will be found to be in the English nomenclature only. These are either cases in which the English and the International descriptive terms were identical, and the printing of both was therefore superfluous; or else cases in which in the original the reference was wholly in German.

Measurements given in the original in centimetres have in all cases been reduced to inches. In illustrations of fotal parts the age of the fotus is given in months from the date of fertilization of the ovum. On the Continent, however, the period of utero-gestation is usually reckoned as ten "months" of four weeks each; not, as with us, as nine calendar months. To avoid mistake, I have in all such cases ofter the word "month" or "months" added in parentheses the words "months of four weeks each."

I cannot dismiss mention of the works of reference I have employed without alluding to the German-English "Dictionary of Medical Terms," by Treves and Lang-a book invaluable to all those engaged in the translation of German medical works.

Since this Atlas is intended for the use of beginners, as well as for that of advanced students of human anatomy and of practitioners of medicine, I may fitly conclude this preface witl a few words on the general principles of anatomical nomenclature. For descriptive purposes the body is regarded as being in the upright posture, with the arms extended by the sides, and the hands fully supinated, so that the palms look forward. With this attitude kept in mind, the meaning of the erms superior and inferior, anterior and posterior, external and internal, is obvious. Sometimes, however, descriptive terms of another kind are used, to remove the confusion liable to arise from the adoption by man of an attitude different from that of all the other vertebrata, and to homolog ze the nomenclature of human with that of comparative anatomy. Thus, cephalic and caudal in comparative anatomy correspond respectively with superior and inferior in human anatomy; ventral and dorsal, with anierior and posterior. Dividing the body into right and left halves by a vertical median plane, which cuts the surface of the body at the median line, medial or mesial and lateral correspond respectively with internal and external in denoting position respectively nearer to, or more remote from, the median pla e. Other terms in frequent use are superficial and deep, central and peripheral, proximal and distul; these are self-explanatory.

In some cases descriptive terms applied to portions of certain structures denote the relation of these portions to other structures, as when we speak of the vertebral and the sternal extremities of the ribs, or the acromial and the sternal extremities of the clavicle. Terms of similar import are radial and ulnar applied to structures of the forearm; tibial and fibular (or peroneal) of the leg; palmar and dorsal of the hand; plantar and dorsal of the foot; fexor and extensor of any of the extr.mities. It is in be noted that internal and external are sometimes used in a sense different from that previously explained, being employed to denote the interior and exterior positions respectively; cither in relation to the general axis of the body or to the axis of one of its cavities. In this sense, for instance, we may speak of the intemal and the external tables of the cranial vault, or of the internal and the external oblique muscles of the abdomen; but it is, as a rule, better to use the words inner and outer to denote this relation, and to reserve internul and external for position in $r$ spect to the median plare.

Finally we have to explain the terms used to denote certain directions, more e-pecially the direction of certain secions: these are horizontal and vertical, requiring no definition; sagitlal, denoting a dorso-ventral direction either in or parallel to the median plane; and frontal or coronal: which are synonymous term 3 , denating direction in at transverse vertical plane.

The definition of many of the terms used in descriptive anatomy, such as condyle and tuberosity, process and tubercle, sinus and cavity, ligament, tendon, and aponeurosis, would be superfluous, since the student will best gain an accurate notion of their meaning by an examination of the structures to which they are respectively applied.

H. EDEN PAUL. 


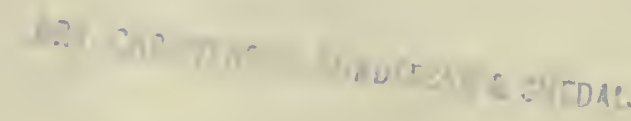

\section{REGIONES \\ CORPORIS HUMANI}

\section{THE REGIONS}

OF THE HUMAN BODY 


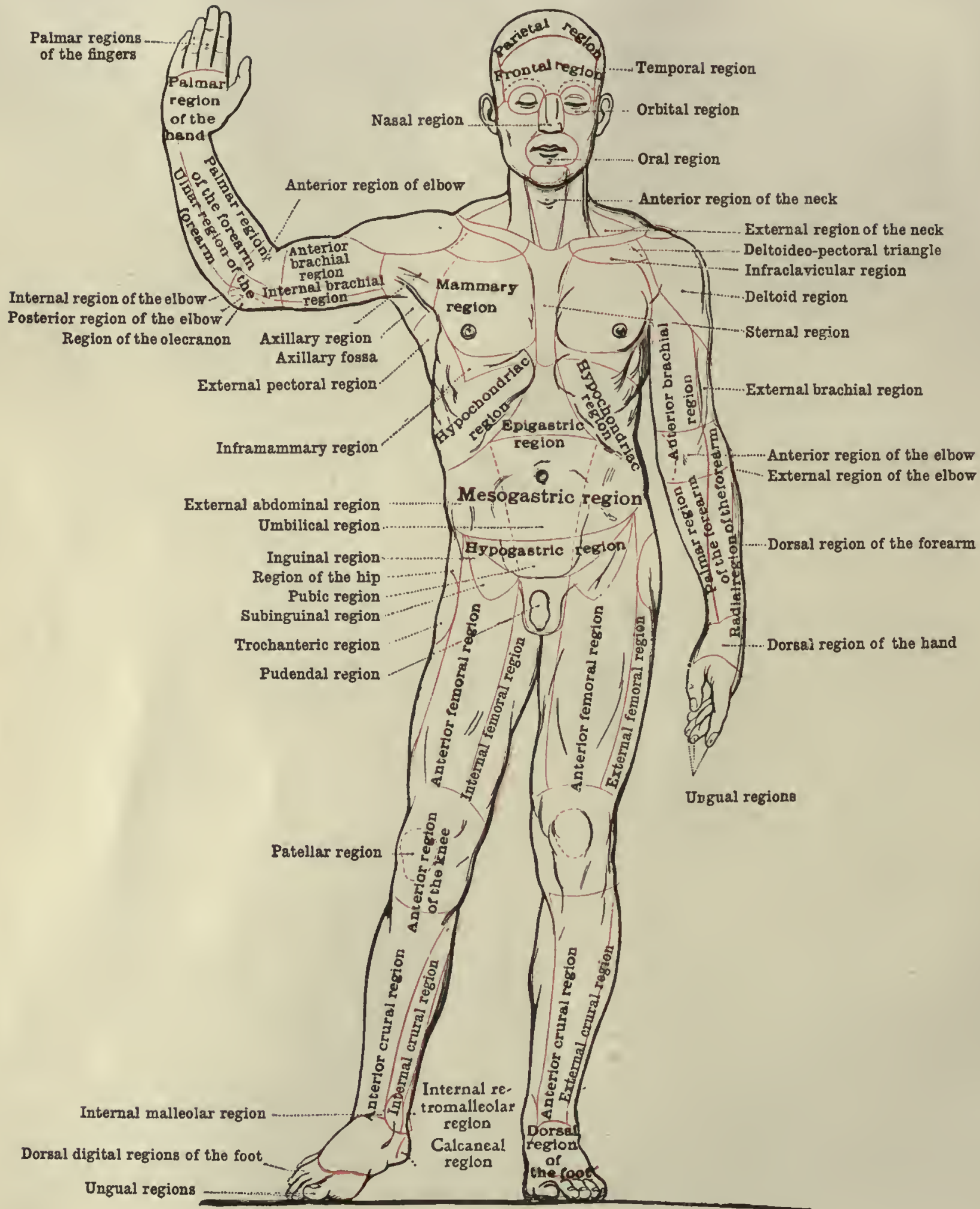

Fig. I.-Anterior Surface of the Body.

Regions of the Human Body. 


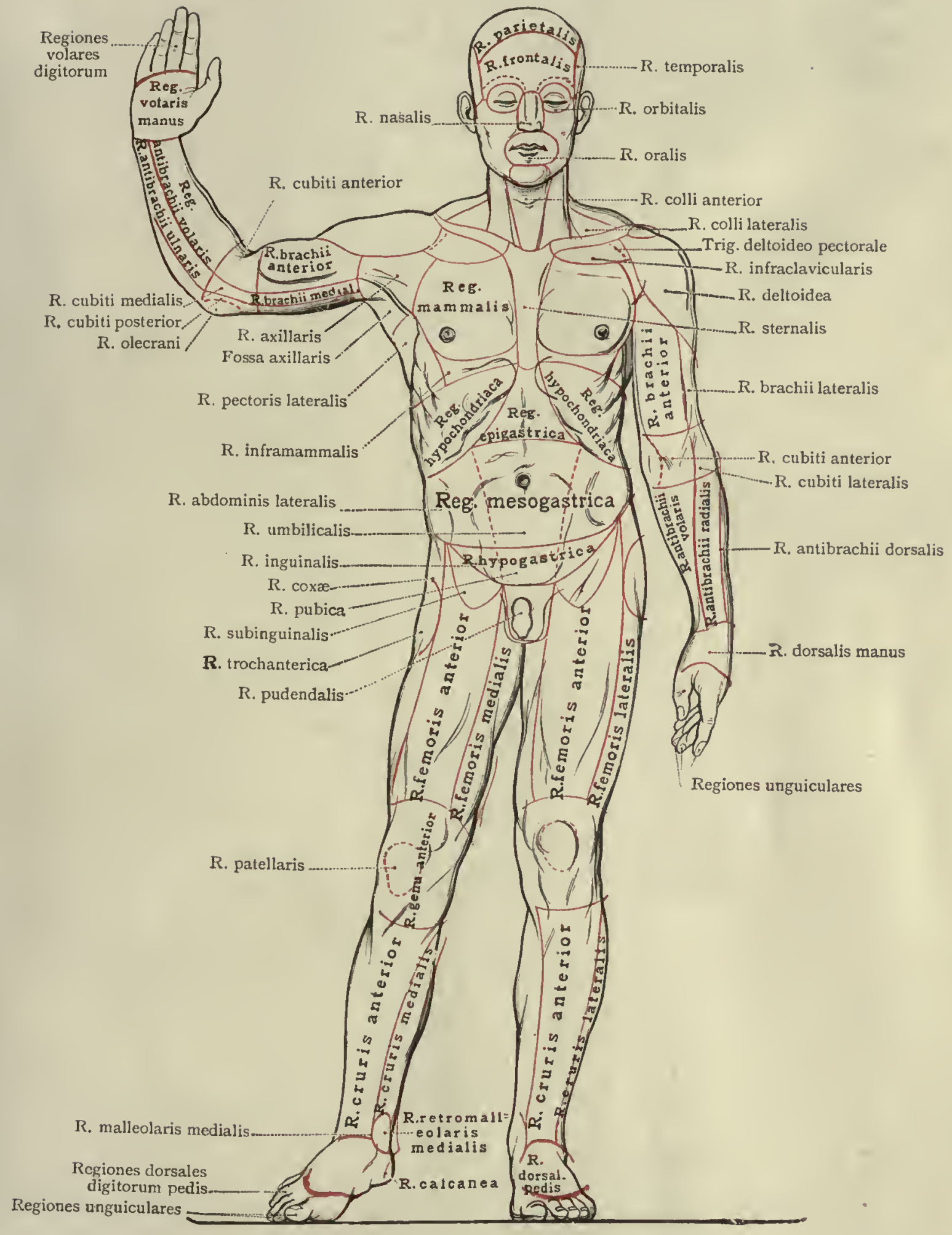

Fig. I $a$.-Anterior Surface of the Body.

\section{Regiones Corporis Humani.}




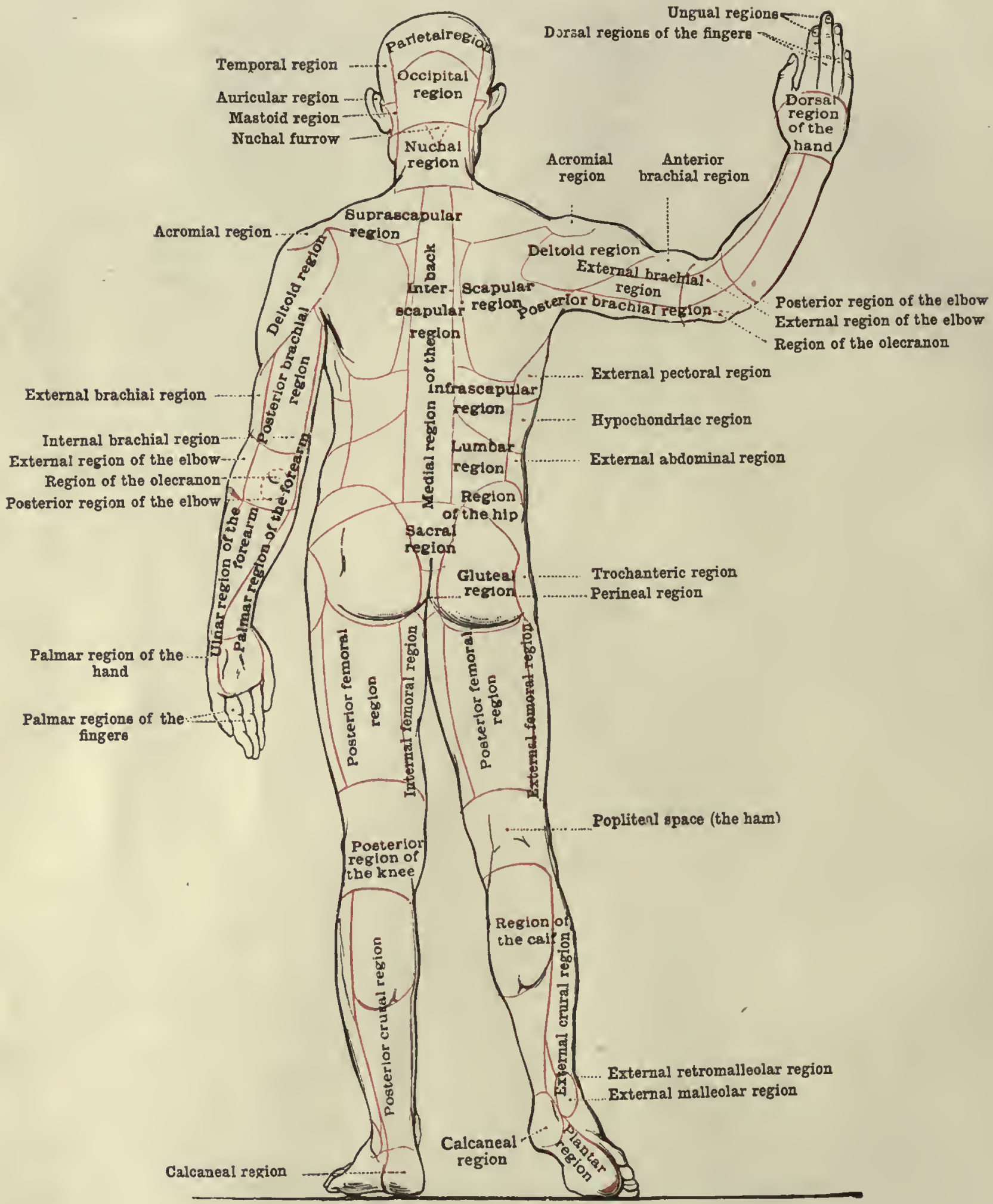

Fig. 2.-Posterior Surface of the Body.

Regions of the Human Body. 


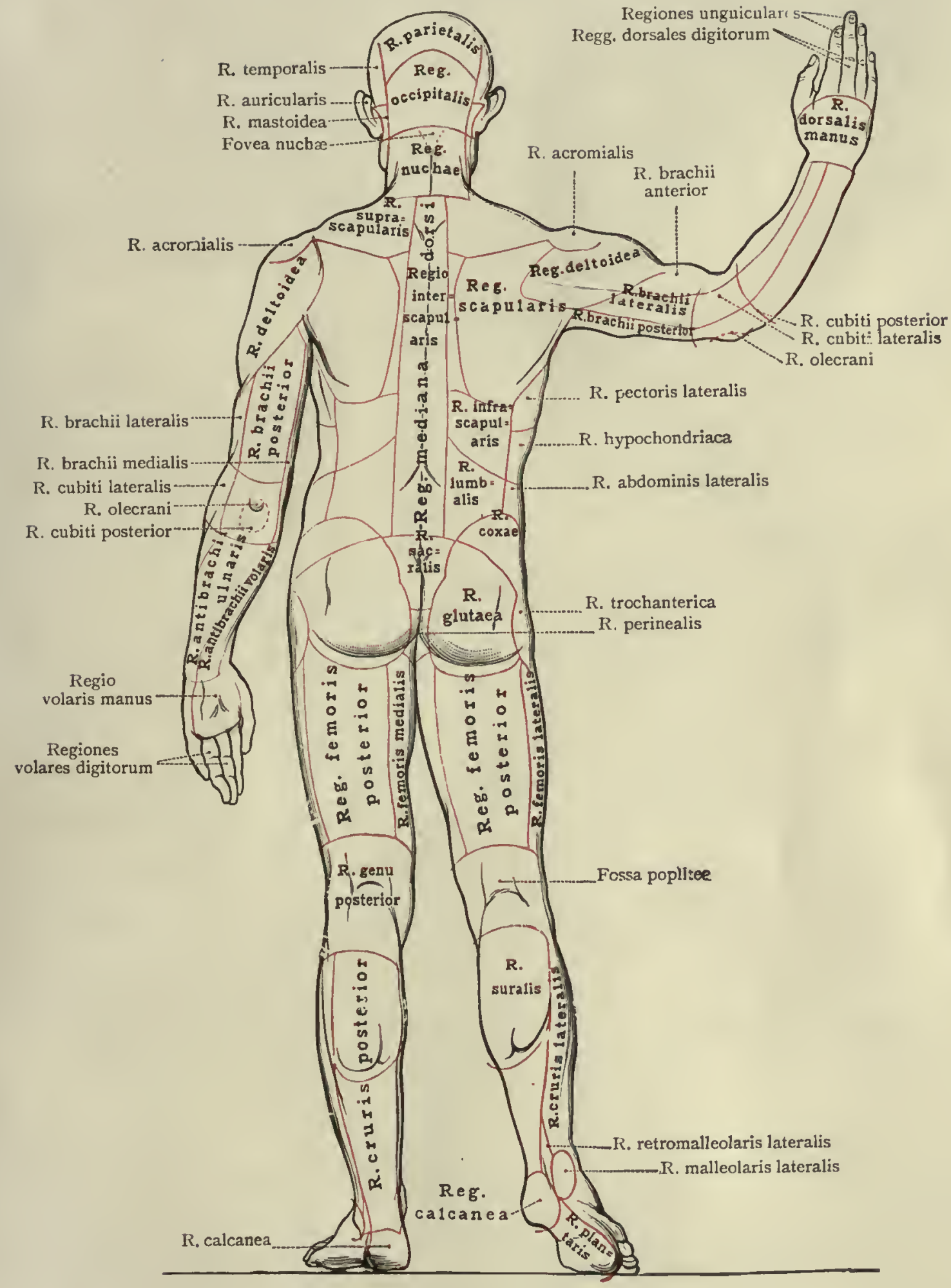

Fig. 2a.-Posterior Surface of the Body.

Regiones Corporis Humani. 


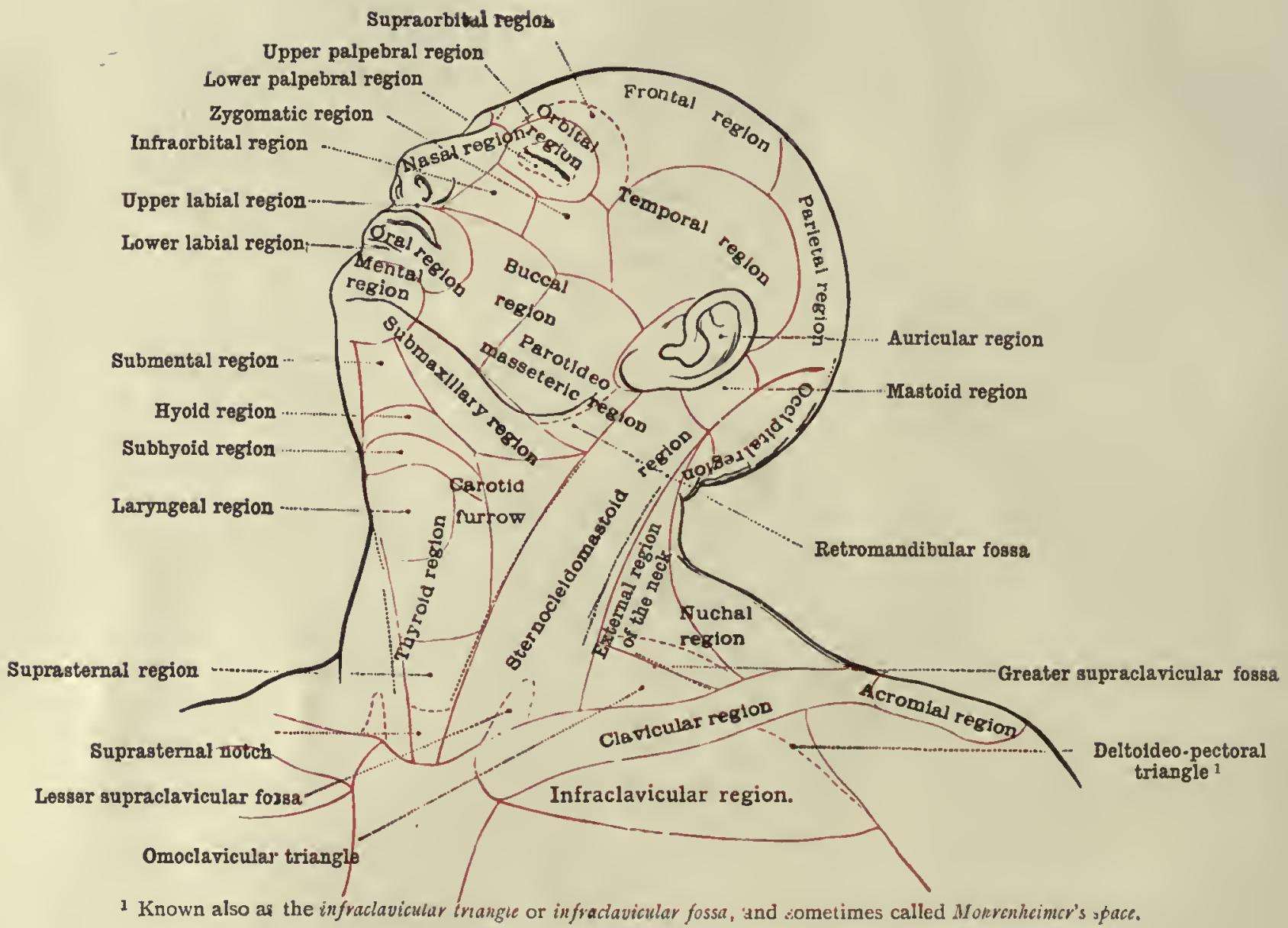

Fig. 3.-Head and NeCr.

Regions of the Head and Neck. 


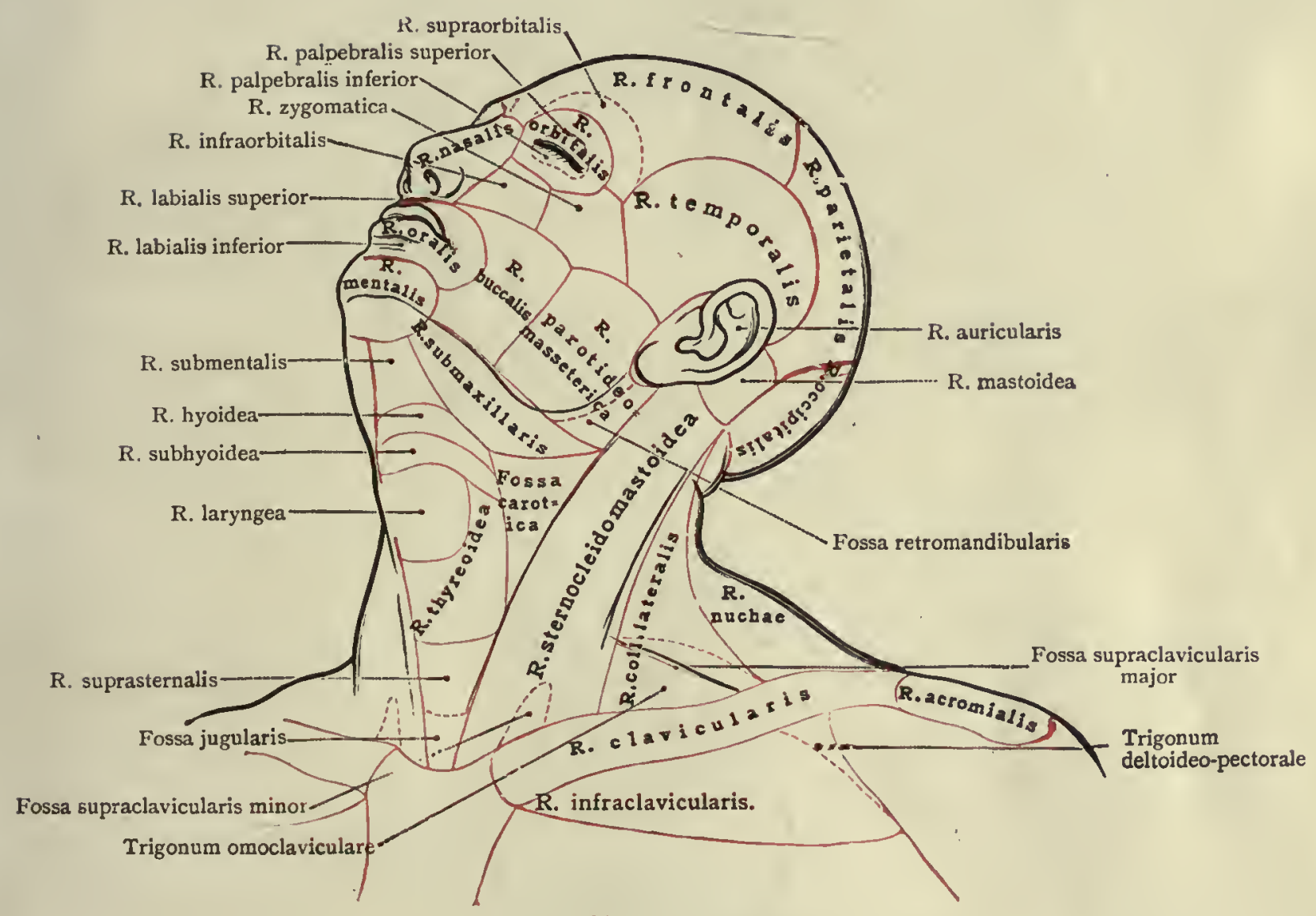

Fig. 3a.-HEAJ AND NECK. 


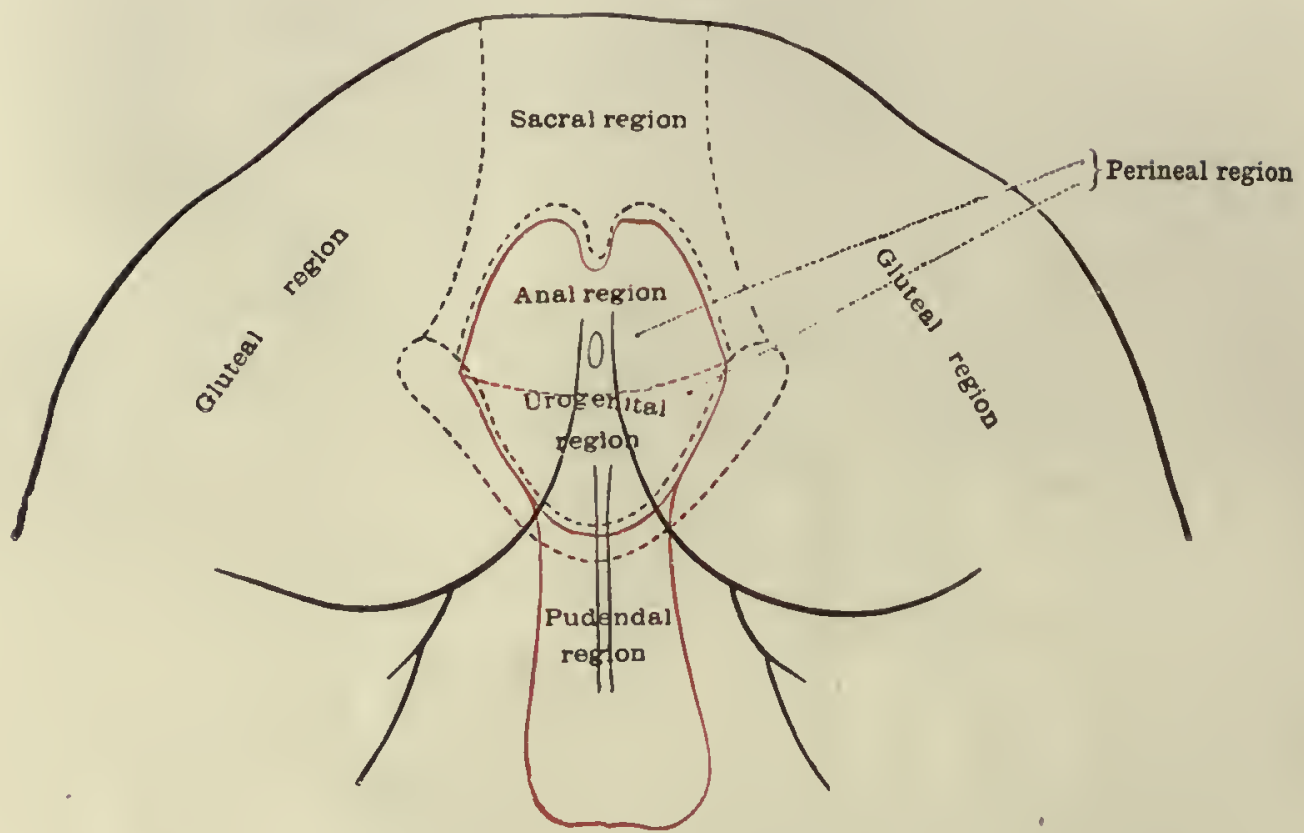

Fig. 4.-Male Perineal Region.

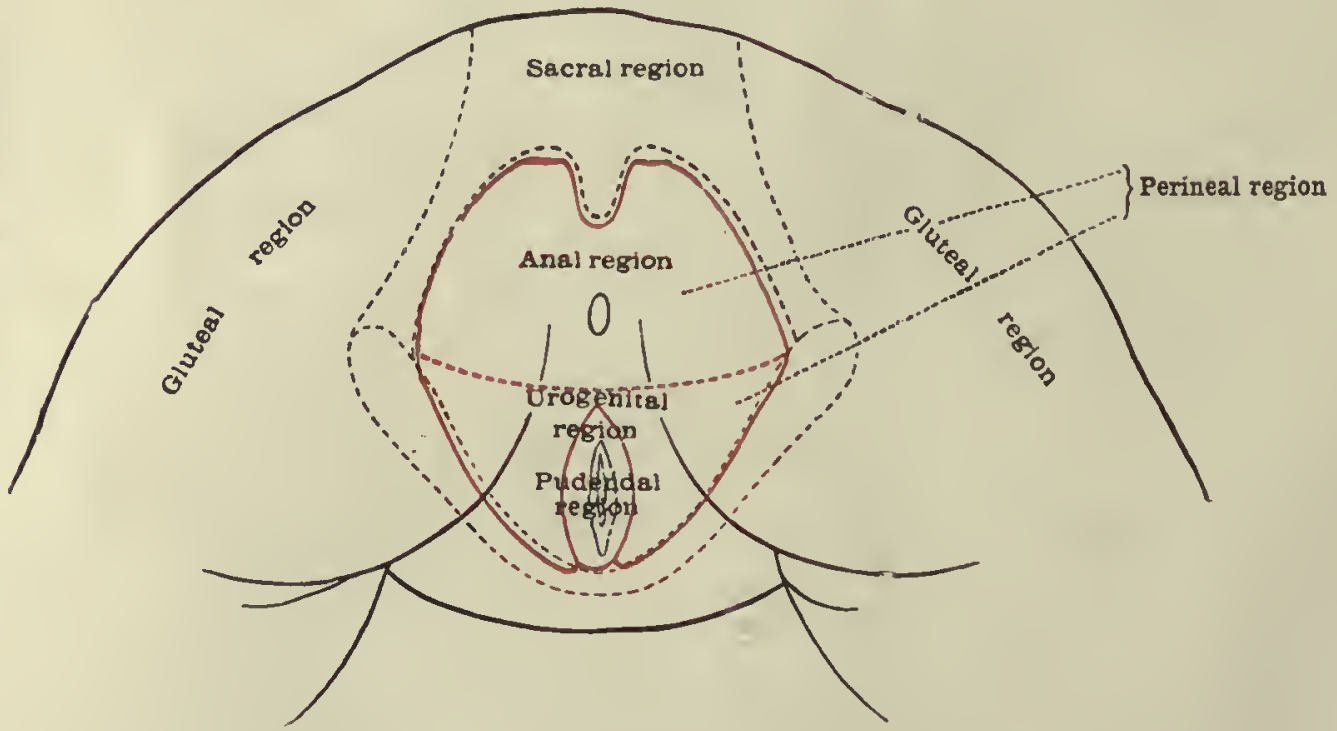

Fig. 5.-Female Perineal Region. 


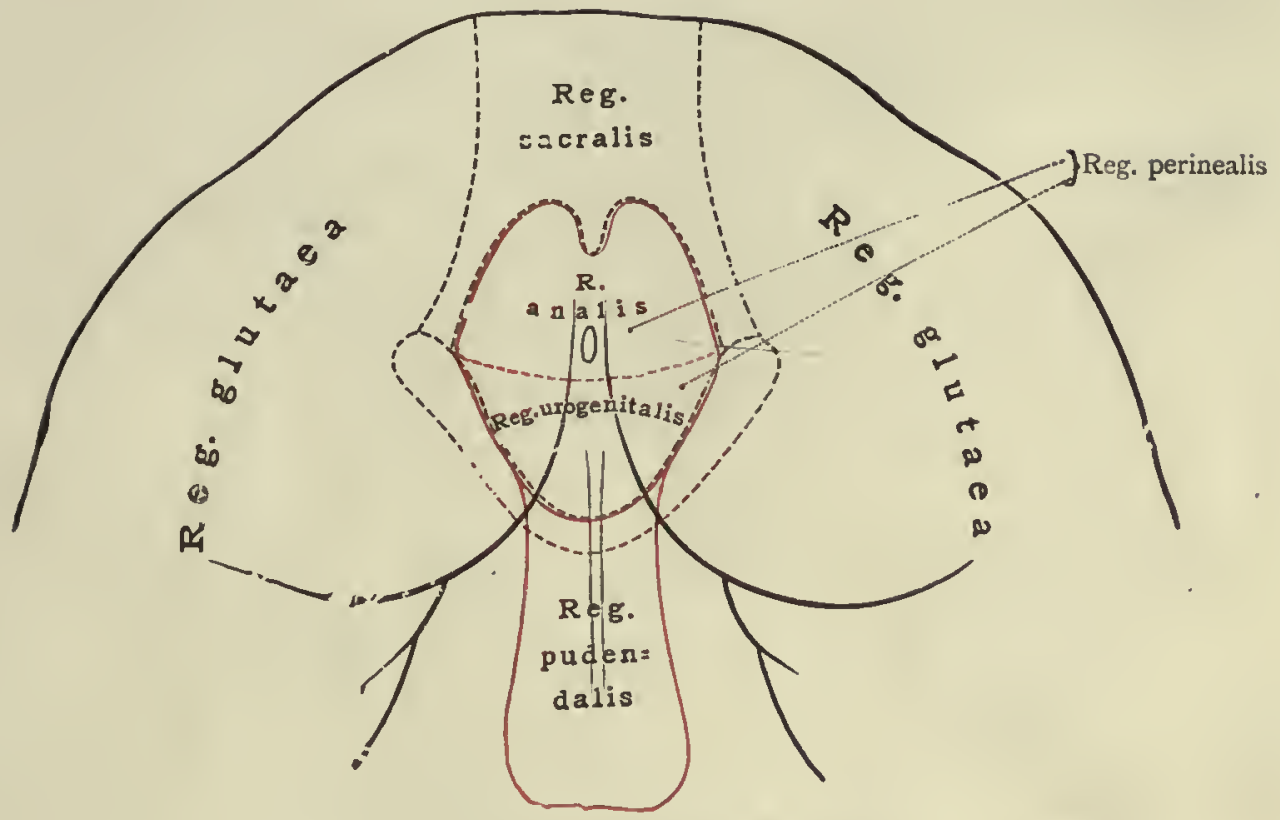

Fig. 4a.-Male Perineal Region.

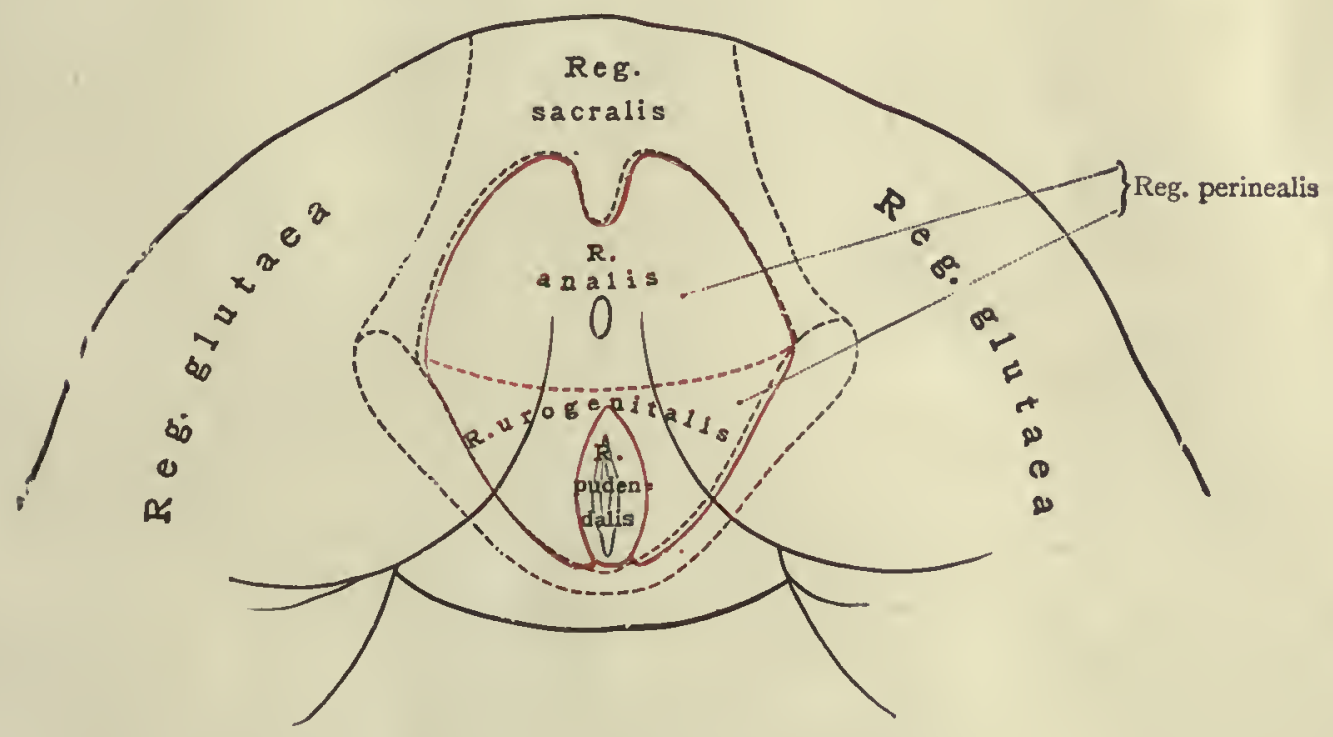

Fig. 5a.-Female Perineal Region.

Regio Perinealis. 

OSTEOLOGIA OSTEOLOGY 

THE STRUCTURE OF THE BONES 


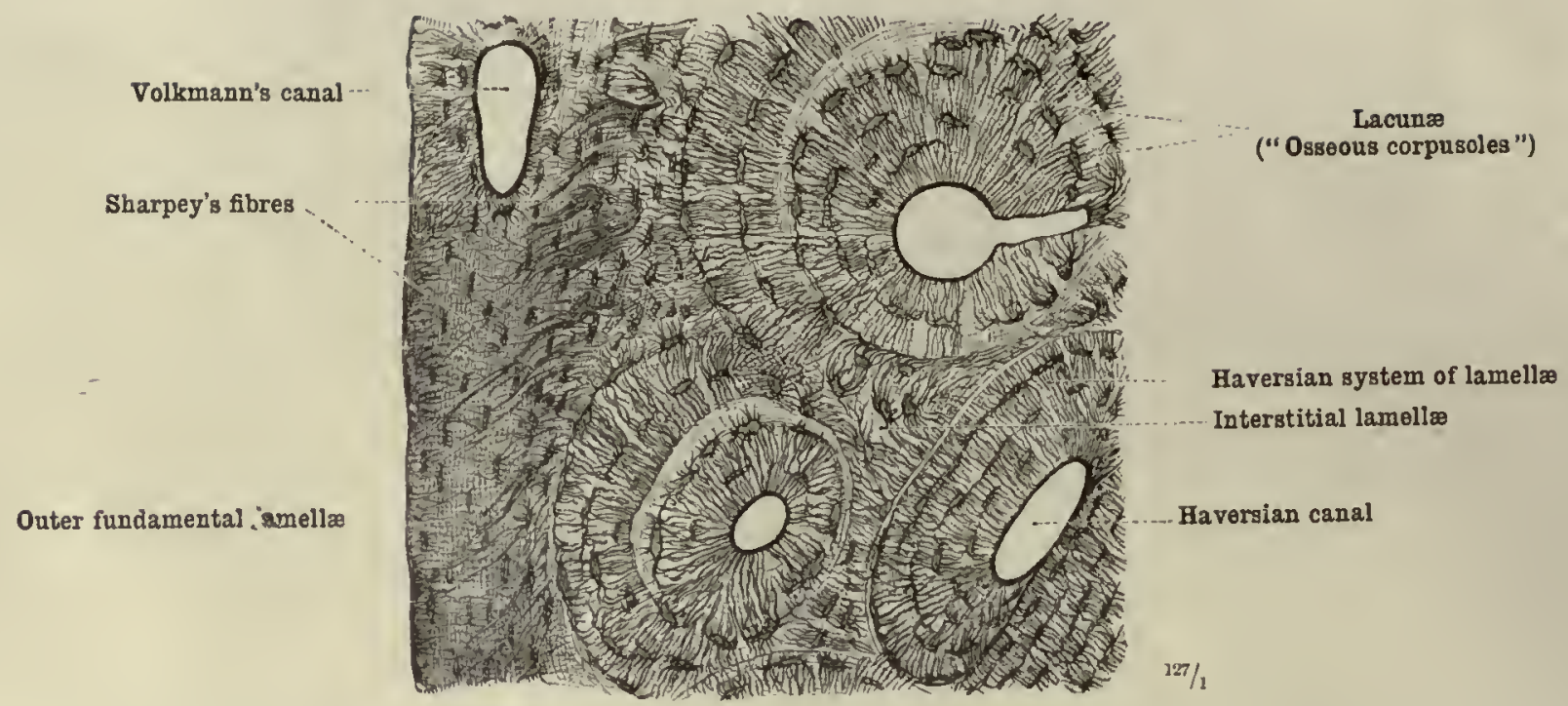

Fig. 6.-Portion of a Cross-Section through the Compact Tissue of a long Bone.

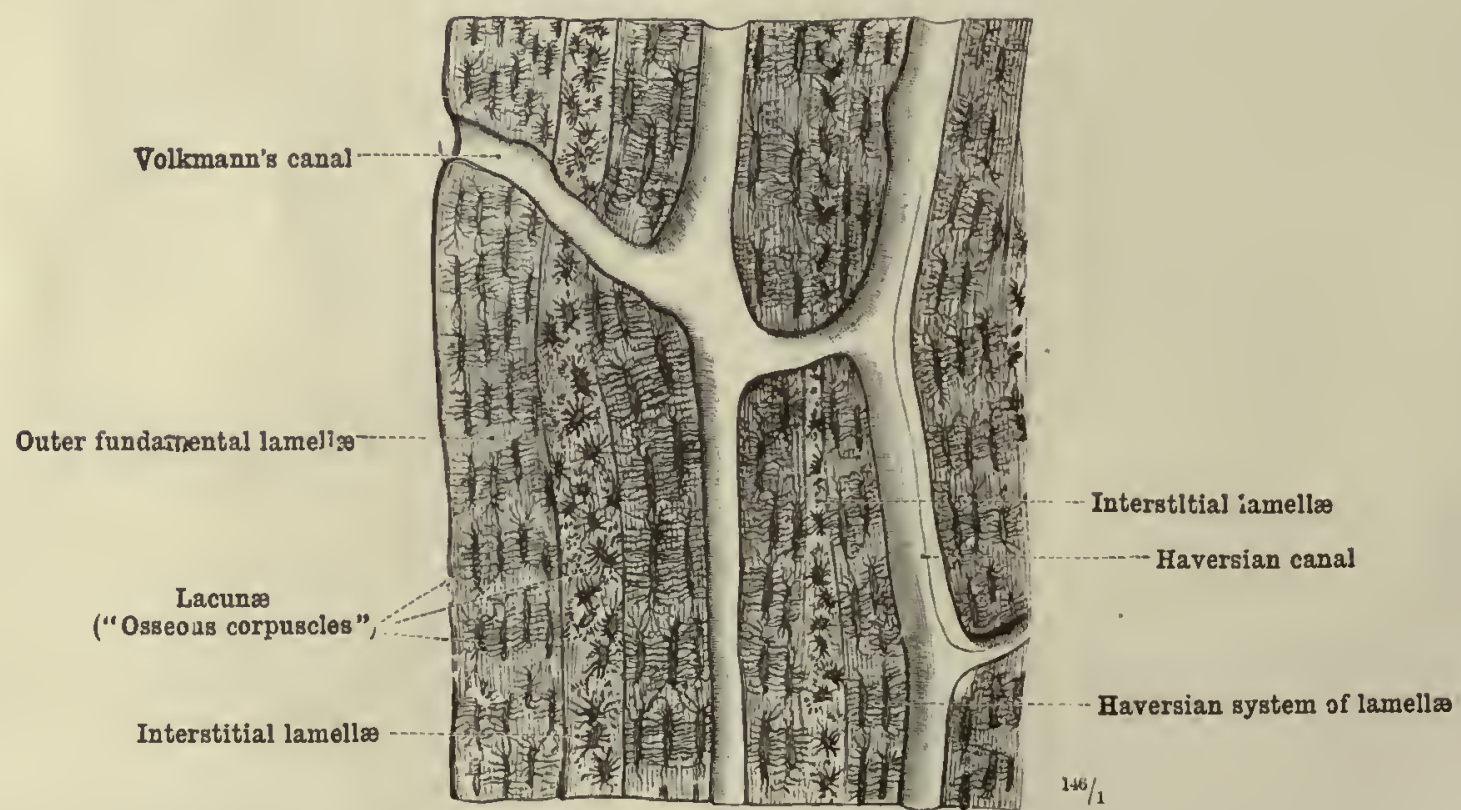

Fig. 7.-Portion of a Longitudinal Section through the Compact Tissue of a Long Bone. 


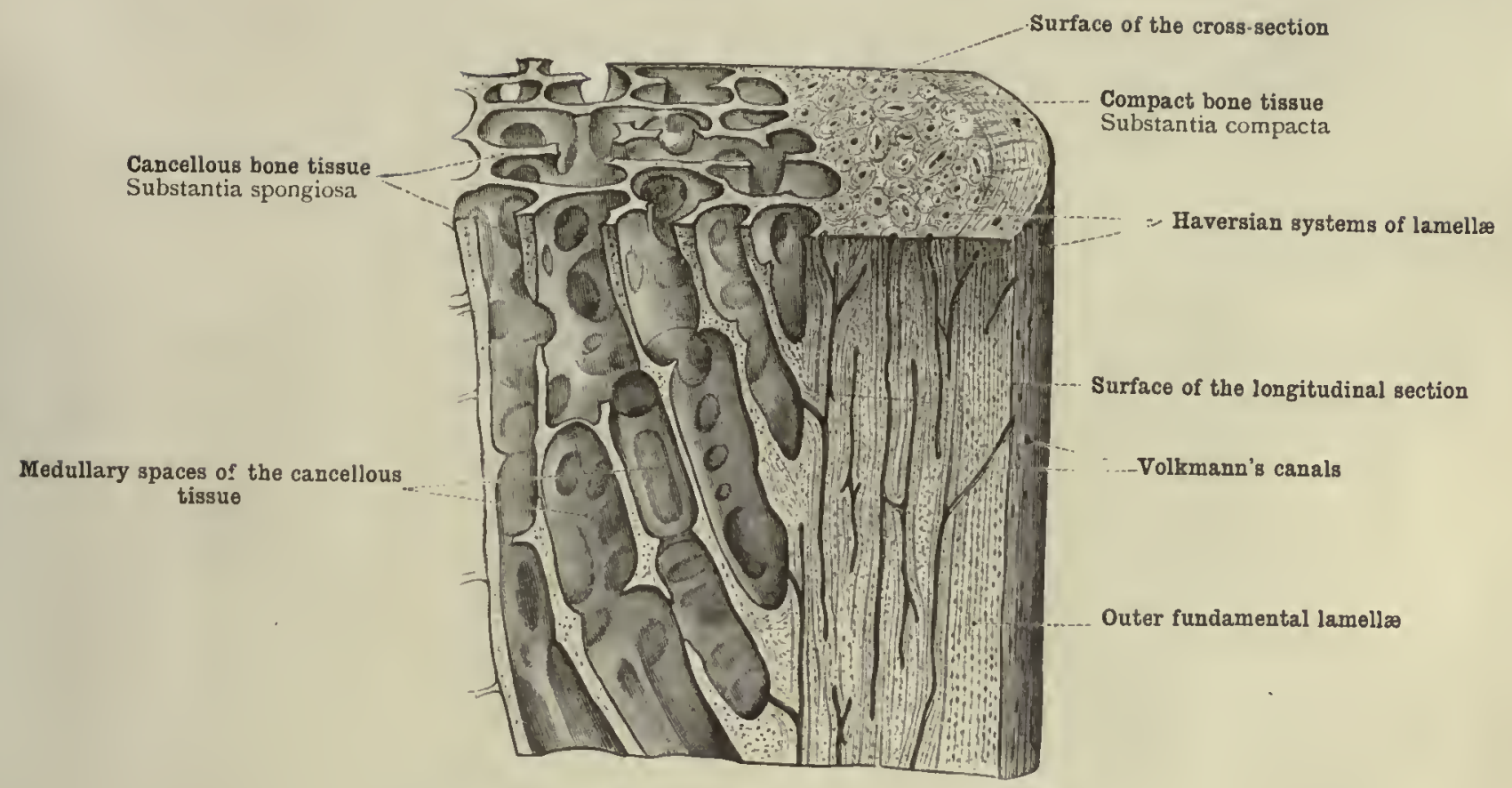

Fig. 8.-Diagram of the Structure of Bone.
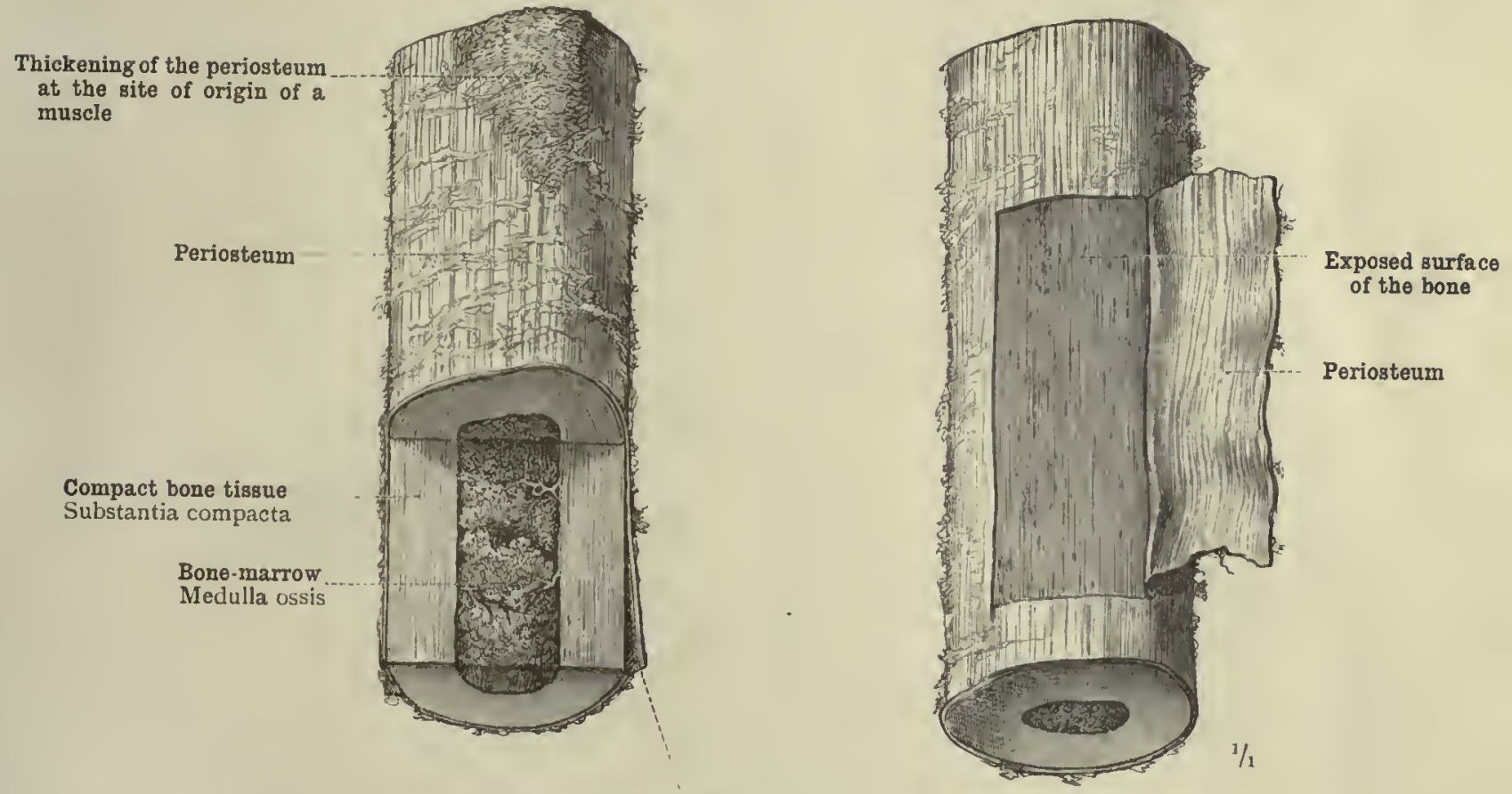

\section{Periosteum}

Fig. 9.-Part of the Middle Segment of the Femur from which the Périosteum IIAS BEEN PARTIALLY REMOVED.

The medullary canal (cavum medullare) has been opened, and the bone-marrow (medulla ossis) is seen.

Periosteum and Bone-Marrow (Medulla Ossium). 


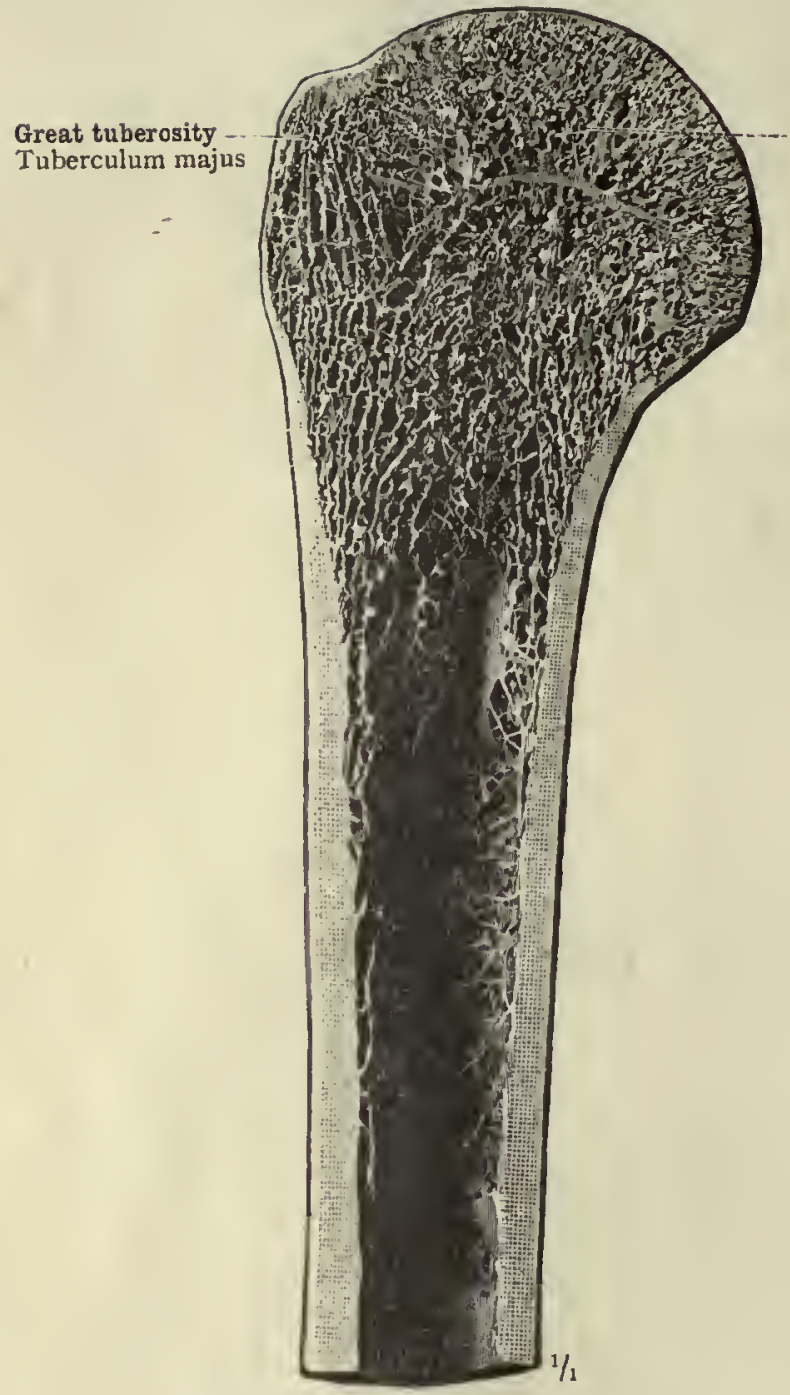

Fig. IO.-Proximal Portion in Frontal Section.
Head of the humerus

Caput humeri

Trochlea humeri

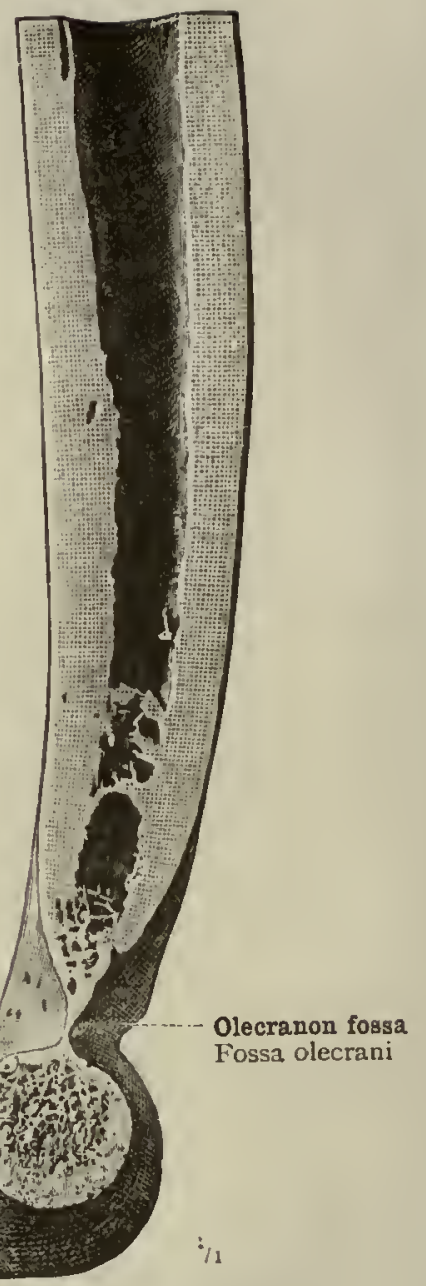

Fig. il,-Distal Portion in Sagittal Section.

Humerus-Arm-bone: Substantia compacta et substantia spongiosa ossium-Compact and cancellous tissue of the bones. 


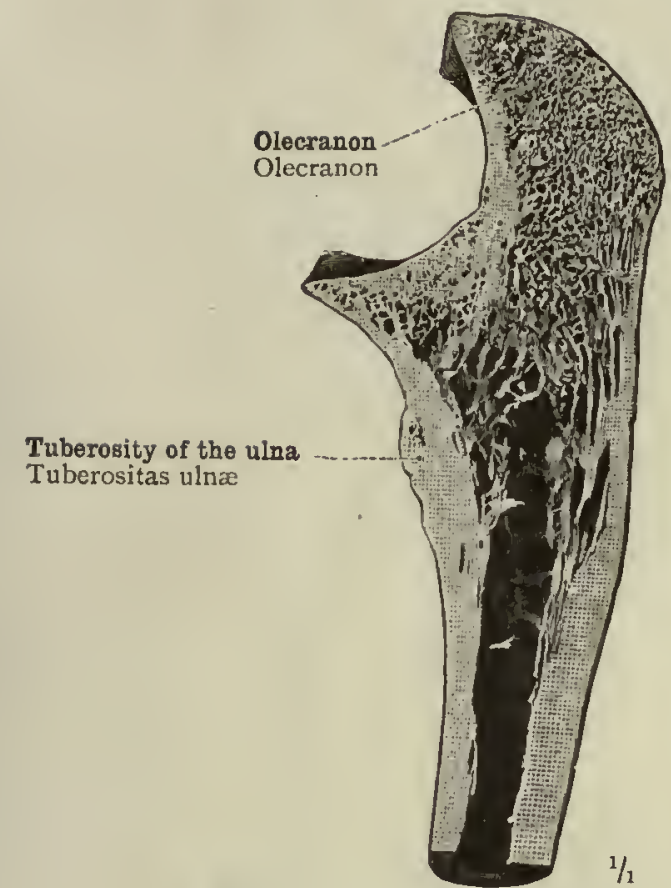

Fig. I2.-Proximal Portion in Sagittal Section.

\section{Ulna.}

Tuberosity of the radius Tuberositas radii

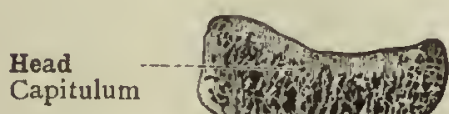

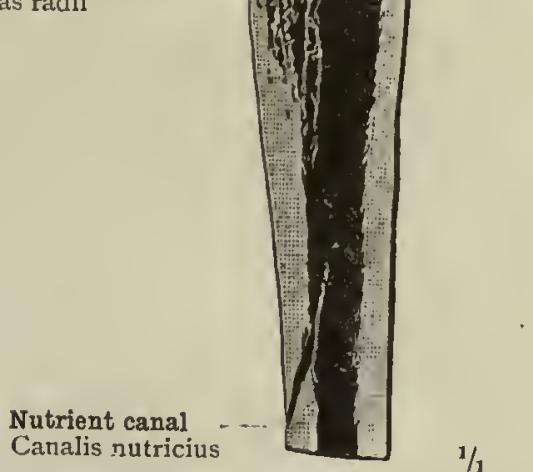

Fig. I4.-Proximal Portion.

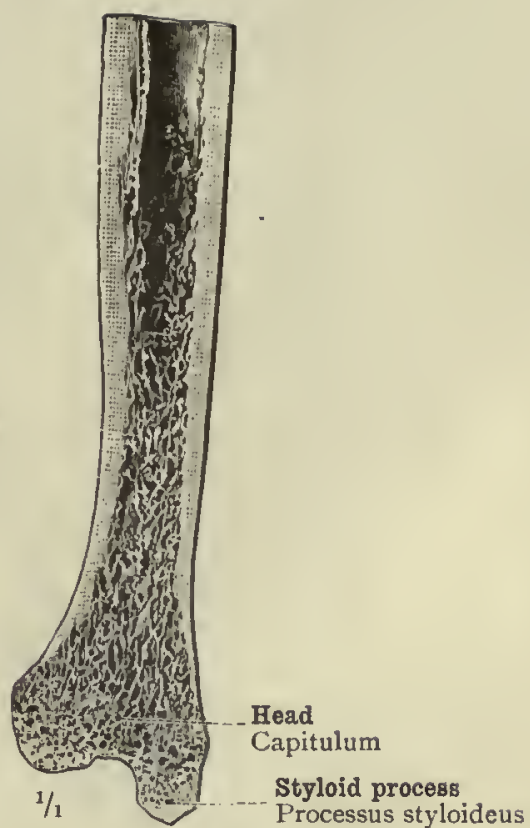

Fig. 13.-Distal Portion in Frontal Section.

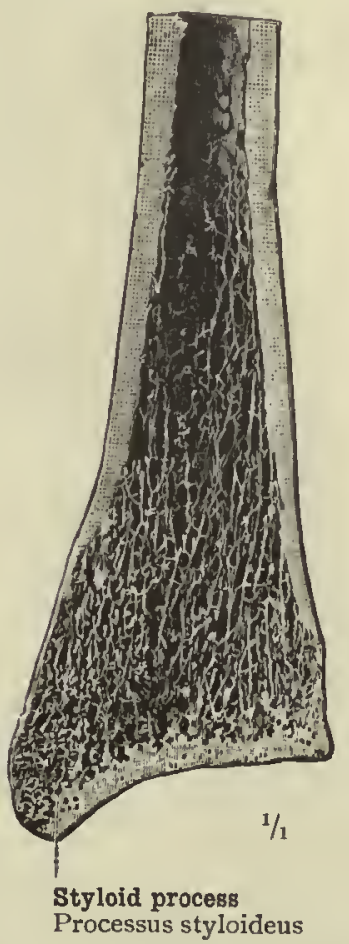

Fig. 15.-Distal Portion.

Radius.

Substantia compacta et substantia spongiosa ossium_..Compact and cancellous tissue of the bones. 


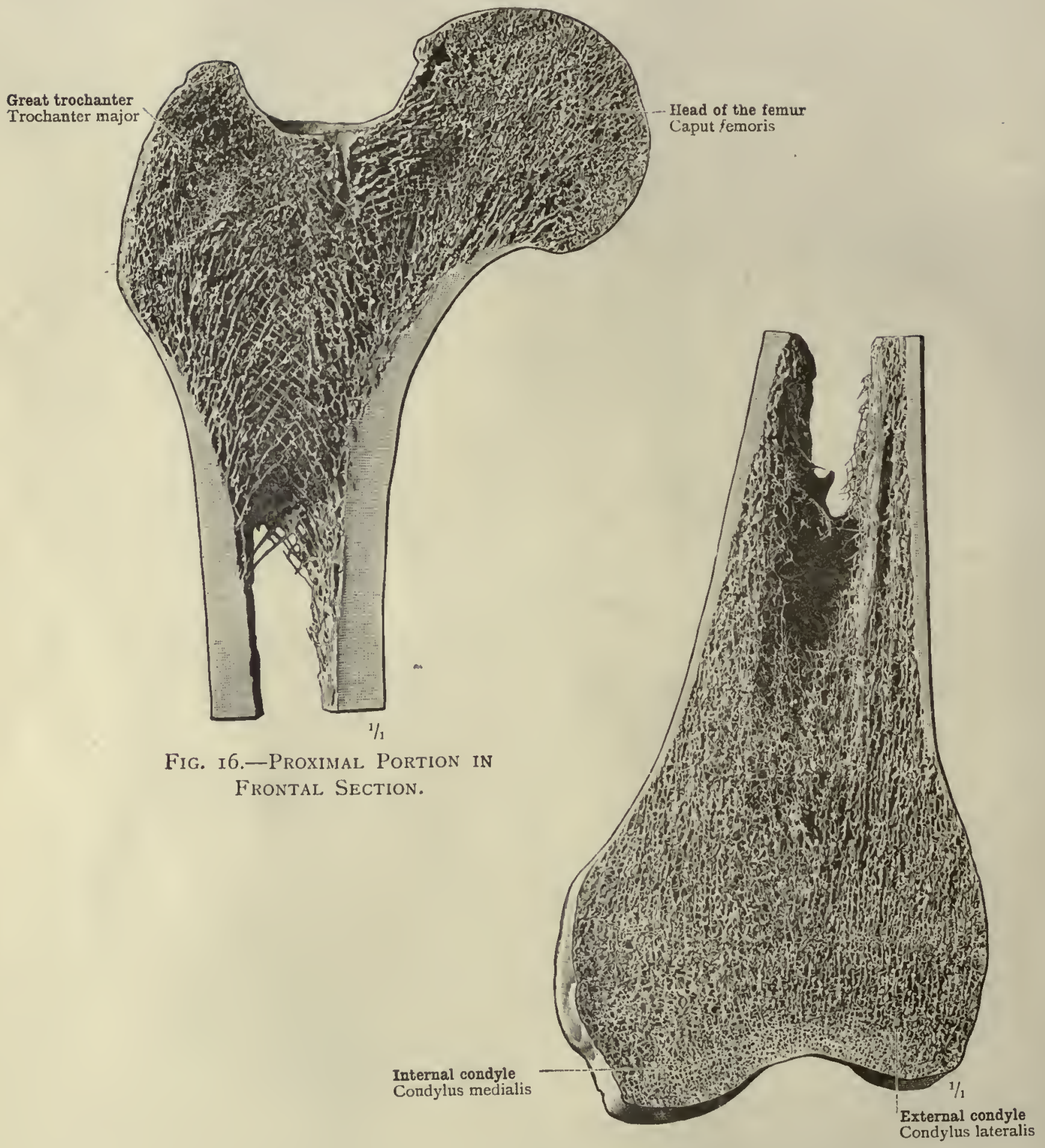

Fig. i7.-Distal Portion in Frontal Section.

Femur-Thigh-bone: Substantia compacta et substantia spongiosa ossium-Compact and cancellous tissue of the bones.

Ossa longa-Long bones. 


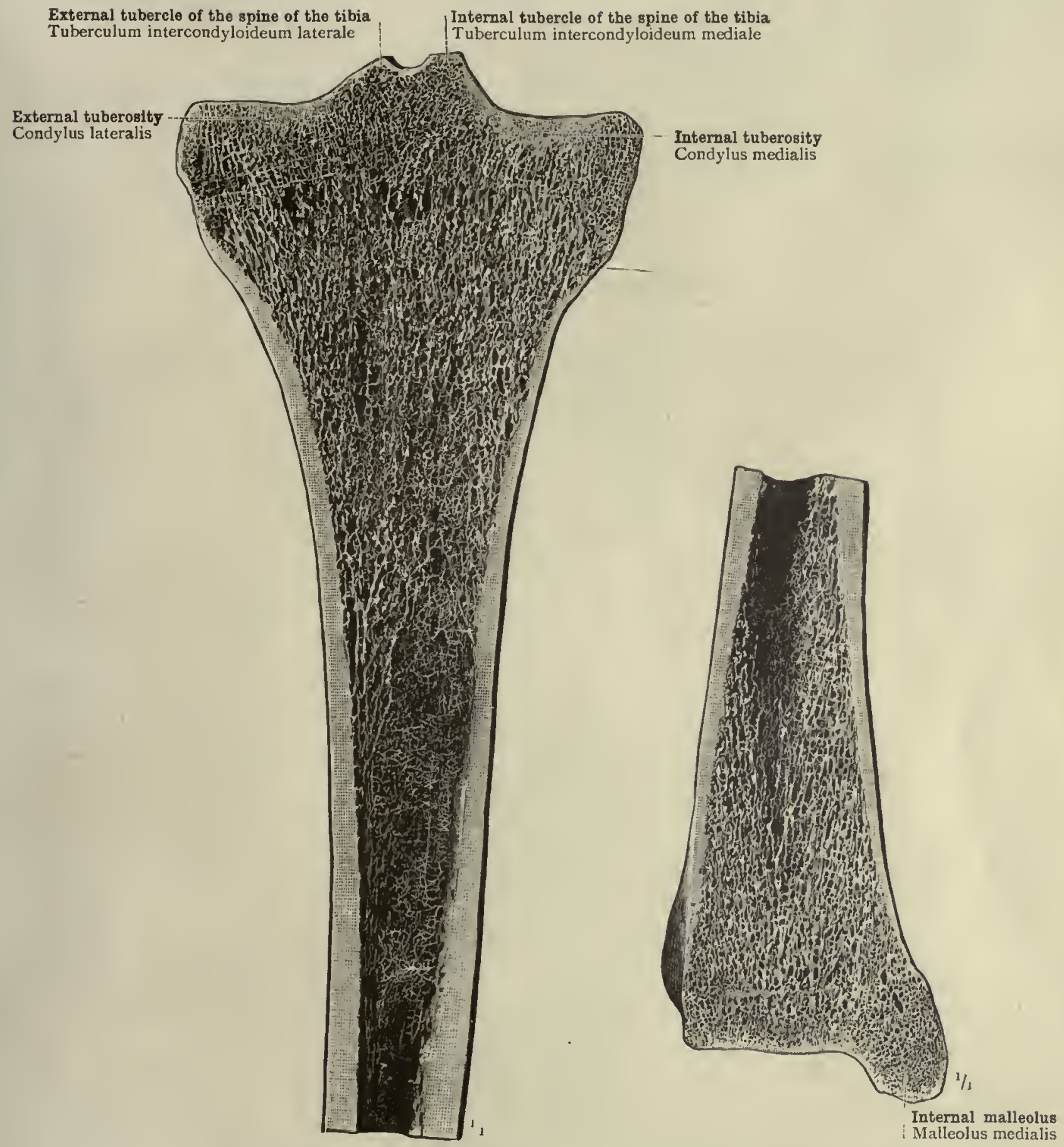

Fig. i8.-Proximal Portion in Frontal Section.

Fig. I9.-Distal Portion in Frontal Section.

Tibia_Shin-bone: Substantia compacta et substantia spongiosa ossium-Compact and cancellous tissue of the bones. 


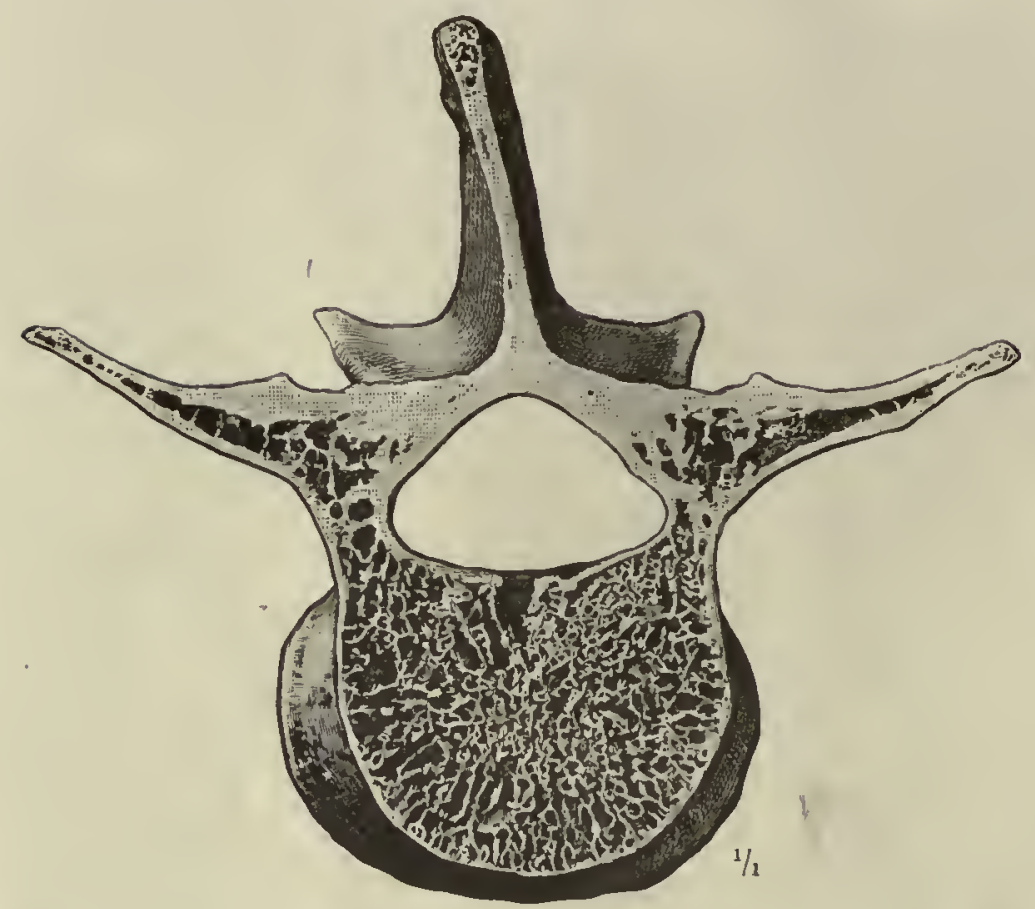

Fig. 20.-Third Lumbar Vertebra in Horizontal Section.

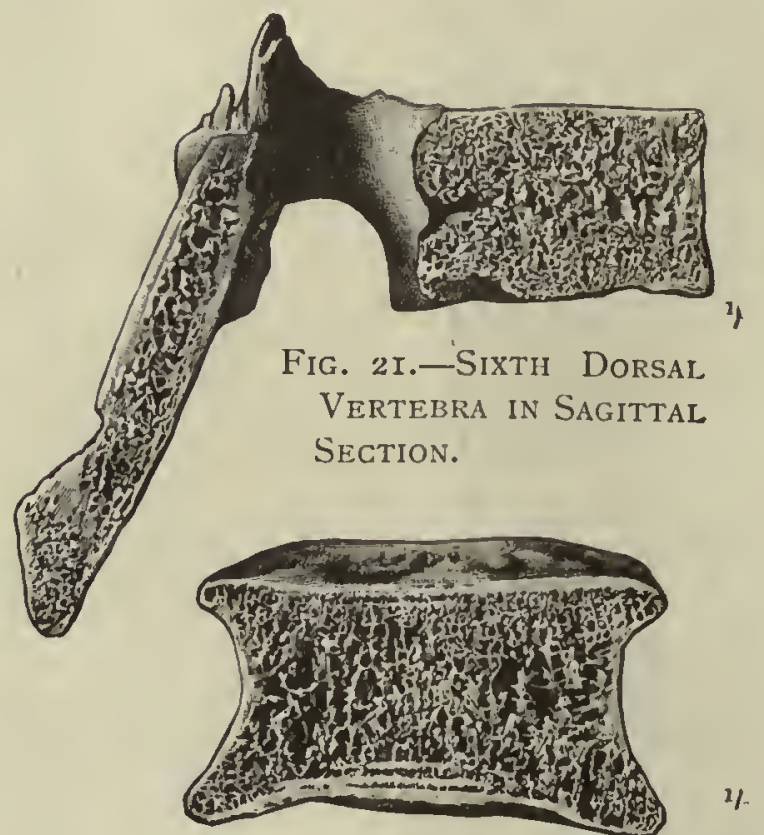

Fig. 22.-Body of the Second Lumbar Vertebra in Frontal Section.

Vertebræ: Substantia compacta et substantia spongiosa ossium-Compact and cancellous tissue of the bones.

Ossa brevia_Short bones. 


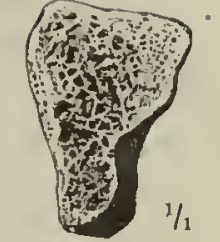

Frontal section.

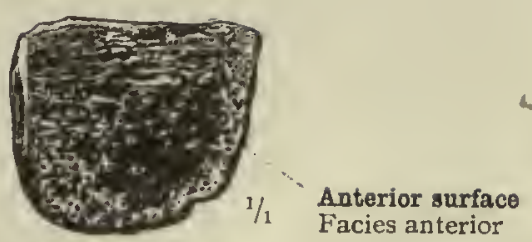

Sagitial Section.

Fig. 23.-Os Cuneiforme III.. the External Cuneiform Bone.

\section{Head of the astragaius Caput tali}

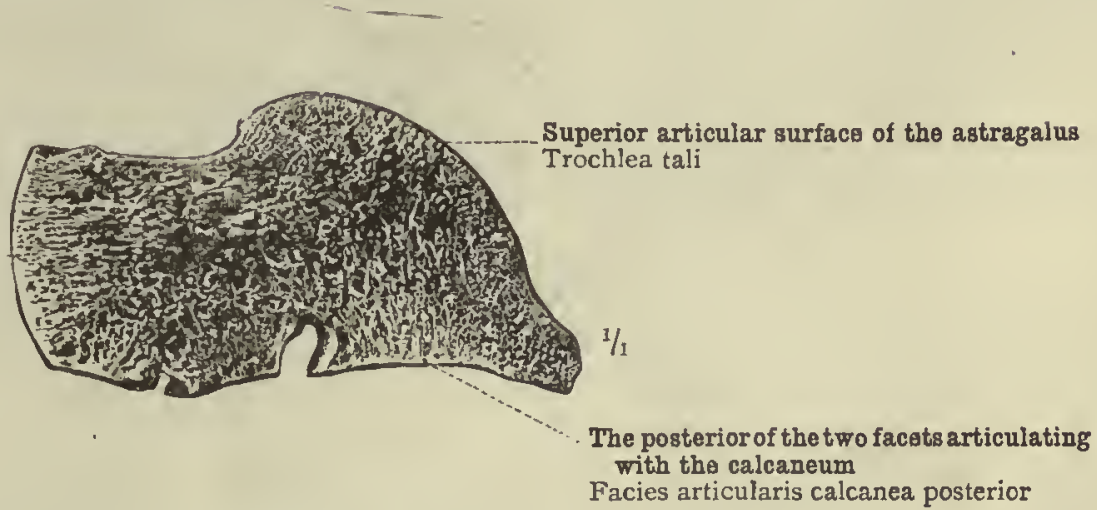

Fig. 24.-Talus, the Astragalus, in Sagittal Section.

Posterior articular facet for the astragalus Facies articularis posterior

$-$
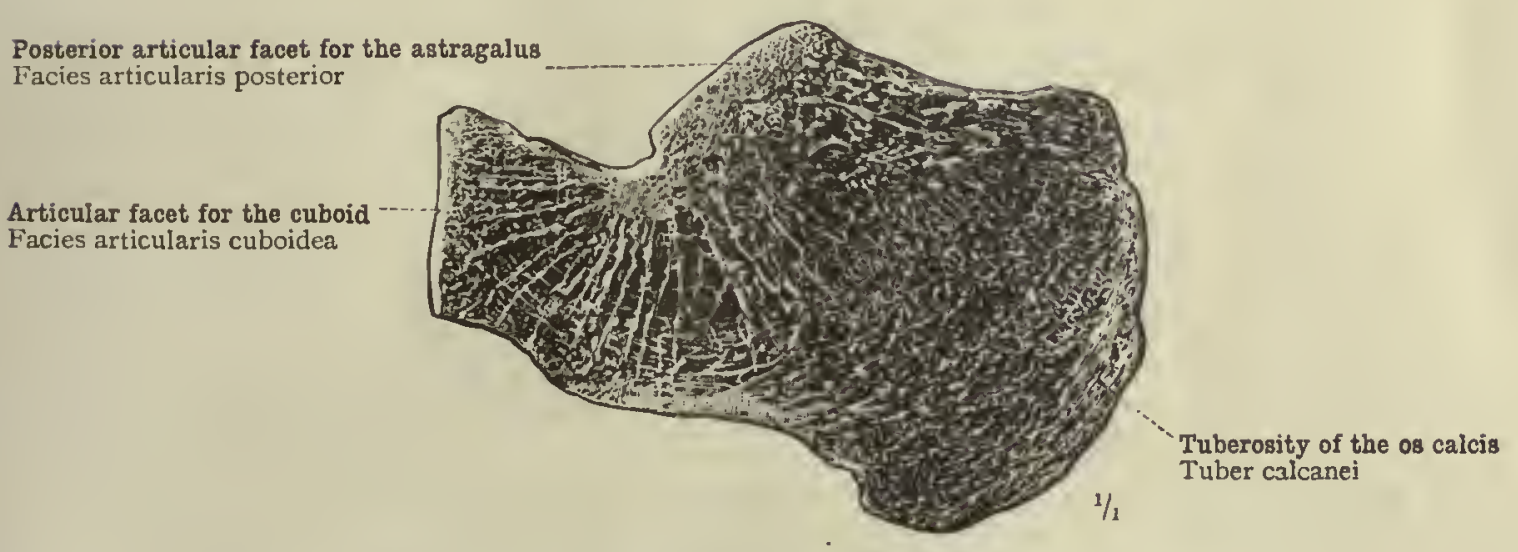

Articular facet for the cuboid

Facies articularis cuboidea

Hig. 25.-Calcaneum, the Os Calcis, in Sagittal Section.

Ossa tarsi-Tarsal bones : Substantia compacta et substantia spongiosa ossium-Compact and cancellous tissue of the bones.

Ossa brevia-Short bones. 


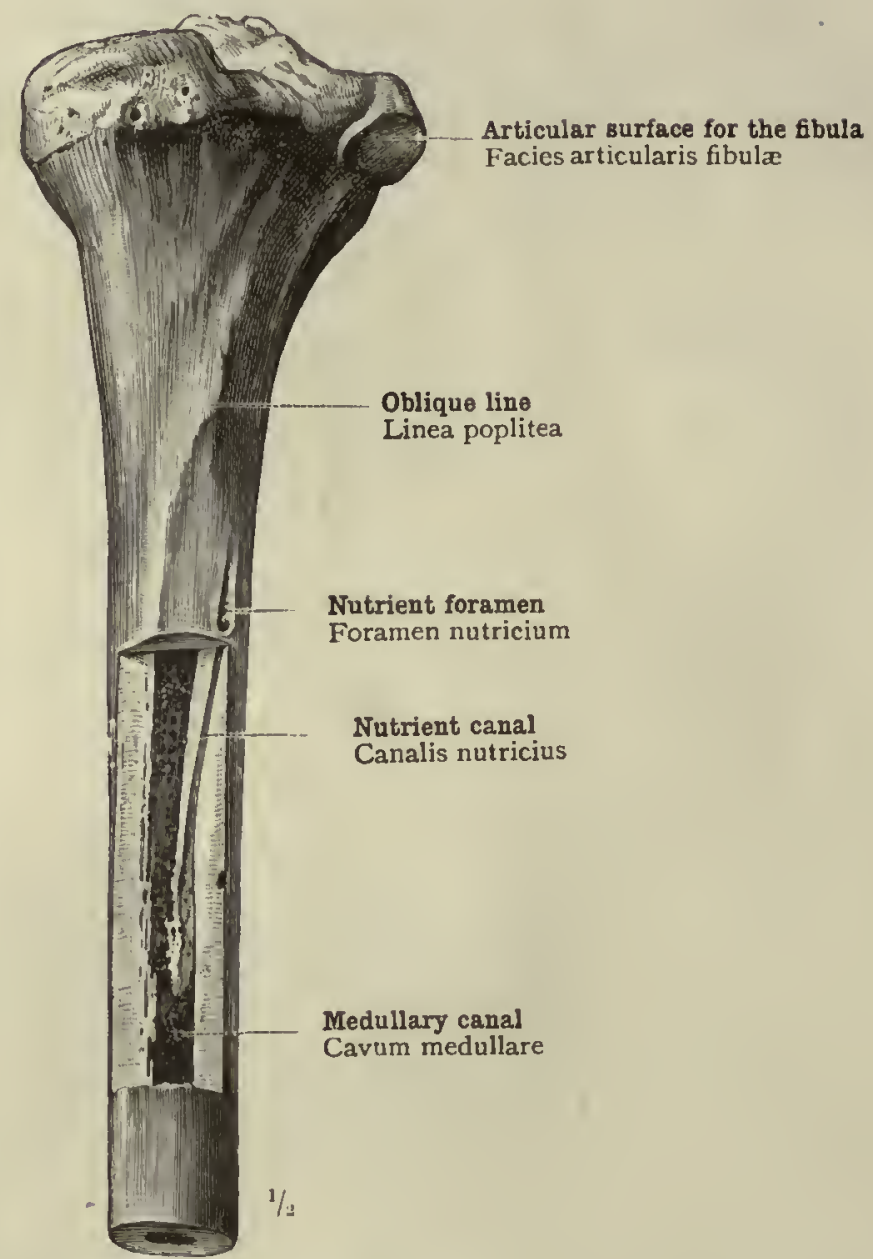

Fig. 26. - Nutrient Foramen and Nutrient Canal of the Right Tibia. SEEN FROM BEHIND.

by sawing away a portion of the snaft the whole length of the nutrient canal has been opened up. 


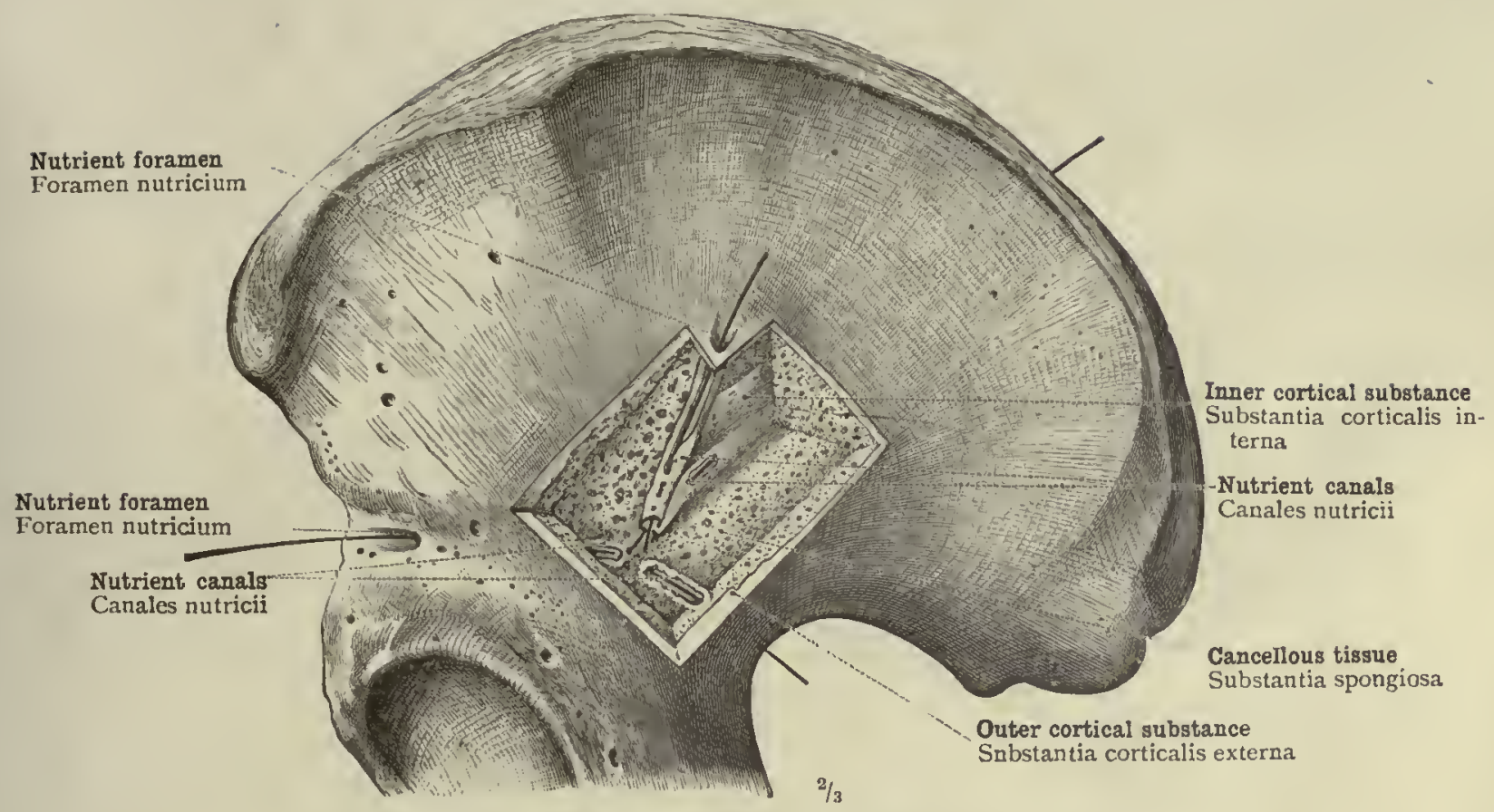

Fig. 27.-OUter Surface of Left Ilium.

By the removal of the outer compact layer and the cancellous tissue of a portion of the bone, the nutrient canals have been displayed. The bristles projecting towards the right above and below show that the nutrient canals into which they have been inserted open on the inner surface of the bone-that turned away from the observer.

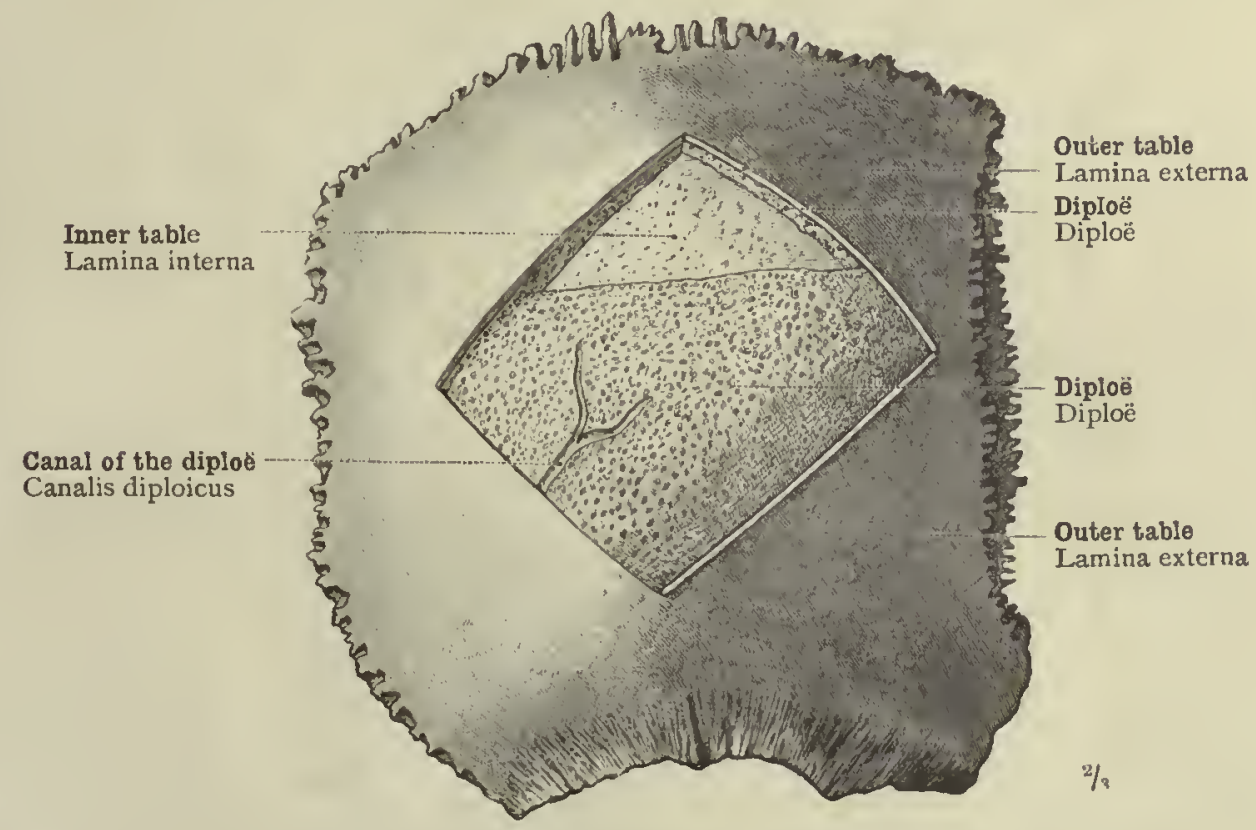

Fig. 28,-Os Parietale, Parietal Bone, prepared to show the Diplö̈ and the Compact Inner table. Seen from without.

Substantia compacta, substantia spongiosa, et canales nutricii-Compact tissue, cancellous tissue, and nutrient canals.

Ossa plana-Flat bones. 

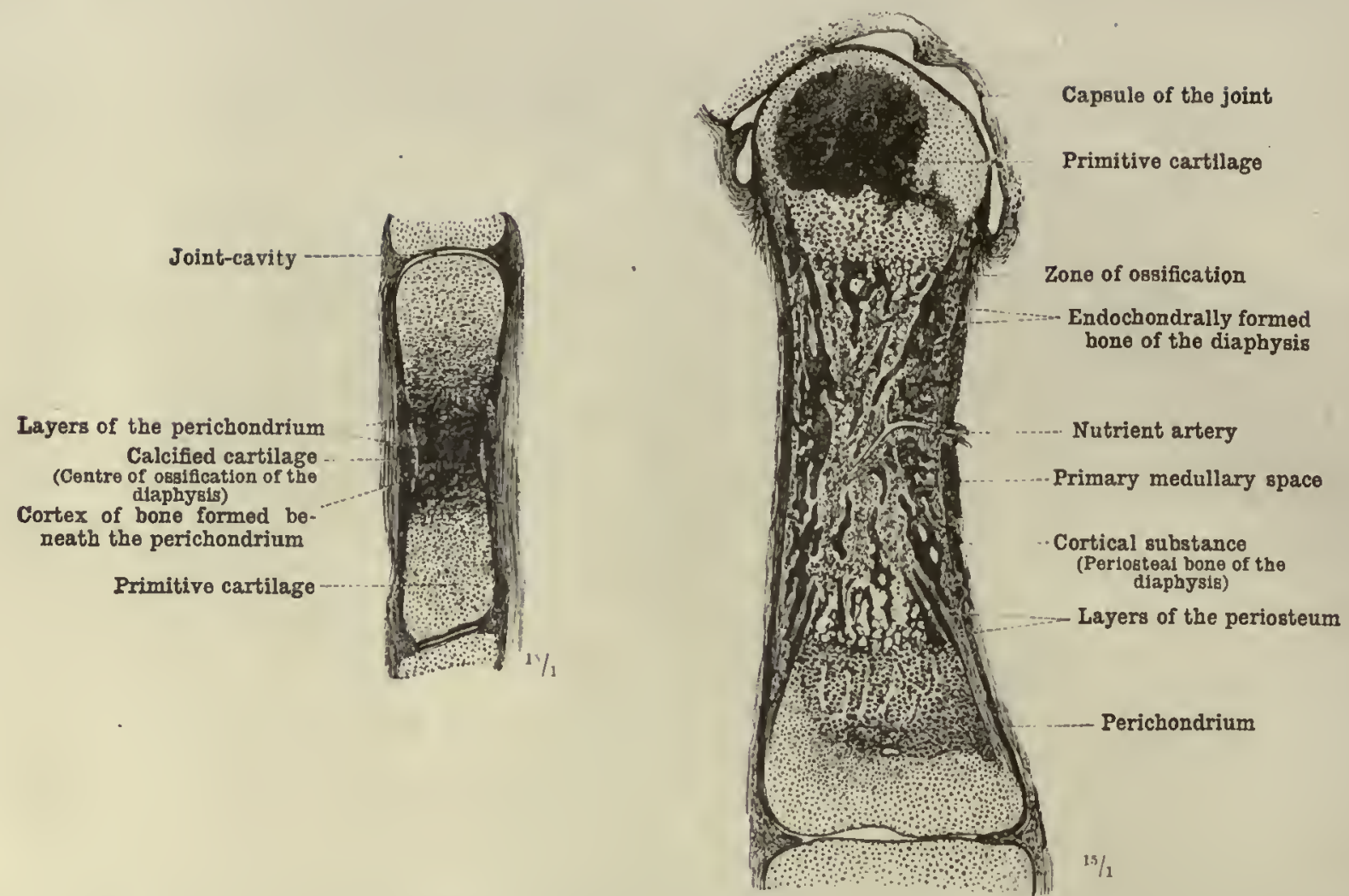

Figs. 29 and 30.-Two Stages in the Intracartilaginous Ossification of Long Bones, as shown by Longitudinal Sections of the Phalanges of a Human fietus.

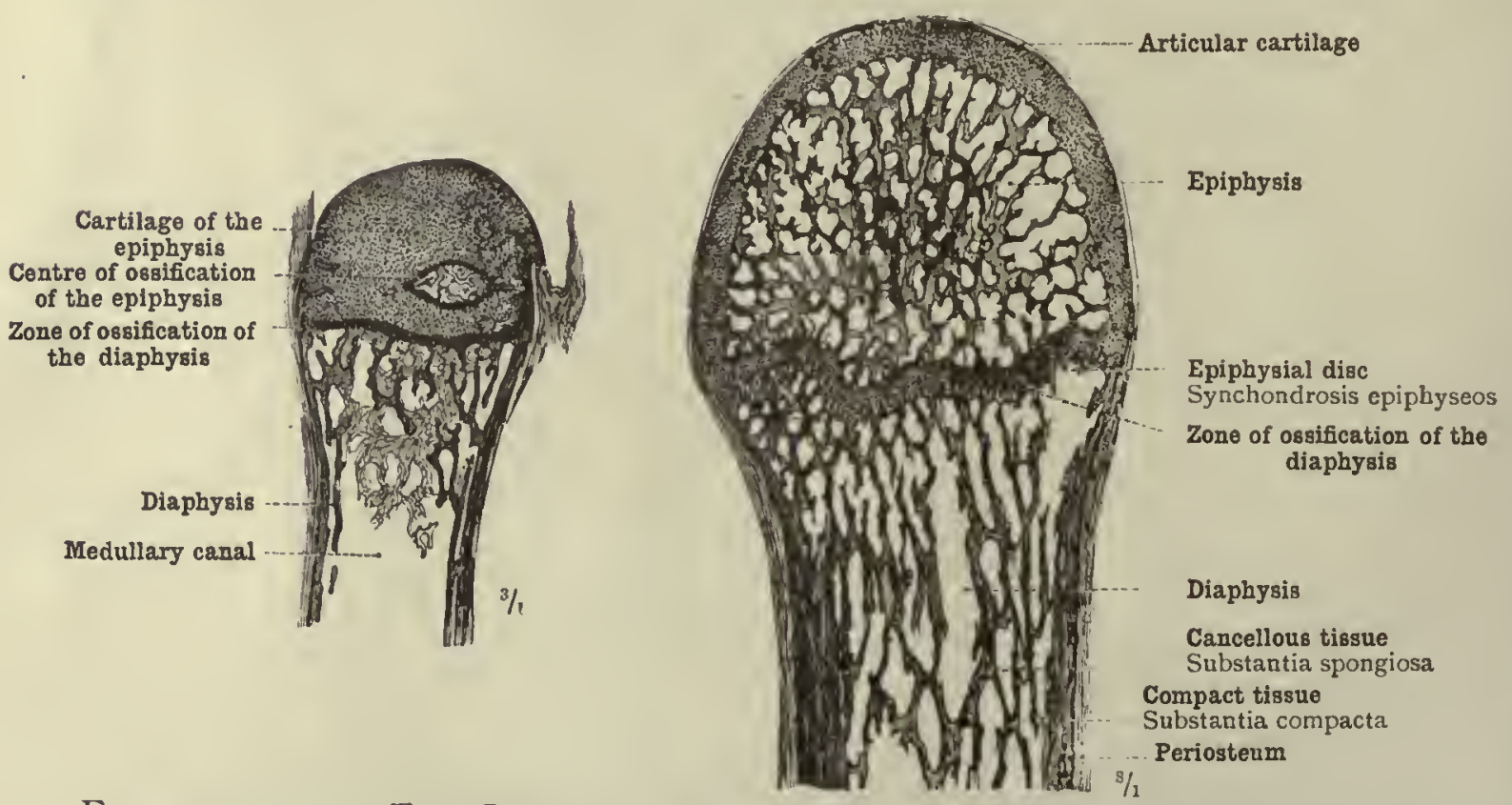

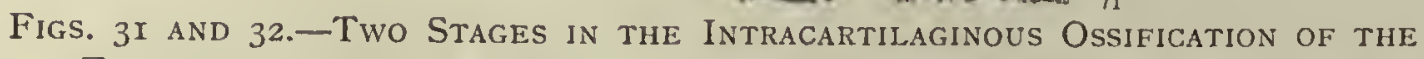
Epiphysis of a Long Bone, as shown by Longitudinal Sections of the Distal Portions of Metacarpal Bones. 


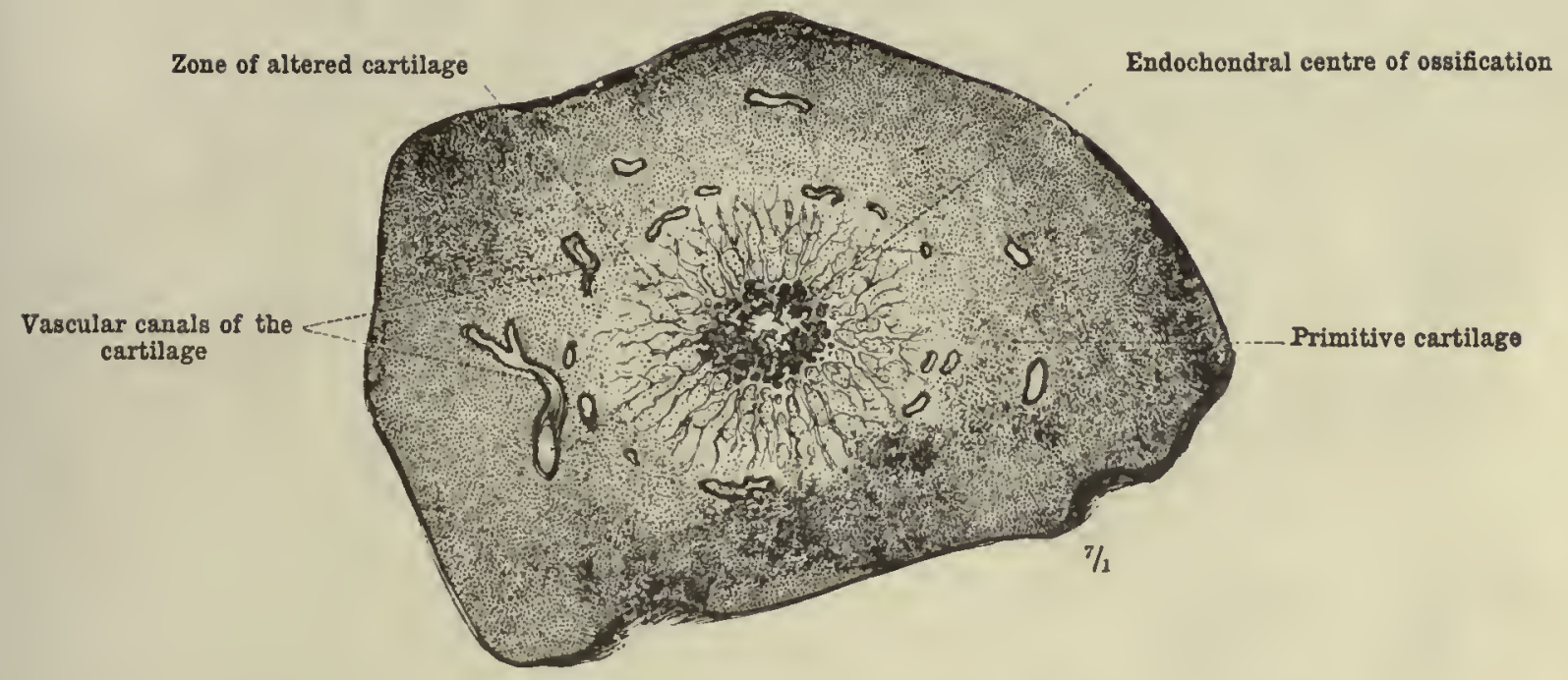

Fig. 33.-Intracartilaginous Ossification of a Short Bone.

A section of the cuboid bone of a new-born child.

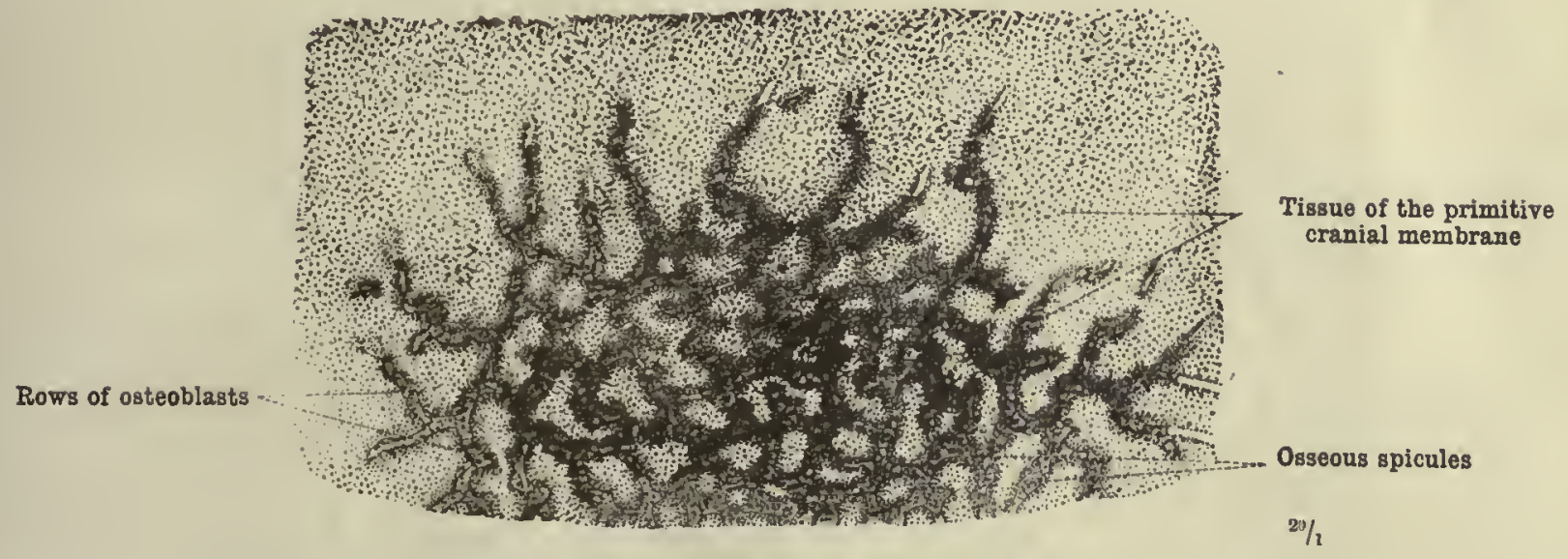

Fig. 34.-Intramembranous Ossification of the Bones of the Cranial Vault.

Upper half of the parietal bone of a human foetus in the eleventh week of intra-uterine life. 


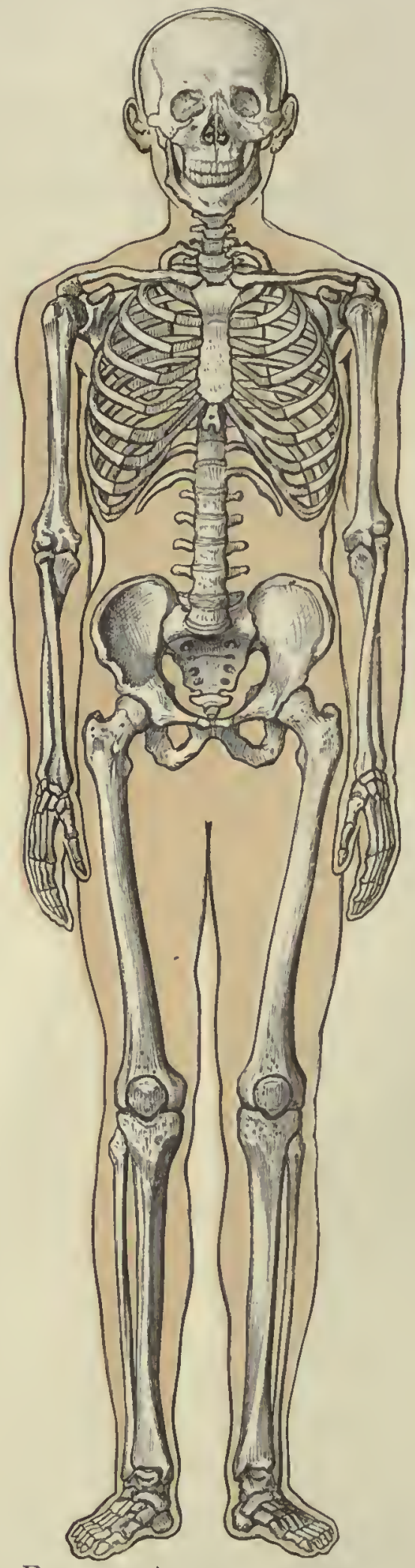

Fig. 35.-ANterior Aspect.

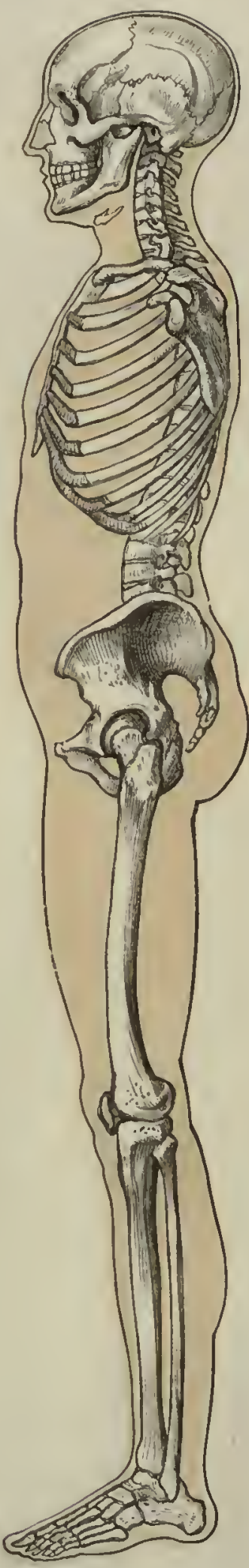

Fig. 36.-Viewed from the Left Side, THE ARM HAVING BEEN REMOVED.

Skeleton humanum-The human skeleton. 


\section{SKELETON TRUNCI}

THE AXIAL SKELETON 


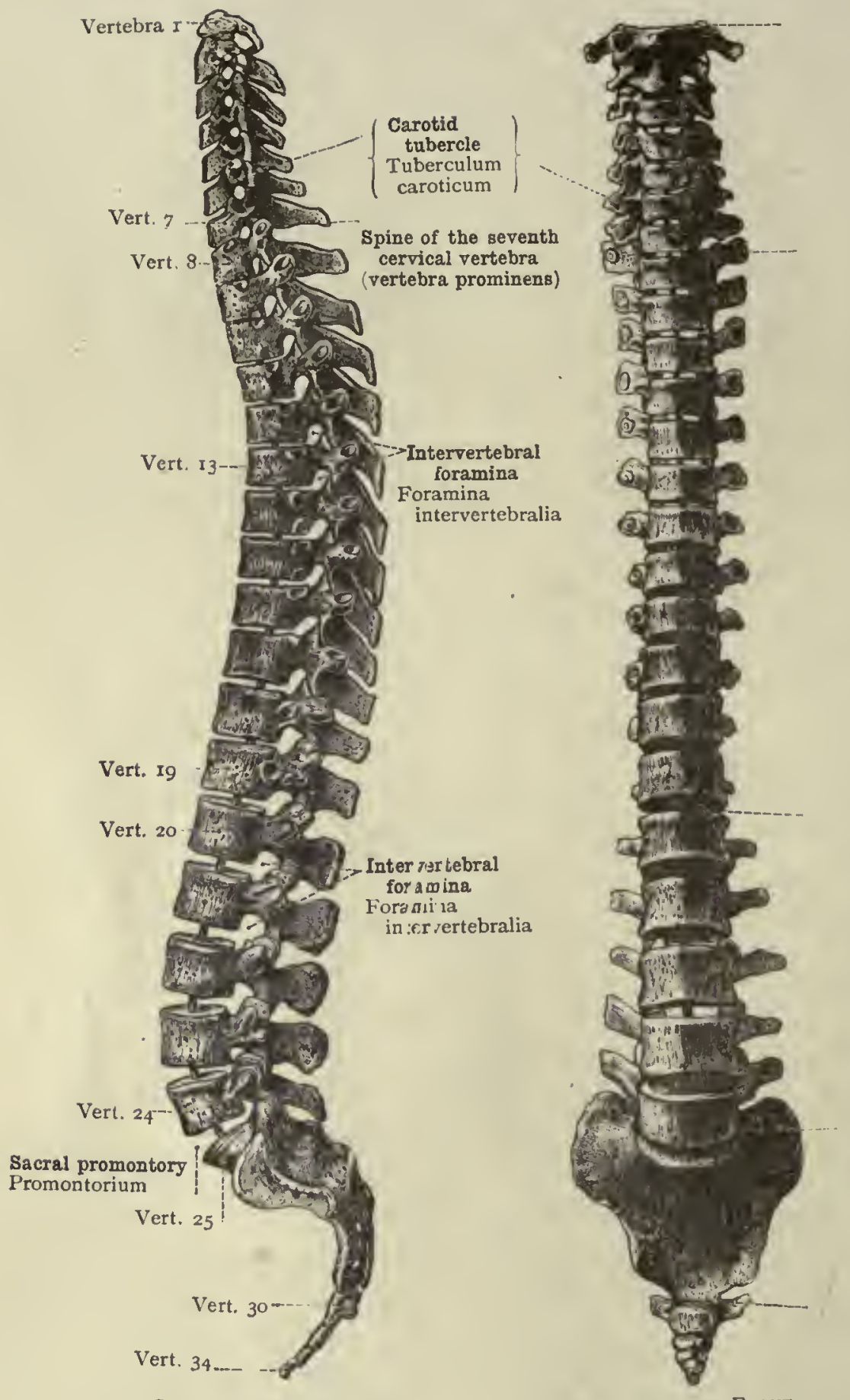

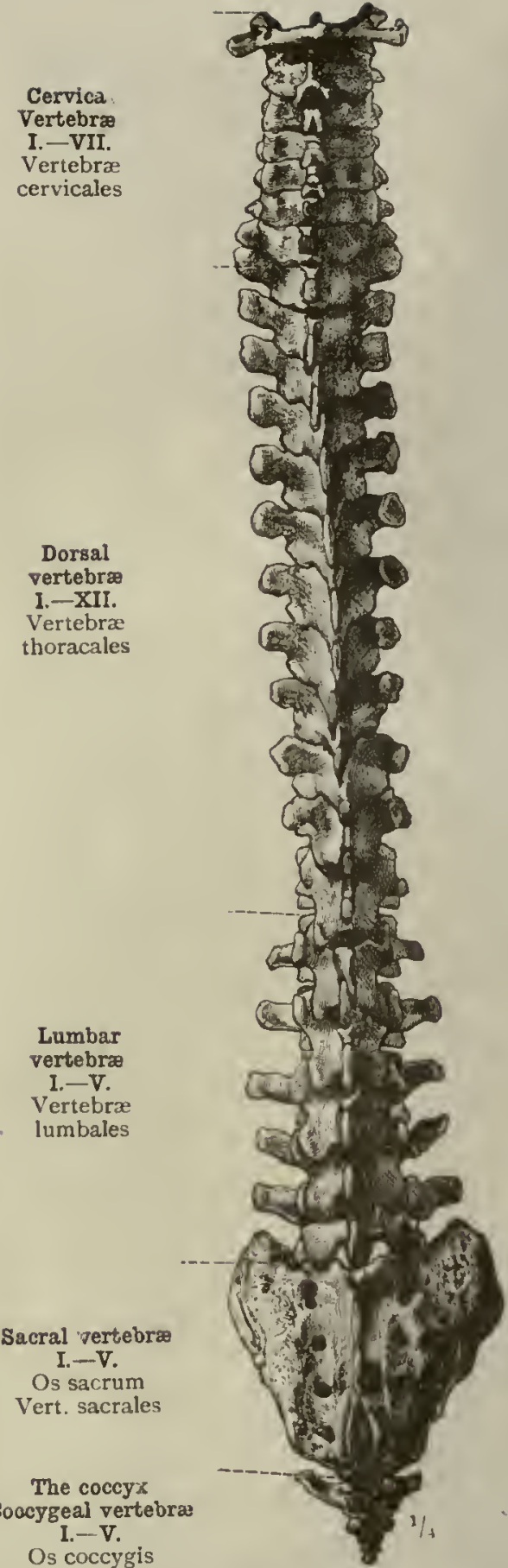

Os coccygis

SEEN FROM THE FRONT.
SEEN FROM BEHIND,

Fig. 37.-The Vertebral Column as a Whole. Classification and Nomenclature OF THE VERTEBRE.

Columna vertebralis--The spinal column. 


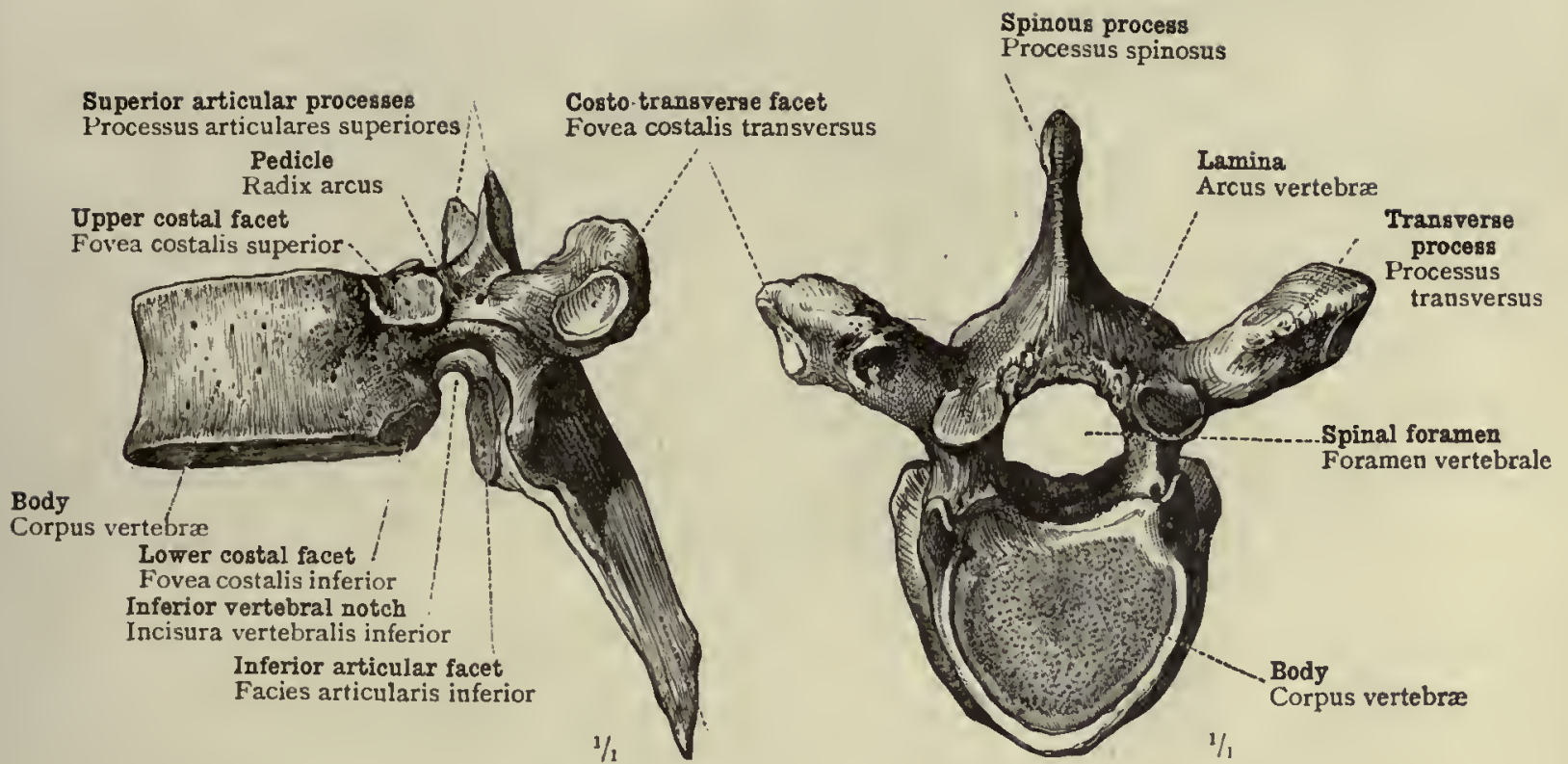

FIG. 38.-SEEN FROM THE LEFT Side.

Fig. 39.-SEen from Above.

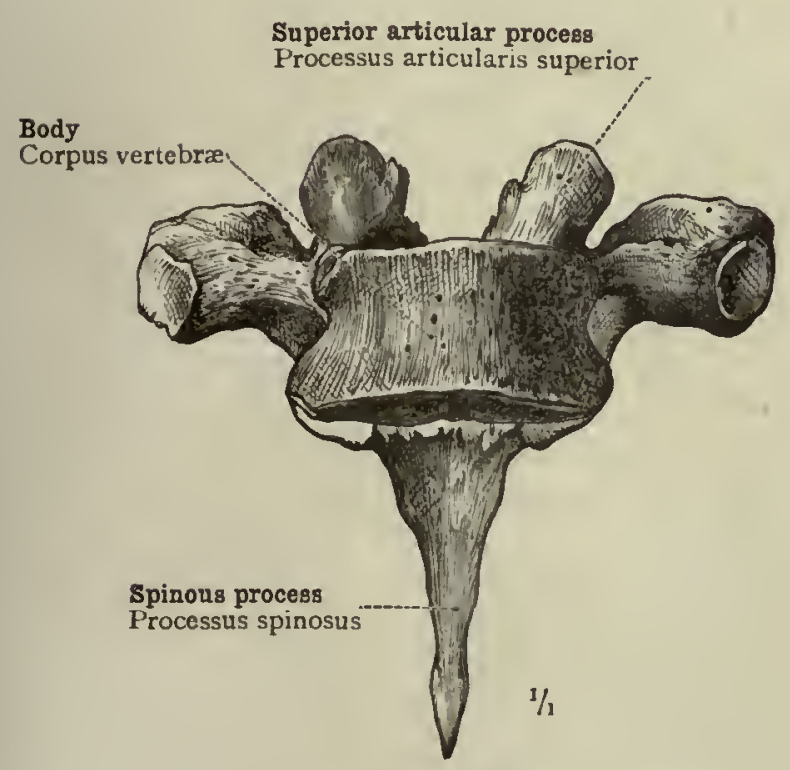

Fig. 40.-SEEN From BEFORE.

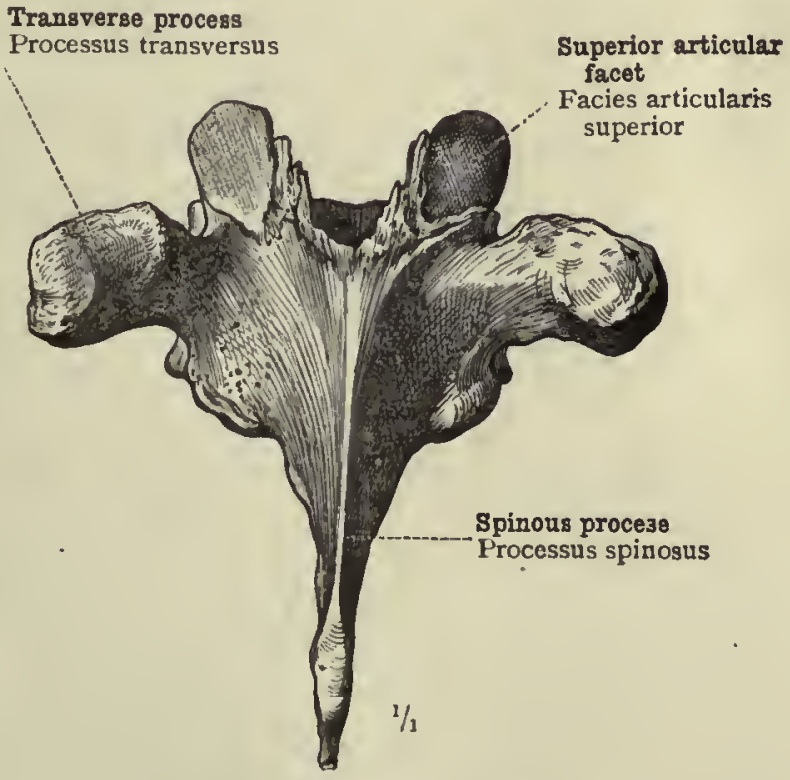

FIG. 4I.-SEEN FROM BEHIND.

Vertebræ: Vertebra thoracalis VI.-Sixth dorsal vertebra. 


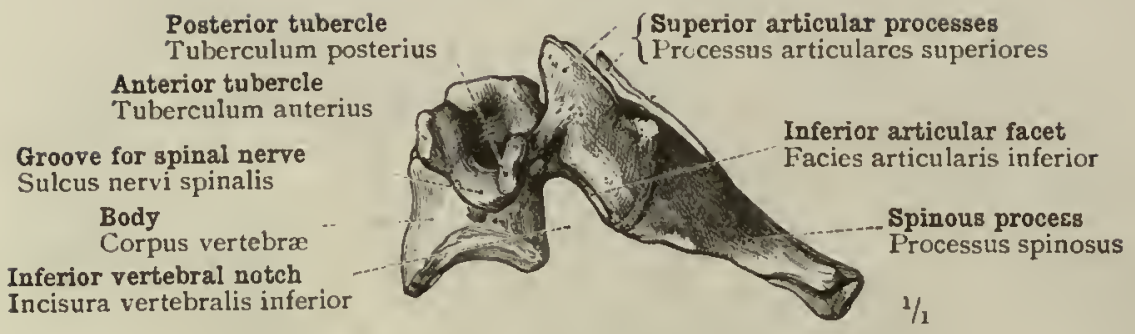

Fig. 42.- SeEn From the Left Side.

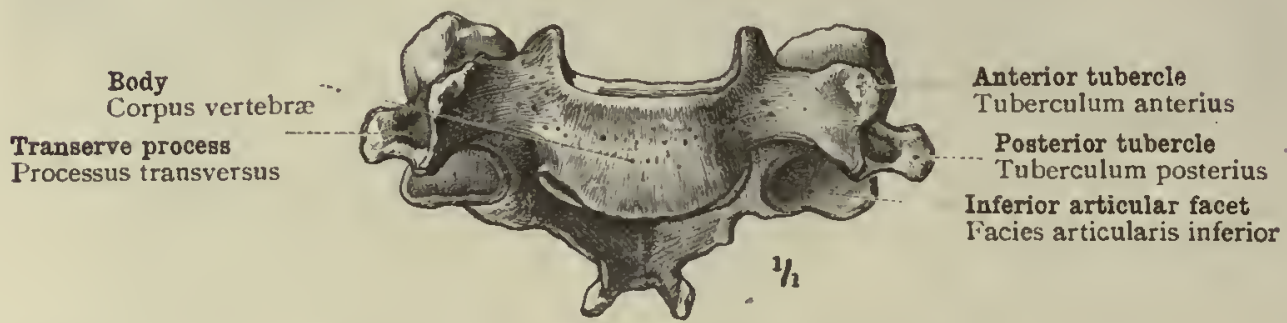

Fig. 43.-SEEN FROM BEFORE.
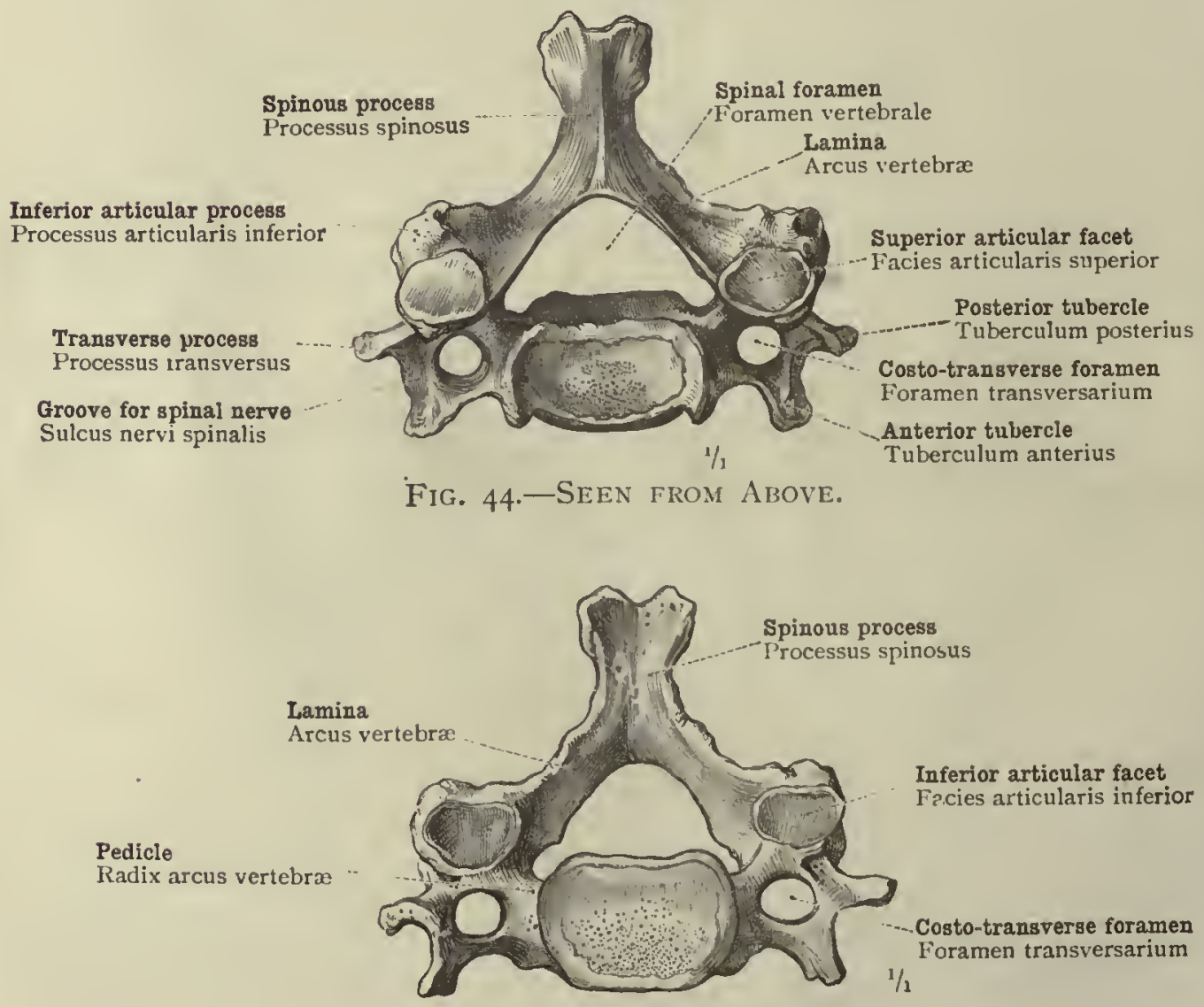

Fig. 45.-Seen from Below.

Vertebræ: Vertebra cervicalis V.-Fifth cervical vertebra. 

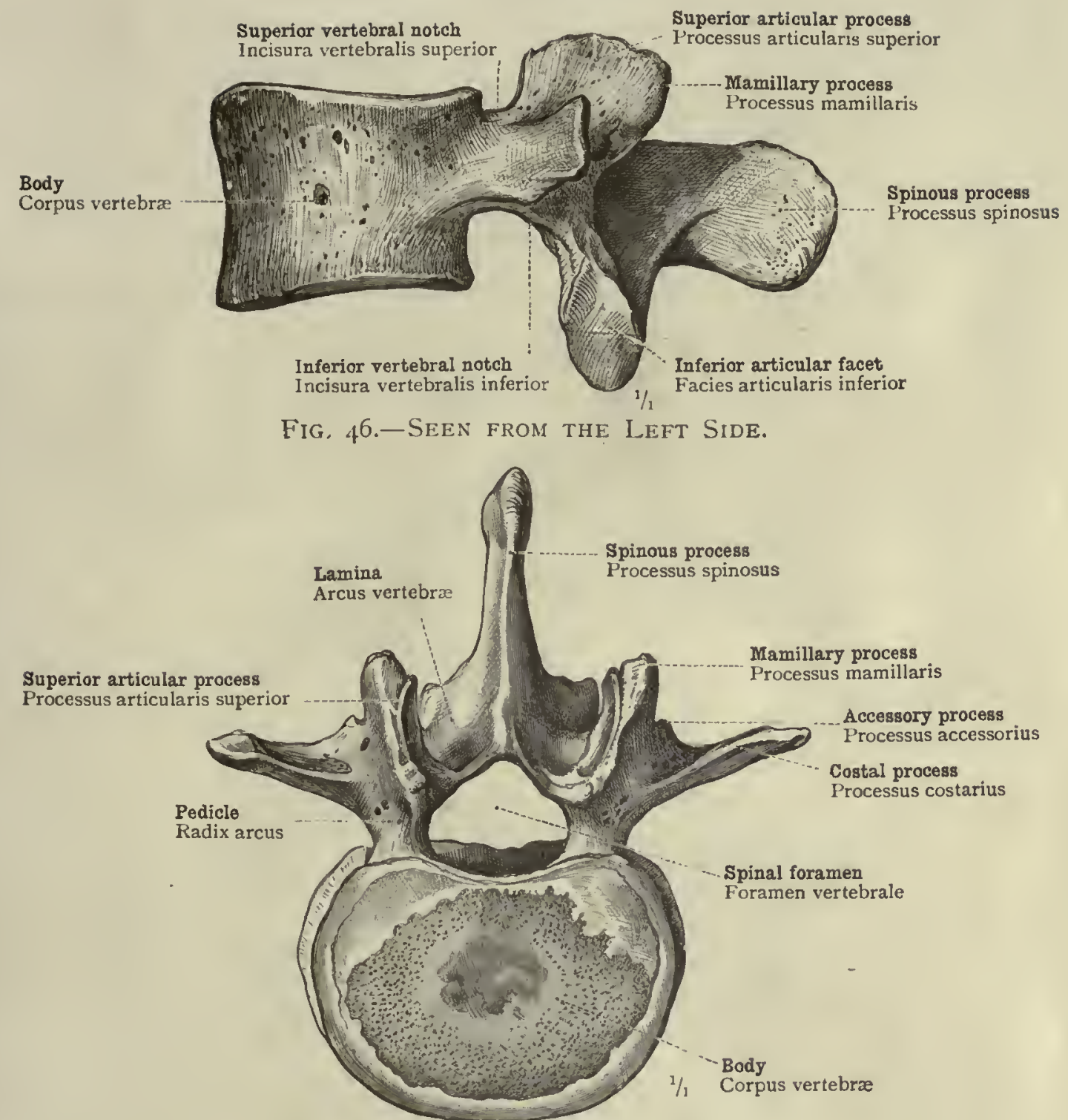

FIG. 47.-SEEN FROM ABOVE.

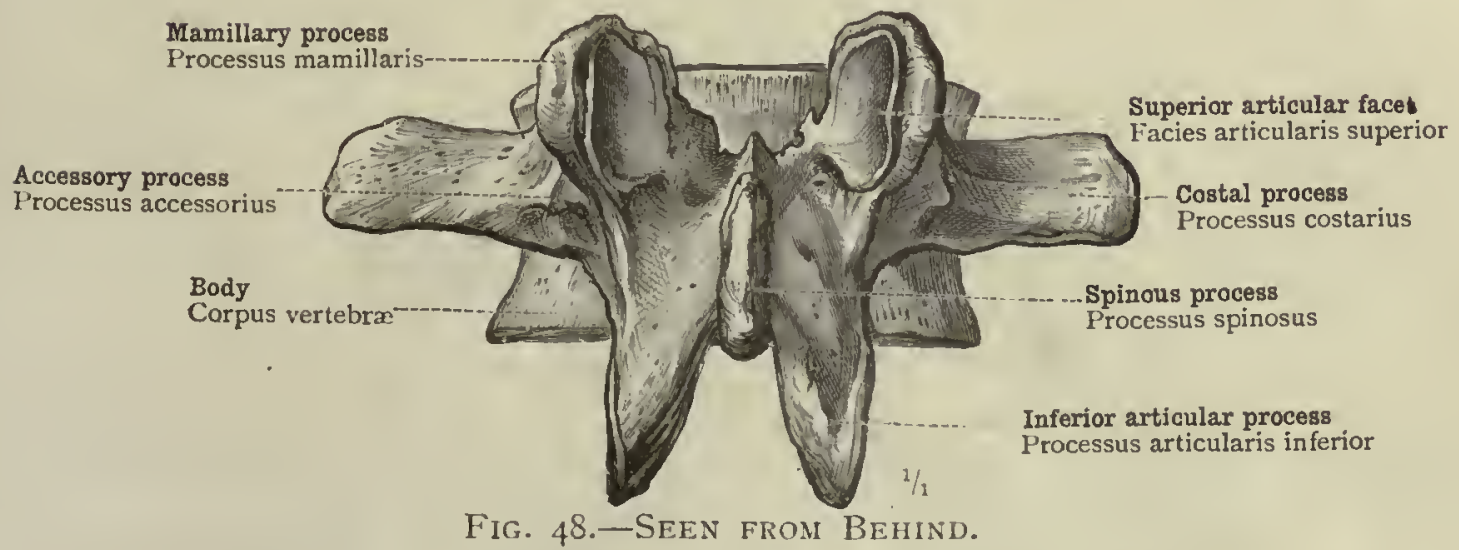

Vertebræ: Vertebra lumbalis II.-Second lumbar vertebra. 


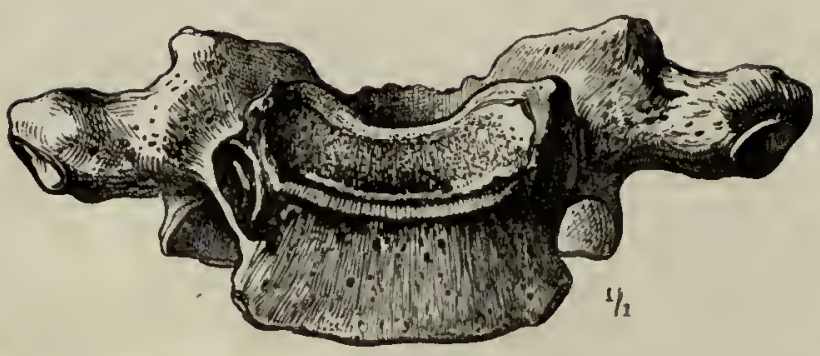

Fig. 49.-Vertebra Thoracalis I.-First Dorsal Vertebra. Seen from Beforb.

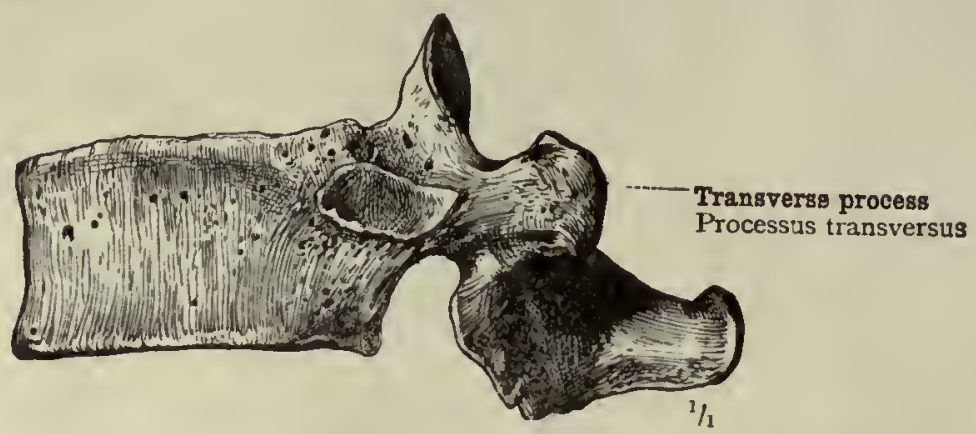

Fig. 50.-Vertebra Thoracalis XI.-Eleventh Dorsal Vertebra. Seen from the Left Side.

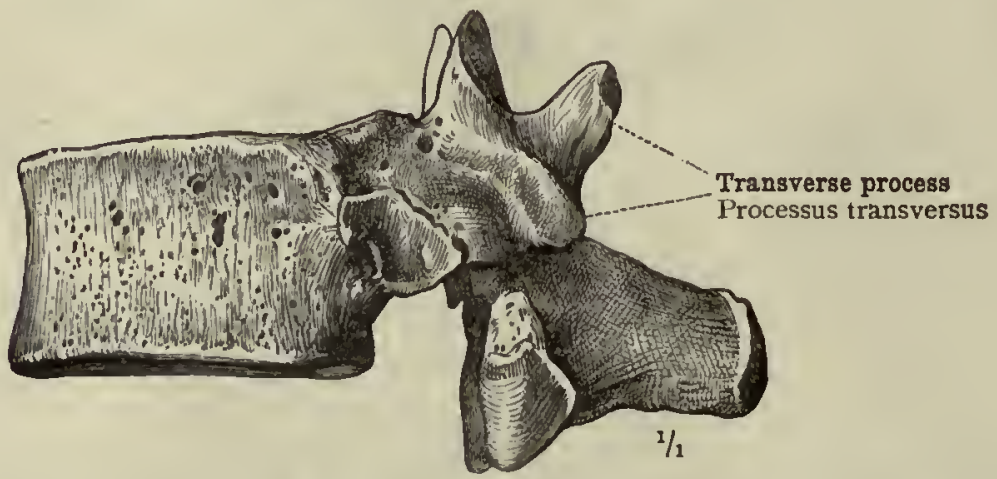

Fig. 51.-Vertebra Thoracalis XII.-Twelfth Dorsal Vertebra. Seen from the Left Side.

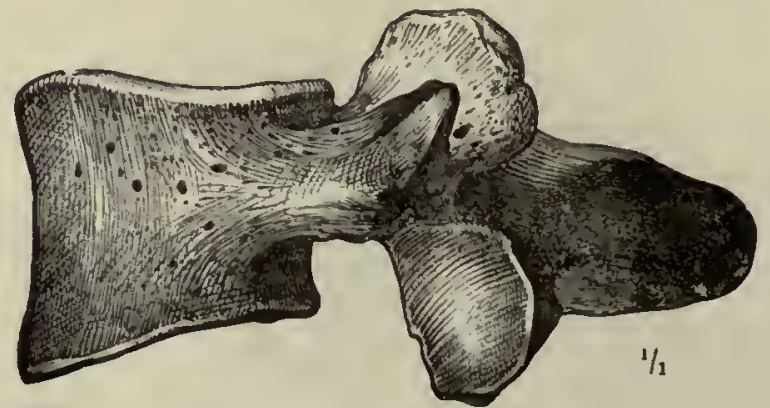

Fig. 52.-Vertebra Lumbalis V.-Fifth Lumbar Vertebra. Seen from the Left Side.

Vertebræ: Transitional forms of the dorsal and lumbar vertebræ. 


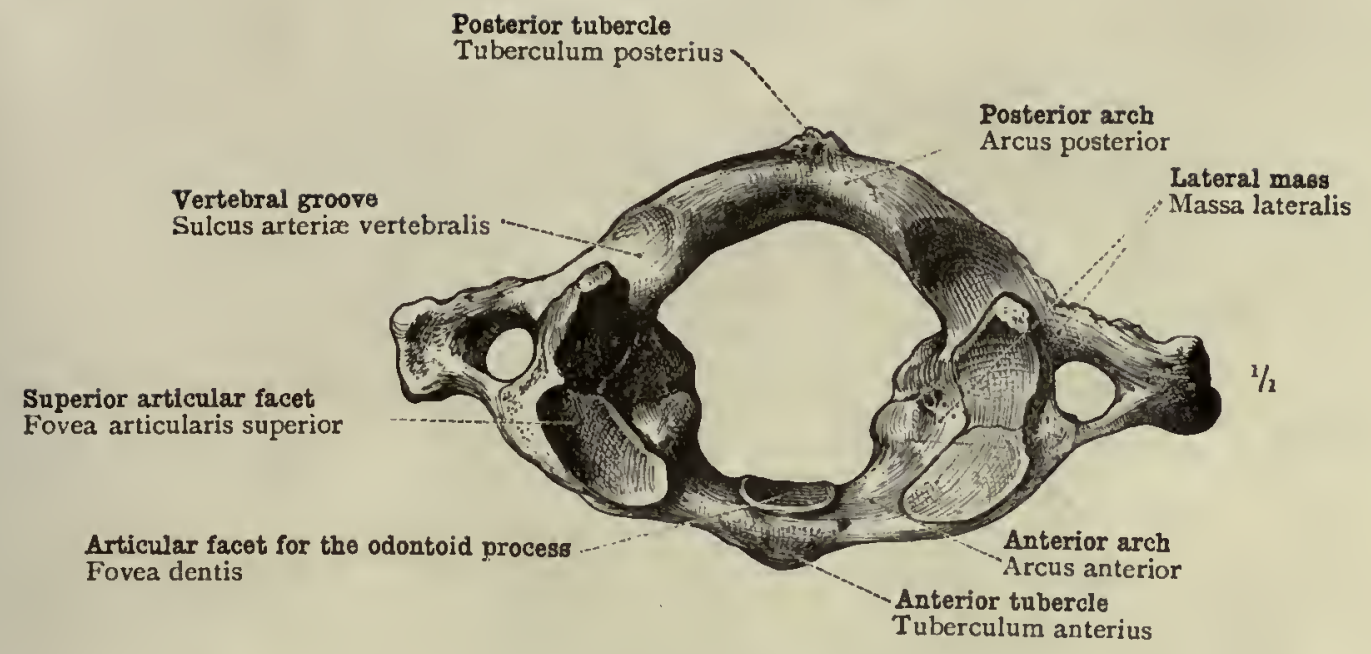

Fig. 53.-The Atlas, or First Cervical Vertebra. Seen from Above.

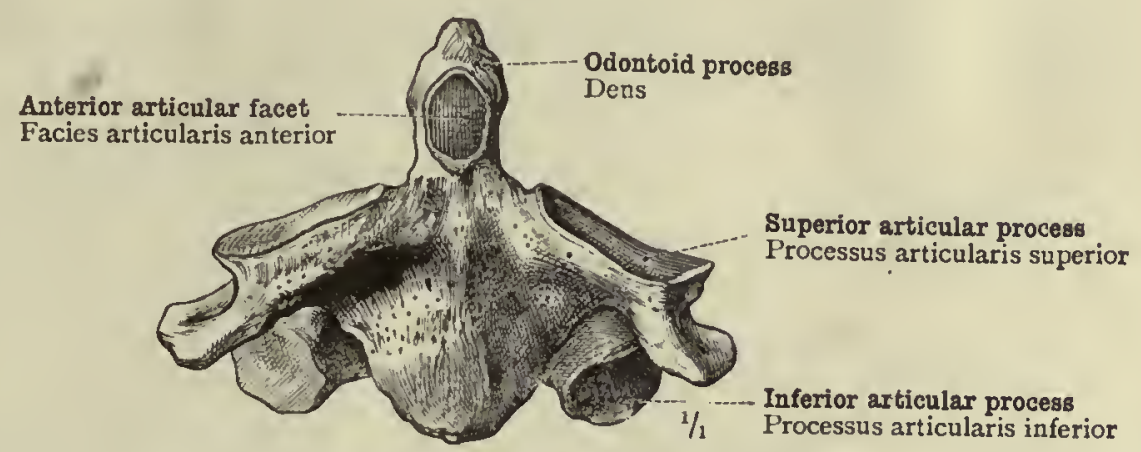

Fig. 54.-Epistropheus, the Axis, or Second Cervical Vertebra. Seen from Before.

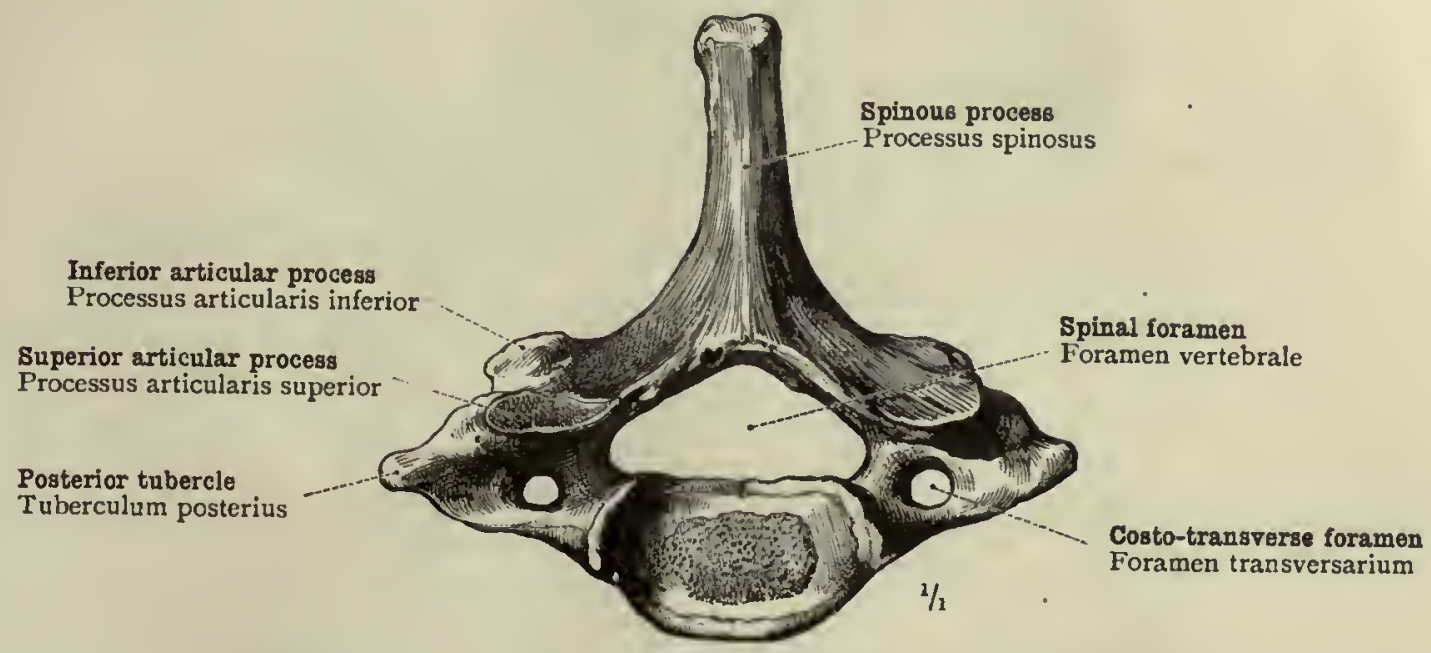

Fig. 55.-Vertebra Cervicalis ViI.-Seventh Cervicaí Vertebra. Seen from Above.

Vertebræ: The atypical cervical vertebræ. 
Sacral portion of the brim of the pelvis

Pars sacralis linex terminalis

Transverse ridges.

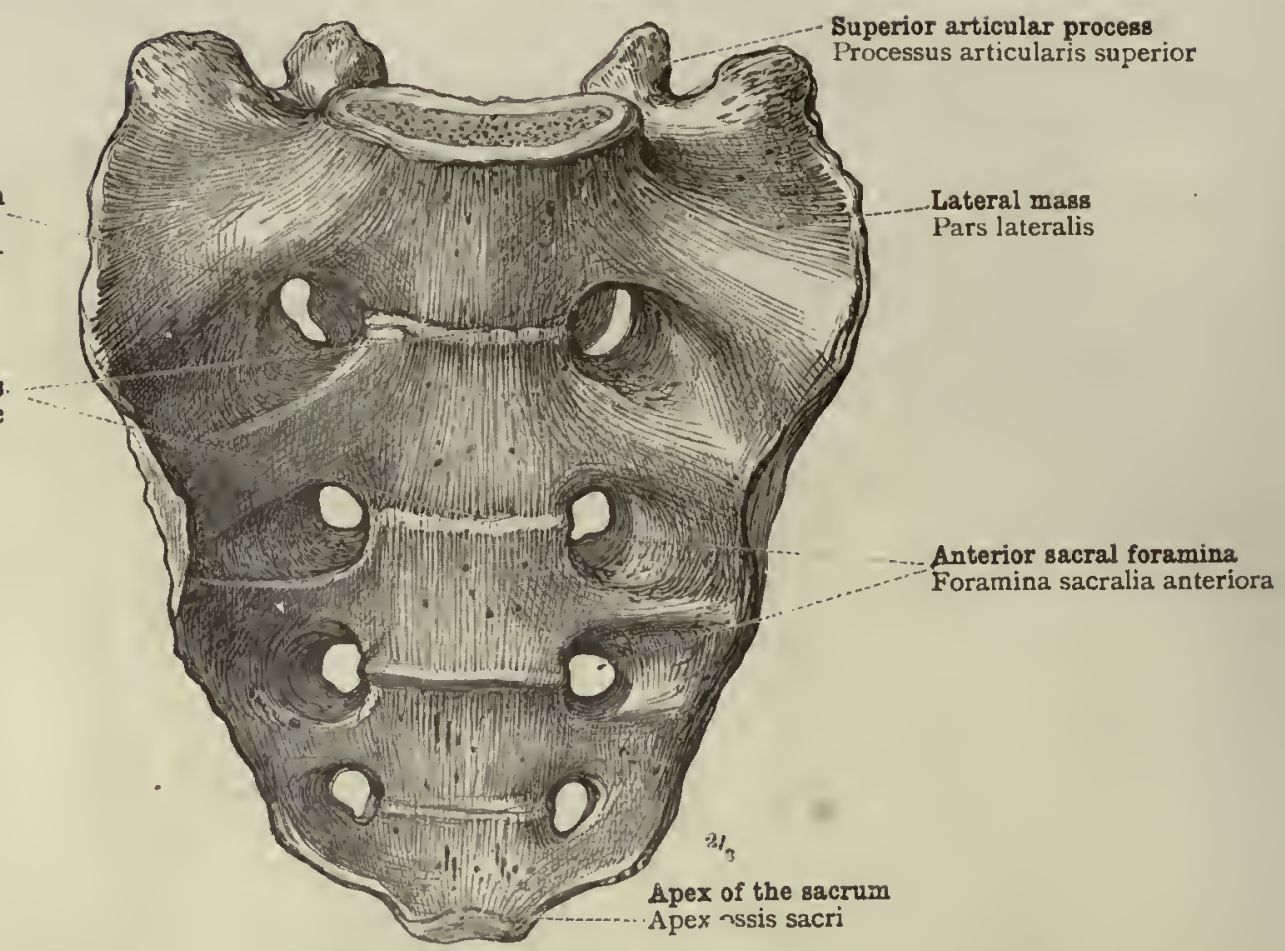

Fig. 56.-Male Sacrum (Facies Pelvina-Pelvic Surface). Seen from Before.

Sacral portion of the brim of the pelvis

Pars sacralis linea ter. minalis

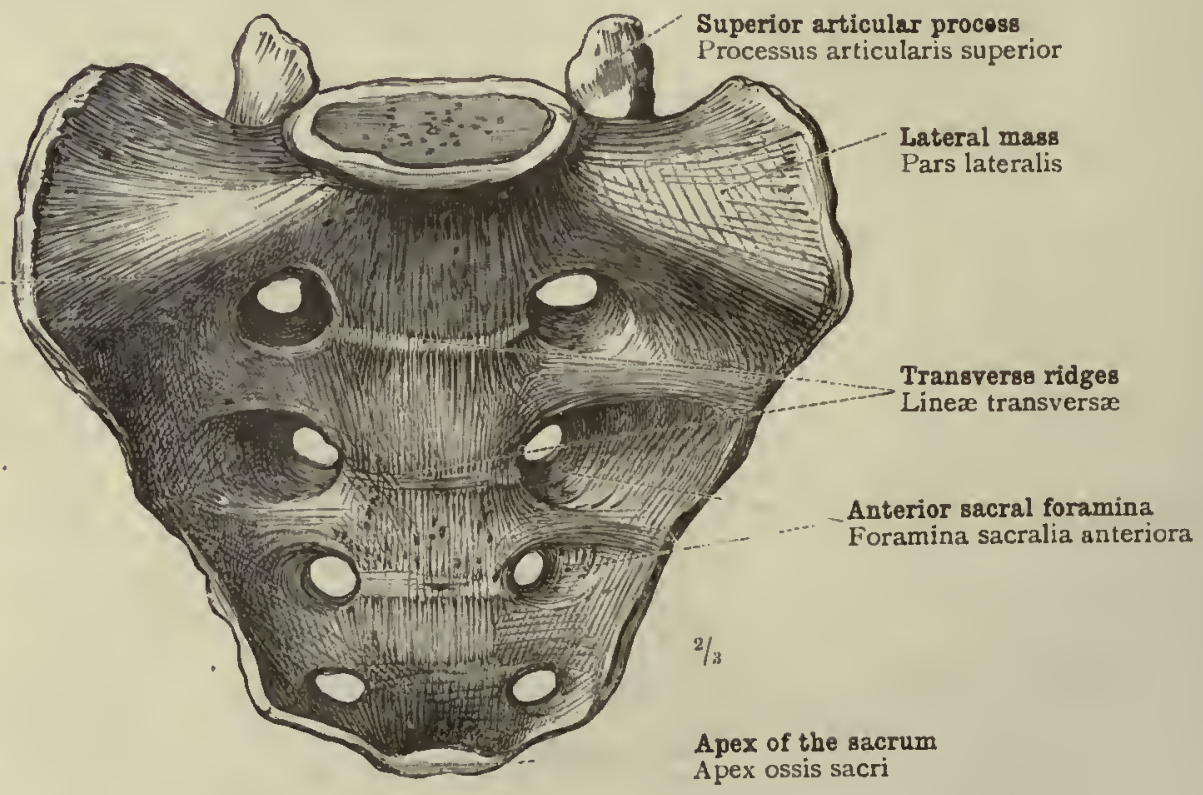

Fig. 57.-Female Sacrum (Facies Pelvina-Pelvic Surface). Seen from Before. 


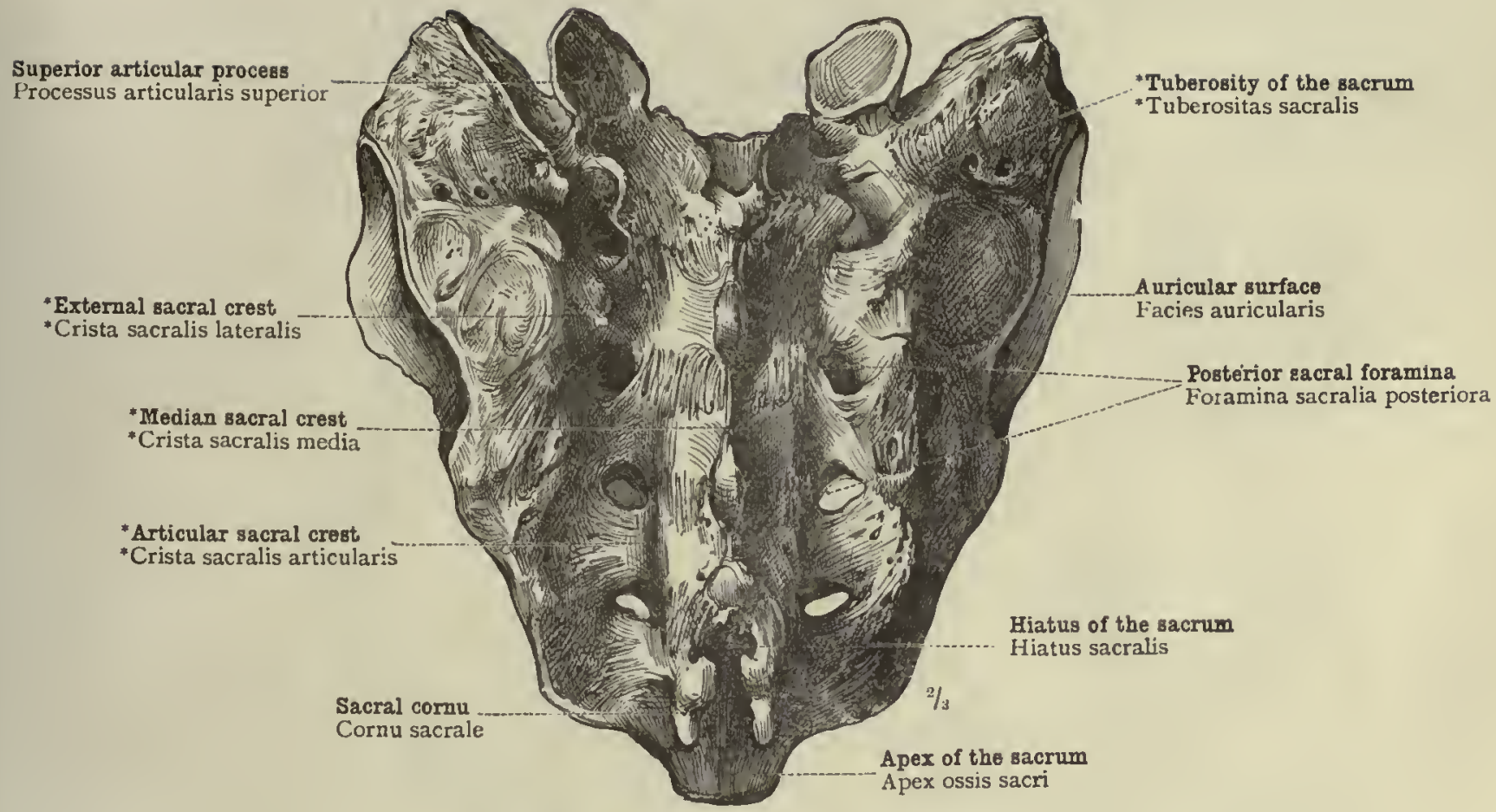

Fig. 58.-Male Sacrum (Facies Dorsalis-Dorsal Surface). Seen from Behind.

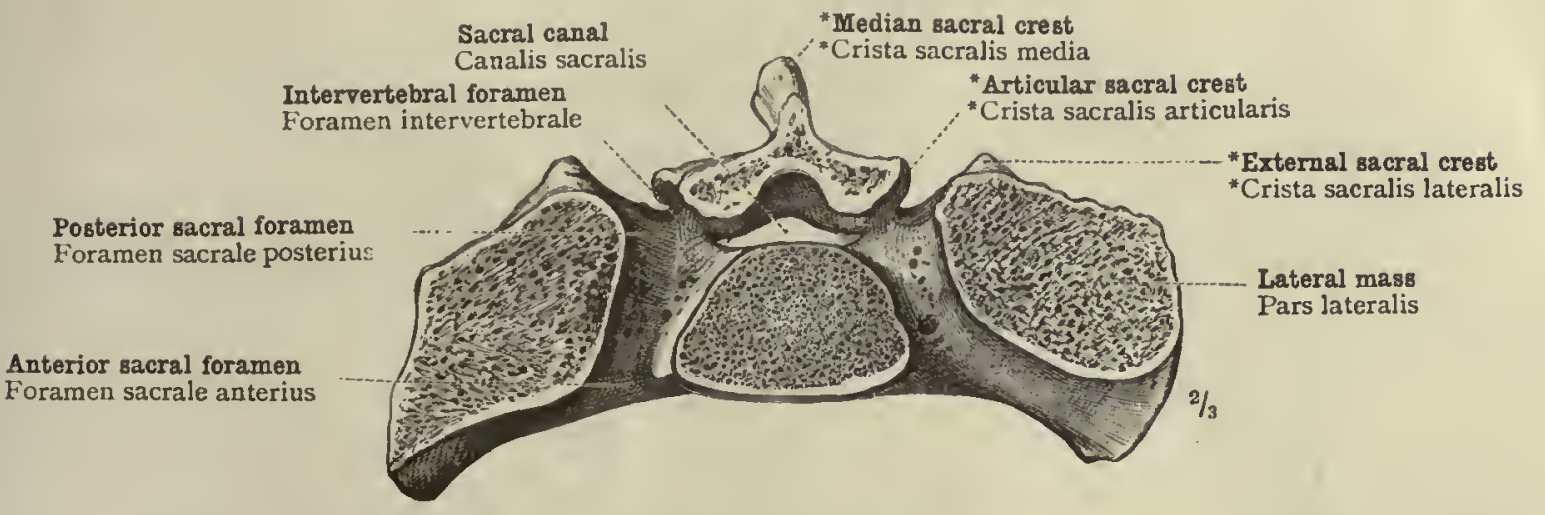

Fig. 59.-Transverse Section through the Sacrum at the Level of the First Set of SaCral Foramina. 


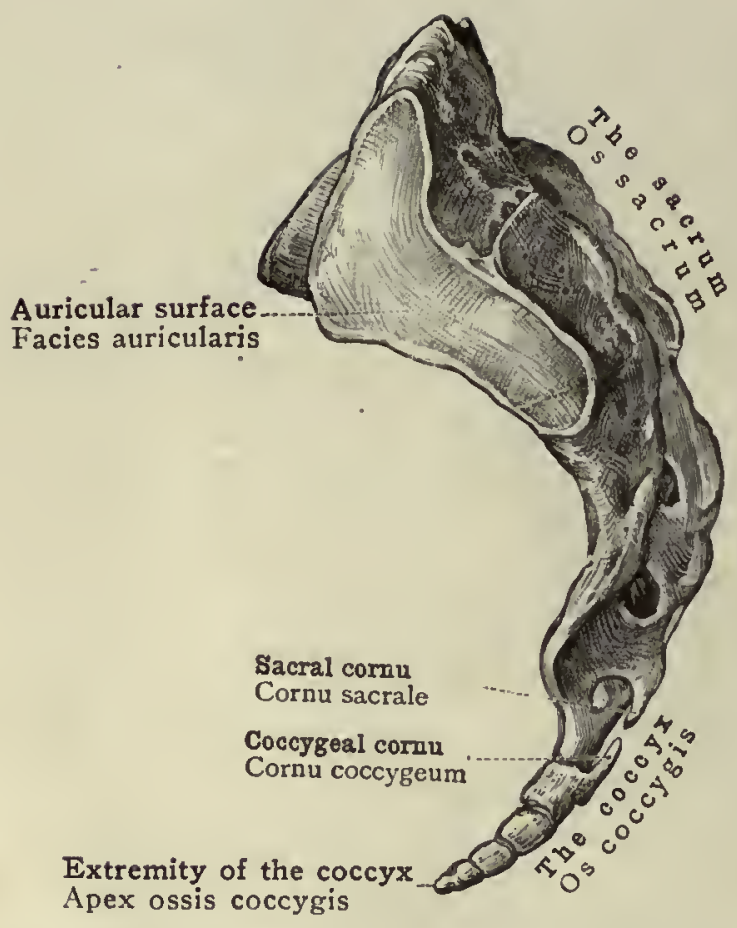

Fig. 60.-Sacrua and Coccyx. SEen from THE LEFT SIDE.

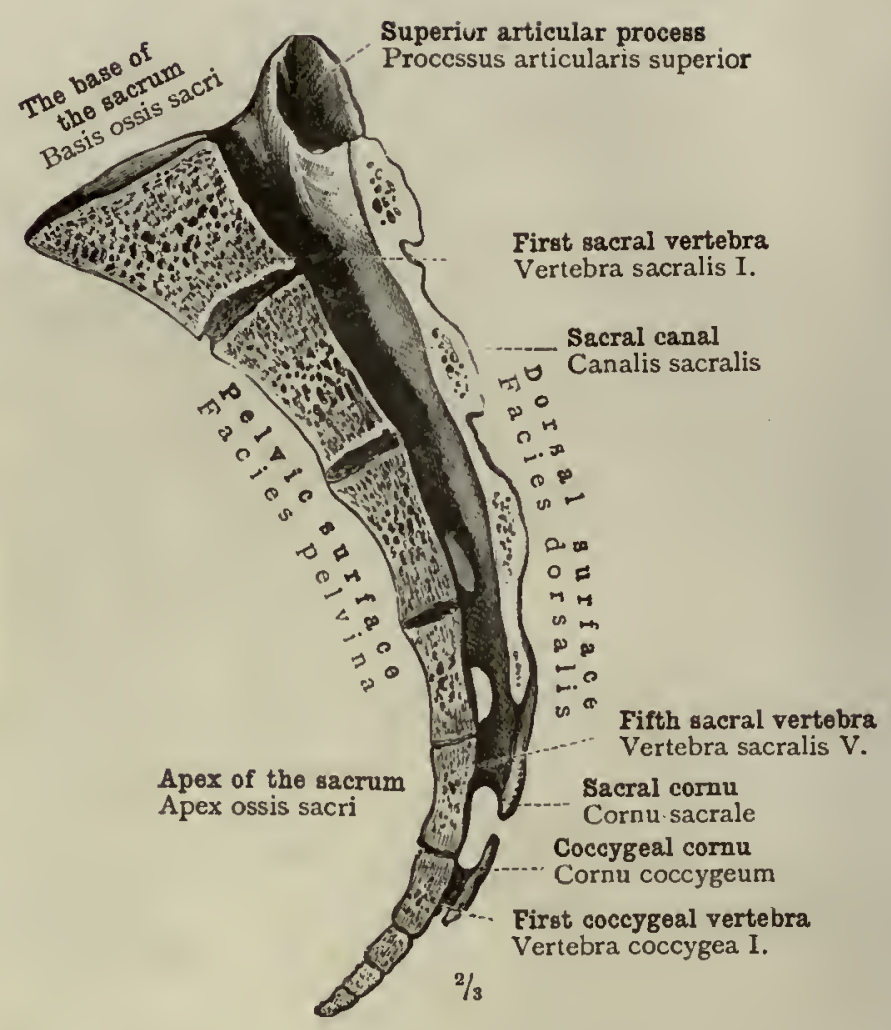

Fig. 61.-Sacrum and Coccyx in Sagittal Section THROUGH THE MEDIAN Line.

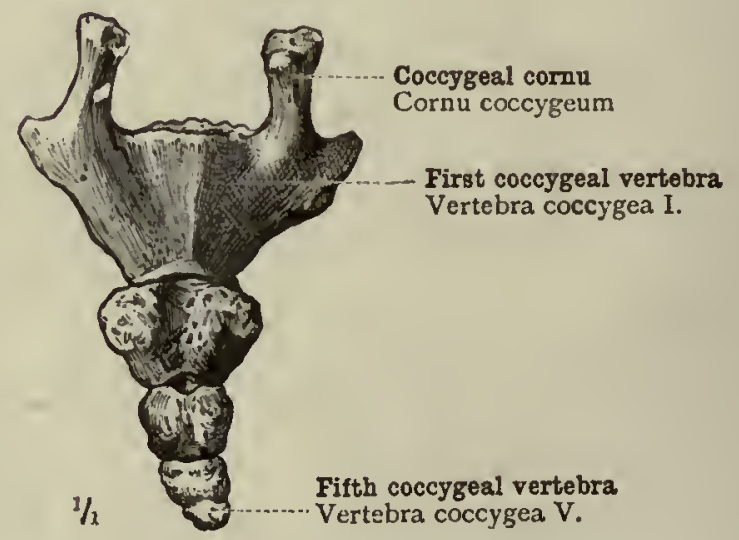

FIG. 63.-COCCYX SEEN FROM BEHIND. 


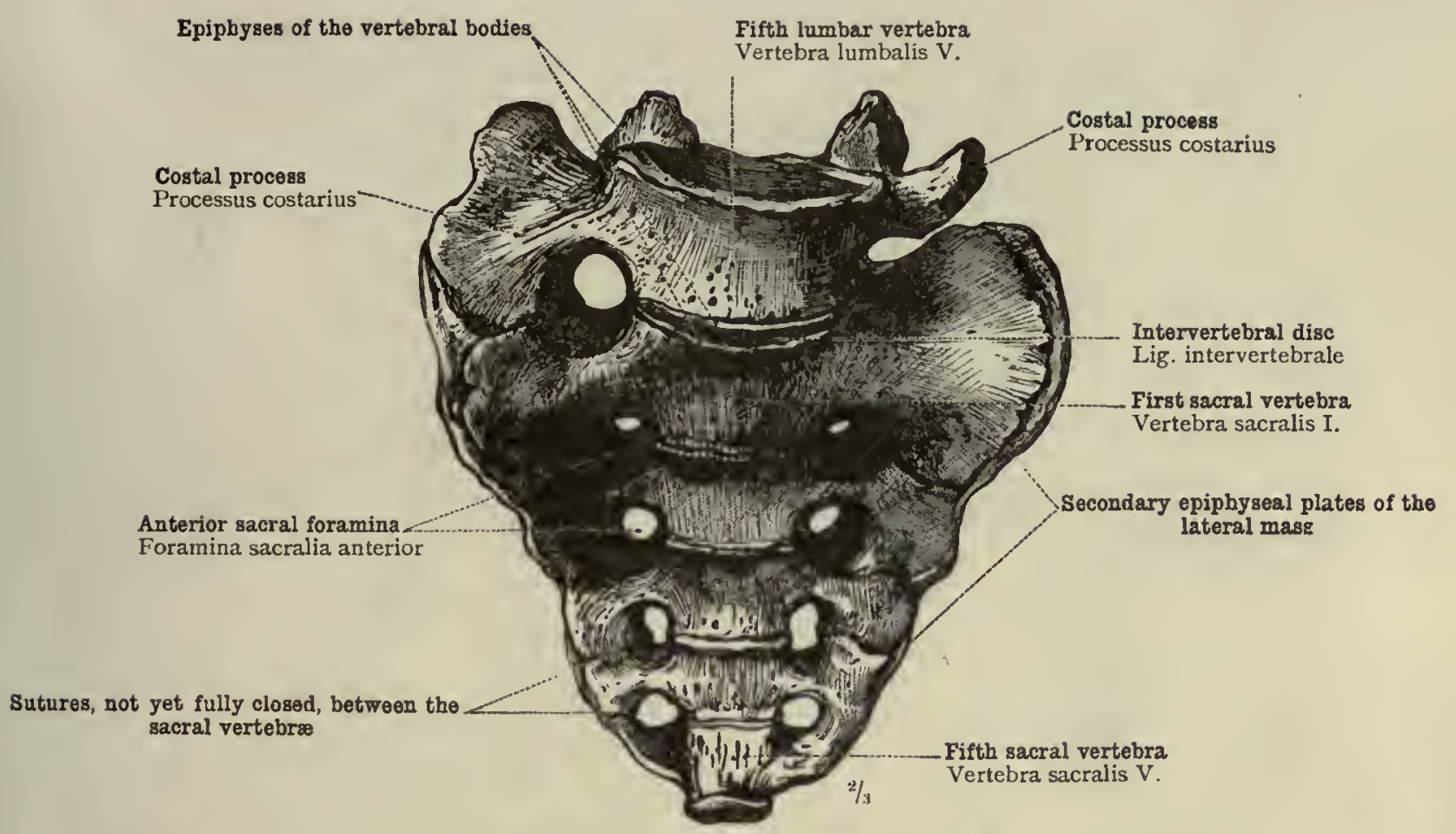

Fig. 64.-Unilateral Assimilation and Commencing Ankylosis of the Fifth Lumbar Vertebra with the Sacrum. Seen from Before.

From a boy seventeen years of age. Epiphyses on the bodies of the sacral vertebra, and along the lateral margins of the sacruin.

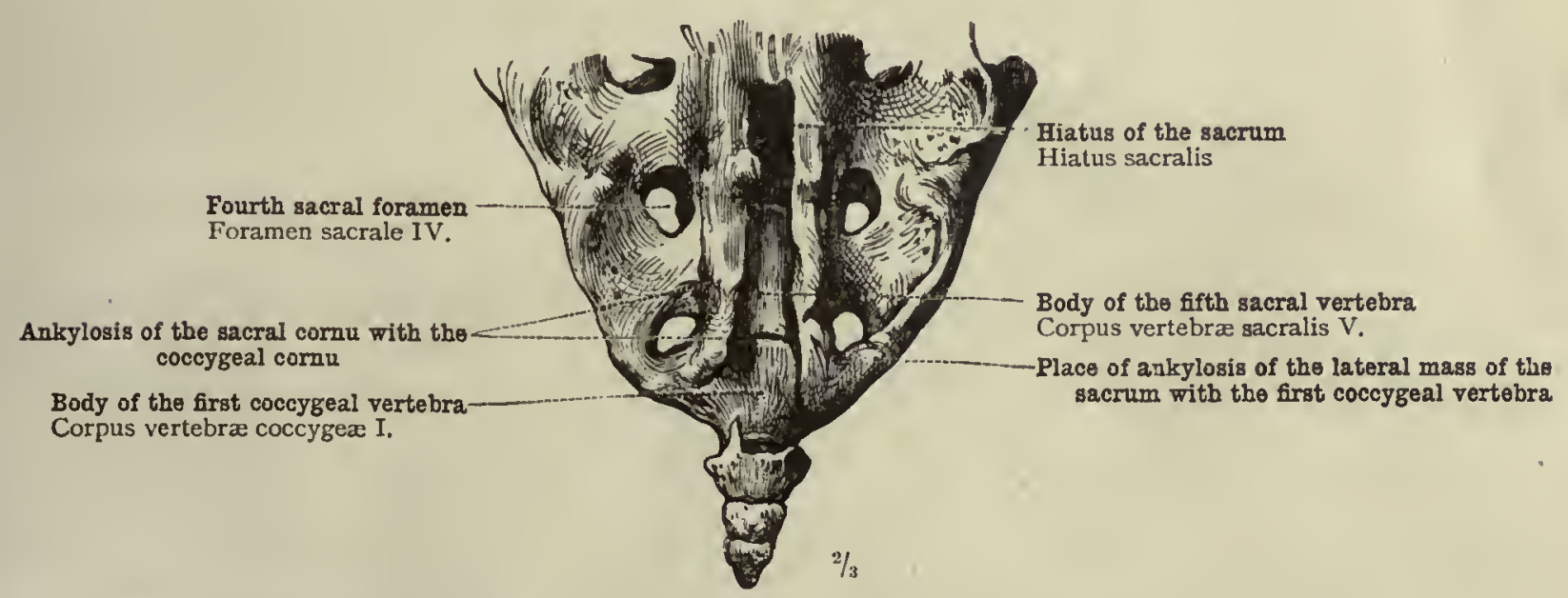

Fig. 65.-Ankylosis of the Sacrum with the Coccyx. Seen from Behind.

From a man forty years of age.

Anomalous Ankyloses of the Sacrum. 

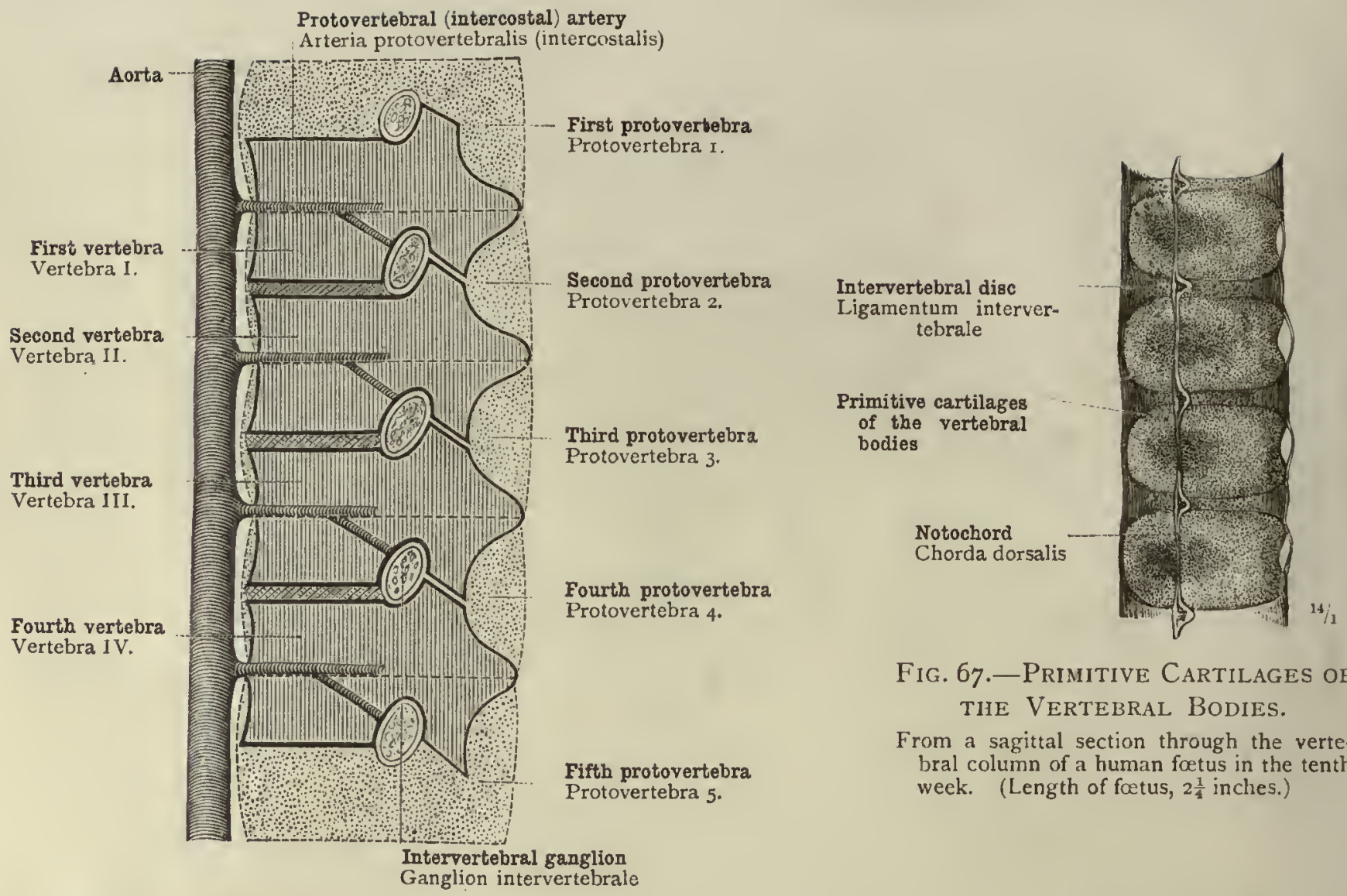

Fig. 66.-Diagram showing the Relations of the ProtoVertebre to the Vertebre. (From von EbNer.)
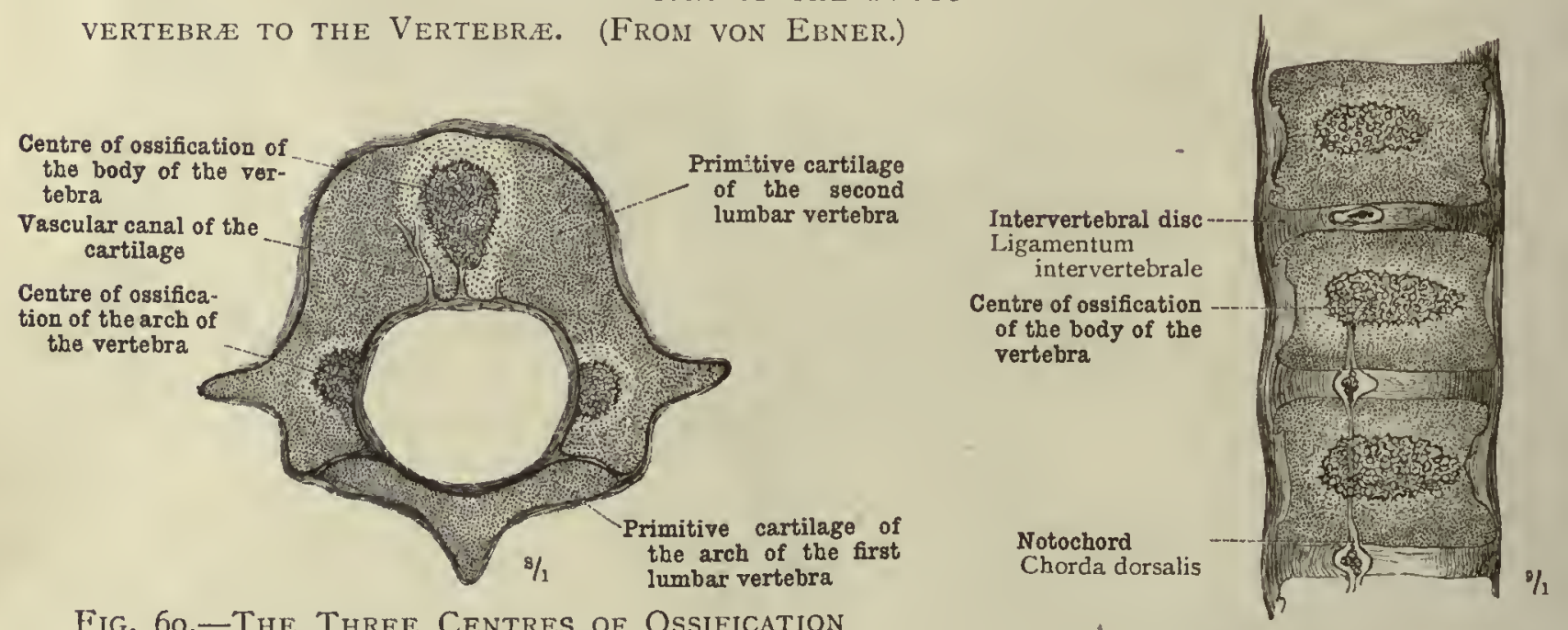

Fig. 69.-The Three Centres of Ossification OF A VERTEBRA.

Horizontal scction through the second and a portion of the first lumbar vertebre of a human foetus in the beginning of the fifth month (months of four weeks each). (Length of foetus, $5 \frac{1}{2}$ inches.)

Fig. 67.-Primitive Cartilages of the Vertebral Bodies.

From a sagittal section through the vertebral column of a human foetus in the tenth week. (Length of fotus, $2 \frac{1}{4}$ inches.) 


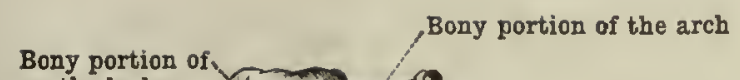
the body
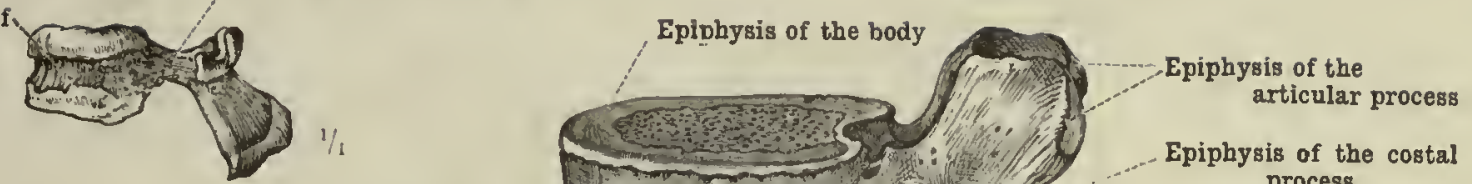

Fig. 70-First Lumbar Vertebra OF A NEW-BORN ChILd.

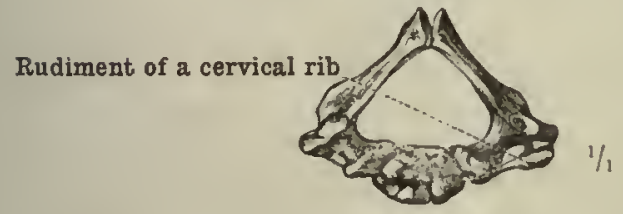

Fig. 72.-The Seventh Cervical Vertebra OF A NEW-BORN ChILd.

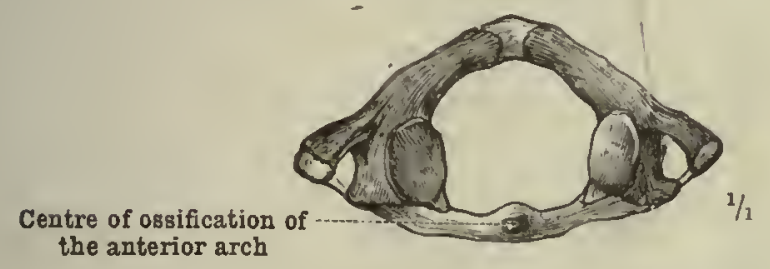
Fig. 73.-The Atlas at THE END OF THE FIRST YEAR.

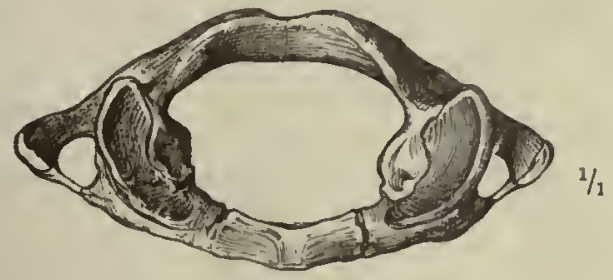

Fig. 75.-The Atlas in the Fourth Year.

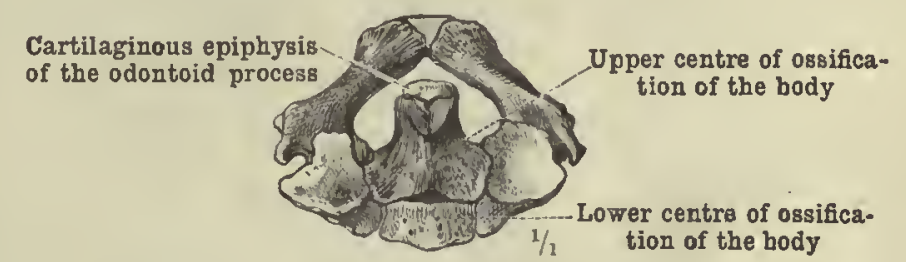

Fig. 74.-ThE AXIS AT the END OF THE FIRST YEAR.

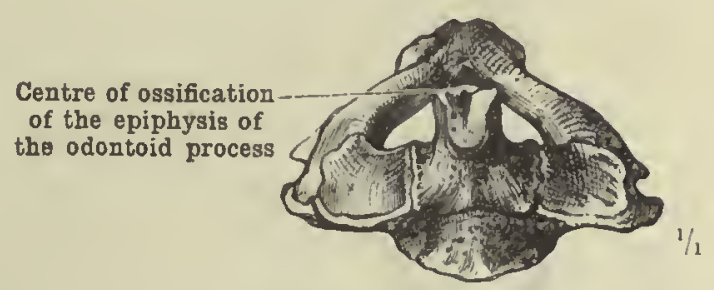

Fig. 76.-The Axis in the Fourth Year.
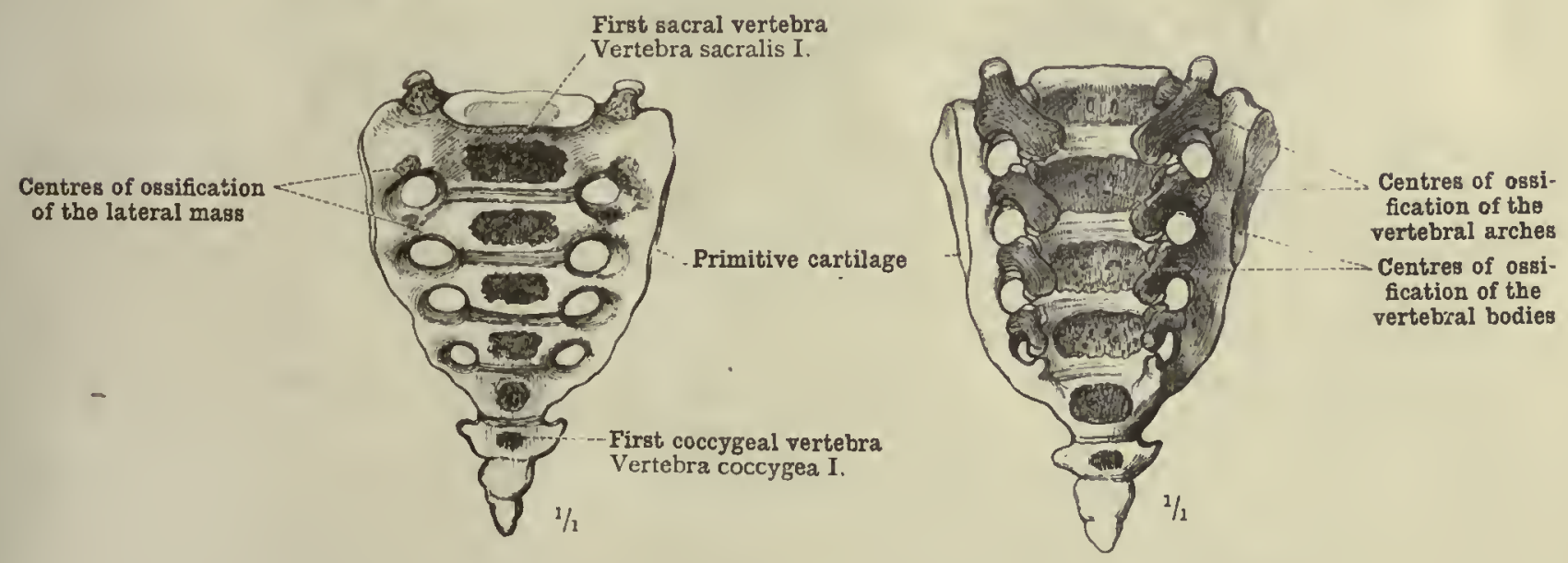

Fig. 77.-SEEN FROM BEFORE.

Fig. 78.-SEEN FROM BEHIND.

Development of the Vertebra: The centres of ossification in the sacrum and coccyx of a child at the age of two months. 


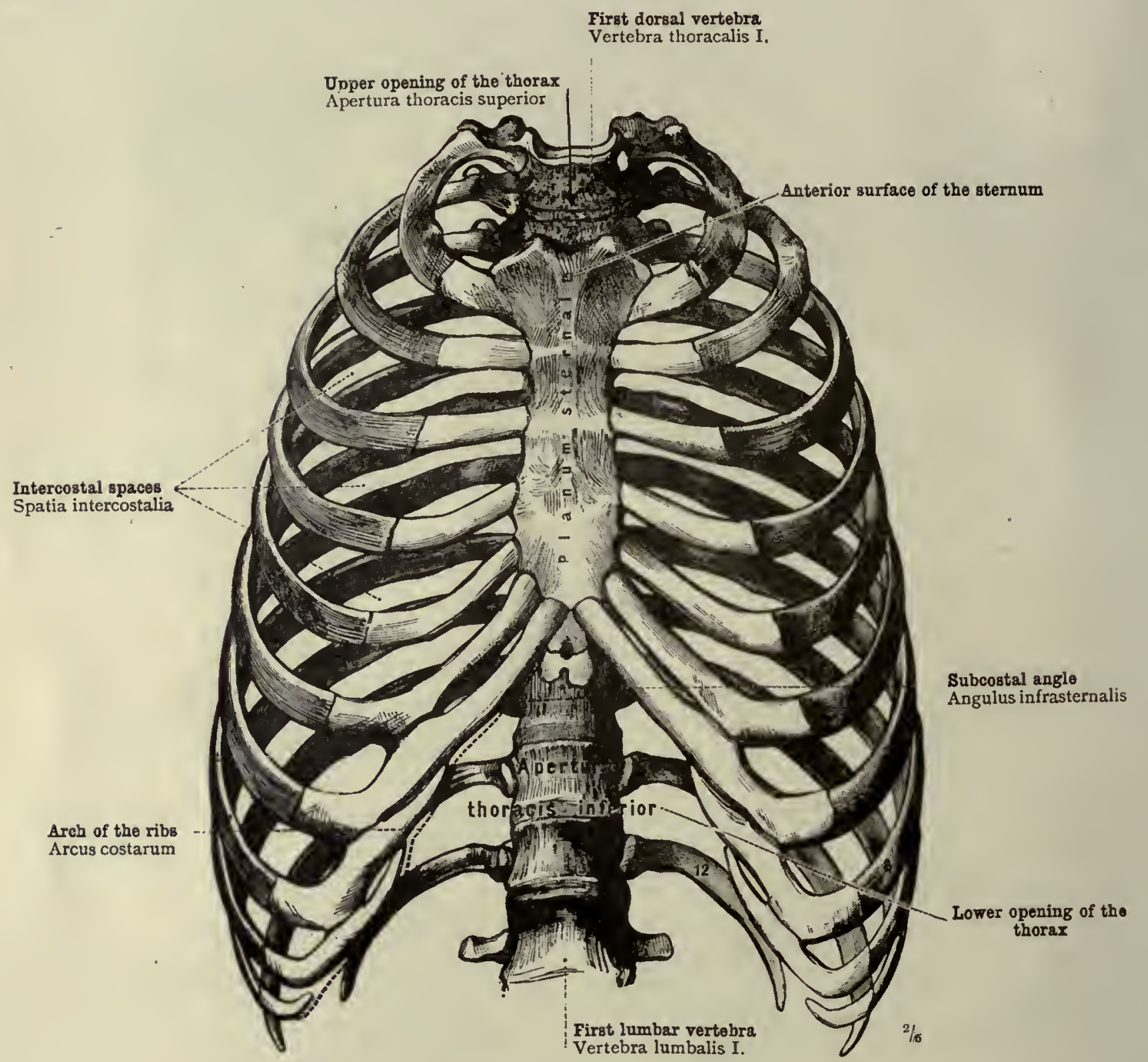

$(1-7$, Costæ veræ, sternal or true ribs; 8-12, Costæ spuriæ, asternal or false ribs ; 11 and 12 , Costæ fluctuantes, foating ribs.)

Fig. 79.-The Thorax seen from Before. 


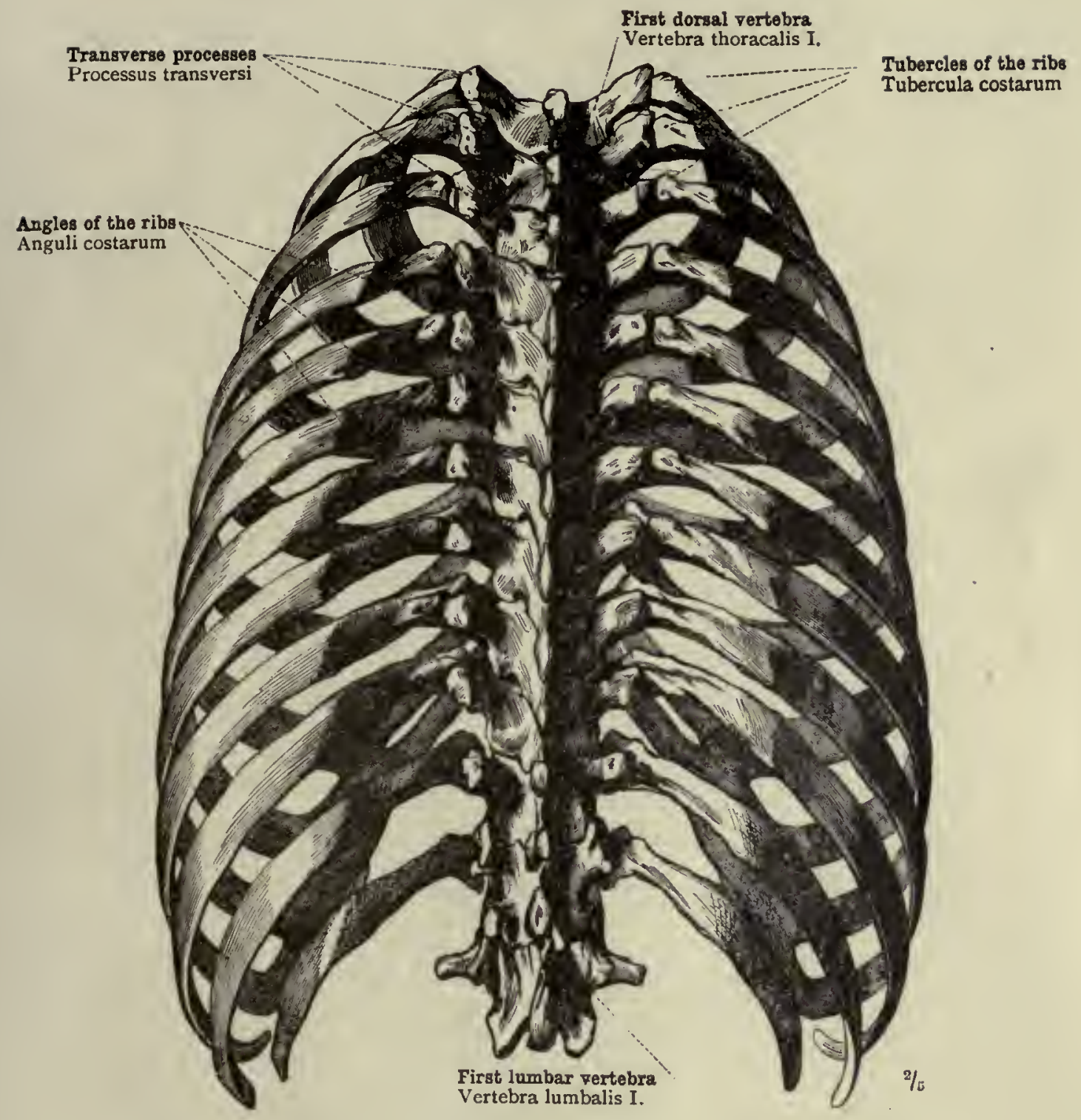

Fig. 80.-The Thorax SEen From BehiNd. 


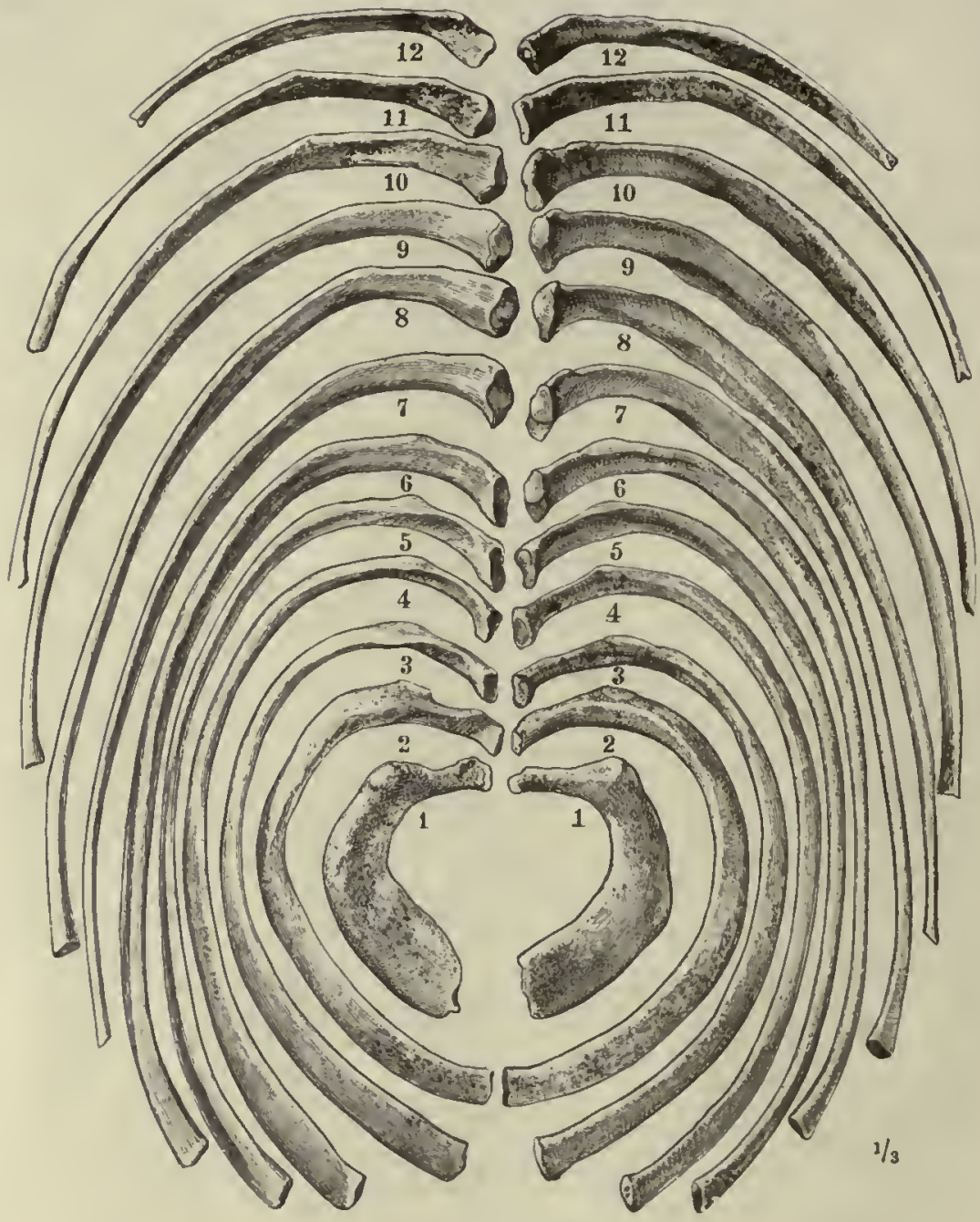

Fig. 8i.-The Twelve Pairs of Ribs. 


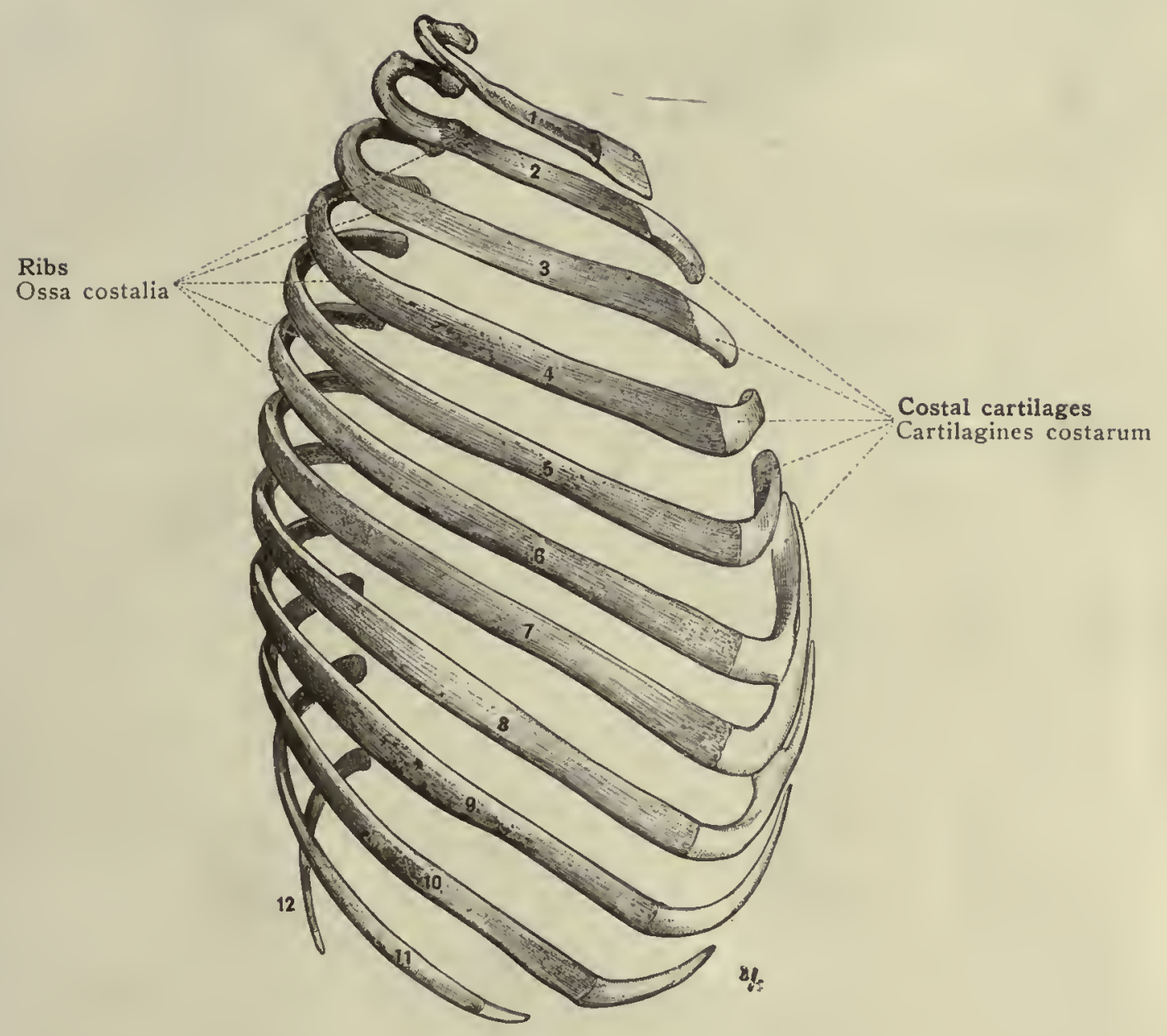

Fig. 82.-The Twelve Ribs of the Right Side in their Natural Position. SeEn Fron the Right. 


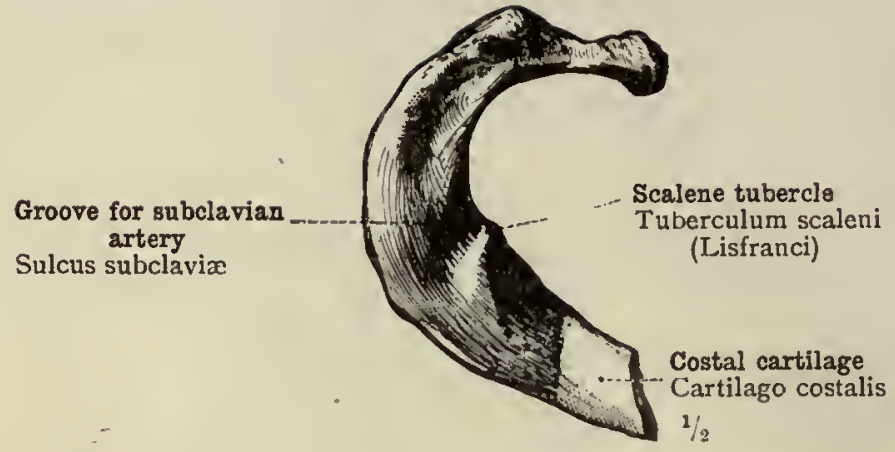

FIG. 83.-FIRST (RIGHT) Rib. SEE.i FROM ABOVE.

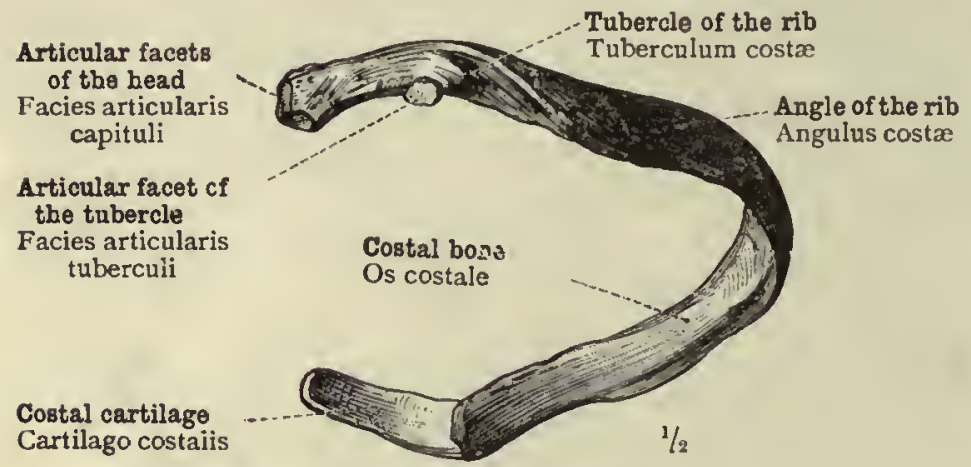

Fig. 85.-FonRth (RIght) Rib. SEEN FROM BEHIND.

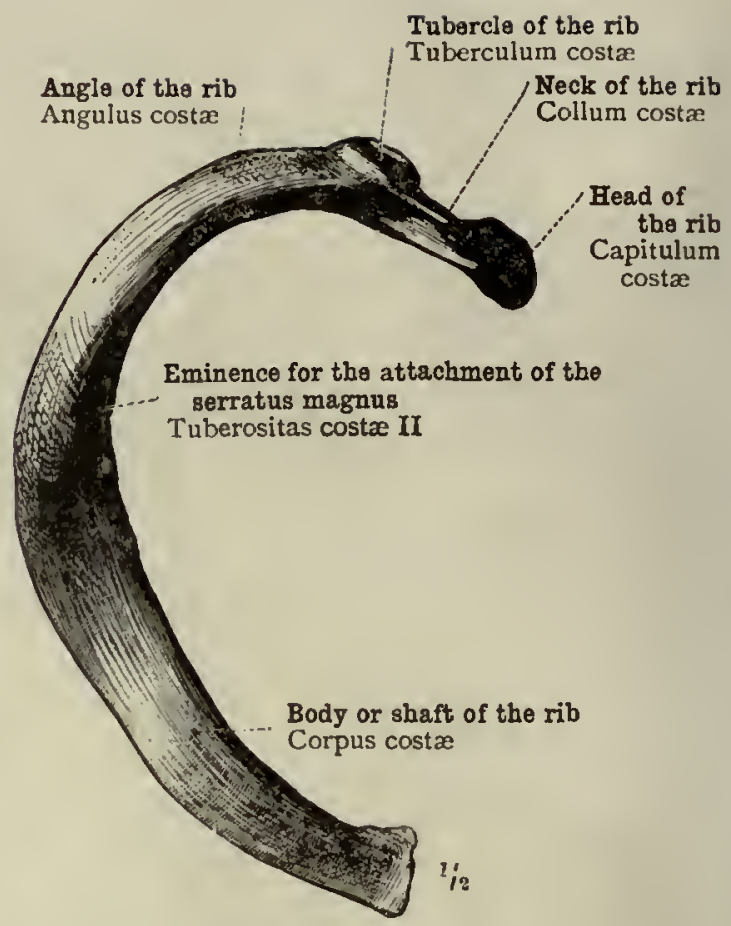

Fig. 84.-Second (Right) Rib. SeEn from Above.

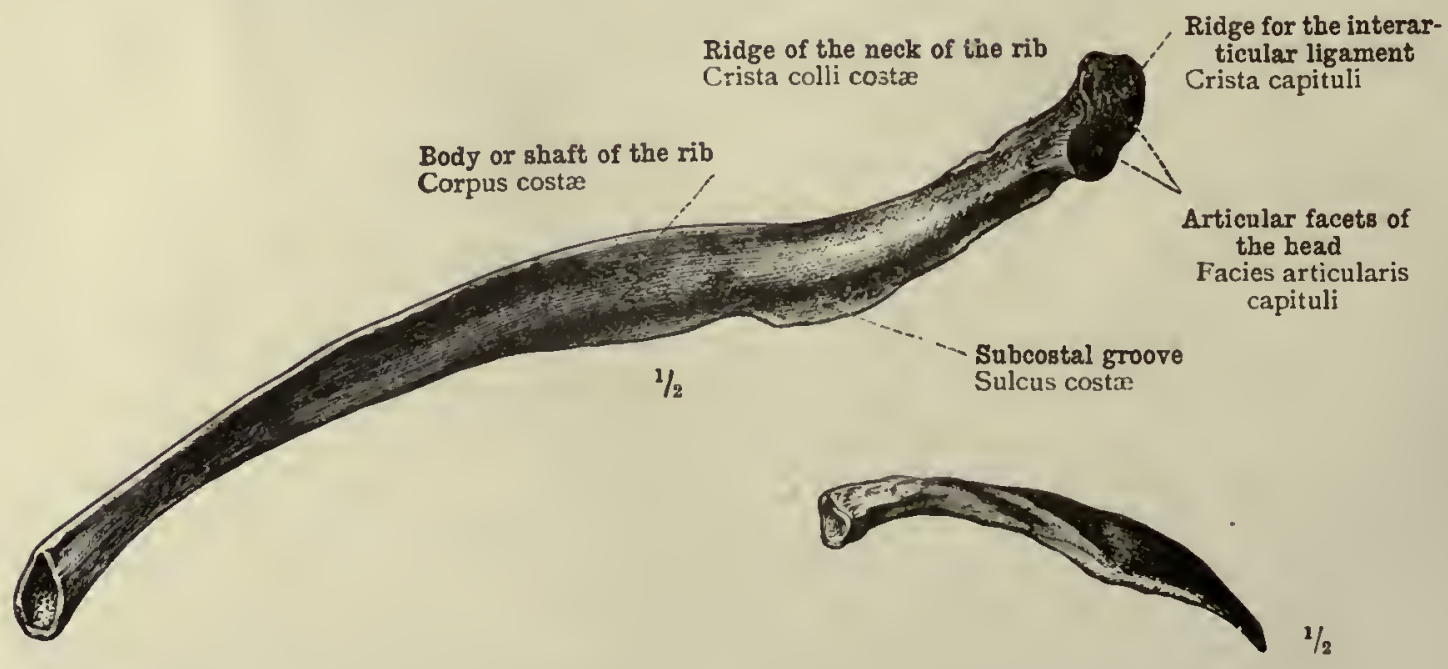

Fig. 86.-Seventh (Right) Rib. SEEN FROM WITHIN.
Fig. 87.-Twelftil (Right) Rib. SEEN FROM Within. 


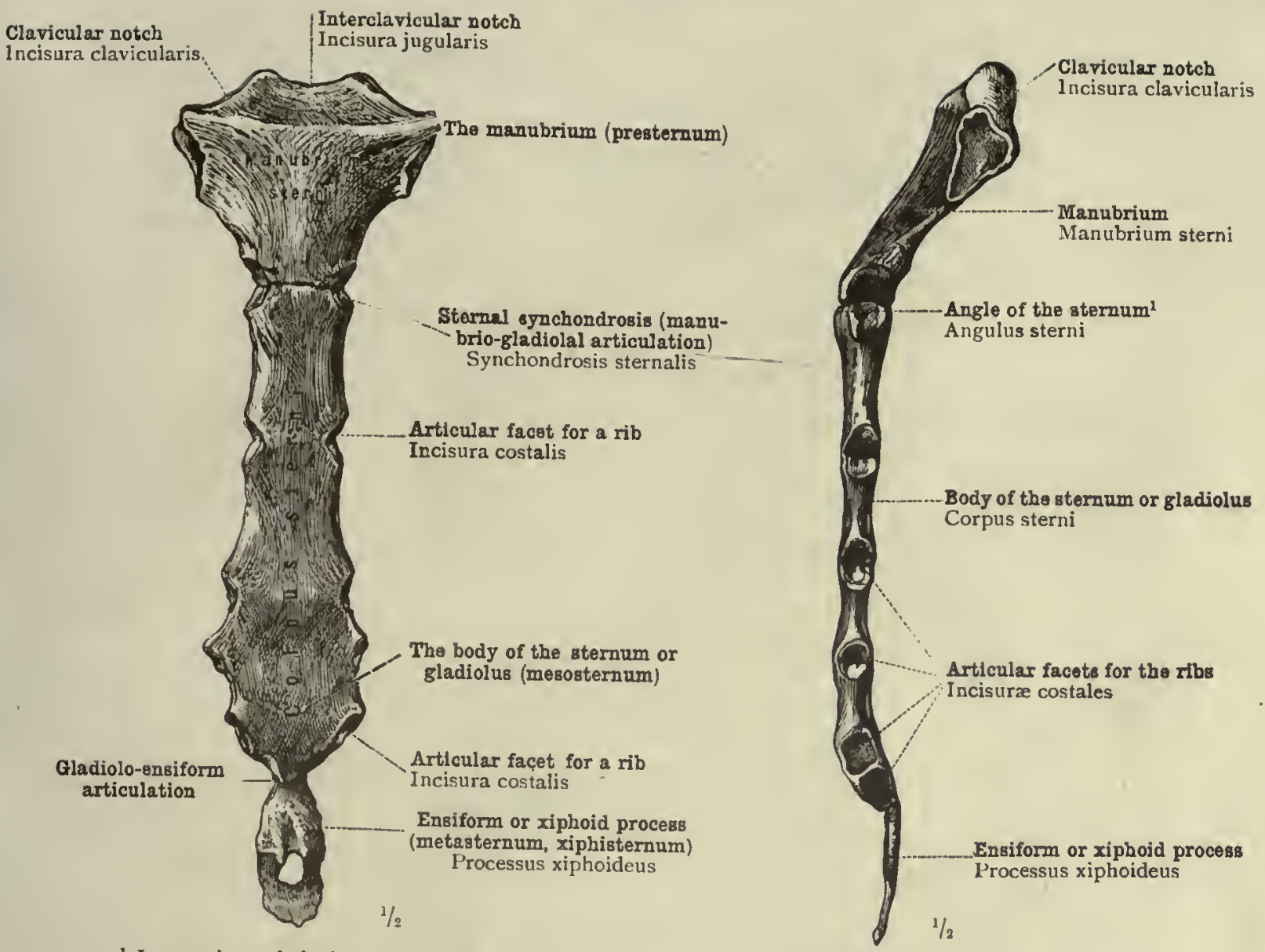

1 In certain pathological conditions the angle between the manubrium and the body of the sternum becomes less obtuse, and therefore more prominent. It is then known as angulus Ludovici, or Ludwig's
angle.-Tr.

FIG. 88.-THE STERNUM SEEN FROM BEFORE.

Fig. 89.-The Sternum SEen FROM THE LEFT SIDE.

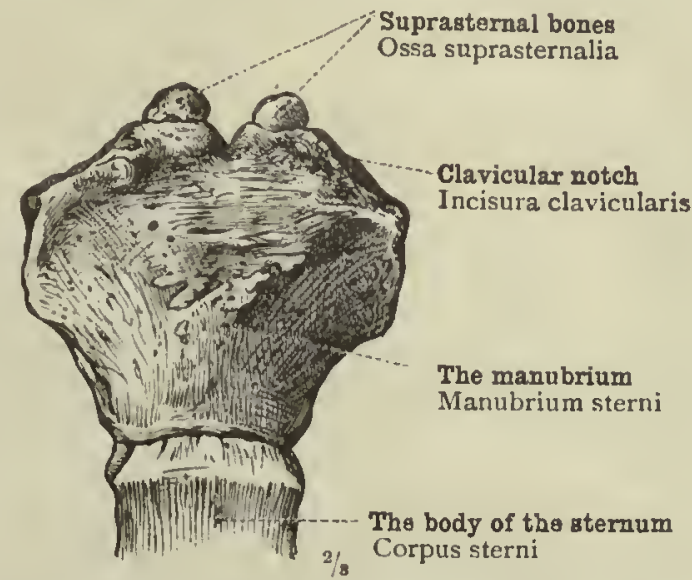

Fig. 90.-The Upper Portion of the Sternum with the Suprasternal Bones (a Rare Variety). Seen from Before.

Sternum-The breast-bone. 

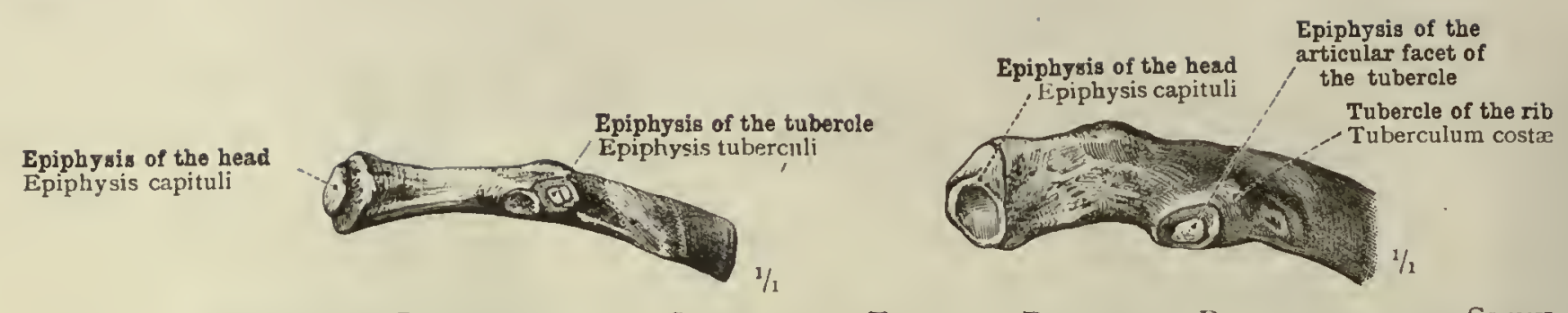

Fig. 91.-Posterior Portion of the Sixth Rib, in the Fifteenth Year.

Fig. 92.-Posterior Portion of the Sixth Rib, IN the Eighteenth Year.

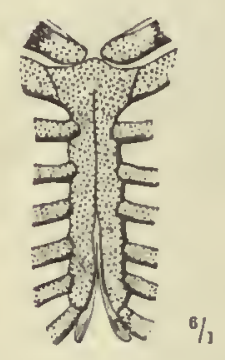

Fig. 93.-Divided PRIMItive Cartilage of the STERNUM.

From a human foetus of two months (months of four weeks each).

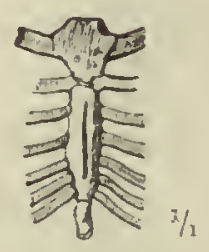

Fig. 94--Primitive Cartilage OF THE STERNUM.

From a human foetus of four months (months of four weeks each).

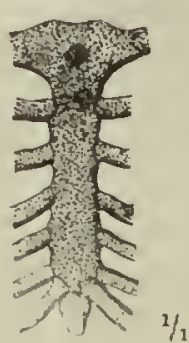

Fig. 95.-Primitive Cartilage of the Sternum with the First Centre of OssificaTION IN THE MANUBRIUM.

From a human foetus in the second half of the sixth month (montlis of four weeks each).

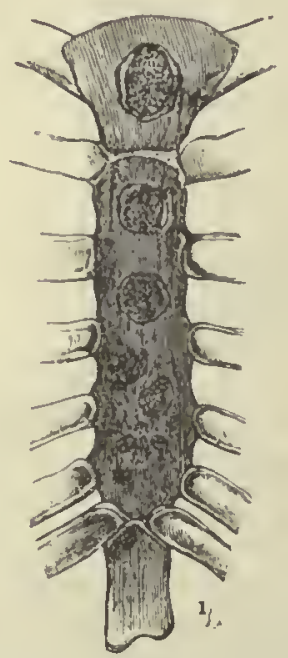

Fig. 96.-Centres of Ossification in the Sternum of a New-BORN Child.

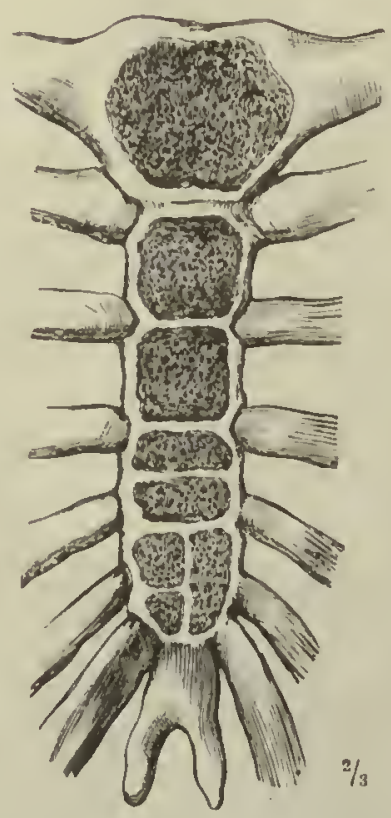

Fig. 97.-Sternum of a Boy at the AGE OF EleVEN Years.

Development of the Ríbs and the Sternum. 


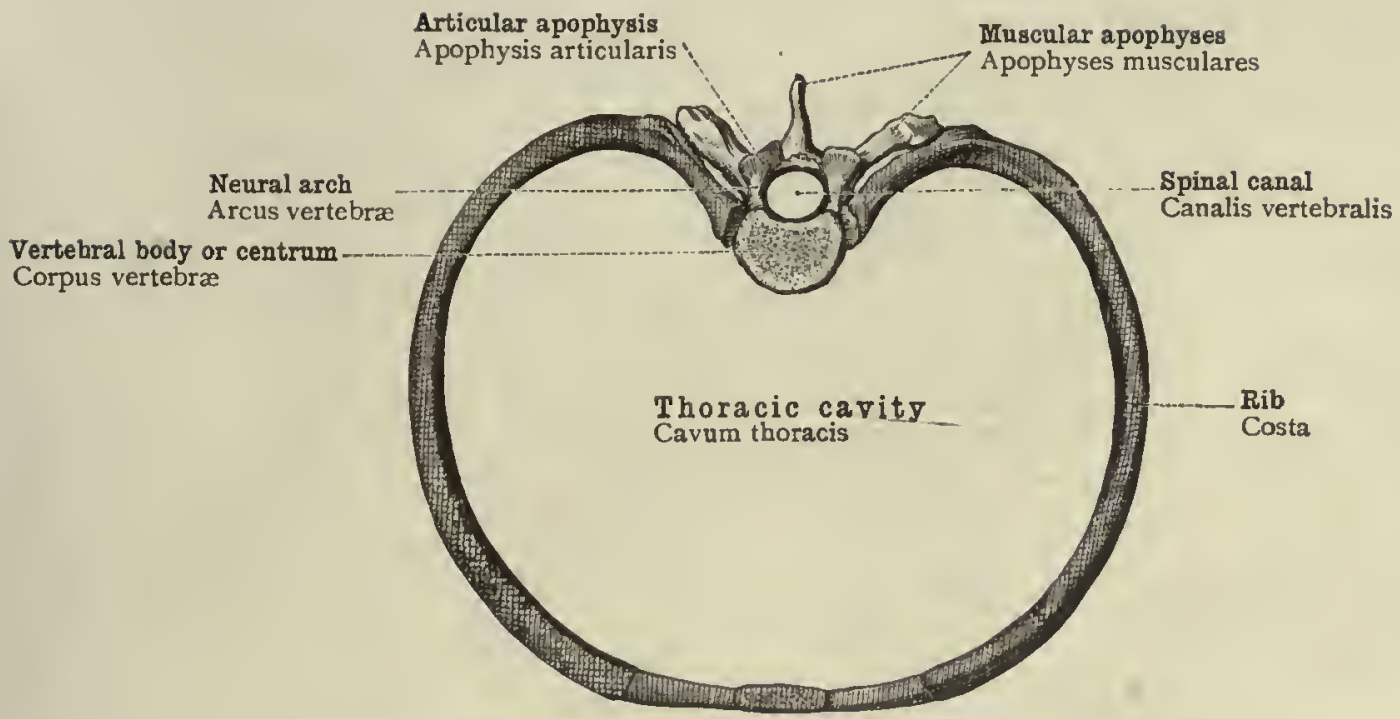

Fig. 98.-Skeleton of a Thoracic Segment.

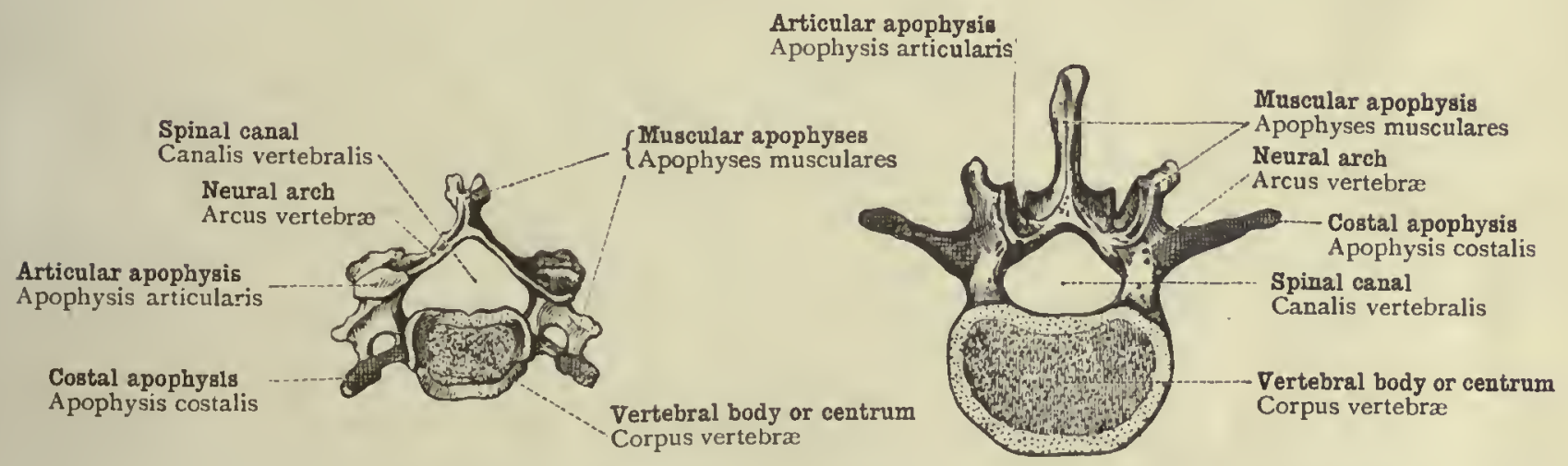

Fig. 99.-Skeleton of a Cervical Segment.

Fig. ioo.-Skeleton of a Lumbar Segment.

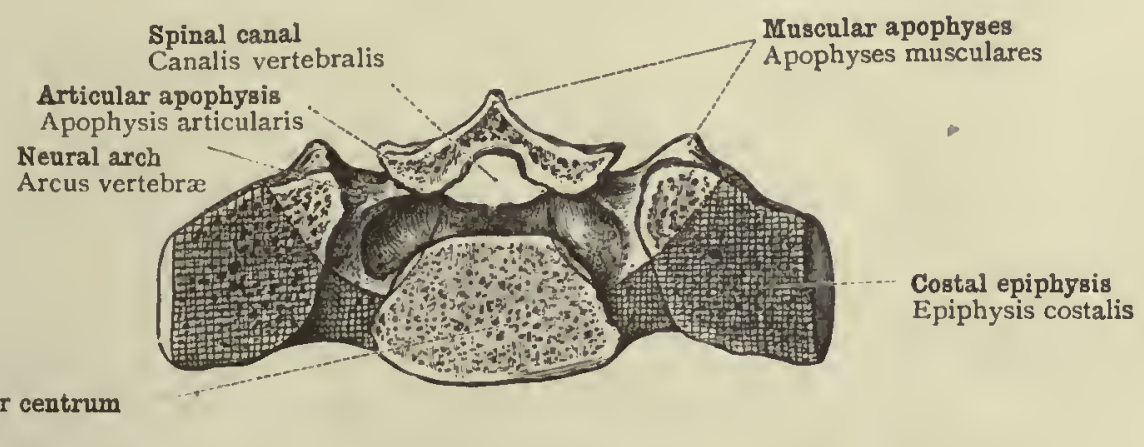

Fig. roi.-Skeleton of a Sacral Segment:

The Homologous Skeletal Parts of the Segments of the Body. 



\section{CRANIUM ET OSSA CRANII}

\section{THE SKULL}

AND THE BONES OF THE SKULL 


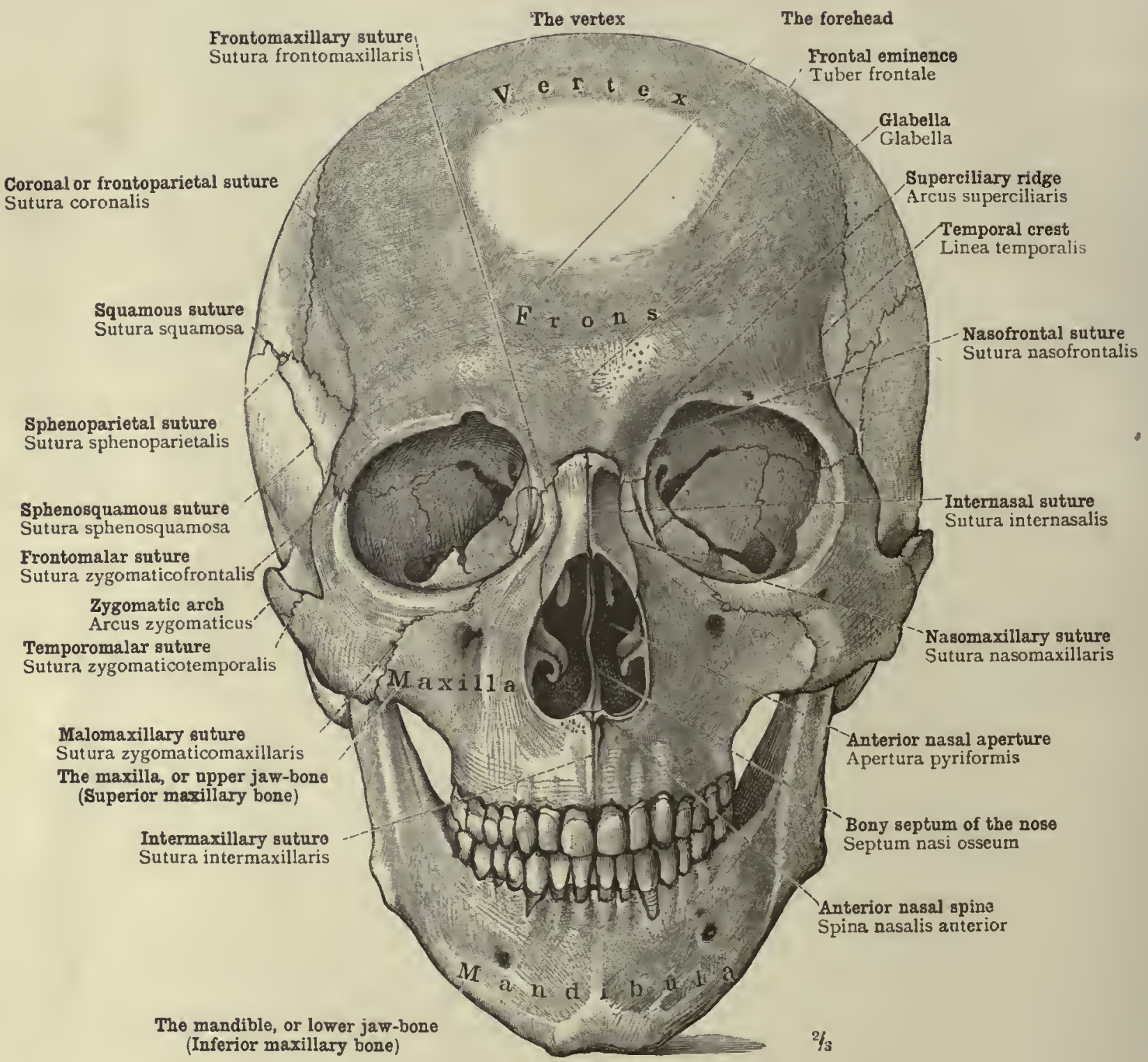

Fig. 102.-The SkUll SEen from Before: Norma Frontalis. 


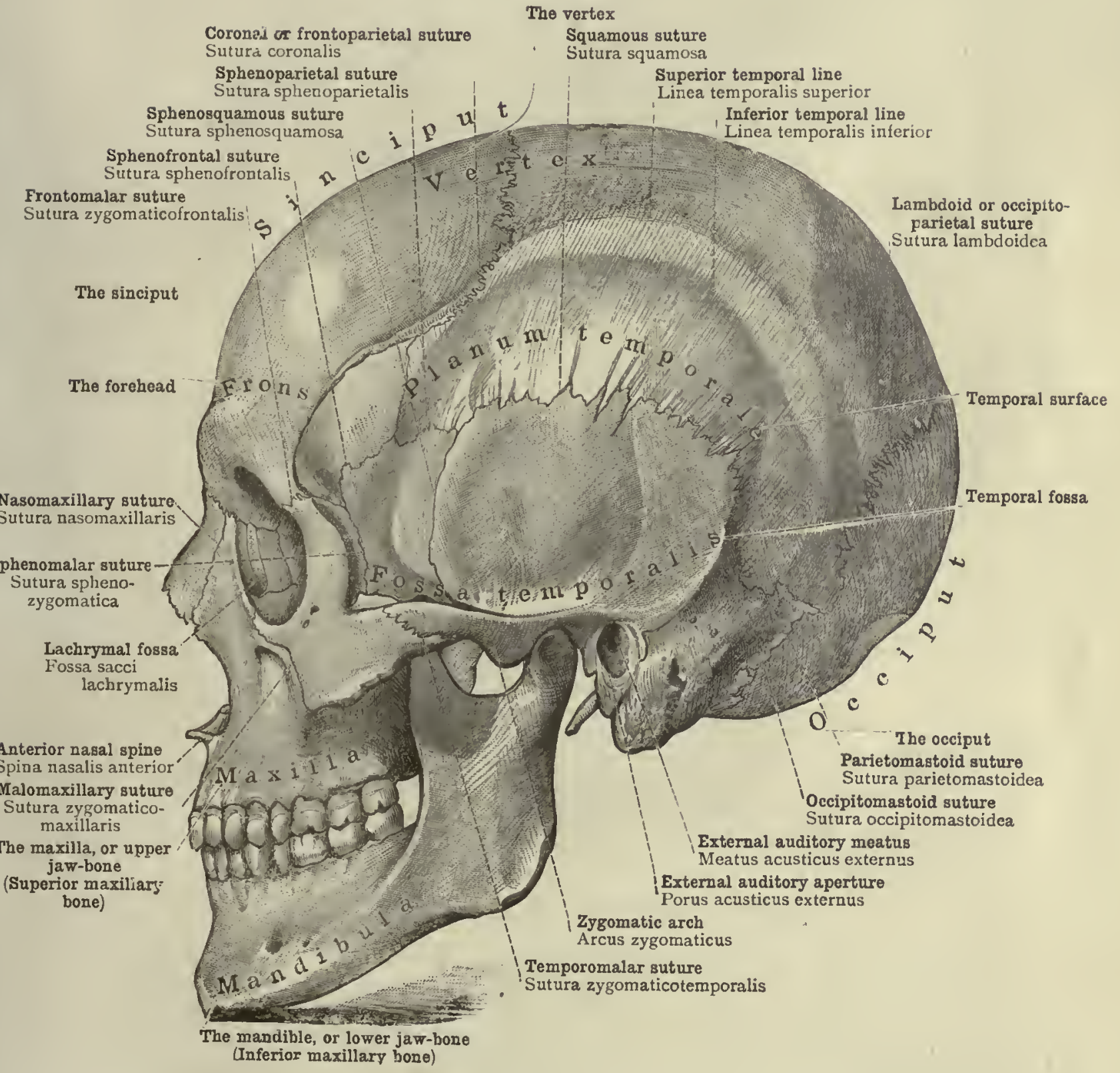

Fig. I03.-The SkUlL SEen From the Left Side: NorMa Lateralis. 


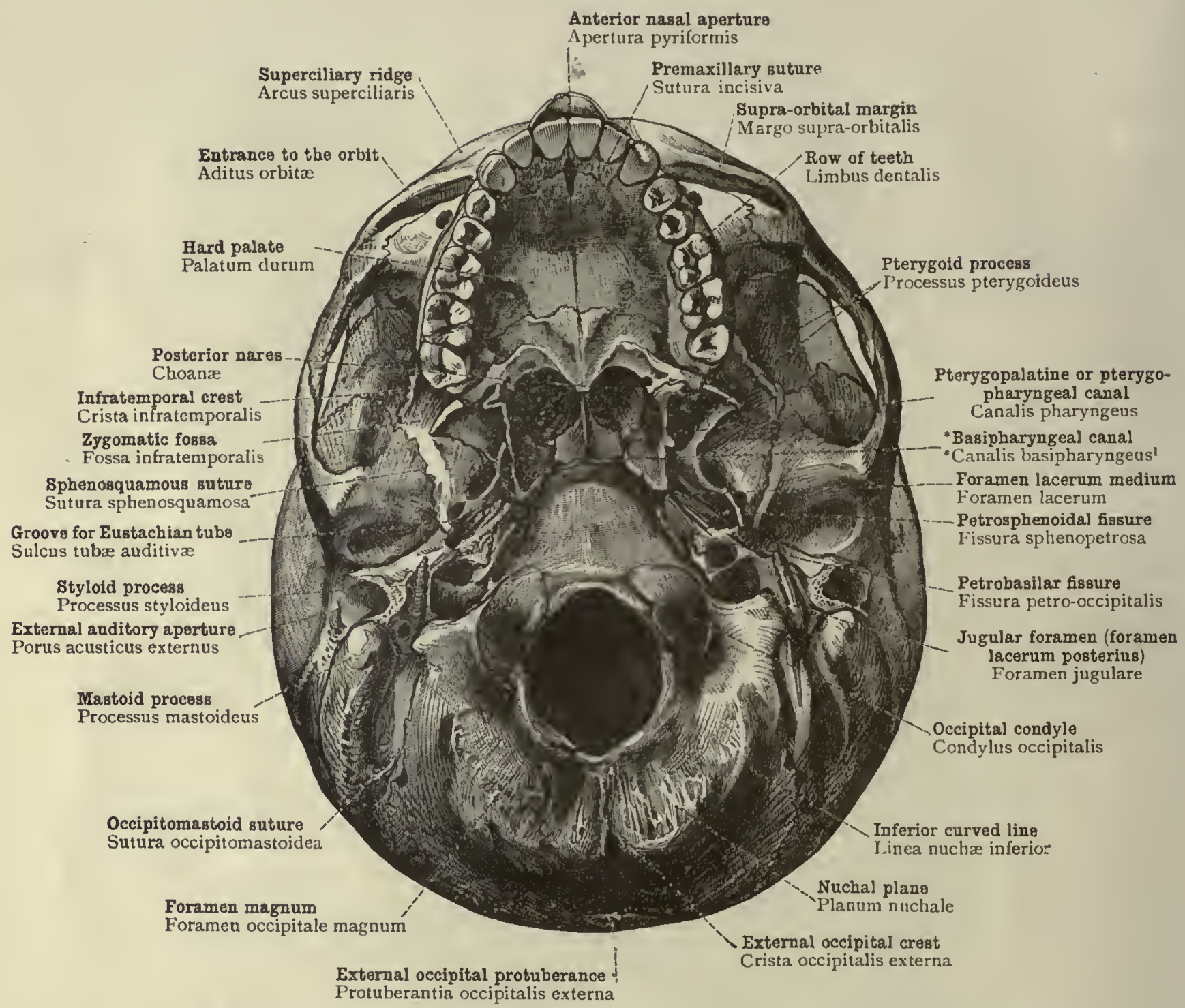

1 "Canalis basipharyngeus, " basipharyngeal canal: This term is not often used by English anatomists, nor even is the canal itself mentioned by Quain. Macalister, however, in his description of the vomer, writes (p. 233): "In the region of its sphenoidal articulation there are three canals transmitting small vessels in the young skull, which usually become obliterated with advancing age; these are-one median vomerine canal between the vomer and the root of the rostrum, and a lateral on each side between the extremity of the ala vomeris and the vaginal process. These run parallel to, and may communicate with, the pterygopharyngeal [pterygopalatine] canal in the vaginal process." The two lateral canals here mentioned are those called by Toldt * canales basipharyngei, $-\mathrm{T}_{\mathrm{R}}$.

Fig. 104.-External Aspect of the Base of the Skull: Basis Cranit Externa. 


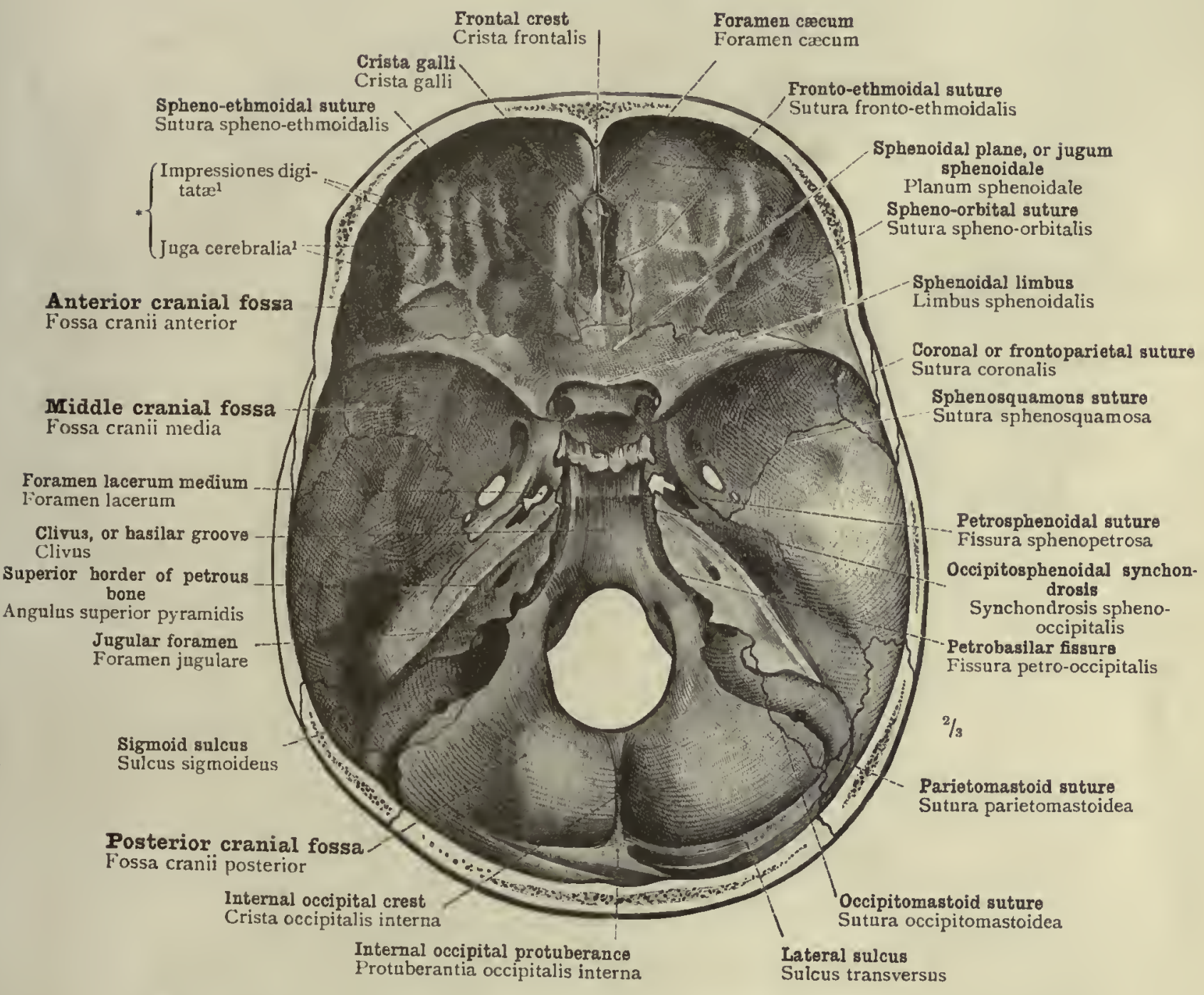
1 Mouldings of the bone corresponding with the sulci and convolutions of the inferior surface of the frontal
lobe of the cerebrum.

Fig. I05.-Internal Aspect of the Base of the Skull-Basis Cranil Interna: Fossa: Cranil Anterior, Media, et Posterior-The Anterior, Mrddle, and Posterior Cranial fosse. Seen from Above. 


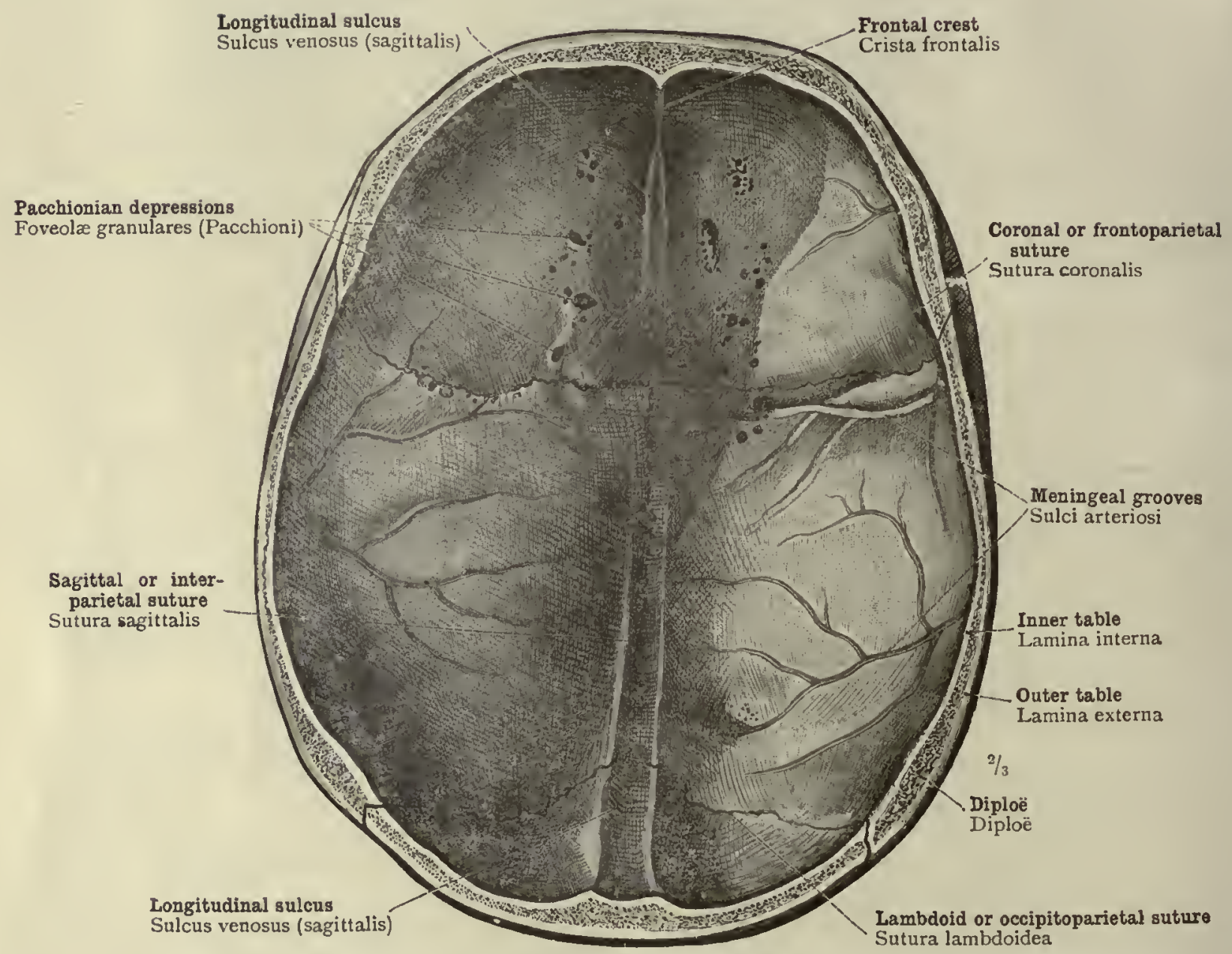

Fig. I06.-Calvaria-The Skullcap, or Roof of the Skull. Inner Aspect. 


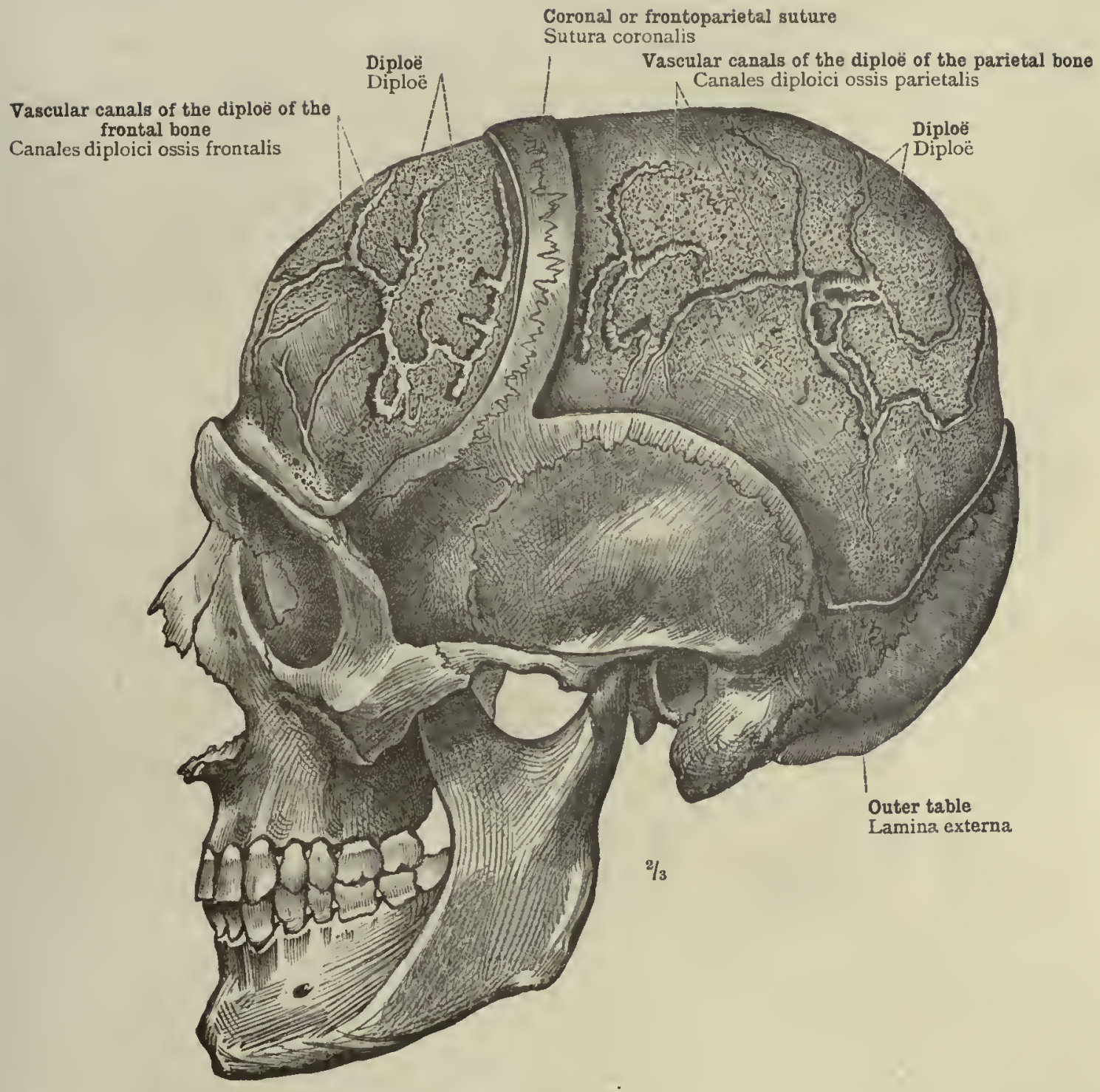

Fig. ro7.-Vascular Canals of the Diplö̈ of the Roof of the Skull, shown by Removal of the Outer Table of Compact Bo::e from the Frontal Bone and the Parietal Bone: Canales Diploici (Brescheti). Seen from the Left Side. 


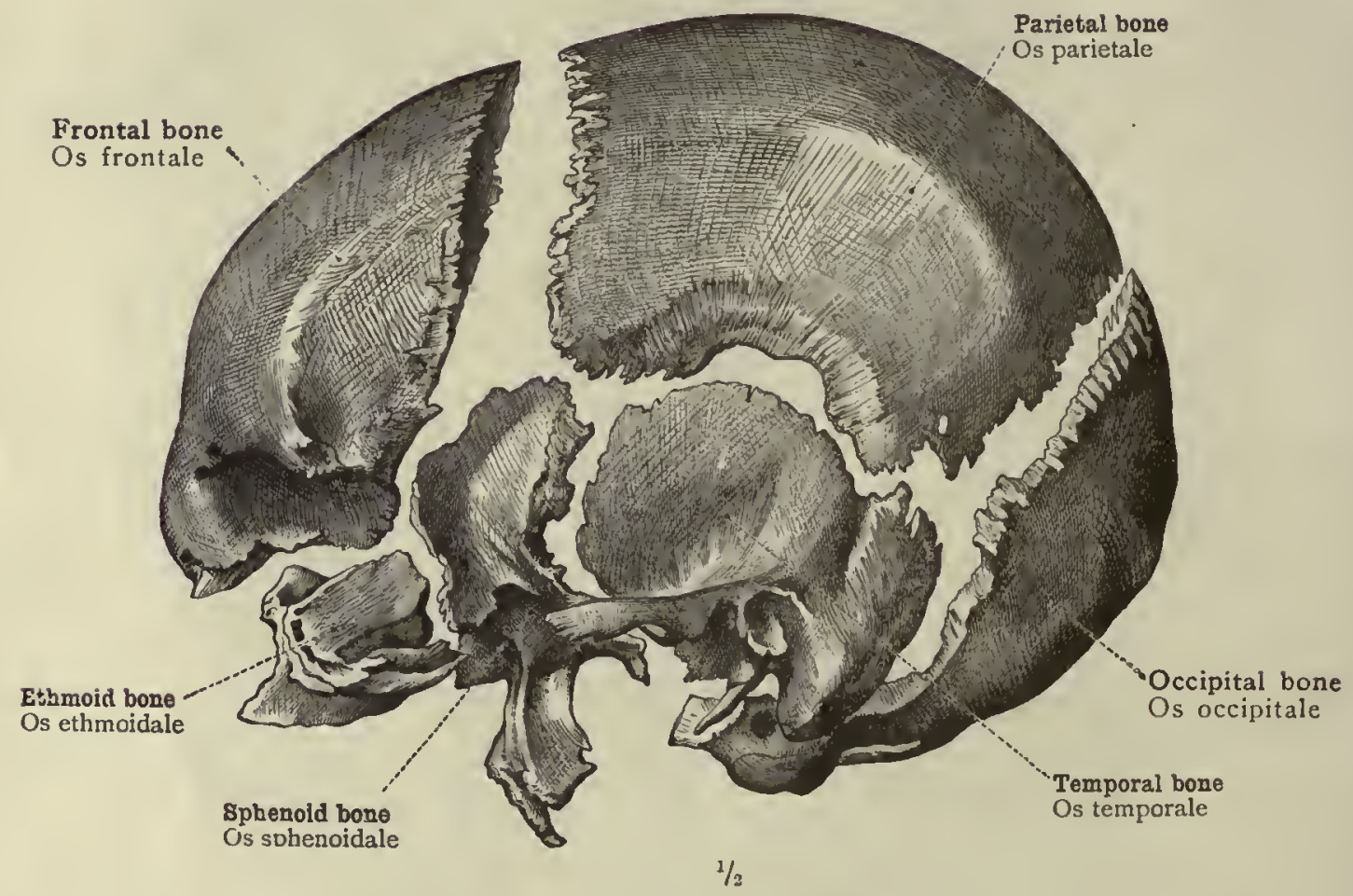

Fig. 108.-The Separate Bones of wilichi the Cranium Cerebrale or Cranium PROPER CONSISTS. 


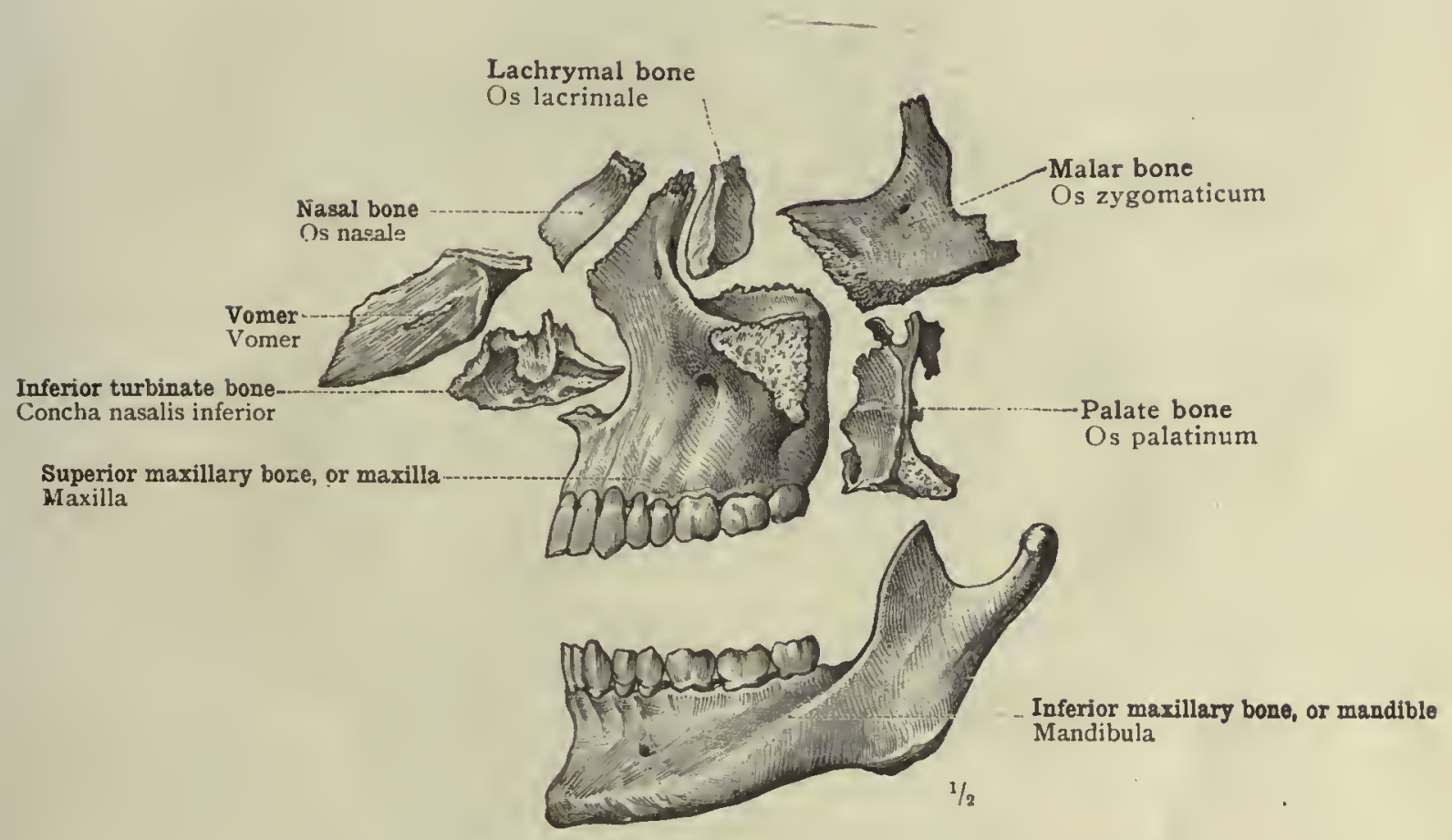

Fig. Iog.-The Separate Bones of which the Cranium Viscerale (Facies Ossea), or Facial PORtion of the SkUll, consists. 


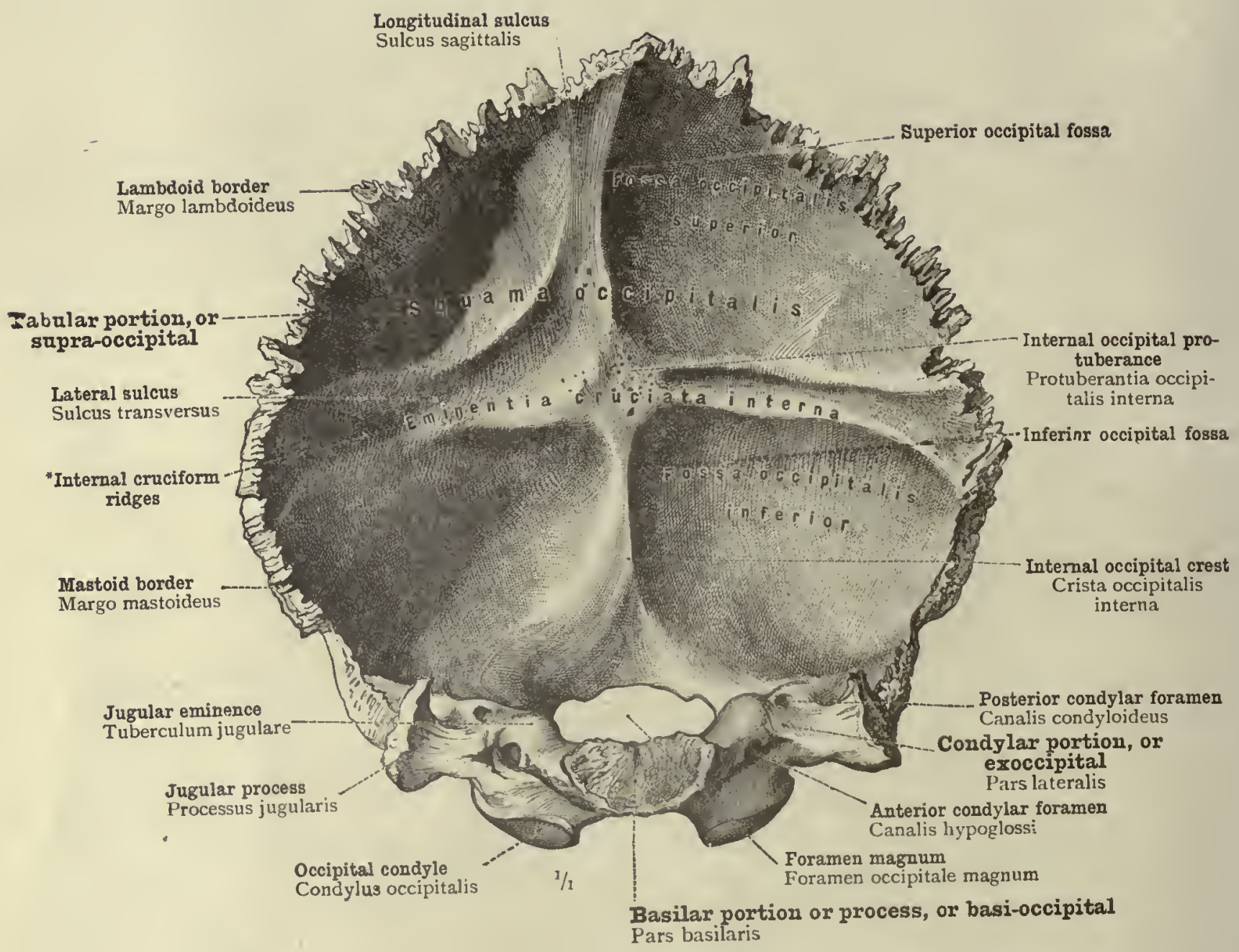

Fig. ilo.-Anterior (Internal) Aspect of the Occipital Bone. 


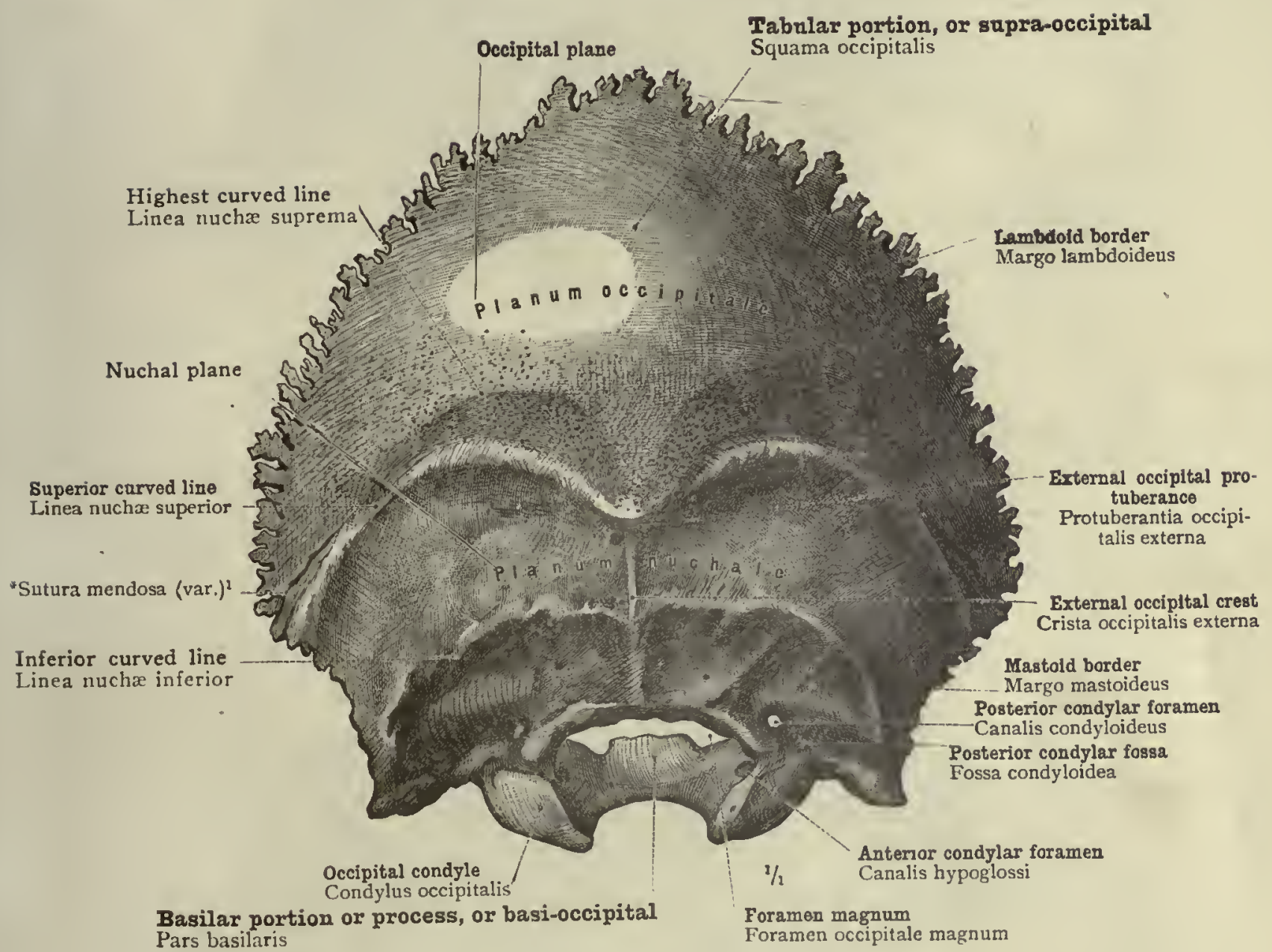

1 See foot-note to p. 57 .

Fig. ili.-Posterior (External) Aspect of the Occipital Bone.

Os occipitale-The occipital bone. 
Tabnlar portion, or supra-occipital

Squama occipitalis

External occipital crest $\quad$ External occipital protuberance

Crista occipitalis externa

Protuberantia occipitalis externa

Crest for the rectus capitis posticus minor muscle.

Crista $\mathrm{m}$. recti capitis minoris

Crest for the rectus capitis posticus major muscle

Crista m. recti capitis majoris

Posterior condylar foramen

Canalis condyloideus

Foramen magnum

Foramen occipitale magnum

\section{Condylar portion, or exoccipital \\ Pars lateralis}

Occipital condyle

Condylus occipitalis

Posterior condylar foramen

Canalis hypoglossi

\section{Basilar portion or process, or basi-occipital} Pars basilaris

1 Pharyngeal spine.-U.S.

Fig. i i2.- The Occipital Bone seen from Below (External Basal Surface).

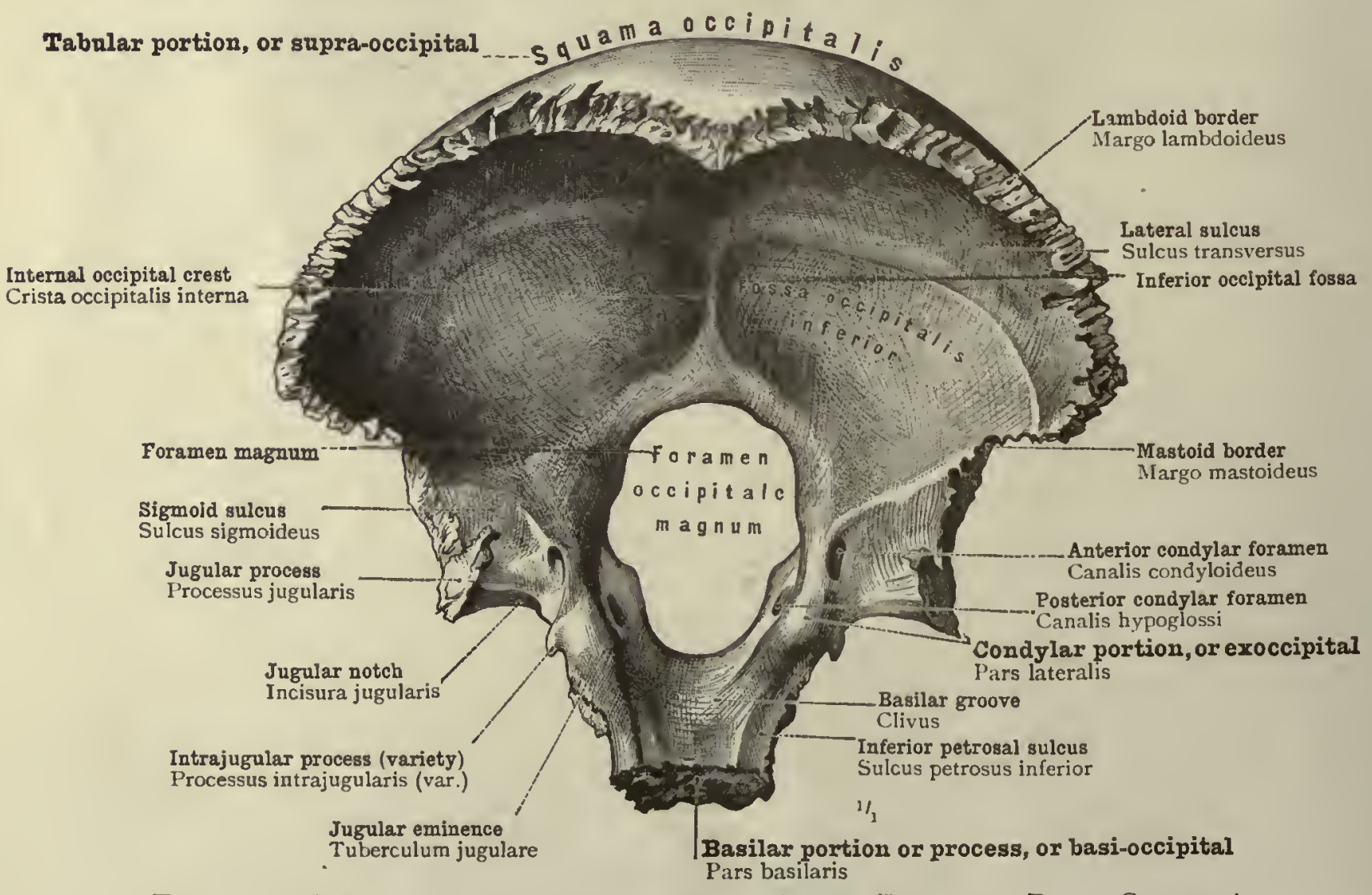

Fig. Ii3.-The Occipital Bone seen from Above (Internal Basal. Surface).

Os occipitale-The occipital bone. 


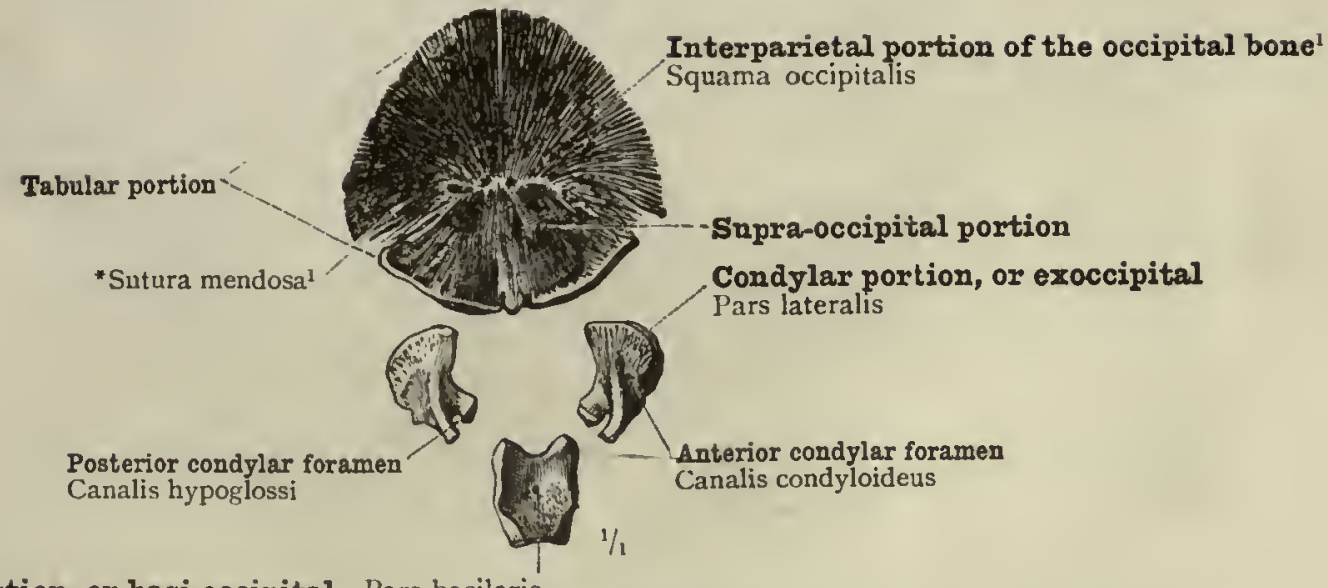

Basilar portior, or basi-occipital-Pars basilaris

Fig. il4.-The Portions of the Occipital Bone from a Human Fetus at the End of the Sixth Month (Months of Four Weeks Each). Seen from Within.

Body-length, 12 inches.

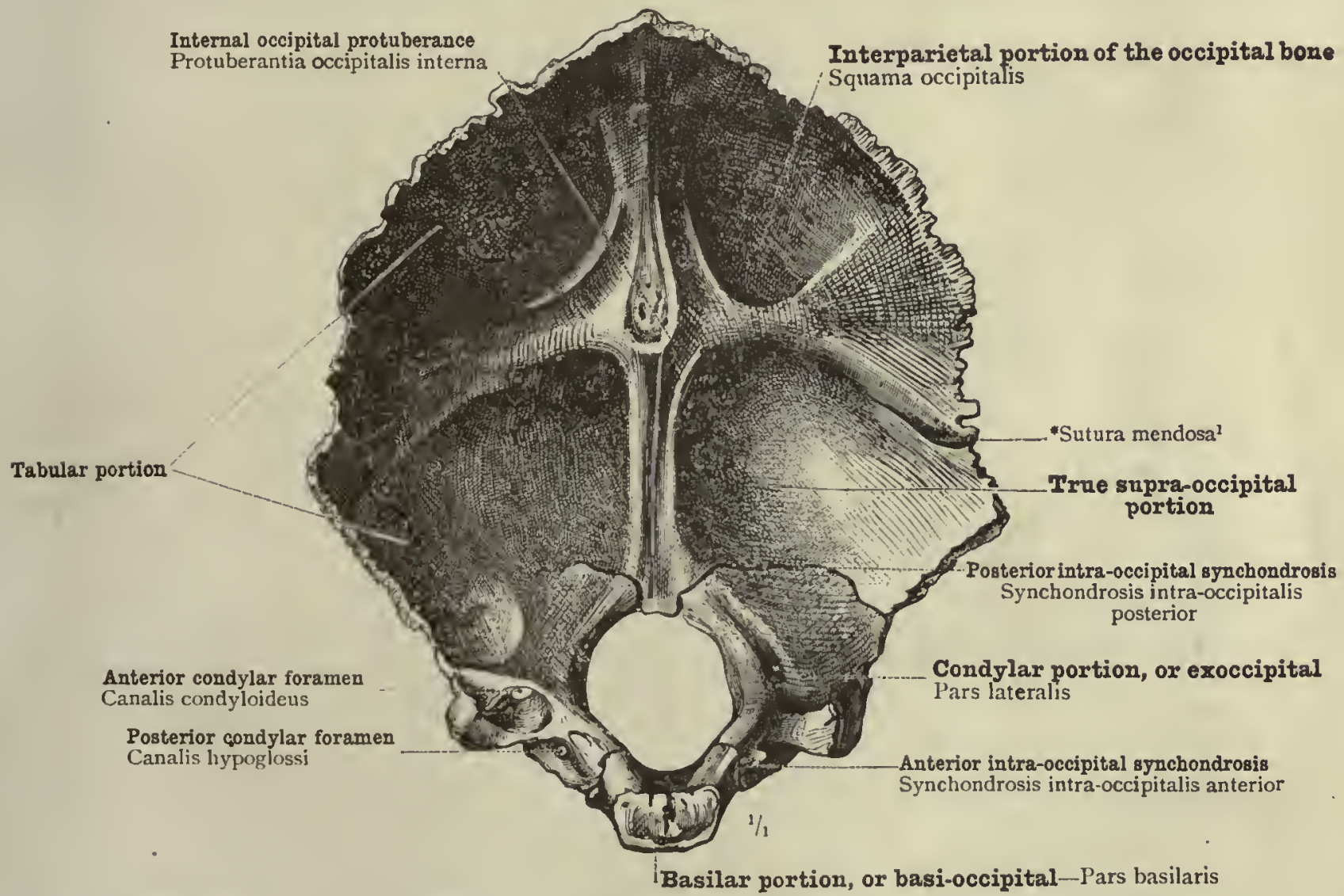

Fig. i 5.-The Occipital Bone of a Child aged Fiftén Months. Seen from Within.

- The human occipital bone consists of four elements, which are still separate at binh, being united hy intervening cartilage; tbese are, the basilar portion, (basilar process), the two condylar portions, and the tabular portion. In comparative anatomy these are known respectively as basi-occipital, exaccipitals, and supra-accipital. The basi-occipital and the exoccipitals ossify each from a single nucleus: the supra-cripital ssifies from four puclei, an supraiplo the superior curved line. Not uncommonly this bssure persists on one or both sides throus life, and in rare cases there is a persistent suture running right these two parts, the lower, which the tabular portion of the rccipital hone into two paris ("Sutura mendosa; see Figs, 11r and ri4). Or with the parts, the lower, which belongs tn the base of the skull and ossifies in cartilage, is the prnper supravoccipital element, homologous represents the represents the interparietal bone of many animals. This part alone is entitled to the name squama occipitalis, a term, however, little used is of surgical importance, since, in cases of injury to the back of the head, it is, if present, liable to be mistaken for fracture.-Tr. 


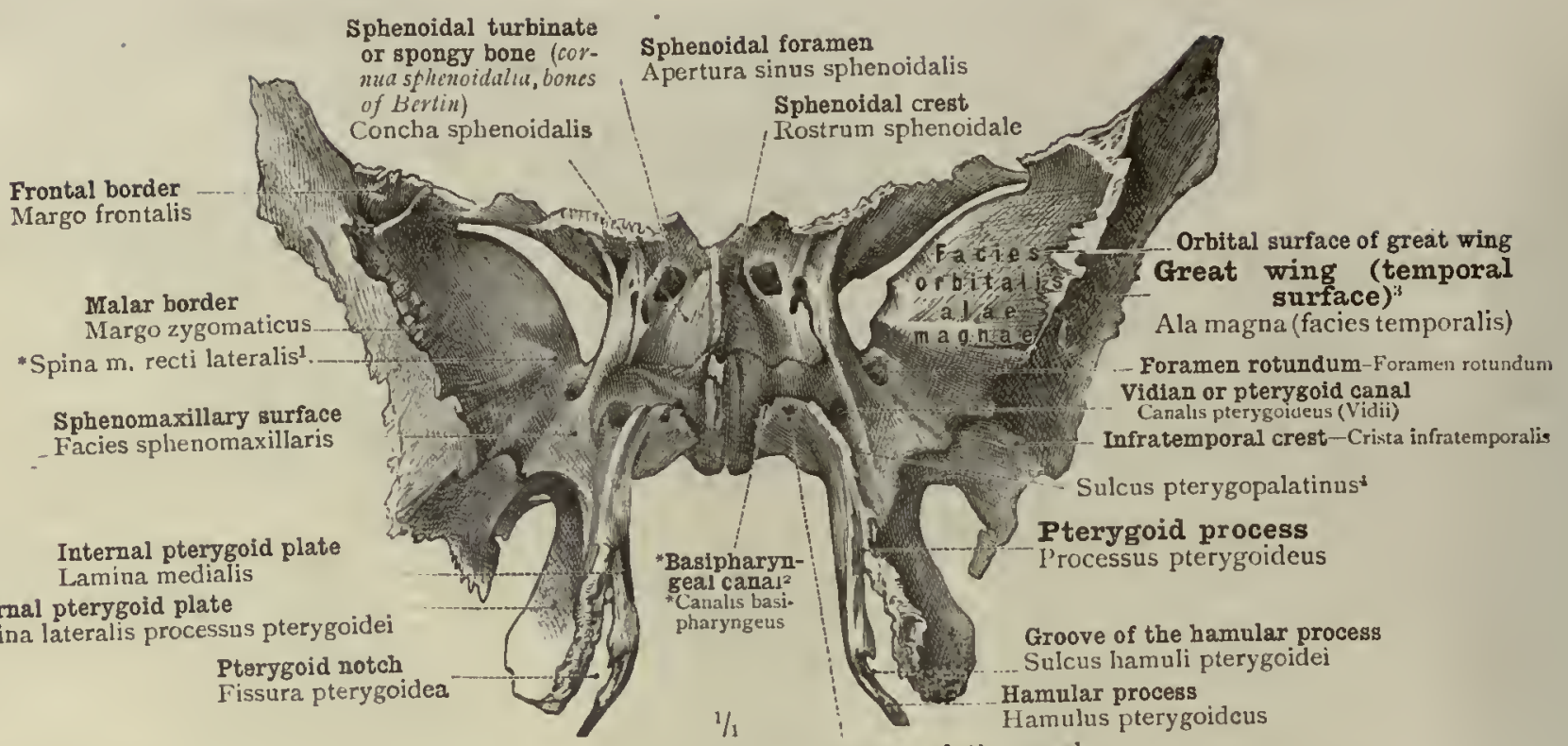

Pterygopalatine canal

Canalis pharyngeus

1 Spine for the attachment of the lower head of the external rectus muscle of the eyeball.

2 See note to p. 48 . 2 See note to p. 48 .
4 As mentioned in the Preface, the canal called by English anatomists palatomaxillary or foslerior falatine canal is by Toldt called pre calls the pterygotalatine groove, leads down into that canal, but does not form a part of it, since it lies between the palate bone and the superior maxillary bone.-TR.

\section{Fig. im6.-The SPHenold Bone SEen From Before.}

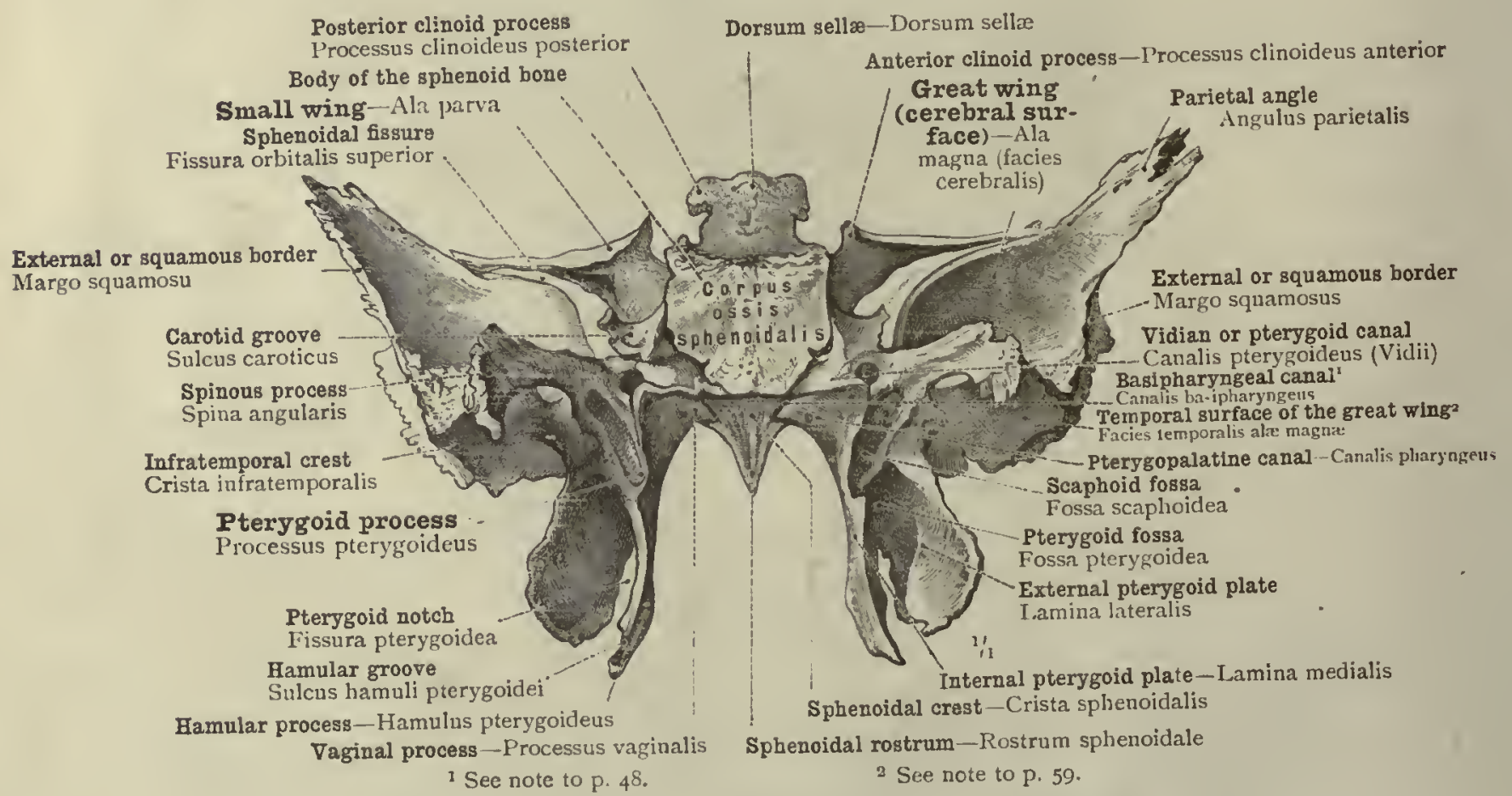

Fig. it7.-The Sphenoid Bone seen from Behind. 


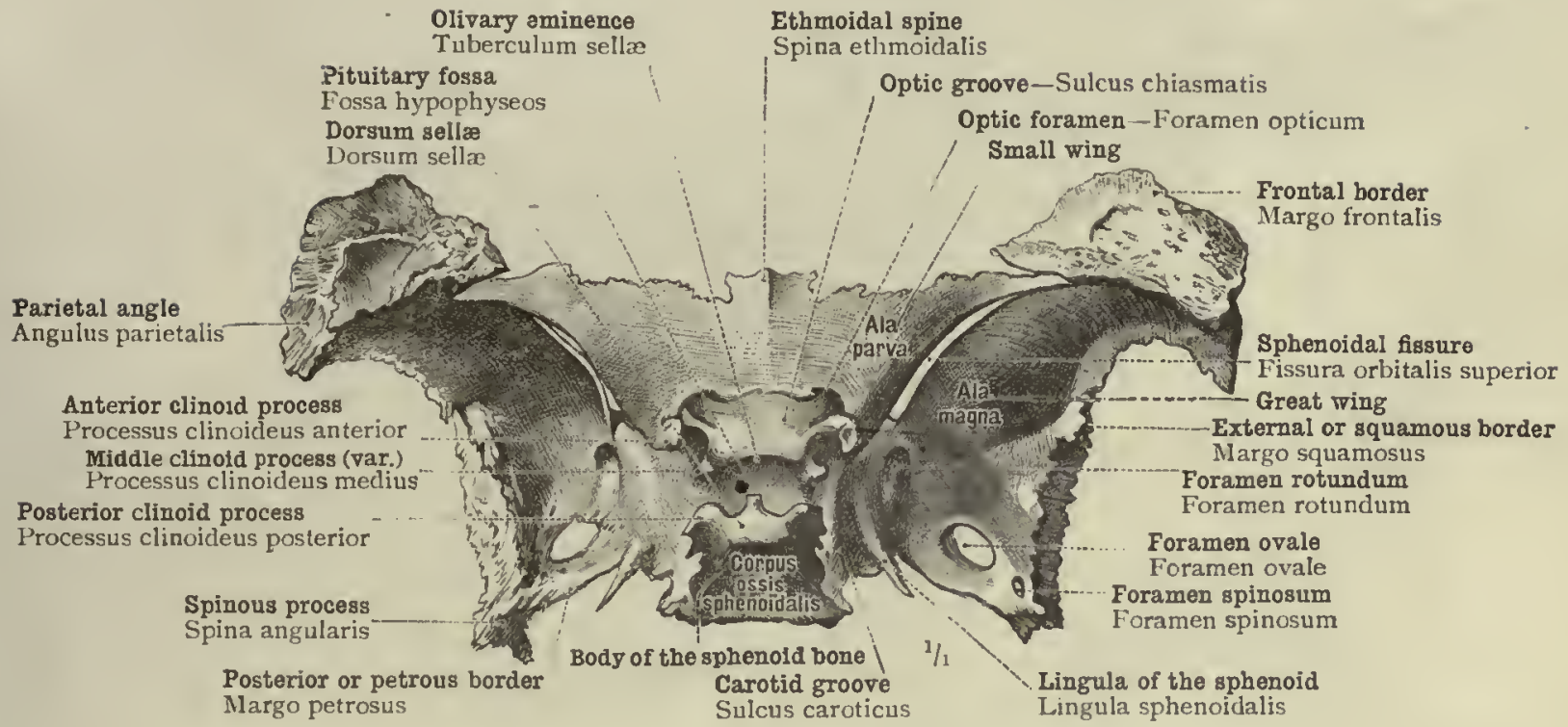

Fig. im8.-The Sphenoid Bone seen from Above (Cerebral Aspect).

Sphenoidal foramen

Apertura sinus sphenoidalis

Orbital border (of the sphenoidal turbinate bone)

Margo orbitalis

Sphenoidal fissure-Fissura orbitalis superior

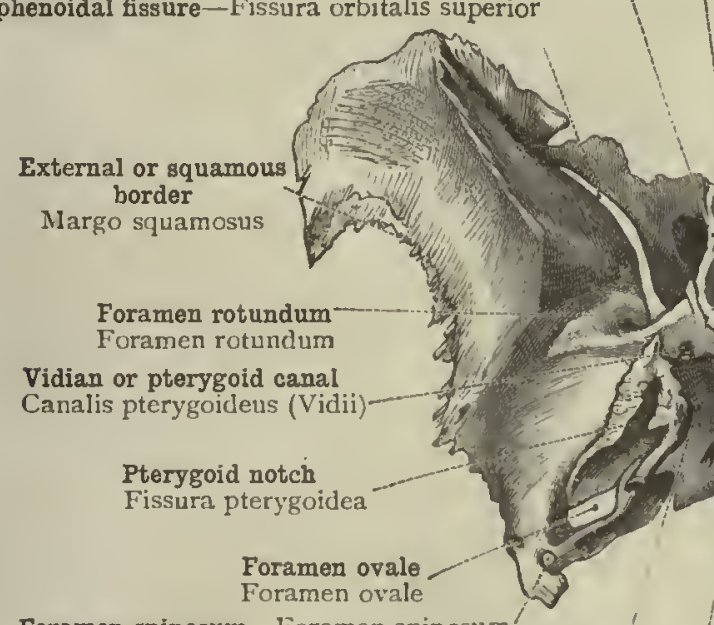

Foramen spinosum - I'oramen spinosum ${ }^{\prime}$

Pterygoid process

Processus pterygoideus

Vaginal process - l'rocessus vaginalis

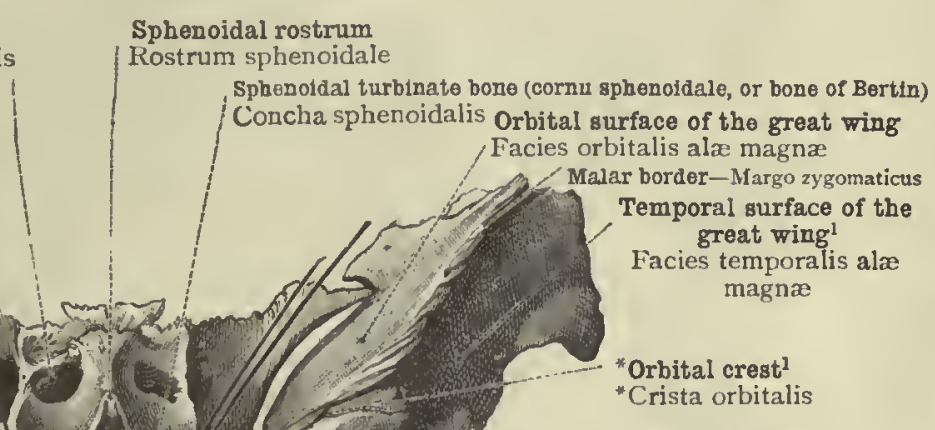

Sphenoidal rostrum

Rostrum sphenoidale

nfratemporal crest

Crista infratemporalis

Temporal surface of the great wing ${ }^{1}$

Facies temporalis alæ magnæ

The Continental nomenclature differs here from that of English anatomists. What is called by the author facics temtoralis alie magne, the temporal surface of the great wing, is in England known as the temporozygomatic surface, being divided by the infratemporal crest into an upper temporal surface and a lower sphenomarillary surface. As regards the term crista nrbitalis, the crest, this is not used by Quain at all, while Macalister applies it to the lozer marqin of the sphenoidal fissure, the free border separating the orbital from the cerehral surface of the great wing. Toldt, on the other hand, as an examintion of Fig. 110 shows, means by crista arbitalis the posterior margin of the sphcnomaxillary fissure, free border separating, the orbital from the zygomatic surface of the great wing. $-T R$.

2 See note to p. $4^{8 .}$

Fig. img.-The Sphenoid Bone seen from Below (External Aspect).

Os sphenoidale-The sphenoid bone. 
Parietal angle Anterior clinoid process Angulus parietalis -. Processus clinoideus anterior

Temporal surface of the great wing ${ }^{2}$ Facies temporalis ala magna

Malar border Margo zygomaticus External or squamous border Margo squamosus

Infratemporal crest Crista infratemporalis

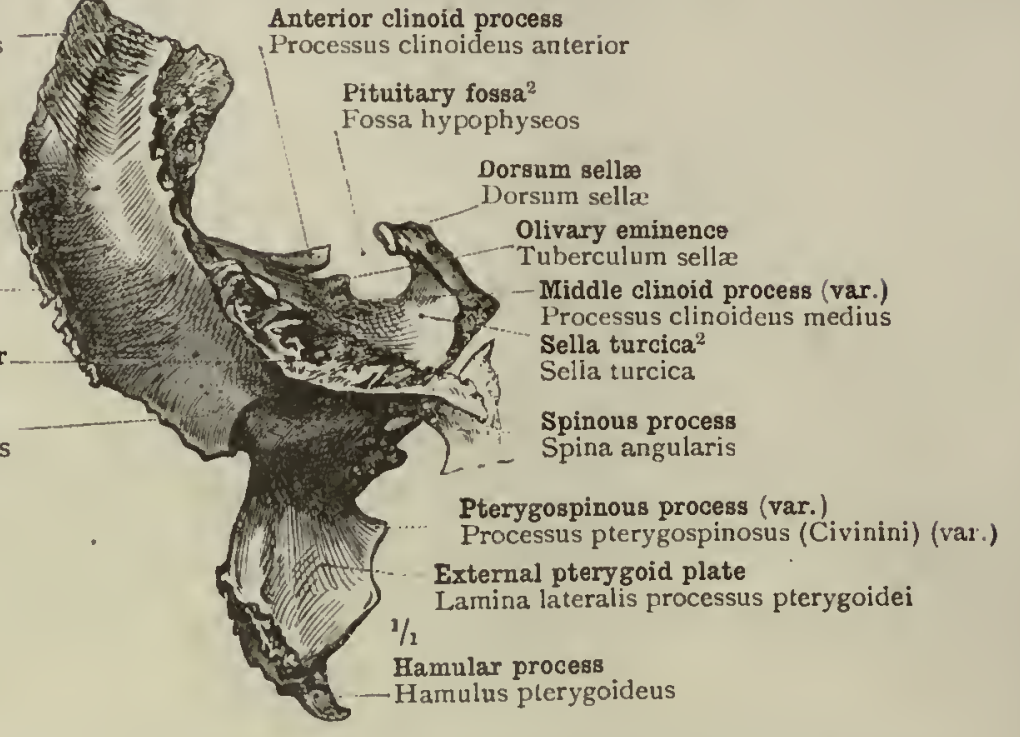

See note to p. 59 .
2 English anatomist - use the terms pituitary fos.a and sella turcica as synonyms ; Toldt, more accurately, distinguishes between them, meaning by pituitary fossa (Fossa hypophyseos) the deep pit on the upper surface of the body of the sphenoid bone which lndges the pituitary body or hypophysis cerebri, and by sella turcica the saddle-shaped surface which forms the floor of that fossa. - TR.

Fig. I20.-The Sphenoid Bone seen from the Left Side (Temporozygomatic Surface). ${ }^{1}$

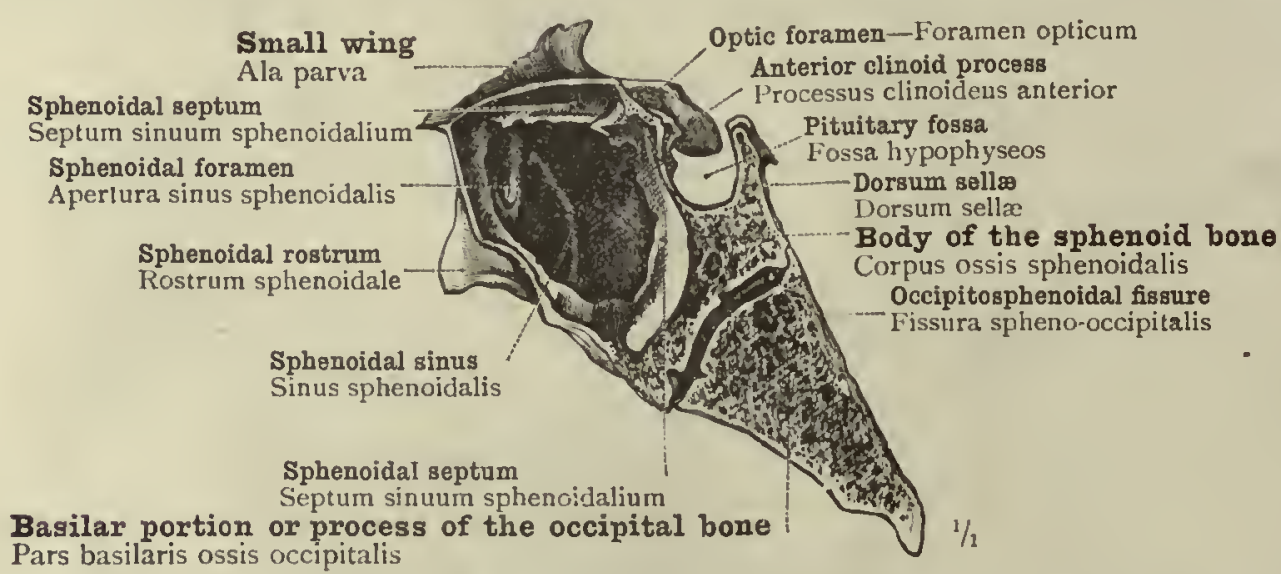

Fig. i2i.-The Sphenoidal Sinuses in Median Sagittal. Section, the Greater Part of the Sphenoidal Septum having been removed. Seen from the Left Side.

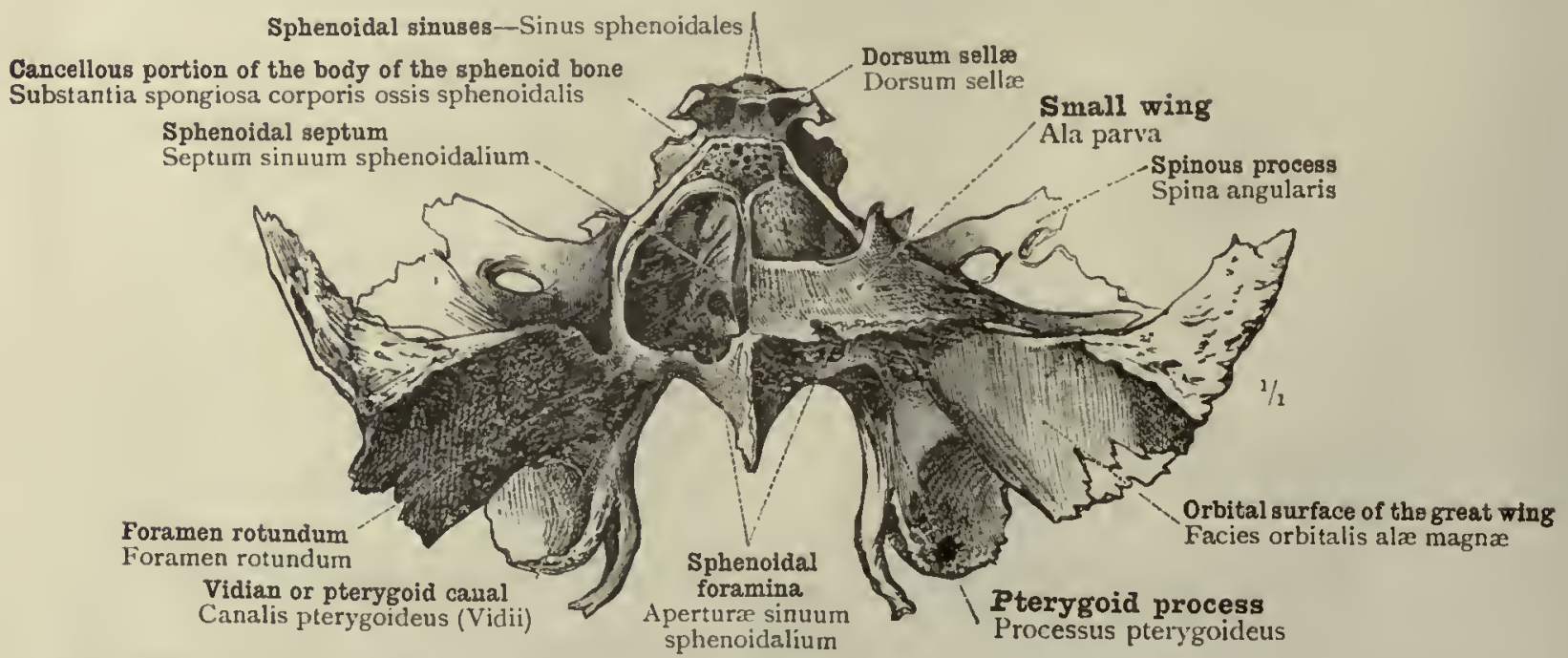

Fig. I22.-Tile Spijenoidal Sinuses, EXPOSEd from Above by the Removal of the InNER LAMElla of COMPACT BONE.

The right sinus is opened from above; the left is unopened.

Os sphenoidale-The sphenoid bone. 
Body of the sphenoid bone (presphenoid portion)--Corpus ossis sphenoidalis (pars anterior) Internal pterygoid plate - Lamina medialis processus pterygoidei

Small wing (orbitosphenoid)

Vaginal process - Processus vaginalis
Foramen rotundum - Foramen rotundum

Cerebral surface of the great wing

Facies cerebralis alx magnx

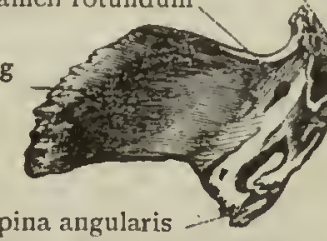

Spinous process-Spina angularis

Intersphenoidal synchondrosis Synchondrosis intersphenoidalis

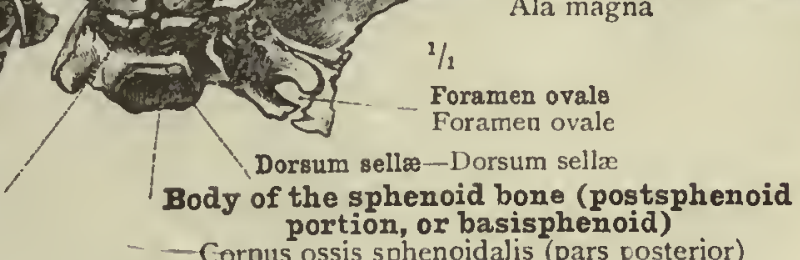

Fig. I23.-The Sphenoid Bone of a Boy born at Full Term, seen from Above. Body-length, 19 inches.

Optic foramen-Foramen opticum

Small wing (orbitosphenoid) - Ala parva

Body of the sphenoid bone (presphenoid portion)

Great wing (alisphenoid)

Ala magna

Temporal suriace of the great wing

Facies temporalis alæ magnæ (see note on p. 59)

Pterygoid process

Processus pterygoideus
Body of the sphenoid bone (postsphenoid portion, or

basisphenoid)-Corpus ossis sphenoidalis (pars posterior)
'Corpus ossis sphenoidalis (pars anterior) FIG. I24.-The Sphenoid Bone of A Boy bORN AT Full TERM, seen From Below.

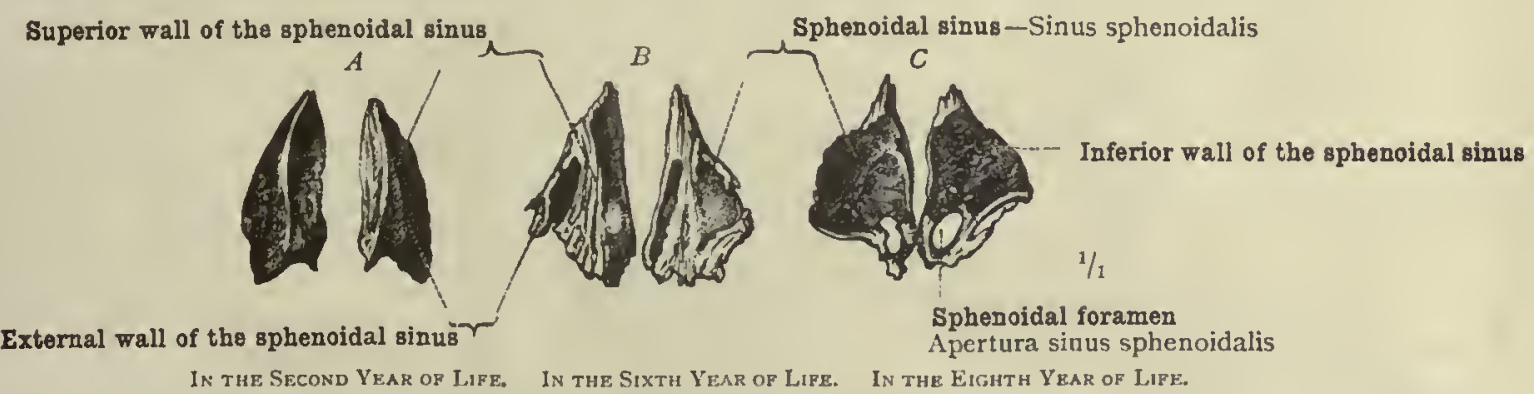

Fig. 125.-Concha Sphenoidales-The Sphenoidal Turbinate Bones. Seen from Above.

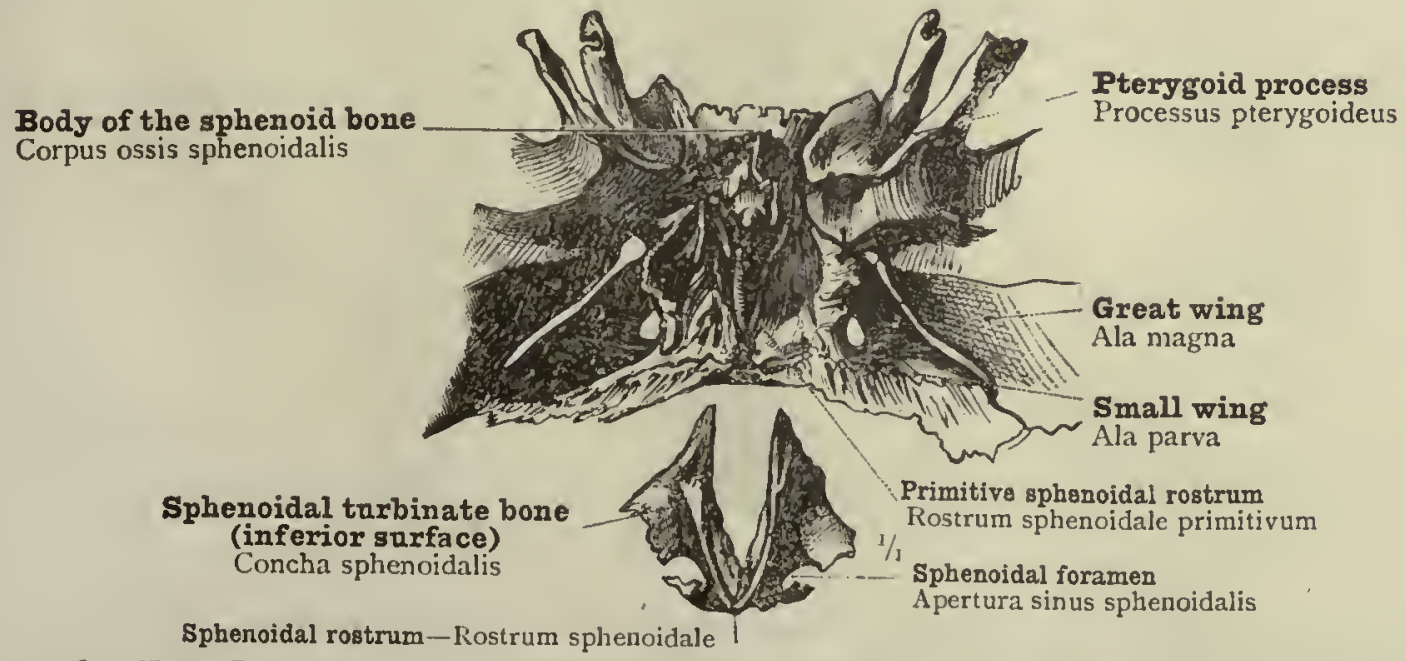

Fig. I26.- The Relation of the Sphenoinal Turbinate Bones to the Inferior Surface of the Sphenoid Bone in the Sixth Year of Life. 


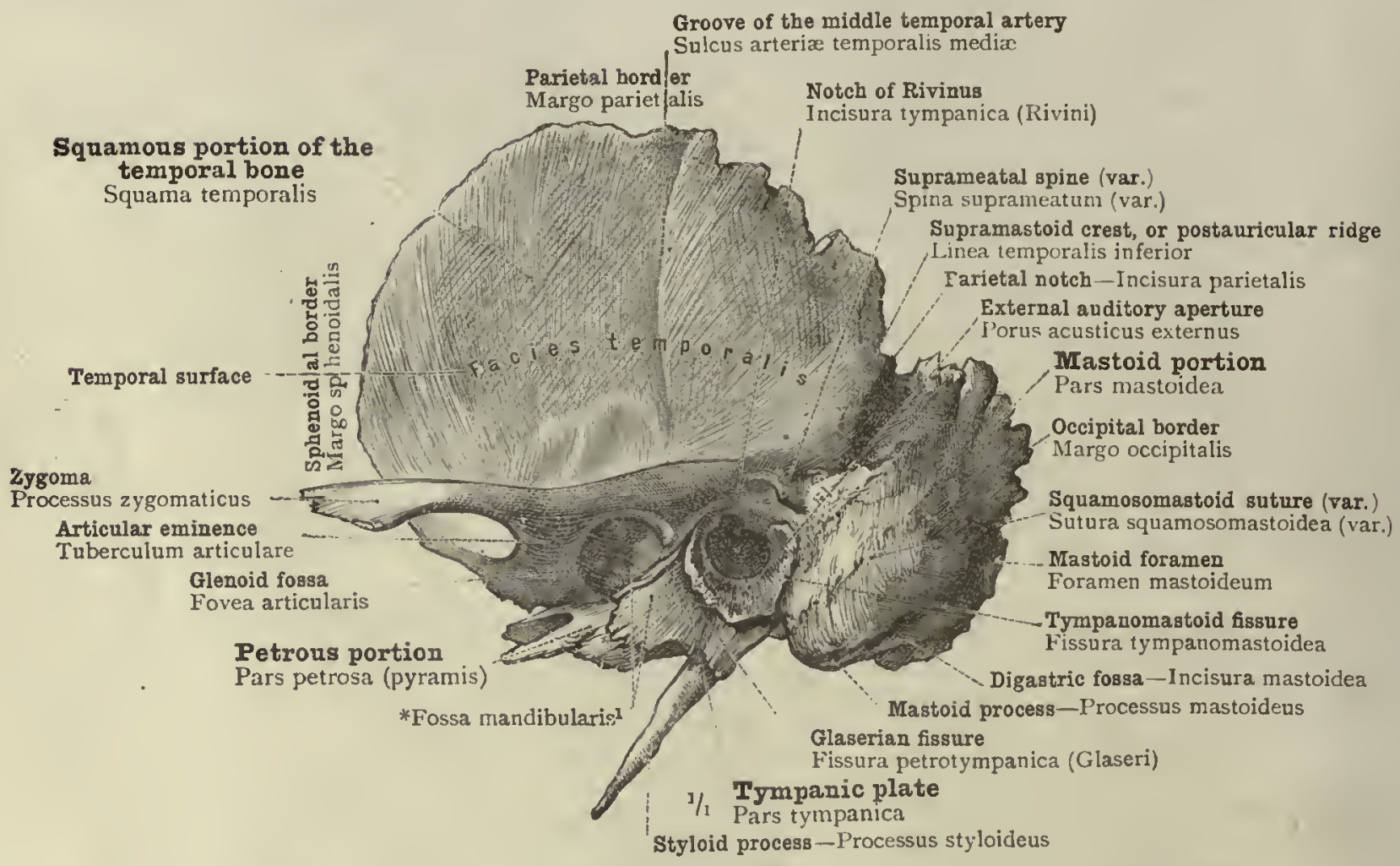

1 What is called the mandibular fossa by Toldt is the posteror non-articular portion of the glenoid fossa (separated from the articular portion by the Glaserian fissure). Its floor is formed by the tympanic plate. and it lodges a portion of the parotid gland. $-T R$.

Fig. I27.-The Left Temporal Bone seen from the Outer Side (Temporal Surface).

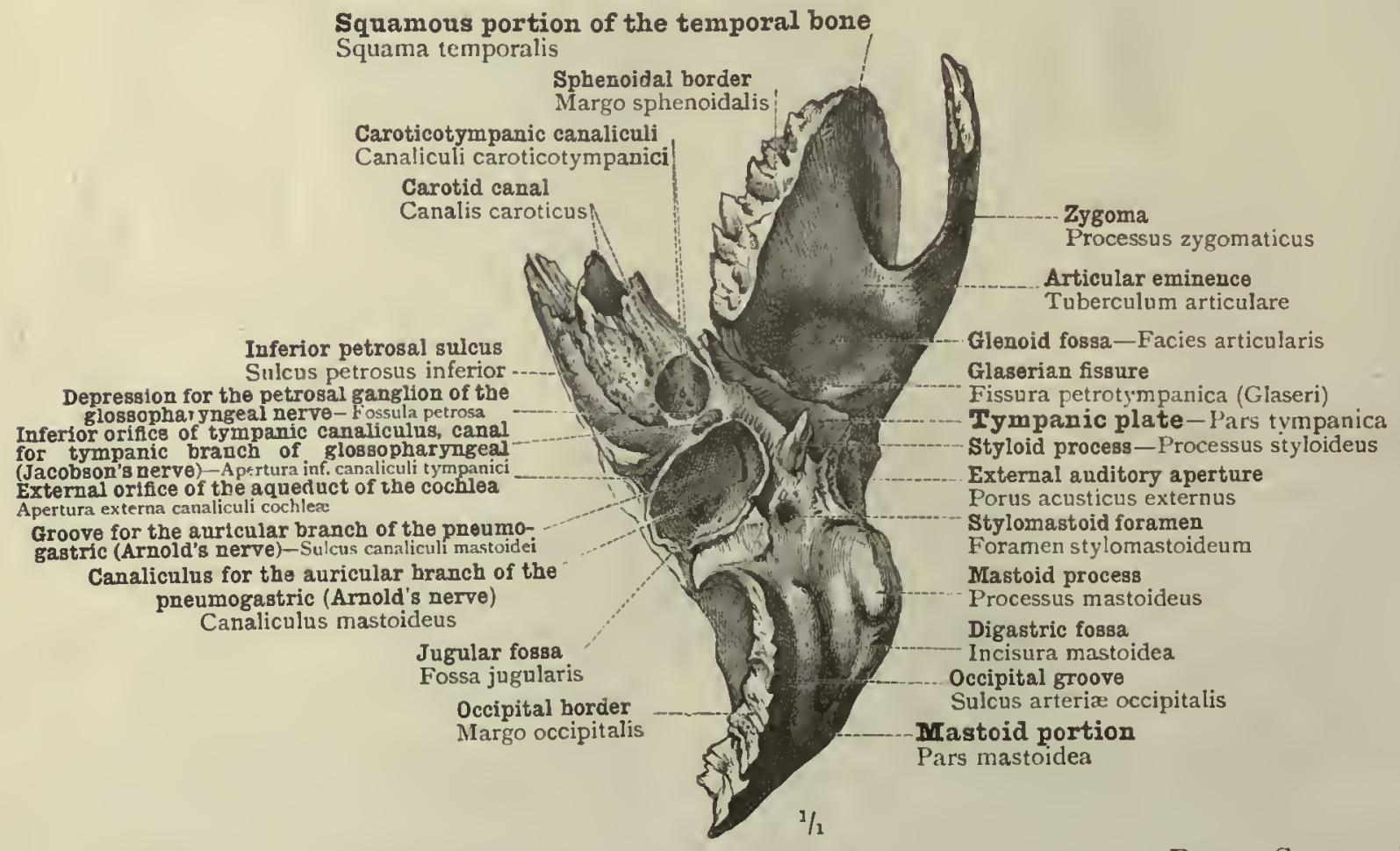

Squamous portion of the temporal bone Squama temporalis

Caroticotympanic canalicul

Carotid canal Canalis caroticus

Fig. 128.-The Left Temporal Bone seen from Below (External Basal Surface). Os temporale--The temporal bone. 


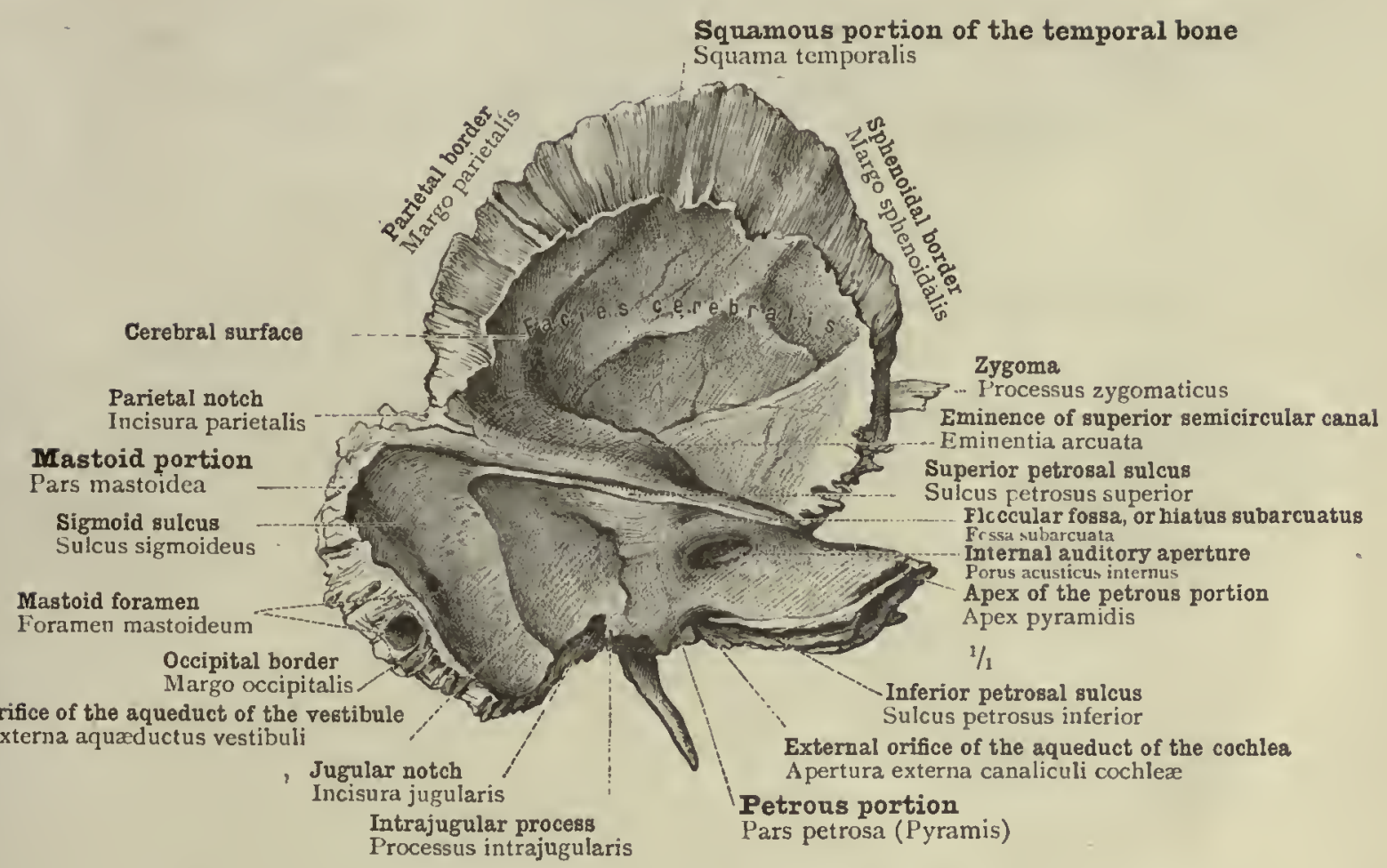

Fig. I29.-The Left Temporal Bone seen from Within (Cerebral Surface).

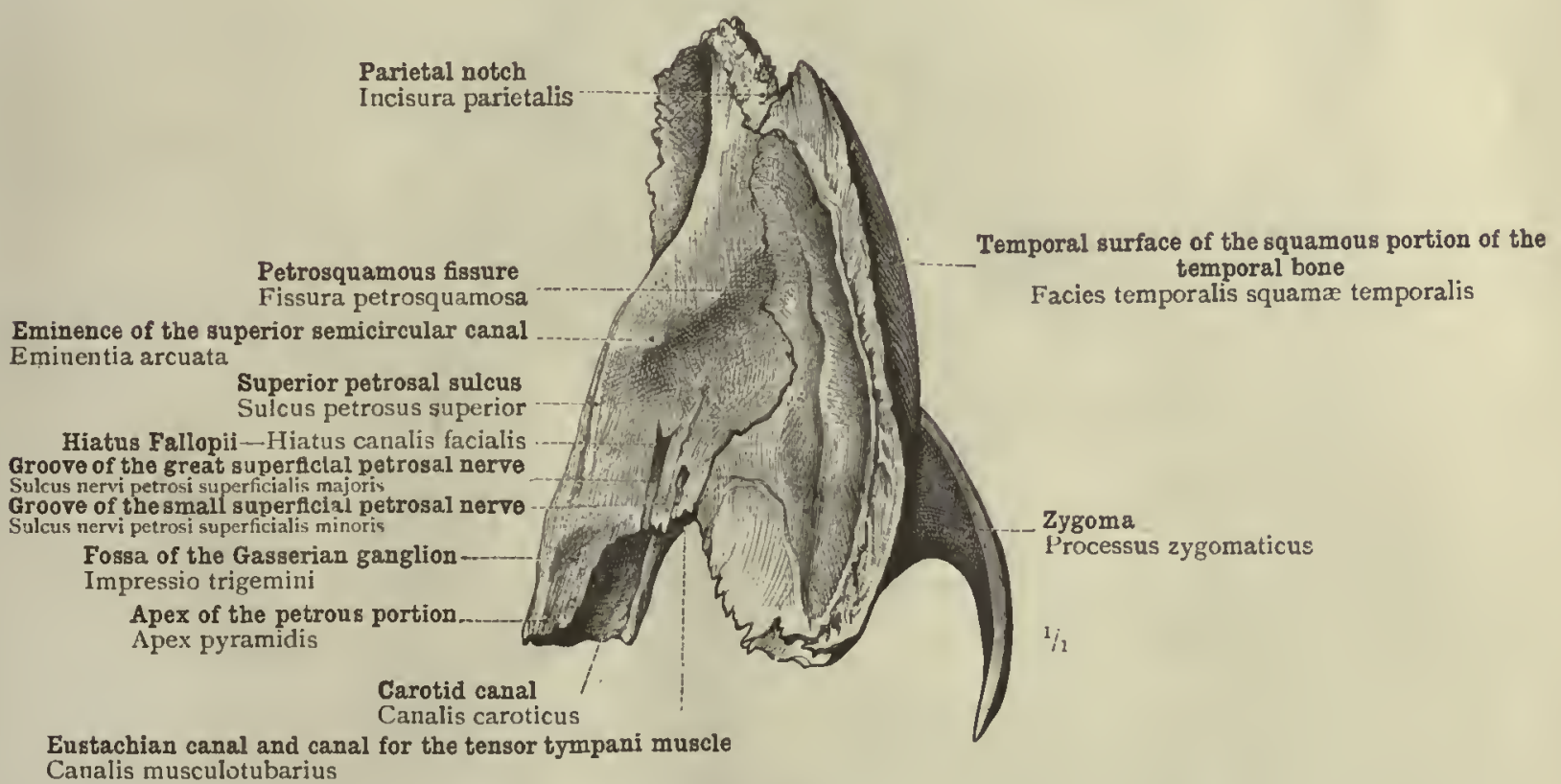

Fig. I30.-The Left Temporal Bone seen from Above (Internal Basal Surface). 


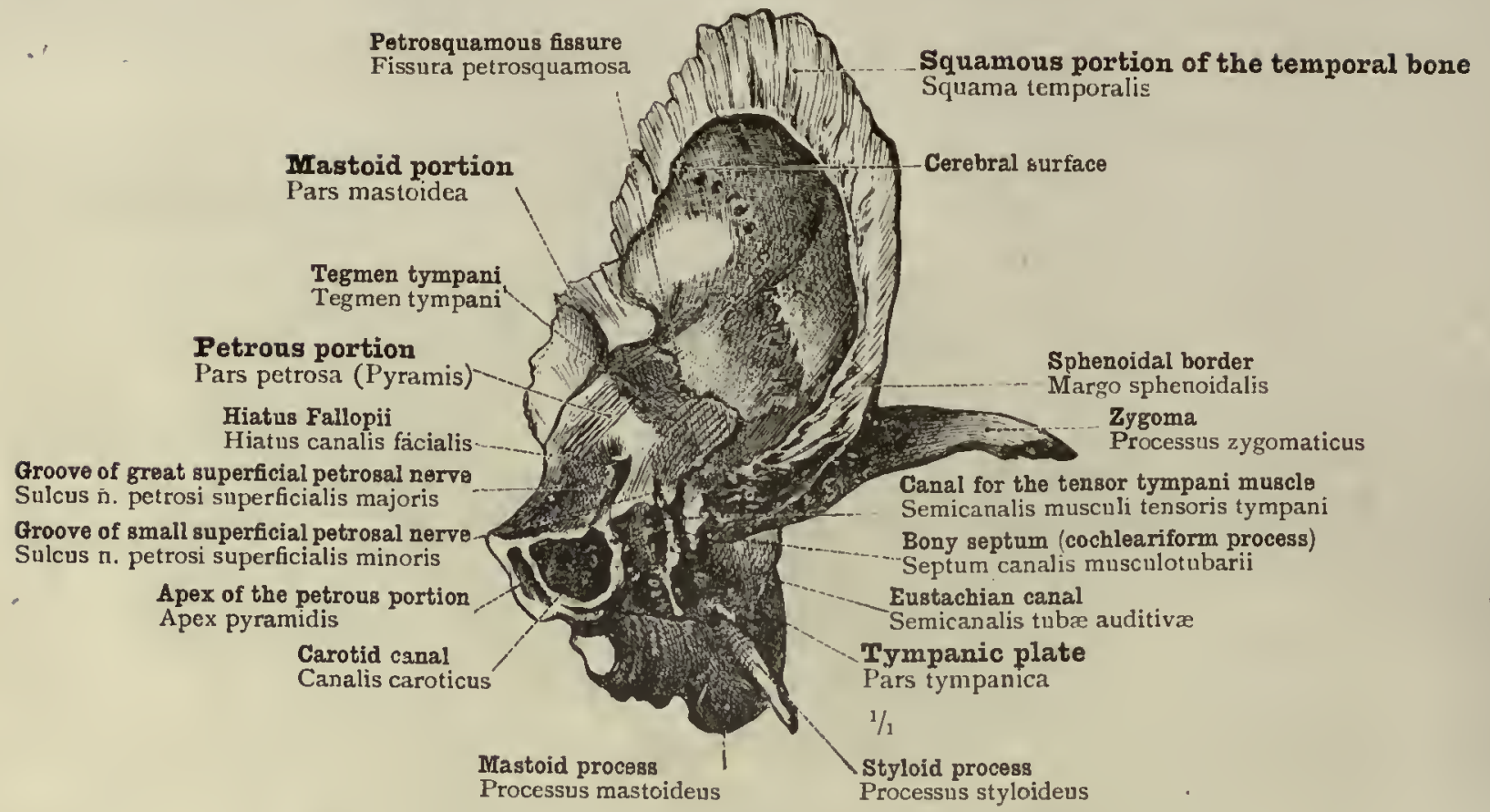

Fig. i3i.-The Left Temporal Bone seen from Before.

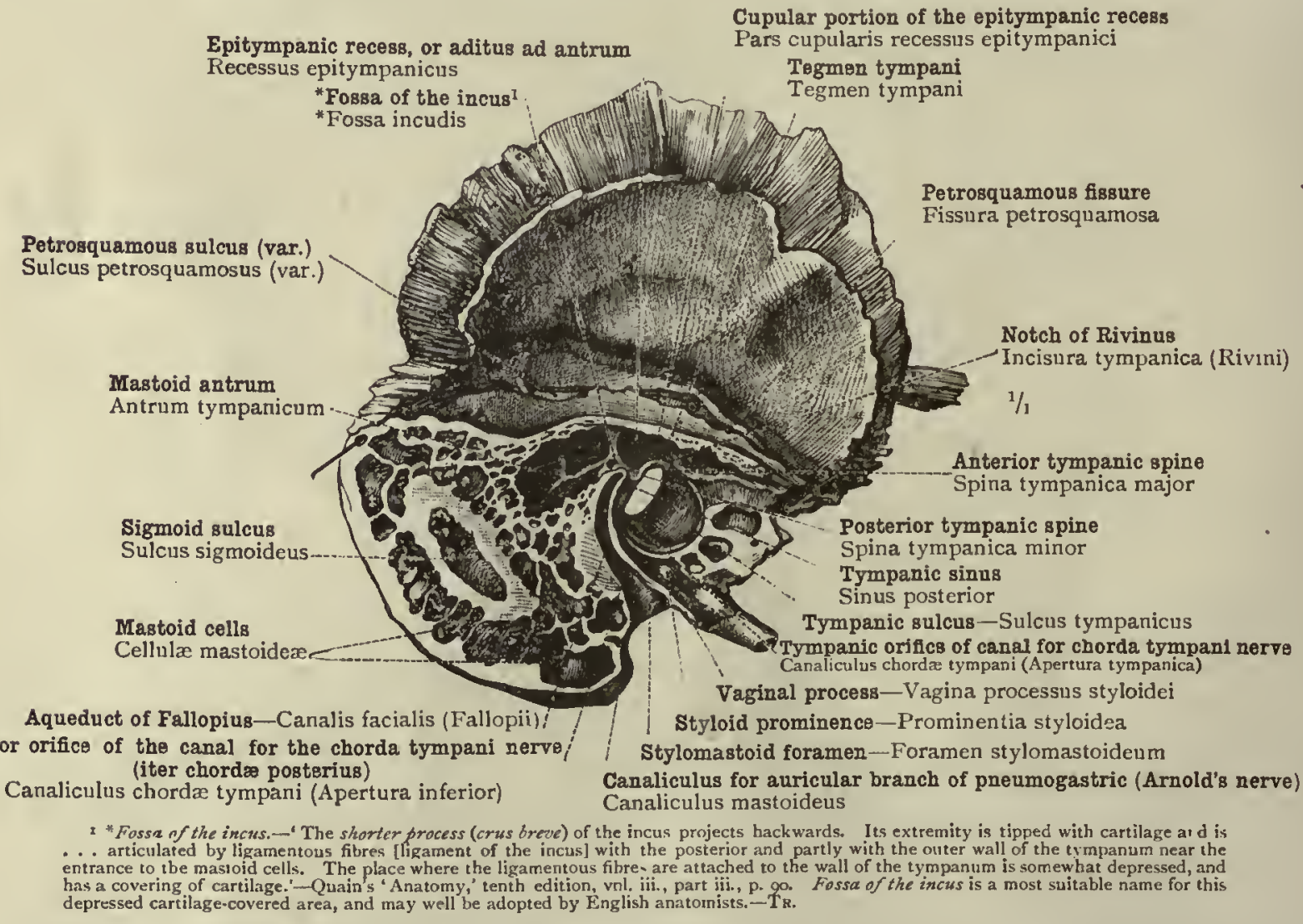

Fig. I32.-The External Wall of the Tympanum and the Mastoid Cells displayed By a Section through the Left Temporal Bone in a Plane parallel with the Souamous Portion of that Bone.

The petrosquamous sulcus (along which a sound has been passed) is in this specimen partly bridged over by bone; anteriorly it communicates with the outer surface of the bone by means of a spurious jugular foramen-foramen jugulare spurium (Variety).

Os temporale-The temporal bone. 


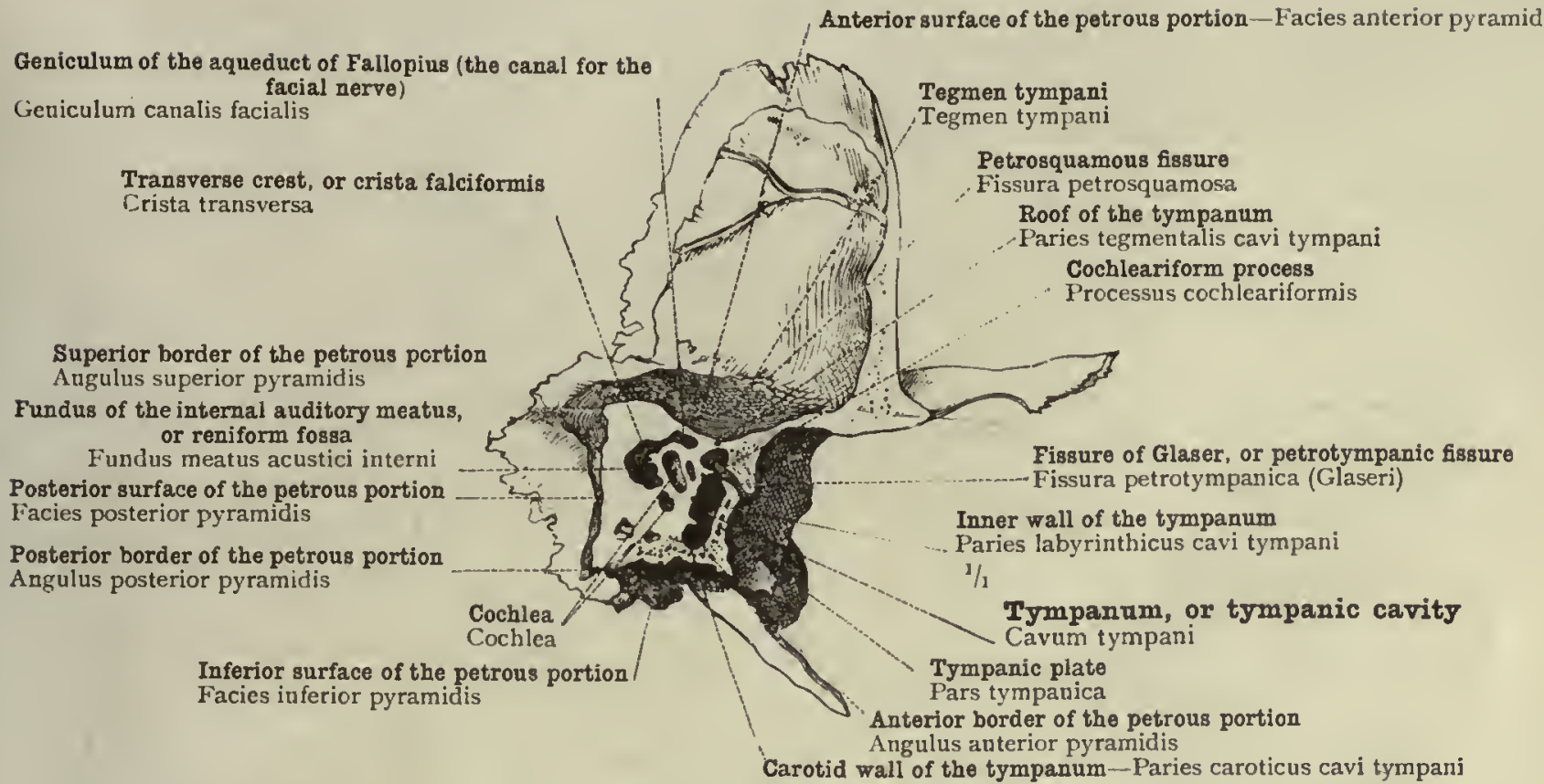

Fig. I33.-Vertical Section through the Petrous Portion of the Left Temporal Bone and througi the Anterior Part of the Souamous Portion. (Nomenclature of, the Surface and Borders of the Petrous Portion.)

\section{Carotid canal Tympanic canaliculus (for Jacobson's nerve) Canalis caroticus Canaliculus tympanicus}

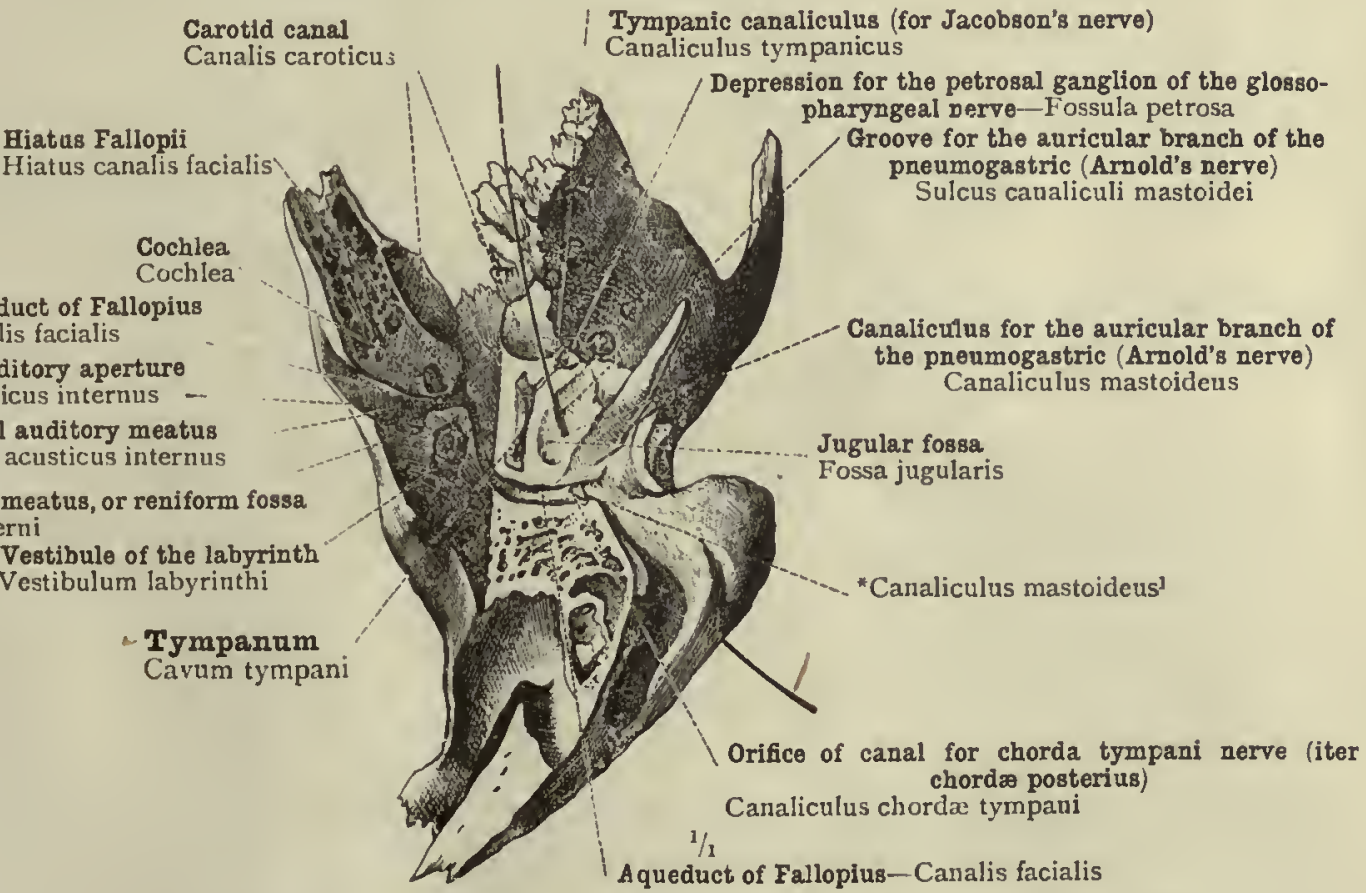

Fig. 134.-Agueductus Fallopil, or Canal for the Facial Nerve, shown from Beneath by the Removal of a Wedge-shaped Piece from the Petrous Portion of the Left TEMPORAL BONE.

The canaliculus tympanicus, for the tympanic branch of the glossopharyngeal nerve (Jacobson's nerve), is also opened up throughout its whole length. A sound has been.passed through the canaliculus for the auricular branch of the pneumogastric nerve (nerve of Arnold). In the Continental nomenclature this canaliculus is known as the canaliculus mastoideus. 


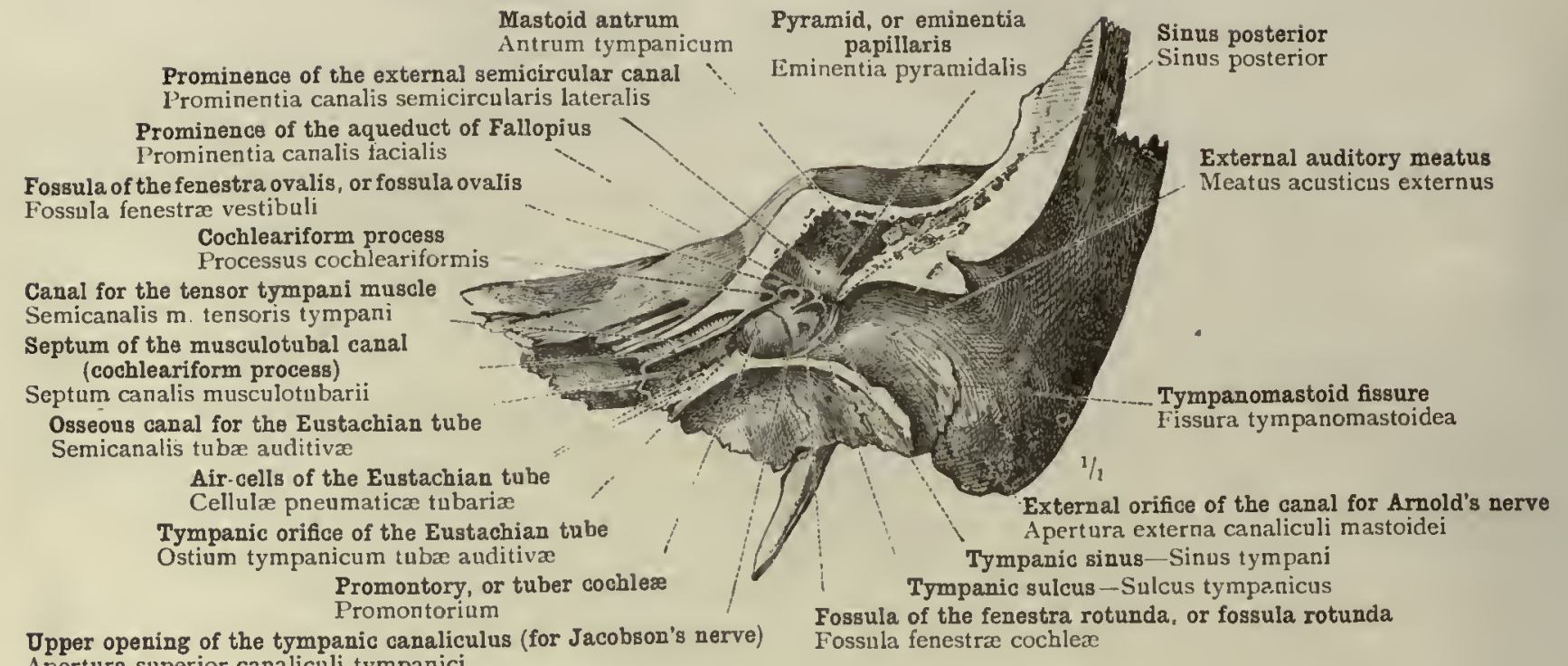
Apertura superior canaliculi tympanici

Fig. I35.-Vertical Section through the Left Temporal Bone in a Plane parallel with the Superior Border of the Petrous Poltion, and passing through the Middle of the External Auditory Meatus, to demonstrate the lympanic Cavity, Cavum TyMPANi, AND THE AdjoININg PARTs.

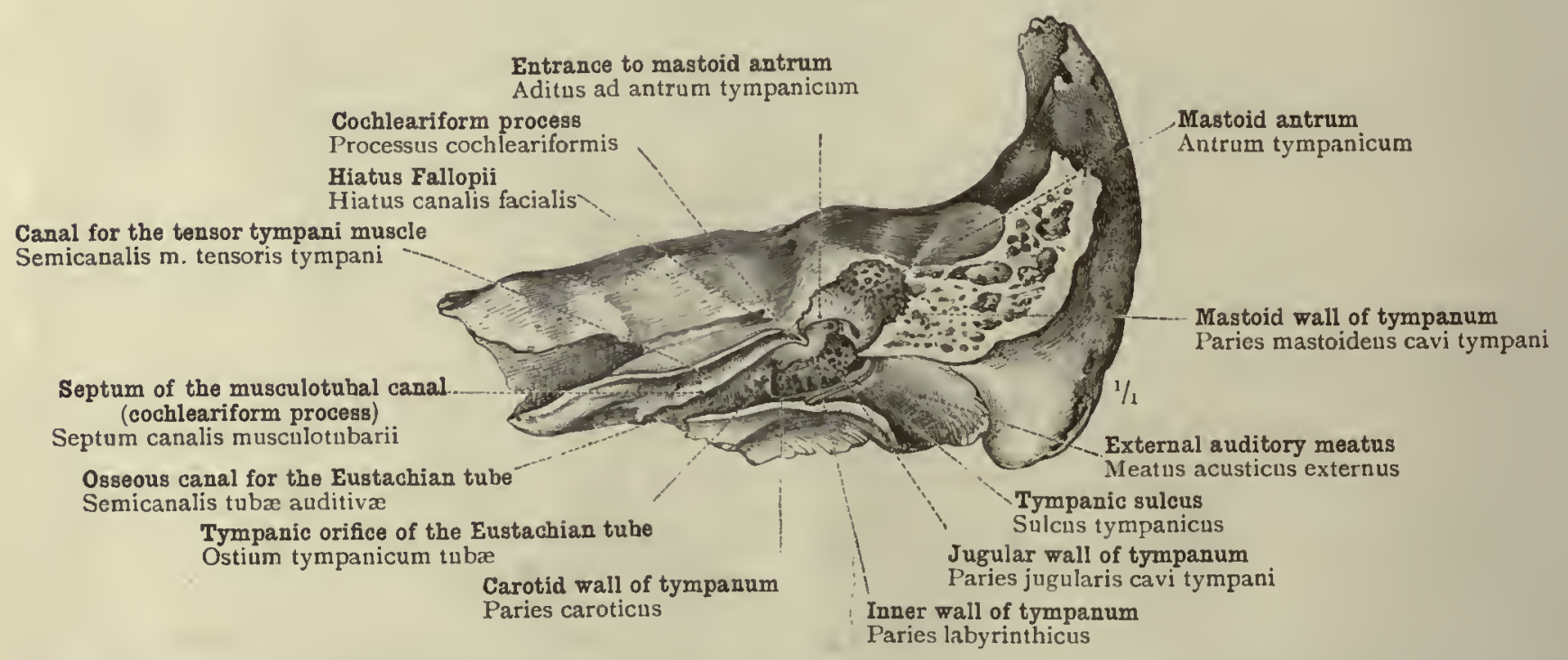

Fig. I36. Vertical Section through the Left Temporal Bone in a Plane parallel with the Superior Border of the Petrous Portion, the Section passing along the Posterior Wall of the External Auditory Meatus, to demonstrate the Tympanic Cavity, Cavum Tympani, and the Adjoining Parts. 
Deficiency in the tympanic wall of the aqueduct of Fallopius (variety)

Prominence of the external semicircular canal Prominentia canalis semicircularis lateralis

Fenestra ovalis-Fenestra vestibuli

Fenestra rotunda-Fenestra cochlex
Promontory-Promontorium

Hiatus Fallopii-Hiatus canalis facialis

Canal for the tensor tympani muscle

Semicanalis $\mathrm{m}$. tens. tympani -

Septum of the musculotubal canal (cochleariform process)

Septum canalis musculotubarii

Groove for the Gasserian ganglion Impressio trigemini

Carotid canal-Canalis caroticus

Osseous canal for the Eustachian tube

Semicanalis tubæ auditivæ

Caroticotympanic canaliculi Canaliculi caroticotympanici Tympanic cells Cellula tympanica

Canaliculus for the chorda tympani nerve (iter chordæ posterius) .. Canaliculus chordx tympañ

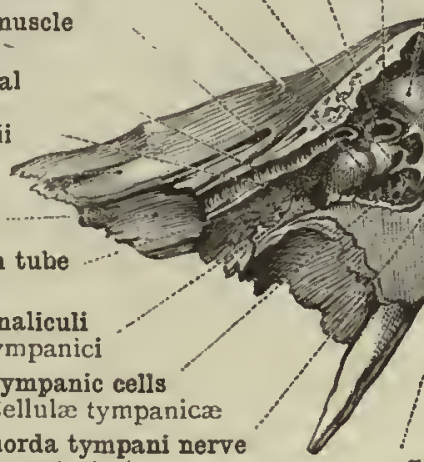

Stylomastoid foramen Entrance to mastoid antrum-Aditus ad antrum tympanicum Entrance to mastoid antrum-Aditus ad antrum tympanicum
Ponticulus promontorii-Ponticulus promontorii

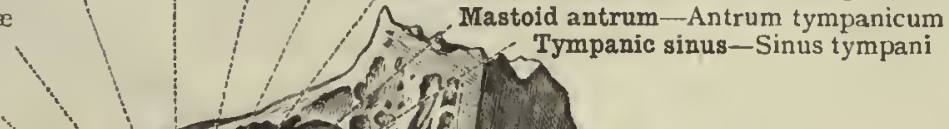

oramen stylomastoideum

Fig. I37.-Vertical Section through the Left Temporal Bone, crossing obliguely the Superior Border of the Petrous Portion, and passing through the Anterior Purtion of the Mastoid Process, to demonstrate the Tympanic Cavity, Cavum Tympani, and the Adjoining Parts (especially the Mastoid antrum and the Mastoid Cells).

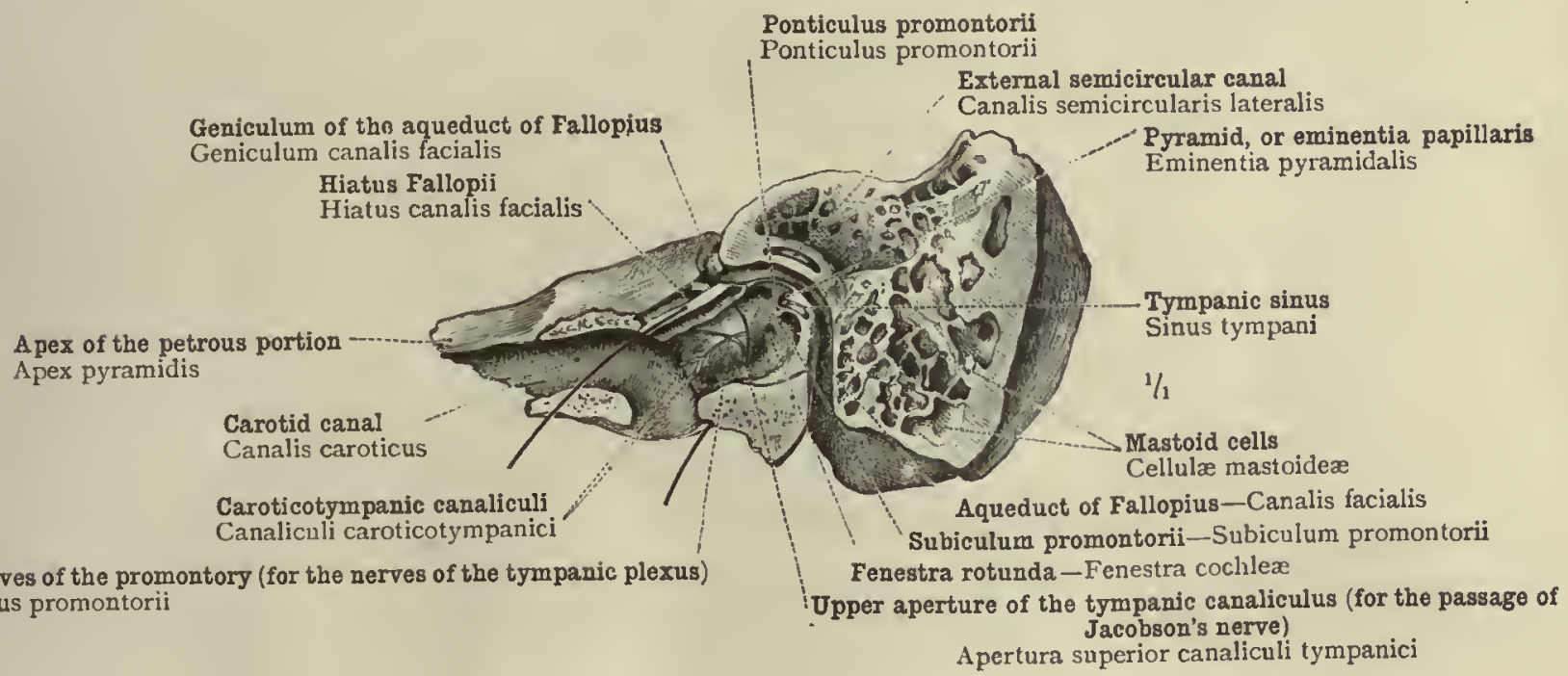

Fig. i38.-Vertical Section through the Left Temporal Bone, crossing obliduely the Superior Border of the Petrous Portion, and passing through the Posterior Portion of the Mastoid Process, to demonstrate the Tympanic Cavity, Cavum Tympani, And the Adjolning Parts.

A bristle has been passed through the canaliculus tympanicus (the canal for Jacobson's nerve-the tympanic branch of the glossopharyngeal. nerve) into the tympanum, and, after traversing this cavity, leaves it by the canaliculus that opens into the groove for the small superficial petrosal nerve. 
Superior semicircular canal-Canalis semicircularis superior Anterior surface of petrous portion-Facies anterior pyramidis

Vestibule of the labyrinth.

Vestibulum labyrinthi

Geniculum of the aqueduct of Fallopius -

Geniculum canalis tacialis

Cochleariform process

i'rocessus cochleariformis
External semicircular canal

Canalis semicircularis lateralis

Superior border of the petrous bone

Angulus superior pyramidis

Posterior semicircular canal

Canalis semicircularis posterior

_- Posterior surface of the petrous bose

Facies posterior pyramidis

\section{Promontory}

Promontorium

Aqueduct of Fallopius

Canalis facialis

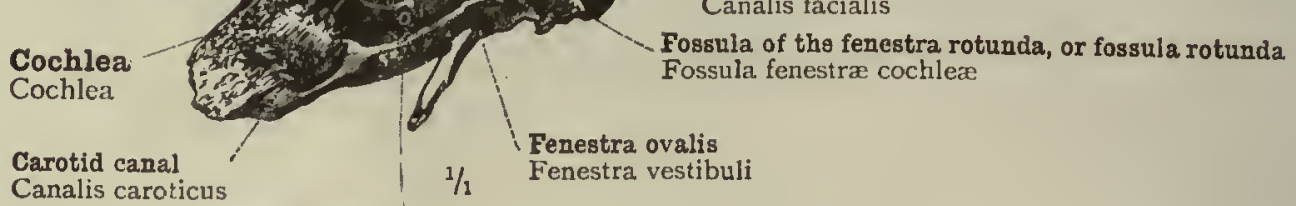

Jugular fossa

Fossa jugularis

Fig. I39. - The Bony Labyrinth, Labyrinthus Osseus, shown in the Left Petrous Portion. Seen obliquely from in Front and below. The Osseous Semicircular Canals and also the Canal of the Cochlea have been partly opened. The Relations betiveen the Aqueduct of Fallopius and the Osseous Labyrinth are clearly shown.

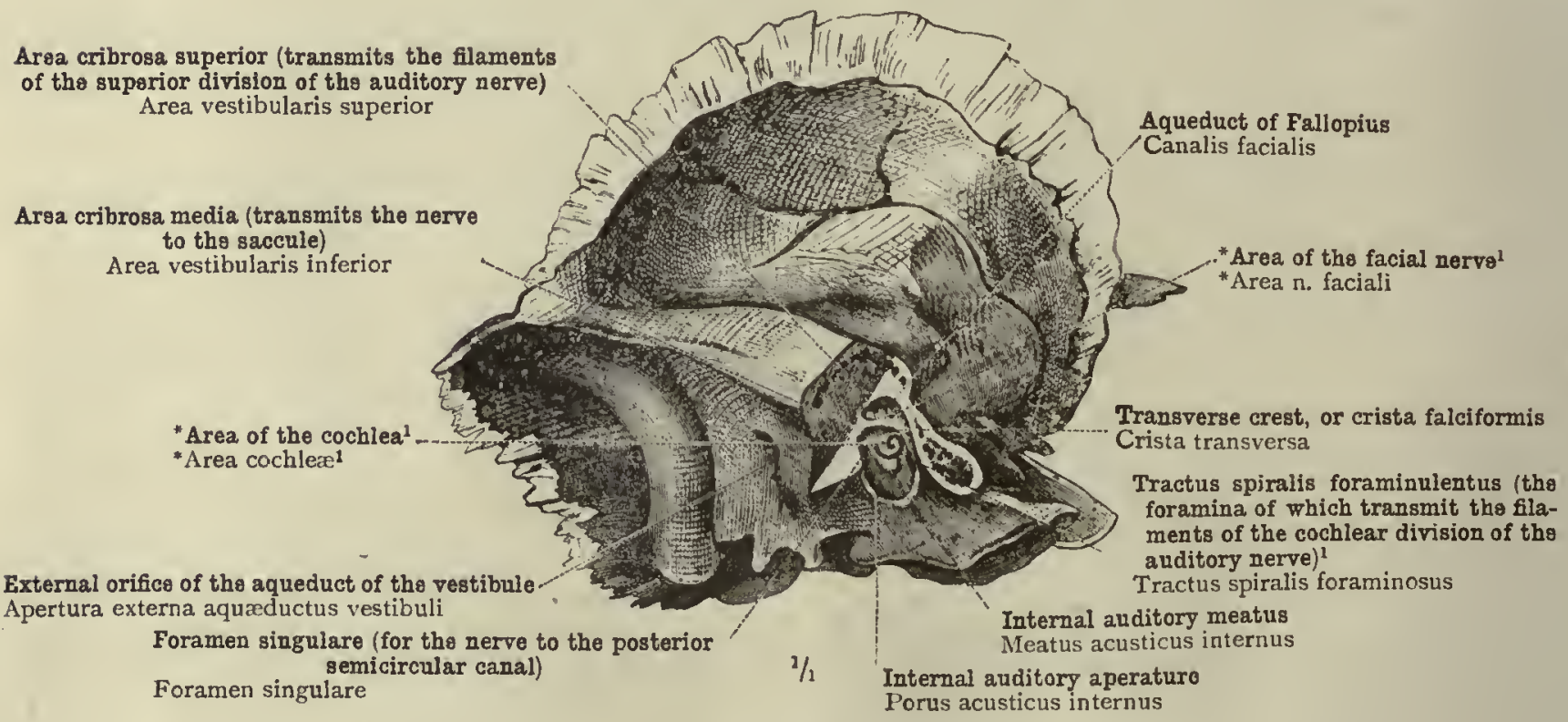

1 The helicoid depression of the tractus spiralis foraminulentus corresponds witl the base of the cochlea, and at the centre of the helix is the foramen centrale cochlex, the orifice of the central canal of the modiolus. On the significance of this term Area of the Cochlea, see also note ${ }^{534}$. p. 956y, in the Appendix to Part VI. ; and on the significance of the term Area of the Facial Nerve, see note ${ }^{538}$ on the same page.

Fig. I40.-The Internal Auditory Meatus, Meatus Acusticus Internus, exposed from Above by the Removal of a Right-angled Wedge from the Petrous Portion of the Left Temporal Bone, displaying the Fundus of the Internal Auditory Meatus, or Reniform Fossa. divided by the Transverse Crest, or -Crista FalciFORMIS, INTO SUPERIOR AND INFERIOR FOSSE. JEEN FROM BEHIND AND ABOVE. 


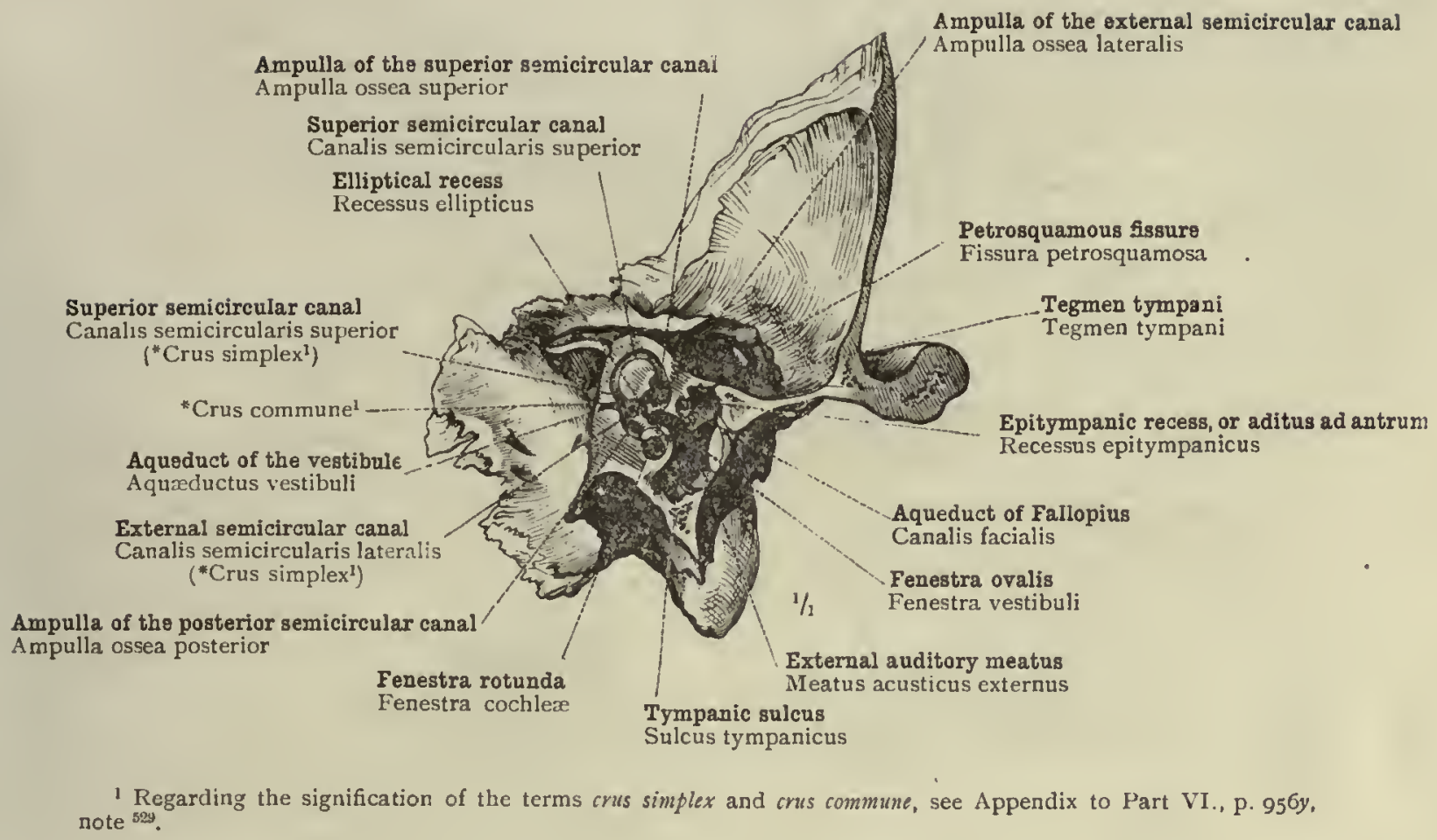

Fig. I4I.-Portions of the Osseous Labyrinth and the Tympanum, shown in the Left Temporal Bone by a Vertical Section through the Petrous Portion in the Plane of the Superior Semicircular Canal. Seen obliguely from in Front and Within.

The fenestra ovalis is divided vertically.

Posterior semicircular canal External semicircular canal

Canalis semicircularis posterior, Canalis semicircularis lateralis

superior semicircular canal-Canalis semicircularis superior

Crest of the vestibule-Crista vestibuli :

Internal auditory meatus -

Meatus acusticus internus

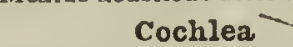

Cochlea

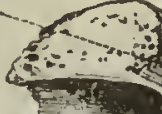

Carotid canal

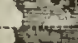

Canalis caroticus 

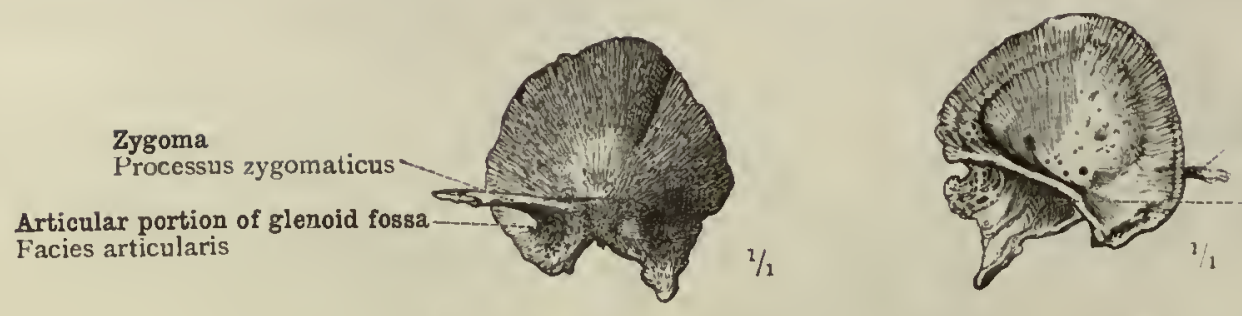

Zygoma
I'rocessus zygomaticus

Epitympanic recess Recessus epitympanicus

Squamous Portion of Temporal BONE-Squama Temporalis.

* Posterior tympanic process

* Processus tympanicus posterior

*Anterior tympanic process

*Processus tympanicus anterior

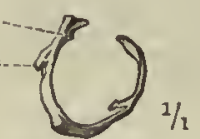

$1 / 1$

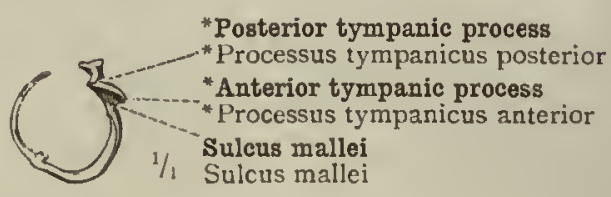

TyMPanic Ring-Annulus Tympanicus.
Tegmen tympani Mastoid antrum

Tegmen tympani Antrum tympanicum

Apex of the petrous portion

A pex pyramidis

Canal for tensor tympani muscle.

Semicanalis $\mathrm{m}$. tensoris tympani

\section{Tympanum}

Cavum tympani

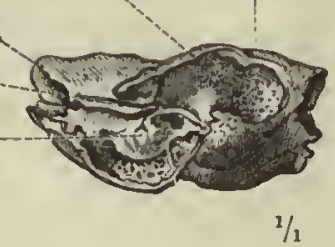

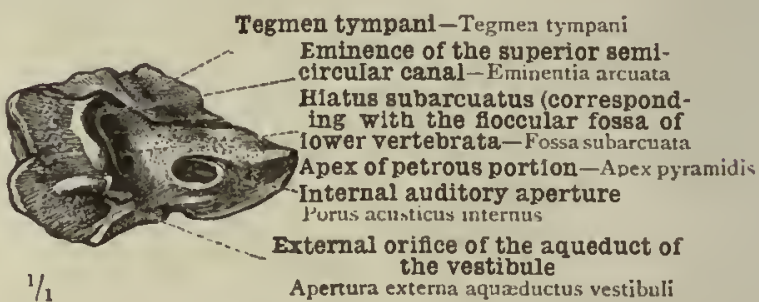

Apertura externa aquaeductus vestibuli

Petrous Portion of Temporal Bone-Pars Petrosa (Pyramis).

Fig. I43.-SEen From Without.

Fig. I44.-SEEN From Within.

The Three Parts of the Left Temporal Bone from an Eight-Months Fotus (Months OF FOUR WEEKS EACH).

Body-length, $15 \frac{1}{2}$ inches.

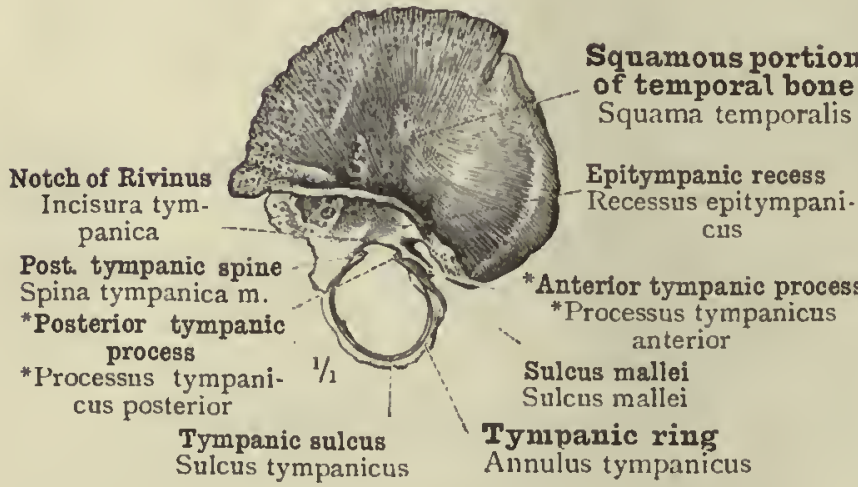

Fig. I45.-The Souamous Portion of the Temporal Bone and the Tympanic Ring united, SEEN FROM IVITHiN. From a foctus at term (body-length, 19 inches).

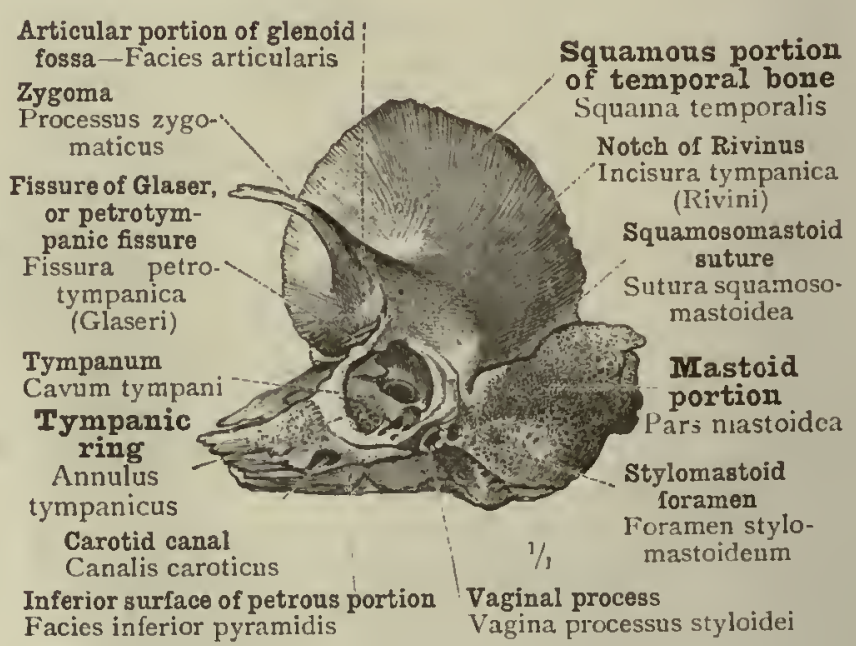

Fig. I46.-The Three Portions of The Left Temporal Bone united. Seen FROM WITHOUT AND BELOW.

From a ncw-lborn male infant (body-length, $2 \mathrm{I}$ inches). 


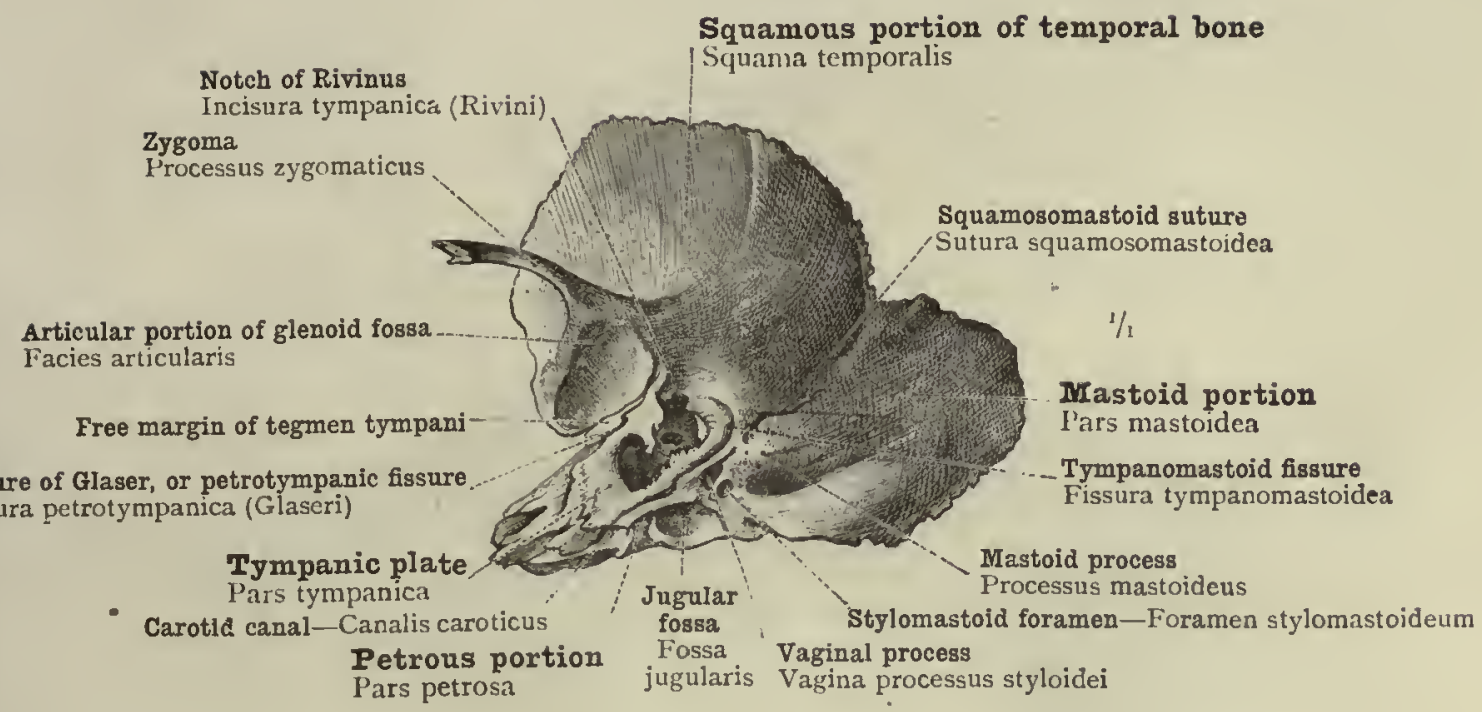

Fig. I47.-The Left Temporal Bone of a Boy at the Age of Eight Months: Formation of the Tympanic Plate and of the External Auditory Meatus. Seen obliguely Front Without and Below.

Anterior tympanic process

Processus tympanicus anterior.

Fissure of Glaser, or petrotympanic fisqure Fissura petrotympanica

\section{IIargin of tegmen tympani \\ Petrous portion}

Tympanic plate

Pars tympanica

Squamous portion of temporal bone Squama temporalis

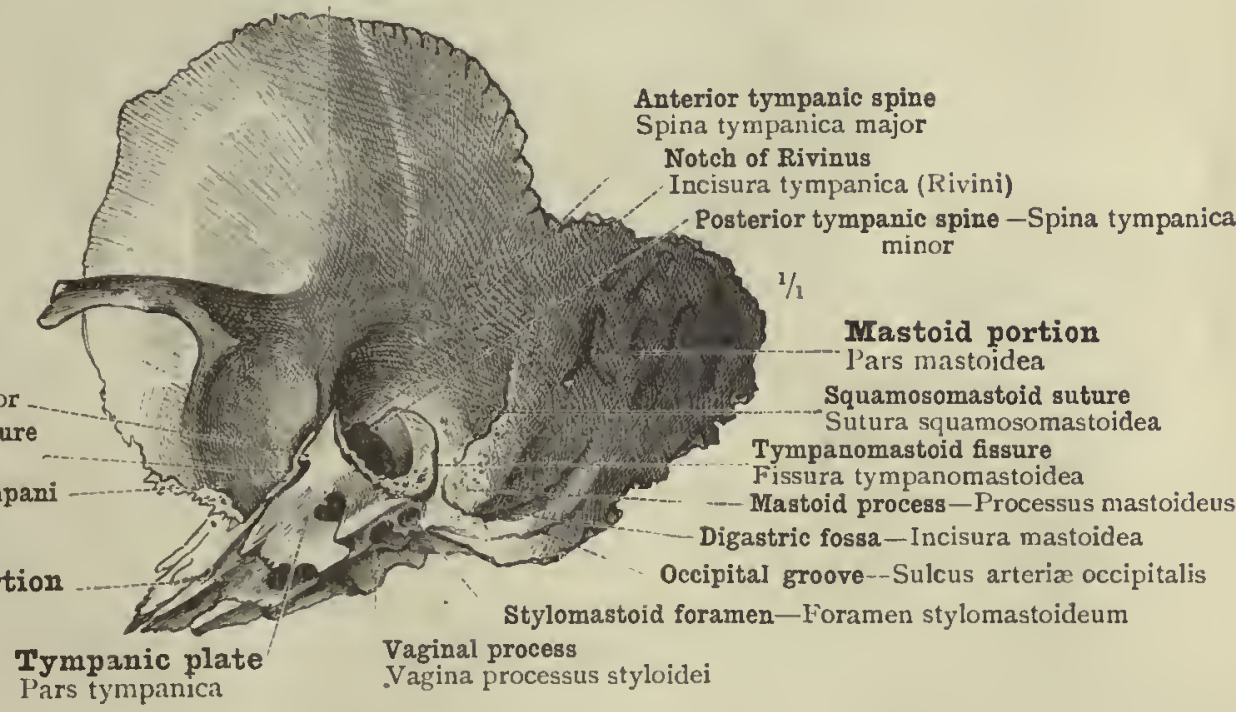

Fig. i48.-Thä Left Temporal. Bone of a Girl at the Age of Three Years: Formation of the Tympanic Plate and of the External Auditory Meatus. Seen obliguely FROM Without AND Below.

Development of the Temporal Bones. 


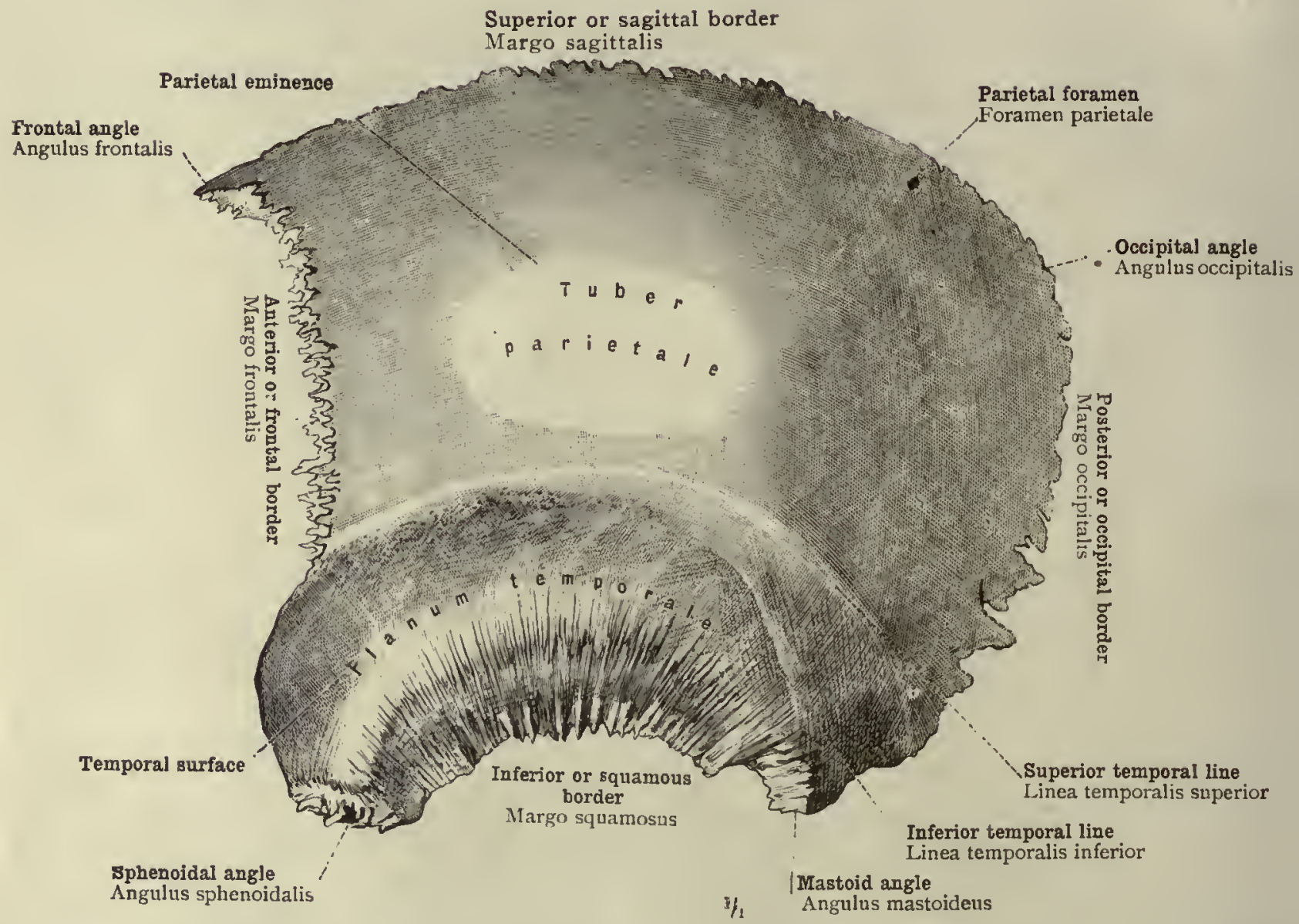

Fig. I49. - The Left Parietal Bone seen from Without. External Surface: Facies Parietalis. 


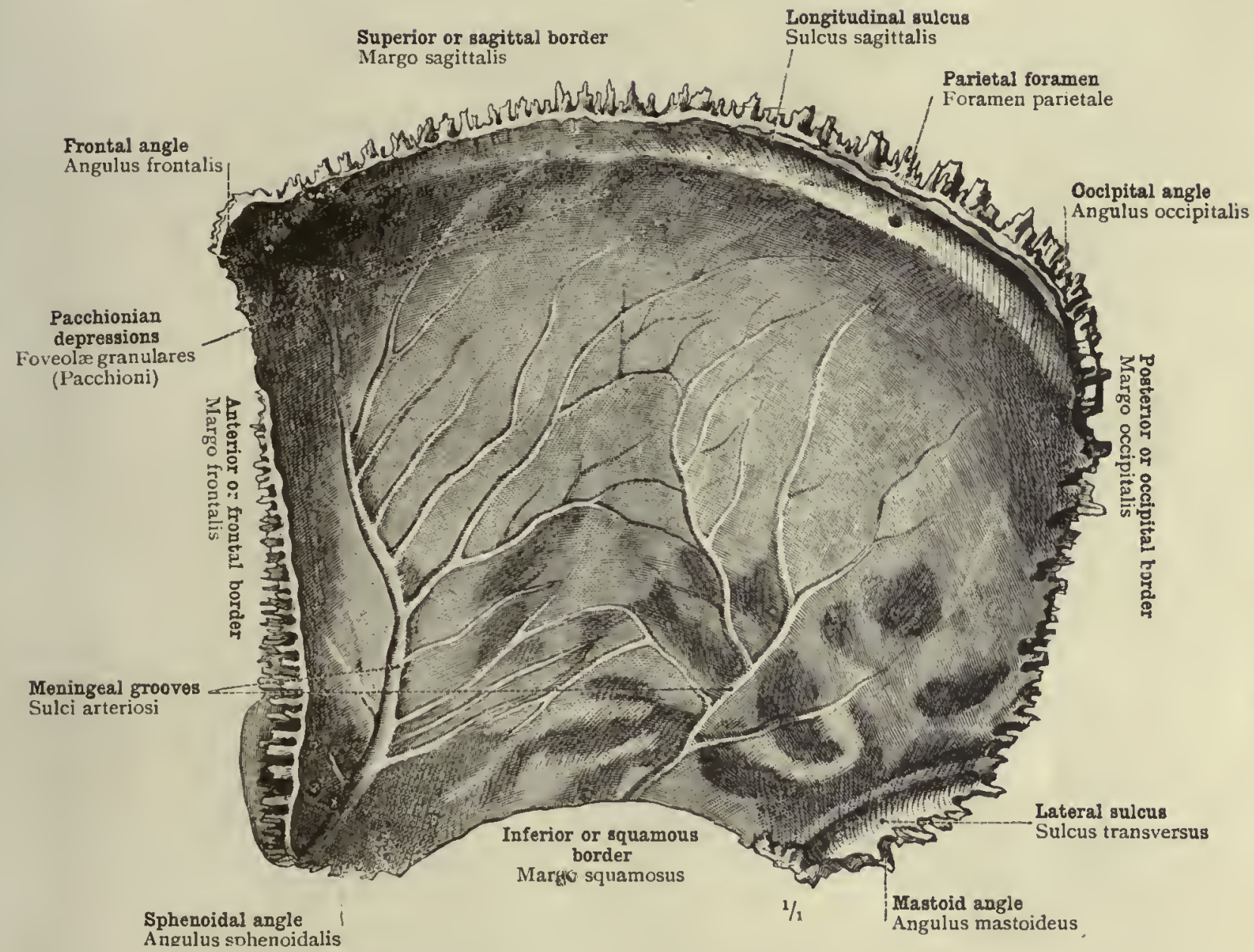

Fig. I50.-The Right Parietal Bone seen from Without. Internal Surface: Facies Cerebralis. 


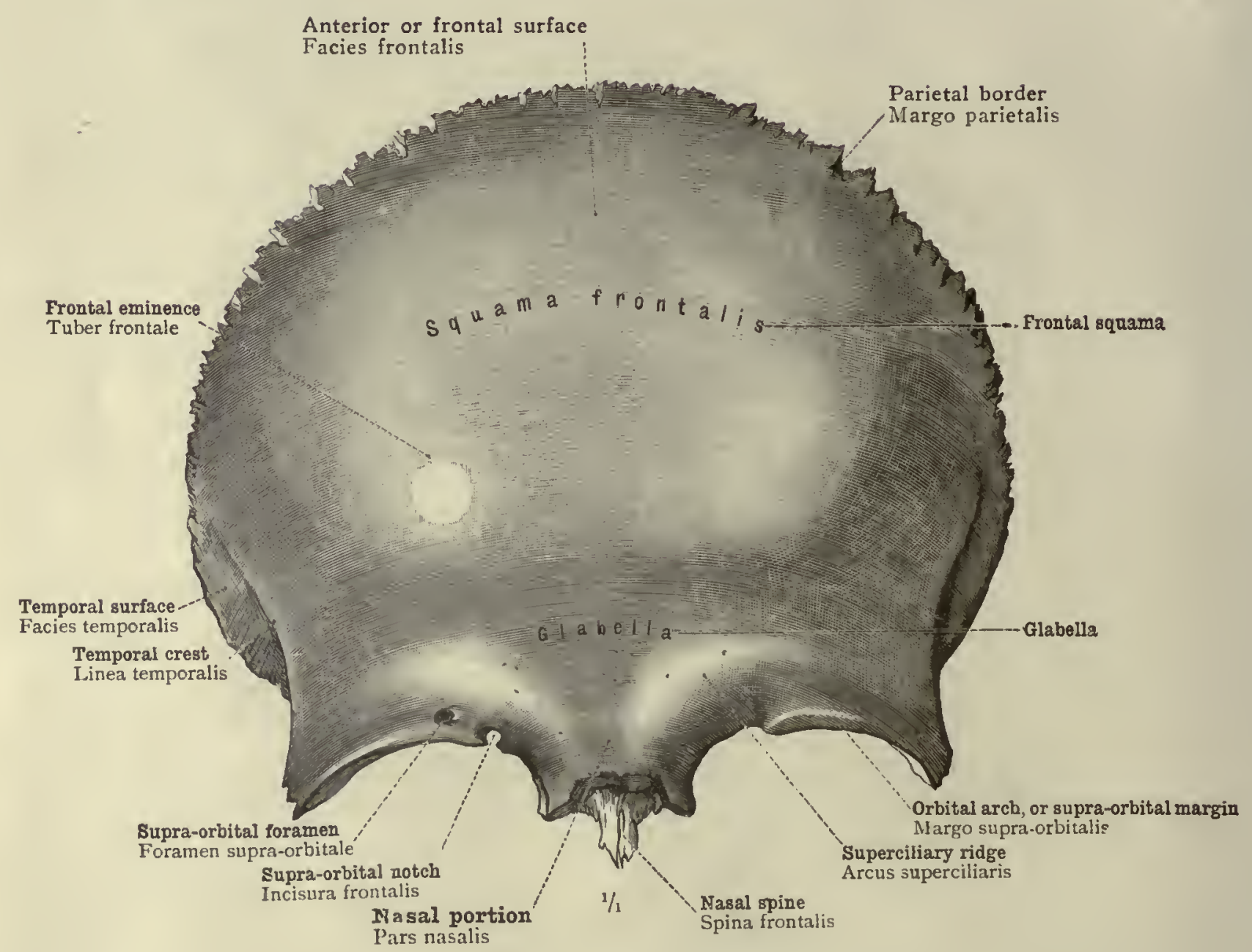

Fig. 151.-The Frontal Bone seen from Before. External Surface: Facies Frontalis. 


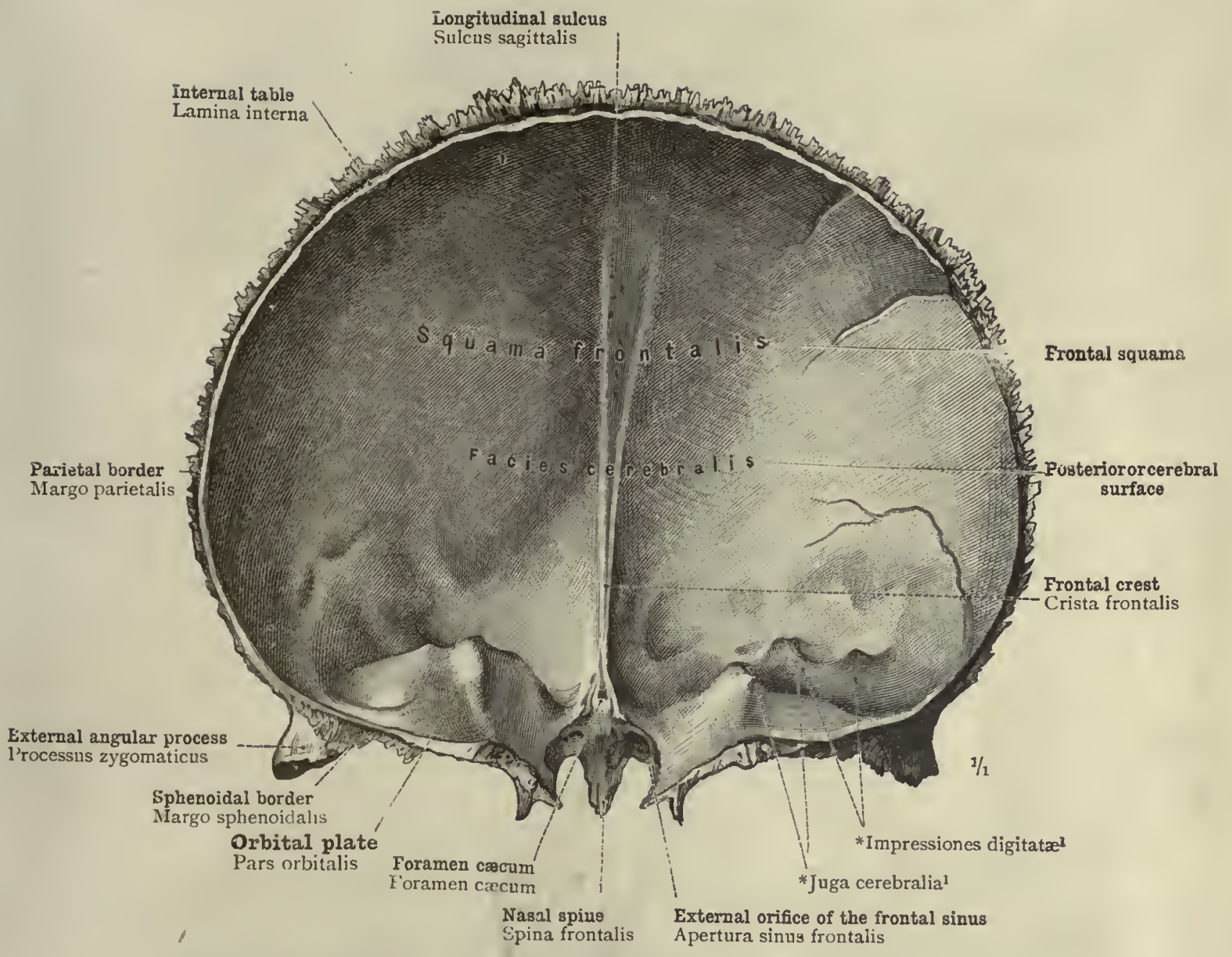

1 Ridges (juga cerebralia) and sulci (impressiones digitatx) corresponding respectively to the sulci and convolutions of the superjacent portion of the frontal lobes of the cerebrum. - TR.

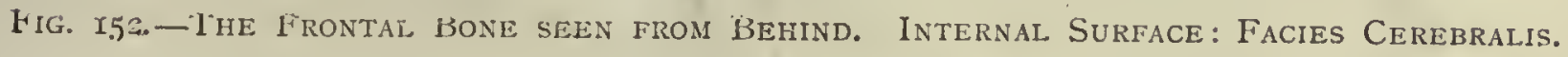




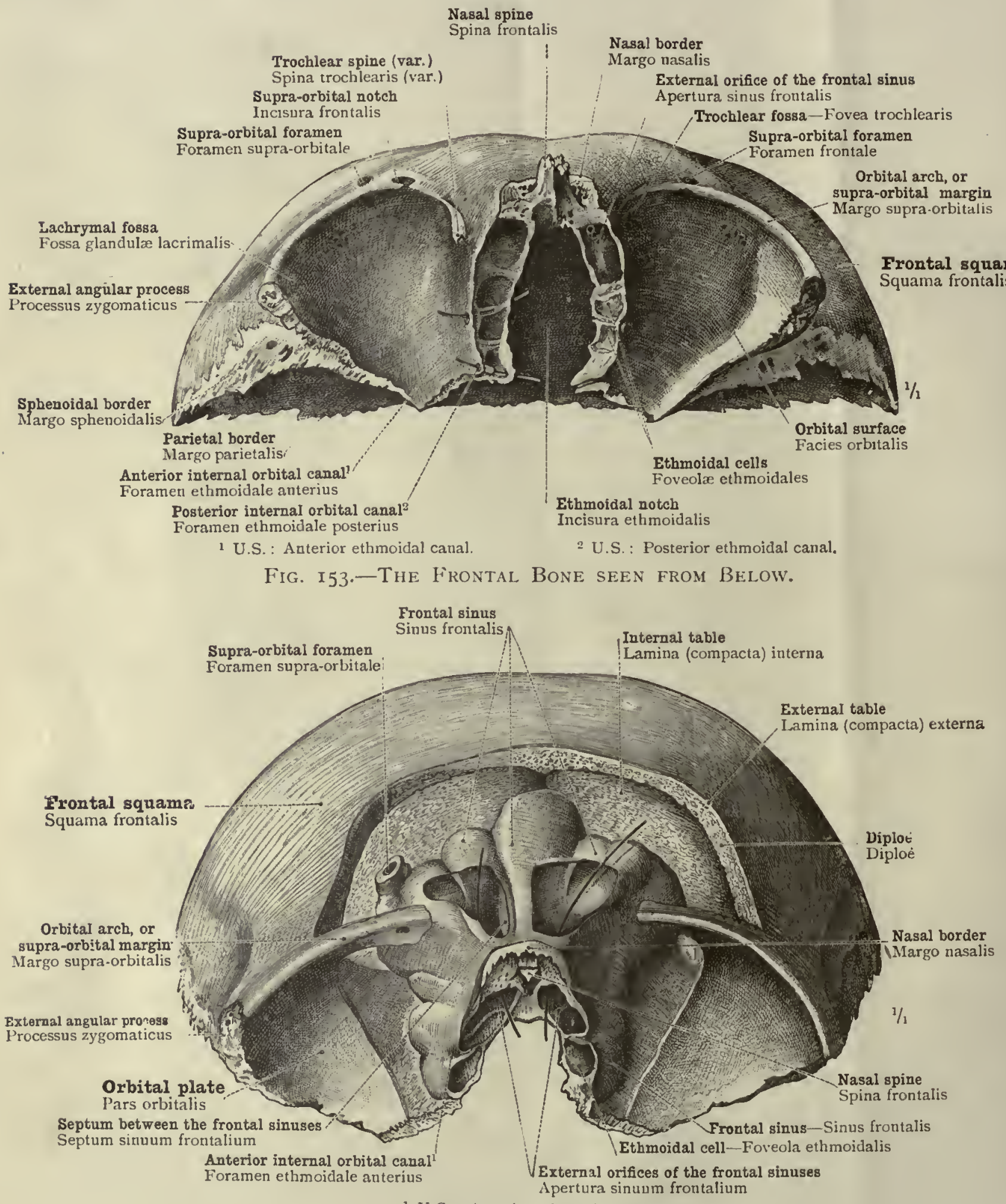

1 U.S. : Anterior ethmoidal canal.

Fig. I54.-The Frontal Sinuses, Sinus Frontales, shown by tile Removal of the External. Table and the Diplö̈, and partly opened up. Seen from Before and Below. 


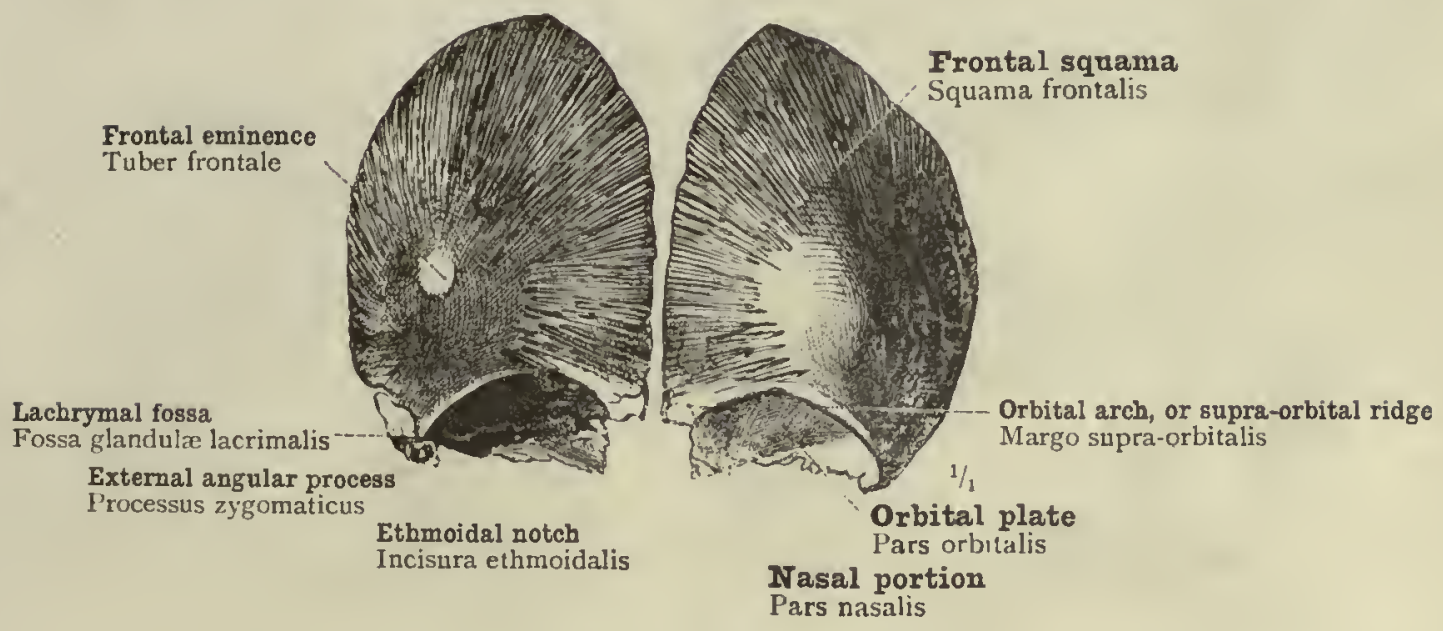

Fig. I55.-The Two Halves of the frontal Bone from a Human foetus in the Eighth Month (Months of Four Weeks Each). Seen from Before.

Body-length of foetus 15 inches.

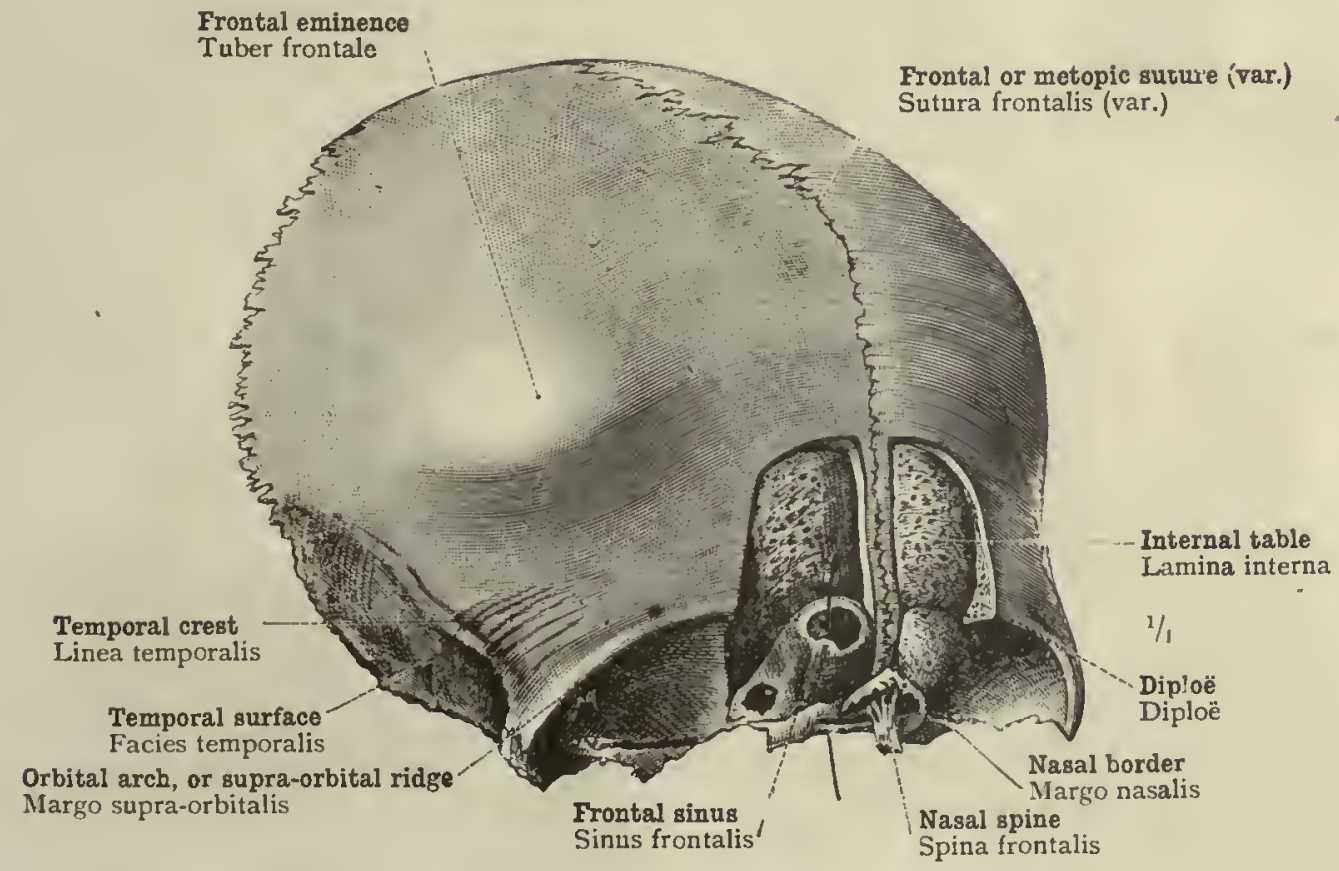

Fig. I56.-The Frontal Bone of a Girl aged Seven Years in which the Frontal Sinuses have been exposed. Seen obliquely from Before and from the Right SidE. 


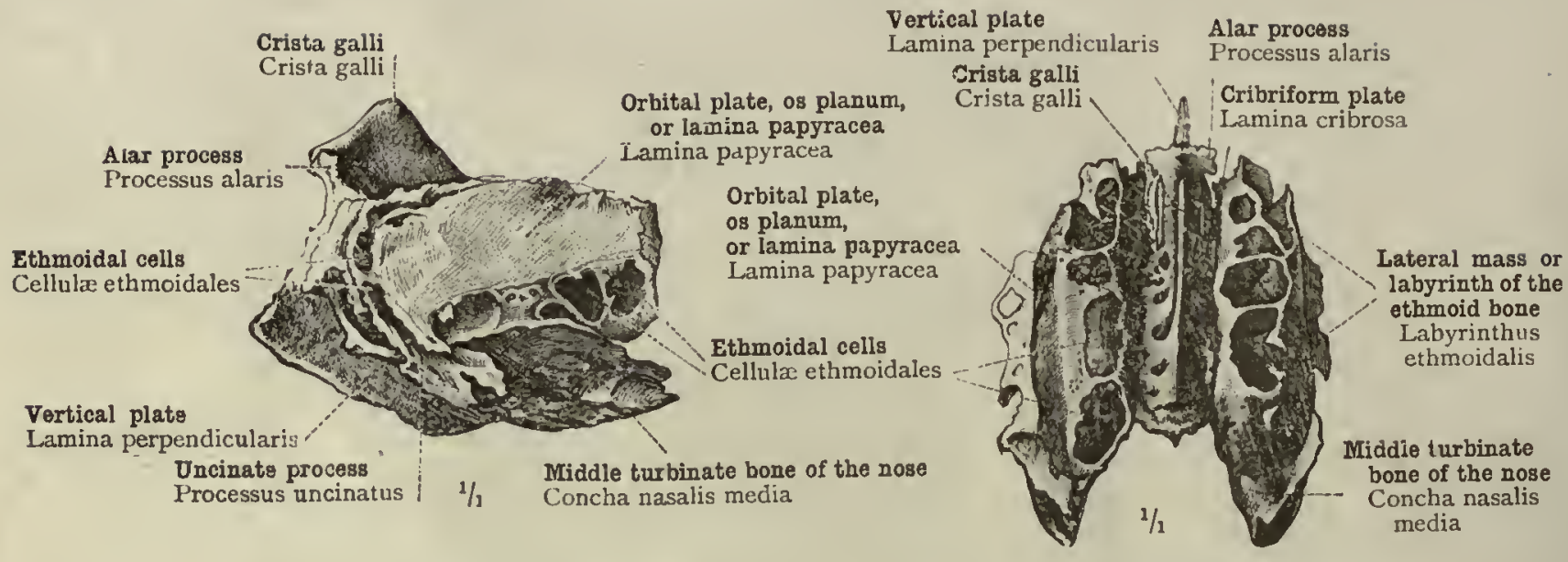

Fig. 157.-The EthMold Bone SeEN From
The LeFt Side
Fig. I58.-The EThmoid Bone SEEN FROM ABOVE.

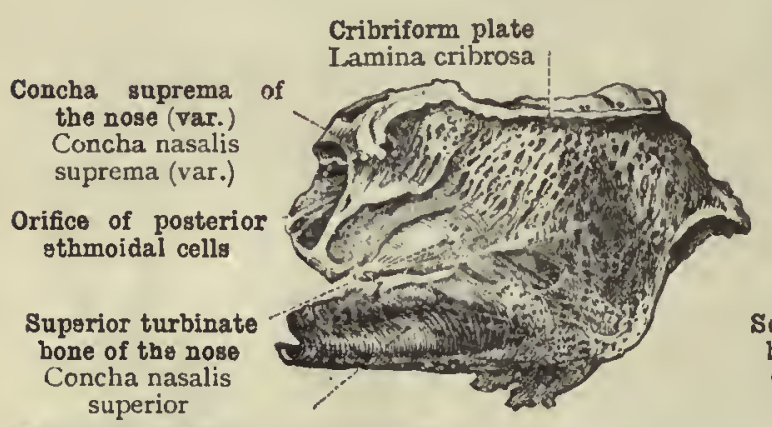

Middle turbinate bone of the nose Concha nasalis media

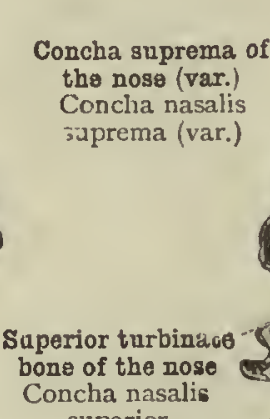
superior

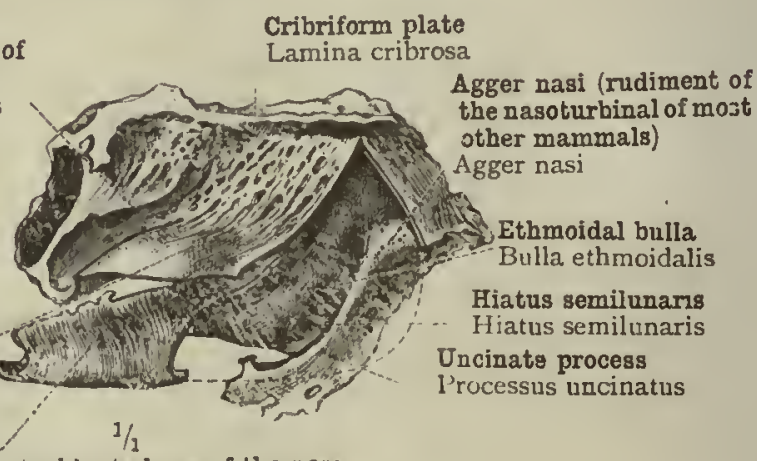

Middle turbinate bons of the nose Concha nasalis media

Fig. I59.-The Left Half of the Ethmoid BONE SEEN FROM Within. SUPERIOR AND Midule Turbinate Bones.

Fig: I60.-The Left HalF of the EThmoid BONE SEEN FROM WITHIN.

The anterin portion of the middle turbinate bone of the nose has been removed. The free border of the removed portion is indicated by a dotted line.

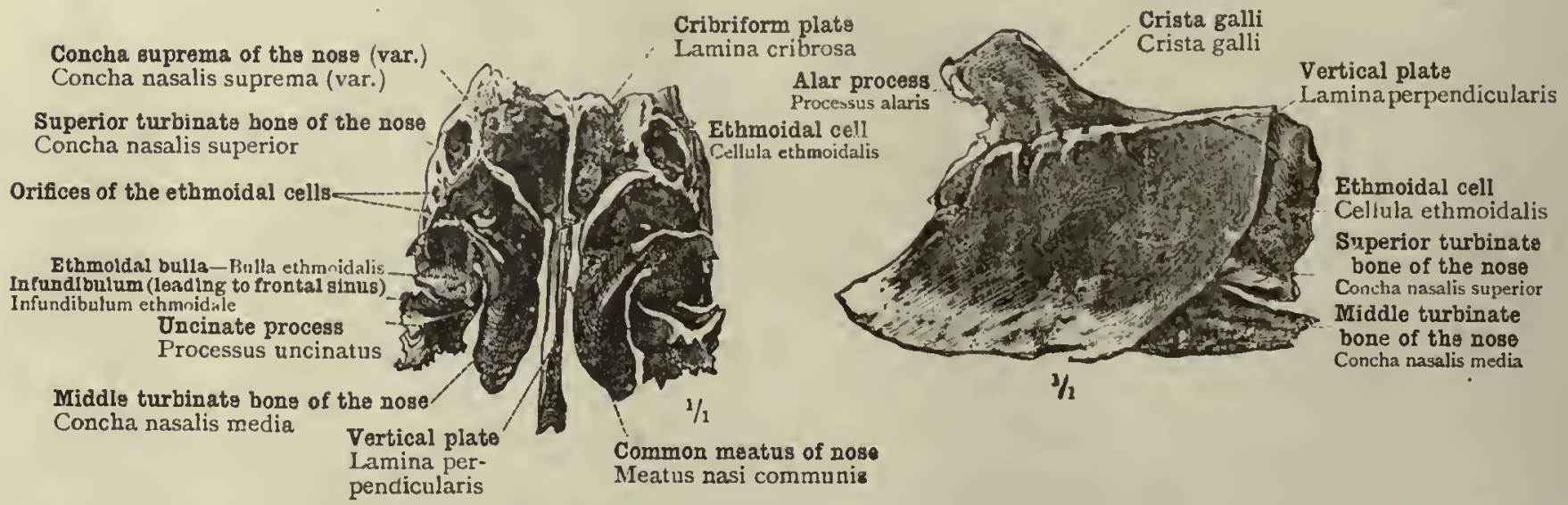

FIG. I6I.-The ETHMOID BONE SEEN FROM Behind and Below. Vertical Plate of THE Ethmoid as Upper Part of the Bony Septum of the Nose.

Fig. 162.--AN Ethmold BONE THE Left LATERAL MASS OF WHICH HAS BEEN RENOVED. The entire surface of the vertical plate is exposed. 


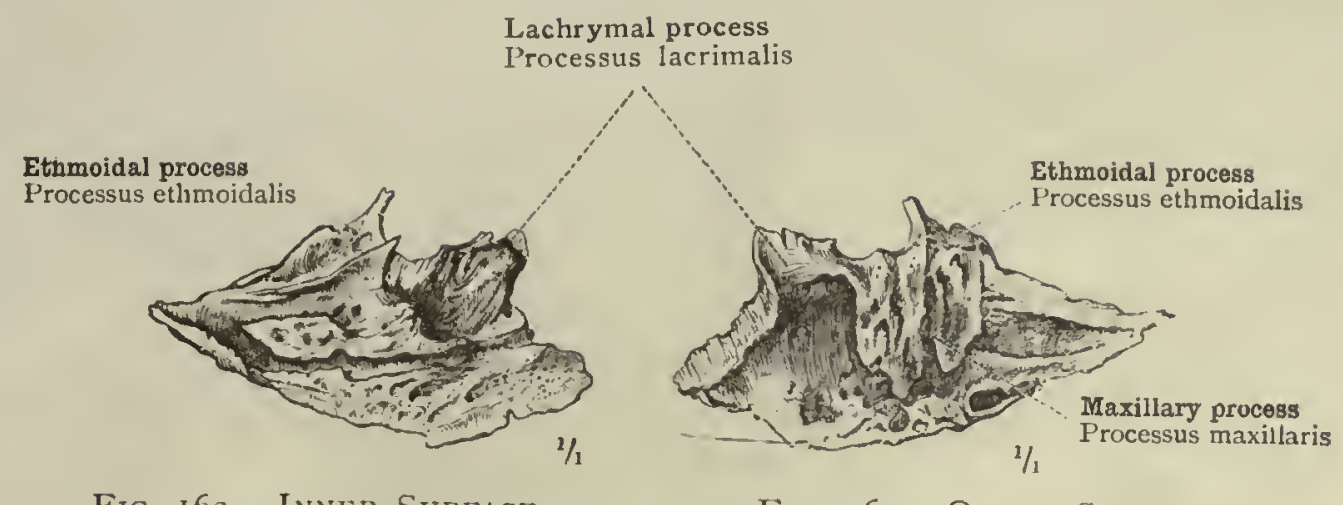

FiG. I63.-InNer SURface.

Fig. i64.-OUter Surface.

Concia Nasalis Inferior-The Inferior Turbinate Bone of the Left Side.

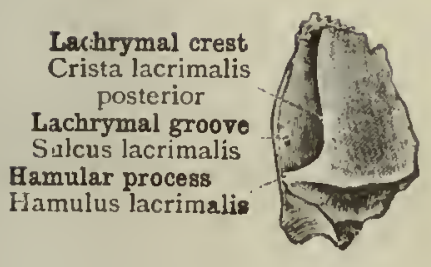

Fig. 165.-External SURFACE.

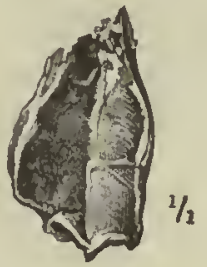

FIG. I66.-INTEKITAL SURFACE.

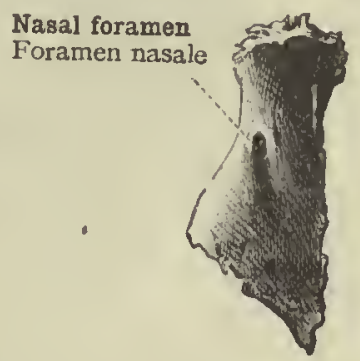

Fig. I67.-ANTERIOR Surface.

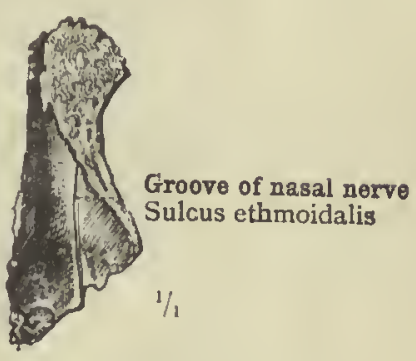

FIG. I68.-POSTERIOR Surface.
Os Lacrimale: Lacitryall Bone OF THE LEFT SidE.

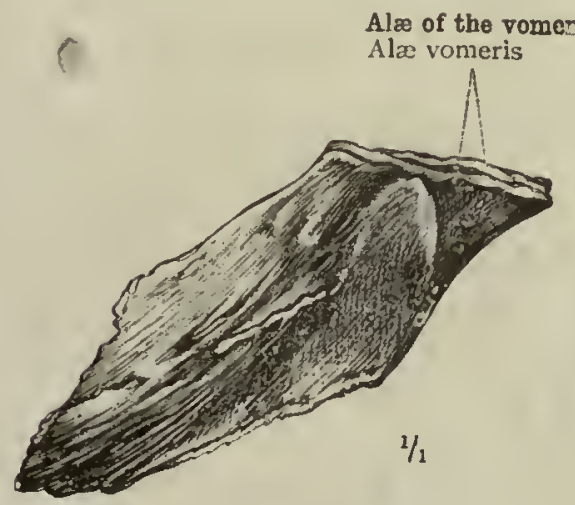

Fig. i69.-Seen from tite Left Side.
Os Nasale: Nasal Bone OF THE LEFT SIDE.

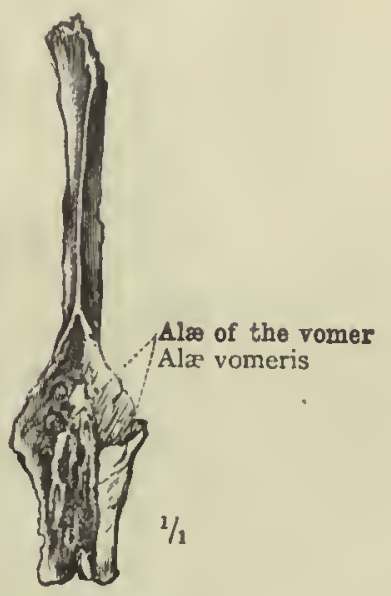

Fig. I7O.-SEen From ABOVE.

VOMER-THE VOMEr.

Bones of the Nasal Region. 


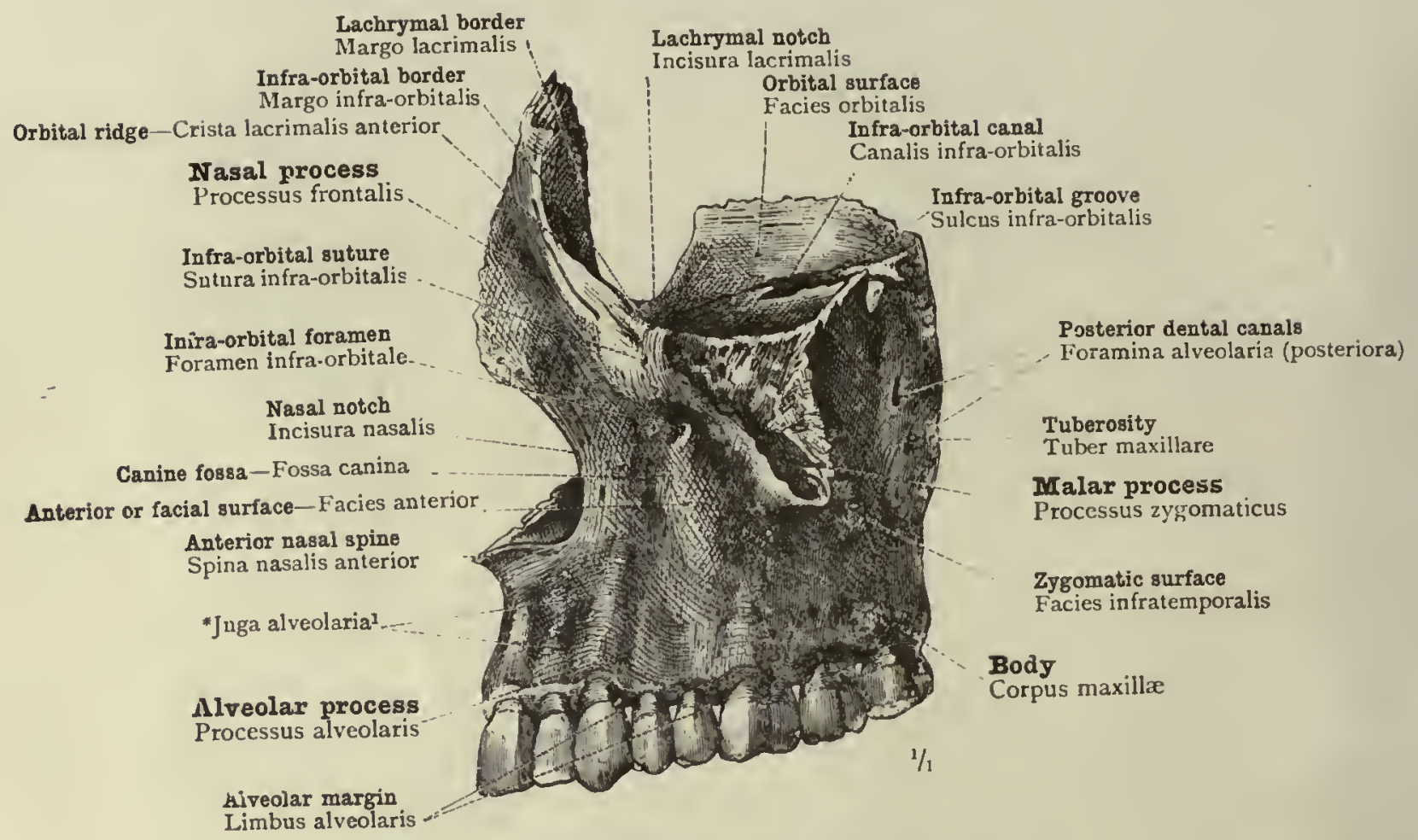

1 Eminences corresponding in position to the fangs of the teeth

Fig. I7I.-Left Superior Maxillary Bone: External Surface.

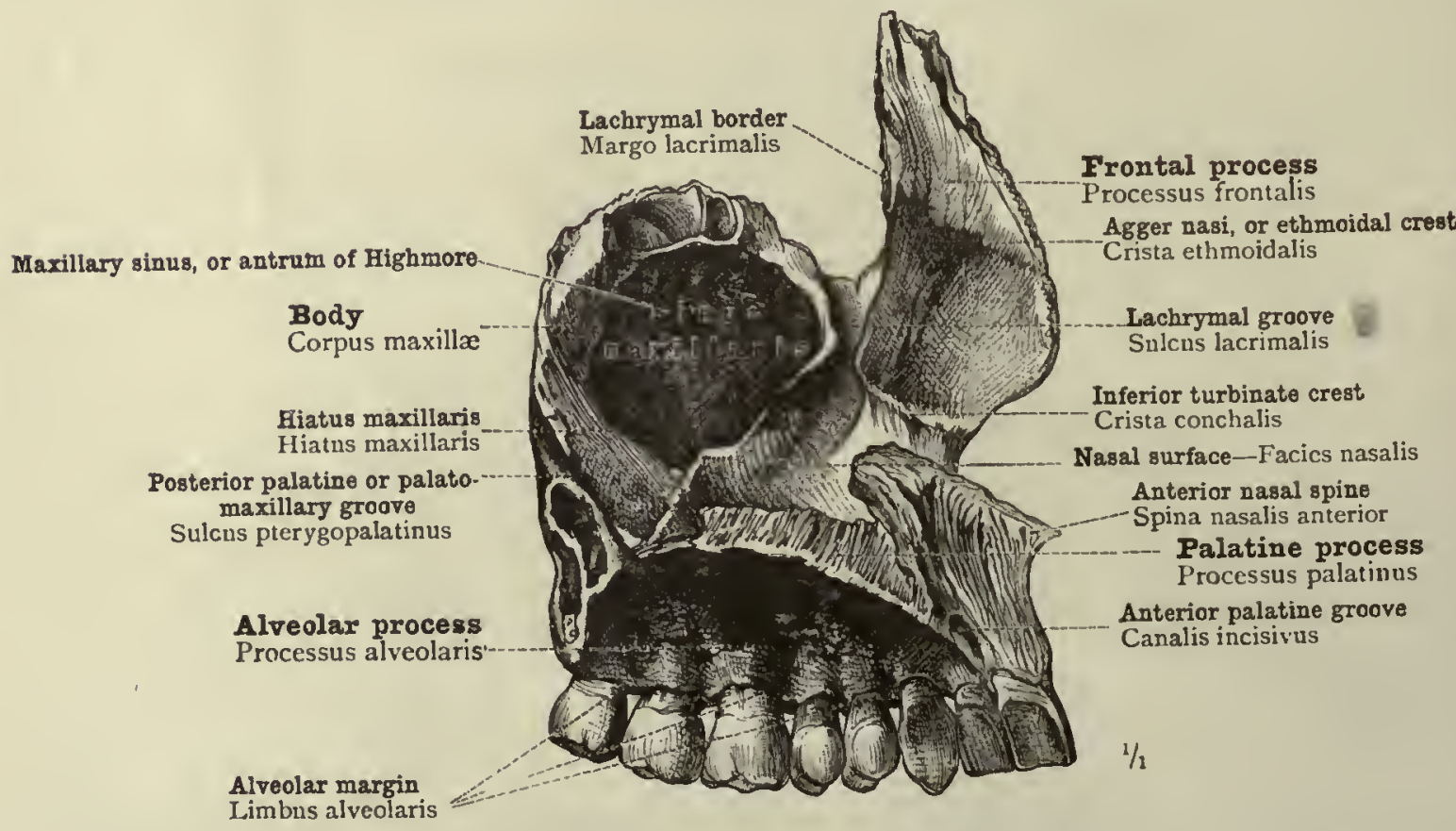

Fig. i72.-Left Superior Maxillary Bone: Internal Surface. View into the Maxillary Sinus, or ANtrum of Highmore.

Maxilla_Superior maxilla. 
Nasal process

Processus frontalis

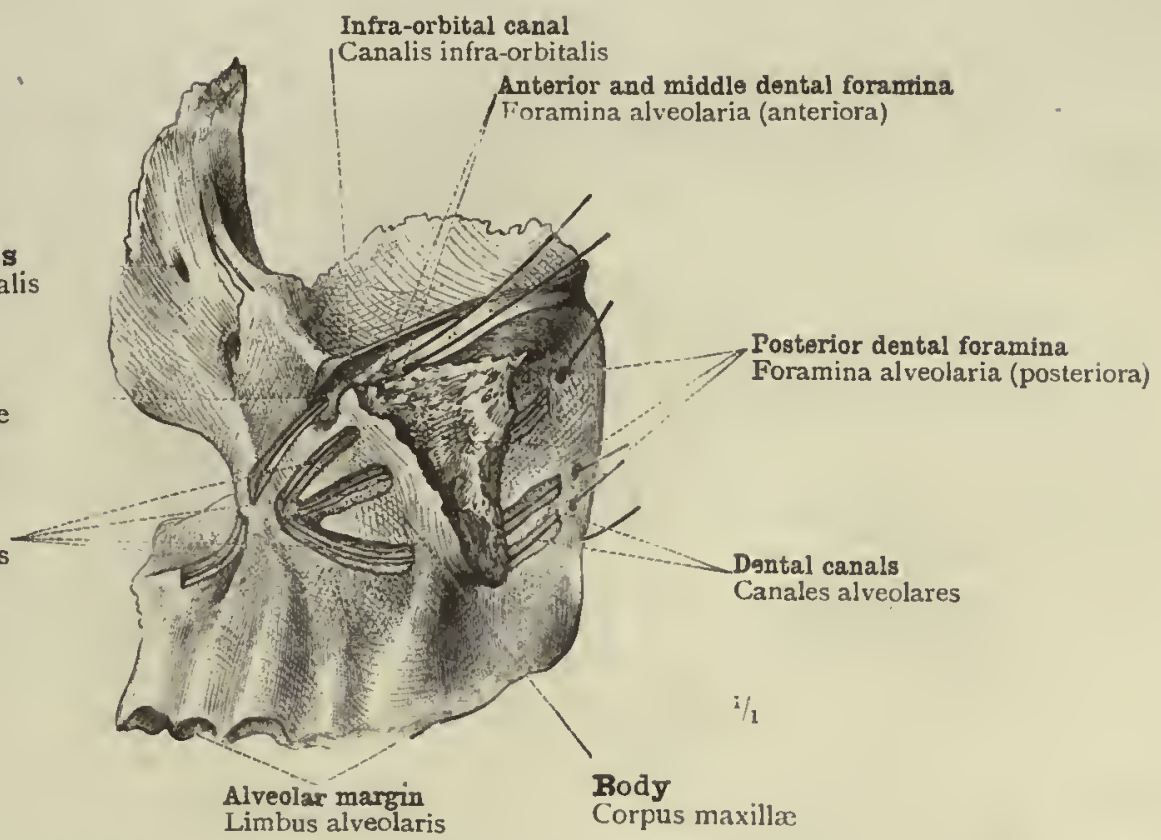

Fig. I73--The Left Superior Maxillary Bone. External Surface.

The dental canals are exposed by partial removal of the superficial plate of bone, and their rourse is shown by means of bristles passed through them.

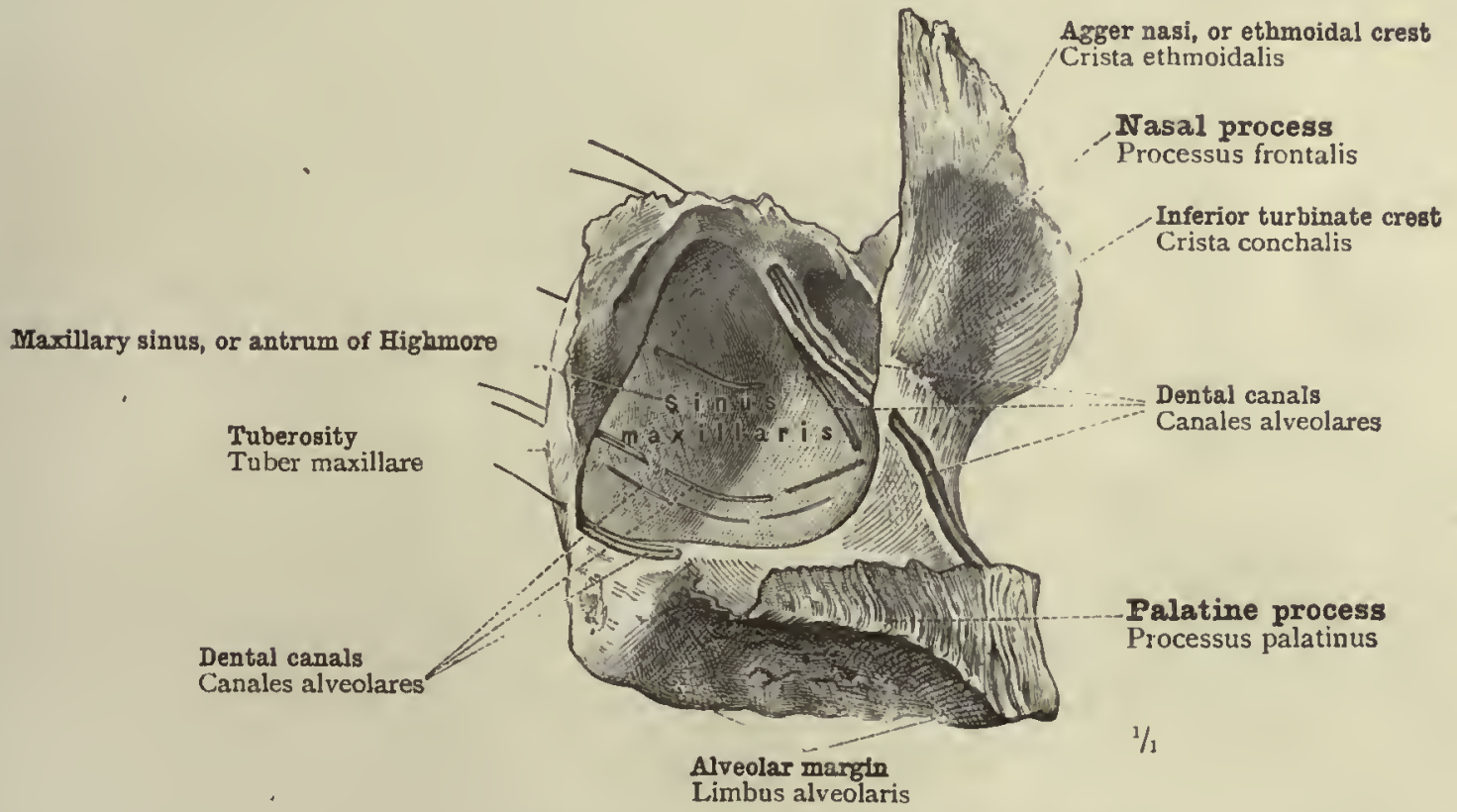

Fig. I74.-The Left Superior Maxillary Bone. Internal Surface.

The foremost and the hindmost of the dental canals have been exposed by the removal of the superficial plate of bone. By means of bristles passed through the canals the situation of the respective dental foramina is indicated. Most of the inner wall of the antrum of Highmore has been cut away. 


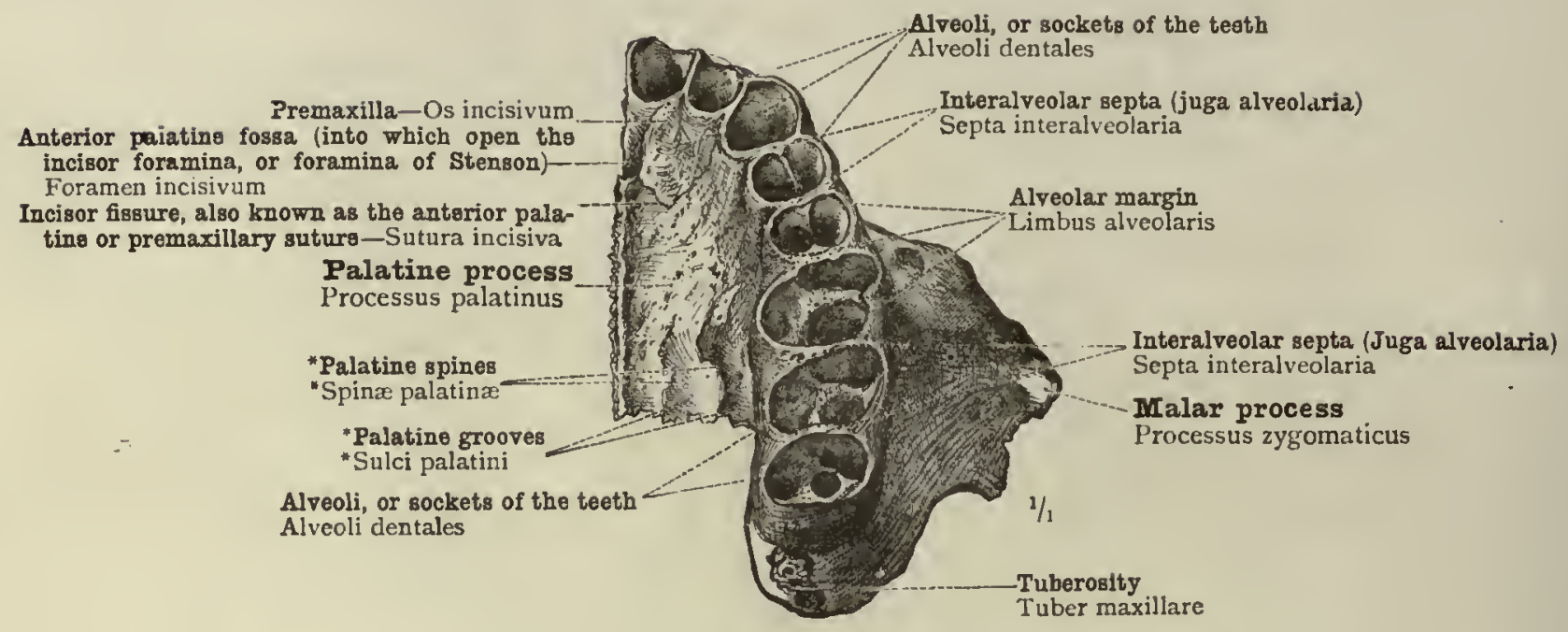

Fig. 175.-The Left Superior Maxillary Bone. Seen from Below.

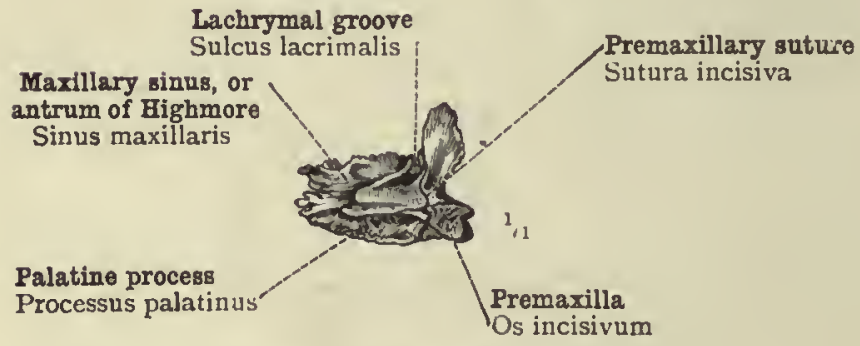

Fig. I76.-SEEN FROM THE INNER Side.

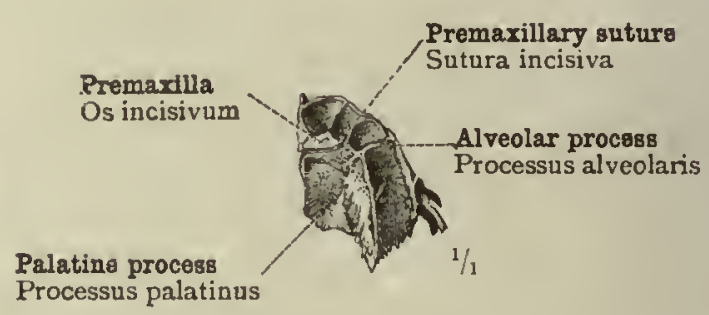

FIG. 177.- SEEN FROM BELOW.

The Left Superior Maxillary Bone of a Fotus at the End of the Sixth MONTH (MONTHS of Four WeEks EACH).

Body-length, 12 inches.

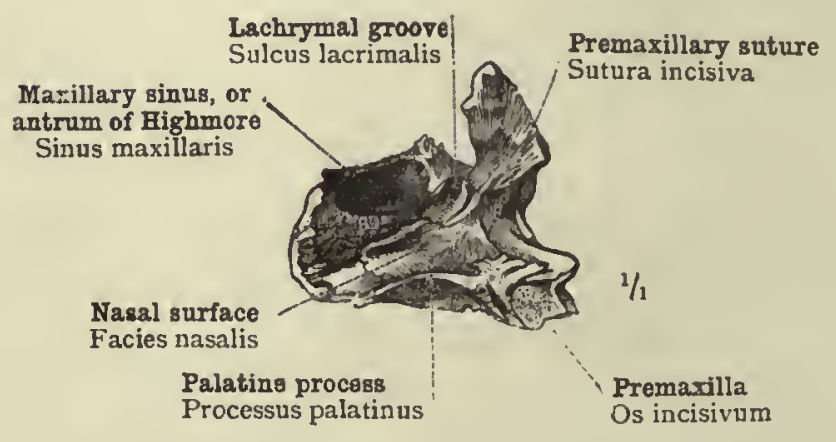

FIG. I78.-SEEN FROM THE INNER Side.

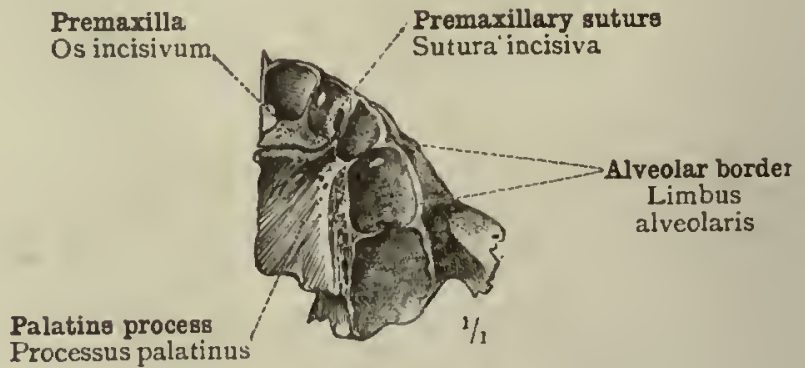

FIG. I79. SEEN FROM BELOW. The Left Superior Maxillary Bone of a Boy born at Full Term.

Body.length, 2 I inches. 


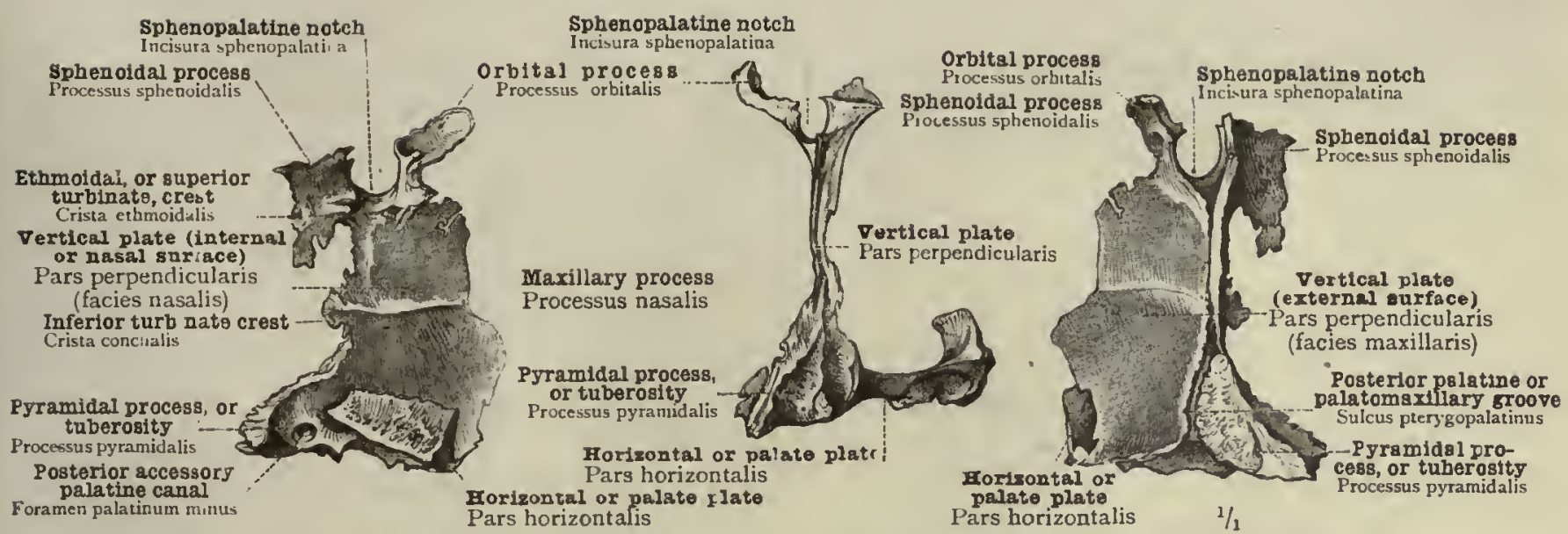

Fig. i80.--Inner Surface. Fig. i81.-Seen from Behind. Fig. i82.-Outer Surface. Os Palatinum.-The Palate-Bone (of the Left Side).

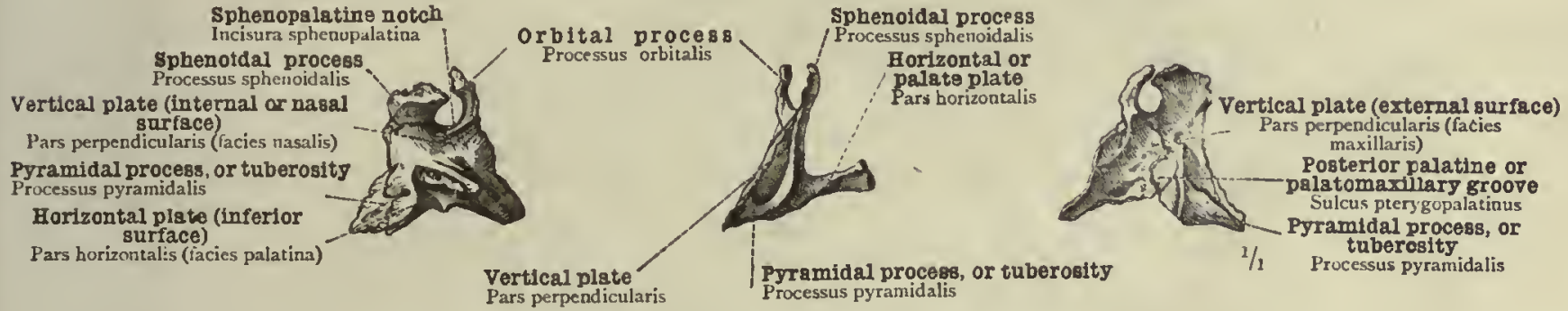

Fig. I83.-Inner Surface. Fig. I84.-Seen from Behind. Fig. 185.-Outer Surface. The Left Palate-Bone of a Boy born at Full Term.

Body-length, 21 inches.

Frontal process

Processus frontosphenoidalis

Orbital orifice of the temporal

Foramen zygomatico-orbitale

Orbital process (orbital surface)

Lamina orbitalis (facies orbitalis)

Orbital oriflce of the

malar canal

Foramen zygumaticoorhitale

Orbital border

Margo infra-orbisali,

Malar oriflce of the malar canal Foramen zygomaticofaciale

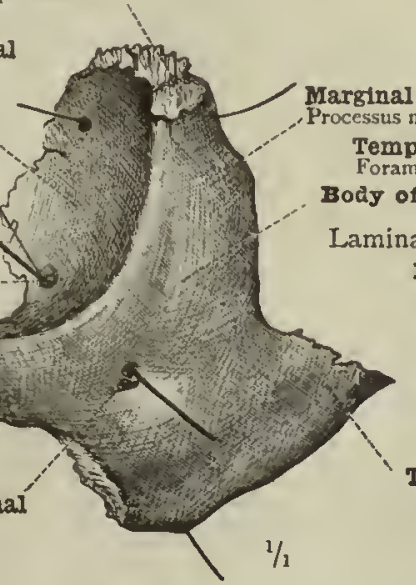

Temporal orifice of the temporal canal the malax bone (malax
surface)
malaris (facies malaris) malax bone (malax
surface) malaris (facies malaris) Body of the malax bone Lamina malaris (facies temporalis
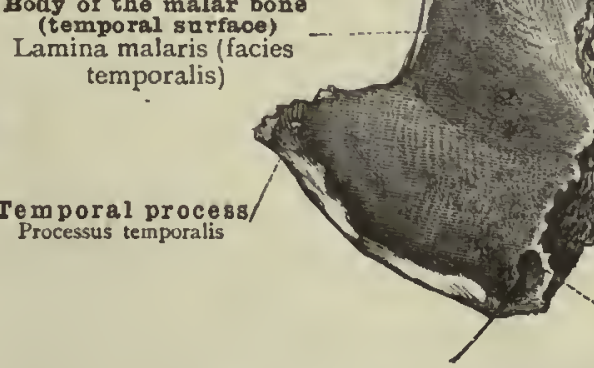

Aoceseory temporal Aocessory temporal
orffics of the malar canal Foramen rygomaticotemporale

FIG. I87.-SEEN FROM BEHIND.

Fig. I86.-SEEN FROM BEFORE.

Os Zygomaticum-Malar Bone (OF the Left Side). 

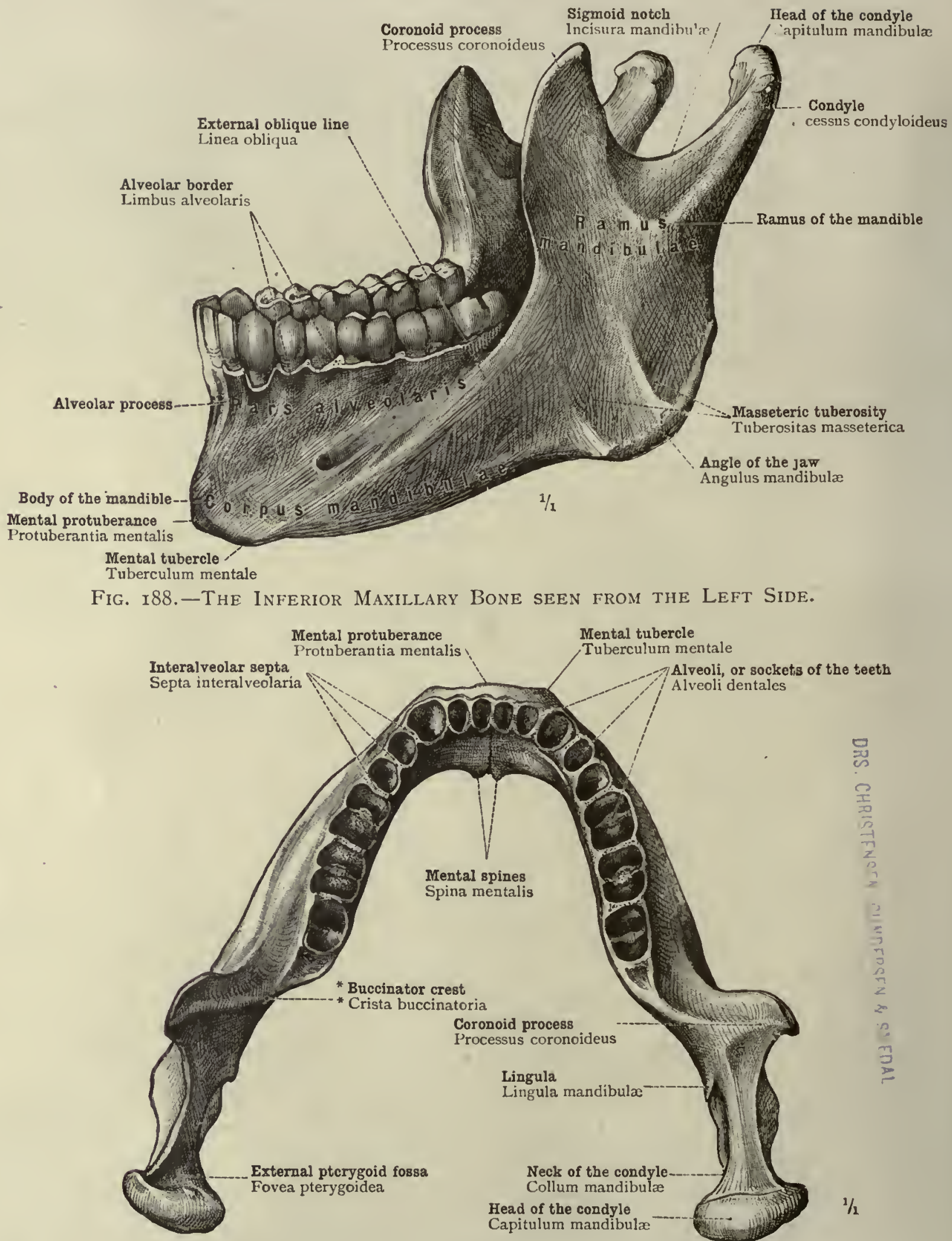

Fig. I89.-The Inferior Maxillary Bone seen from Above.

Mandibula-The inferior maxillary bone, lower jaw, or mandible, 


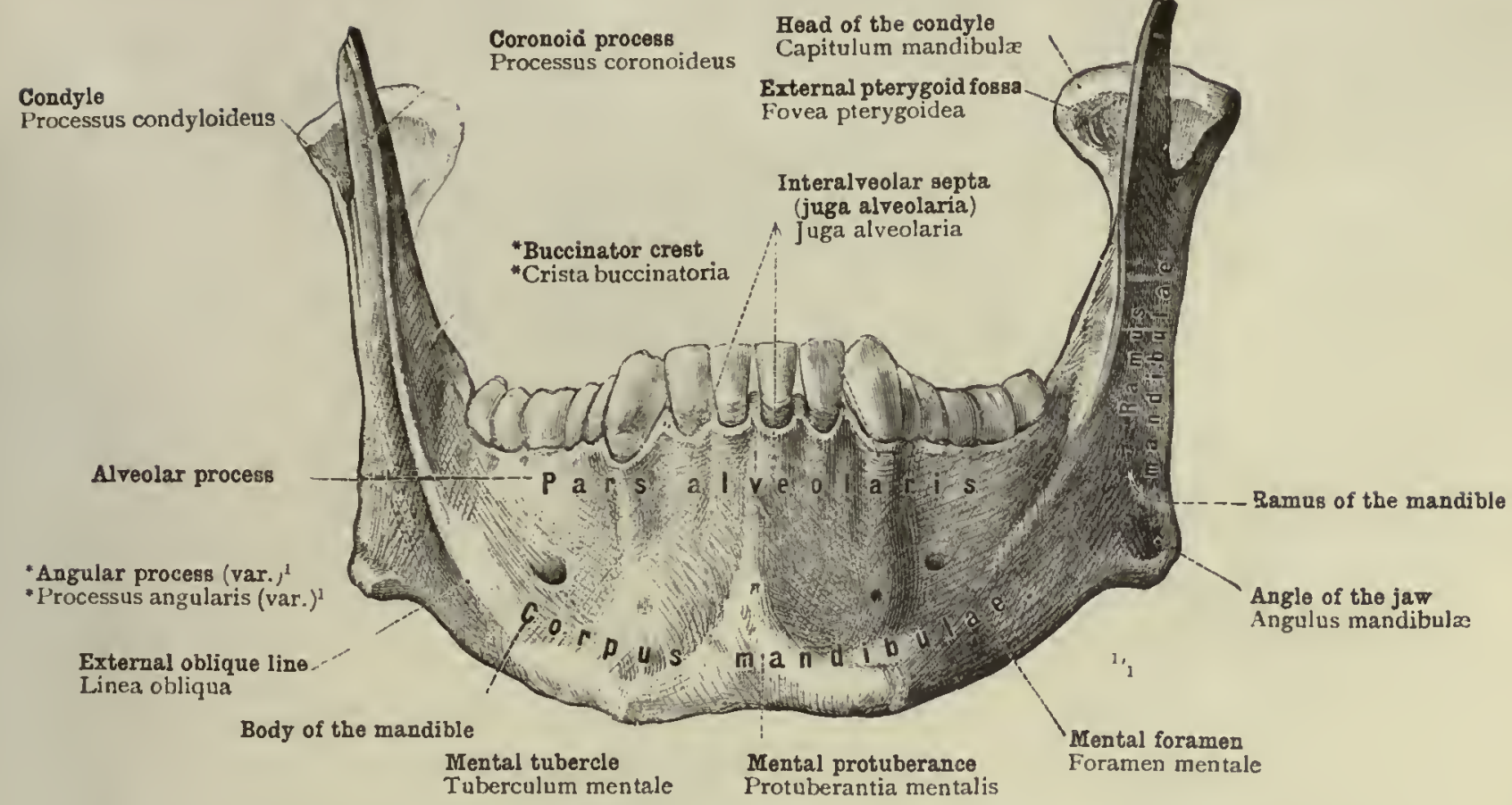

Fig. Igo.-The INFERIor Maxillary Bone seen from Before.

1 "The angle of the jaw," writes Quain, ". . . is more or less rounded off." The specimen from which Fig. Igo was drawn has, however, an abnormal projection at each angle, to which in the German nomenclature the numa processus angularis (vur.) is given. This variety is not described by Quain or by Macalister.- TR.

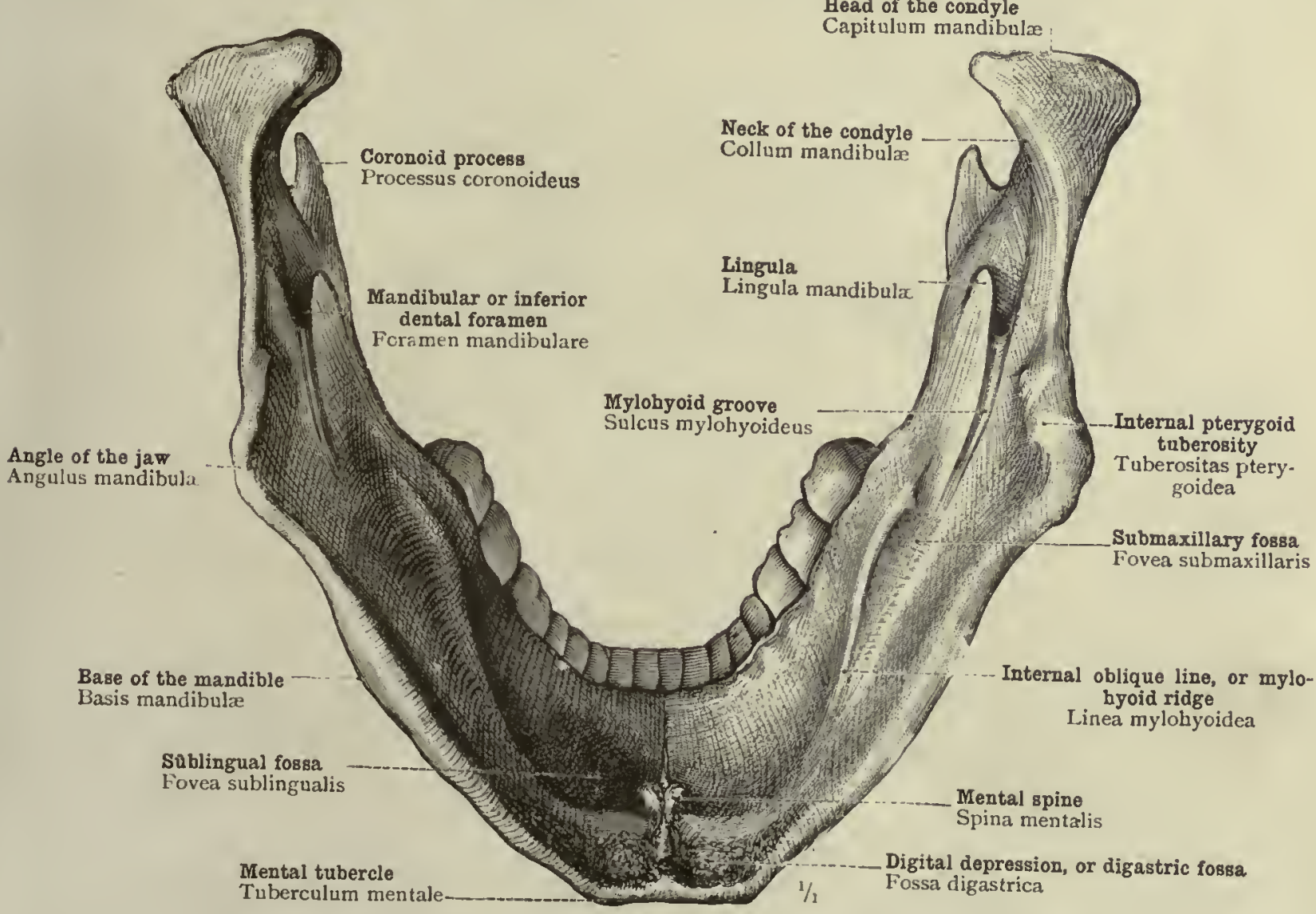

Fig. igi.-The Inferior Maxillary Bone seen from Behind.

Mandibula-The inferior maxillary bone, lower jaw, or mandible. 


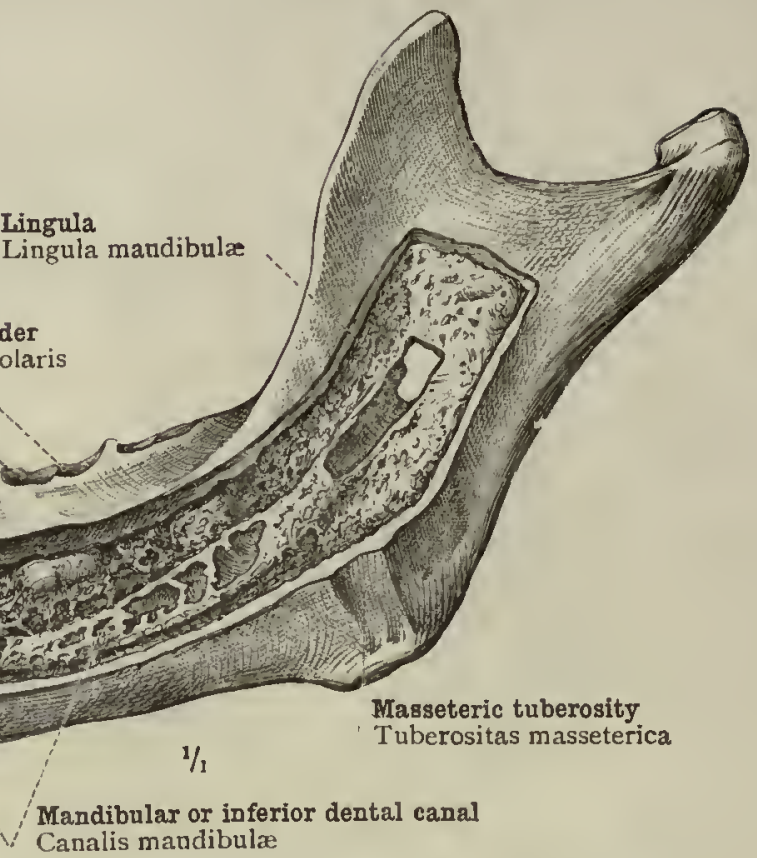

Fig. 192.-THE INFERIOR MAXILlaRy BONE SEEN From THE LEFT Side.

The mandibular or inferior denlal canal has been exposed by the removal of a pertion of the superficial flate of bone.

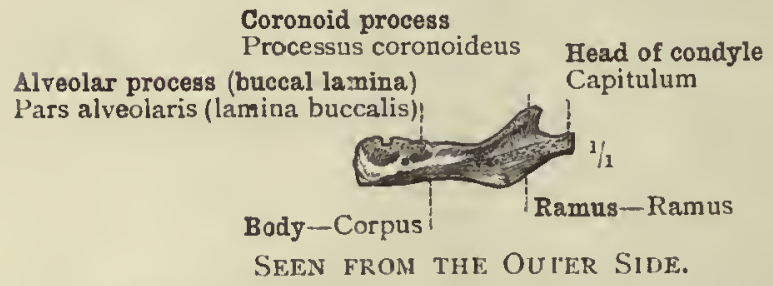

Alveolar process (lingual lamina)
Pars alveolaris (lamina lingua:is)

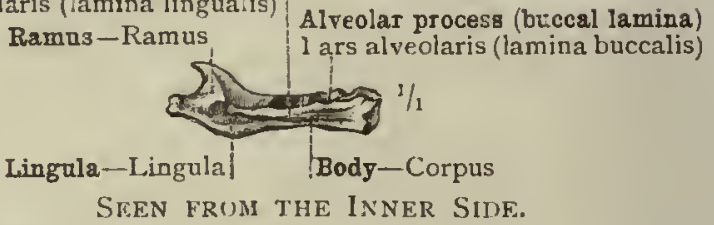

Fig. 193.-ThF, Left Half of the Inferior Maxillary Bone of a Human EMbryo at the END of the Fifth MONTh (MUAThS OF Four Weeks Each).

Body-length, $7 \frac{1}{2}$ inches.

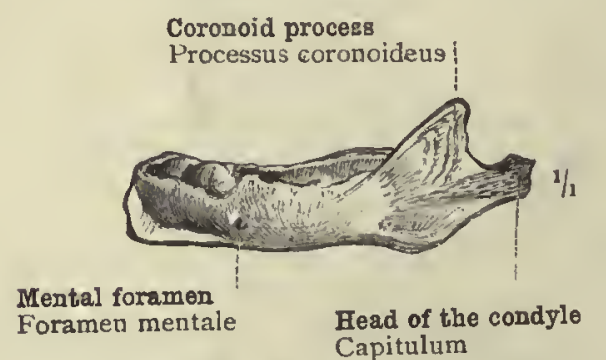

SEEN FROM THE OUTER SIDE.

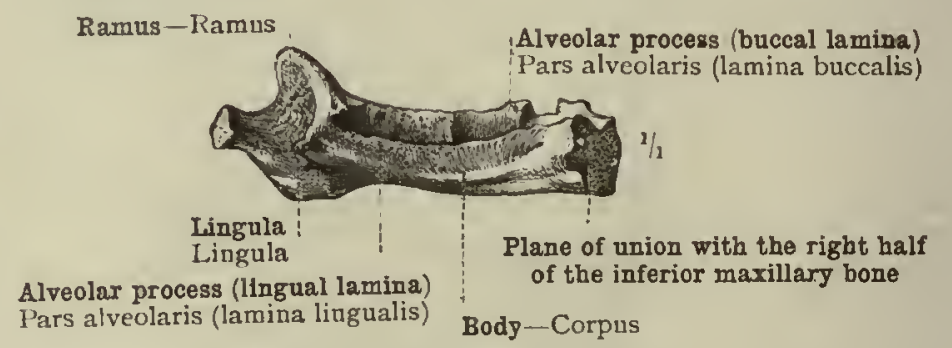

SEEN FROM THE INNER SIDE.

Fig. 194. -THE Lefr Half of THE Inferior Maxillary Bone of a Human EMbryo in the MidDle of the EIGHTH MONTH (MONTHS OF FOUR WeEkS EACH).

Borly-length, ${ }_{5}$ inches.

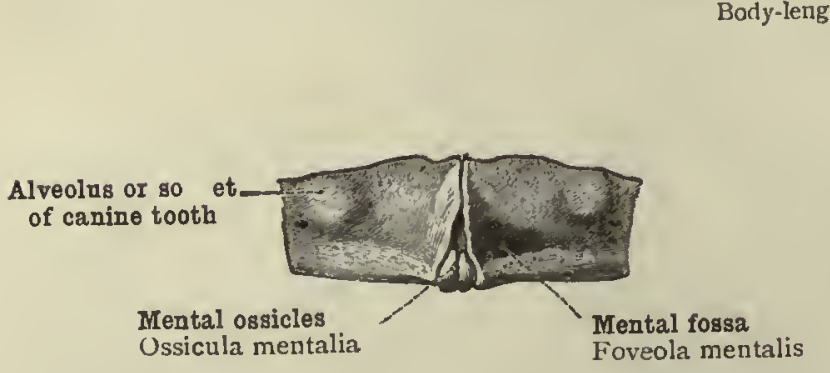

F1G. I95.-MENTAL REgion OF A NEW-BORN BOY. THE LATERAL HALVE; OF THE INFERIOR MAXILLARY BONE. HAVE NOT YFT UNITED; BETWEEN THEM ARE THE MENTAL OSSICles. SEEN FROM BEFORE.

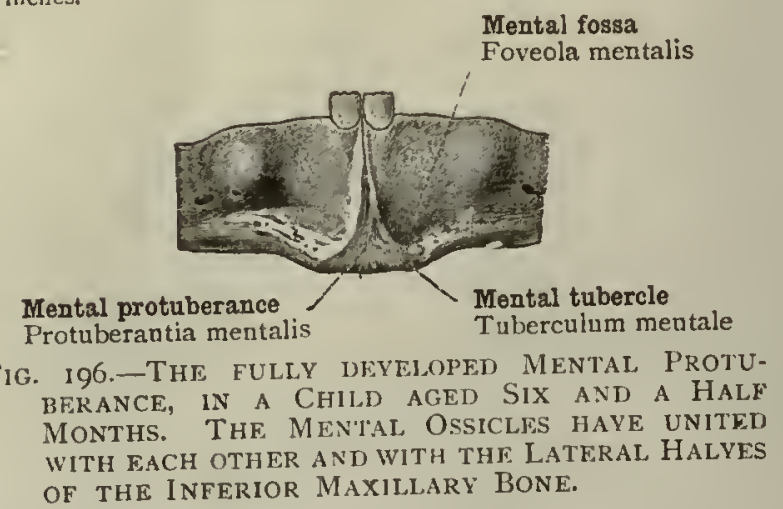

Mental fossa Foveola mentalis

Mandibula-The inferior maxillary bone, lower jaw, or mandible. 


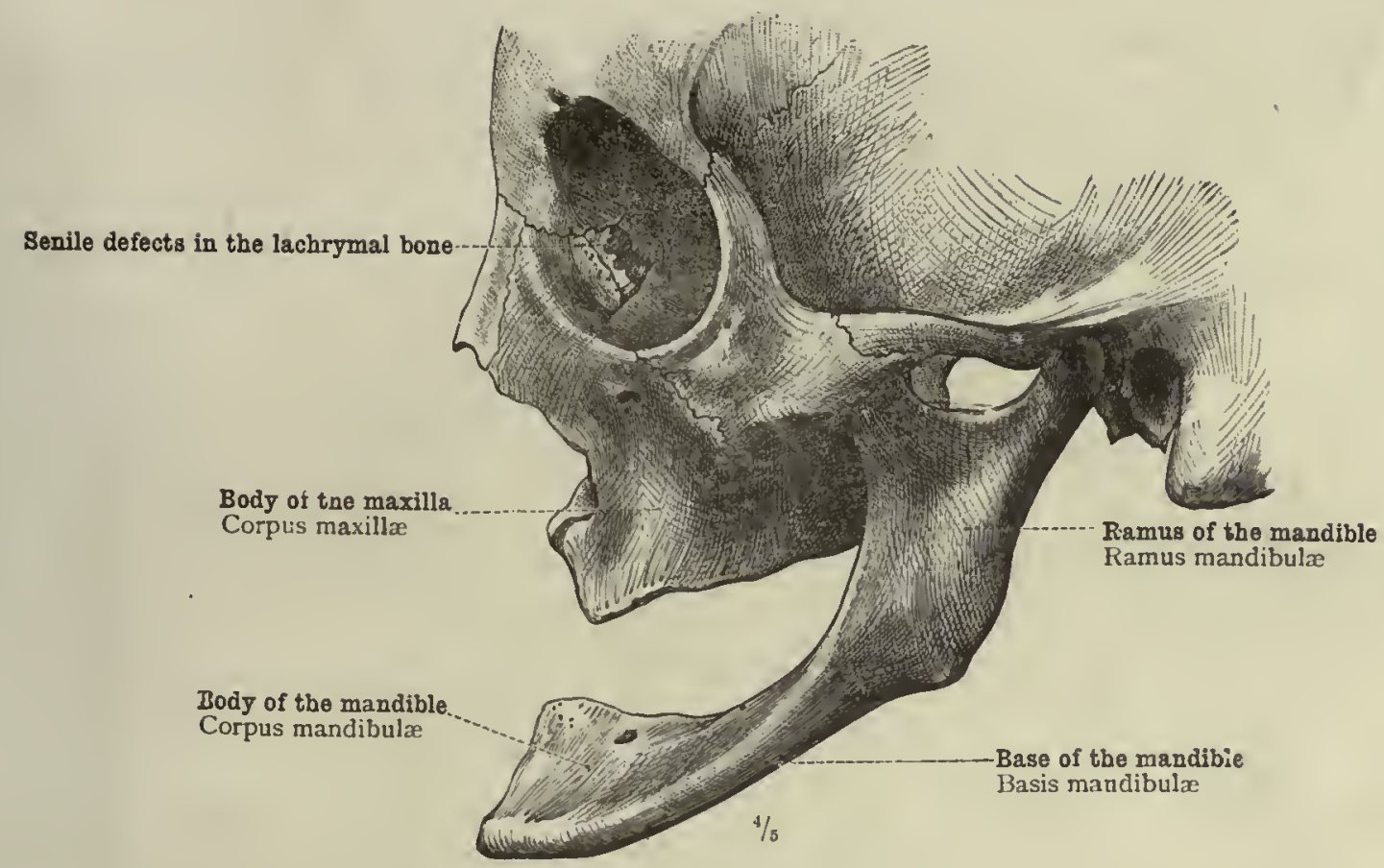

Fig. 197.-Facial Portion of the Skull of a Woman aged Eighty-Four Years, showing Atrophy of the Alveolar Processes of the Superior and Inferior Maxillary Bones (NUTCRACKER FACE).

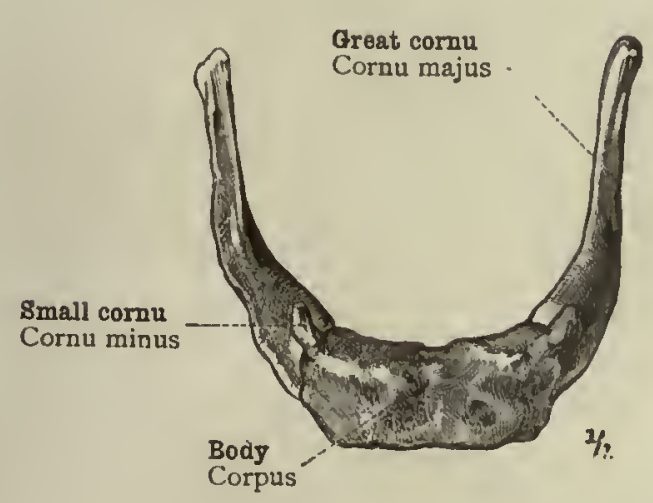

Fig. Ig8.-SEen From ABove.

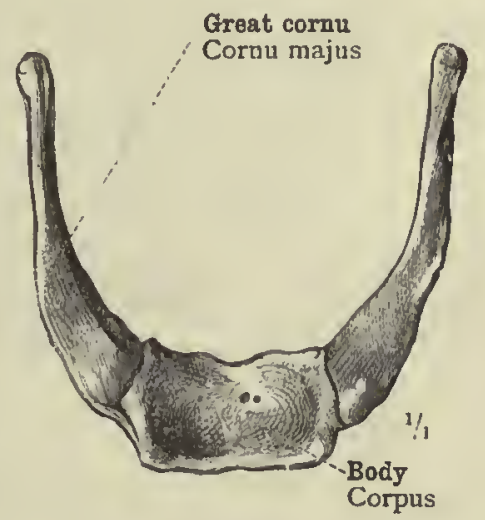

Fig. I99.-SEEN FROM Below.

OS Hroldeum-The Hroid Bone.

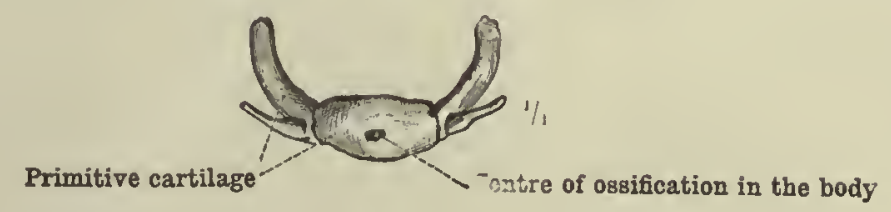

Fig. 200.-Tie Hyoid Bone of a Boy, still-born at Full Term.

Body-length, $2 \mathrm{I}$ inclies.

Senile atrophy of the jaws: Os hyoideum-the hyoid bone. 


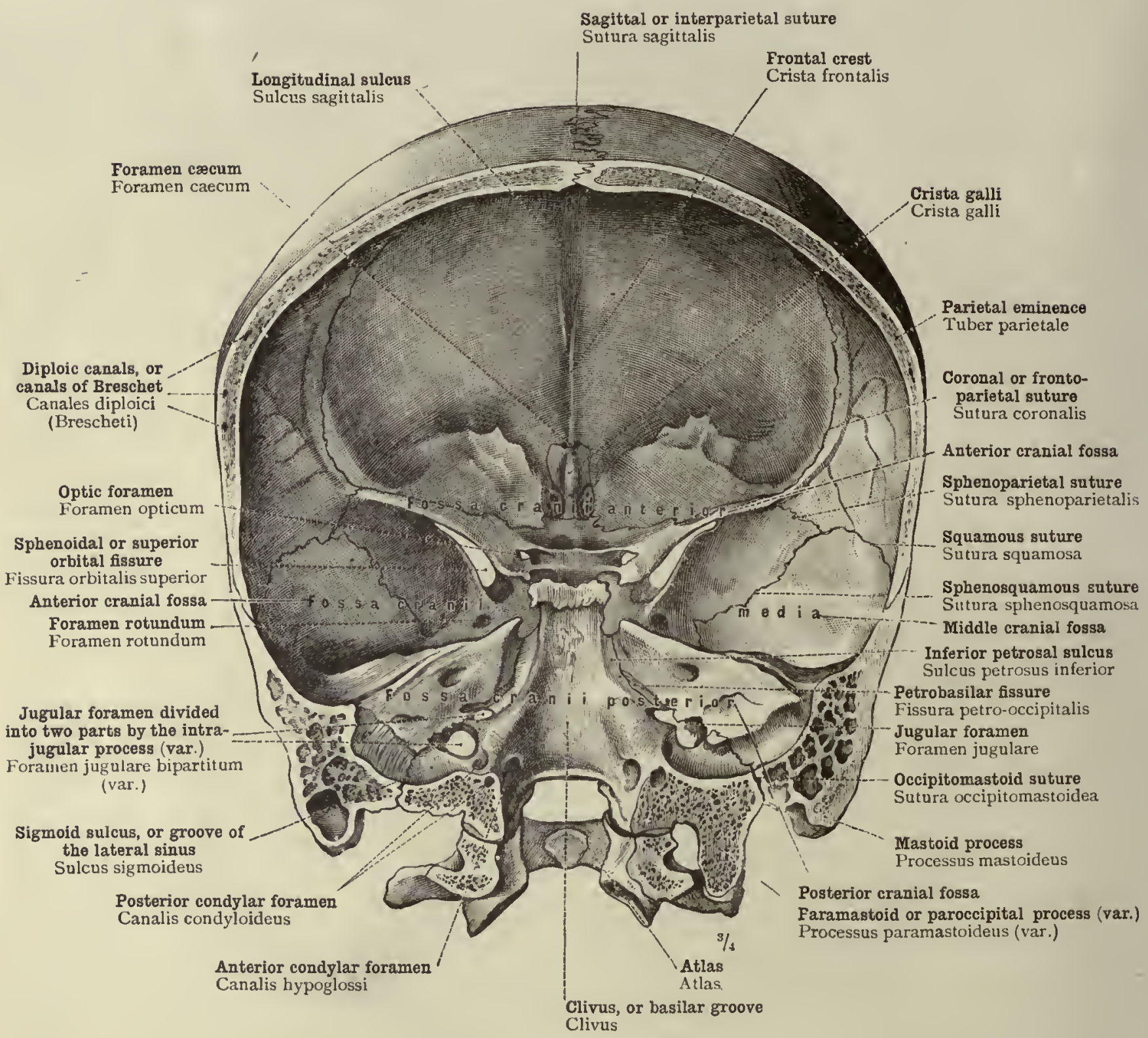

Fig. 201.-Skull divided into an Anterior and a Posterior Portion by a Frontal Section passing through the Mastoid Processes. The first Cervical Vertebra has also been Divided by the Section, and left attached to the Skull.

View of the Anterior Portion of the Cranial Cavity. The Anterior and Middle Cranial Fossa, as well as the Anterior Portion of the Posterior Cranial fossa, seen from Behind. On the Rigit Side is a Paramastold Pirocess articulating with the atlas. 


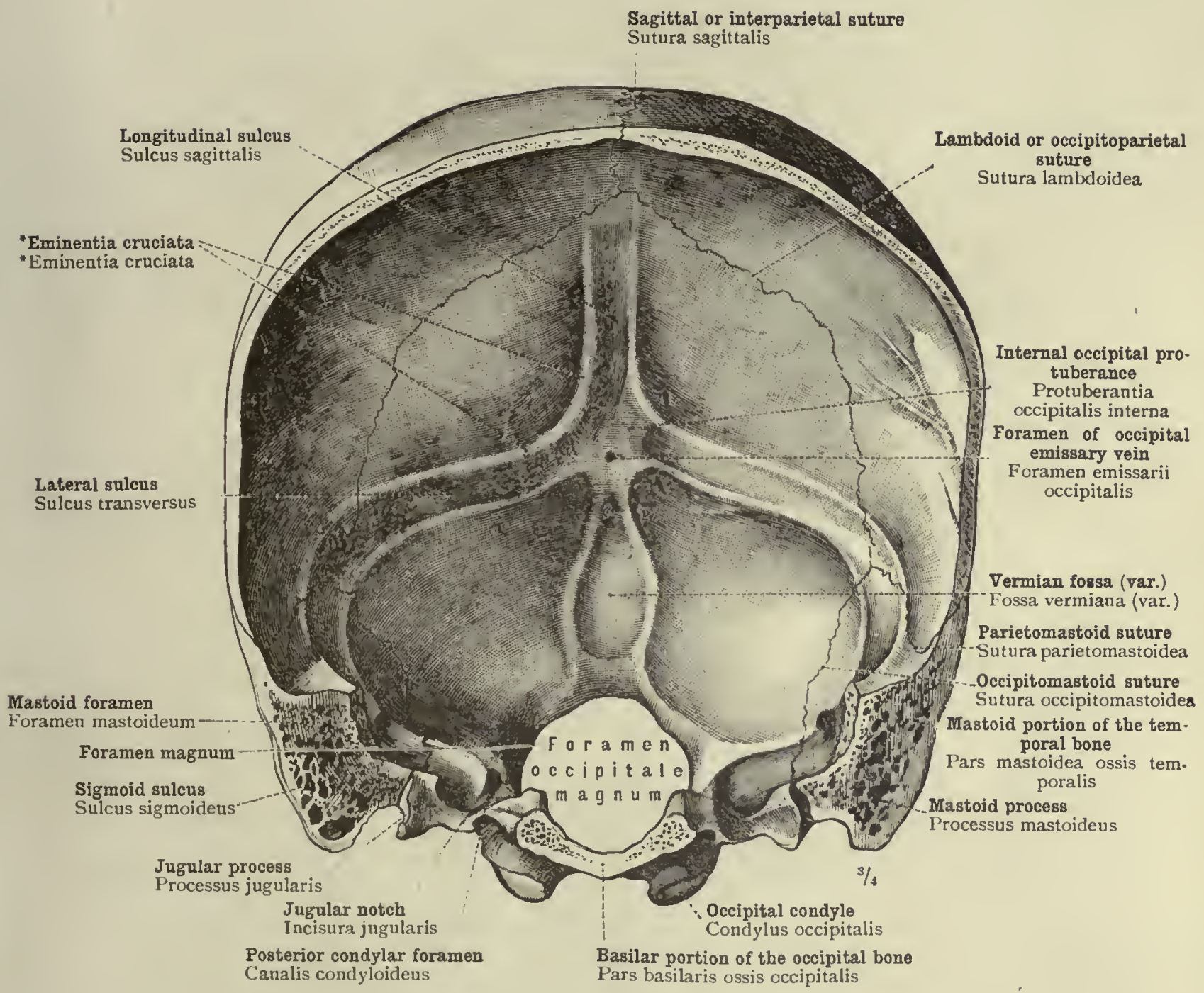

Fig. 202.-Skull divided into an Anterior and a Posterior Portion by a Frontal Section passing through the Mastoid Processes and the Basilar Portion of the Occipital Bone. View of the Posterior portion of the Cranial Cavity. The Division of the Longitudinal Sulcus into Right Lateral and Left Lateral Sulcus is shown. The Lateral Sulcus passes on either Side into the Sigmoid Sulcus, Which terminates in the Jugular Foramen. 
Anterior internal orbital canal ${ }^{1}$ - Foramen ethmoidale anterius

Cribriform plate-Lamina cribrosa

Middle turbinate bone-Concha nasalis media

Superior turbinate bone-Concha nasalis superior

Superior meatus of the nose-Meatus nasi superior

spheno ethmoidal recess-Recessus spheno-ethmoidalis

Sphenoidal foramen

Apertura sinus sphenoidalis

Sphenoidal sinus-Sinus sphenoidalis

Sphenopalatine foramen
Foramen sphenopal atinum

Basipharyngeal canal ${ }^{2}$ Canalis basipharyngeus

Vaginal process of sphenoid Processus vaginalis

Pterygopalatine canal
Canalis pharyngeus

Nasopharyngeal meatus

Meatus nasopharygeus

Accessory palatine canals

Foramina palatina minora (Canales palatini)

Posterior nasal spine

Spina nasalis posterior

Orifice of the posterior palatine canal

Foramen palatinum majus

1 U.S. : Anterior ethmoidal canal

Fig. 203.-The External Wall of the Nasal Cavity with the Turbinate Bones and the Nasal Meatus: Median Sagitial Section. Left Side.

\title{
Line of detachment of the middle turbinate bone of the nose Orifice of the ethmoidal cells
}

Superior turbinate bone-Concha nasalis superior

Spheno-ethmoidal recess-Recessus spleno-etlimoidalis

Sphenopalatine foramen

Foramen sphenopalatinum:

Basipharyngeal canal'
Canalis basipharyng.us

Vaginal process of sphenoid

Processus vaginalis

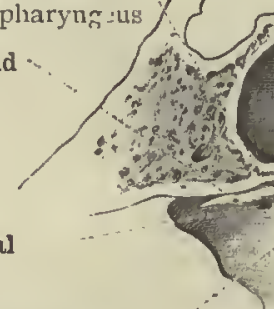

Pterygopalatine canal

Canalis pharyngeus

Sphenoidal process

Processus sphenoidalis

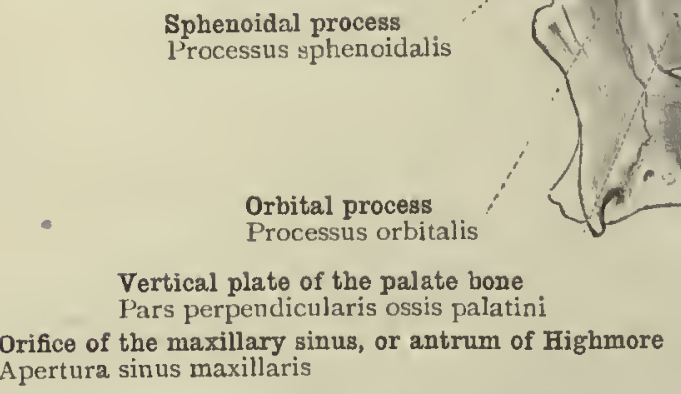

Horizontal plate of the palate hone

l'ars horizontalis ossis palatini

Apertura sinus maxillaris
Transverse or posterior suture of the palate

2 See note to p. 48.

Nasofrontal suture

Sutura nasofrontalis

Nasal spine

Agger nasi, or ethomoidal crest Agger nasi

Nasal bone

Middle meatus of the nose

Meatus nasi medius

Atrium of the midale meatus

Atrium meatus medii

Pyriform or anterior nasal aperture Apertura piriformis

Inferior turbinate bone of the nose Concha nasalis inferior

Anterior nasal spine

Spina nasalis anterior

Inferior meatus of the nose

leatus nasi inferior

!

Process vaginalis

lers horizontalis ossis palatini

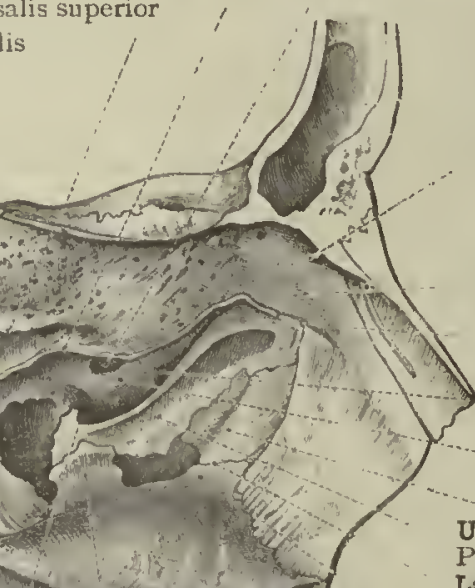

\author{
Frontal sinus \\ Sinus frontalis \\ Sulcus olfactorius \\ Sulcus olfactorius
}

Agger nasi, or ethmoidal crest

Agger nasi

Orifice of the frontal sinus

Apertura sinus frontalis

Hiatus semilunaris

Hiatus semilunaris infundib، li

Ethmoidal bulla

Bulla ethmoidalis

L. Lachrymal bone-Os Jacrimale

Uncinate process

Processus uncinatus

Lachrymoturbinal suture

Sutura lacrimocons of the inferior tur

binate bone
1 Processus lacrimal is conch inferioris

Inferior turbinate bone

Concha nasalis inferior

Inferior meatus of the nose

Meatus nasi inferior

Palatine process of superior maxillary hone

l'rocessus palatinus maxillæ

Ethmoidal process of the inferior turbinate bone

Processus ethmoidalis conclix inferioris

1 See note to $\Gamma .48$.

Fig. 204.-Tie External Wall of the Nasal Cayity: Median Sagittal Section. Left Side. The middle turbinate bone of the nose has been cut away.

Cavum nasi-Nasal cavity. 
Anterior internal orbital canal ${ }^{2}$ Foramen ethmoidale anterius

Crihriform plate of the ethmoid Lamina cribrosa

Orbital plate, os planum, or lamina papyracea,

of the ethmoid bone-Lamina papyracea

Posterior internal orbital canal ${ }^{1}$

Foramen ethmoidale posterius

Orbital process of the palate bone-Processus orbitalis

Orifice of the sphenoidal sinus

Apertura sinus sphenoidalis

Sphenopalatins foramen-Foramen sphenopalatinum

Sphenoidal process of the palate bone

Processus sphenoidalis

Sphenoidal ginus

Sinus sphenoidalis

Pterygopalatine canal

Canalis pharyngeus

Vaginal process of sphenoid

Processus vaginalis

Spinous process of sphenold

bong-Spina angularis

Pterygospinous foramen (var.)

Foramen pterýgospinosum (var.)

Pterygospinous process, or process of Civinini (var.)

Frocessus pterygospinosus (Civinini) (var.)

Vertical plate of the palate bone

Pars perpendicularis ossis palatini

Pterygoid process $\left\{\begin{array}{l}\text { External pterygold plate } \\ \text { Lamina lateralis } \\ \text { Internal pterygoid plate } \\ \text { l.amina medialis }\end{array}\right.$

Hamular process-Hamulus pterygoidens

Posterior nasal spine-Spina nasalis posterior

Horizontal plate of the palate bone-Pars horizontalis ossis palatini

1 U.S. : Posterior ethmoidal canal.
Lachrymo-ethmoidal suture

Sutura lacrimo-ethmoidalis

Frontolachrymal suture

Sutura frontolacrimalis

Nasofrontal suture

Sutura nasofrontalis

Nasal spine of frontal bone

Spina frontalis

Groove of the nasal nerve

Sulcus ethmoidalis

Nasal bons

Os nasale

Lachrymal bone-Os lacrimale

Nasal process of superior maxillary bone-Processus frontalis maxilla

Lachrymomaxillary suture

Sutura lacrimomaxillaris

Lachrymal groove

Sulcus lacrimalis

Anterior nasal spine

Spina nasalis anterior

$1 / 1$

Nasal surface of the superior maxillary bone

Facies nasalis maxillæ

Anterior palatine groove

Canalis incisivus

Palate process of the superior maxillary bons Processes palatinus maxilla

Orifice of the maxillary sinus,

or antrum of Highmore

Hiatus maxillaris

2 U.S. : Anterior ethmoidal canal.

Fig. 205.-The External Wall of the Nasal Cavity after Removal of the Three Turbinate Bones and the Lateral Mass of the Ethmoid: Median Sagittal Section. LEFT SIDE.

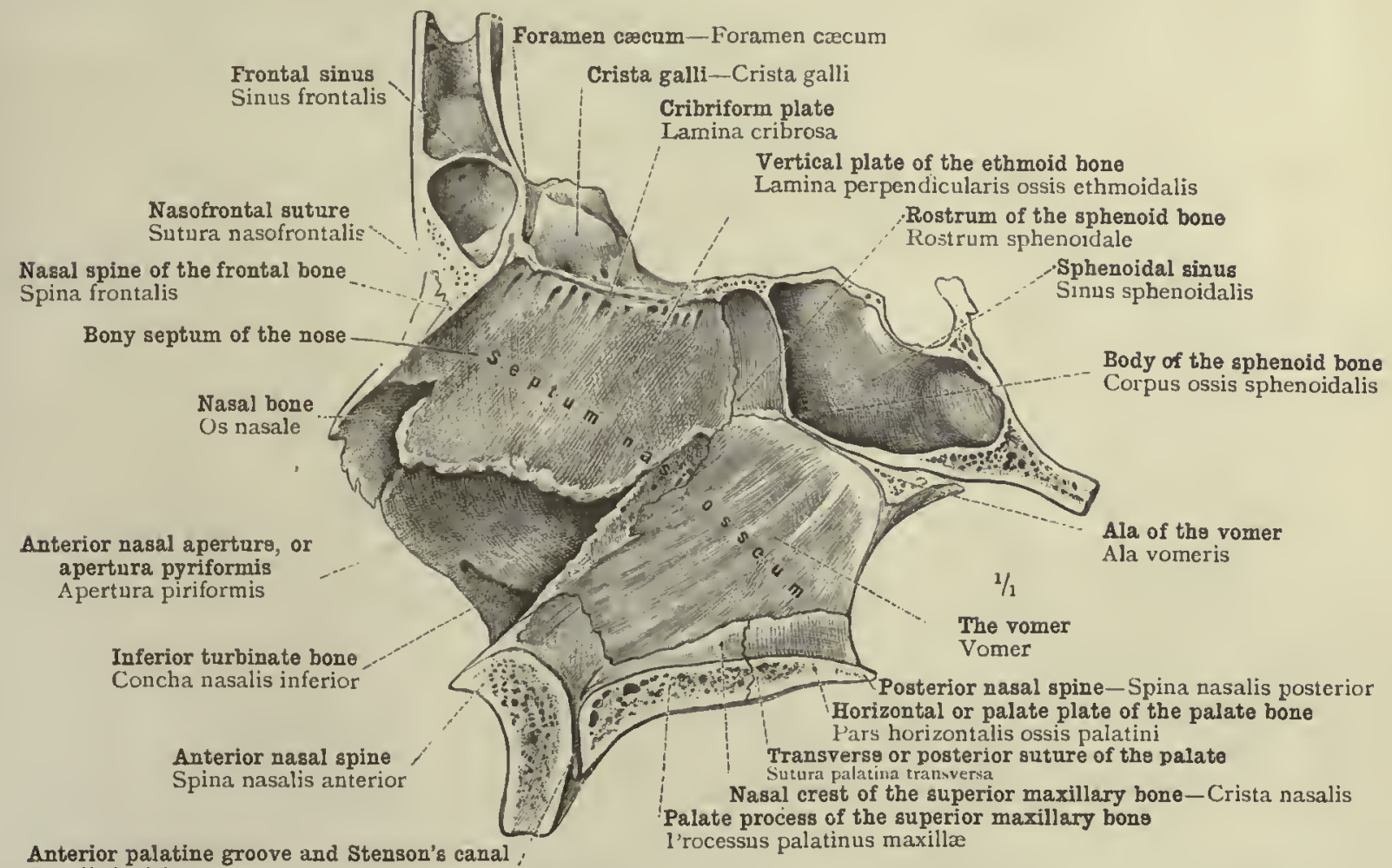

Anterior palatine groove and Stenson's canal :

Anterior palatine
Canalis incisivus

Fig. 206.-The Bony Septum of the Nose seen from the Left Side: Sagittal. Section of the Facial Part of the Skull, a Little to the left of the Median Plane. 


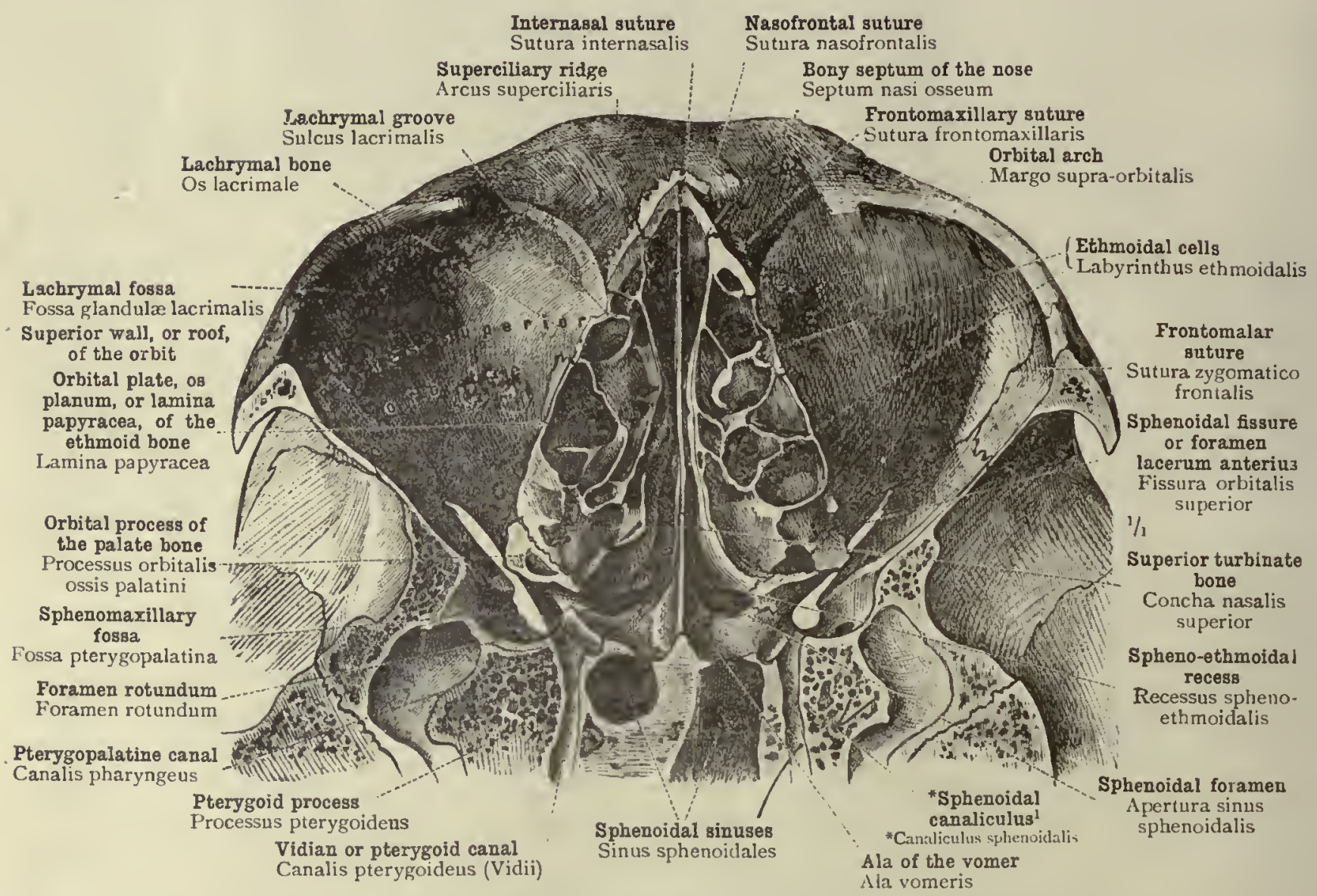

1 I am indebted to Professor Toldt for the following account of the "Sphenoidal canaliculus, which is accurately described neither by Quain nor by Macalister: "It begins in the scaphoil fossa and divides as it ascends into two branches, the inner of which opens into the Vidian canal, while the outer opens on the cerebral surface of the great wing of the sphenoid bone, between the lingula of the sphenoid bone and the foramen ovale." The outer branch is termed by Einglish anatomists the foramen of Vesalius, and transmits an emissary vein: the inner branch gives passage to the sphenoidal branch of the otic ganglion, by means of which this ganglion communicates with the Vidian nerve.- $T$ R.

Fig. 207.-By Means of a nearly Horizontal Section passing tirougil the Centre of the Entrance to the Orbit, the Upper Parts of the Nasal fossa and of the Orbits are displayed. Seen from Below.

Posteriorly the section passes through the body of the sphenoid bone and the root of the pterygoid process, opening up the Vidian canal through its whole length. A bristle las been passed into the *sphenoidal cansliculus ${ }^{1}$ from the Vitian canal. The lateral masses of the ethmoid bone (ethmoidal labyrinths) are divided in the horizontal plane. 


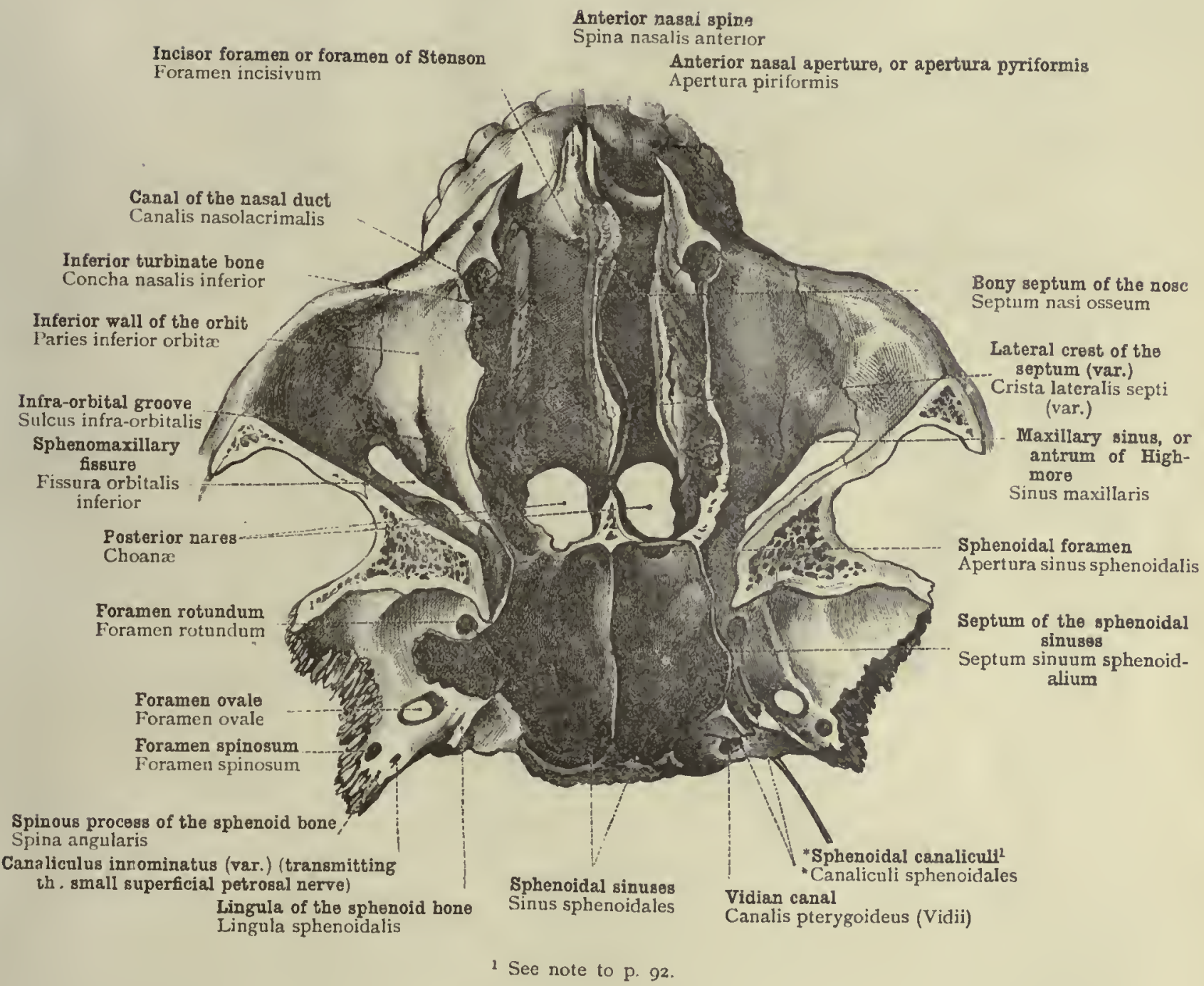

Fig. 208.-By Means of a nearly Horizontal Section in a Plane a Little above that of the Inferior Walls of the Orbits, the Lower Portions of the Nasal Foss AND of the ORbits have been exposed. SEen from ABove.

Posteriorly the section passes through the sphenoidal sinuses, in this specimen exceptionally capacious.

The upper orifices of the *sphenoidal canaliculus (see note 10 p. 92) are indicated by bristles. 


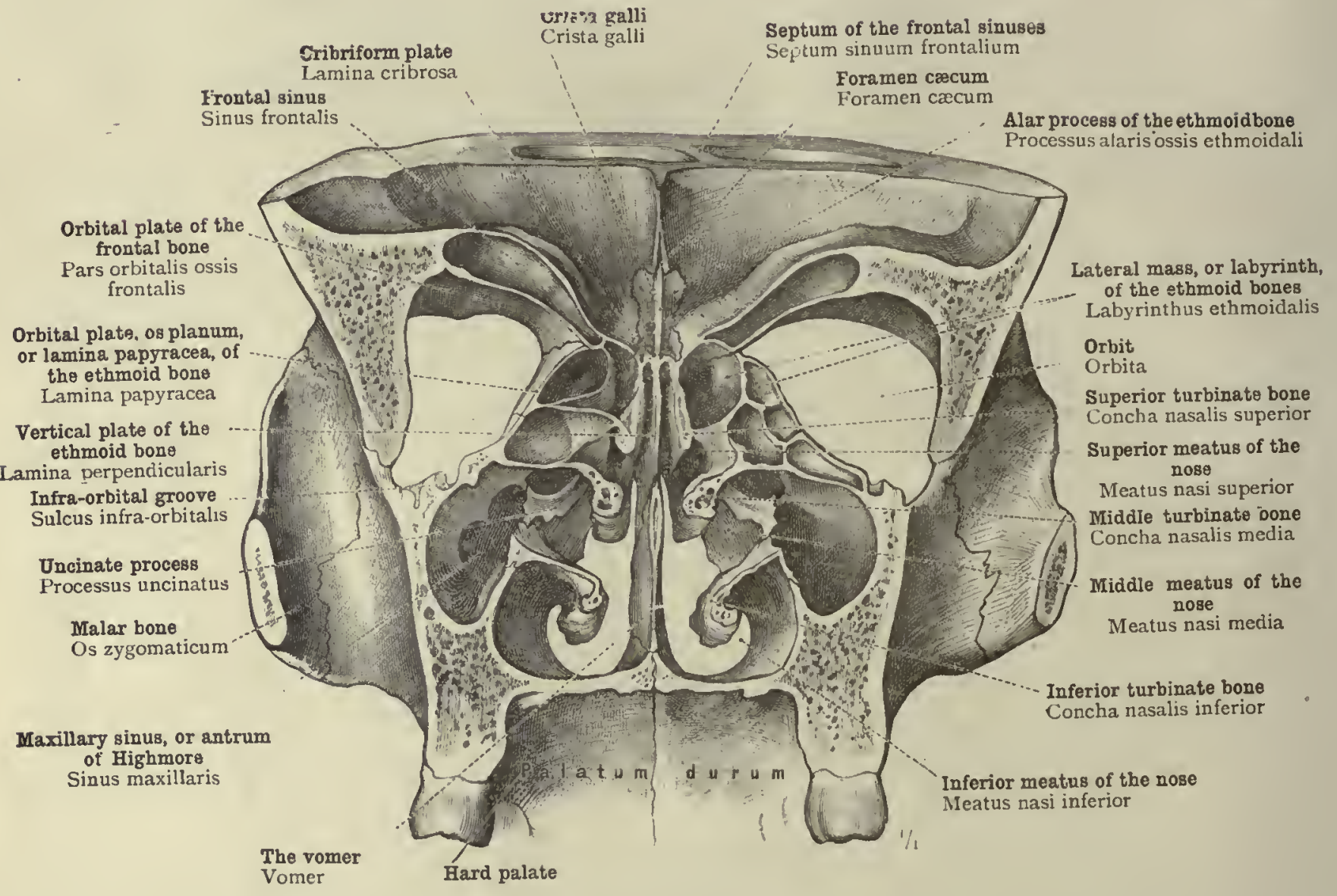

Fig. 209.-By Means of a Section passing through the most Anterior Portions of Both Zygomatic Arches, the Nasal Cavity and the Orbits are divided towards their Posterior Extremities in the Frontal Plane.

The anterior portion of the skull thus divided is figured from behind. The three turbinate bones of the nose and the three nasal meatus, as well as the bony septum of the nose, are seen in frontal section. The maxillary sinuses are also opened up, and the communication of these sinuses with the general cavity of the nose is to be seen above the uncinate process. 


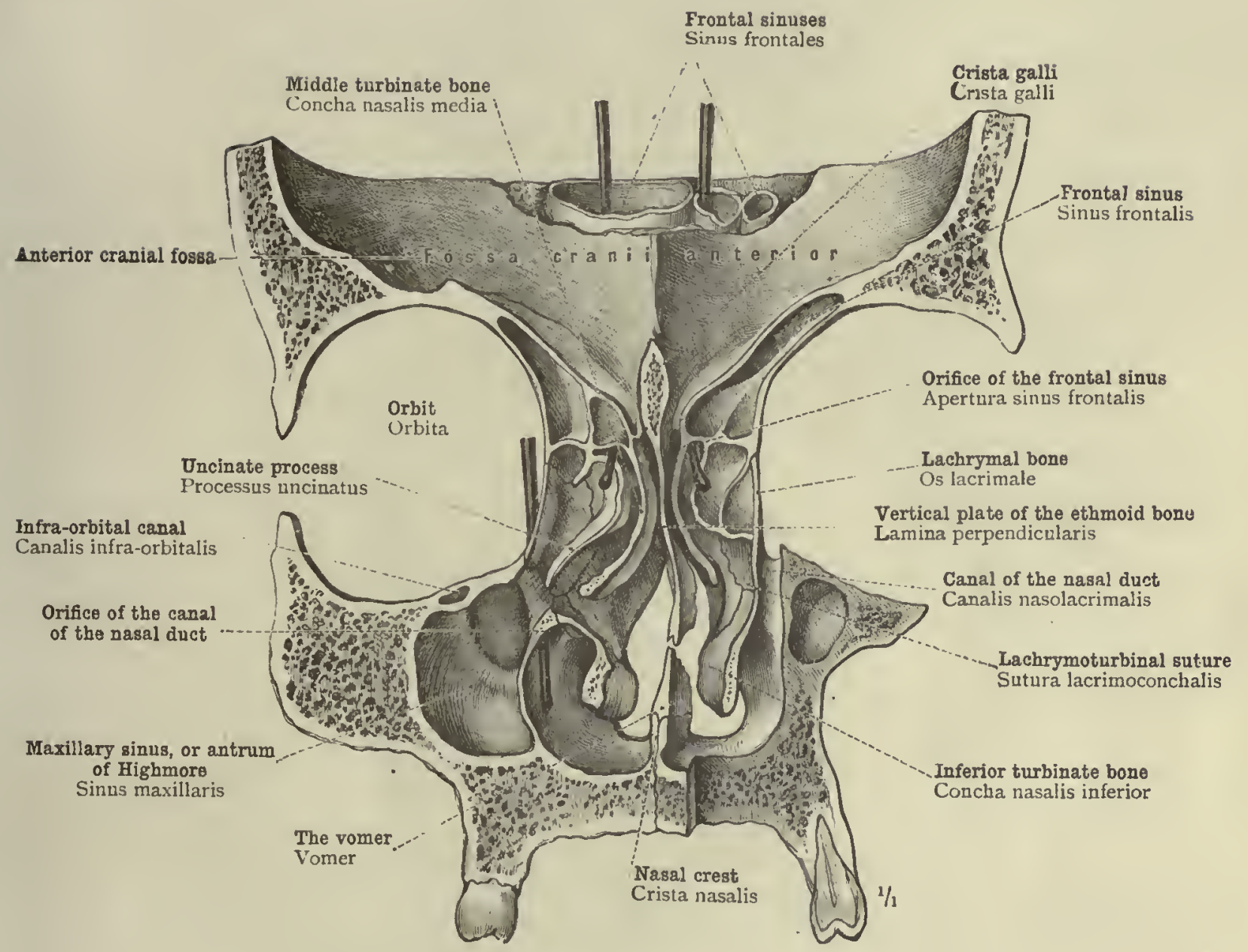

Fig. 2io.-By Means of a Section passing vertically through the Posterior Portions of Both Lachryal Bones, the Anterior Portion of the Nasal Cavity and of the Orbits is displayed in Frontal Section. Seen from Behind.

From the right side of the anterior portion of the skull thus divided, a layer of bone a quarter of an inch in thickness has been removed by a section in a plane parallel with the first section, so as to open up the canal of the nasal duct, canalis nasolacrimalis, in its entirc length. The sounds passed into the two frontal sinuses indicate the orifices of these sinuses in the nasal fosse. A third sound lias becn passed through the left canal of the nasal duct from the orbit into the nasal cavity. 


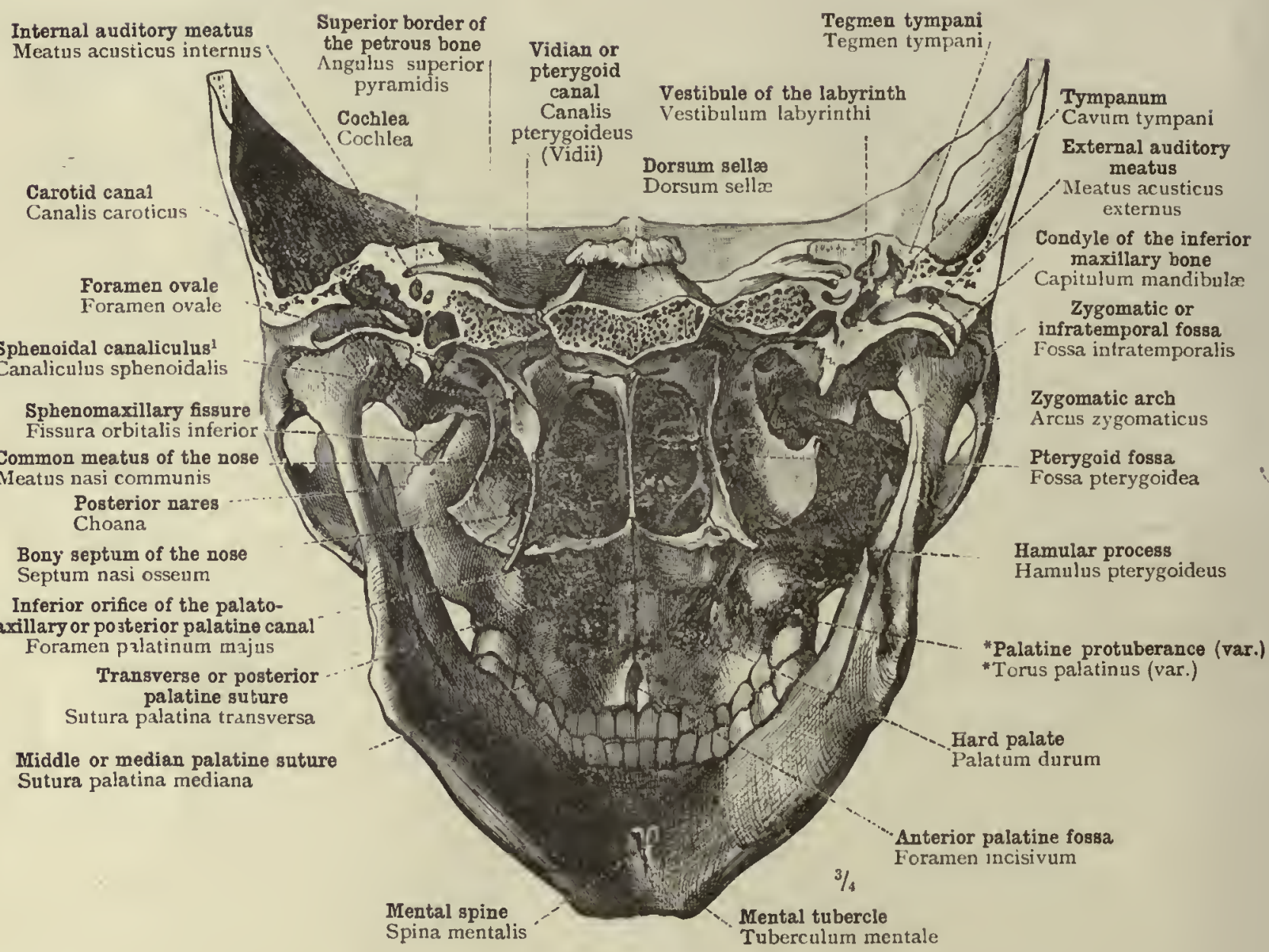

1 See note to p. 92 .

Fig. 2it.-Anterior Portion of the Skull, separated from the Posterior Portion by a Frontal Section passing through the Two External Auditory Meatus.

The view trom behind shows the posterior nares with the posterior border of the bony septum of the nose, the bony framework of the oral cavity, and the zygomatic fossa ; further, in frontal section, the tympanic carities, with portions of the bony labyrinths and the internal auditory meatus. 


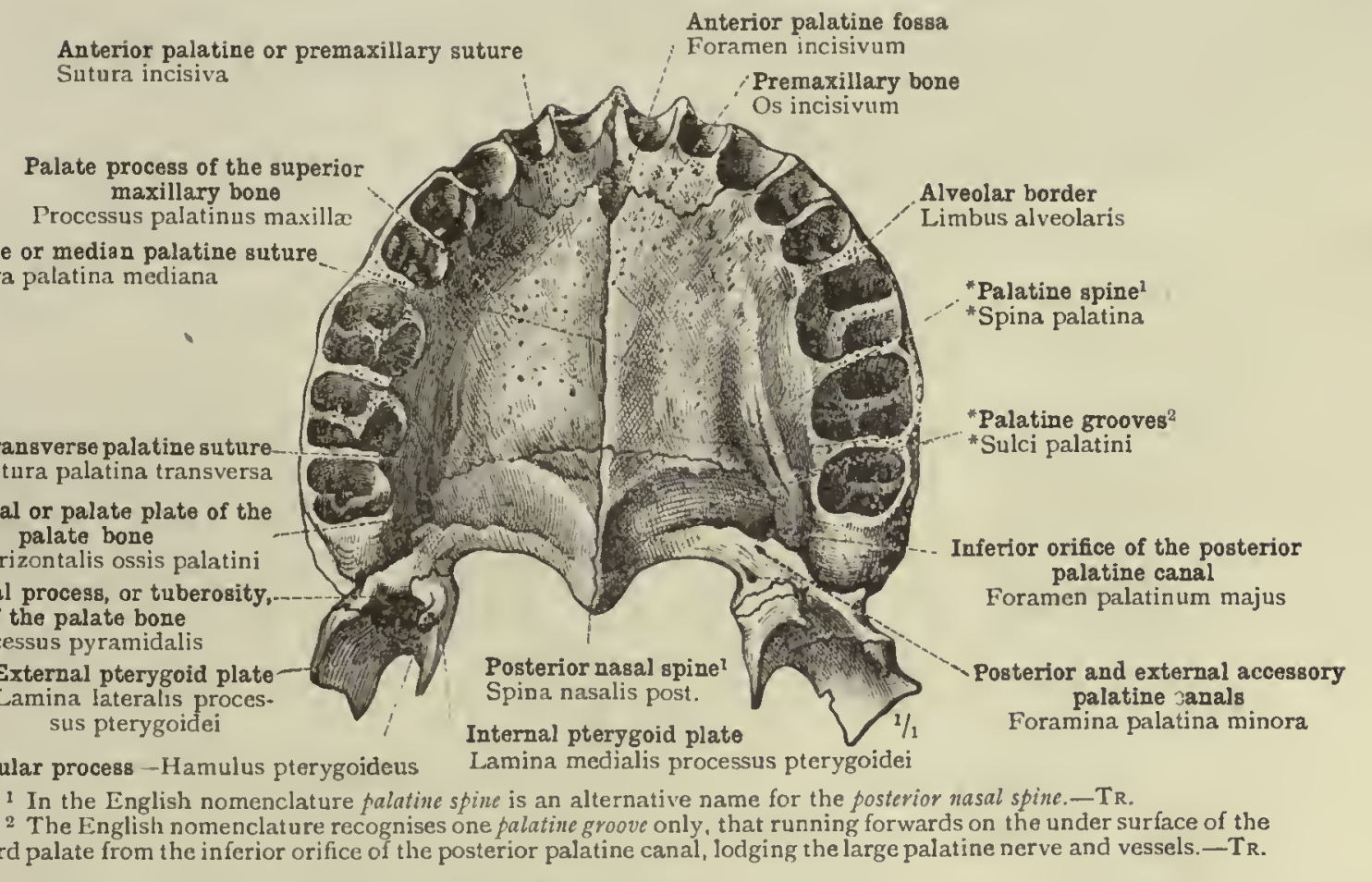

Fig. 212.-The Hard Palate, Palatum Durum, with the Alveolar Process of the SUPERIOR Maxillary Bone, REMOVEd By a SEction passing horizontally through both Superior Maxillary Bones above the Floor of the Nasal Foss a. Seen from BELOW.

Posterior or transverse pala tine suture

Horizontal or palate plate of the Pars horizontalis ossis palatini

Pyramidal process, or tuberosity

of the palate bone

External pterygoid plate sus pterygoidei

Hamular process - Hamulus pterygoideus
Anterior palatine fossa

Premaxillary bone

$\therefore$ Os incisivum

Palatine spine

Spina palatina

Palatine grooves ${ }^{2}$

Sulci palatini

orifice of the posterior

Foramen palatinum majus

palatine zanals
Foramina palatina minora

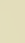




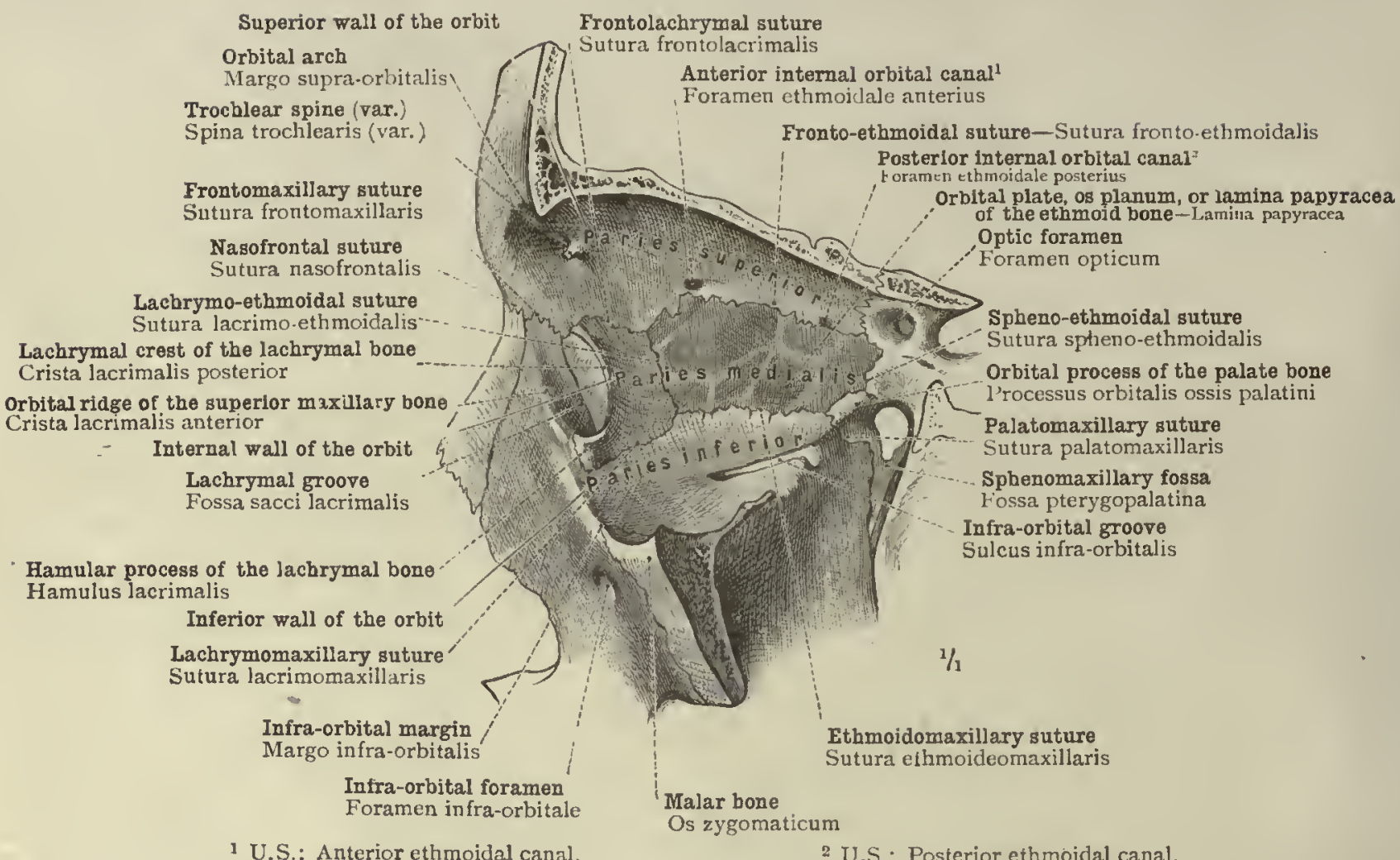

Fig. 2i4.-Internal Portion of the Left Orbit, shown by the Removal of the External Wall. Seen from the Left Side.

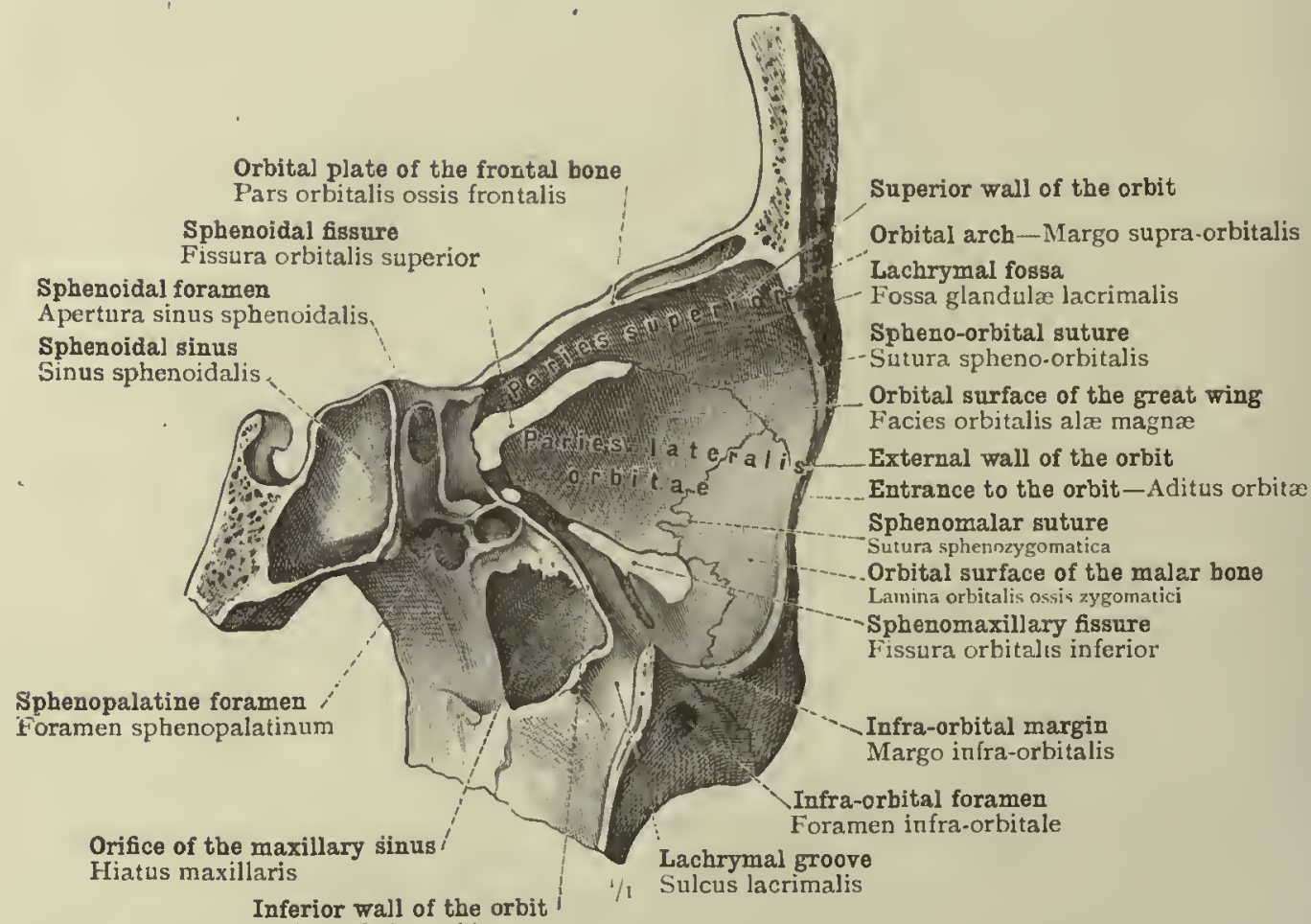
Paries inferior orbita

Fig. 2i5.-External Portion of the Left Orbit, shown by the Removal of the Internal Wall of the Orbit and of a Portion of the Superior Maxillary Bone i.s a LONGitudinal.Ly hemisected SKull. 
Uncinate process of the ethmoid bone Processus uncinatus ossis ethmoidalis Inferior wall of the orbit Paries inferior orbitic

Orifice of the maxillary sinus Hiatus maxillaris

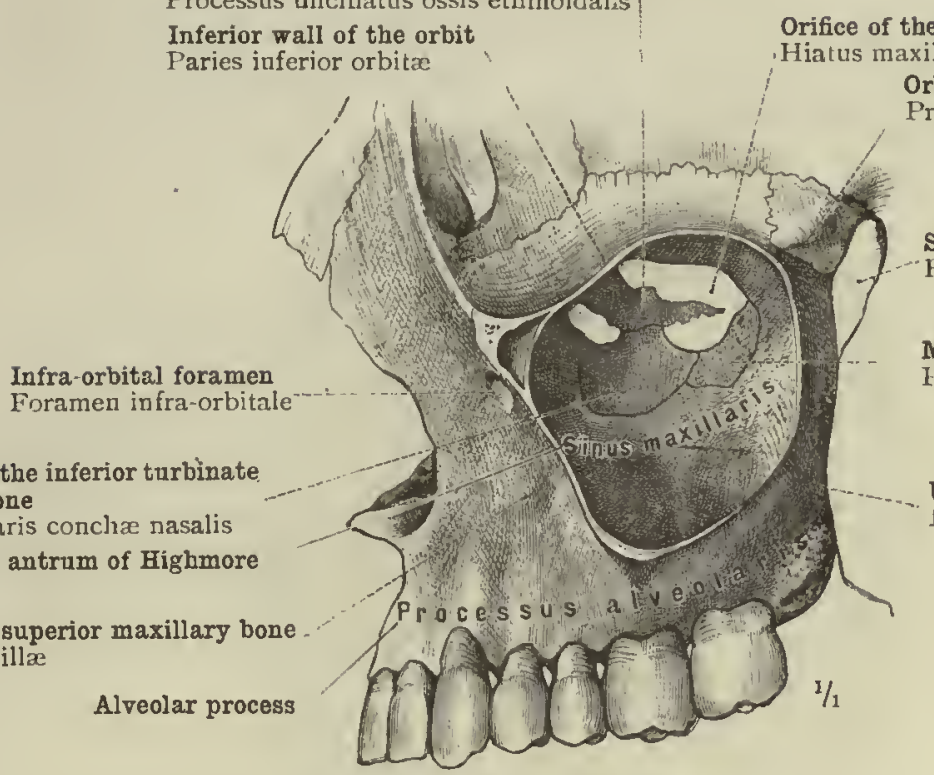

Alveolar process
Orbital process of the palate bone

Processus orbitalis ossis palatini

Sphenomaxillary fossa

Fossa pterygopalatina

Maxillary process of the palate bone Processus nasalis ossis palatini

Cuberosity of the superior maxillary bone ruber maxillare

Processus maxillaris conchæ nasalis Maxillary sinus, or antrum of Highmore

Body of the superior maxillary bone Corpus maxilla

Fig. 2i6. -The Left Maxillary Sinus, or Antrum of Highmore, Shown by the Removal of the External Wall of the Body of the Superior Maxillaky Bone and the Malar Bone. Seen from the Left Side.

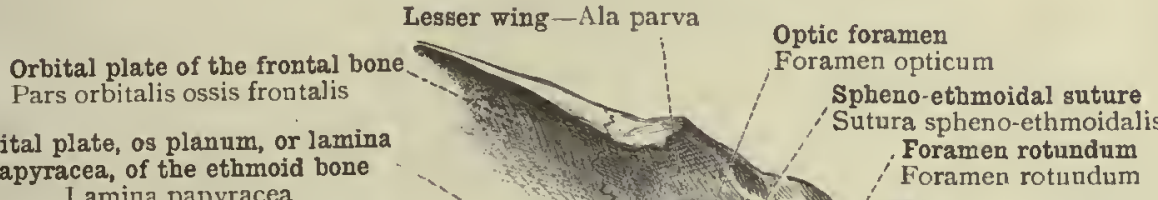
papyracea, of the ethmoid bone Lamina papyracea

Palato-ethmoidal suture Sutura palato-ethmoidalis

Orbital process of the palate bone Processus orbitalis ossis palatini

Orbital surface of the superior maxillary bone-Facies orbitalis maxillæ Sphenopalatine foramen Foramen sphenopalatinum Infra-orbital groove Sulcus infra-orbitalis

Sphenomaxillary fossa Fossa pterygopalatina

Vertical plate of the palate bone Pars perpendicularis ossis palatini

Posterior palatine or palatomaxillary canal-Canalis pterygopaiatinus Posterior dental canal Foramen alveolare (posterius)

Zygomatic surface of the superior maxillary bone Facies infratemporalis maxilla

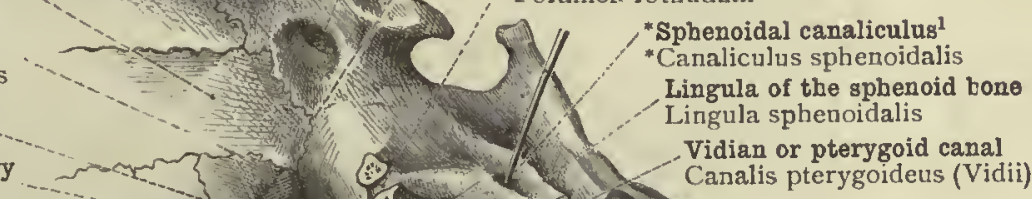
*Sphenoidal canaliculus ${ }^{1}$ Lingula of the sphenoid bone Vidian or pterygoid canal

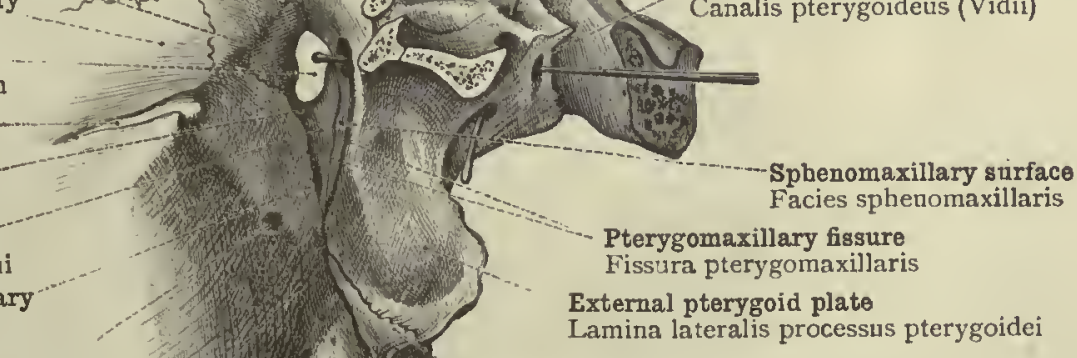
Lamina lateralis processus pterygoidei

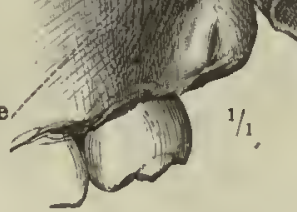

1 See note to p. 92 .

Fig. 217.-The Left Sphenomaxillary Fossa, shown by Removal of the Malar Bone, the Temporal Bone, and the Great Wing of the Sphenoid Bone. Seen from THE LEFT SIDE.

A sound has been passed through the Vidian canal, and another through the ${ }^{*}$ sphenoidal canaliculus ${ }^{1}$ (exceptionally large in this specimen).

Sinus maxillaris-Maxillary sinus, or antrum of Highmore.-Fossa pterygopalatina-Sphenomaxillary fossa. 


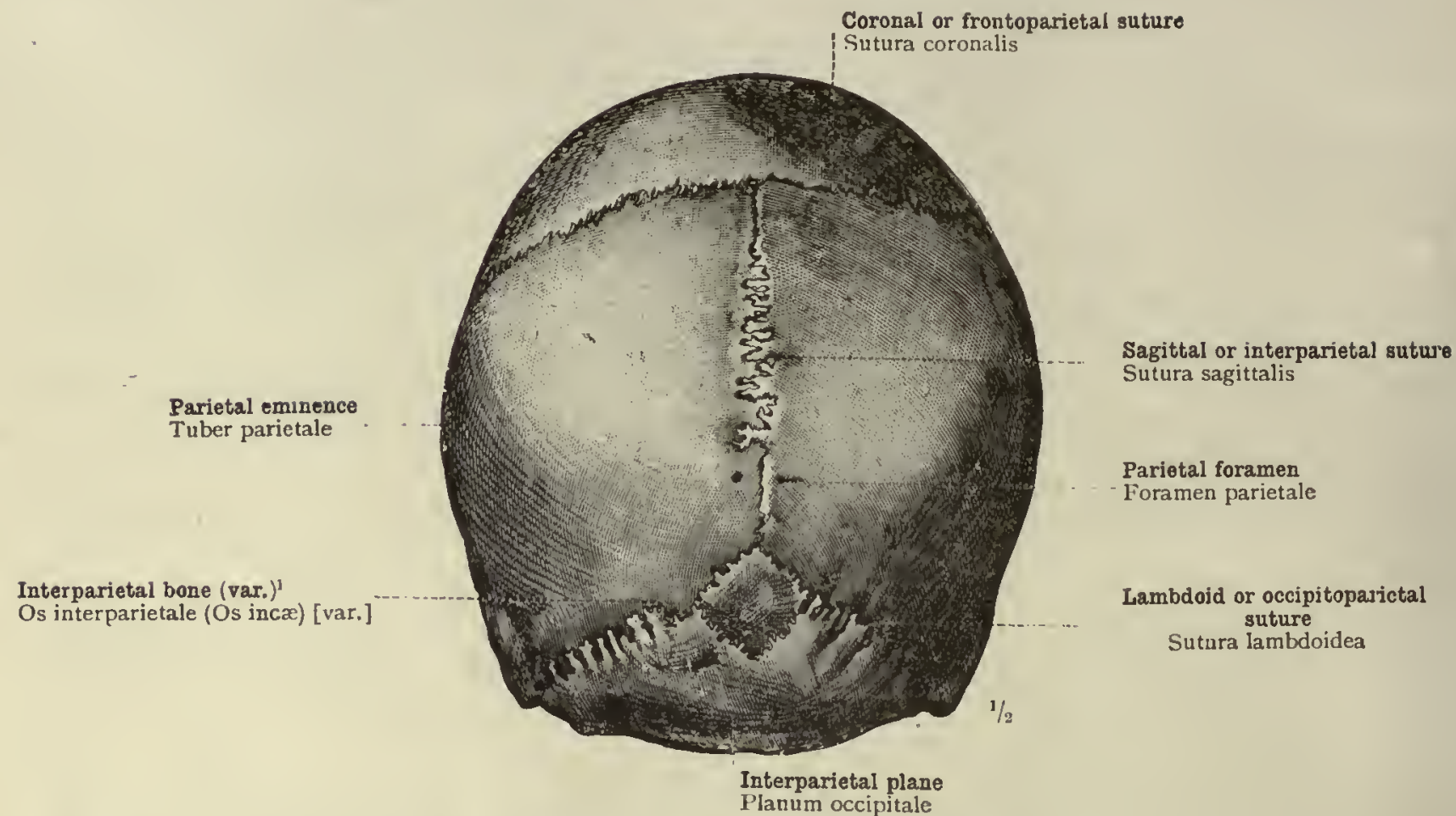

Fig. 2 I8. - A Large Wormian Bone in the Uppermost Part of the Lambdoid Suture.

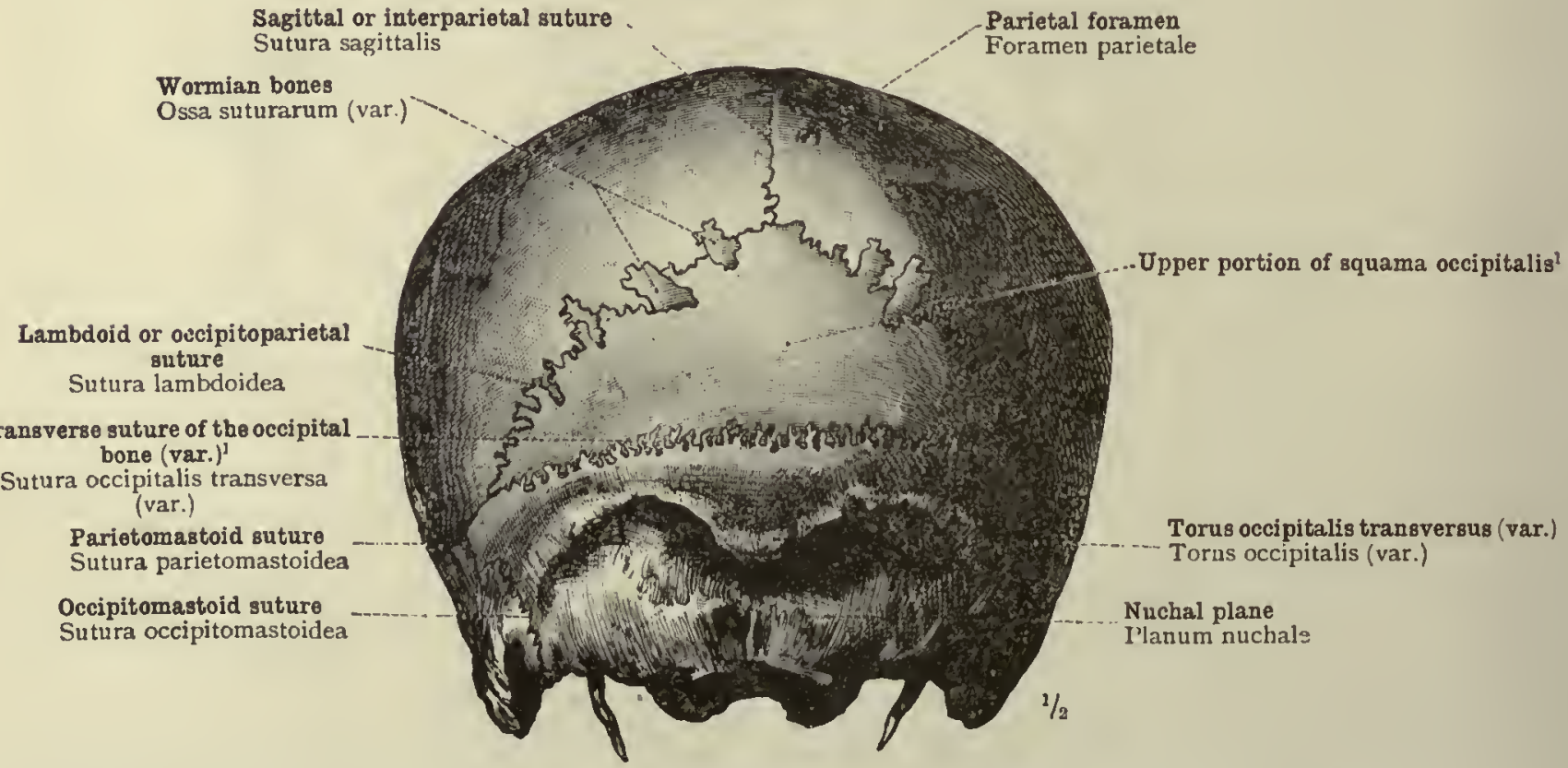

Fig. 219.-Transverse Subdivision of the Squama Occipitalis. Several Wormian Bones in the Lambdoid Suture.

1 See note to p. 57 .

Ossa suturarum-Wormian bones. 


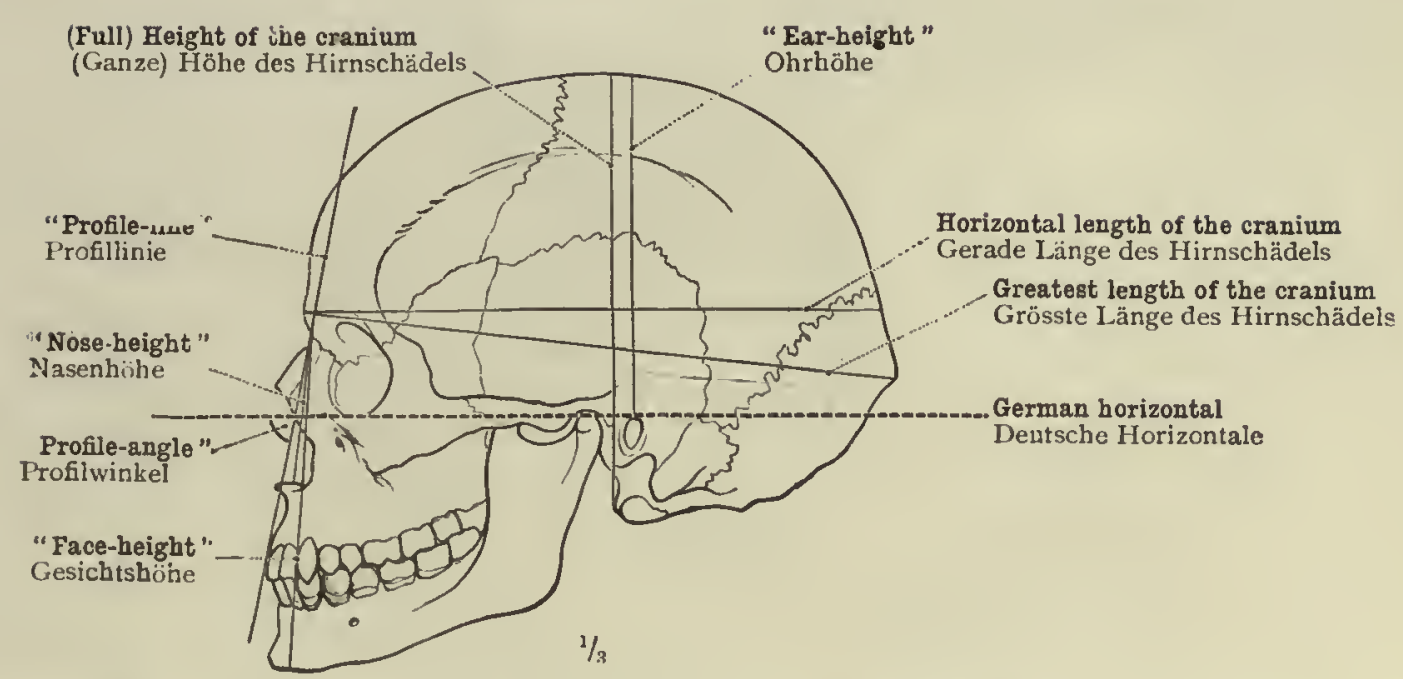

Fig. 220.-Side-View of the Skull: Norma Lateralis.

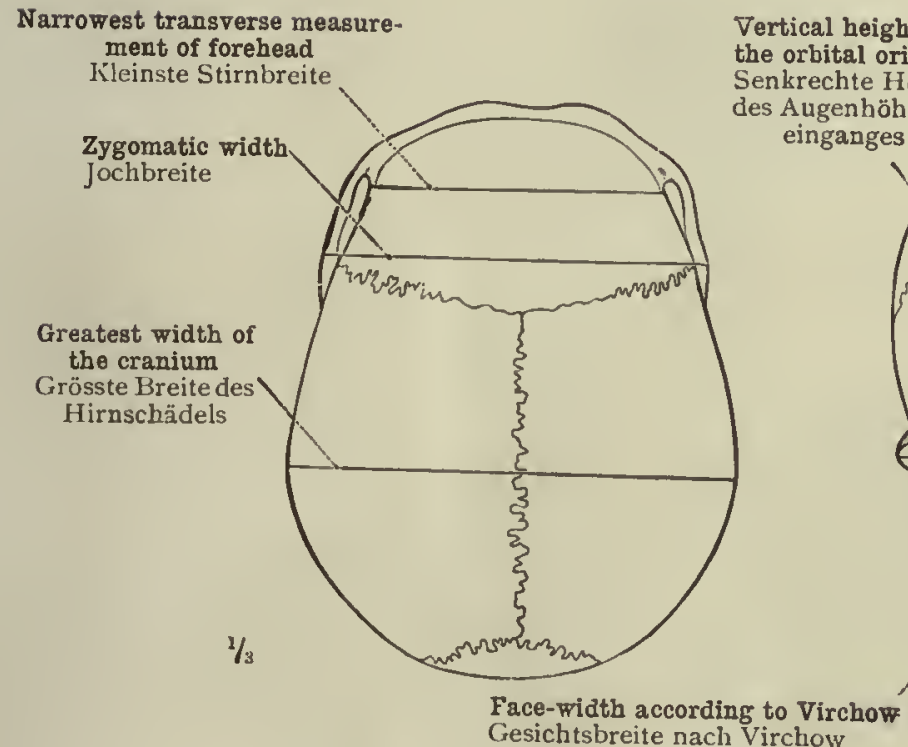

Fig. 221.-Skull SeEn from ABove Norma Verticalis.

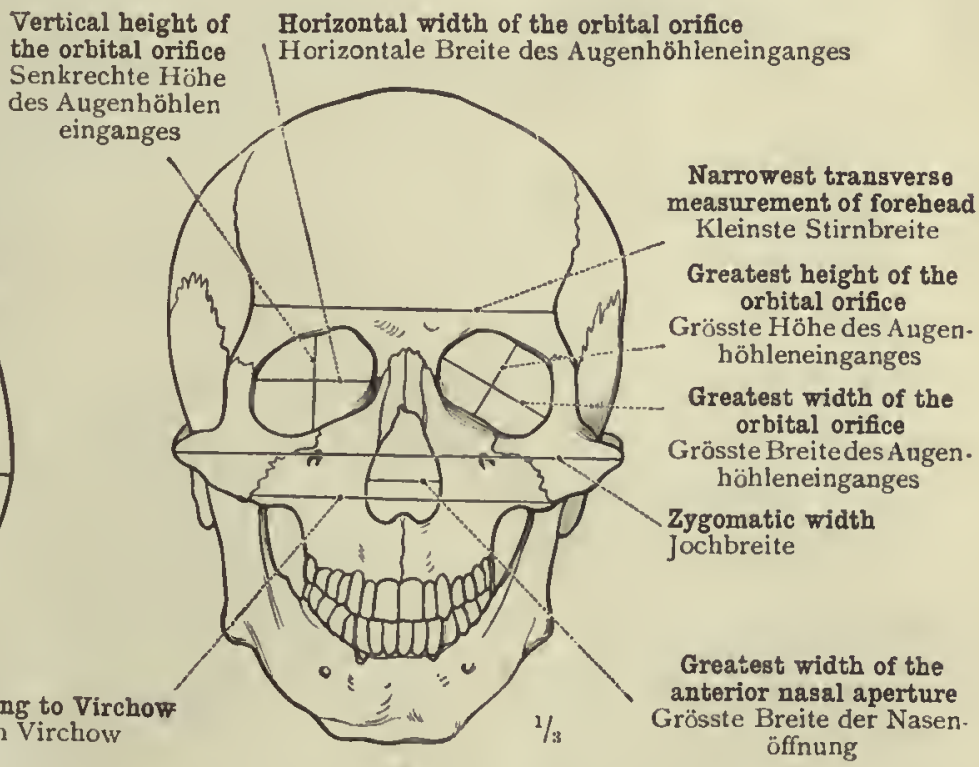

Fig. 222.-Front VIEW OF THE SkULL: Norma Frontalis.

Translator's Note.-The above measurements do not fully correspond with those used by English craniologists. For this reason a purely literal translation of the German terms has been given. 


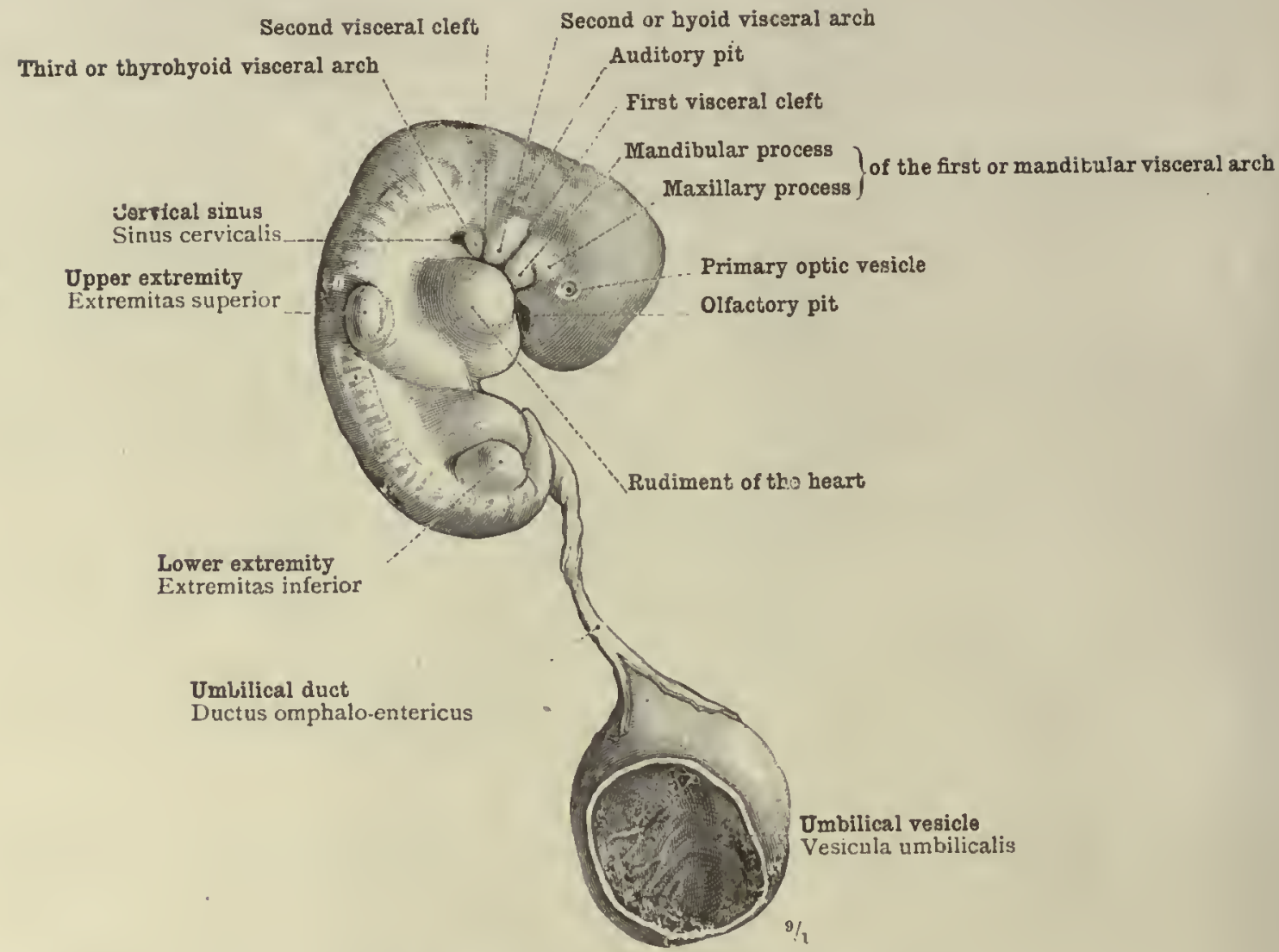

Fig. 223.-Human Embryo, Four Weeks old.

The umbilical vesicle has been opened.

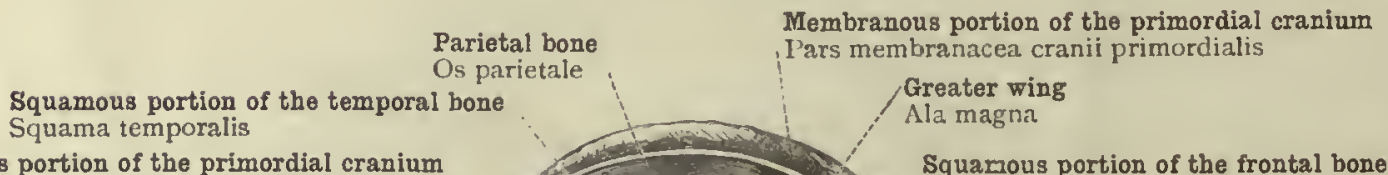

Membranous portion of the primordial cranium Pars membranacea cranii primordialis

intermembranous part of the supra-occipital portion of the occipital bone

Pars intermembranacea squamæ occipitalis

S 1 erior semloircular canal-Canalis semicircularis superior Cartilaginous portion of the primordial cranium Pars cartilaginea cranii primordialis

Intercartilaginous part of the supra-occipital portion of the occipital bone ${ }^{1}$

Pars intercartilaginea squamæ occipitalis

Primitive cartilage of the petrous portion of the temporal bone

Centre of ossification for the lateral portion of the occipital bone (exoccipital) ${ }^{1}$

Centre of ossification for the basilar portion of the $1 / 1$. The vomer occipital bone (basi-occipital) ${ }^{1}$
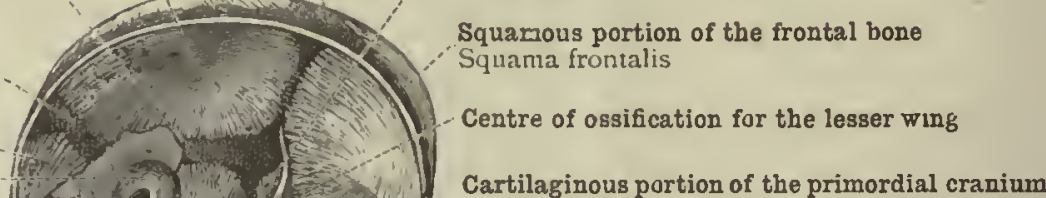
ars cartilaginea cranii primordialis (Planum sphenoidale)

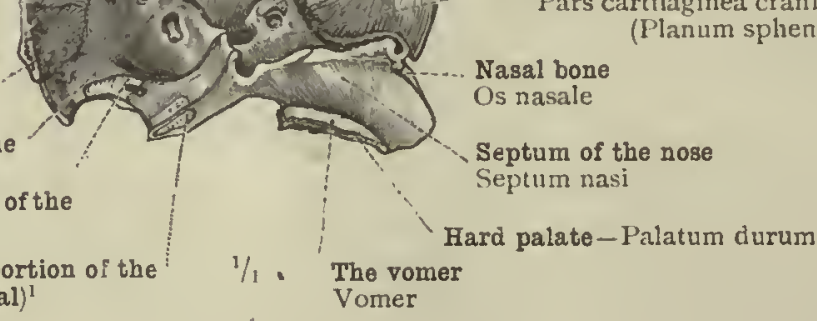

1 See note to p. 57.

Fig. 224. -The Left Half of the Skull of a Human Foitus at tine End of the Fourth Month (Months of Four Weeks Each). Seen from IVithin. The Cartilaginous Portion of the Primordial Cranium (Chondrociranium) is coloured Blue.

Body-length, $4 \frac{1}{2}$ inches. 
Squamous portion of the temporal bone Squama temporalis

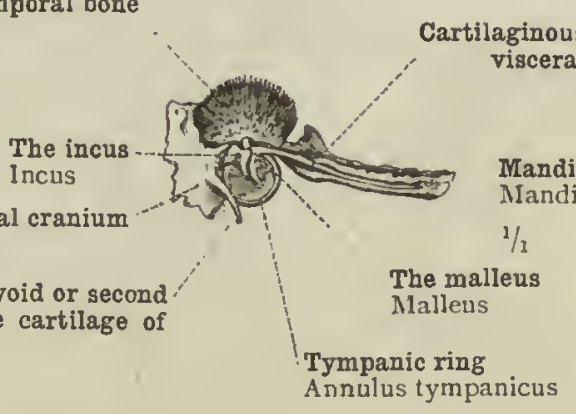

Cartilaginous portion of the primordial cranium Pars cartilaginea cranii primordialis

Cartilaginous bar of the hyoid or second visceral arch (primitive cartilage of the styloid process)

Fig. 225.-Tile Squamous Portion of the Temporal Bone, the Tympanic Membrane with the Malleus, the Incus, and Meckel's Cartilage, from a Human Fotus in the First Hai.f of the Fifth Month (Months of Four Weeks Each). Seen from Within.

Body-length, $5 \frac{1}{2}$ inches.

Squamous portion of the temporal bone Parietal bone

Squama temporalis $\quad$ Os parietale

Membranous portion of the primordial cranium $\quad$ Tympanic ring

Pars membranacea cranii primordialis

Squama frontalis

Cartilaginous bar of the mandibular or first visceral arch (Meckel's cartilage)

Cartilaginous bar of the hyoid or second visceral arch (styloid process, stylohyoid ligament, and small cornu of the hyoid bone)

\section{Maxilla}

\section{Mandible}

Mandibula

Primitive cartilage of the hyoid bone

Knorpelanlage des Os hyoideum

Cartilaginous portion of the primordial cranium

Pars cartilaginea cranii primordialis

$$
1 \text { See note to p. } 57 \text {. }
$$

Intermembranous part of the supra-occipltal portion of uhe occipital bone ${ }^{1}$

Pars intermembranacea squamæ occipitalis

Cartilaginous portion of the primordial cranium Pars cartilaginea cranii primordialis

Intracartilaginous part of the supra-occipital portion of the occipital bonet

Pars intracartilaginea squamx occipitalis

Foramen magnum

Foramen occipitale magnum

$1 / 1$

Lateral portion of the occipital bone (exoccipital) Pars lateralis ossis occipitalis

Basilar portion of the occipital bone (basi-occipital) ${ }^{1}$ Pars basilaris ossis occipitalis

Primitive cartilage of the petrous portion

of the temporal bone

Knorpelanlage der Pars petrosa

Fig. 226. - The Skull of a Human Fotus in the Middle of the Fifth Montil (Months of Four Weeks Each). Seen from the Left Side and Below.

Body length, $6 \frac{1}{2}$ inches. The cartilaginous bars of the visccral arches are displayed, and these, together witls the cartilaginous portion of the primordial cranium, are coloured blue. Part of the cartilagc of the left side of the inferior maxilla has bcen removed in older to lay bare a ! ortion of Meckel's cartilage which lies beneath it.

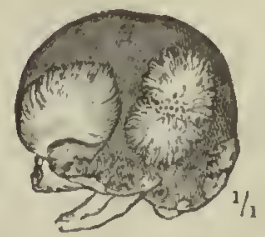

Fig. 227.-The Dried Skull of a Human FETUS IN THE MIDDLF OF THE FOURTII MONTH (MONTHS OF FOUR WEEKS $\mathrm{E}_{\mathrm{ACH}}$.

Body-length, $3 \frac{1}{2}$ inches.

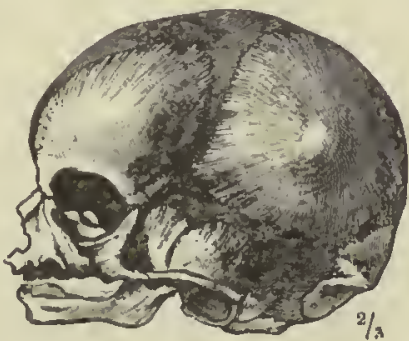

Fig. 228.-The Dried Skull of a Human FGetUs at THE END OF THE Sixth MONTH (MONTHS OF FOUR WEEKS EACH).

Body-length, $11 \frac{1}{3}$ inches.

Development of the Skull. 


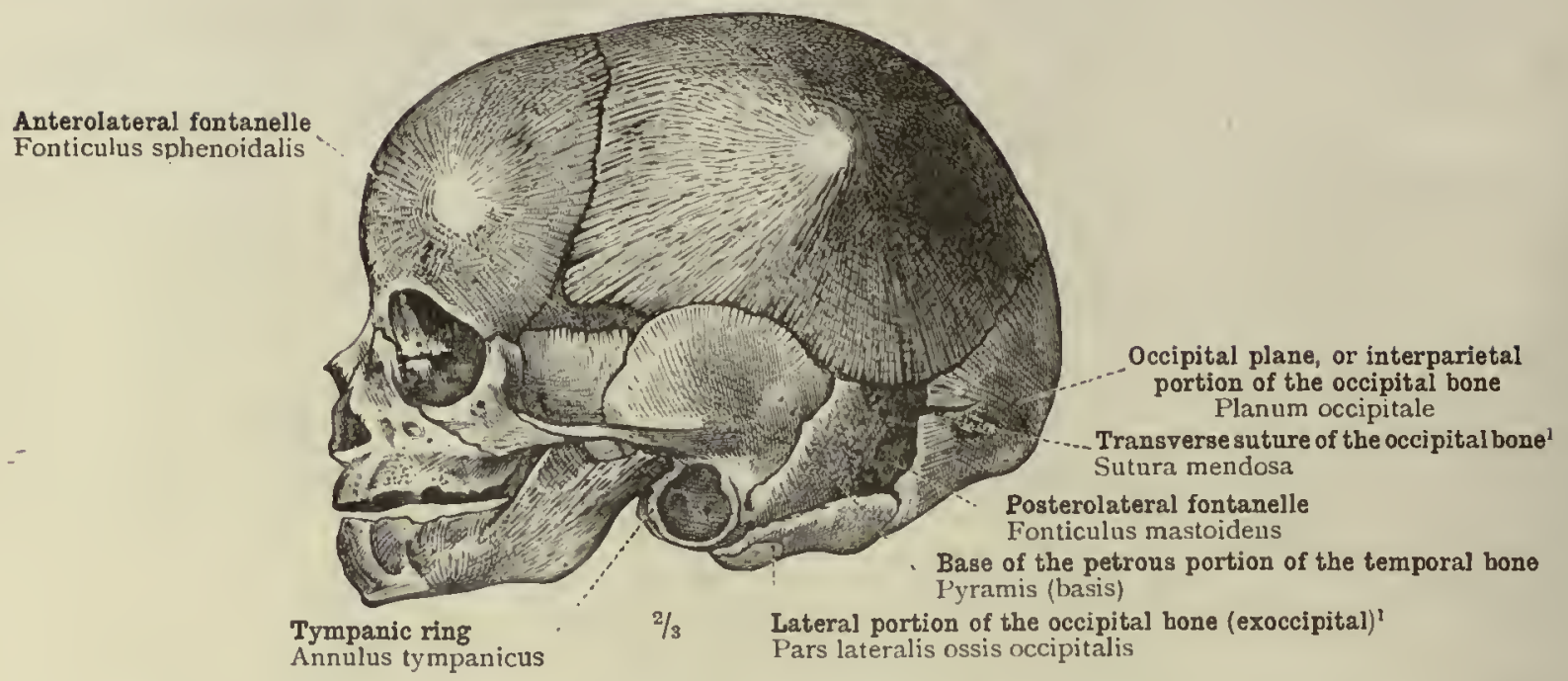

Fig. 229.-The Dried Skull of an Infant born at Full Term. Seen from the Left Side.

Body-length, 20 in inches. In the anterolateral fontanelle there remains part of the membranous portion of the primordial cranium (membrane of the fontanelle); in the posterolateral fontanelle there remains part of the cartil trinous portion of the primordial cranium.

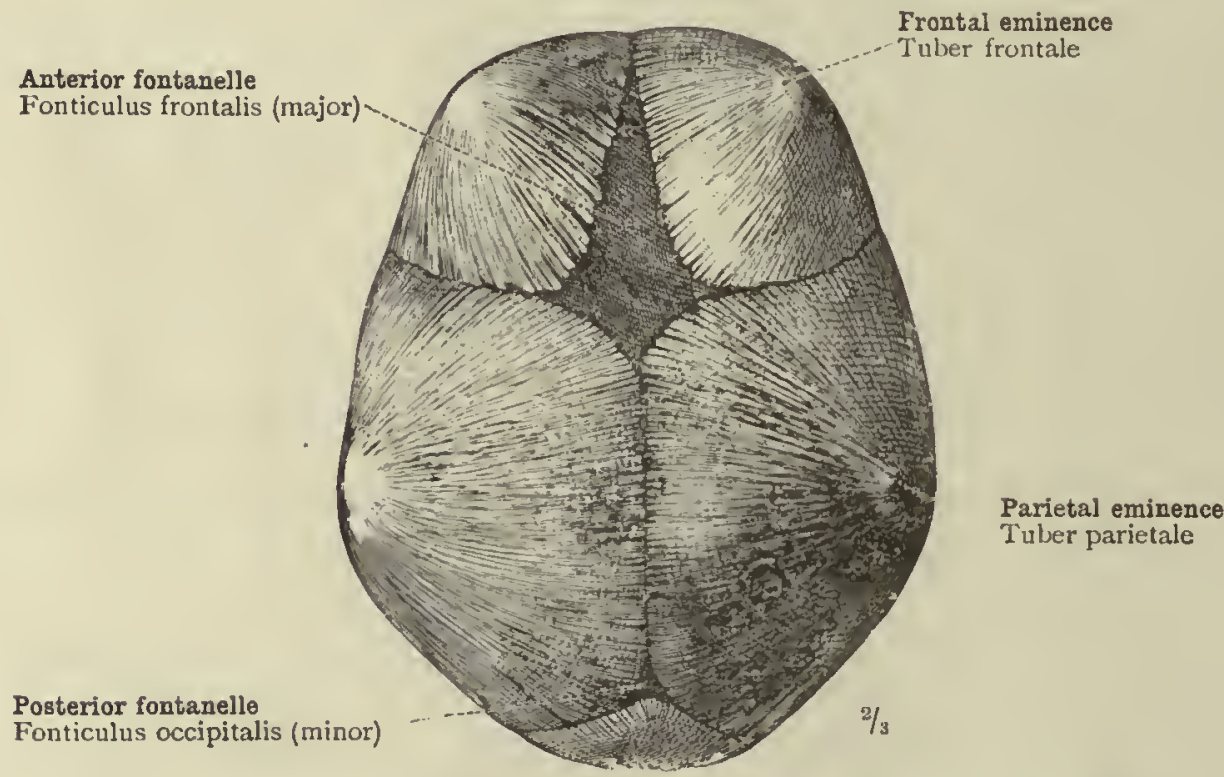

Supra-occipital portion of the occipital bone? Squama occipitalis

Fig. 230.-Tile Dried Skull of an Infant born at Full Term. Seen from Above. Body-leugth, 201 inches. In the anterior and in the posterior fontanelle there remain parts of the membranous portion of the primordial cranium.

1 See note to p. 57 .

\section{Development of the Skull,}




\section{SKELETON EXTREMITATUM, SUPERIORIS ET INFERIORIS}

THE SKELETON OF THE UPPER AND LOWER EXTREMITIES

(THE APPENDICULAR SKELETON) 


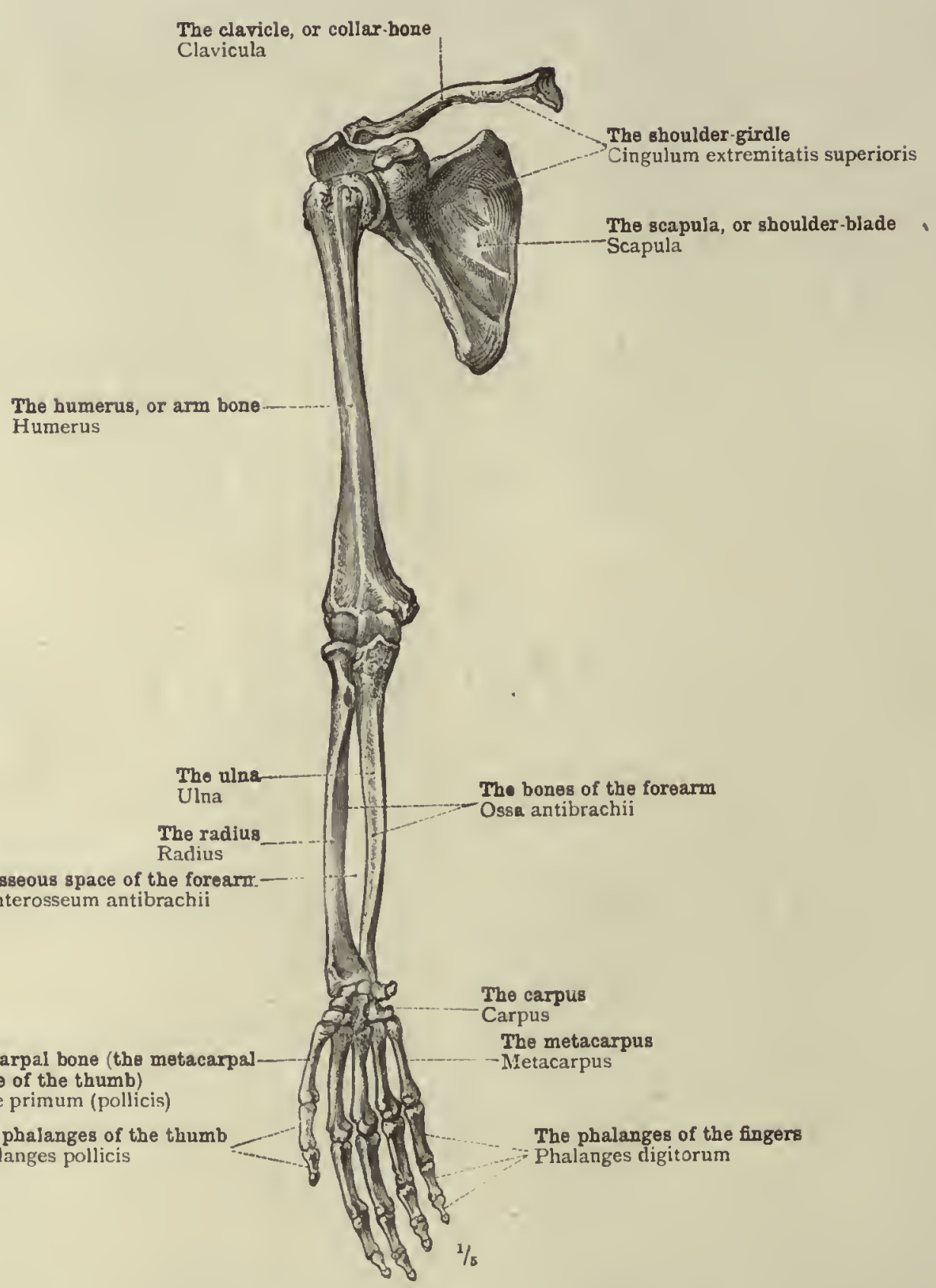

Fig 231.-The Skeleton of the Upper Extremity.

Skeleton extremitatis superioris-The skeleton of the upper extremity. 


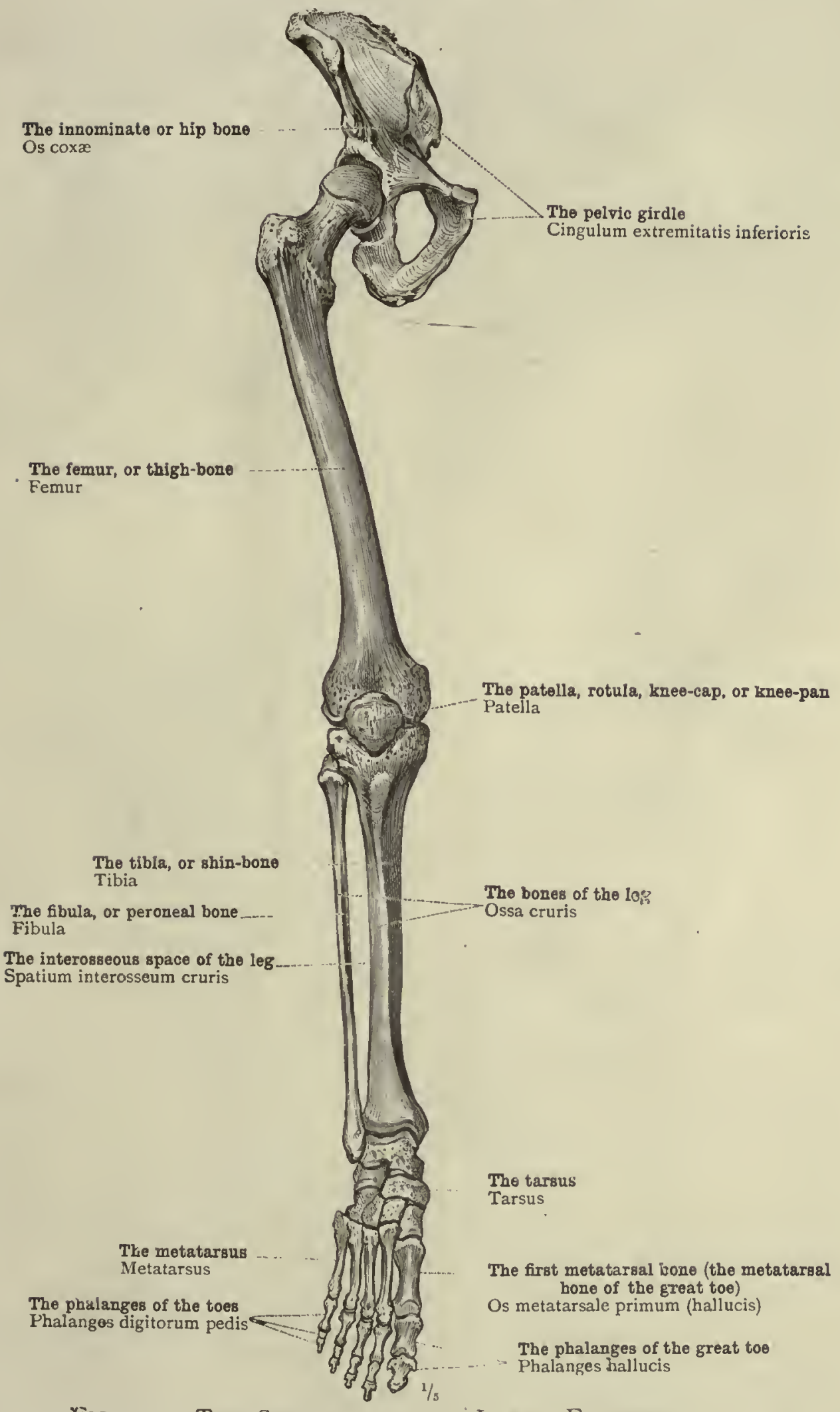

Fig. 232.-Tine Skeleton of the Lower Extremity.

Skeleton extremitatis inferioris-The skeleton of the lower extremity. 


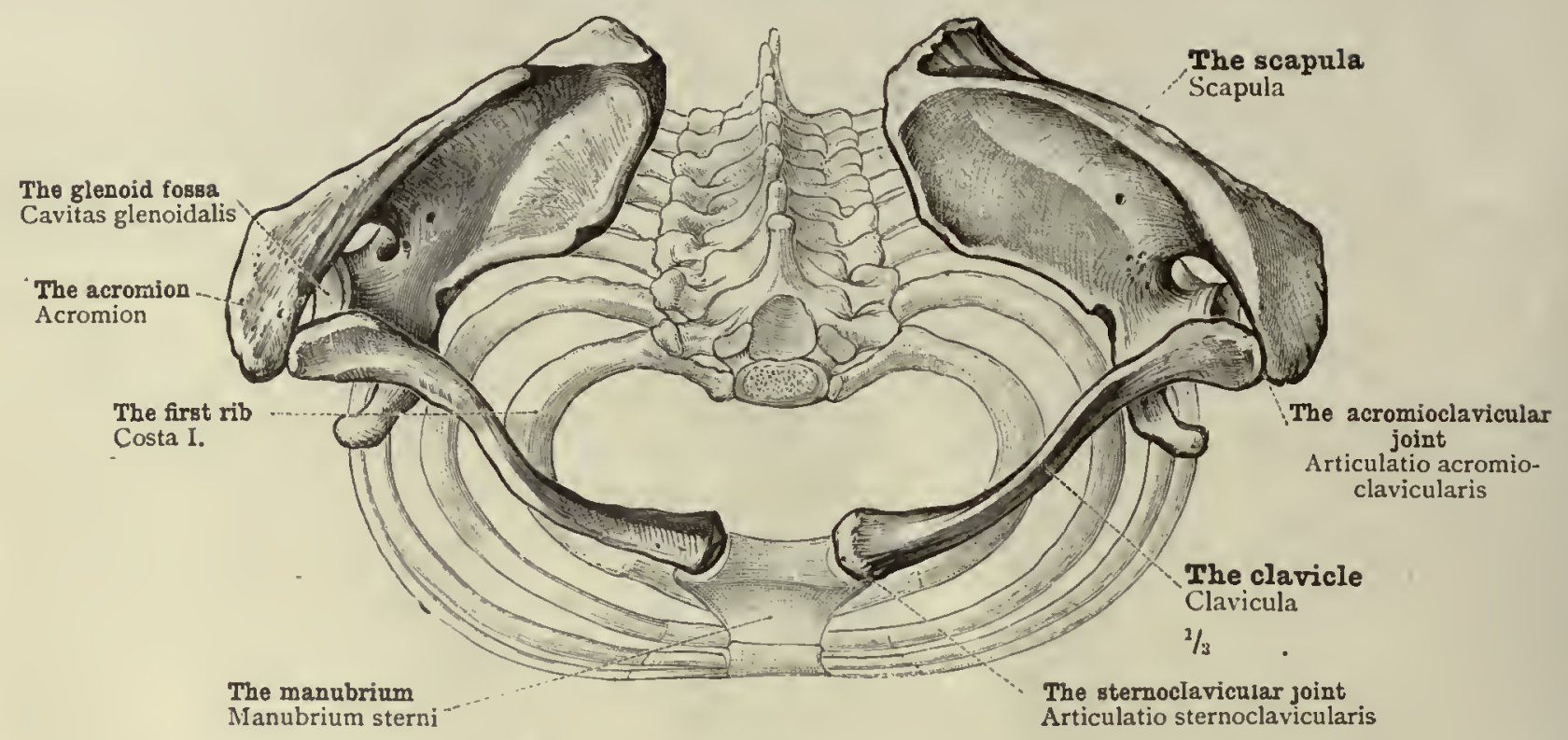

Fig. 233.-The Shoulder-Girdle and its Relation to the Thorax. Seen from Above.

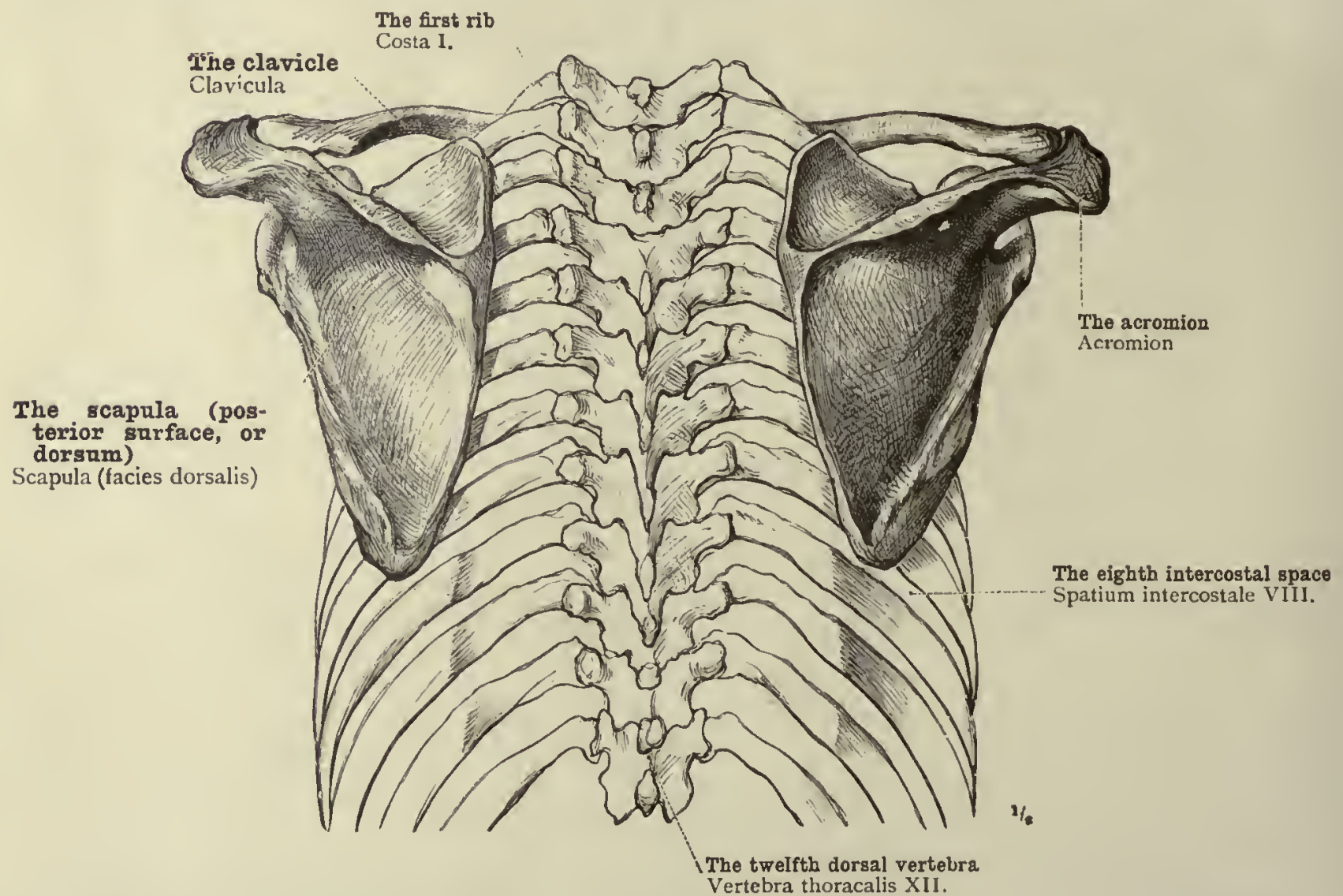

Fig. 234.-Tile Siloulder-Girdle and its Relation to the Thorax. Seen from Behind. Cingulum extremitatis superioris-The shoulder-girdle. 


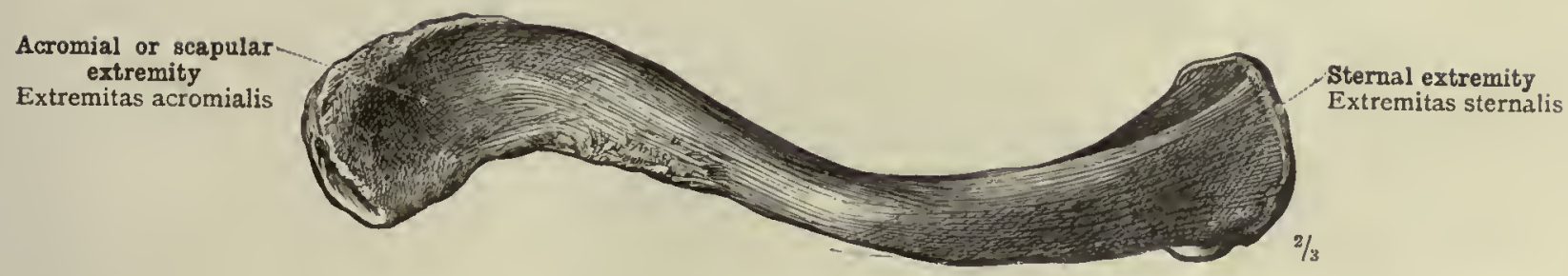

Fig. 235.-The Right Clavicle seen from Above.

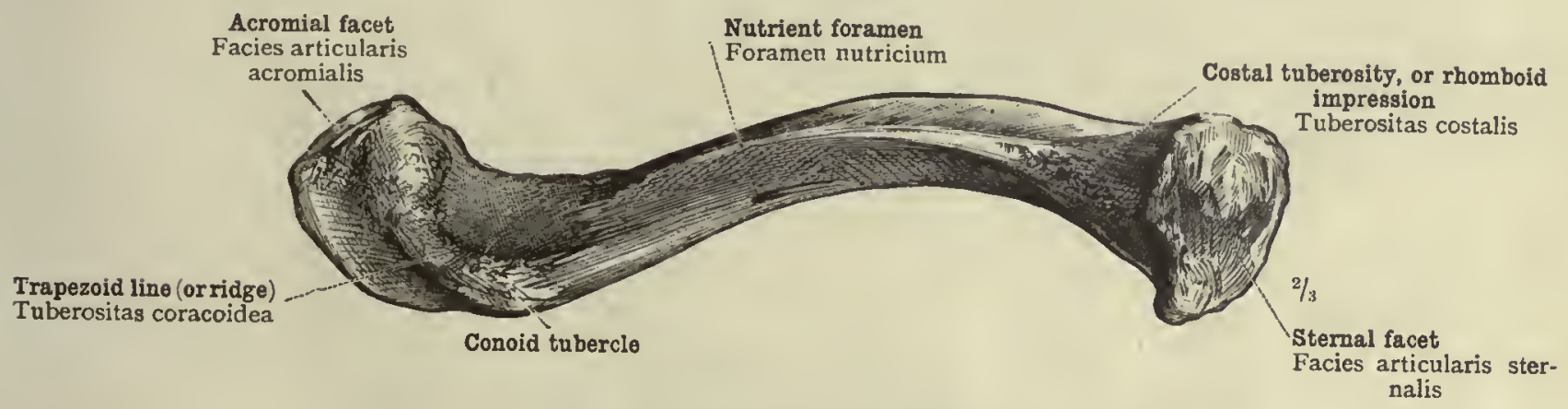

Fig. 23 - -The Right Clavicle seen from Below.

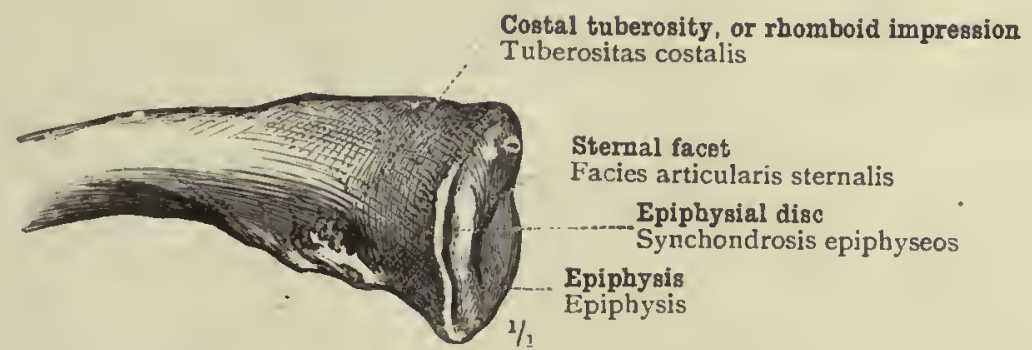

Fig. 237.-Sternai- Fixtpemity of the Right Clavicle of a Female aged Twenty Years, with a Sternal Epiphysis. Seen from Before.

Clavicula-The clavicic. 


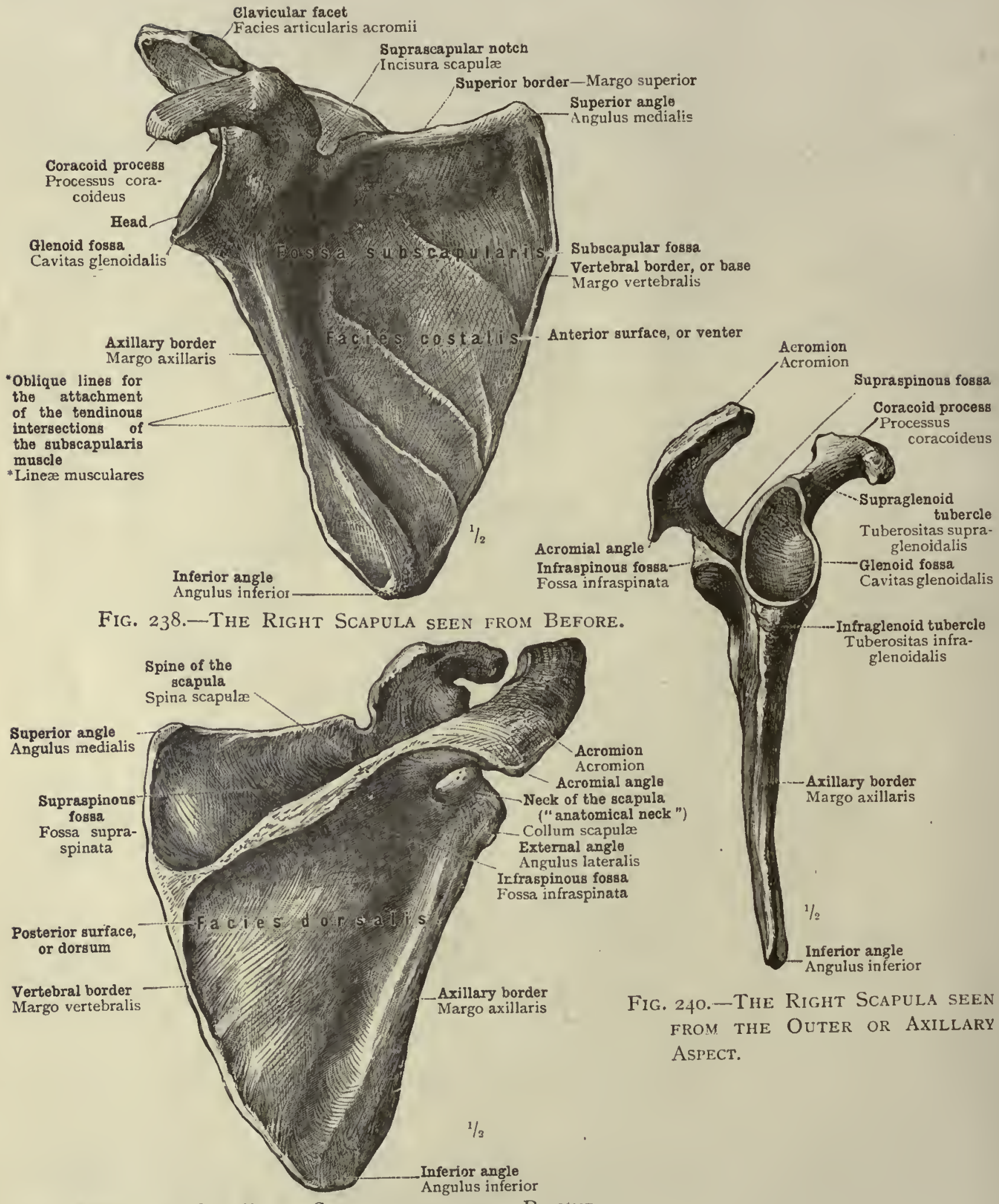

Fig. 239.-The Right Scapula SEEN From BEHIND. 


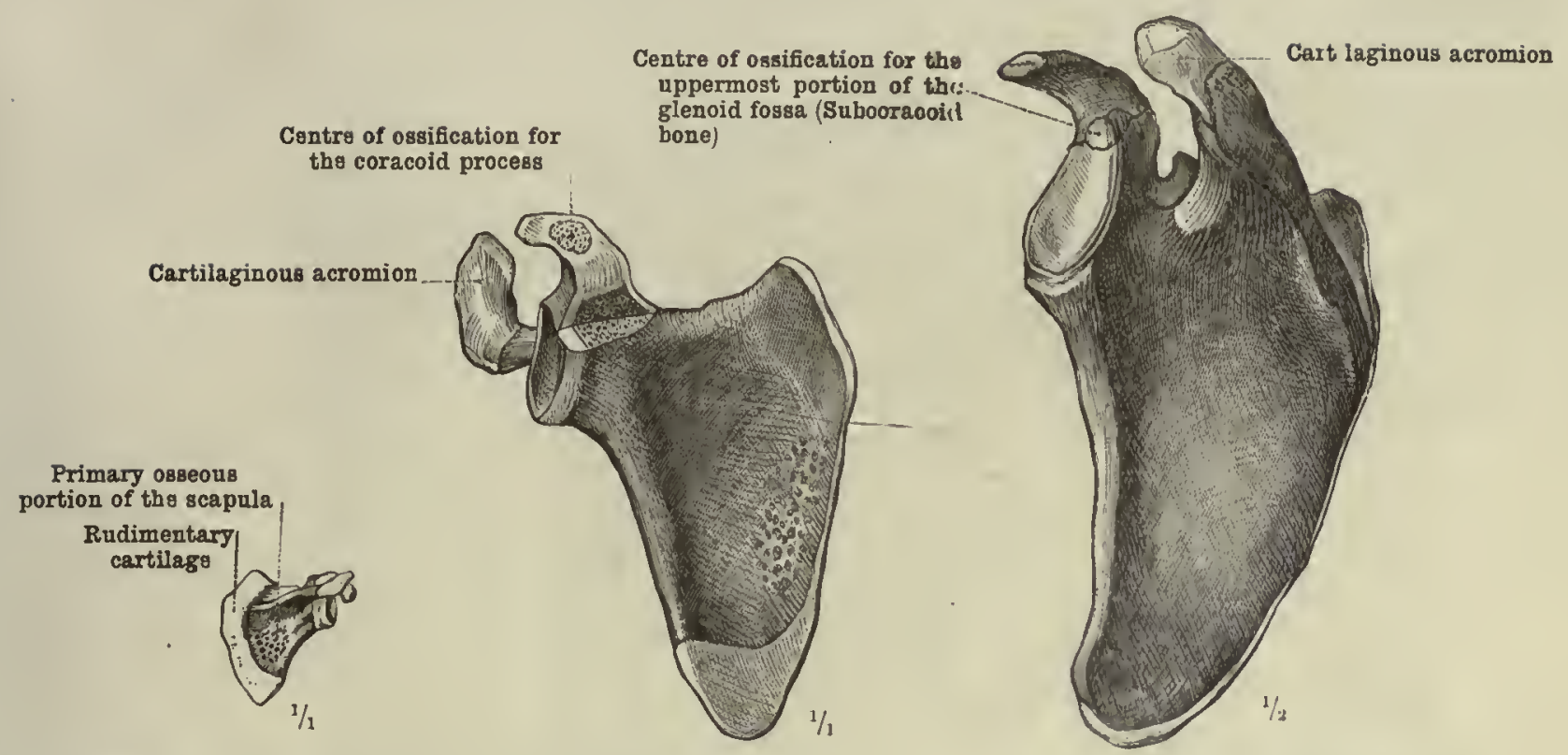

FIG. 24I.-IN THE FIFTH

MONTH OF INTRA-UTERINE

Fig. 242.-IN THE SECOND Year of Life.
Fig. 243.-IN THE FIFTEENTH YEAR OF LIFE.

LifE (MONTHS OF Four

WEEKS EACH).

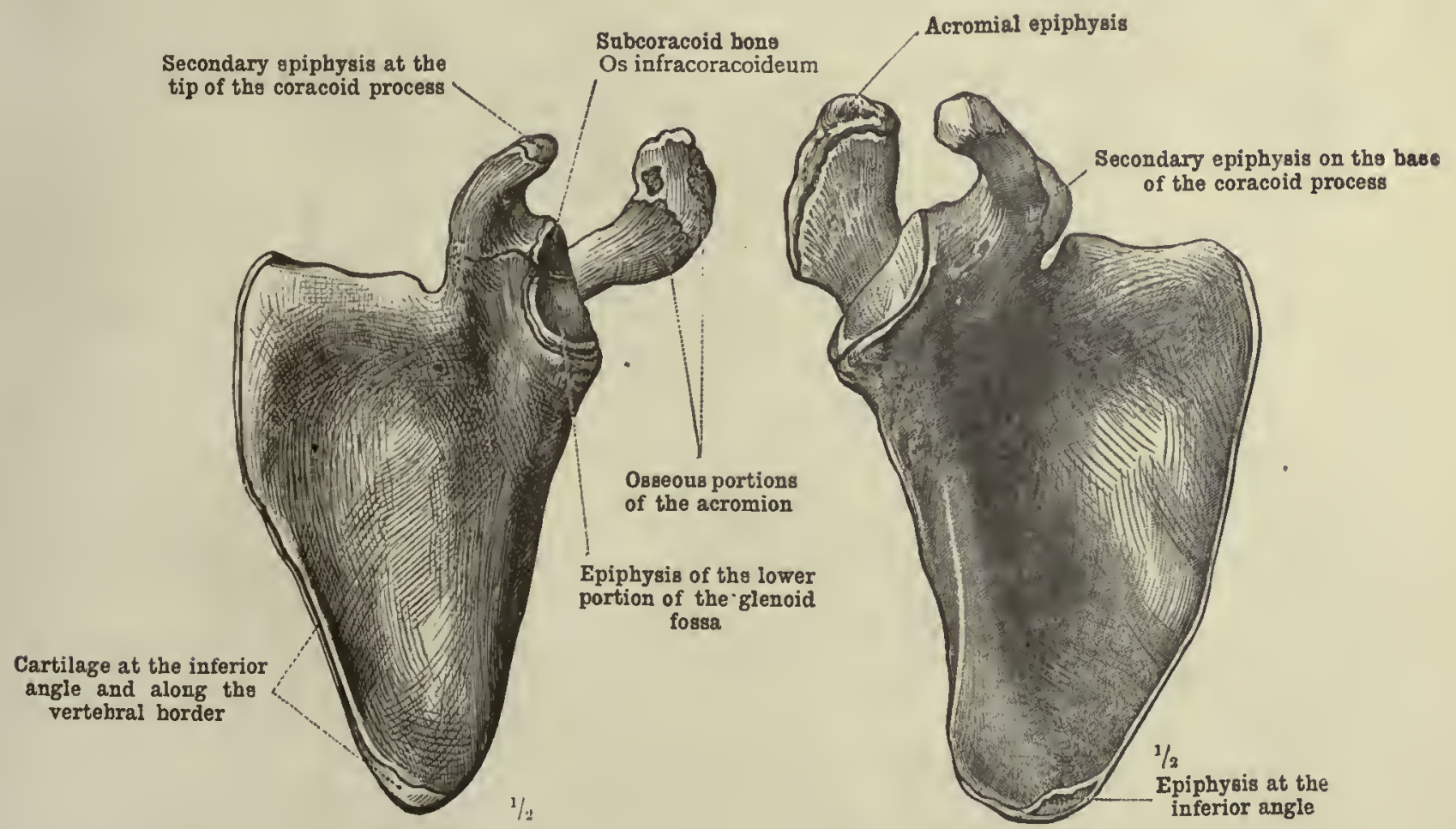

Fig. 244.-In the Seventeenth Year OF LIFE.

Fig. 245.-IN The Nineteenth Year OF LIFE. 


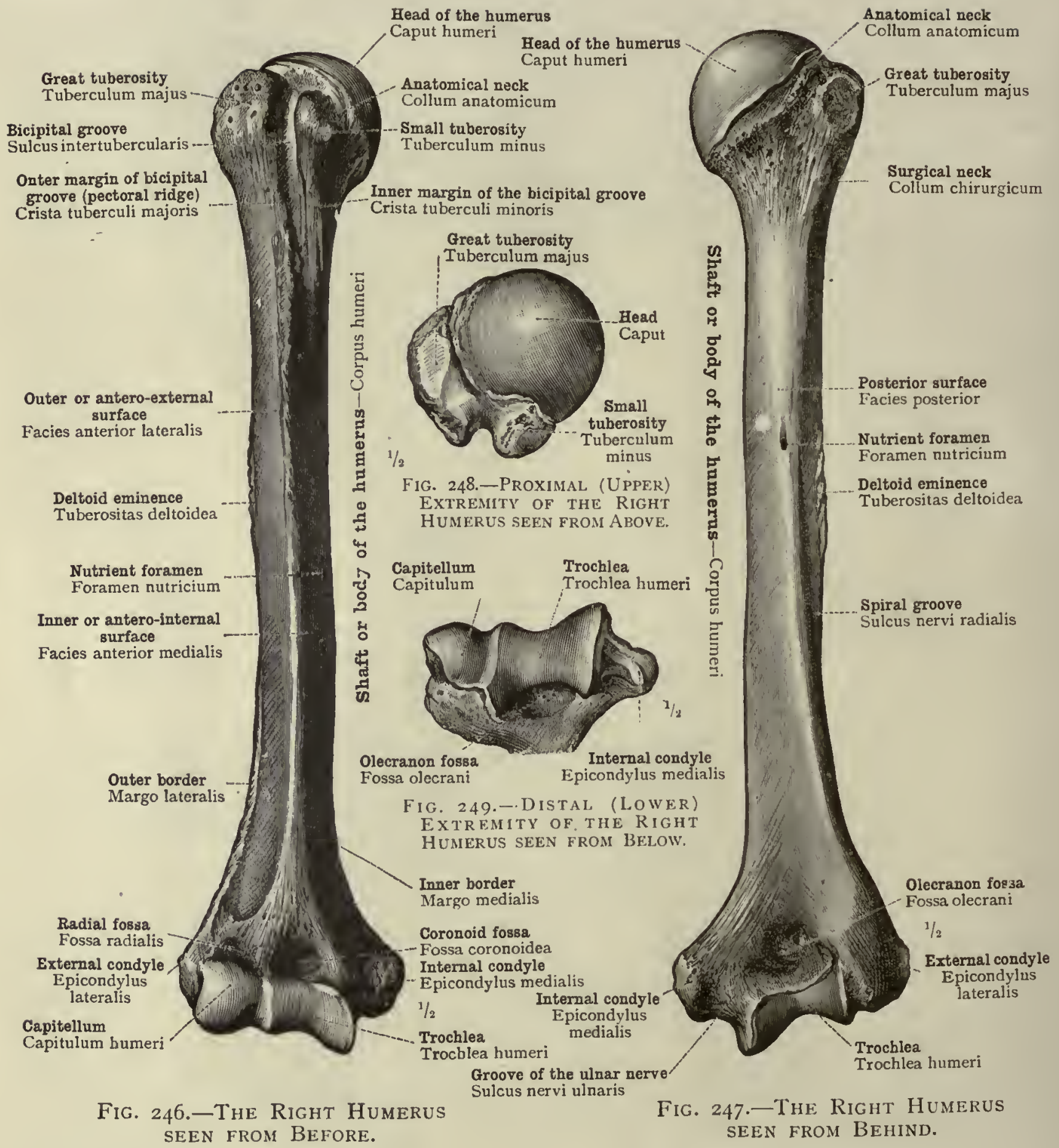

Humerus-The humerus. 
Centre of ossification in the head of the humerus
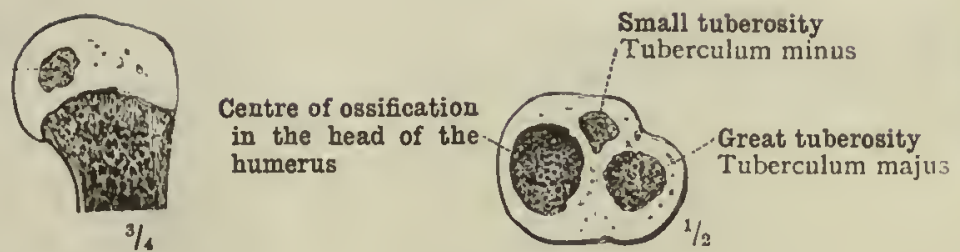

FIG. 252.-FrOM A BOY AGED THREE YeARS

(HORIZONTAJ, SECTION.)
Fig. 250.-From A GIRL AGED FOUR MONTHS.
Centre of ossification in the head of the humerus

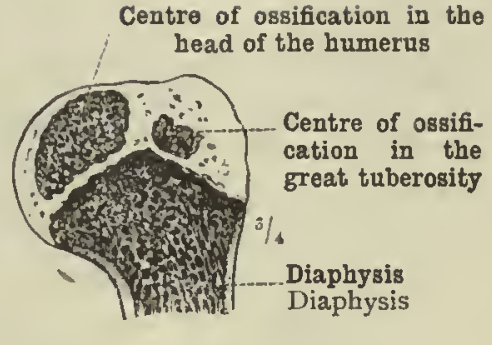

FIG. 25I.-From A BOY AGED Two YEARS.

Tile Centres of Ossification of the Proximal Extremity of tile Humerus.

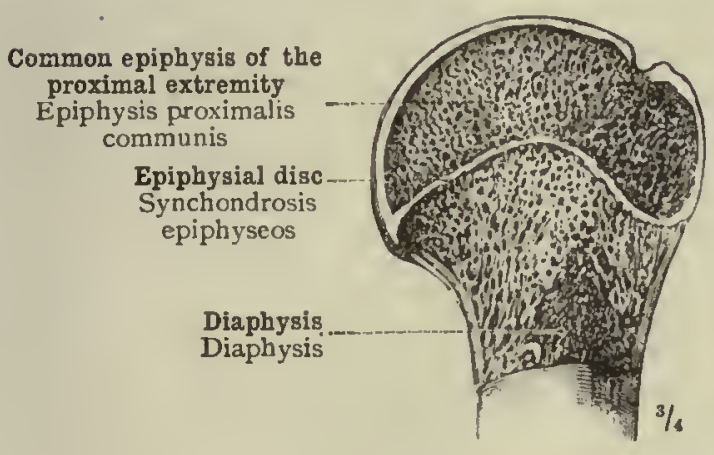

FIG. 253.-FROM A BOY AGED THIRTEEN YEARs.

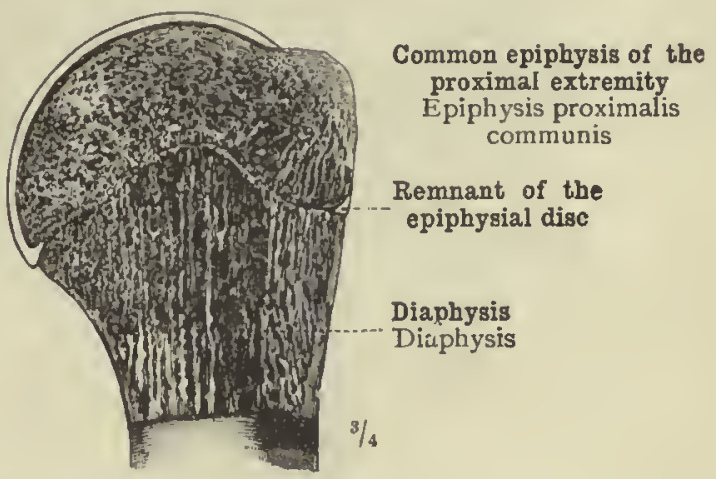

Fig. 254.-FroM a GirL AGED Nineteen Years.

The Common Epiphysis of the Proximal Extremity of the Humerus.

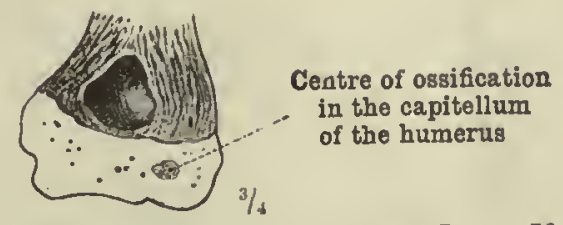

Fig. 255.-From a Boy aged Two and a Half Years.

Centre of ossification of the internal condyle

Centre of ossification of the trochlea

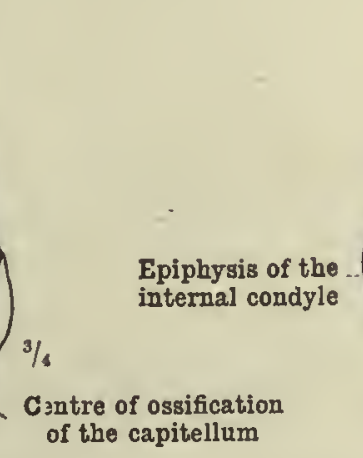

of the capitellum

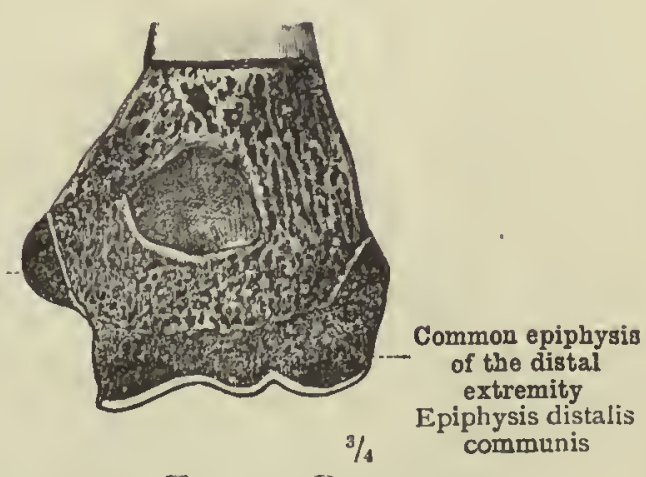

FIG. 257.-FrOM A BOY AGED Seventeen Years.

Fig. 256.-From a BoY AGED Thirteen Years.

OF THE HuMERUS. 


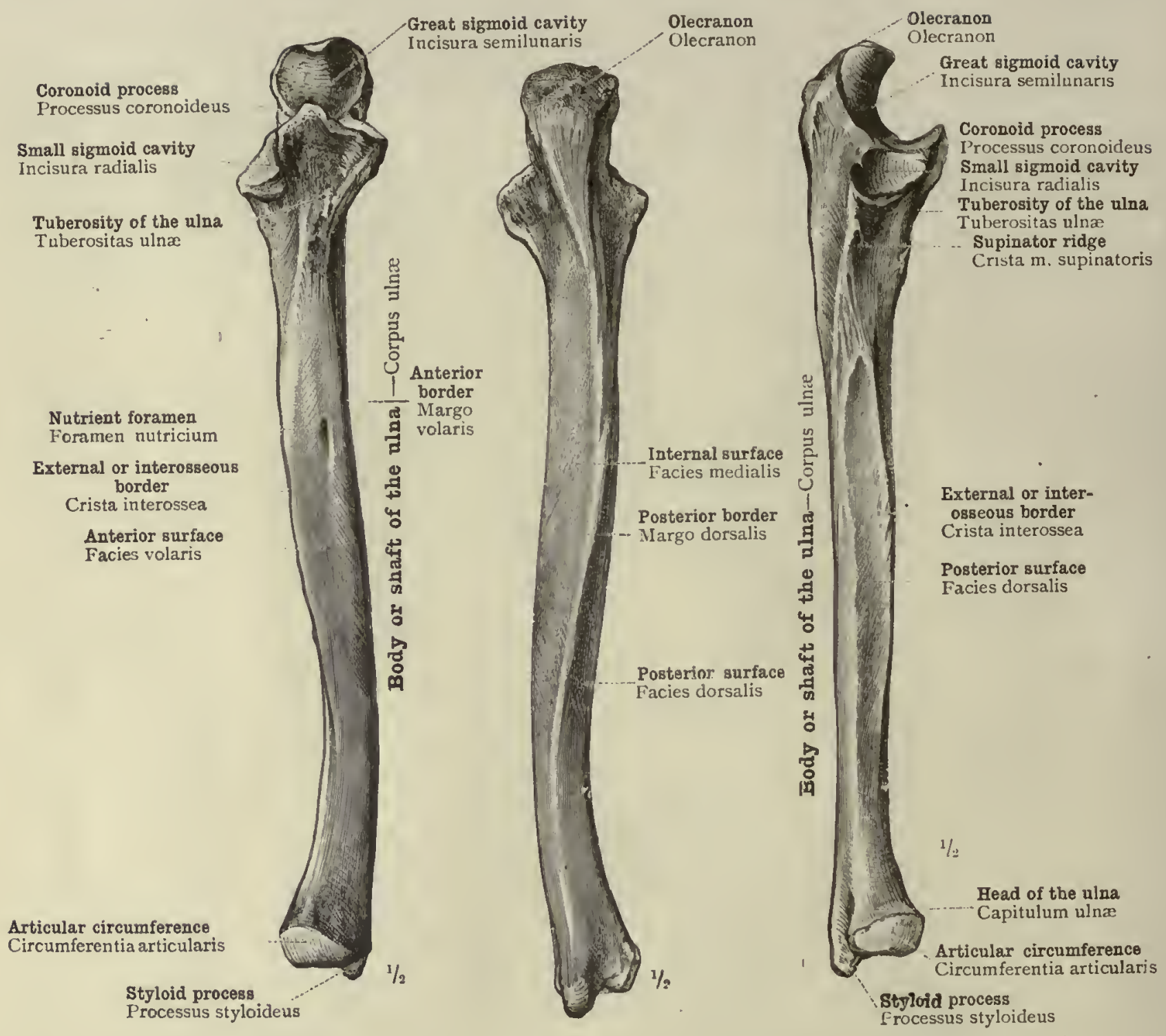

Fig. 258.-Anterior Aspect. Fig. 259.-Posterior Aspect.

Fig. 260.-External Aspect. The Ulna of the Right Side.

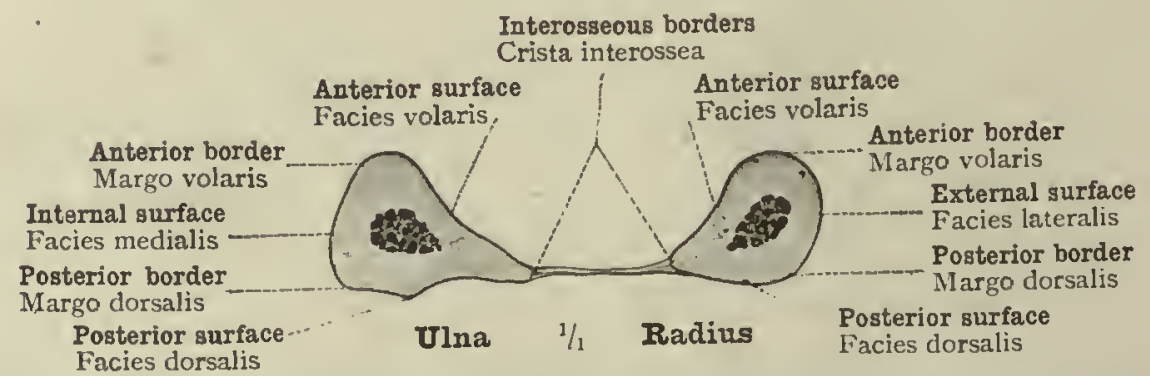

Fig. 261.-Transverse (Horizontal) Section throvgh the Middle of the Ulna and the RADIUS, With the INTERosseous Membrane, in Supination. 


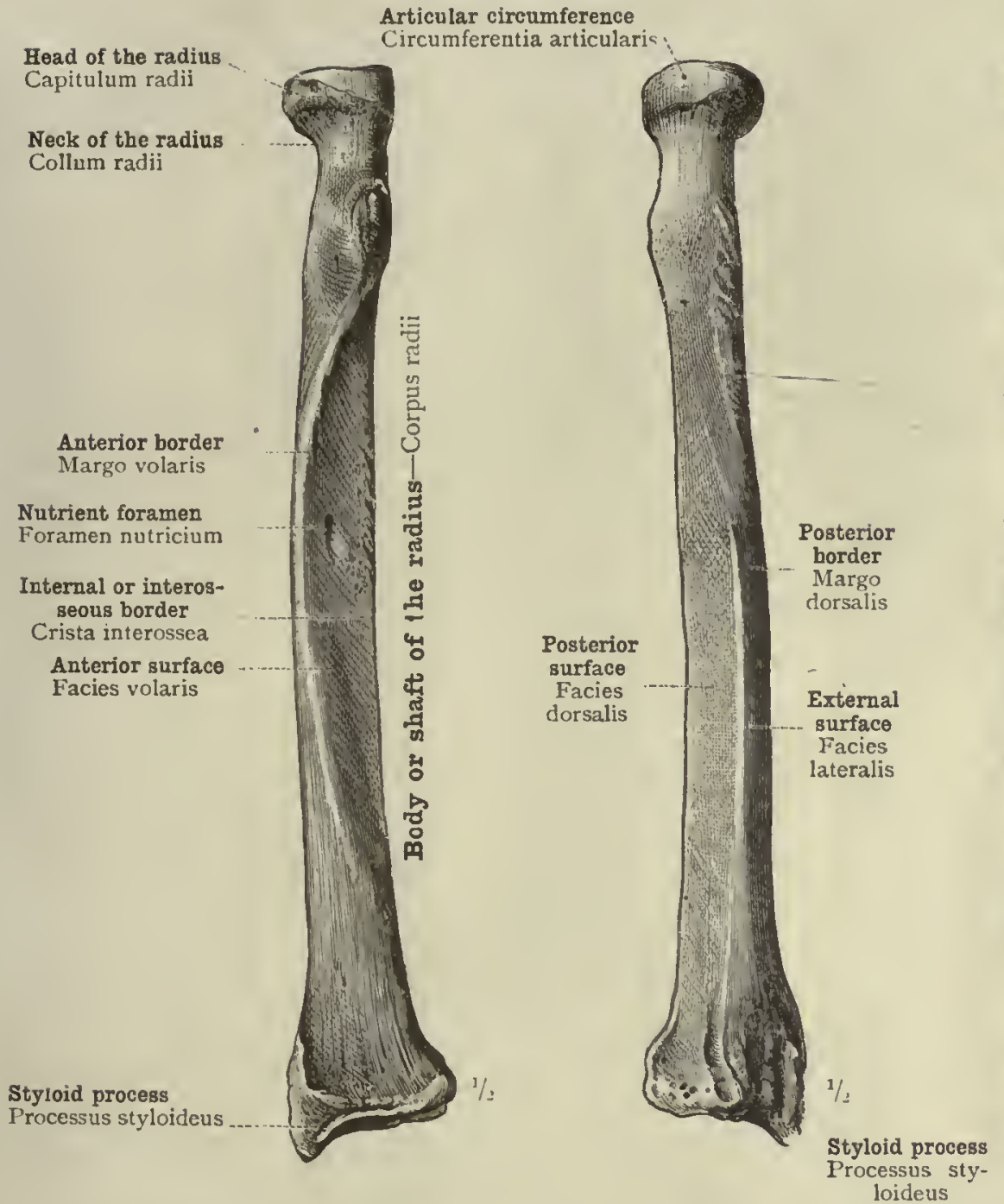

Fig. 262.-Anterior Aspect. Fig. 263.-Posterior Aspect.

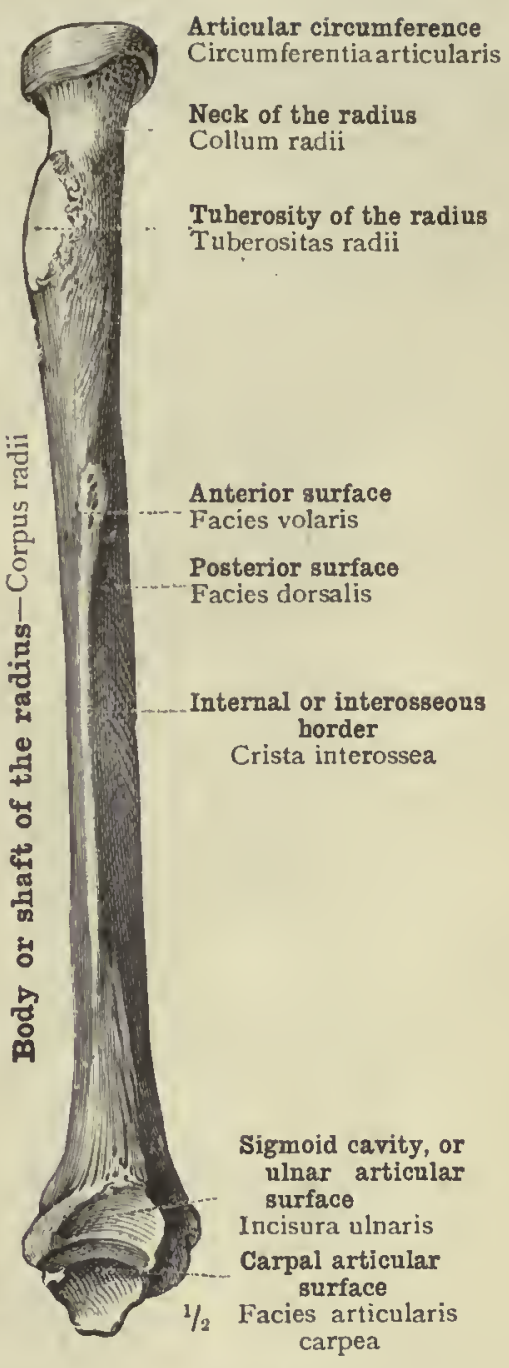

Fig. 264.-Internal Aspect. The Radius of the Right Side.

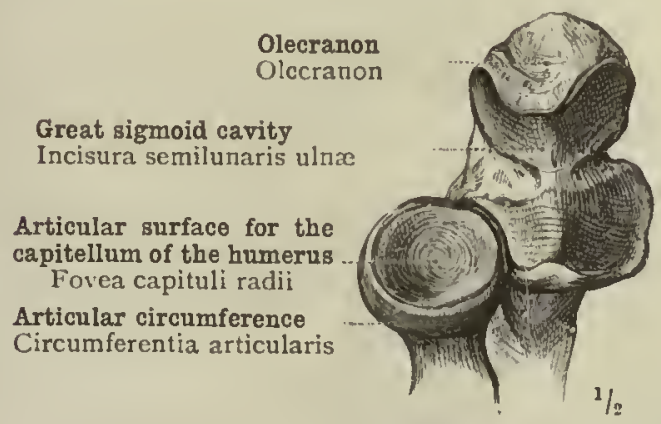

Fig. 265.-The Proximal Extremities of tile Bones of the Right ForeARM SEEN FROM ABOVE.

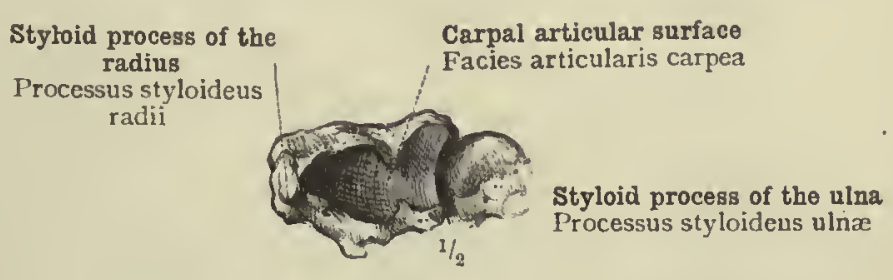

F1G. 266.-The Distal Extremities OF THE BONES OF THE Right Forearm SEEN FROM BELOW. 

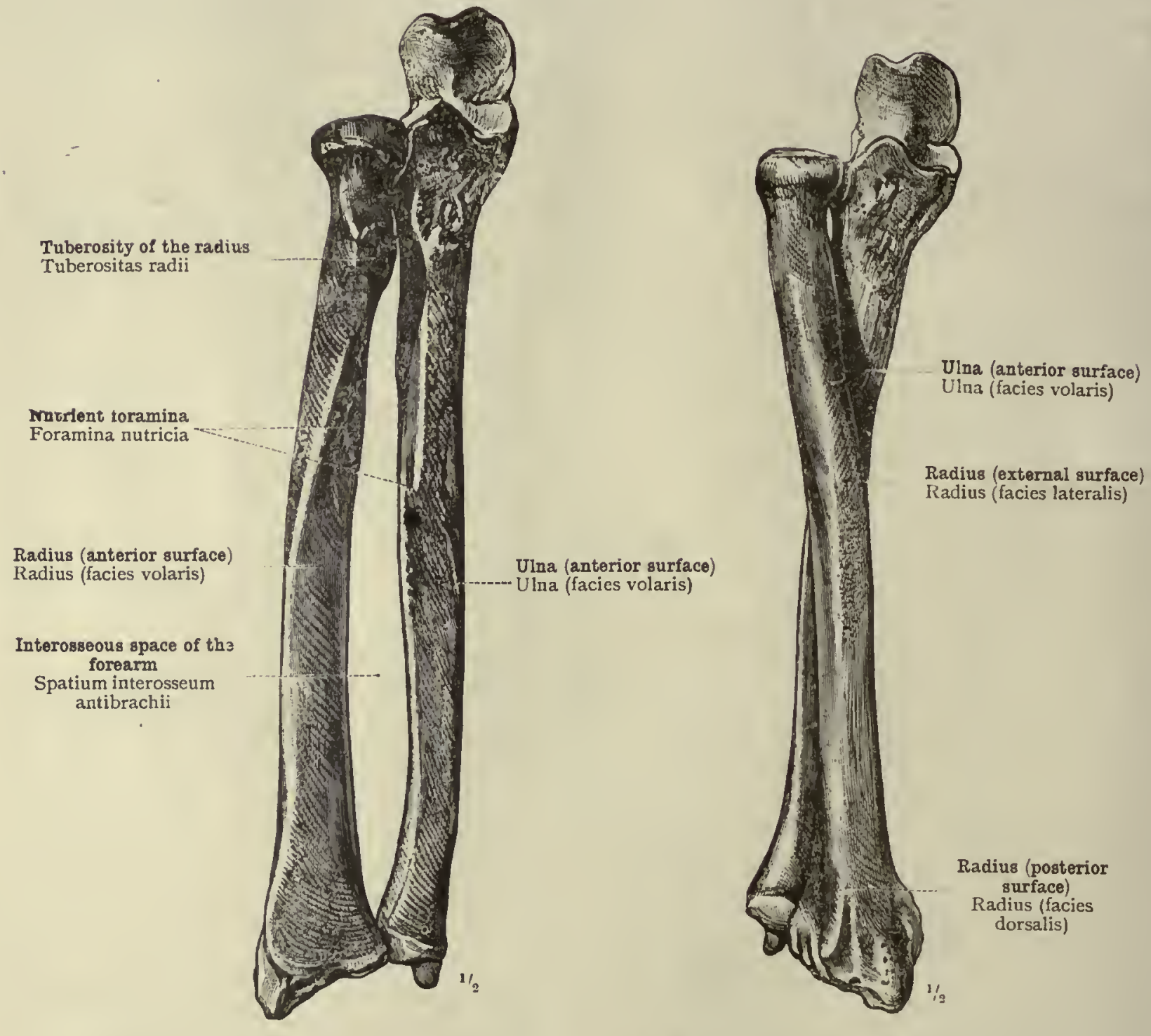

FIG. 267.-THE BONES OF THE Righs Forearm, in Supination.

Fig. 268.-TIIE BONES OF THE RIGHT Forearm, in Pronation. 


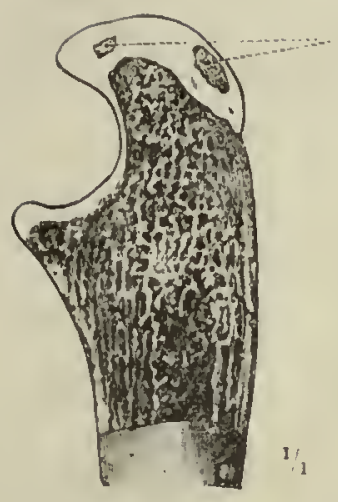

FIG. 269.-From a Boy AGED THIRTEEN Years.
Centres of ossification in the olecranon

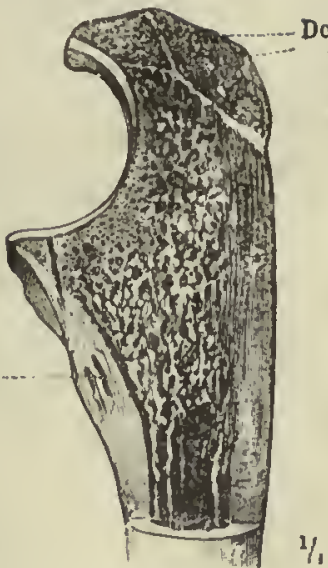

FIG. 270.-From A BoY AGED SEVENTEEN Years.

The Development of the Epiphysis of the Proximal Extremity of the Ulna.

Centry of ossification in the head of the ulna

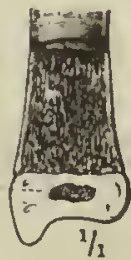

FIG. 27I.-FROM A GIRL AGED Six Years.
Tuberosity of the ulna Tuberositas ulnæ

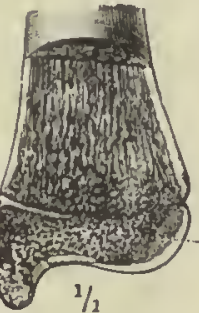

Epiphysis of the head of the ulna in the act of uniting witb the shaft

Fig. 272.-Frol a Young MaN AGED Nineteen Years.

The Development of the Epiphysis of the Distal Extremity of the Ulna.

Centre of ossification in the head of the radius

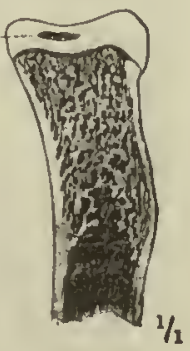

Fig. 273.-From a BoY aged Five Years. The Development of the Epiphysis of the Proximal Extremity of the Radius.

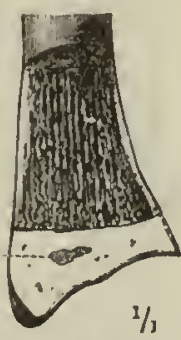

FIG. 275.-FROM A GIRL AGED TwO YEAR:.

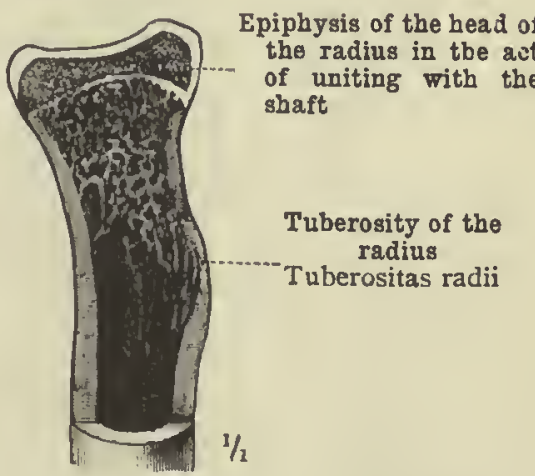

Fig. 274.-From a Boy aged Seventeen Years.

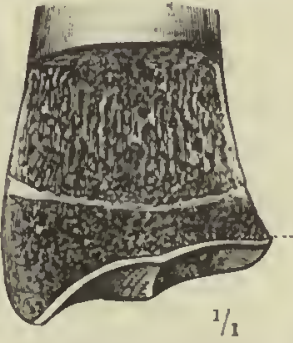

Distal epiphysis of the radins in the act of uniting with the shaft

FIG. 276.-From a YOUNG MAN AGED Nineteen Years.

The Development of the Epiphysis of the Distal Extremity of the Radius. 


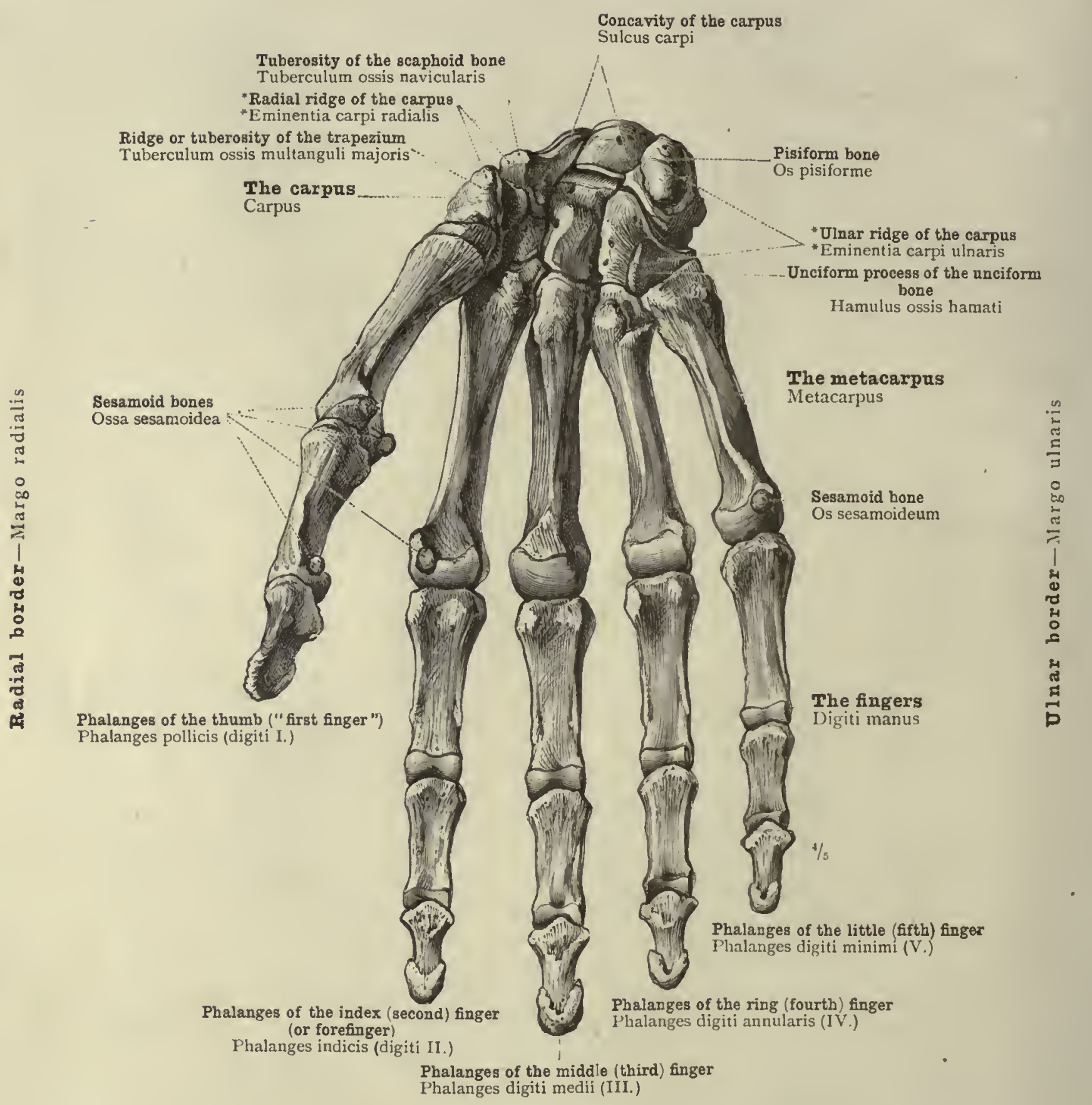

Fig. 277.-Palmar aspect of tije Skeleton of the Right Hand (Facies Volaris). 
Lunar (or semilunar) bone

Pyramidal or cuneiform bone Os triquetrum
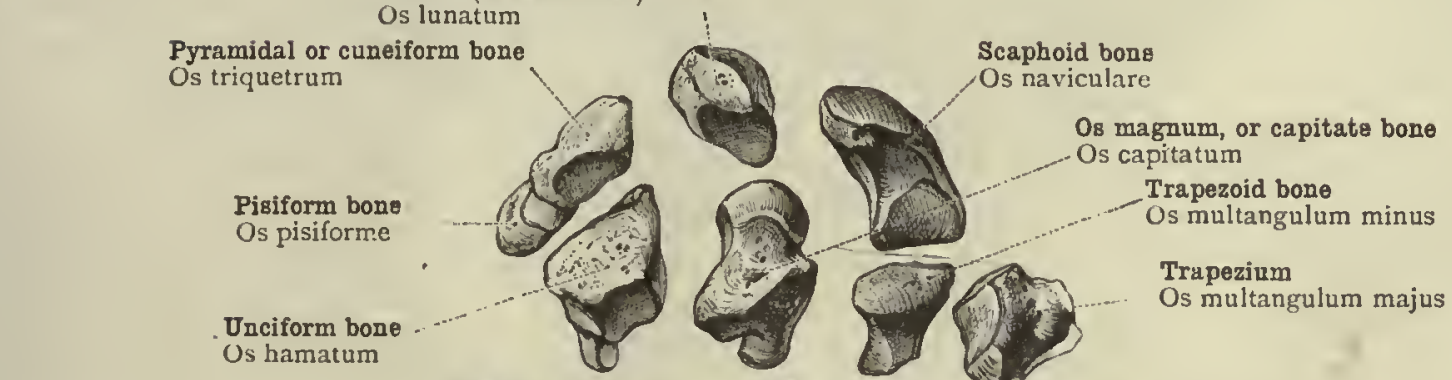

Metacarpal bones (second to fifth)

Ossa metacarpalia II. - V
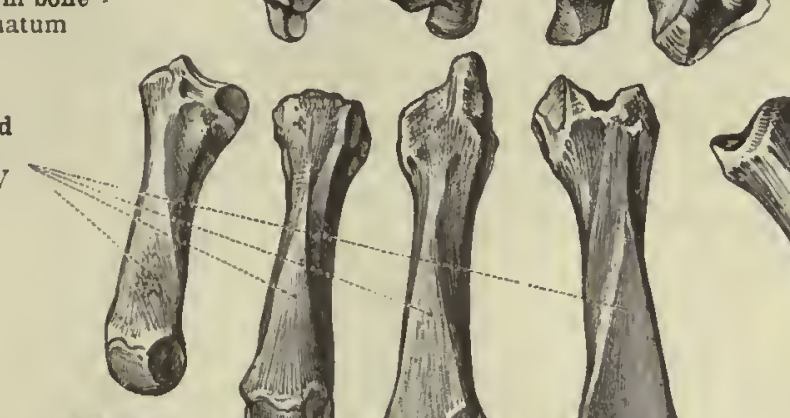

Os multangulum majus

Proximal or first phalanges of the fingers (second to fiftb)

Phalanx prima digitorum II. $-V$.$$
\text { II. }-V
$$

Medial or second pbalanges of the fingers (second to fifth)

Phalanx secunda digi. torum II.-V

$$
\text { to }
$$$$
\text { (n) }
$$
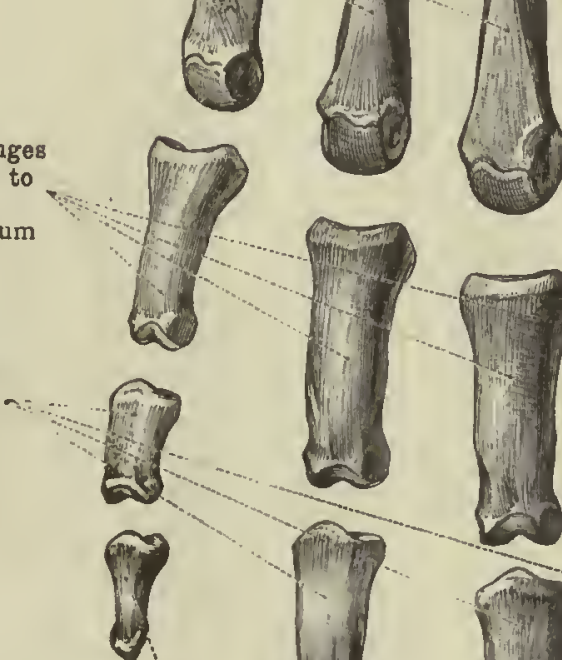
Ungual, terminal, or tbird phalanges of
the fingers (second to fifth)
Phalanx tertia digitorum II -V.

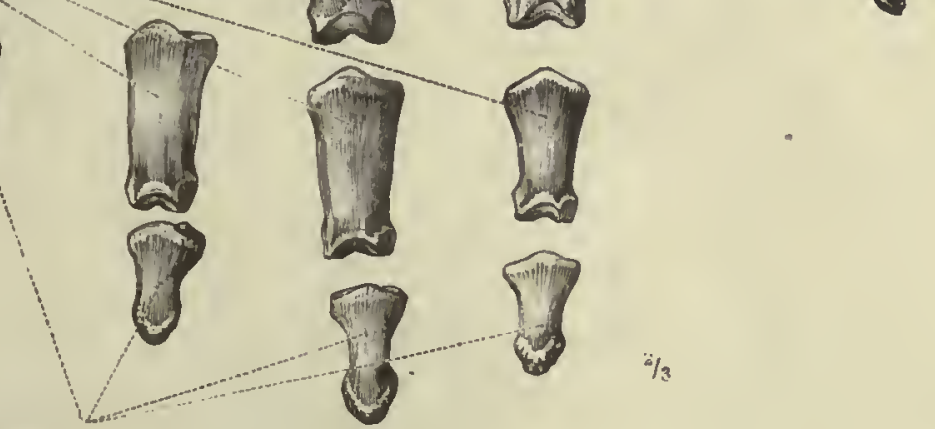

Distal or second phalanx of the thumb Phalanx secunda pollicis

\footnotetext{
Fig. 278.-Dorsal Aspect of the Bones of the Right Hand seyn from the Dorsal Side (Facies Dorsalis).
} 
Dorsal transverse ridge

Articular facet for the os magnum

Articular facet for the lunar bone
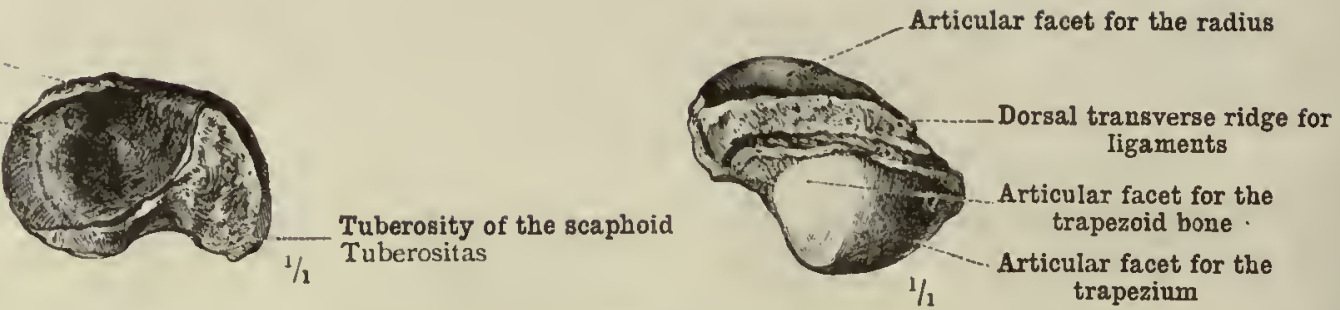

Fig. 279.-Distal Aspect.

Fig. 280.-Posterior Aspect.

Os Naviculare Manus-The Right Scapiloid Bone.

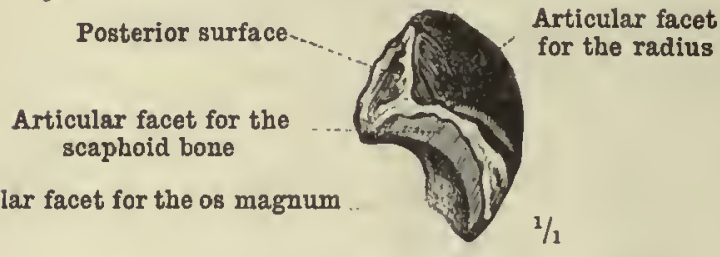

Fig. 28I.-Radial Aspect.

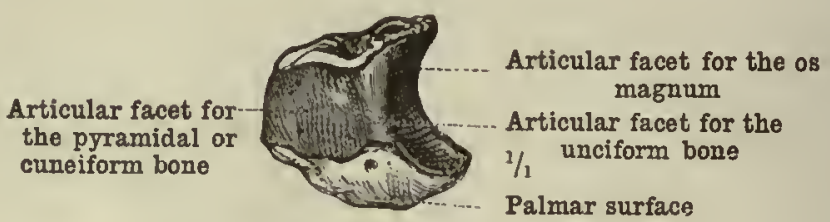

Fig. 282.-ULnAR AsPEct.

Os Lunatum-'The Right Lunar (or Semilunar) Bone.

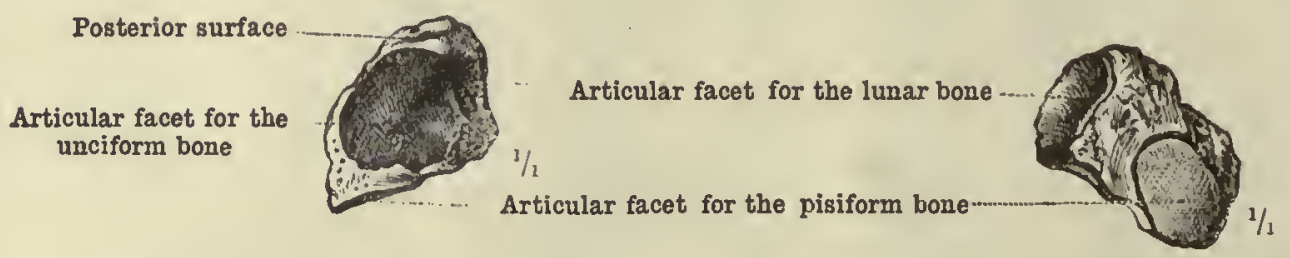

FIG. 283.-RADIAL AsPect.

Fig. 284. - Palmar Aspect.

Os Triguetrum-The Right Pyramidal or Cuneiform Bone.

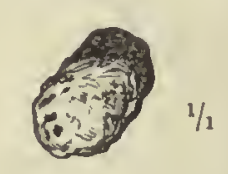

Fig. 285.-Palmar Aspect.

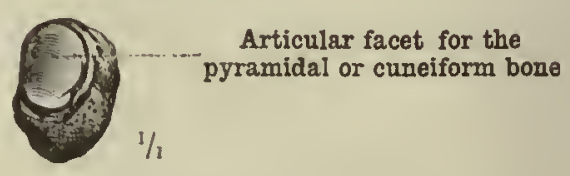

Fig. 286.-Posterior Aspect.

\section{Os Pisiforme-The Right Pisiform Bone.}

Lunar (or semilunar) bone

Os lunatum

Pyramidal or cuneiform bone Os triquetrum

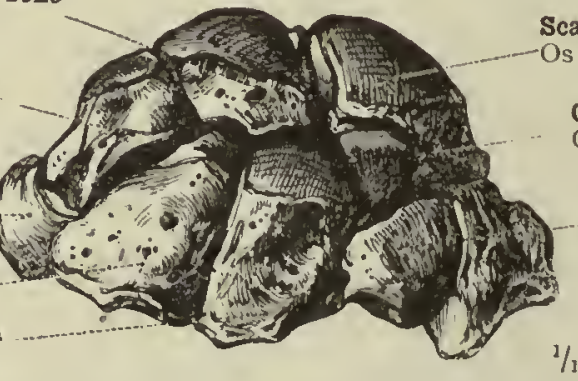

Scaphoid bone

Central boue of the carpus (var.)

Os centrale carpi (var.)

Trapezoid bone

Os multangulum minus

Trapezium

Os multangulum majus

Os magnum, or capitate bone Os capitatum

$1 / 3$

Fig. 287. The Posterior Aspect of the Right Carpus, containing an Os Centrale.

Ossa carpi-The bones of the carpus: first, superior, or proximal row. 


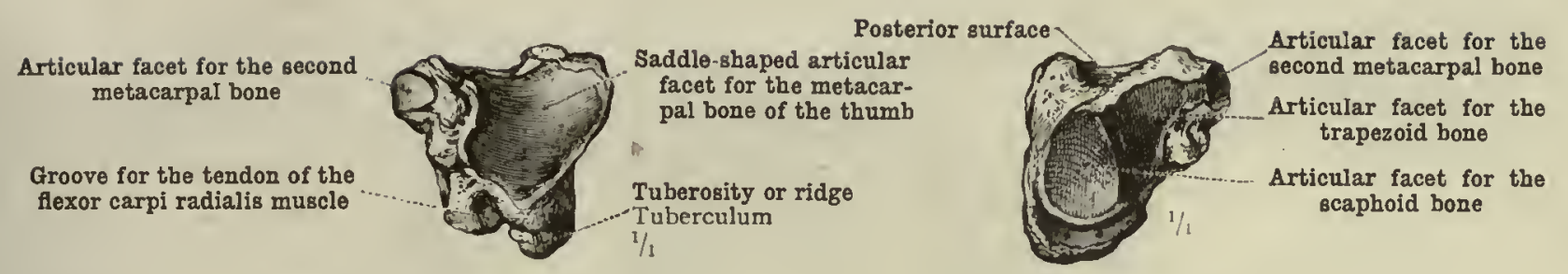

Fig. 288.-Distal Aspect.

Fig. 289.-Ulnar Aspect.

Os Multangulum Majus-The Right Trapezium.

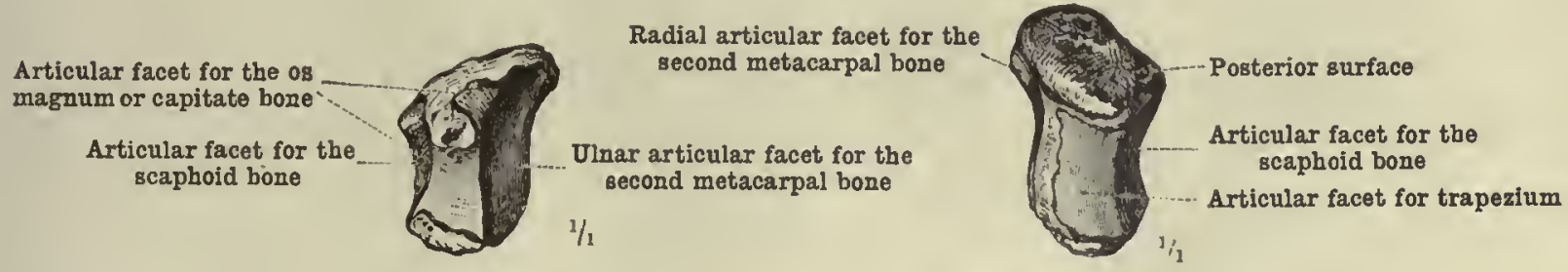

Fig. 290.-Ulanar Aspect.

Fig. 29I.-RAdial Ȧspect.

Os Multangulum Minus-The Right Trapezoid Bone.

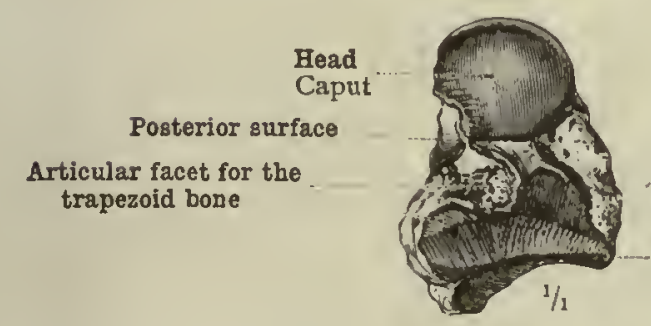

Fig. 292.-Radial Aspect.

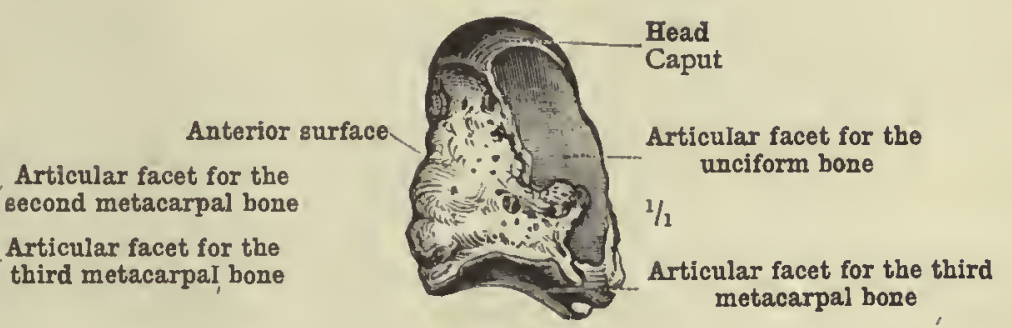

Fig. 293.-Ullnar Aspect.

Os Capitatum-The Right Os Magnum or Capitate Bone.

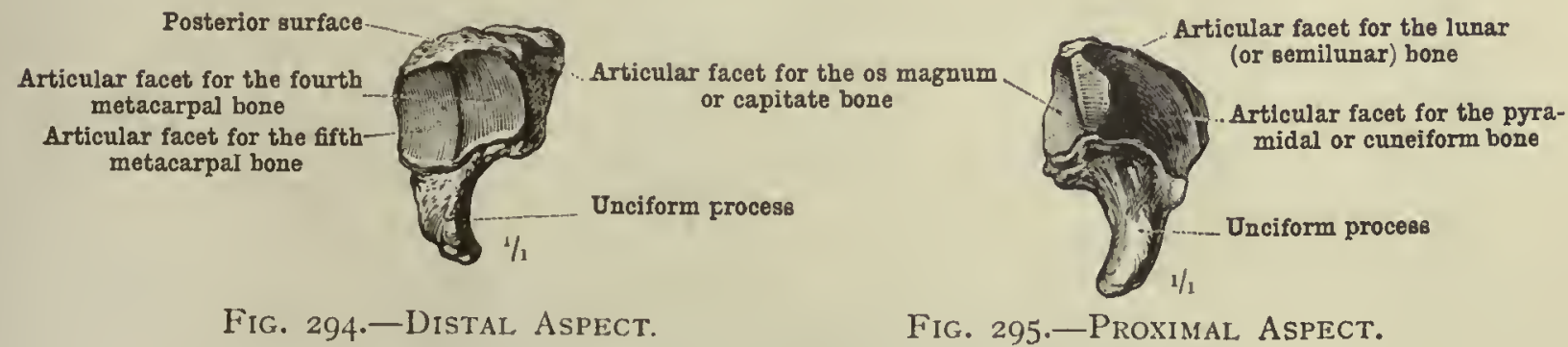

Os Hamatum - The Right Unciform Bone.

Ossa-carpi-The bones of the carpus: second, inferior, or distal row. 
Articular facets for ths third metacarpal bone
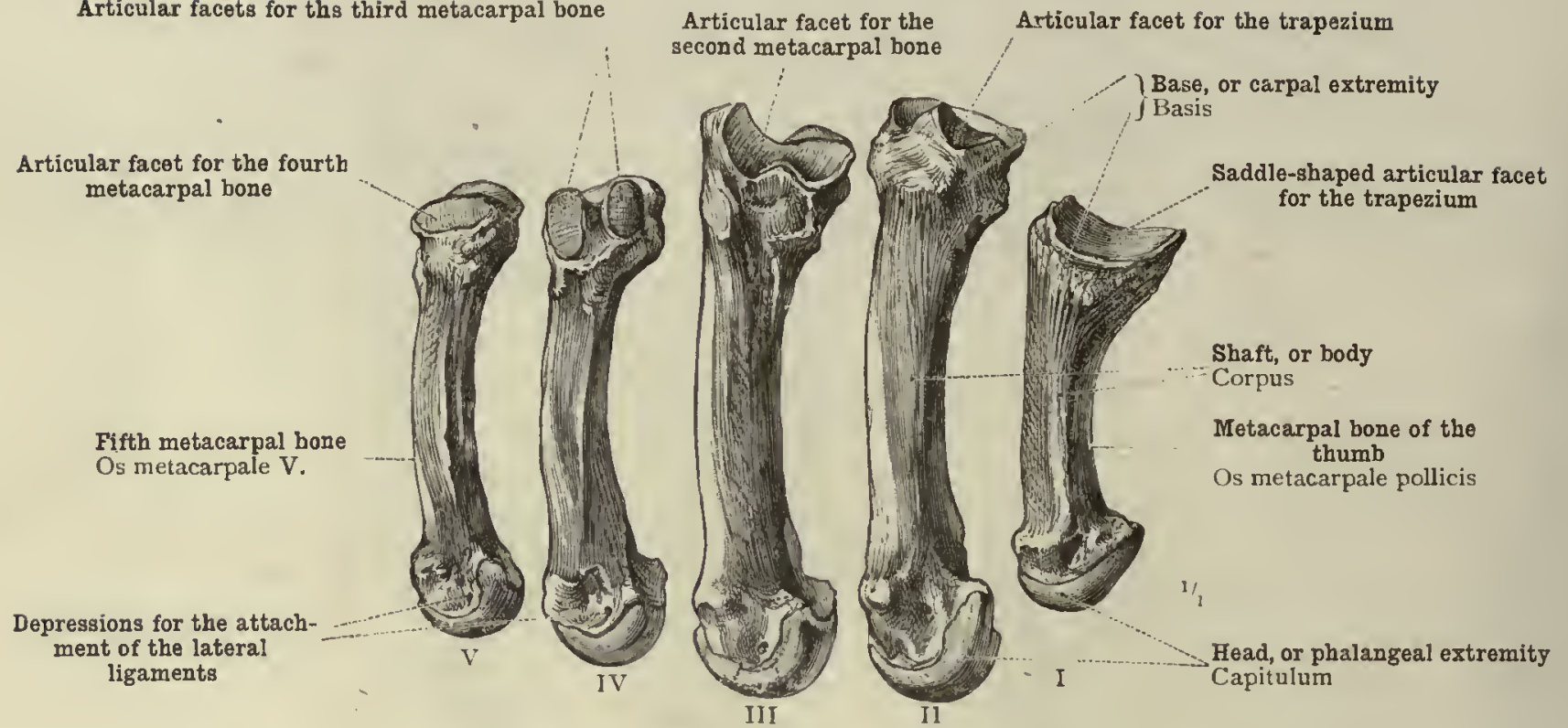

Fig. 296.-Radial Aspect of the Five Metacarpal Bones of the Right Hand.

Styloid process of the third metacarpal bone

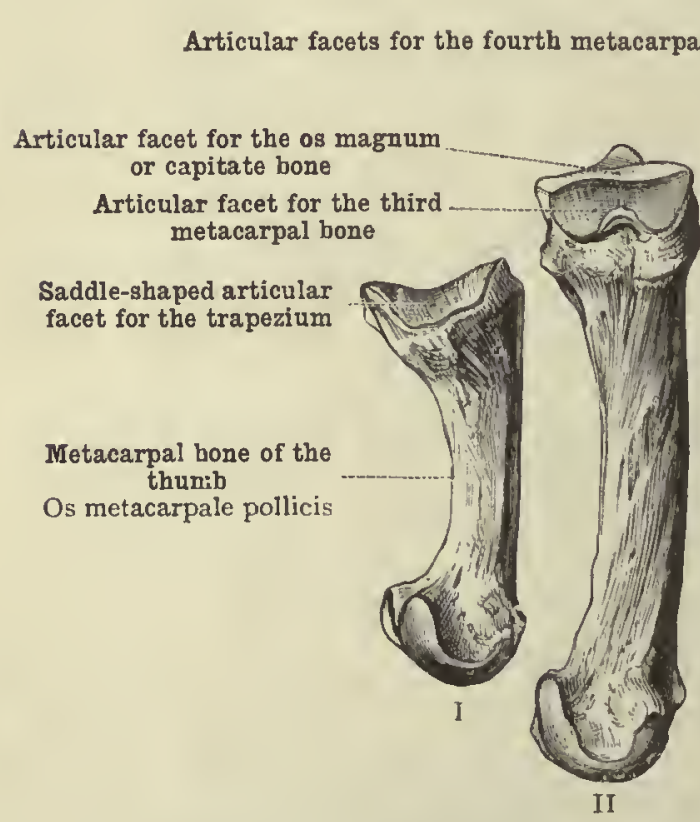

(a)

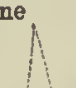
Processus styloideus

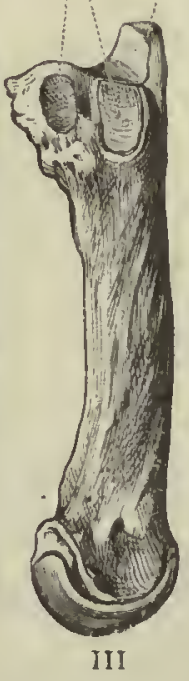

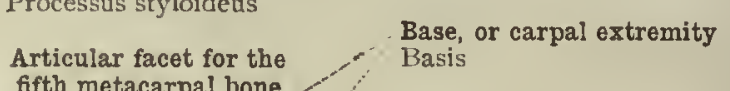

Articular facet for the fifth metacarpal bone

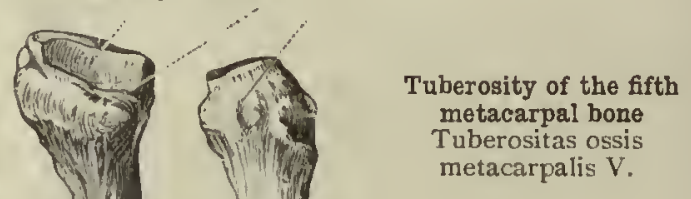

Shaft, or body

Corpus Depressions for the attach-
ment of the lateral ligaments

Head, or phalangeal extremity Capitulum

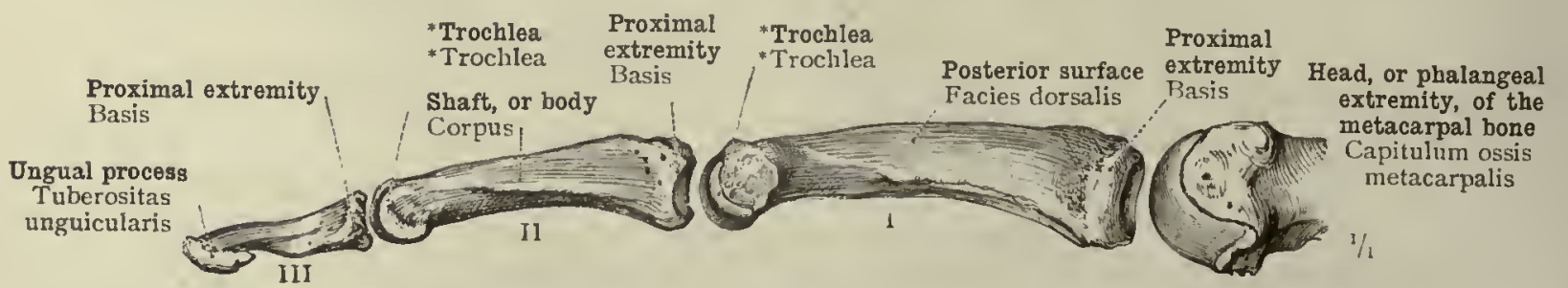

Fig. 298.-Radial Aspect of the Bones of tie Right Index Finger (Margo Radialis Digiti Secundi).

The Metacarpal Bones of the Hand and the Phalanges of the Fingers. 


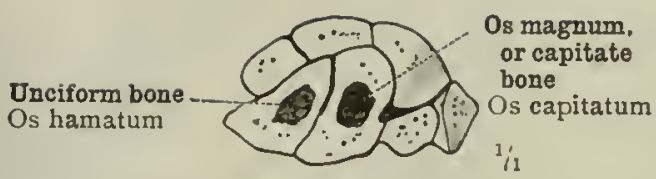

FIG. 299.-IN THE SECOND YEAR OF LIFE.

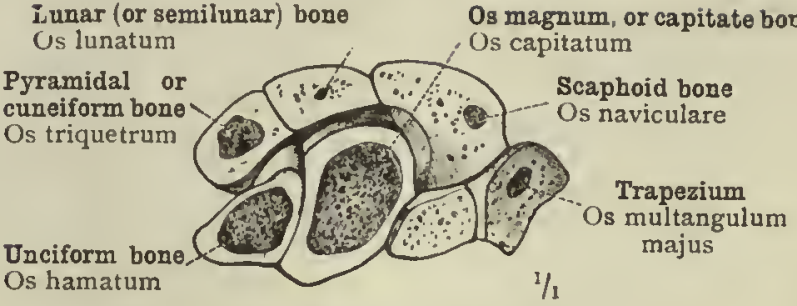

Fig. 300.-In the Seventh Year OF LIFE.

Centres of Ossification of thf Carpus (Sections paraliel to the Posterior Surface).

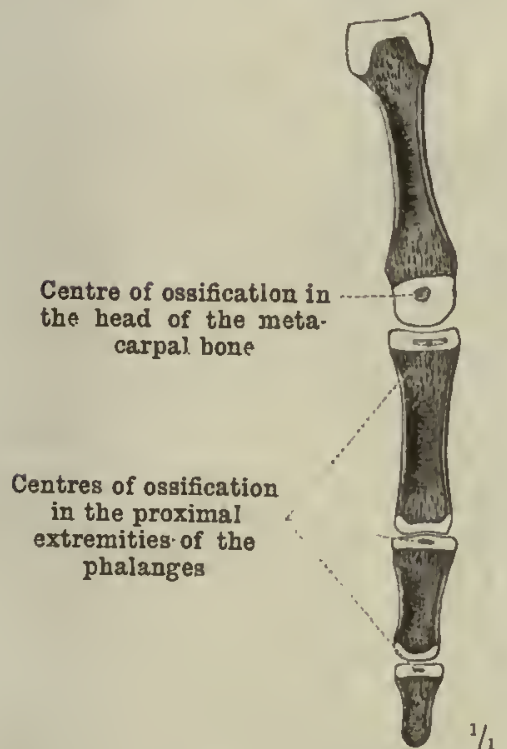

FIG. 301.-MIDdLE. FingER IN THE SECOND YEAR OF LIFE.

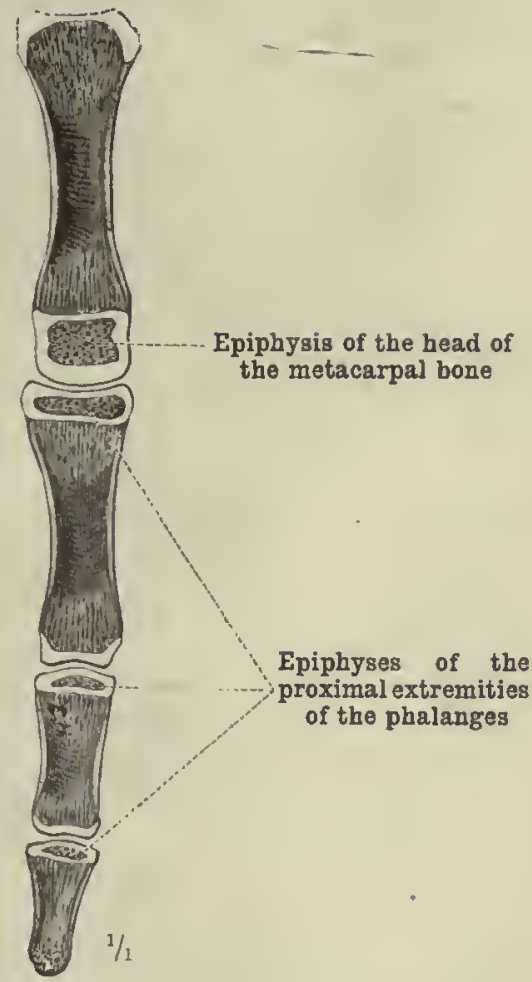

FIG. 302.-MIDDLE Finger IN THE SeVEnTH Year of Life.

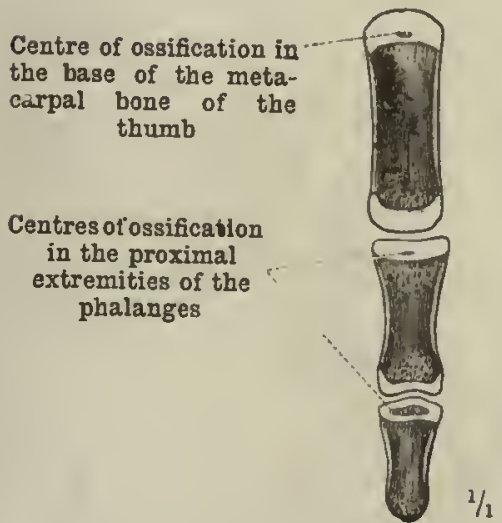

FIG. 304.-Bones OF THE THUMB IN THE FourTh YEAR OF LIFF.

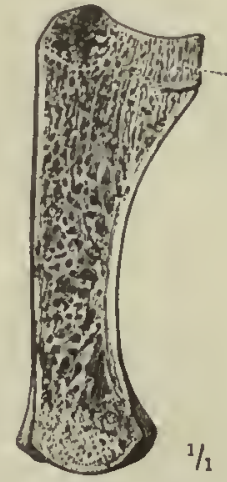

Fig, 305,-MetacarPal BONE OF THE THUMB IN THE EIGHTEENTH YFAR OF LIFE.

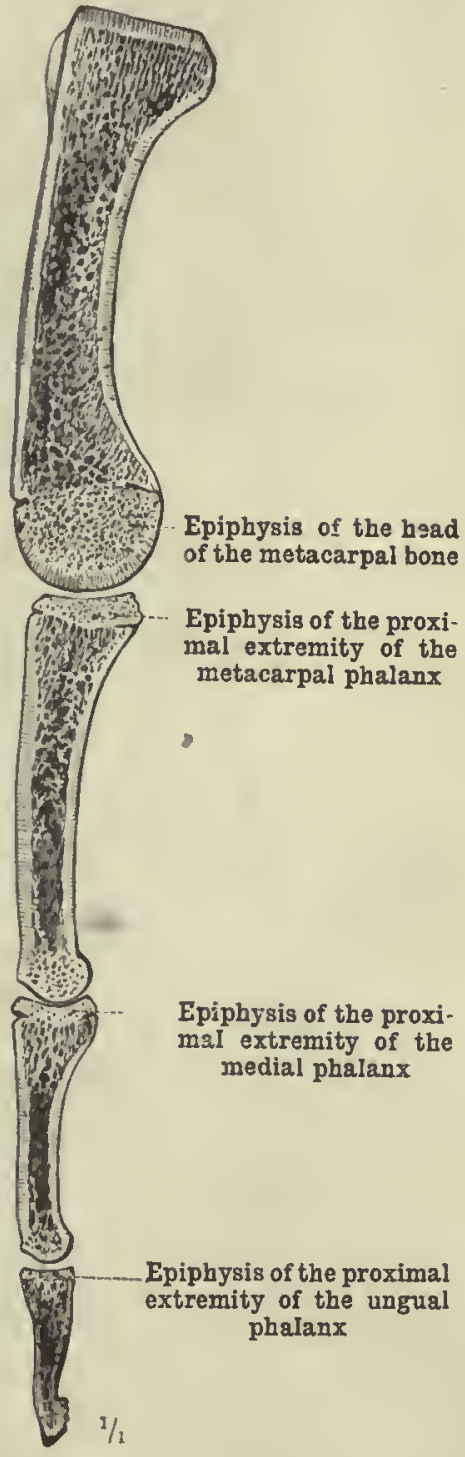

FIG. 303--Epiphyses of THE Bones OF THE MidDle Finger IN THE ACT OF UNITING IVITH THE SHaFTS: Seventeenth Year of Life.

Development of the Bones of the Hand. 


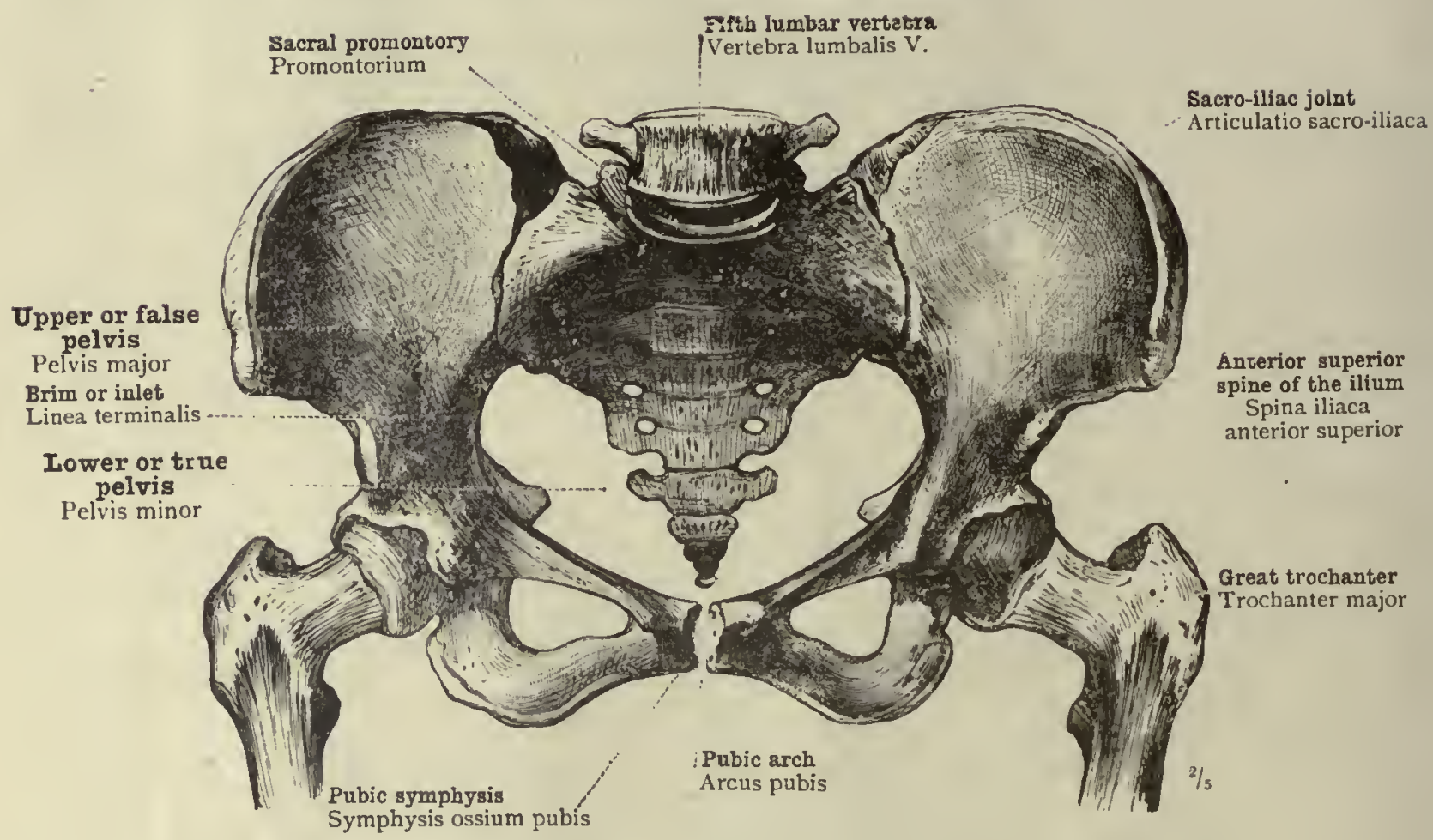

Fig. 306.-Pelvis Muliebris-The Female Pelvis. Anterior Aspect.

The formation of the pelvis out of the sacrum and coccyx and the two innominate bones. The iliac portions of the innominate bones with the base of the sacrum constitute the upper or false pelvis; the pubic and ischiatic portions of the innominate bones with the sacrum and the coccyx constitute the lower or true pelvis; the boundary between the false and the true pelvis corresponds with the upper aperture or entrance of the true pelvis, the line separating the two being known as the brim or inlet of the true pelvis. Regarded as the means of attachment of the lower limb to the trunk, the pelvis is the cingulum extremitatis inferioris, or pelvic girdle. 


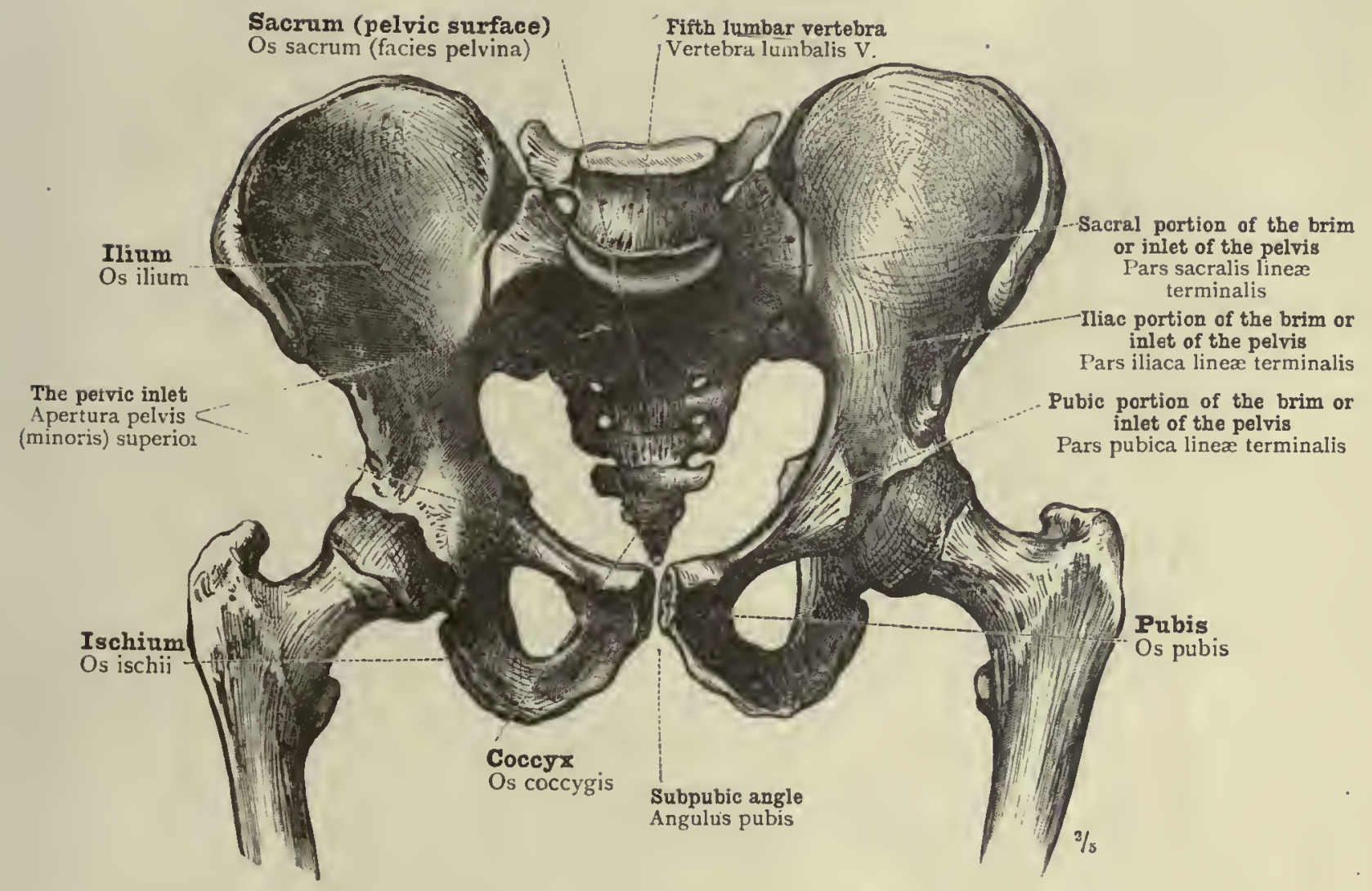

Fig. 307.-Pelvis Virilis-The Male Pelvis. Anterior Aspect.

The upper or false and the lower or true pelvis, pelvis major and pelvis minor. The brim of the true pelvis is divided into a sacral, an iliac, and a pubic portion.

Cingulum extremitatis inferioris-Pelvic girdle. 


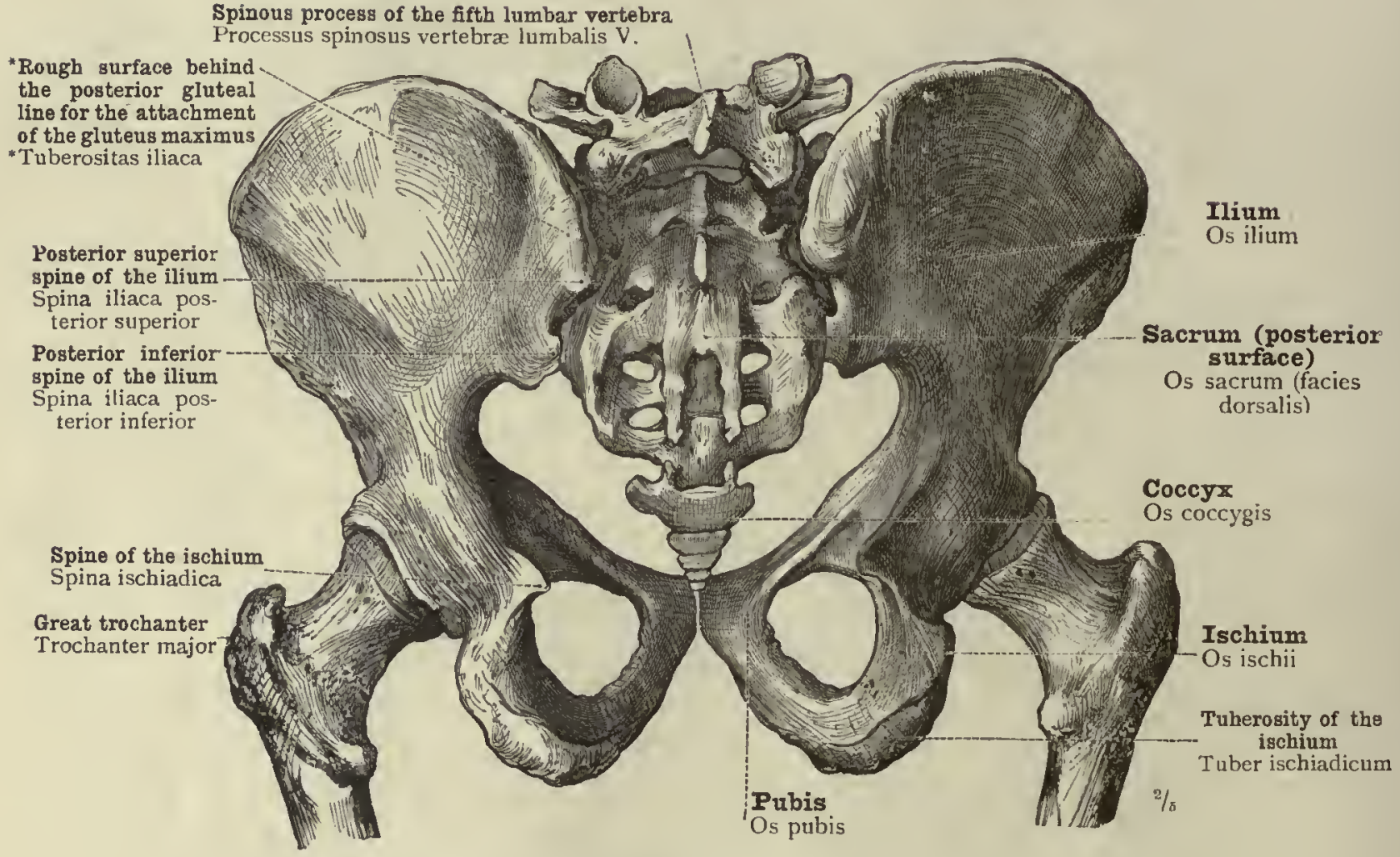

\section{Fig. 308.-Pelvis Virilis-The Male Pelvis. Posterior Aspect.}

The pelvic outlct, apcrtura pelvis (minoris) inferior, in the bony pelvis appears to be bounded on either side by the lower borders of the pubis and the ischium and the greater and lesser sciatic notches, incisura ischiadice major ct minor, and behind by the projecting part of the sacrum and by the coccyx. But inasmuch as on either side there are two strong ligaments arising from the sacrum and coccyx, the great and the small sacrosciatic ligaments, ligamenta sacrotuberosum et sacrospinosurn, which stretch across the two sciatic notches, and thus enlarge the posterior and lateral walls of the true pelvis, by this mcans the sciatic notches are filled in, and the outlet of the pelvis is notably diminished in size. 


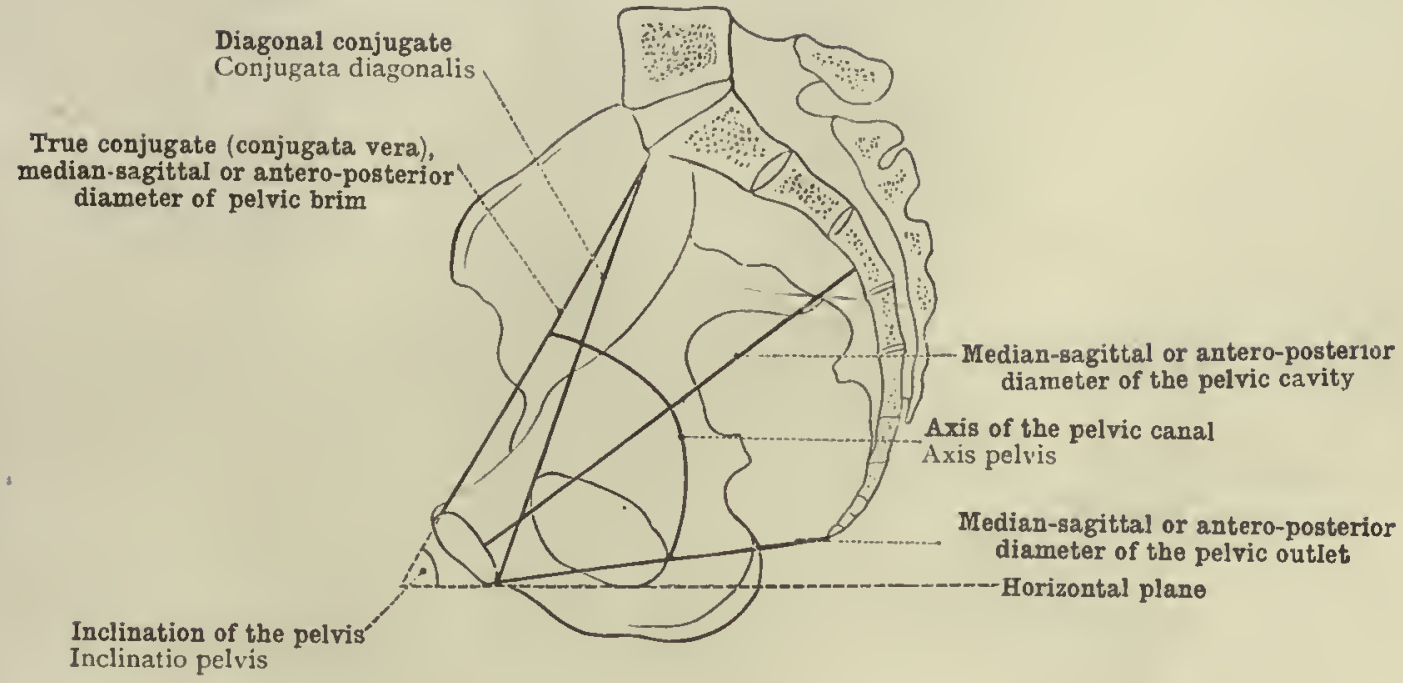

Fig. 309.-The Median-Sagittal or Antero-Posterior vianeters of the True Pelvis.

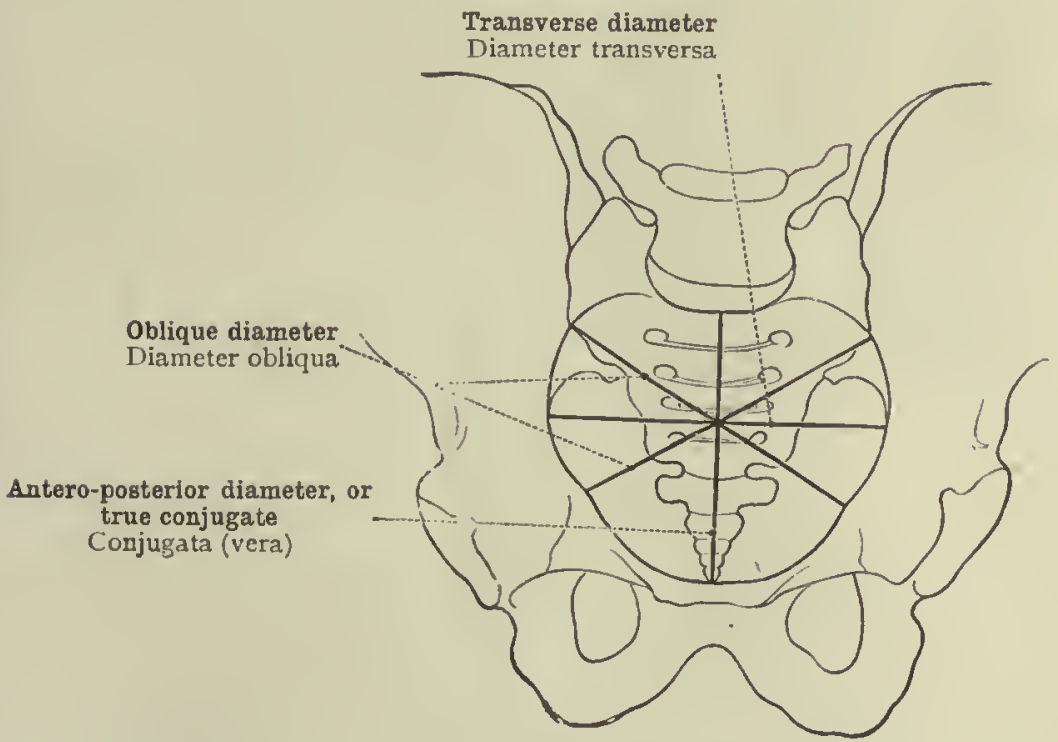

Fig. 310.-Tile Diameters of the Pelvic inlet (Apertura Pelvis Superior).

The Principal Diameters of the True Pelvis. 


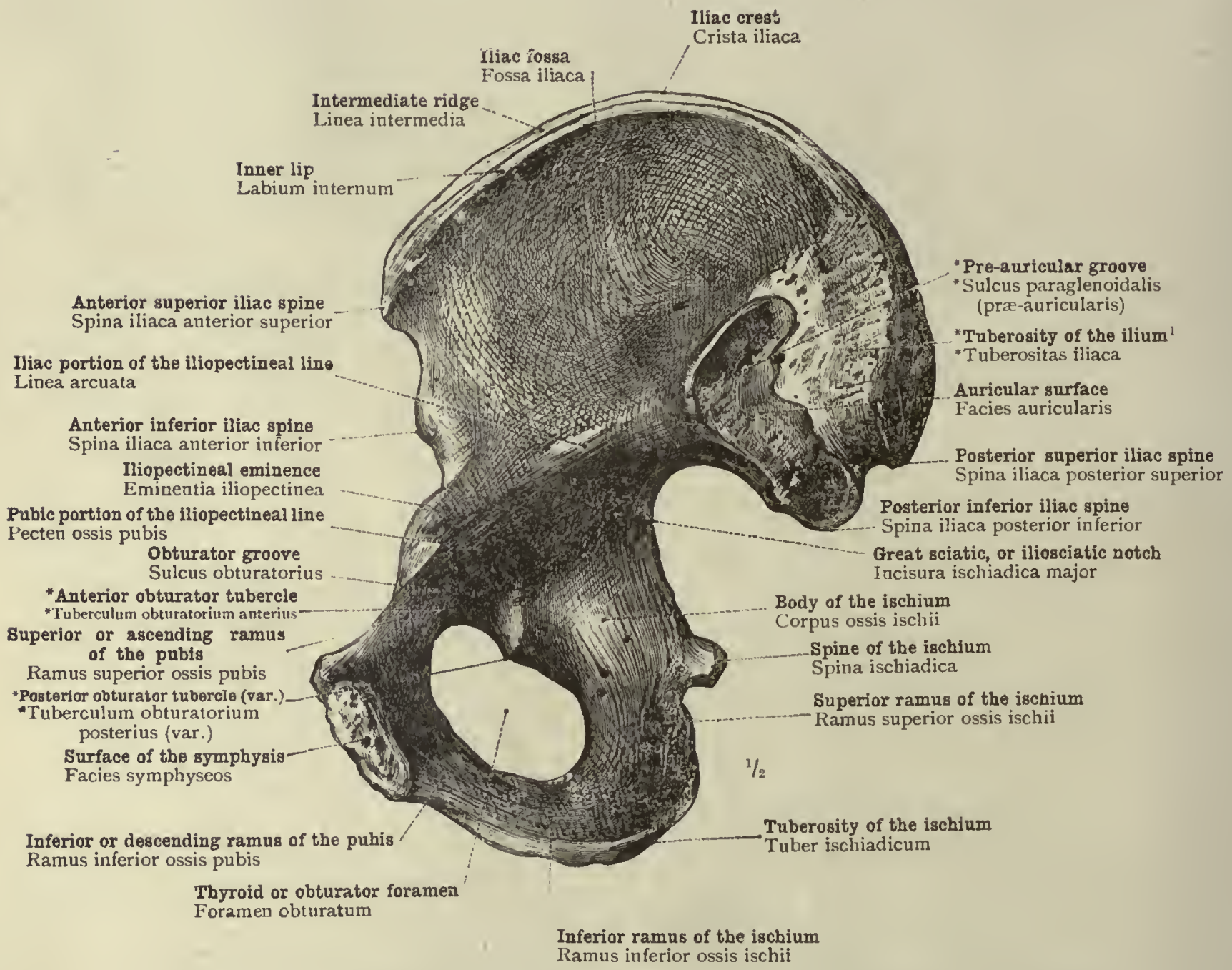

1 This term, which is seldom used by English anatomists, denotes the posterior fifth of the crest of the ilium and the rough surface of bonc immediately below the crest on either side.-Tr.

\section{Fig. 3il.-The Right Hip-Bone. InNer Aspect.}

The ilium forms the upper part of the os innominatum. The slightly concave inner surface of the upper and anterior part of the ilium, known as the iliac fossa, is directed towards the observer; behind the fossa is the auricular surface for articulation with the sacrum; and behind the auricular surface is the internal rough surface of the *tuberosity of the ilium. The ipper border of the ilium is the iliac crest, the anterior extremity of which forms the anterior superior itiac spine, the posterior extremity, the posterior superior iliac spine. From the anterior border of the ilium projects the anterior inferior iliac spine, from the posterior border, the posterior interior iliac spine. The superior or ascending and the inferior or descending ramus of the pubis and the superior and inferior ramus of the ischium, surrounding the obturator foramen, are all seen from the internal or pelvic aspect. The surface of the pubic symphysis, by means of which the two pubic bones articulate, forms the internal limiting surface of the os pubis. 


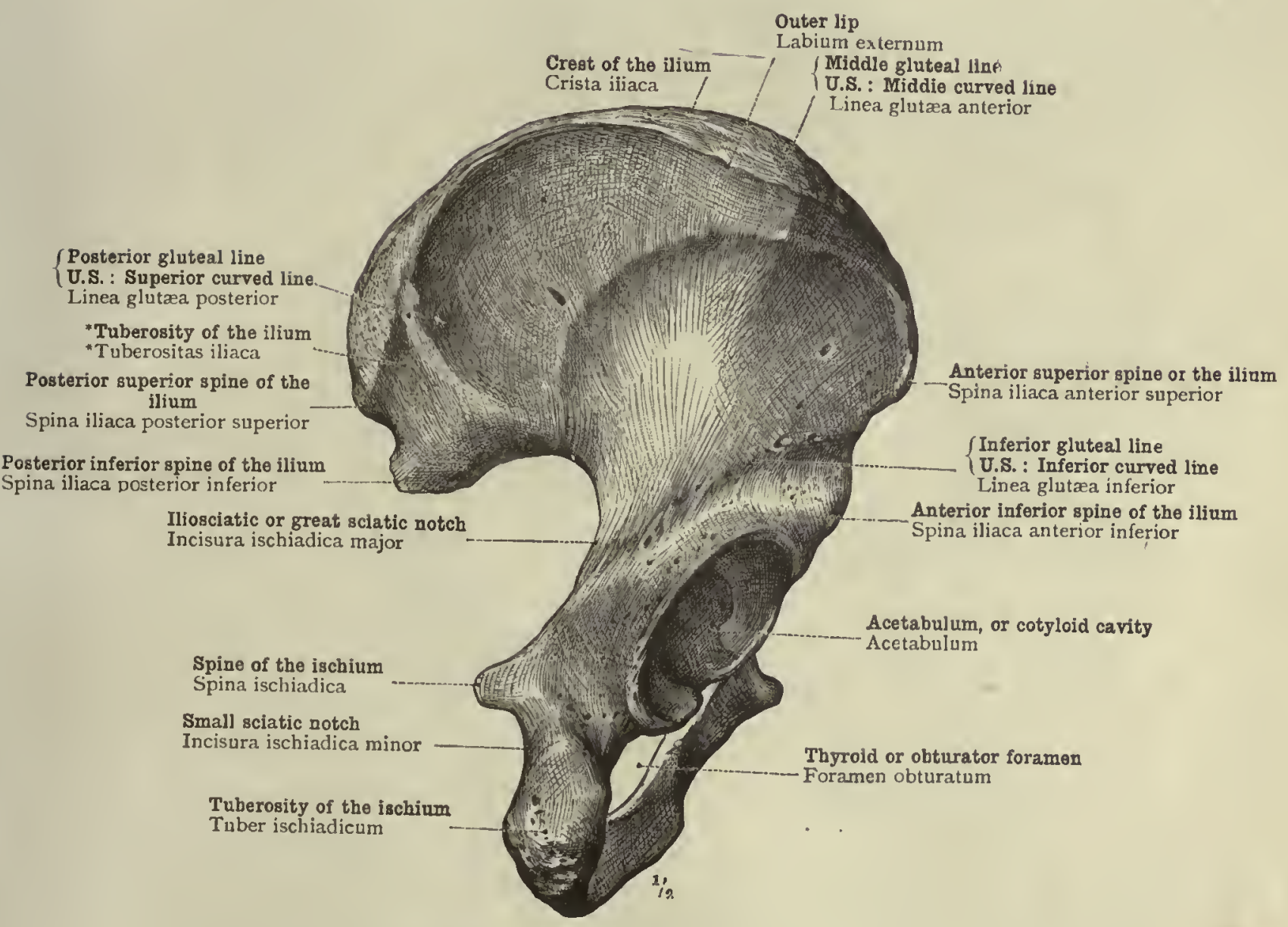

Fig. 3I2.-The Right Hip-Bone, Outer Side. Posterior Aspect.

The outer surface of the ilium is seen, divided by the three gluteal lines into areas from which the three gluteal muscles respectively arise. The spine of the ischium projects backwards from the posterior border of the hip-bone; above this spine is the iliosciatic or great sciatic notch, below it is the small
sciatic notch. The lowest portion of the bon tne iscnium. The acetabulum is viewed obliquely from behind. 


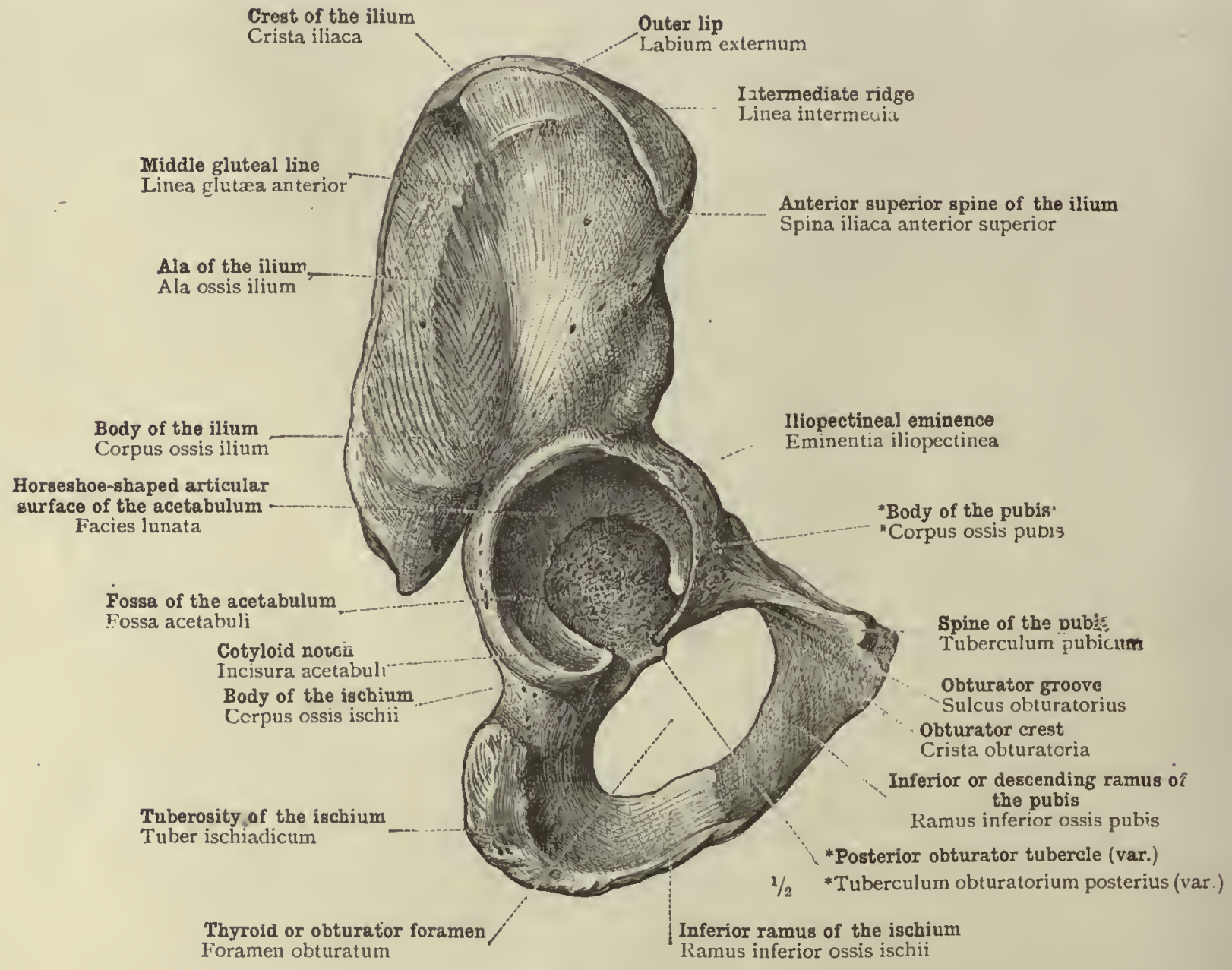

iBody of the pubis: The use of this term by English anatomists is a variable one. Macalister, whose terminology here, as usual, is in conformity with that of Continental anatomists, writes: "The pubis consists of a body which forms a little less than one-fifth of the acetabulum .. " Ouain, on the other hand. writes: "The flat portion between the rami [of the pubis] is the body"; and Young, in his "Synopsis of Human Anatomy" (U.S.), follows Quain's usage. The Continental application of the term has, however, the advantage in the point of consistency, the body being then, in the case of each of the three elements of the hip-bone, the thickened portion taking part in the formation of the acetabulum, of which the body of the tubis constitutes about one-fifth, the body of the ilimm nearly two-fiftlis, and the body of the ischium the lemainder. $-T_{R}$.

\section{Fig. 3i3.-The Right Hip-Bone, Outer Side. Seen from thì Righr.}

For this illustration the hip-bone has been so placed that a direct view of the interior of the acetabulum is obtained; this consists of two portions, the rough, nearly circular fossa of the acetabulum, and the horse-shoe shaped articular surface (facies lunata-covered in the recent state with cartilage); opposite the fossa of the acetabulum, the rim bounding the depression is interrupted by the cotyloid notch (incisura acetabuli). The three bones which, separate at first, subsequently unite to form the hip.bone, all take part in the formation of the acetabulum (see note' above). 


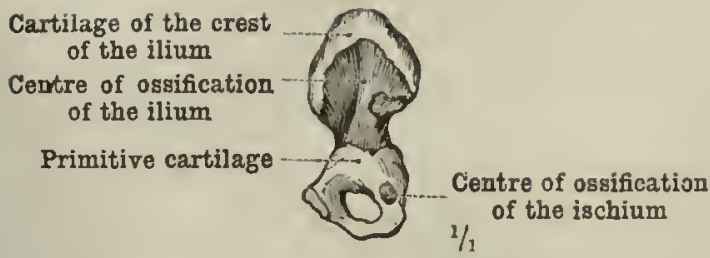

Fig. 3I4.--IN The Fifth MONTh OF F(ETAL

Life (Months of Four Weeks Each).

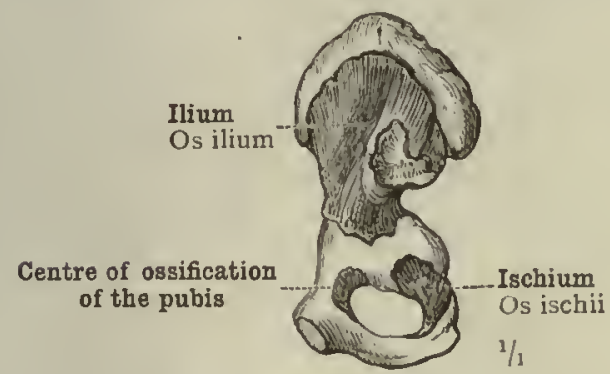

Fig. 315.-In the Sixth Month of Fotal Life (Months of Four WeEks Each).

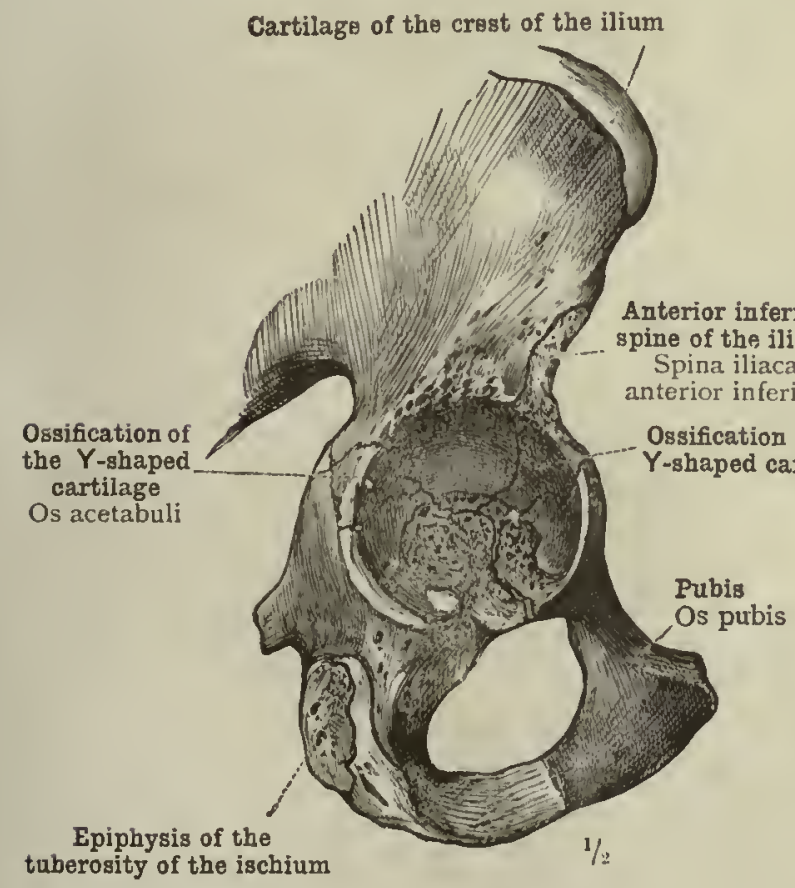

Iig. 3i7.-In the Fourteenth Year of Life.

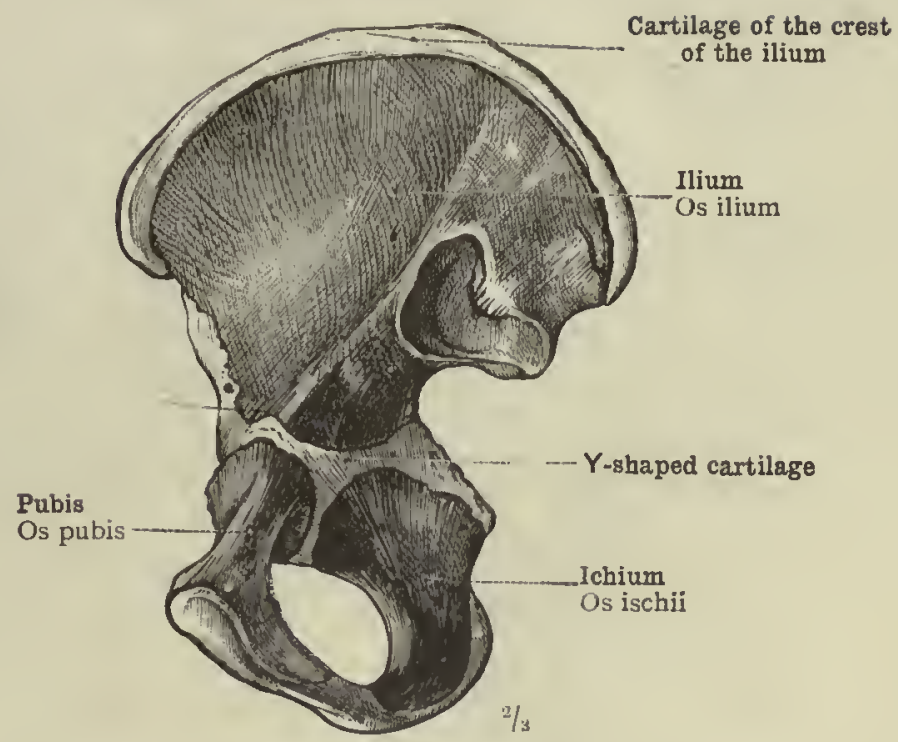

Fig. 316.-In the Fourth Year of Life.

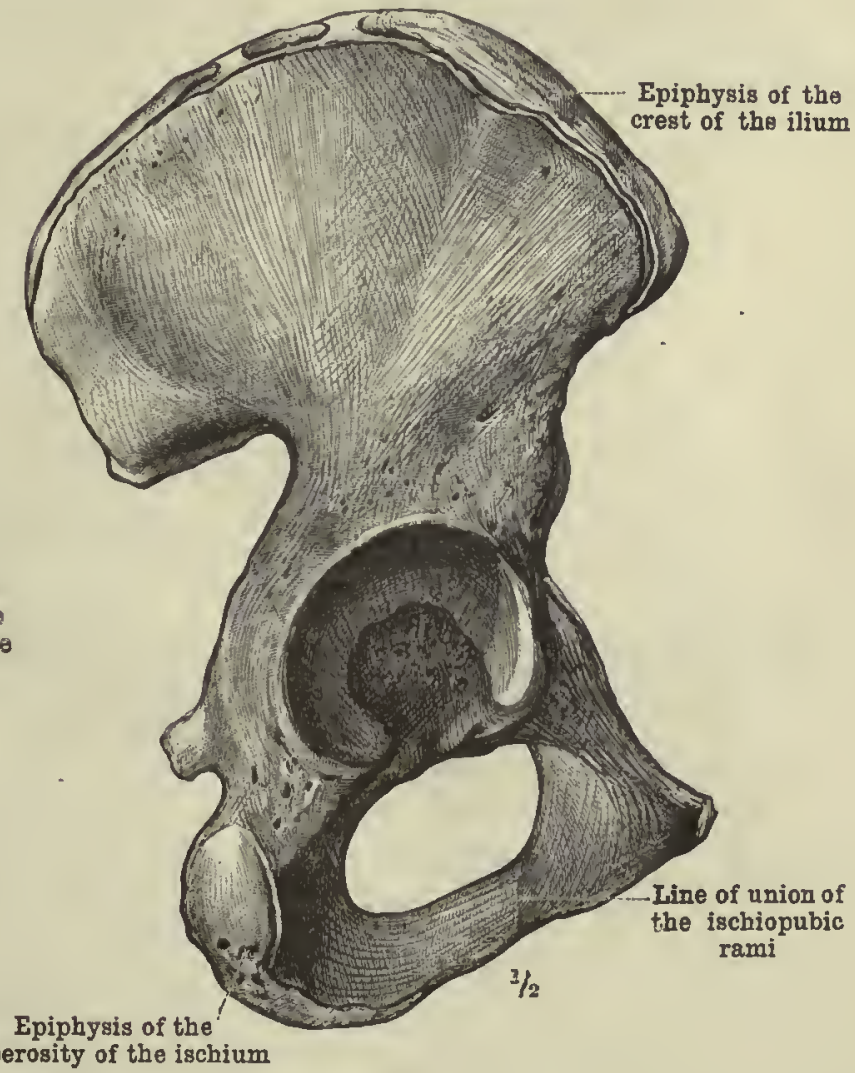

Fig. 3i8.-In the Seventeenth Year of Life. 


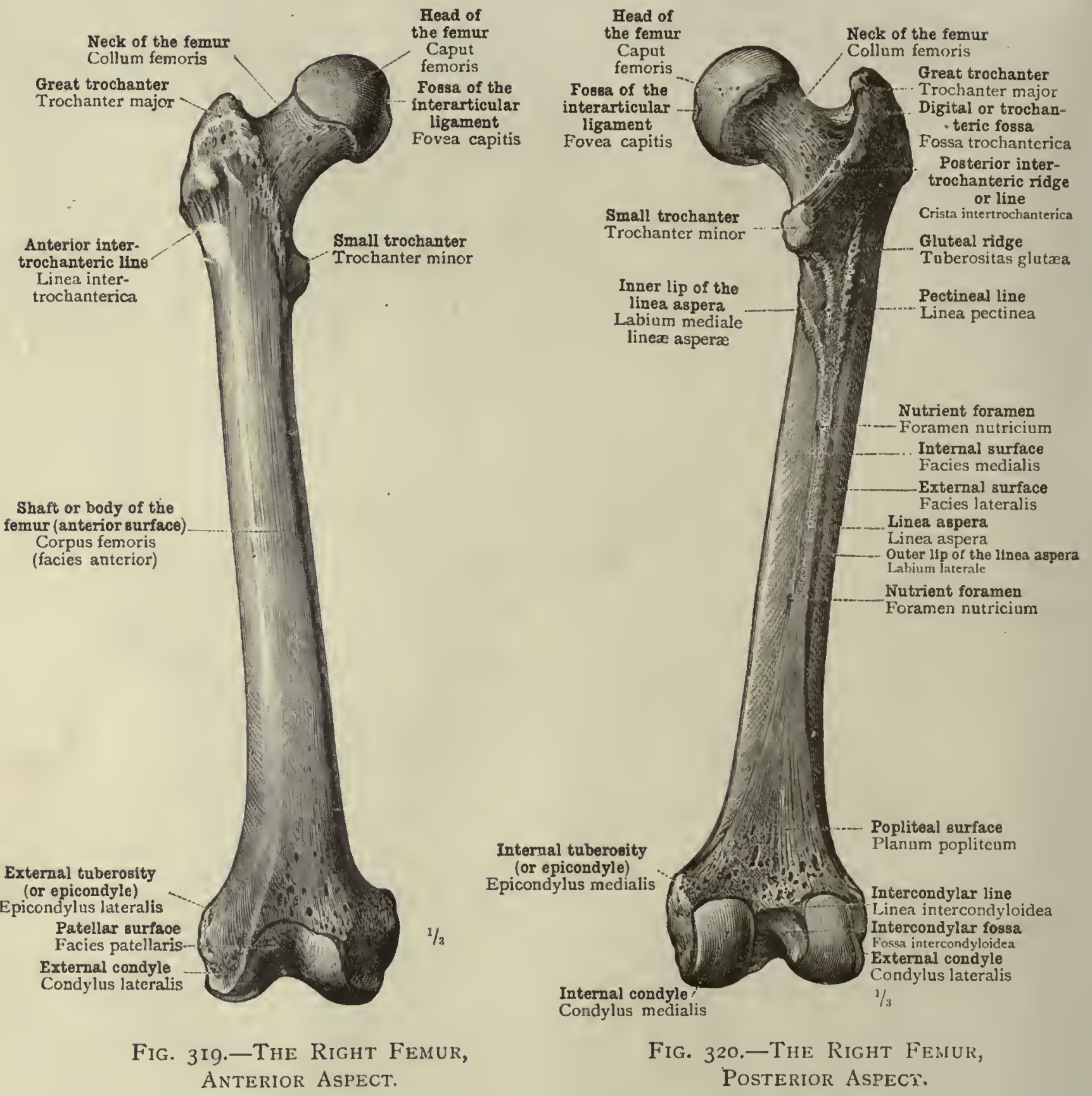

Femur-The femur, or thigh-bone. 


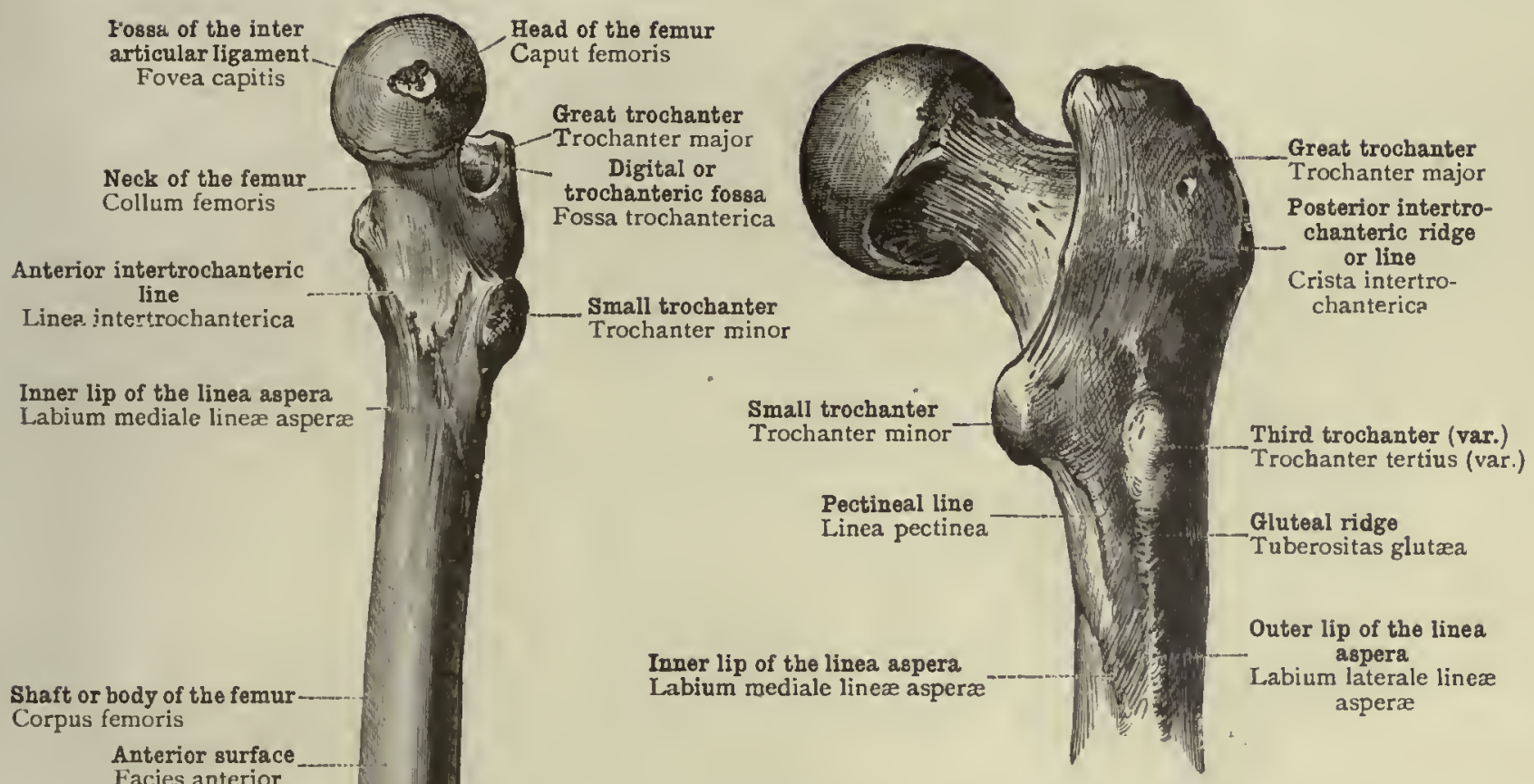

Anterior surface

Internal surface

Facies medialis

Facies patellaris

Internal tuberosity, or epicondyle Epicondylus medialis
Fig. 322.-The Upper Portion of the Right Femur: Third Trochanter (Var.). Seen FROM BEHIND.

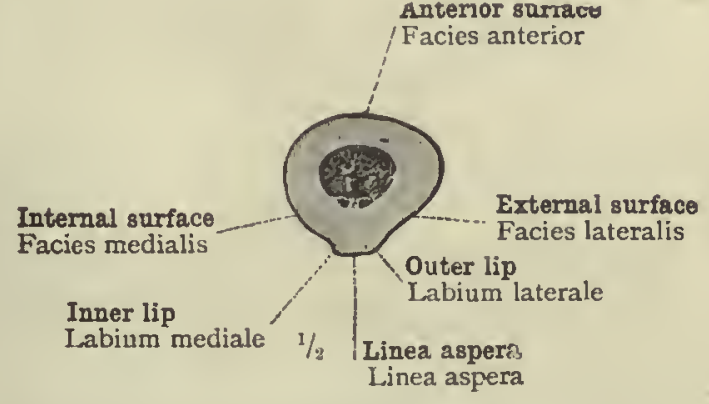

FIG. 323.-TRANSVERSE SECtion THROUGH THE Midde OF THE Shaft OF THE Right FEMUR.
Fig. 321.-The Right FeMUR, INTERNAL ASPECT. 


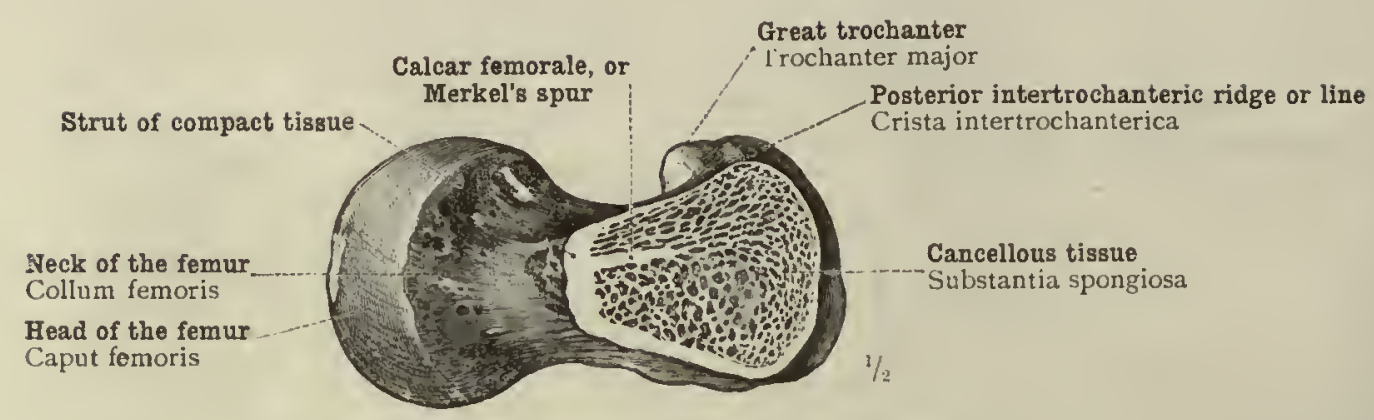

Fig. 324.-Horizontal Section tilrough the Proximal Extremity of the Right fiemur, above the Small Trochanter, to show tile Calcar Femorale.

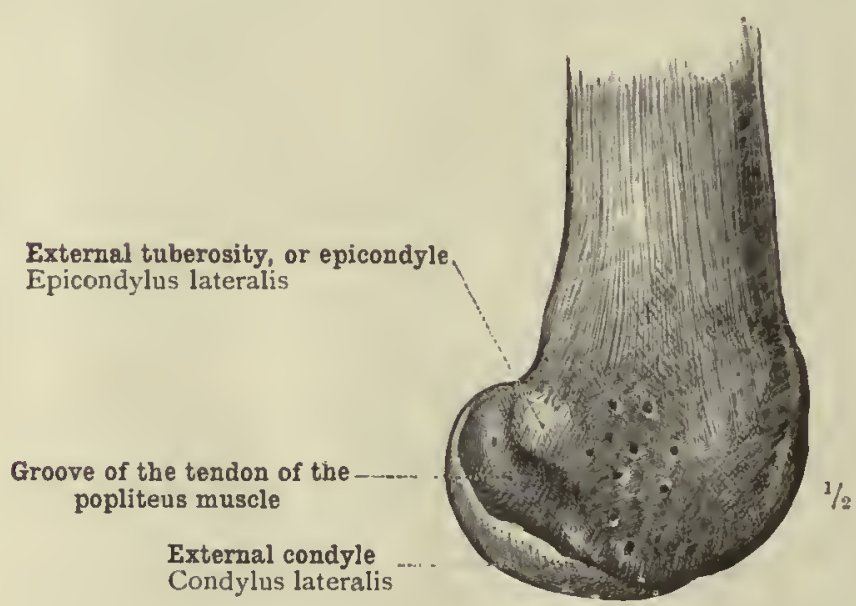

Fig. 325.-Distal Extremity of the Right Femur. Seen from the Outer Side.

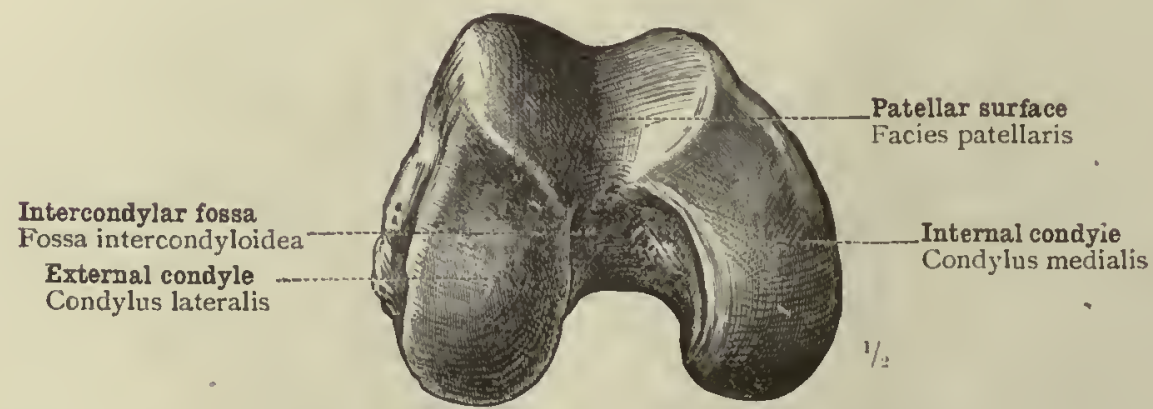

Fig. 326.-Distal Articular Extremity of the Rigit Femur. Seen from Below. 

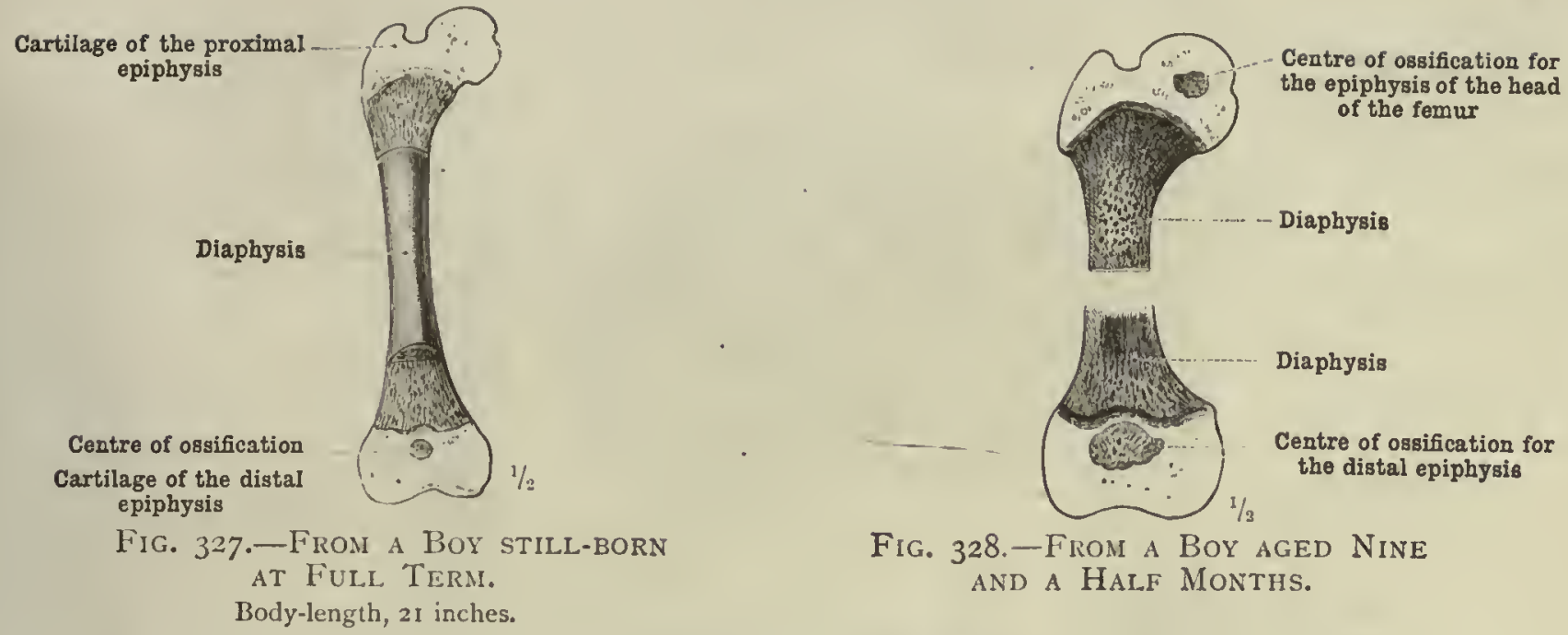

Fig. 328.-From a BoY AGED Nine AND A HalF MoNTHS.

The Centres of Ossification of the Proximal and Distal Epiphyses.
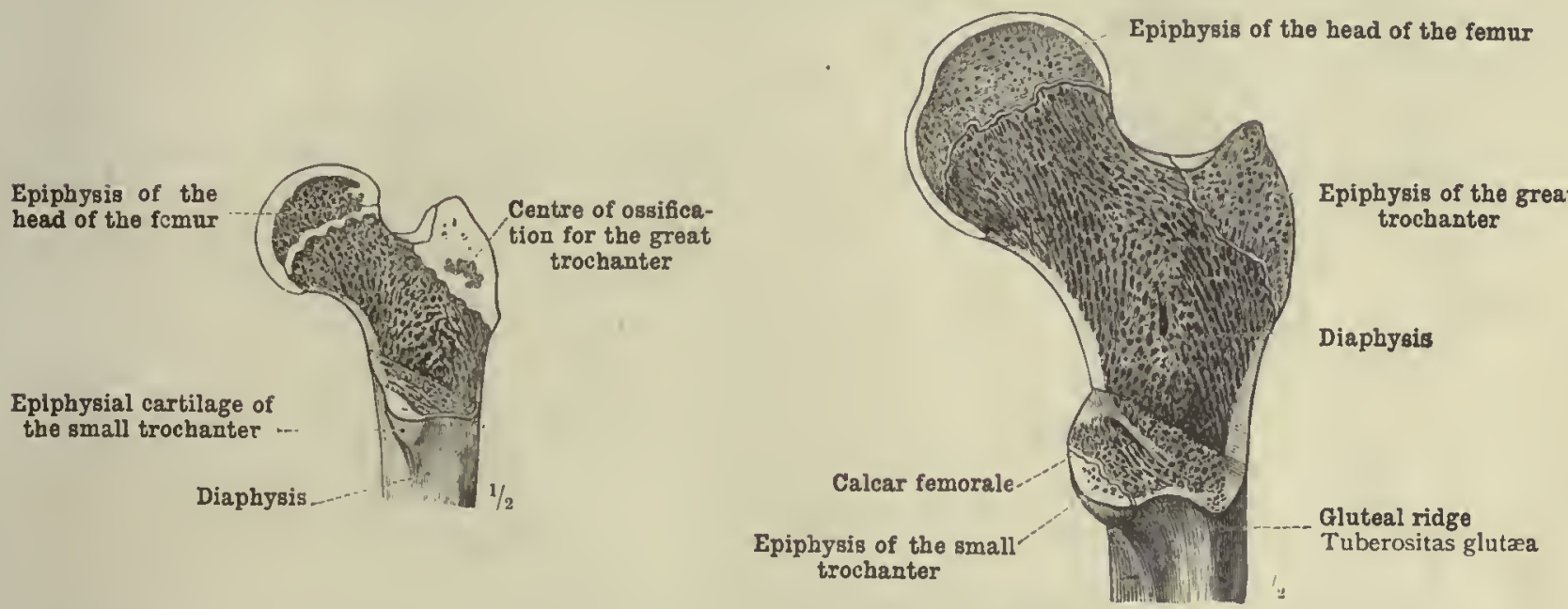

Fig. 329.-From a Girl aged Seven Years. Fig. 330.-From a Girl aged Fifteen Years. The Epiphyses of the Proximal Extremity. Epiphysial disc
Synchondrosis epiphyseos

Distal epiphysis Epiphysis distalis

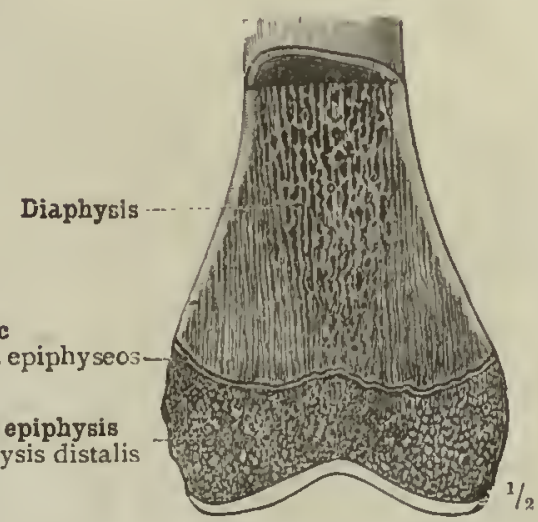

Fig. 33I.-In Frontal Section.

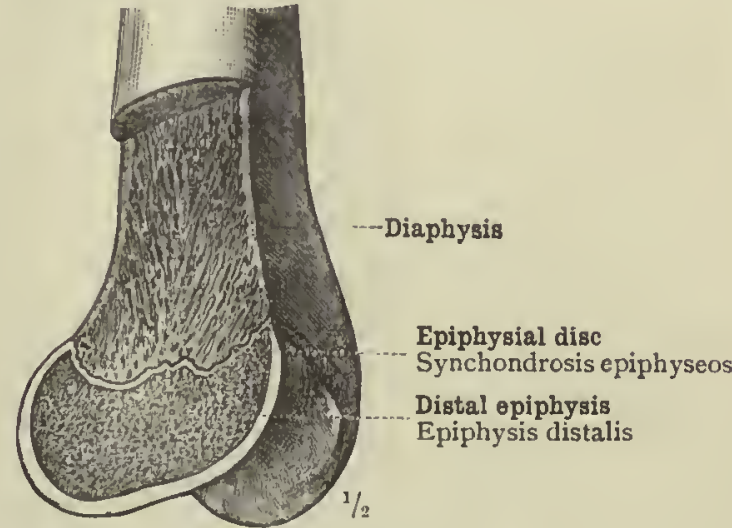

Fig. 332.-In Sagittal Section.

The Epiphysis of the Distal Extremity from a Girl aged Fifteen Years.

\section{Development of the Femur.}




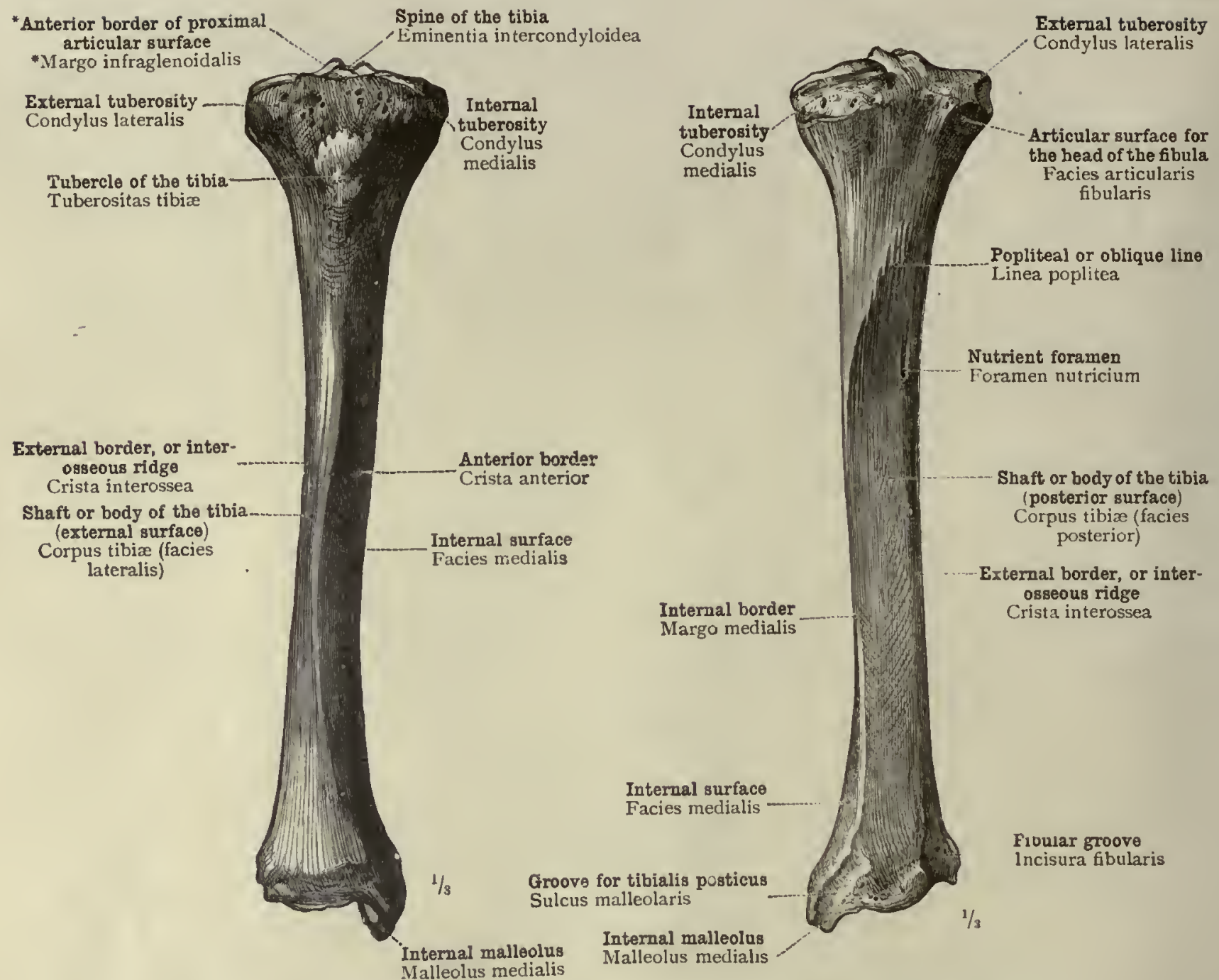

Fig. 333.-ANTERIor Aspect.

Fig. 334.-POSTERIOR ASPECT.

The Right Tibia.

Base of the patella -

Basis patellæ

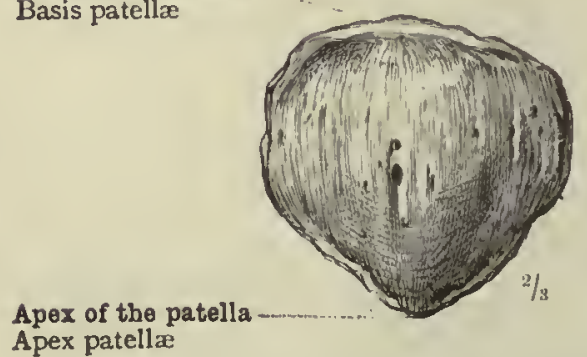

Fig. 335.-ANTERIOR SURFACE.

The Right Patelia.

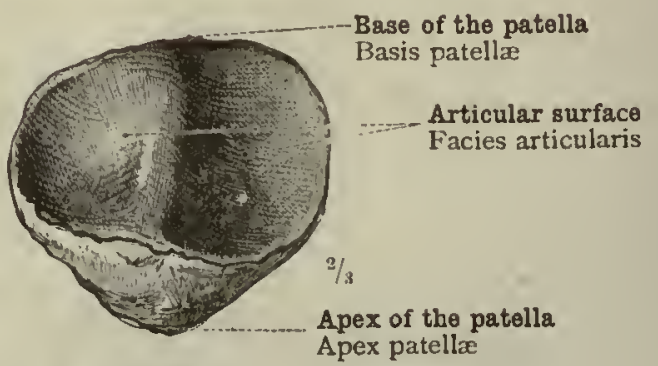

Fig. 336.-Posterior SURFack.

Ossa cruris-The bones of the leg: the patella, rotula, or knee-pan. 
Tubercle of the tibia-Tuberositas tibir:

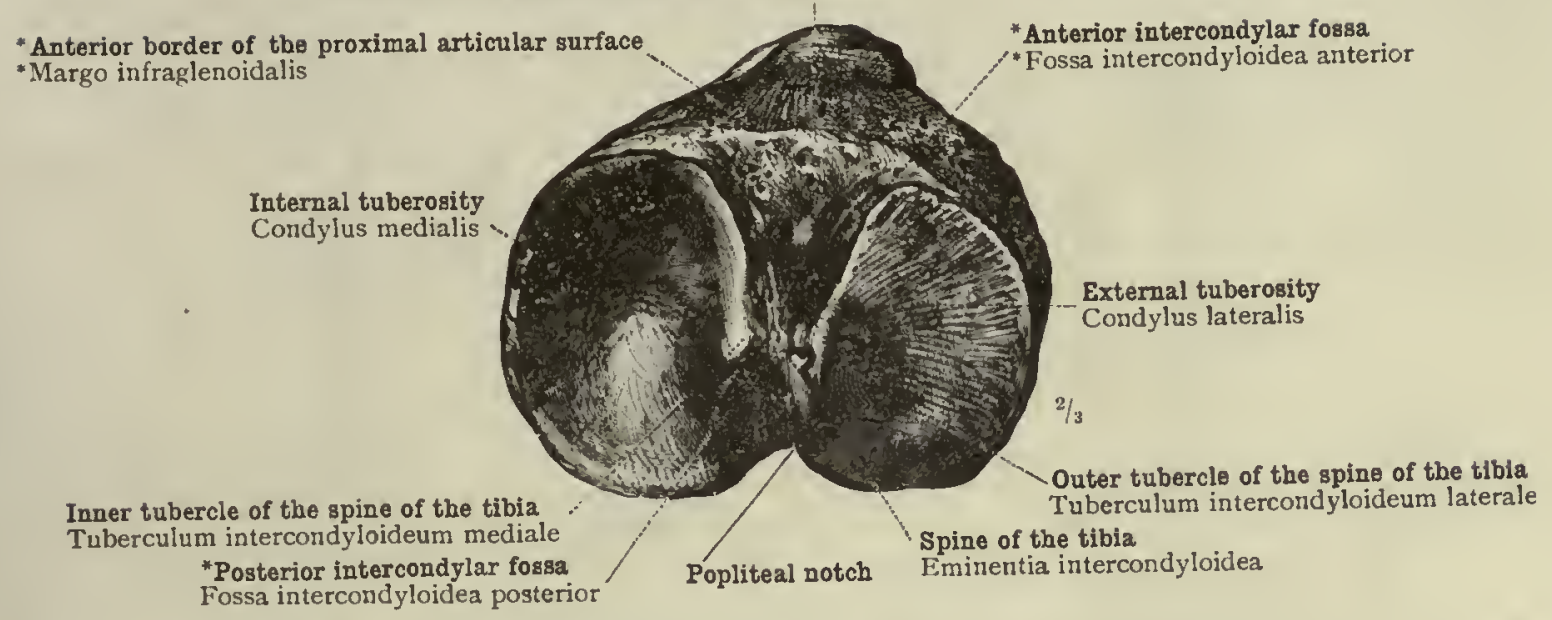

Fig. 338.-Facies Articularis Superior Tibize-The Proximal Articular Surface of the Right Tibia.

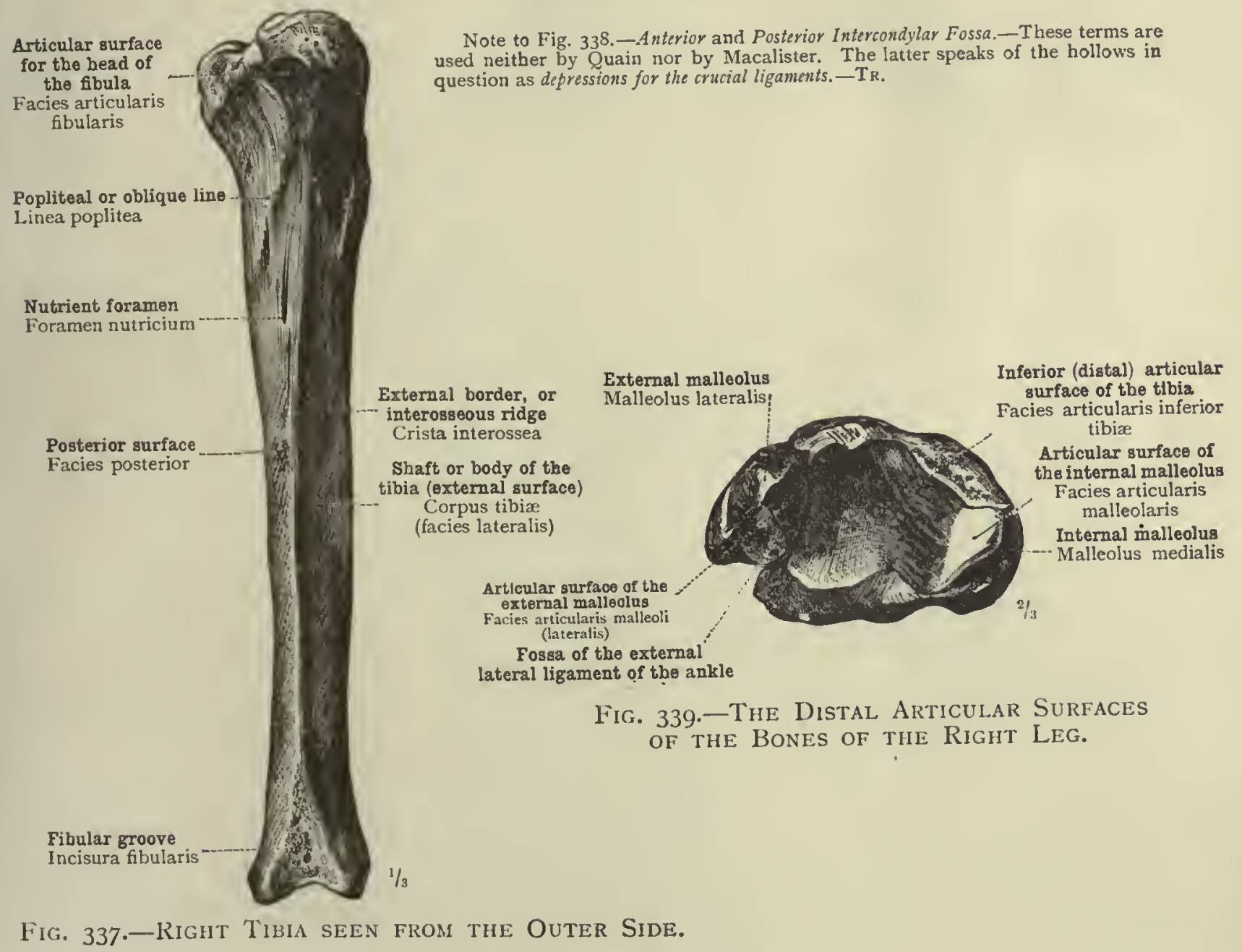

Ossa cruris-Bones of the leg. 


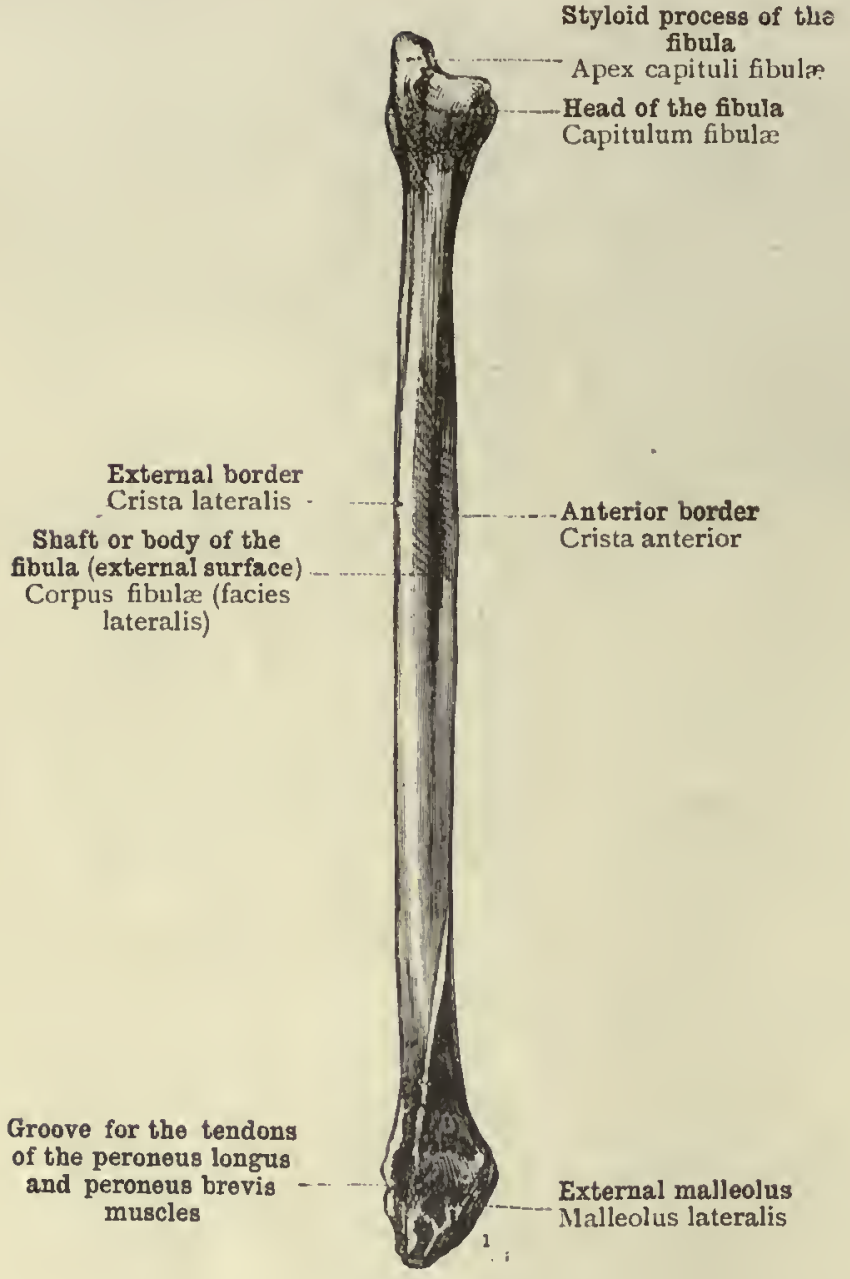

Fig. 340.-External Aspect.

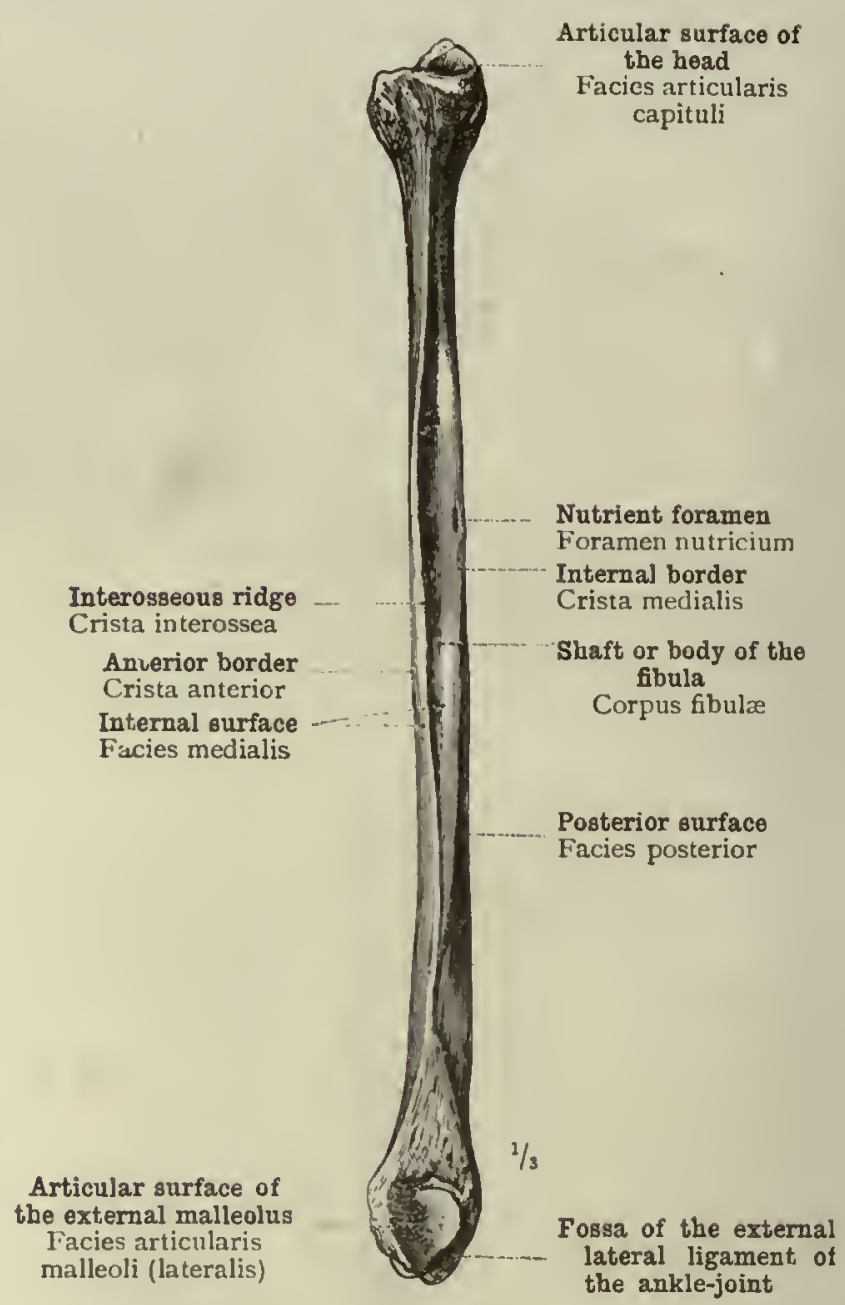

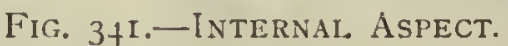

The Right Fibula or Peroneal Bone.

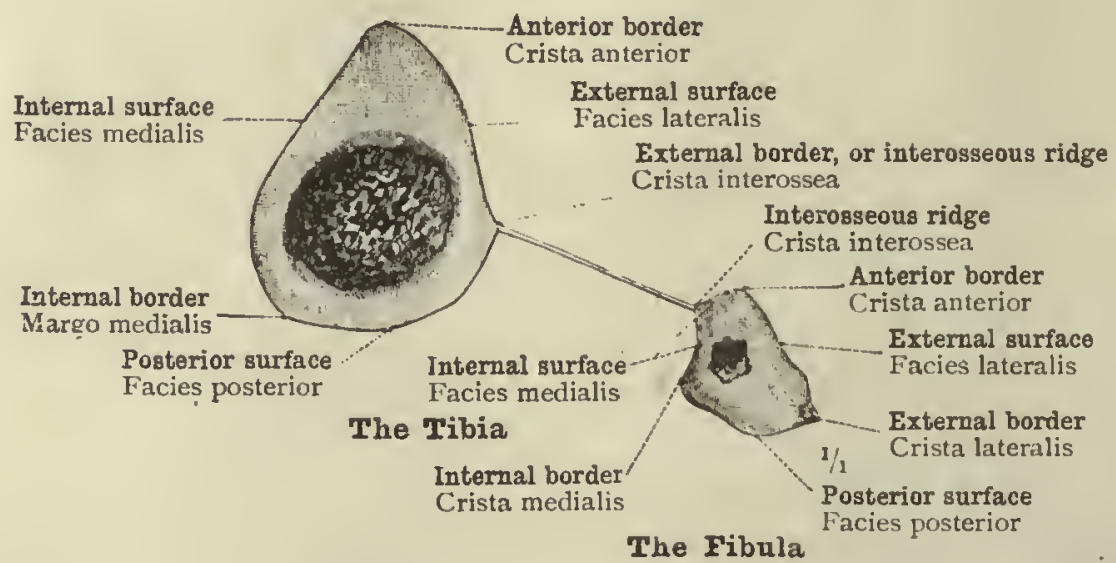

Fig. 342.-Transverse Section through the Middle of the Bones of the Right Leg. witil the Interosseous Membrane,

ussa cruris-Bones of the leg. 


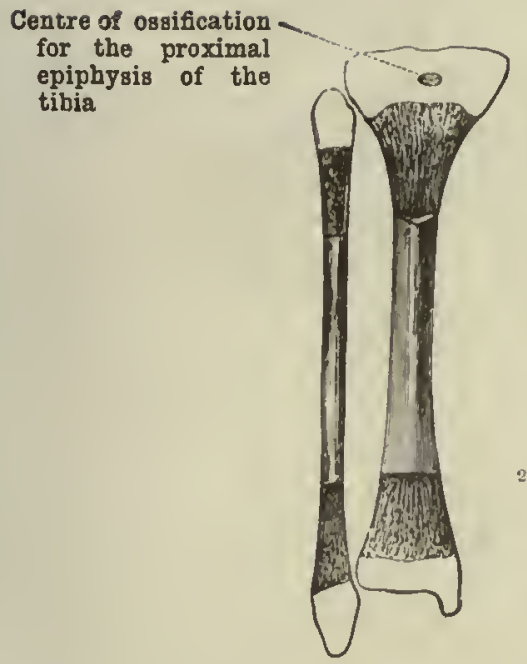

Fig. 343.-From A BOY STILLBORN AT FULL TERM.

Body length, 21 inches.

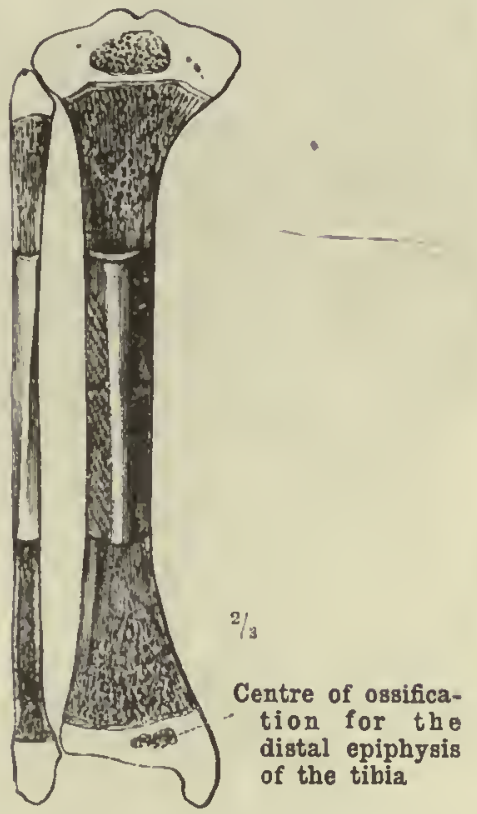

Fig. 344.-From a Boy AGED Nine ANd a Half Months.

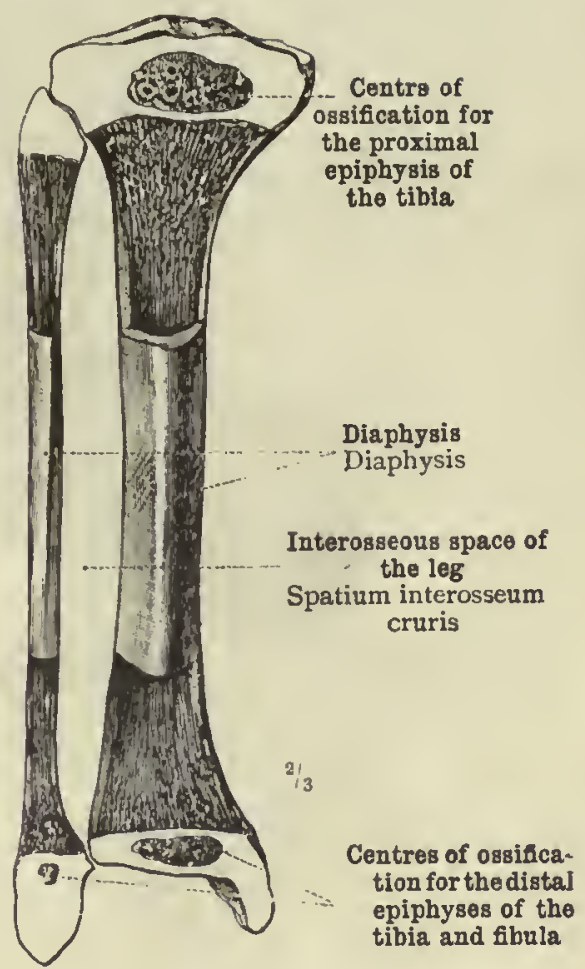

FIG. 345.-FrOM A BOY AGED ONE AND a Half Years.

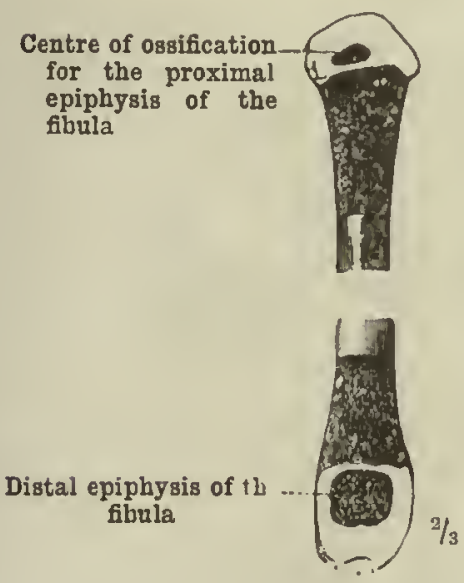

Fig. 346.-Proximal AND Distal Portions of tile Fibula of a Girl aGED Four and a HalF Years.

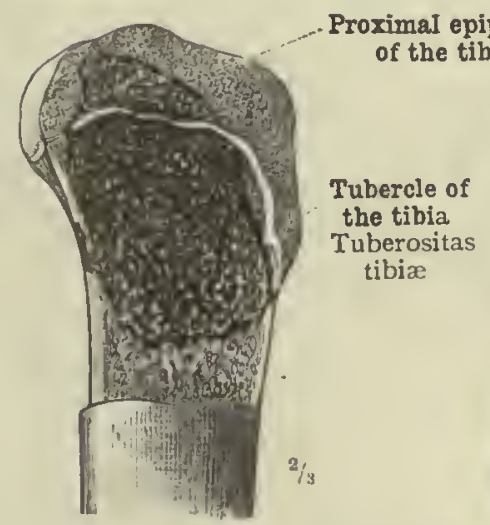

Fig. 347.- Proximal Portion of the Tibia of a Girl AGED FifTEEN YEARS. Sagittal Section.
Distal epiphyses of the tibia and fibula $2 / 8$

Fig. 348.-The Distal Portions OF THE BONES OF THE LEg OF A GirL AGED FifTEEN Years. Frontal Section. 


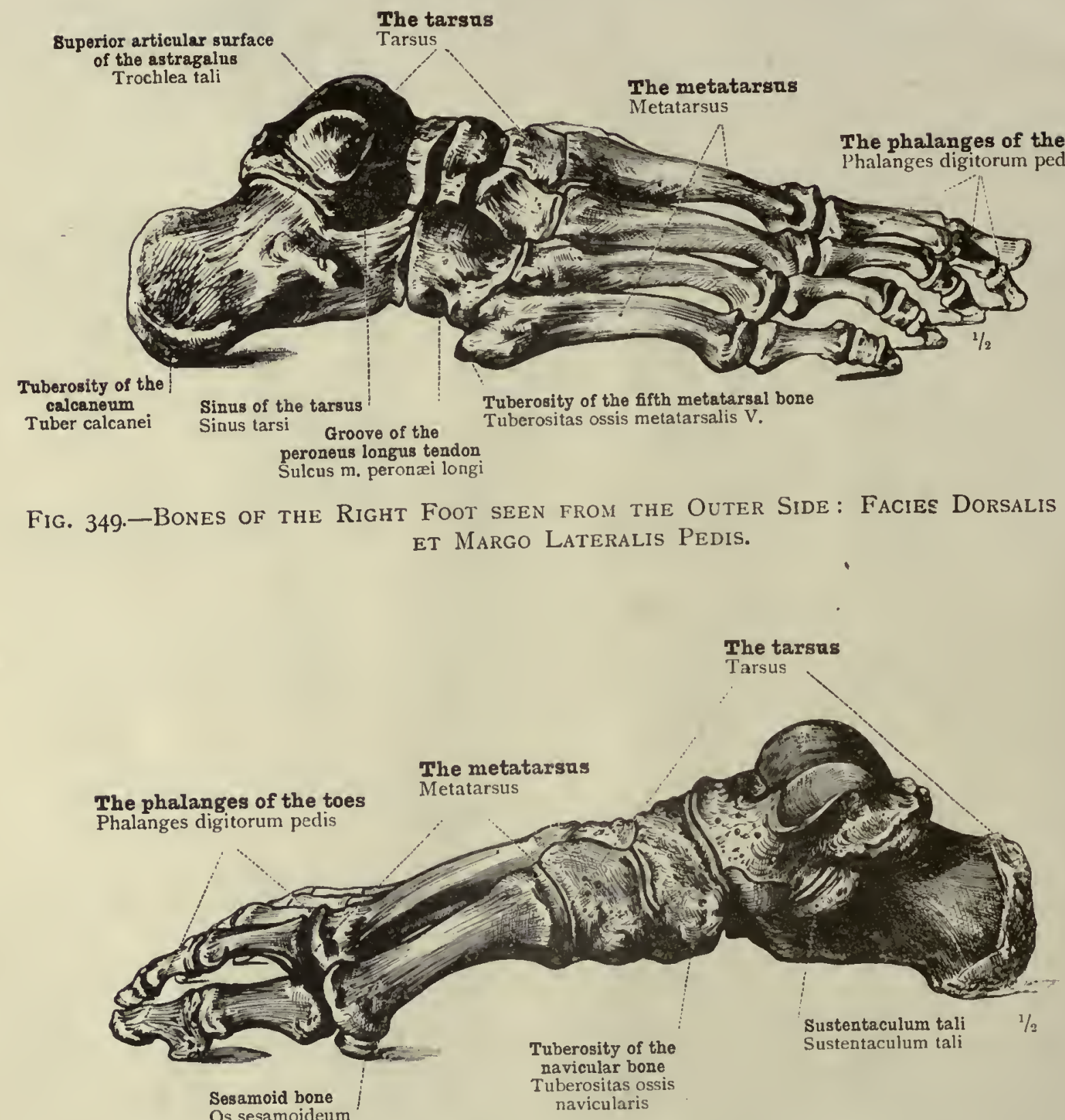

Fig. 350.-The Bones of the Right Foot seen from the InNer Side: - Margo Medialis Pedis.

Skeleton pedis-Bones of the foot. 


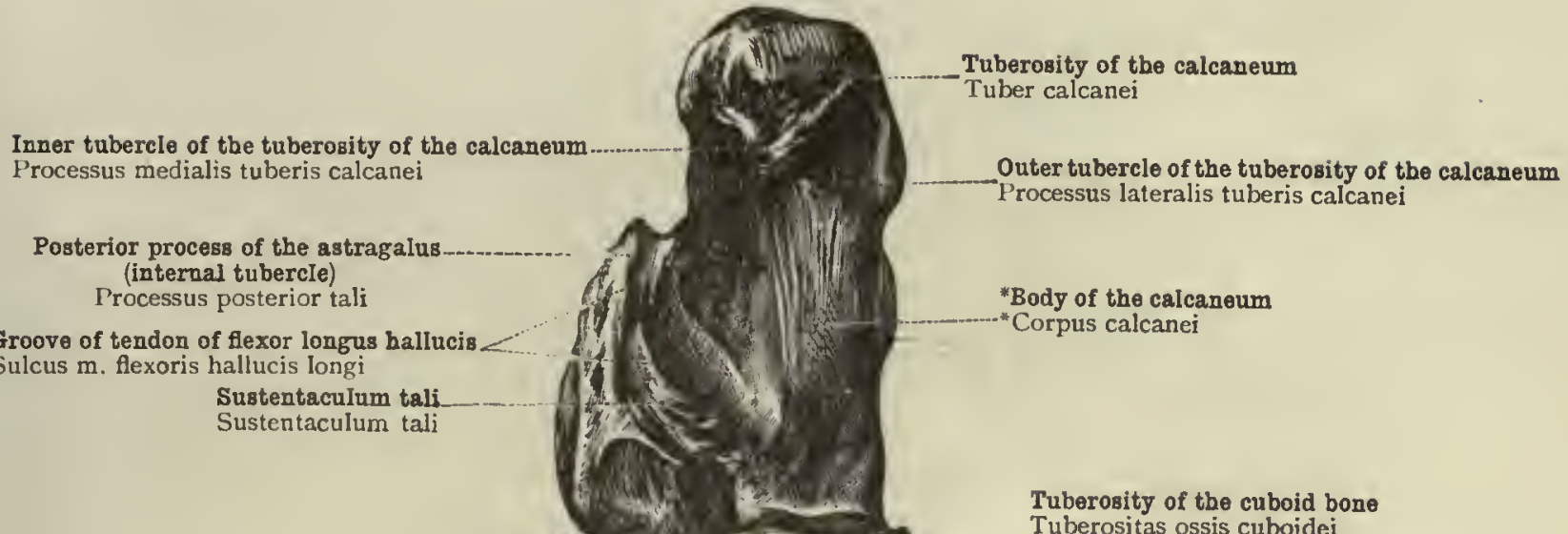

Tuberositas ossis navicularis

Internal cuneiform bon Os cuneiforme I.
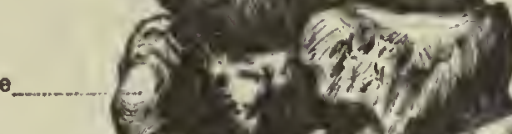

Tuberositas ossis cuboide

Groove of the peronæus longus tendon

Sulcus m. peronæi longi

Tuberosity of the fiftb metatarsal bone Tuberositas ossis metatarsalis $\mathrm{V}$

Tuberosity of the first metatarsal bone Tuberositas ossis metatarsalis I.

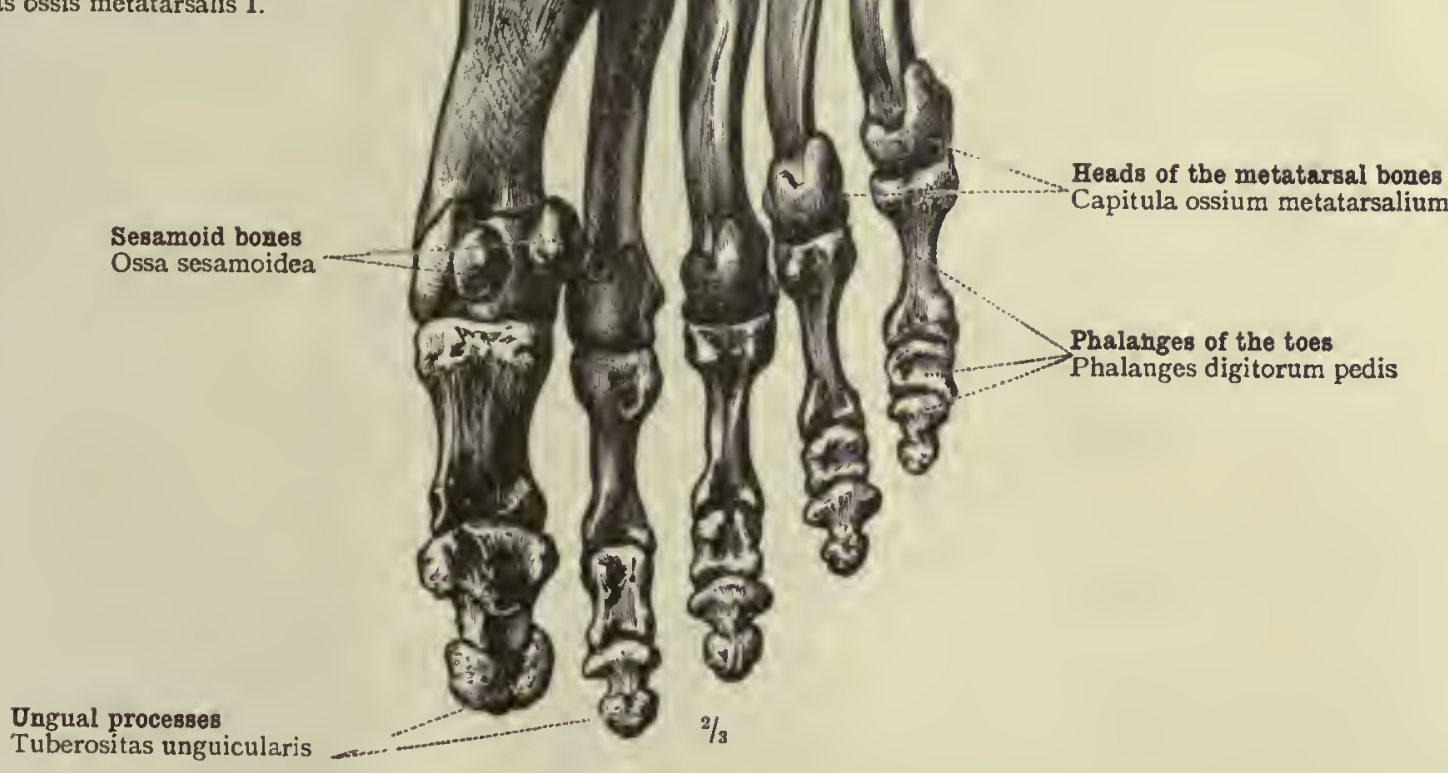

Fig. 351.-The Bones of the Rreht Foot sefn from the Plantar Side: Facies Plantaris Pedis. 


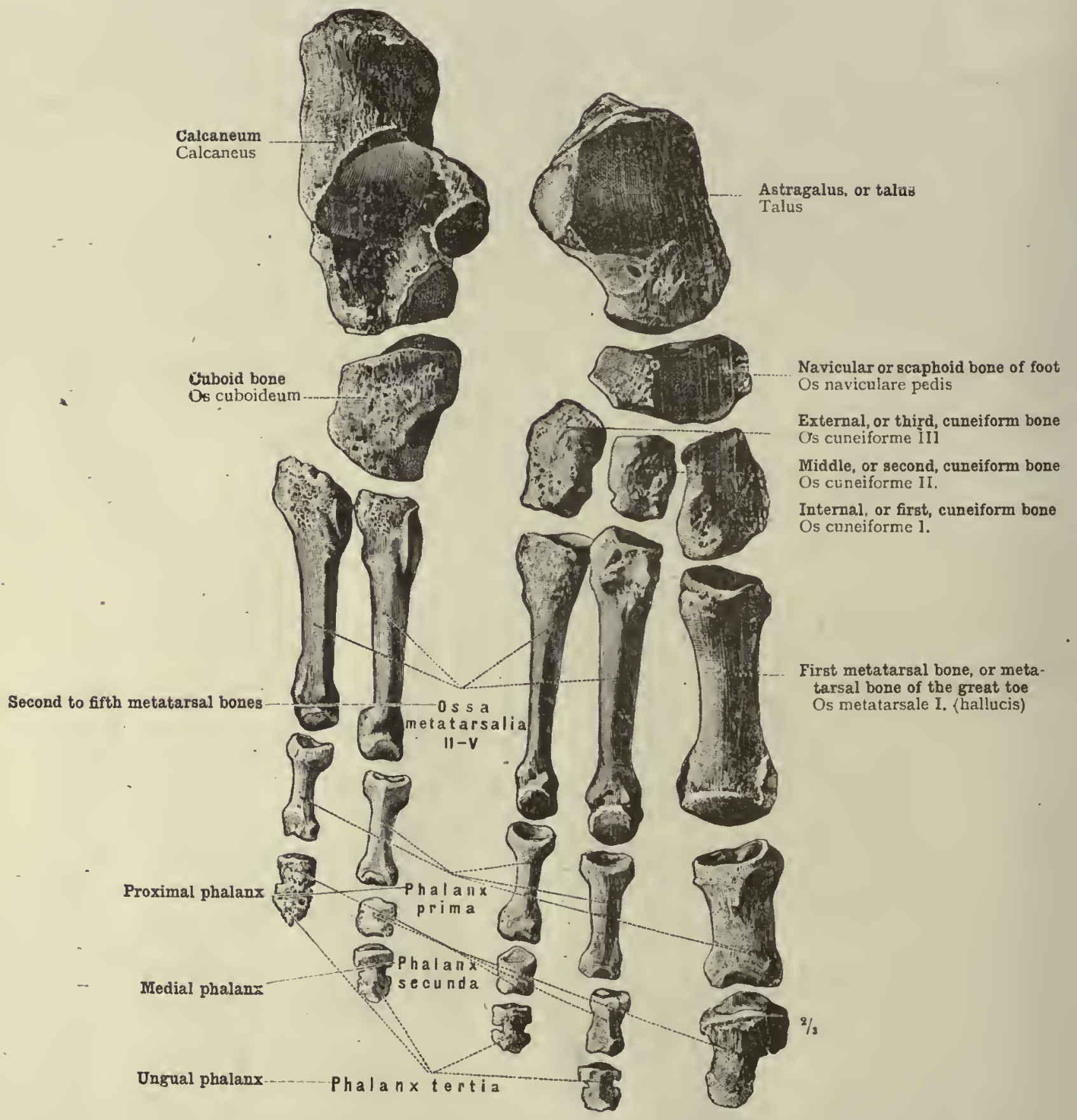

Fig. 352. - The Bones of the Right Foot seen from the Dorsal Side (arranged in Two LONGITUDINAL ROWS).

Skeleton pedis-Bones of the font. 


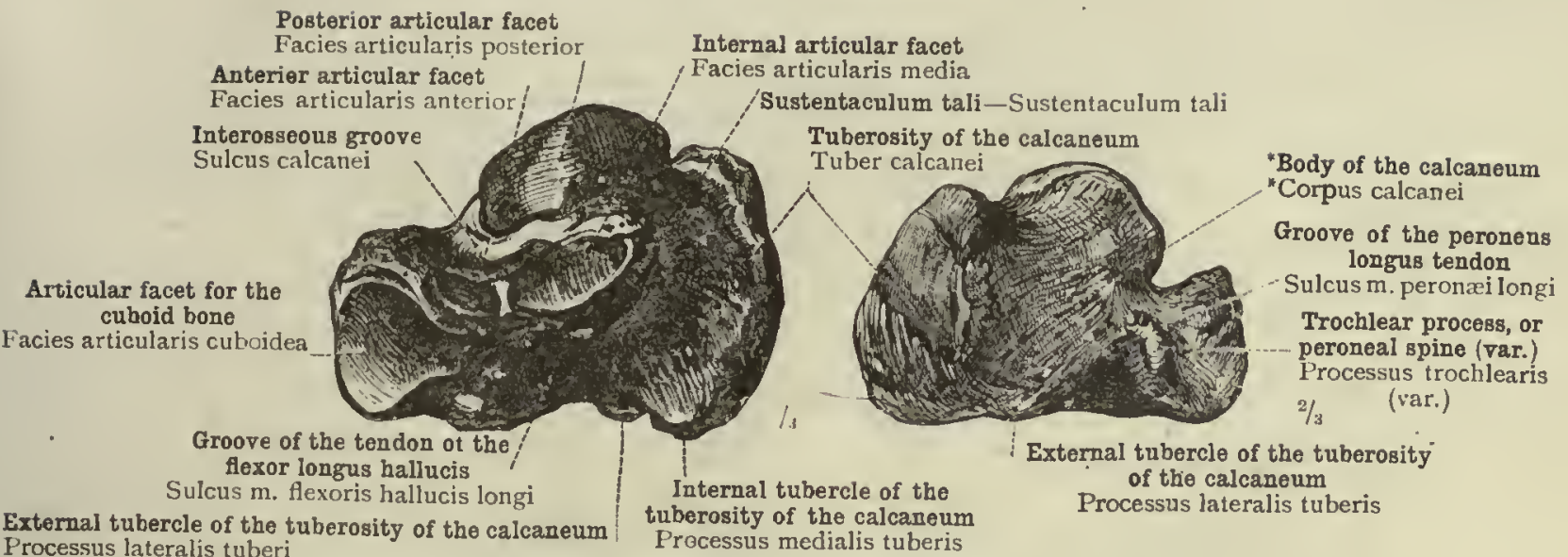
Processus lateralis tuberi

\section{Fig. 353.-SEen Obliguely From WITHIN AND BEIORE.}

\section{F1G. 354.-SEEN OBLIQUEI.Y FROM WiTHOUT AND BEHIND.}

The Right Calcaneum or Os Calcis.

Head of the astragalus (articular facet for the navicular bone)

Caput tali (facies articularis navicularis)

Neck of the astragalus Collum tali

Interosseous groove Sulcus tali

Body of the astragalus Corpus tali

Articular facet for the external malleolus Facies malleolaris lateralis
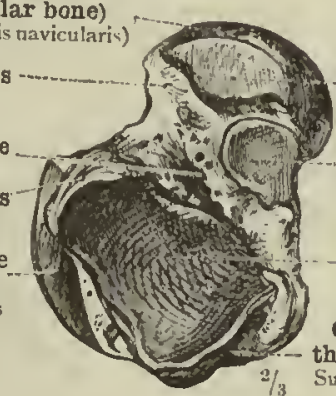

Anterior articuiar facet for the calcaneum

Facies articularis calInternal articuiar facet for the calcaneum Facies articularis calcanea media

Posterior articular facet for the calcaneum Facies articularis calcanea posterior

Groove of the tendon of the flexor longus hallucis Sulcus $\mathrm{m}$. flexoris hallucis longi

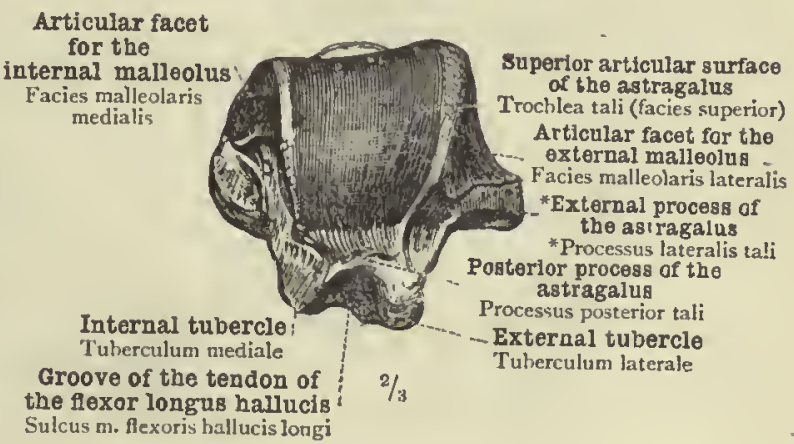

F1G. 356.-SEEN FROM BËHIND.

FIG. 355.-SeEN From Below.

The Right Astragalus.

Articular facet for the calcaneum Facies articularis calcanea

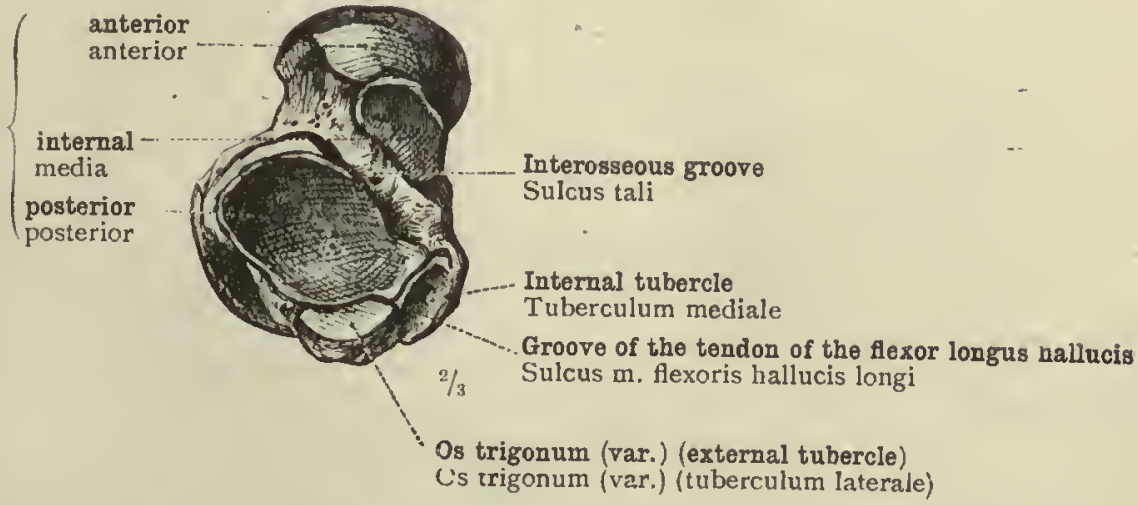

Fig. 357.-The Right astragalus, with an Os Trigonum (Var.). Seen from Below. 

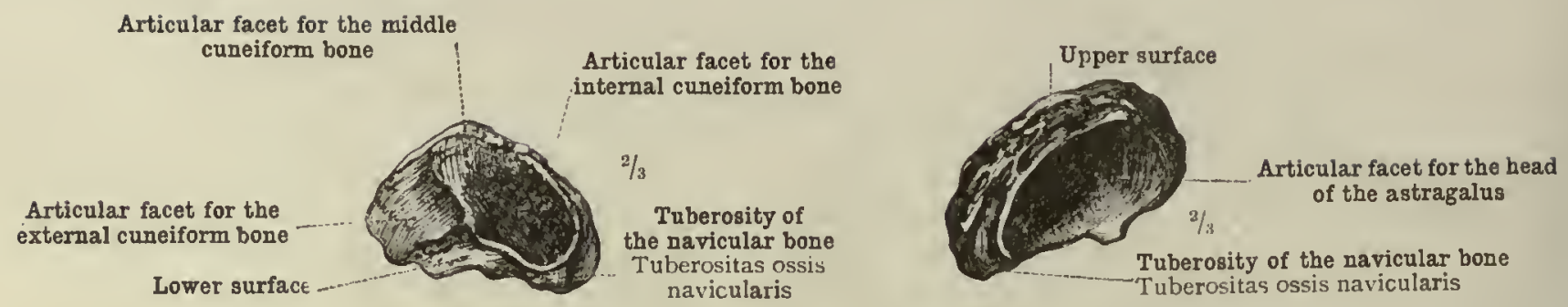

Fig. 358.-ANTERIOR ASPECT.

lig. 359.-POSTERIOR Aspect.

Os Naviculare Pedis-The Right Navicular or Scaphoid Bone of the Foot.

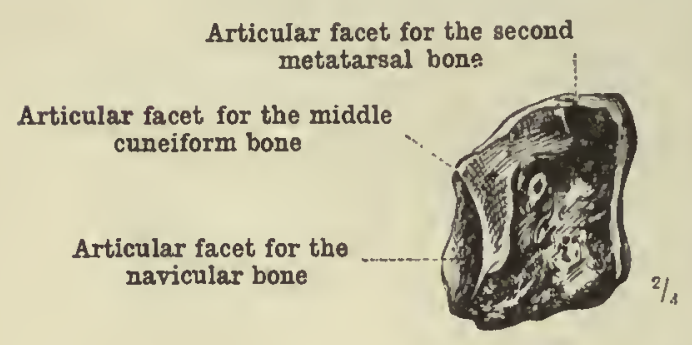

Fig. 360.-External Aspect.

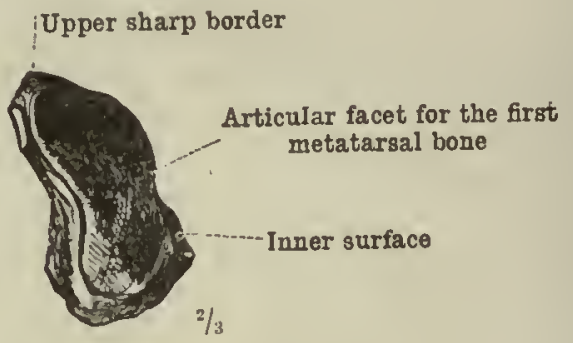

Fig. 36r.-ANTERIOR Aspect.

Os Cuneiforme I.-The Right Internal Cuneiform Bone.

\begin{abstract}
Articular facet for the internal cuneiform bone Upper surface
\end{abstract}

\section{Articular facet} for the second metatarsal bone

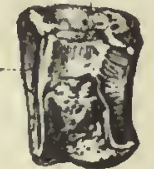

InNER Aspect.

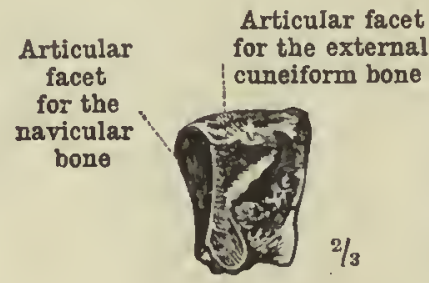

Outer Aspect.
Fig. 362.-Os Cuneiforme II.-The Right Midde Cuneiform Bone.
Articular facet for the second metatarsal bone

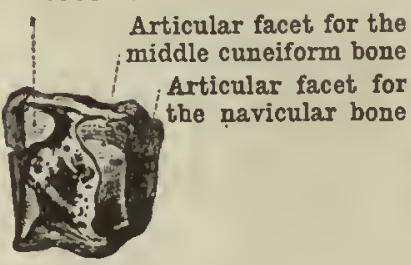

INNER ASPECT.

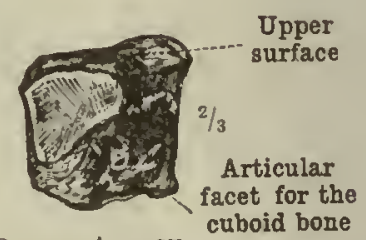

Outer Aspect.
Fig. 363.-Os Cuneiforme III.-The Right External Cuneiform Bone.

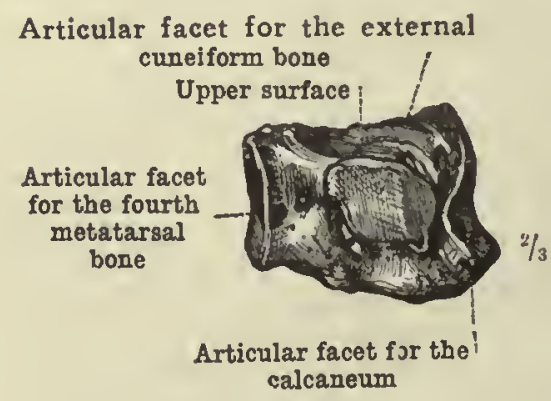

Fig. 364.-InNer Aspect.

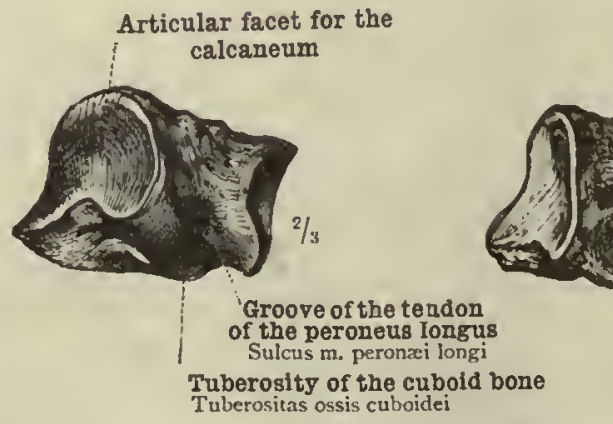

Uppor surface

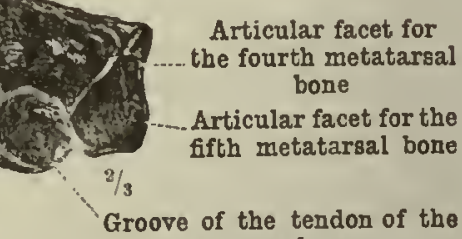
peroneus longus Sulcus $m$, peronxi longi

Fig. 366.-Outer Aspect.

Fig. 365.-SEeN OBLIQUELY FROM Without and BeHIND.

Os Cuboideum-The Right Cuboid Bone. 


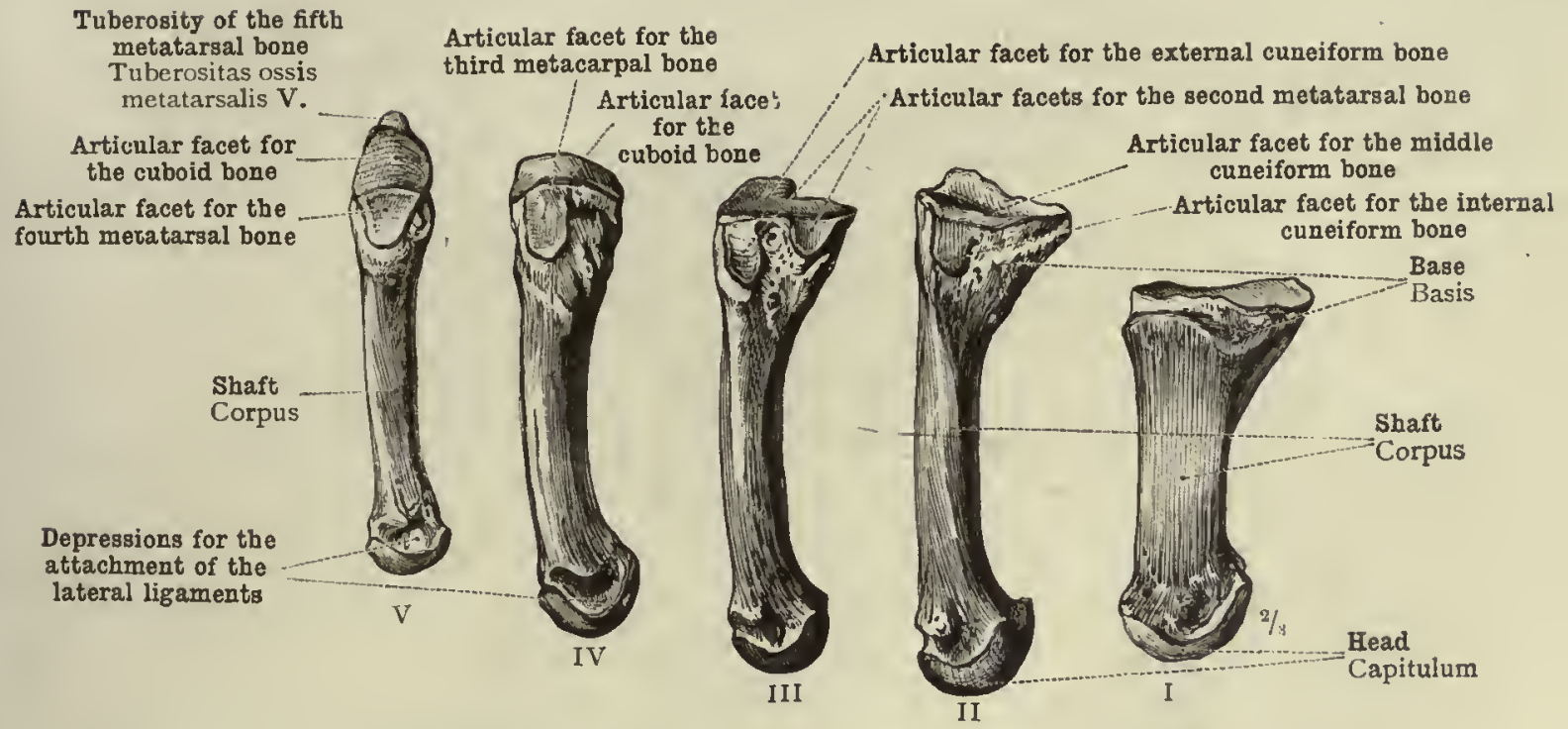

Fig. 367.-The Metatarsal Bones of the Right Foot seen from the Inner Side.

Articular facet for the fourth metatarsal bone Articular facet for the external cuneiform bone :

Articular facets for the third metatarsal bone

Tuberosity of the first metatarsal bone Tuberositas ossis metatarsalis I.

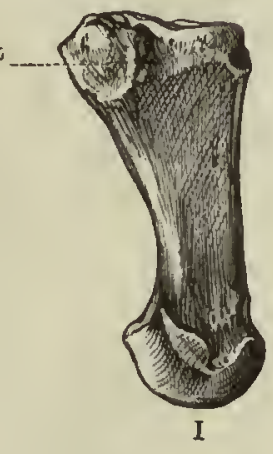

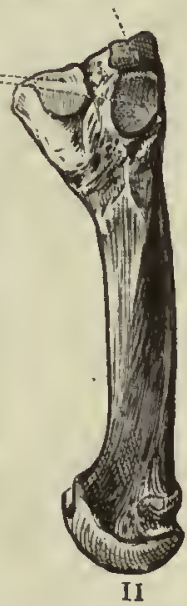

II

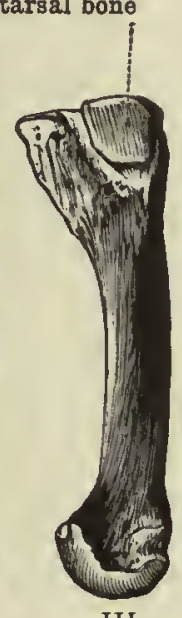

III
Articular facet for the fifth metatarsal bone

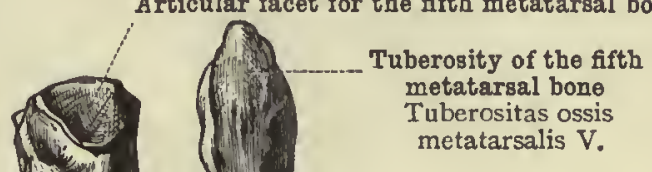
metatarsal bone metatarsalis V.

Depressions for the attachment of the lateral ligaments

Fig. 368.-The Metatarsal Bones of the Right Foot seen from the Outer Side.
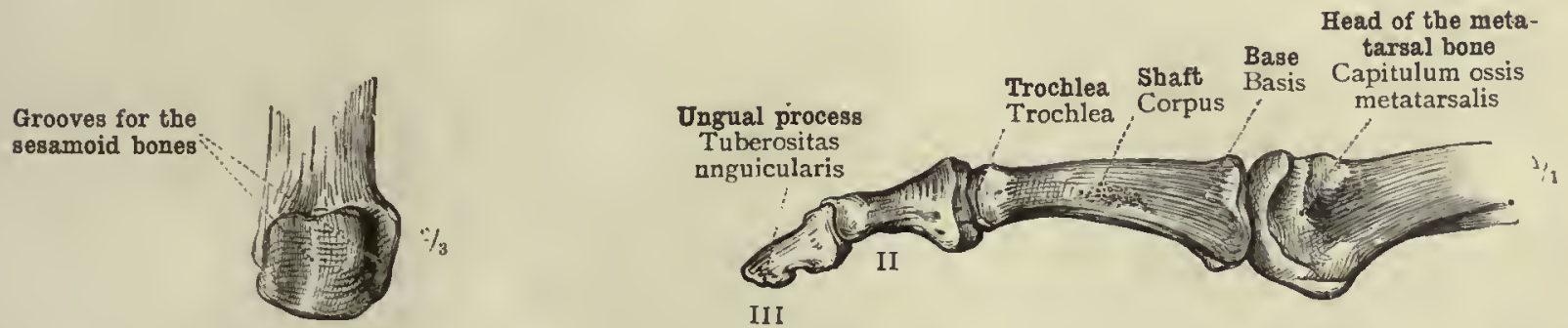

Fig. 370.-Thr Phalanges of the Second Toe seen From the INNer Side (Margo Medialis Digiti Secundi Pedis).
Head of the Metatarsal Bone of the Great Toe (Capitulum Ossis Metatarsalis Hallucis). 


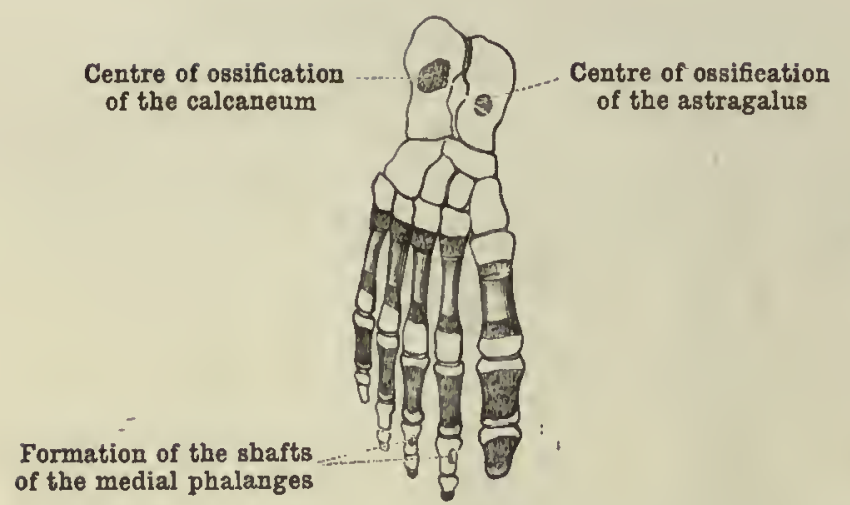

Fig. 37I.-From a Human FEtus iN THE Middle of the Ninth Month (Months of Four WeEks Each).

Body-length, $17 \frac{1}{2}$ inches.

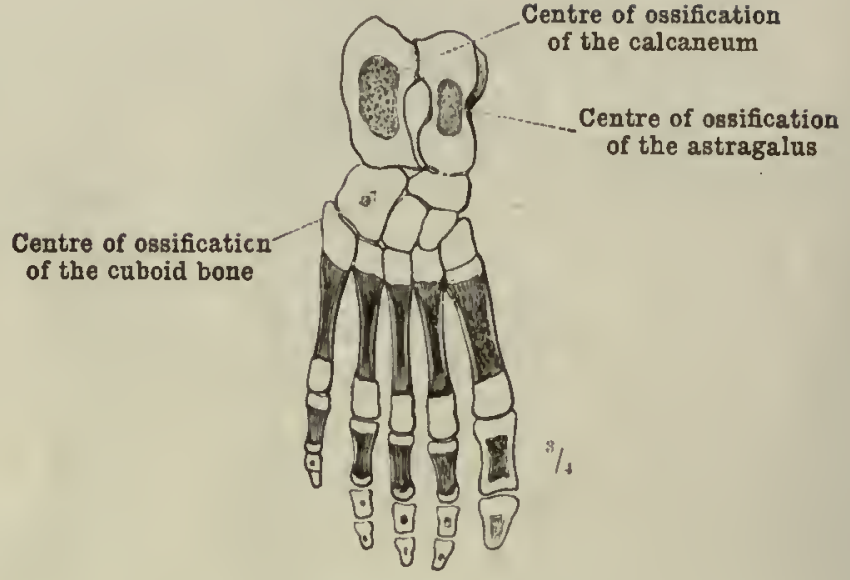

FIG. 372.-FROM A BOY STILL-BORN at Full Term.

Body-length, 22 inches.

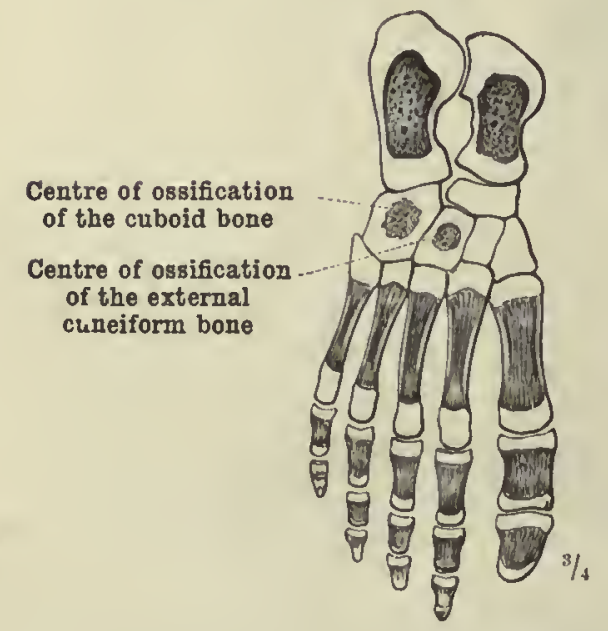

FIG. 373.-From A BOY AGED TWELVE WEEKS.

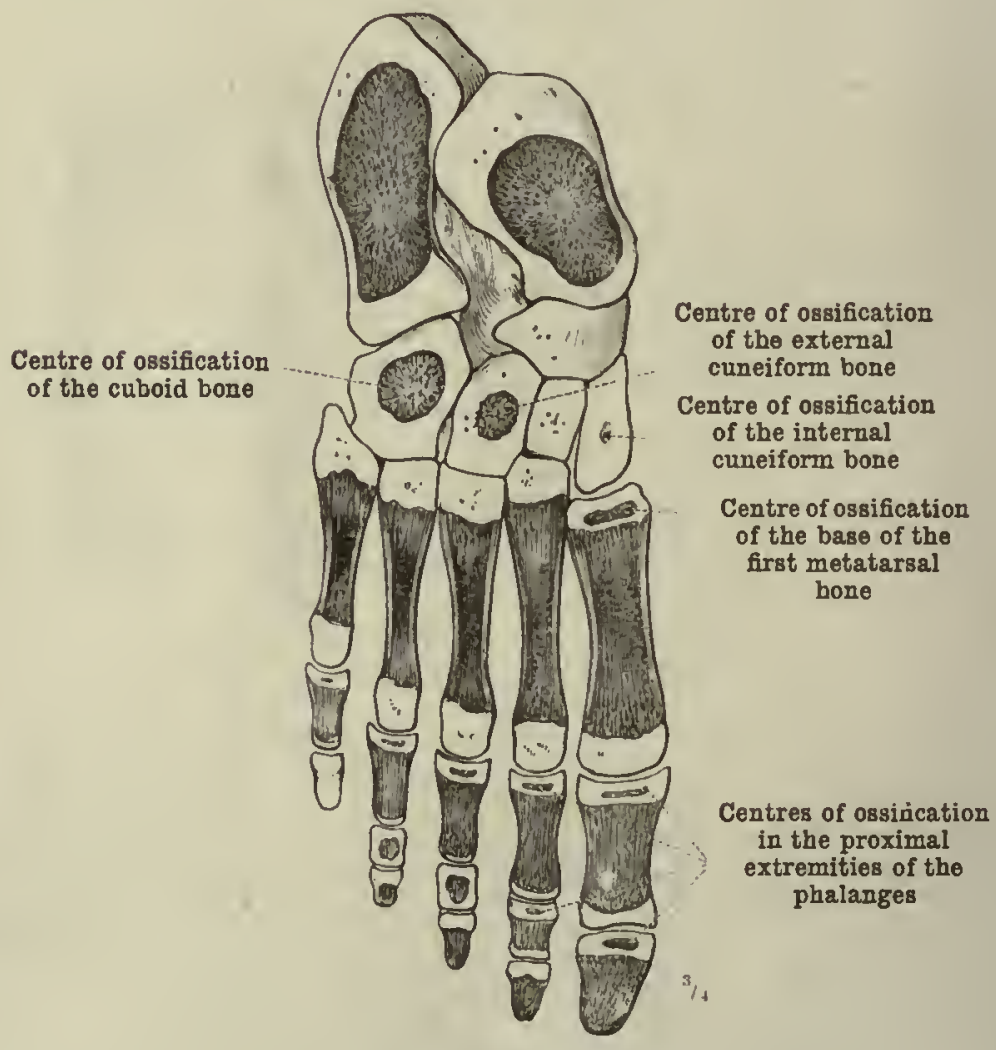

FIG. 374.-FrOM A BOY AGED

THREE YeARs.

Development of the Bones of the Foot. 


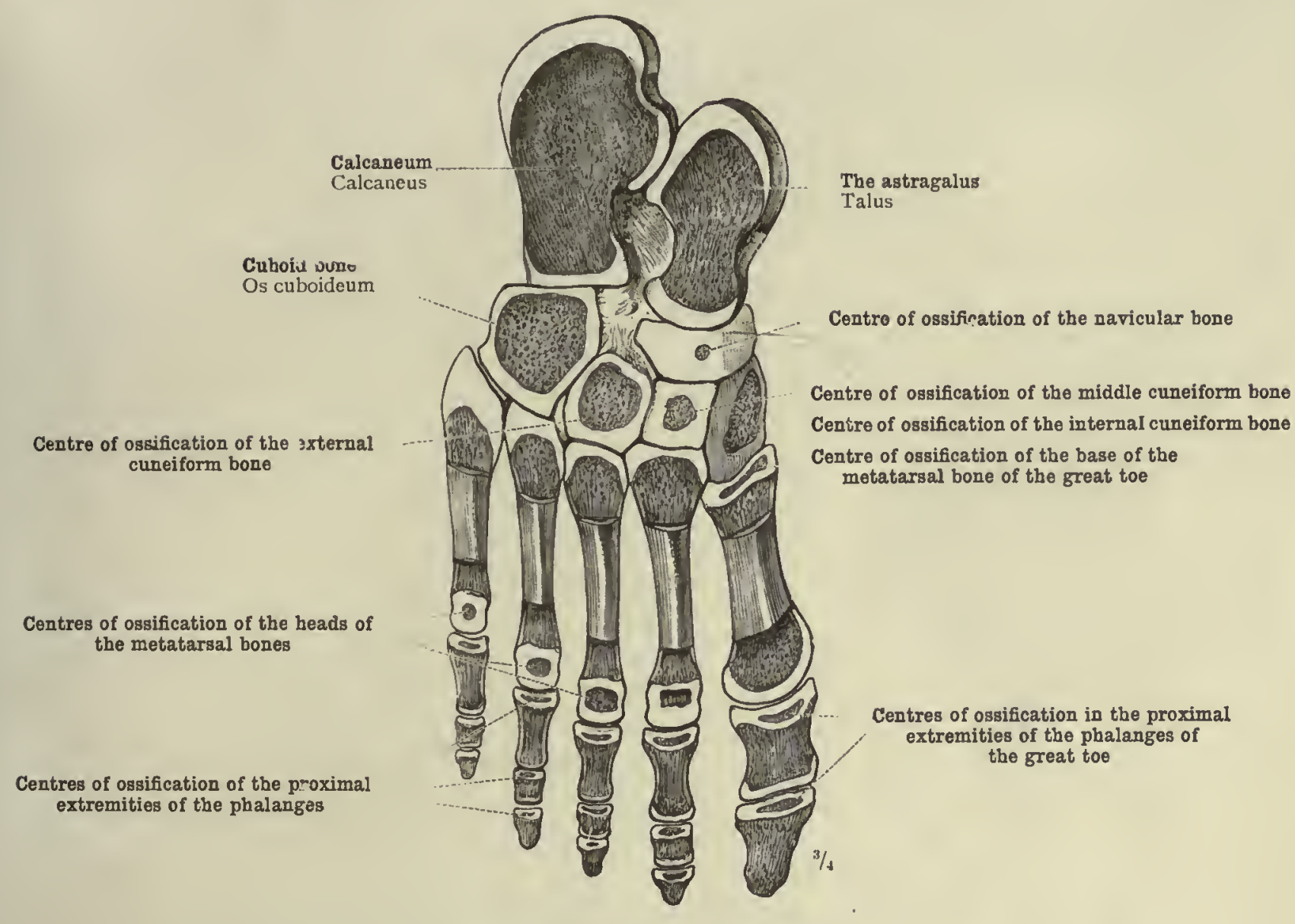

Fig: 375.-Ossification of the Bones of the Foot in a Girl aged Six Years.

Centre of ossification of the epiphysis of the tuberosity uf

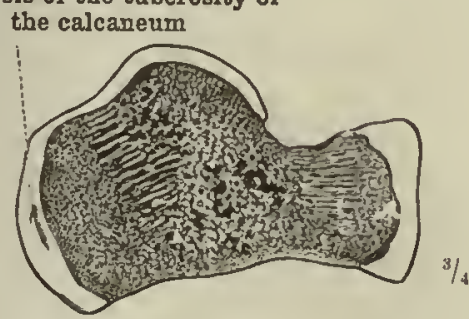

FIG. 376.-FROM A GIRL AGED EIGHT YEARS.

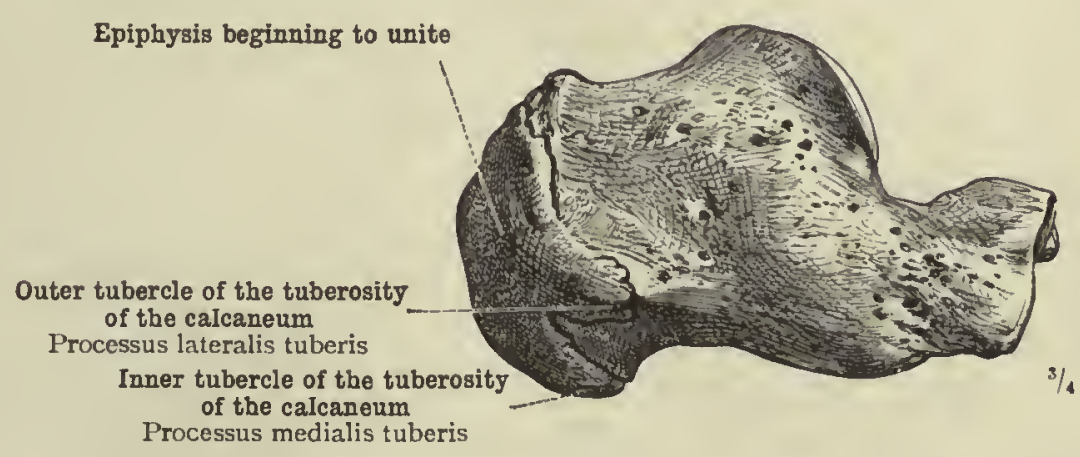

Fig. 377.-From a Young Man aged Eighteen YEARS (EPIPHYSIS BEgINNING TO UNITE).

Epiphysis of the Tuberosity of the Calcaneum.

Development of the Bones of the Foot. 



\section{INDEX}

TO MIIE

\section{REGIONS OF THE HUMAN BODY}

AND TO THE

OSTEOLOGY 


\section{N D E X}

\section{TO THE REGIONS OF THE HUMAN BODY.}

A.

ABDomen, external region of the, 2,3 regions of, 2,3

Abdominal regions, 2,3

Acromial region, 3,4

Anal region, 5

Auricular region, 3, 4

Axillary region, 2

Back, medial region of the, 3 regions of the, 3

Brachial region, anterior, 2, 3 external, 2,3 internal, 2, 3

Buccal region, 4 posterior, 3

Calcaneal region, 2,3

Calf, region of the, 3

Clavicular region, 4

Crural region, anterior, 2 external, 2, 3
internal, 2
posterior, 3

Deltoid region, 2, 3

D.

Digital regions of the foot, dorsal, 2

\section{E.}

Elbow, anterior region of the, 2 external region of the, 2,3 internal region of the, 2 posterior region of the, 2,3

Epigastric region, 2

\section{F.}

Face, regions of the, 2, 4

Fenoral region, anterior, 2

$$
\begin{aligned}
& \text { external, 2, } 3 \\
& \text { internal, 2, } 3 \\
& \text { posterior, } 2
\end{aligned}
$$

Fingers, palnar regions of the, 2, 3 dorsal regions of tlie, 3

Foot, dorsal region of the, 2 plantar region of the, 3

Forearu1, dorsal region of the, 2 palmar region of the, 2,3 radial region of the, 2 ulnar region of the $, 2,3$

Fossa axillaris, $2 a$

carotica, $4 a$

jugularis, $4 a$

poplitea, $3 a$

retromandibularis, $4 a$

supraclavicularis major, $4 \mathrm{a}$ ninor, $4 a$

Fossa, axillary, 2 infraclavicular, 2 , note, 4 , note retromandibular, 4 supraclavicular, greater, 4

Fovea nuchr, $3 a$

Frontal region, 2, 4

Furrow, carotid, 4
Gluteal region, 3, 5

G.

H.

Ham, the, 3

Hand, dorsal region of the, 2,3 palmar region of the, 2,3

IIead, regions of the, 4

Hip, region of the, 2,3

Hyoid region, 4

Hypochondriac region, 2, 3

Hypogastric region, 2

Infraclavicular region, 2, 4

I.

Inframammary region, 2

Infra-orbital region, 4

Infrascapular region, 3

Inguinal region, 2

Interscapular region, 3

K.

Knee, anterior region of the, 2 posterior region of the, 3

Jabial region, lower, 4

upper, 4

Laryngeal region, 4

Lisfranc, tubercle of, 40

Lower extremity, regions of the, 2, 3

Lumbar region, 3

M.

Maljeolar reyion, external, 3 internal, 2

Mammary region, 2

Mastoid region, 3,4

Mental region, 4

Mesogastric region, 2

Mohrenheiner's space, 2, note, 4 , note

N.

Nasal region, 2, 4

Neck, anterior region of the, 2 external region of the, 2 regions of the, 4

ivucinal region, 3,4

Occipital region, 3,4

Olecranon, region of the, 2,3

Oral region, 2,4

Orbital region, 2,4

Palpebral region, lower, 4 upper, 4

Parietal region, 2-4

Parotideoniasseteric region, 4

Patellar region, 2

Pectoral regions, 2, 3 region, externaì, 2, 3

Perineal region, 3. 5

Pubic region, 2

Pudendal region, 2, 5 
R.

Regions of the humau body, I $\bullet 5$

Regio vel regiones:

abdominis, $2 a, 3 a$

acromialis, $3 a, 4 a$

alis, $2 a, 3$

analis, $5 a$

antibrachii dorsalis, $2 a$

radialis, $2 a$

ulnaris, $2 a, 3 a$

anricularis, $3 a, 4 a$

ris, $2 a, 3 a$

axillaris, $2 a$

brachii auterior, $2 a, 3 a$

lateralis, $2 a, 3 a$ medialis, $2 a, 3 a$

buccalis, $4 a$ posterior, $3 a$

calcanea, $2 a, 3 a$

capitis, $4 a$

clavicularis, $4 a$

colli, $4 a$

anterior, $2 a$

lateralis, $2 a, 4 a$

corpnris humani, a $a-5 a$

coxae, $2 a, 3 a$

cruris anterior, $2 a$

lateralis, $2 a, 3 a$

nuedialis, $2 a$

posterior, $3 a$

cubiti anterior, $2 a$

lateralis, $2 a, 3 a$

medialis, $2 a$

posterior, $2 a, 3 a$

deltoidea, $2 a, 3 a$

digitorum (u1anus), $2 a, 3 a$ pedis, $2 a$

dorsales digitorum (manus), $3 a$ pedis, $2 a$

dorsalis manus, $2 a, 3 a$

dorsi, $3 a$

epigastrica, $2 a$

extrentitat is inferioris, $2 a, 3 a$

faciei, $2 a, 4 a$

superioris, $2 a, 3^{a}$

feuroris anterior, $2 a$

lateralis, $2 a, 3 a$

medialis, $2 a, 3 a$

frontalis, $2 a, 4 a$

posterior, $3 a$

genn anterior, $2 a$ posterior, $3 a$

glut:ea, $3 a, 5 a$

hyoidea, $4 a$

hypocliondriaca, $2 a, 3 a$

liypogastrica, $2 a$

infraclavicularis, $2 a, 4 a$

infraunamualis, $2 a$

infra-orbitalis, $4 n$

infrascapularis, $3 a$

inguinalis, $2 a$

interscapularis, $3: 2$

labialis inferior, $4 a$ superior, $4 a$

laryngea, $4 a$

lumbalis, $3 a$

malleolaris lateralis, $3 a$

medlialis, $2 a$

nianıualis, $2 a$

w1astoidea, $3 a, 4 a$

mediana dorsi, $3 a$

incutalis, $4 a$

inesngastrica, $2 a$
Regio vel regiones :

nasalis, $2 a, 4 a$

unchie, $3 a, 4 a$

occipitalis, $3 a, 4 a$

olecrani, $2 a, 3 a$

oralis, $2 a, 4 a$

orbitalis, $2 a, 4 a$

palpebralis inferior, $4 a$ superior, $4 a$

parietalis, $2 a, 3 a, 4 a$

parotideonnasseterica, $4 a$

patellaris, $2 a$

pectoris, $2 a, 3 a$ lateralis, $2 a, 3$

perinealis, $3 a, 5 a$

plantaris pedis, $3 a$

pubica, $2 a$

putendalis, $2 a, 5 a$

retromallcolaris lateralis, $3 a$

sacralis, $3 a, 5 a$

medialis, $2 a$

scapularis, $3 a$

sternalis, $2 a$

sternocleidotnastoidea, $4 a$

subhyoidea, $4 a$

subinguinalis, $2 a$

subulaxillaris, $4 a$

submentalis, $4 a$

supra-orbitalis, $4 a$

suprascapularis, $3 a$

suprasternalis, $4 a$

suralis, $3 a$

teis poralis, $2 a, 3 a, 4 a$

thyreoidea, $4 a$

trochanterica, $2 a, 3 z$

unibilicalis, $2 a$

unguiculares, $2 a, 3 a$

urogenitalis, $5 a$

volares digitorum, $2 a, 3 a$

volaris matnus, $2 a, 3 a$

zygonnatica, $4 a$

Retromalleolar region, exterual, 3 internal, 2

Sacral region, 3,5

S.

Scapnlar region,

Space, Mohrenheinter's, 2, note, 4 , note popliteal, 3

Sternal region, 2

Sternocleidomastoid region, 4

Subliyoid region, 4

Subinguinal region, 2

Submaxillary region, 4

Subuental region, 4

Supra-orbital region, 4

Suprascapular region, 3

Suprasterual regiou, 4

Tempóral region, 2-4

Thyroid region, 4

Triangle, deltoideopectoral, 2, 4 infraclavicular, 2 , note, 4 , note omoclavicular, 4

Trigonum deltoideopectorale, $2 a, 4 a$ omoclaviculare, $4 a$

Trochanteric region, 2,3

Iubercle of Lisfranc, 40

Vanbilical region, 2

U.

Ungual regions, 2,3

Upper extremity, regions of tlie, 2, 3

Urogenital region, 5

Zygonatic region, 4 


\section{N D EX}

\section{TO THE OSTEOLOGY}

Certain names in this Index have an asterisk $\left(^{*}\right)$ prefixed; these, as more fully explained in the Translator's Preface, being terms that form part of the English nomenclature used in this work, but which are not commonly employed by English anatomists. To other nanies it dagiseri) is prefixed : these are
Latin names used by the author in the original work, but not included in the ofticial nomenclature of the "Anatomische (iesellschaft."

ACETABULUM, I29

Acromion, I08, IIO, 1 I I

†Aditus ad antrum tympanicum, 66, 67 orbitæ, 48 , 95

Agger nasi, 78, 90

Air-cells of the Fustaclian tube, 66

Ala nıagna, 58-6t

ossis ilii, I 30

parva, $58-6$ I

Ale vomeris, 79, 91, 92

Alisphenoid, $6 \mathrm{I}$

Alveolæe dentales mandibulæe (lower jaw-bone), 84 maxillæ (upper jaw-bone), 82

Ampulla ossea lateralis, 69 posterior, 69 superior, 69

Ampulla, osseous, of the external semicircular canal, 60 of the posterior semicircular canal, 69

Angle, acromial, I Io of the superior semicircular canal, 69

of the jaw, 84,85

of Ludwig, 41

of the parietal bone, frontal, 72,73

mastoid, 72,73

occipital, 72,73

splenoidal, 72, 73

of the pubis, 125

of the ribs, 37,40

of the scapula, inferior, IIo

internal, 1 io

superior, IIO

of the sphenoid bone, parietal, $5^{8-60}$

of the sternum, 41

subcostal, 36

Angulus anterior pyramidis, 65

costæ, 37,40

frontalis (ossis parietalis), 72,73

inferior (scapulæ), I Io

infrasternalis, 36

lateralis (scapulæ), I Io

Ludovici, 41

mandibula, 84,85

111astoideus (ossis parietalis), 72, 73

medialis (scapulæ), t10

occipitalis (ossis parietalis), 72, 73

parietalis (ossis sphenoidalis), 58.60

posterior pyramidis, 65

pubis, I 25

sphenoidalis (ossis parietalis), 72,73

sterni, 4I

superior pyranidis, 49,65

Annulus tympanicus, 70, 103, 104

Antrum of Highmore, 80-82, 93-95, 97, 99

mastoid, 64, 66, 67, 70

orifice of the, 90

entrance to, 66,67

tympanicnm, 64, 66, 67,70

Apertura vel aperturæ:

externa aquaductns vestibuli, $63,68,70$ canaliculi cochlew, 62,63 mastoidei, 66
Apertura vel aperturæ:

$+\quad$ inferior canaliculi tympanici, 62

interna canaliculi cochler, 69

pelvis [minoris] inferior, 126, 127

piriformis, $46,48,90,91,93$

superior, 124, 125, 127

$+\quad$ sinus maxillaris, 90 splienoidalis, 58-61, 90-9.3

1. sinum frontalium, $75,76,90,95$ superior canaliculi tympanici, 66, 67 thoracis inferior, 36 superior, 36

tympanica canaliculi chordæ, 64

Apex capituli fibulae, $13^{8}$

$+\quad$ ossis coccygis, 32

sacri, 30,31

patellæ, 136

pyranidis, $63,64,67,70$

Apophysis articularis (articular apophysis), 43 costalis (costal apopbysis), 43

muscularis (nuwscular apophysis), 43

Aqureductus vestibuli, 69

Aqueduct of the cochlea, external orifice, 62,63 of Fallopius, 64-69 internal orifice, 69 of the restibule, 60 deficiency in its tympanic wall, $C$

Arch of the atlas, anterior, 29 external orifice $63,68,70$

neural, or vertebral, 25,26

orbital, $48,74,76,77,92,9^{8}$

pubic, I 24

of the ribs, 36

zygomatic, 46-48, 96

Arcus anterior atlantis, 29

costarum, 36

posterior atlantis, 29

pubis, 124

superciliaris, $46,48,74$

vertebræ, 25,26

zygonaticus, 46-48, 96

*Area coclilex, 68

cribrosa media, 68 superior, 68

* of the facial nerve, 68

nervi facialis, $6 \mathrm{~s}$

vestibularis inferior, 68 superior, 68

Arnold's nerve, canal for, $62,64,65$

Arteria 11utricia, 20 protovertebralis, 34

Artery, intercostal, primitive, 34 nutrient, 20 protovertebral, 34

Articulation, nuanubrio-gladiolal, 41

Astragalus, $17,142,143$

Atlas, 29

developnent of, 35

Atrinm meatus medii (atrium of the middle neatus). 90 Auditory aperture, external, 47, 48, 62 internal, $63,65,68,70$ 
Axis of the pelvis, 127

Axis, the, 29

$$
\text { development of, } 35
$$

\section{B.}

Base of the mandible, 85,87 of the patella, 136 of the sacru1n, 32 of the skull, external aspect, 48 internal aspect, 49

Bases of the metacarpal bones, 122 of the metatarsal bones, 145 of the phalanges of the fingers, 122 of the toes, 145

Basilar portion of the occipital bone, $54-57,60$

Basi-occipital portion of the occipital bone, 54-57, 60, and note, p. 57

Basis cranii externa, 48 interna, 49 mandibulæ, 85,87 ossis sacri, 32

ossium metacarpalium, I 22 inetatarsalium, I45

patellæ, ${ }^{3} 36$

phalangis manus, I 22 pedis, 143

Basisplrenoid, 58-6i

Bertin, bones of, $58,59,61$

Bodies of the metacarpal bones, 122

of the metatarsal bones, 145

of the phalanges of the fingers, 122

of the ribs, 40 of the toes, 145

of the vertebra, 25-27

Body of the astragalus, 143

of the calcaneum, I4I, 143

of the feniur, 132,133

of the fibula, 138

of the humerus, II2

of the hyoid bone, 87

of the ilium, 130

of the inferior maxillary bone, $84-87$

of the ischium, 128,130

of the malar bone, 83

of the mandible, $84-87$

of the maxilla, $80,81,87,89$

of the os calcis, 14 I, 143

of the pubis, 130

of the radius, 115

of the sphenoid bone, $58.6 \mathrm{I}$

of the sternum, 4I

of the superior n1axillary bone, $80,81,87,89$

of the tibia, 136,137

of the ulna, 114

Bone, capitate, II9-121

central, of the carpus, 120

cuboid, 142, 144

cuneiform, of foot, external, 17, 142, 144

first, $141,142,144$

internal, 14I, 142, 144

middle, 142,144

second, I42, 144

of hand, 119,120

third, $17,142,144$

ethmoid, 52, 73

frontal, $52,74-76$

$$
\text { development of, } 77
$$

hip-, $107,128-130$ development of, 131

hyoid, 87

innominate, $107,128-130$ development of, 131

interparietal, 100 , note to p. 57

lachrymal, 53. 79, 90-92, 95

lunar, II9, I 20

malar, 53,83

-11narrow, II

maxillary, inferior, $46,47,53,84-86$

development of, 86
Bone, maxillary, superior, $46,47,53,80,81$

metacarpal, first, 106, I I9

development of, $8 z$

nasal, $53,79,90$, 91

navicular, 142,144

occipital, 52, 54-56

palate, 53,83 developnent of, 57 , and note

parietal, 19, 52, 72, 73

development of, 21

pisiform, I 8 - 120

premaxillary, 82, 97

pyramidal, II 9,120

scaplioid, I19, 120

sphenoid, 52, 58-60 development of, 61

-sphenoidal spongy, 58, 59, 61 turbinate, $58,59,6$ i

subcoracoid, If I

temporal, 52, 62-69 development of, 70,71

trapezoid, II9-12I

turbinate of the nose, highest, 78

unciforn, I19-12I

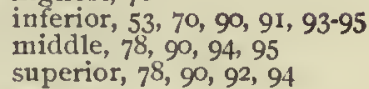

Bones, general considerations, 9-21 development of, $20,2 \mathrm{I}$

flat, I9

long, 12-15

minute structure, Io

of Bertin, $58,59,61$ short, 16, I7, 2I

of the carpus, 120, I2I

$$
\text { development of, I23 }
$$

of the cranium proper, 52

of the face, 53

of the forearm, 106, 114-116

development of, II7

of the leg, 107, 136-138

development of, 139

netacarpal, 119, 122

development of, 123

metatarsa1, 142, 145 development of, 146, I47

sesamoid, of foot, 140, 141

$$
\text { of hand, } 118
$$

of the skull, 52-104

suprasternal, 4 I

of the tarsus, $17,143,144$

Wormian, 100 development of, 146, 147

Border of the fibula, anterior, ${ }_{3} 8$ external, 138 internal, 138 interosseous, 138

of the frontal bone, nasal, 76,77 parietal, $74-76$ sphenoilal, 75,76

of the humerus, inner, II 2 outer, II2

of the occipital bone, lambdoid, 54-26 mastoid, $54-56$

of the parietal bone, anterior, 72,73 frontal, 72,73 inferior, 72,73 occipital, 72,73 posterior, 72,73 sagittal, 72, 73 squan11011s, 72,73 superior, 72,73

of the petrous portion of temporal bone, anterior, 65 of the petrous portion of the temporal boue, posterior, 65

of the petrous portion of the temporal bone, superior, 49,65

of the radius, anterior, 114,115 internal, 114,115 posterior, II4, I15 
Bcrder of the scapula, axillary, I 10 superior, IIO vertebral, 110

of the sphenoid, external, $58-60$

$$
\begin{aligned}
& \text { frontal, 58, } 59 \\
& \text { malar, 58-60 } \\
& \text { orbital, } 59 \\
& \text { petrons, } 59 \\
& \text { posterior, } 59 \\
& \text { squamous, } 58-60
\end{aligned}
$$

of the superior maxillary bone, infra-orbital, 80,83 , 98

of the temporal bone, occipital, 62,63

$$
\text { lachrymal, } 80
$$

of the tibia, anterior, 136,138 sphenoidal, $62-64$

external, I36-1 38

of the ulna, anterior, II

$$
\text { external, i I4 }
$$

Breschet's canals, I $, 5 \mathrm{I}, 88$

$$
\text { posterior, II } 4
$$

Brim of the pelvis, I 24 , I 25

$$
\begin{aligned}
& \text { iliac portion, I25 } \\
& \text { pubic portion, 125 } \\
& \text { sacral portion, 30, 125 }
\end{aligned}
$$

Bulla, ethmoidal, 78,90

$$
\text { C. }
$$

Calcaneum, or os calcis (called by Toldt "Calcaneus"), i7, I 42, I 43
development of, I 46,147

Calcar femorale, I34, 135

Calvaria, 50

Canal or canals (see also "Canaliculus"):

for Arnold's nerve, $62,64,65$

$$
\text { external orifice of, } 66
$$

for the auricular branch of the pneumogastric nerve, $62,64,65$

basipliaryngeal (see note to p. 48), 48, 58-60

of Breschet, $19,5 \mathrm{I}, 88$

carotid, $62-65,67,70,71,76$

for the chorda tympani nerve, $64,65,67$

dental, $8 \mathrm{I}$

anterior and middle, $8 \mathrm{I}$

inferior, 86

posterior, So, S1, 99

diploic, 19, 5I, $8 \mathrm{~s}$

ethmoidal, anterior, $76,90,91,98$ posterior, $76,91,98$

of the Eustachian tube, $63,64,66,67,69$

of the facial nerve, 64,69

Haversian, jo

iufra-orbital, 80, 8I, 95

internal orbital, auterior, $76,90,91,98$

for Jacoluson's nerve, $65-67$ posterior, $76,9 \mathrm{~T}, 99$

\section{inferior orifice, 62}

superior orifice, 66,67

malar, 83

mandibular, 86

medullary; II, I8-20

nutrient, I3, I8, I9

palatine, accessory, $83,90,9 \mathrm{I}, 97$

$$
\text { posterior, } 97,99
$$

palato-maxillary, 97,99

$$
\text { inferior orifice of, } 90,96,97
$$

pterygoid (or Vidian), 58, 59, 6r, 92, 93, 96, 99

pterygopalatine, $48,58.60,90.92$

sacral, 3I, 32

semicircular, external, 67-69

$$
\text { posterior, 68, } 69
$$

spinal, 43

$$
\text { superior, } 68,69
$$

temporal, 83

of the tensor tympani inuscle, $63,64,66,67,69$

Vidian (or pterygoid), 58, 59, 6r, 92, 93, 96, 99

Volkmam's, Io, I I
Canaliculus vel canaliculi (see also "Canal"): caroticotym panici, 62,67 chordx tympani, 64, 65, 67 coclilex (apertura exterua), 62,63

$+\quad \begin{aligned} & \text { innominatus, } 93 \\ & \text { mastoideus, } 62,64,65\end{aligned}$ (apertura interna), 69

$+\quad$ sphenoidalis, $92,93,96,99$

Canalis vel canales:

alveolares, $8 \mathrm{I}$

basipharyugeus, $48,58,59,90$

caroticus, $62-65,67,70,71,96$

condyloideus, $54-57,88,89$

diploici [Brescheti], I9, 5I, 88

facialis [Fallopii], 64, 65, 67-69

hypoglossi, 54-57,88

incisivus, 80 , 9 I

infra-orbitalis, $80,8 \mathrm{I}, 95$

mandibulae, 86

musculotubarius, 63,64

nasolacrimalis, 93,95

ntutricius, I3, I8, 19

palatini, 90, 97

pharyngeus, $48,58,59,90-92$

pterygoideus [Vidii], 58, 59, 6I, 92, 93, 96, 99

pterygopalatinus, 97,99

sacralis, 31, 32

semicircularis lateralis, 67-69 posterior, 68,69

vertebralis, 43 superior, 68,69

Capitellum of the humerus, II2

Capitulum costre, 40

$$
\begin{aligned}
& \text { fibula, I } 38 \\
& \text { humeri, II2 } \\
& \text { mandibulæe, } 84-86,96 \\
& \text { ossium metacarpalium, I22 } \\
& \text { metatarsalium, I41, I45 } \\
& \text { raclii, II5 } \\
& \text { ulıæ, I I4 }
\end{aligned}
$$$$
\text { raclii, II5 }
$$

Caput femoris, $132-134$

humeri, II 2

$+\quad$ ossis capitati, I2I

tali, I 43

Carpus, 106, I18

Cartilage, Meckel's, I03

Cartilages, costal, 39,40

Cartilago costalis, 39,40

Cavitas glenoiclalis, I IO, III

Cavity, cranial, 88,89

wedullary, I I, I8.20

nasal, $90-95$

sigmoid (of the radius), IIs

(of the ulua), great, II4, rIs

thoracic, 43

tympanic, 67

+Cavun11 cranii cerebralis, 88,89

medullare, IT, IS-20

nasi, $90-95$

thoracis, 43

tynupani, 65-70, 96

Cells, ethmoidal, $76,78,90$ of the Eustachian tube, 66 mastoid, 64,67

tympanic, 67

Cellulæ etlimoidales, 78 , 90 mastoidea, 64,67

pneumaticæ tubariæe, 66

tympanicæ, 67

Centra of the vertebra, 25-27

Choauze, $48,93,96$

Chorda dorsalis, 34

tympani nerve, canal for, $64,65,67$ orifice of the canal for, 64

Cingulum extremitatis inferioris, 107, 124-126 superioris, 106, 108

Circumference, articular, of the radius, 115 of the nlna, 114 
Circumferentia articularis radii, II5 ulnæ, II

Clavicula (the clavicle), 106, 108, 109

Clivus, $49,56,88$

Coccyx, the, 24, 32, 33, 125, 126 developnent of, 35 extremity of the, 32

Coclilea, $65,68,69$

Collum anatomicum, II 2 clirurgicum, 112 costæ, 40

femoris, I32-1 34

mandibulæe, 84,85

radii, 115

scapula, I Io

tali, 143

Column, spinal, 24 development of, 34,35
vertebral, 24 development of, 34,35

Concavity of the carpus, is

Concha nasalis inferior, $53,79,90,91,93-95$

media, $78,90,94,95$

superior, 78, 90, 92, 94 suprema [Santorini], 78

Conchæ sphenoidales, $58,59,6$ I

Condylar portion of the occipital bone, $54,56,57$, and note, p. 57

Condyle of the femur, external, r32, I34 internal, 132-134

of the liumerus, external, ir

internal, 112

of the inferior niaxillary bone, $84-86,96$

of the nuandible, $84-86,96$

Condyles of the occipital bone, $48,54-56$

Condylus lateralis fernoris, I32, I34 tibiz, 136,137

medialis femoris, $132-134$ tibize, 136,137

occipitalis, $48,54-56$

+Conjugata diagonalis, 127

vera, 127

Conjugate diameter, diagonal, 127

Cornt, coccygeal, 32

$$
\text { true, } 127
$$

of the hyoid bone, great, 87

sacral, 3I, 32

small, 87

Cormua sphenoidalia, $58,59,6$ I

Corpus calcanei, 141, 143

costæ, 40

femoris, $132, I_{33}$

fibulæ, 138

humeri, I12

mandibula, $84-87$

maxilla, 80, 81, 87, 99

ossis liyoidei, 87

ilium, 130

ischii, $128,13^{\circ}$

pubis, 130

splienoiclalis, 58-61

ossium metacarpalium, I22 metatarsalium, $\mathbf{1 4 5}$

phalangis manus, 122

radii, 1 I 5 peclis, 145

sterni, 41

tali, I43

tibiæ, 136, I 37

ulnæ, II4

Costre, 3840

development of, 42

spuria, 36

veræe, 36

Cranionetry, Ior

Cranium, 45-104 cavity of, 88,89

(levelopnient of, IO2-IO4

facíal portiou (cranium viscerale), 53, 96, 97
Cranium, primordial (cranius primordiale), 102, 103 proper (cranium cerebrale), 52, 88, 89

*Crest, buccinator, 84,85

ethmoidal, of the palate-bone, 83

frontal, $49,50,75,85$ of the superior maxillary bone, 80,81

of the fundus of the internal auditory meatus, trans. verse, 65,68

of the ilium, $128-130$

inferior turbinate, of the superior maxillary bone, 8o, 8I

infratemporal, 48, 58-60, and note, p. 59

lachrynal, 79,98

anterior, see "Ridge, orbital"

posterior, see "Crest, lachrymal"

nasal, of the superior maxillary bone, 91, 95, 97

obturator, 130

occipital, external, $48,55,56$

internal, $49,54,56$

of the occipital bone for the rectus capitis posticus major muscle, 56

of the occipital bone for the rectus capitis posticus mituor inuscle, 56

orbital, 59

of the septum of the nose, lateral, 93

sacral, articular, 3 I external, 31 median, 31

splenoidal, 58,59

supramastoid, 62

temporal, 46, 74, 77

transverse, see "Crista falciformis"

turbinate, inferior, of the palate-bone, $3_{3}$

of the superior maxillary bone, $80,8 \mathrm{I}$ superior, of the palate-bone, $8_{3}$

of the vestibule, 69

Crista anterior (fibula), 138 (tibiæ), 136,138

buccinatoria, 84,85

capituli costæ, 40

colli costæ, 40

conclialis (maxillæe), 80, 81 (ossis palatini), 83

ethnoidalis (maxillae), 80, 8I

falciformis, 65,68 (ossis palatini), 83

frontalis, $49,50,75,88$

galli, 49, 78, 88, 94, 95

iliaca, I 28- I 30

infratenıporalis, $48,58-60$

interossea (fibulæ), ${ }_{3} S$ (radii), II 4115 (tibiz), $136-13^{8}$ (ulnæ), I I4

intertrochanterica, I 32-I 34

lacrimalis anterior, 80,98

posterior, 79, 98 fibula), 138 septi (nasi), 93

medialis (fibulæ), 138

musculi recti capitis majoris, 56 supinatoris, 114 minoris, 56

nasalis, 9I, 95, 97

obturatoria, 130

occipitalis externa, $48,55,56$ interna, $49,54,56$

orbitalis (alæ magnæe), 59

sacralis articularis, 31

lateralis, $3 \mathrm{I}$ medialis, 3 I

sphenoidalis, 58,59

transversa, 65, 68

tuberculi majoris, II 2

vestibuli, 69 minoris, 112

Crus commune and crus simplex of the semicircular canals, 69 , and note, p. 69

Cupular portion of the epitympanic recess, 64 
Dens epistrophei, 29

Depression, digital, 85

Depressions for the lateral metatarso-plalangeal ligaments, 145

Pacchionian, 50, 73

Diameter, conjugate, of the pelvis, diagonal, 127

Diameters, oblique, of the pelvis, 127 true, 127

Diapleysis, 20 ransverse, of the pelvis, 127

Digiti (manus), 118 pedis, 140,14

Diploë, 19, 50, 51 of the frontal bone, 76,77

Disc, epiphysial, 20

Dorsum of the foot, 140 of tlie scapula, I10 sellae, 58-6r, 96

\section{E.}

Eminence, articular, 62

deltoid, 112

frontal, $46,74,77,104$

iliopectineal, I28, 130

jugular, 54,56

olivary, $59-61$

parietal, 72, 104

papillary, $66,67,69$

po the second rib for the serratus magnus, 40 of the superior semicircular canal, $63,7^{\circ}$

Eminentia arcuata, 63,70

carpi radialis, 118 ulnaris, 118

cruciata, 54,89

iliopectinea, 128,130

intercondyloidea, $13^{6,} 137$

papillaris, $66,67,69$

pyramiclalis, $66,67,69$

Entrance to the mastoid antrum, 66,67 to the orbit, $48,9^{8}$

Eipicondyle of the femur, external, 132, I34

Epicondylus lateralis (femoris), 132, 134

$$
\begin{aligned}
& \text { internal. I32, } \\
& \text { (femoris), 132, } 134 \\
& \text { (lumeri), I } 12
\end{aligned}
$$

medialis (femoris), 132, 135 (humeri), 112

Epiplysis, 20

Epistrophews, 29

development of, 35

Epitympanic recess, $63,69,70$

Eustachian canal, 63, 64, 66, 67, 69

Extremitas acromialis (clavicula), 109

sternalis (clavicula), 109 Extremity of the clavicle, acromial, 109

Fxoccipital, 54, 56, 57, and note, p. 57

\section{F.}

Facet or facets, articular: of the acromion, clavicular, is of the atlas, superior, 29

of the astragalins for the calcanem11, anterior, 143 middle, 143 posterior, 143

for the external inalleolus, 143 for the internal malleolus, 143 for the navicular bone, 143

of the clavicle, acromial, $\log$ sternal, 109

of the heads of the ribs, 40 of the odontoid process, anterior, 29 of the os calcis, anterior, 143 cuboid, I43 internal, 143 posterior, 143

for the rihs (sternal), 4 I of the tubercles of the ribs, 40
Facet or facets, articular : of the vertebra, inferior, 25-27 superior, $25-27$

Facial portion of the skull, 53

+ Facies, anterior femoris, 132, 133 lateralis humeri, I12 maxilla, 80 medialis lnneri, 112 pyranidis, 65

articularis acromialis (claviculæ), 109 acromii, 1 Io anterior calcanei, 143 epistrophei, 29

calcanea (tali) anterior, I43 media, 143

capituli costre, 40 posterior, 143

carpea, II5 fibula, 138

cuboidea (calcanei), I43

fibularis, 136,137

inferior tibix, 137 vertehrarum, 25-27

malleolaris (tibia), 137 malleoli (lateralis), 137,138 media (calcanei), 143 navicularis (tali), I43 ossis temporalis, $62,70,71$ patellae, 136 posterior (calcanei), 143 sternalis (claviculæ), 109 superior tibiæ, 137 vertebrarum, 25.27

tuberculi costa, 40

auricularis ossis ilium, 128 sacri, 31,32

cerebralis ale magna, 58,6 I ossis frontalis, 75 parietalis, 73 squamæ temporalis, $G_{3}, 64$

costalis scapulae, I 10

dorsalis manus, I19

ossis sacri, $31,32,126$

pedis, 140

radii, $114-116$

scapulæ, I Io

ulnae, II4

frontalis (ossis frontalis), 74

inferior pyramidis, 65

infratemporalis (maxillæ), 80, 99

lateralis femoris, 132,133

fibulae, $13^{8}$

radii, I14. I 16

tihix, 136.138

Innata (acetabuli), I30

malaris (ossis zygomatici), 83

malleolaris lateralis (tali), 143 medialis (tali), 143

maxillaris ossis palatini, $\mathrm{S}_{3}$

medialis femoris, 132,133

fibula, ${ }_{3} 8$ tibiae, 136,138 ulnex, 1 is

nasalis maxille, 80 ossis palatini, $8_{3}$

orbitalis alæe magnze, $5 \mathrm{~s}-61,98$ maxillec, 80 ossis froutalis, 76

ossea, 53 zygomatici, 83

parietalis (ossis parietalis), 72

patellaris, 132-134

pelvina (ossis sacri), 30, 32, I25

posterior fibula, I38

humeri, 112

pyranidis, 65

tibire, $136-13^{8}$

sphenomaxillaris (ala magna), 58, 99 superior (tali), 143 
Fiacies synı physeos, 128 temporalis al:e magnæ, $58.6 \mathrm{I}$ ossis frontalis, 74,77

zygomatici, 83

$+$ volaris manus, I18 squaniae temporalis, 62,63

Femur, tlie, I4, 107, 132-134 development of, 135

Fienestra coclileax, 67,69 ovalis, $67-69$

rotunda, 67,69

vestibuli, $67-69$

Fibres, Sharpey's, Io

Fibula, the, 107,138 development of, 139

Fingers, skeleton of, 18

Fissura orlutalis inferior, $93,96,98$ superior, $58,59,88,92,98$

petro-occipitalis, " $48,49,88$

petrosquamosa, $63,64,69$

petrotympanica [Glaseri], 62, 65, 70, 7I

pterygoidea, 58,59 .

pterygomaxillans, 99

spheno-occipitalis, 60

sphenopetrosa, 48,49

tympanomastoidea, $62,66,7$

Fissure, Glaserian, $62,65,70,7 I$

incisor, 48, 82, 97

occipitosphenoídal, 60

orbital, $58,59,88,92,98$

petrobasilar, $48,49,98$

petrosquamous, $63,64,60$

pterygonaxillary, 99

sphenoniaxillary, $93,96,98$

Fontanelle, anterior, 104

anterolateral, 104

posterior, 104

posterolateral, 104

Fonticulus frontalis [major], IO4

mastoideus, 104

occipitalis [minor], 104

sphenoidalis, IO4

Foranen or foranina:

alveolar, anterior and niicldle, $\boldsymbol{I t}_{\mathrm{t}}$ posterior, 80, $8 \mathrm{r}, 99$

cæcum, 49, 75, S8, 91, 94

condylar, anterior, 54-57, 88 posterior, $54-57,88,89$

costotransverse, 26,29

enissarii occipitalis, 89

emissary, mastoid, $62,63,89$

occipital, 89

of Vesalius, see "Canaliculus splienoidalis," and rote, p. 92

ethmoidale anterius, $76,90,91,98$ posterius, $76,9 \pi, 98$

frontale, 76

iucisivunı, 82, 93, 96, 97

inferior dental, 85

infra-orbital, 8n, 81, 98,99

intervertebral, 24

jugular, $48,49,88$

$$
\text { of the sacrum, } 31
$$

bipartite, 88

divided by an intrajugular process, 88

lacerate, anterior, $58,59,88,92,98$

nuidalle, 48,49

posterior, $48,49,88$

mandibular, 85

maguun, $48,54-56,89$

t11astoid, $62,63,89$

inental, 85,86

nasal, 79

nutricium, 18, 19

clavicula, Iog

feistoris, 132

fitule, 138
Foranen or foramina:

nutricium humeri, II2

ossis ilii, I9

radii, II 5,116

tibiac, $18,136,137$

ulnce, I14, II6

nutrieut, I8, I9

of tlie clavicle, rog

of the fenur, 132

of the fibula, 138

of the humerus, I12

of the ilinun, I9

of the radius, II5, II 6

of tlie tibia, $18,136,137$

of the ulna, II4, II6

obturator, I28-1 30 optic, $59-61,88,98,99$

ovale (of the lip-bone), I28-I 30

(of tlie skull), 59, 6r, 96

palatina minora, $83,90,97$

palatinum majus, $90,96,97$

palatine, grtat, $90,96,97$ parietal, 72, 73, 100 pterygospinous, 91 rotundum, $38-61,88,92,93,99$

sacral, anterior, 30

$$
\text { posterior, } 3 I
$$

singulare, 68

sphenoidal, 58-6I, 90-93

splienopalatiue, 90, 91, 98, 99

spinal, 25-27

spinosumi, 59

of Stenson, 82

stylomastoid, 62; 64, 67, 70, 7 I

supra-orbital, 74,76

thyroid, 128 -I 30

transversariun1, 26, 29

vertebrale, $25-27$

for vertebral artery, 26, 29

of Vesalius, note to p. 92 (see also "Canaliculus, sphenoidal")

zygomaticofaciale, $8_{3}$

zygonliatico-orbitale, 83

zygonaticotemporale, $1_{30}$

Fossa acetabuli, 130

canine, 80

condylar, posterior, 55

coronoid, II2

cranial, anterior, $49,88,95$ middle, 49,88 posterior, 49,88

digastric (of the inferior maxillary bone), 85 (of the temporal bone), 62, $7 \mathrm{x}$

digital, 132, 133

of the external lateral liganent of the ankle-joint, I 37,138

floccular, 63,70

glandula lachrymalis, $76,77,92,98$

of the Gasseriain ganglion, 63

glenoid, of the scapula, I Io, II I of the temporal bone, 62, 70, 7I

liypophyseos, 59-6r, and note to p. 60

iliac, 128

of the incus, 64

infraspinous, 1 ro

infratemporal, 48,96

intercondylar, of the femur, $132, \mathbf{1 3 4}$

of the tibia, anterior, 137

intercondyloidea (fenıoris), 132,134 anterior (tibia), $\mathrm{I} 37$ posterior (tibire), 137

jugular, of the teniporal bone, 62,65

lachrymal, 76, 77, 92, 98

mandibularis, 62

occipital, inferior, 54,56

superior, 54

olecranon, II 2

palatine, anterior, $82,96,97$

pituitary, 59-5I

prenasal, 97 
Fossa, pterygoid, 58, 95

pterygopalatina, 92, 98, 99

radial, I 12

reniform, 65

sacci lacrimalis, $9 S$

scaplioid, $5^{8}$

sphenomaxillary, 92, 98, 99

subarcuata, 63,70

subscapular, i 10

supraspinous, 110

temporal, 47

trochanterica, 132, 133

trochlear, 76

vermian, $8 y$

zygomatic, 48,96

Fossula fenestræ cochlex, 66,68 vestibuli, 66

-of the fenestra ovalis, 66

ovalis, 66

rotunda, 66,68

of the petrous ganglion, 62,65

petrosa, 62,65

rotunda, 66,68

Fovea articularis ossis temporalis, 62 superior atlantis, 29

capitis femoris, 132, 133

capituli radii, 115

costalis, inferior, 25 superior, 25 transversalis, 25

dentis, 29

pterygoidea (processus condyloidei), 84,85

sublingualis, 85

submaxillaris, 85

trochlearis, 76

tFoveolæ ethnoidales, 76

Frons, 46, 47

granulares [Pacchioni], 50, 73

Fundus meatus acustici interni, 65

of the internal auditory meatus, 65

G.

Geniculum of the aqueduct of Fallopius, $65,67,68$ canalis facialis, $65,67,68$

"German horizontal," 101

Girdie, pelvic, 107, 124-126

shoulder, 106, 108

Glabella, 46, 74

Gladiolus, 4I

Great wing of the sphenoid, 58.61

Groove or grooves :

for Arnold's nerve, 62, 65

for the auricular branch of the puenmogastric nerve, 62,65

basilar, $49,56,58$

bicipital, 112

carotid, 58,59

fibular, 136,137

of the hamular process, 58

infra-orbital, $80,93,94,98,99$

interosseous, of the astragalus, 143

of the calcaneum, 143

lachrymal, 98 of the tarsus, 143

of the lachrymal bone, 79,92

of the superior naxillary bone, So, 82 , 91,98

neningeal, 50,73

of the middle temporal artery, 62

inylohyoid, 85

of the nasal nerve, 79, 91

obturator, 128

occipital, 62,71

optic, 59

palatine, 82,97

anterior, 80 , 91

posterior, So

of the palate-bone, 83

of the sphenoid bone, 58 , and note to same
Groove or gruoves :

palatonaxillary, so

$$
\begin{aligned}
& \text { of the palate-bone, } 83 \\
& \text { of the splienoid bone, } 58 \text {, and }
\end{aligned}
$$

preauricular, 128 note to sanie

of the promontory, for the nerves of the tympanic plexus, 67

pterygopalatine, note to p. $5^{8}$

spiral, 112

for spinal nerve, 26

of the subclavian artery, 40

subcostal, 40

of the superficial petrosal nerve, great, 63,64

of the tendon of small, 63,64

tbe flexor carpi radialis muscle, $12 \mathrm{I}$

the flexor longus liallucis muscle, 141,143

the peroneus longus muscle, $140,14 r, 143$, 144

the poplitens nuscle, 134

the tibialis posticus muscle, 136

of the tendons of the peroneal muscles, $13 \mathrm{~S}$

of the ulnar nerve, 112

vertebral (for vertebral artery), 29

Hanulus lacrimalis, 79,98

H.

ossis hamati, 118, 121

pterygoideus, $58,60,95$

Haversian canals, to systen of lamellæ, Io, II

Head of the astragalus, 143

of the capitate bone, 121

of the fenur, $132 \cdot 134$

of the fibula, 138

of the humerus, 112

of the inferior maxillary bone, $84-86,96$

of the mandible, $84-86,96$

of the os magnum, 121

of the radius, 115

of the scapula, 710

of the ulna, I14

Heads of the nietacarpal bones, 112

of the metatarsal bones, 141,145

of the ribs, 40

Heart, rudimentary, 102

Hiatus canalis facialis, $63-67$

Fallopii, 63.67

maxillaris, So, 91, 99

of the sacrum, 31

senilunaris, 78,90

subarcuatis, 63,70

Hip-bone, the, 107, 128-130 development of, 131

Hook of the unciform bonc, 118,121

Horsesloe-shaped articular surface of the acetabulum, 130

Humerus, the, 12, 106, II 2 development of, 113

I.

Iliac portion of the iliopectineal line, 128

Ilium, the, I9, $124-126$

*Impressiones digitatre, 49, 75, and notes, pp. 49 and 75

Impression, rhomboid, 109

Impressio trigemini, 63

Incisura vel incisura:

acetabuli, 130

clavicularis, 41

costales, $4 I$

etlımoidalis, 76,77

fibularis, 136,137

frontalis, 74,76

ischiadica nuajor, 128,129

minor, 129

jugularis ossis occipitalis, 56,89

lacrimalis, 80 temporalis, 63 
Incisura vel incisuræ:

mandibulæ, 8

mastoidea, 62,71

nasalis, 80

parietalis, 62,63

radialis (ulnæ), II4

scapula, I 10

senilunaris, 114,115

spbenopalatina, $\mathrm{S}_{3}$

supra-orbitalis, 74,76

tympanica [Rivini], 62, 64, 70, 71

ulnaris (radii), II5

vertebralis inferior, 25,27

superior, 27

Inclination of the pelvis, 127

Infundibulum, 78

Interparictal bone, note, p. 57

Ischium, the, I24-1 26

Iter cliordæe posterius, $64,65,67$

\section{$J$.}

Jacobson's nerve, canal for, $65-67$

Jaw-bone, lower, $46,47,53,84-86$ development of, 86

upper, $46,47,53,80,81$ development of 82

Jaws, senile atrophy of, 87

Juga alveol aria, 80,85

cerebralia, 49,75

Labium externum (cristæ iliacæ), I29, I30 internun (cristæ iliacæe), I 28

laterale (linere asperæ), I32, 133

mediale (linere asperæ), 132, 133

Labyrinth, bony, $68,69,96$ of the ethmoid bone, $78,92,94$ osseous, $68,69,96$

Laby'rintlu us ethmoidalis, $78,92,94$ osseous, $68,69,96$

Laclirymal canal, 93, 95

Lacuna of bone, ro

Lamina cribrosa, $78,90,91,94$

externa of the cranial bones, 19, 50

interna of the cranial bones, 19,50

lateralis processus pterygoidei, $58,60,61,99$ malaris (ossis zygomatici), 83 medialis processus pterygoidei, $5 \delta, 6$,

$+\quad$ orbitalis (ossis zygomatici), 83,98

papyracea, 78, 91, 92, 94

perpendicularis, $78,91,94,95$

of the vertebræ, 25,26

Limbus alveolaris mandibulæ, 84,86

t deutalis, 48 niaxillæ, 80-82, 97

Linea vel liner:

arcuata (ossis ilii), I 28

aspera (fentoris), 132,133

glutæa anterior, 129,130 inferior, 129

posterior, I29

intercondyloidea (femoris), 132

intermedia (cristæ iliacæ), I 28, I30

intertroclianterica, 132, I33

in usculares (scapulæ), 1 Io

wylohyoidea, 85

nuchæ inferior, $48,55,56$ superior, 55,56 suprema, 55

obliqua (mandibulæ), $84, \mathrm{~S}_{5}$

pectinea (femoris), 132, 133

poplitea, 136,137

temporalis inferior, $47,62,72$

(ossis frontalis), 46, 74, 77 superior, 47,72

terminalis (pelvis), I24, I25 pars iliaca, 125 pubica, 125 sacralis, 30, 125

transversae (ossis sacri), 30
Line or lines :

curved, of the iliun, inferior, 129 iniddle, 129,130 superior, 129 of the occipital bone, highest, 55 inferior, $48,55,56$

gluteal, inferior, 129 superior, 55,56

middle, I 29, I 30

posterior, 129

iliopectineal, iliac portion, 128

intercondylar, pubic portion, 128

intertrochanteric, anterior, 132,133 posterior, $\mathrm{I} 32, \mathrm{I} 33$

oblique, external (of the inferior maxillary bone), 84 , 85

internal (of the inferior naxillary bone), 85 of the scapula, 110 of the tibia, 136,137

pectineal, 132, 133

temiporal, inferior, 47,72

superior, 47,72

trapezoid, rog

Lingula nıandibulæ, $84-86$

sphenoidalis, 59,99

Lip of the crest of the ilium, inner, 128

outer, 129,130

inter, 132,133
outer, 132,133

M.

Malleolus, external, 137,138

internal, 136,137

lateralis, 137,138

medialis, 136,137

Mandibula, $46,47,53,84-86$ developinent, 86

Ianubrium sterni, 4

Margin, alveolar, of the inferior maxillary bone, 84,86 of the superior maxillary bone, $\mathrm{So}-82,97$

of bicipital groove, inner, $I 12$ outer, I 12

supra-orbital, $48,74,76,77,92,98$

Margo axillaris (scapulæ), I 10

dorsalis radii, 114,115 แ111æ, I14

frontalis ossis parietalis, 72,73 splienoidalis, 58,59

infraglenoidalis (tibire), 136,137

infra-orbitalis, $8 \mathrm{a}, 83,98$

lacrimalis (maxillæ), 80

lanbdoideus, $54-56$

lateralis humeri, I12 pedis, 140

mastoideus, $54-56$

medialis humeri, II2 pedis, 140 tibiæ, 136,138

nasalis (ossis frontalis), 76,77

occipitalis ossis parietalis, 72,73 temporalis, 62,6

$+\quad$ orbitalis (ossis sphenoidalis), 59

parietalis ossis frontalis, $74-76$ temporalis, 62,63

+ petrosus (ossis sphenoidalis), 59

sagittalis (ossis parietalis), 72,73

spbenoidalis ossis frontalis, 75,76 teniporalis, $62-64$

squamosus ossis parietalis, 72, 73

superior (scapulæ), I Io sphenoidalis, 58.60

supra-orbitalis, $48,74,76,77,92,98$

vertebralis (scapulæ), I IO

volaris radii, $114, \mathrm{I1} 5$ ulnæ, II4

zygomaticus (ossis sphenoidalis), 58-60

Massa lateralia (atlantis), 29

Masses, lateral (of the atlas), 29 
Mass, lateral, of the ethmoir bone, $78,92,94$ of the sacrum, 30, 3I

Mastoid antruı, $64,66,67,70$ entrance to, 66,67

portion of the temporal bone, $62-64,70,71$

Maxilla, the, $46,47,53,80$, $8 \mathrm{t}$

$$
\text { development of, } 82
$$

Meatus acusticus externus, $47,66,69,71,96$ internus, $65,68,69,96$

auditory, external, $47,66,69,71,96$

nasal, common, 78,96 internal, $65,68,69,90$

inferior, 90,94

middle, 90,94

superior, 90,94

nasi communis, 78,96

inferior, 90,94

medius, 90,94

superior, 90,94

nasopharyngeal, 90

nasopharyngeus, 90

Medulla ossium, II

Membrane of the anterior fontanelle, IOC

Mesosternuni, 4I

Metacarpus, 106, I18

Metatarsus, 107, 140

Mietasternum, 4I

\section{N.}

Nares, posterior, $48,93,96$

Nasal aperture, anterior, 46, 48, 90, 91, 93 posterior, $48,93,96$

Neck, anatomical, of the humerus, II of the astragalus, 143

of the femur, I32. I34

of the inferior maxillary bone, 84,85

of the mandible, 84,85

of the radius, II5

of the scapula, ito

surgical, of the humerus, 112

Necks of the ribs, 40

+ Norma frontalis, 46,101
$+\quad$ lateralis, 47,101

verticalis, IoI

Notch, cotyloid, I30

clavicular, 41

ethmoidal, 76, 77

great sciatic, 128, 129

iliosciatic, 128 , I 29

interclavicular, 40

jugular, of the occipital bone, 56,89

lachrymal, 80 the temporal bone, 63

nasal, So

parietal, 62, 63

popliteal, I 37

pterygoid, 58,80

of Rivinus, 62, 64, 70,71

sciatic, 129

signoid, 84

snall sciatic, 129

sphenopalatine, 83

supra-orbital, 74,76

suprascapular, I 10

vertebral, inferior, 25,27

Notocliord, 34 superior, 27

"Nutcracker face," 87

Nutrient artery, 20

O.

Occiput, 47

Odontoid process, 29

Olecranon, 114, I1 15

Optic vesicle, primary, Io2

Orbit, entrance to the, 48,98

Orbital orifice, height, IOI

$$
\text { width, ror }
$$

Orbitosphenoid, 6I

Orbits, the, $92-95,98$

Orifice of the Fustachian tube, tympanic, 66
Os vel ossa :

+ acetabuli, 13 I

† antibrachii, I06, II4-110 developnent of, $1: 7$ development of, 2 I

capitatu11, II9-121

calcis, $17,142,1.43$ development of, 146,147

carpi, 120, 121 development of, 123

centrale carpi, 120

coccygis, $24,32,33,125,120$

costale, 38,39

developnient of, 35

developnient of, 13 :

cranii, 52-104 cerebralis, 52

$\uparrow$ cruris, 107, $136-138$ development of, 139

cuboideum, L42, 144

cureiforme primum, 14I, 142, 14. secundum, 142, I 44 tertium, $17,142,144$

ethmoidale, 52,78

faciei, 53

frontale, 52, 74-76

hamatum, I19-121

deve

hyoide11m, 87 - 26

+ incæ, 100

incisivum, 82,97

+ infracoracoideum, III

innominatum, 107, 128-130

interparietale, 100 development of, 131

ischii, 124-126

lacrimale, $53,79,90-92,95$

longa, I2-I 5

lunatum, I19, 120

nuagnu11, 119-121

metacarpale I., I06, 119

metacarpalia, 119, 122 development of, 123

metatarsale I., 107, 142

metatarsalia, 142, 145 development of, 146, 147

nultangulum najus, $119-121$

111inus, II9-12I

nasale, $53,79,90,91$

naviculare manus, I $[9, I 20$ pedis, 142, 144

occipitale, 52, 54-56 development of, 57

palatinum, 53,83

parietale, $19,52,72,73$

pisifornte, 118-120 development of, 2I

plantum, 78, 91, 92, 94

plana, 19

pubis, $124-126$

sacrum, 24, 30-33, 125, 126 development of, 35

sesamoidea manus, 118 pedis, I40, $14 \mathrm{I}$

sphenoidale, 52, 58-60

suprasternalia, $4 \mathrm{t}$ development of, 51

suturarum, 100

tarsi, 17, 143, 144

temporale, 52, 62-69 development of, 70,75

trigonum, 143

triquetru111, II9, I 20

zygoniaticum, 53, $8_{3}$

"Osseous corpuscles," Io

Ossification, intracartilaginous, 20 intramentbranous, 21 
Ossification of the $\mathrm{Y}$-sliaped cartilage of the acetabulum, $13 \mathrm{I}$ Osteology, 7 et seq.

Ostium tympanicum tubæ auditive, 66

Palate, hard, $48,94,96,97$

$$
\text { P. }
$$

Palatum durum, 48, 94, 96, 97

Paries carotica cavi tympani, 65, 66 inferior orbita, $93,98,99$

jugularis cavi tymupani, 66

labyrinthica cavi tympani, 65,66

lateralis orbitie, 98

mastoidea cavi tyıpani, 66

medialis orbitze, 98

superior orbitæ, 92,98

tegmentalis cavi tympani, 65

Pars alveolaris mandibulæe, $84-86$

basilaris ossis occipitalis, $54-57$

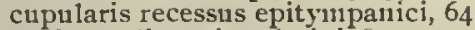

horizontalis ossis palatini, $83,90,91,97$

lateralis ossis occipitalis, $54,56,57$ sacri, 30, 31

mastoidea ossis temporalis, $62-64,70,71$

nasalis ossis frontalis, 74,77

orbitalis ossis frontalis, $75-77,94,98$

perpendicularis ossis palatini, $83,90,91,97,99$

petrosa ossis temporalis, $62-64,70,7 \mathrm{I}$

tympanica ossis temporalis, $62,64,65,71$

Patella, 107, 136

Pecten ossis pubis, 128

Pedicle of the neural arch, 25, 26

Pelvic brinı or inlet, 124, 125, 127 girclle, 107, 124-1 26

outlet, 126, 127

Pelvis, 124, 127

axis of, 127

diameters of, 127

false, 124,125

female, 124

major, 124, 125

male, 125,126

measurements of, 127

$+\quad$ nuliebris, 124

true, $124,125,127$

$+\quad$ virilis, 125,126

Pericliondrium, 20

Periostenm, II, 20

Petrosal ganglion, depression for, 62,65

Petrous portion of the temporal bone, $62-64,67,70,71$

Phalanges digitorum manus, 106, I $8,119,122$ development of, 123 pedis, 107, 140-142, 145 development of, 146,147

hallucis, 107 pollicis, 106

Phalanges of the fingers, 106, $118,119,122$

development of, 123

of the great toe, $10^{\circ}$

of the thumb, 106

of the toes, $107,140-142,145$ development of, 146,147

Pit, olfactory, 102

Plane, nuchal, 48,55 , I00 occipital, 55,100

Planum nuchale, $48,55,100$

$$
\text { occipitale, } 55,100
$$

popliteum, 132

$+\quad$ sternale, 36

temporale, 47,72

Plate, cribriform1, 78, 90, 91, 94 of the ethmoid bone, orbital, 78, 91, 92, 94

vertical, $78,91,94,95$

of the frontal bone, orbital, $75-77,94,98$

of the palate bone, horizontal, $83,90,91,97$

palate, $83,90,91,97$

pterygoid, external, $58,60,6 \mathrm{r}, 99$

vertical, $83,90,91,97,99$

internal, 58,6

Ponticulus promontorii, 67
Portion, nasal, of the frontal bone, 74, 77

Porus acusticus externus, $47,48,62$

Postsphenoirl, 6i internus, $63,65,68,70$

Premaxilla, 82, 97

Presphenoid, 6I

Presternum, 41

Process or processes :

accessory, 27

alar, 78,94

articular, of tle sacrum, superior, 30-32 of the vertebra, inferior, $25-27,29$ superior, $25-27,29$

of the astragalus, external, 143

posterior, 14I, 143

trochlear, 143

basilar, of the occipital bone, 54-57, 60

clinoid, anterior, $58-60$

niiddle, 59,60

posterior, 58,59

cochleariform, 64-68

coracoid, IIO, III

coronoid (of the mandible), 84,86

costal, 27 of the ulna), II4

ensiform, 41

ethmoidal, 79, 90

of frontal bone, external angular, 75-77

bumular, of the lachrymal bone, 79,98 of the sphenoid bone, $58,60,95$

intrajugular, of the occipital bone, 63

jugular, $54,56,89$ of the temporal bone, 56

laclirymal, 79, 90

of the malar bone, frontal, 83 nuarginal, 83 orbital, 83,98 temporal, 83

mamillary, 27

mastoid, $48,62,64,67,71,88$

maxillary, of the inferior turbinate bone, 7999 nasal, of the palate bone, 83,99

of the maxillary bone (inferior), alveolar, $84-86$ coronoid, $84-86$

(superior), alveolar, 80, 82, 99 malar, 80,82 rasal, 80,81 , 91 palatine, $80-82,90$,

odontoid, 29 91,97

of the palate bone, orbital, $83,90-92,98,99$ pyramidal, $83,97,99$ sphenoidal, $83,90,91$

paramastoid, 88

paroccipital, 88

pterygoid, 48, 58-61, 91, 92

pterygospinous, 60, 91

spinous, of the sphenoid bone, $5^{8-6 r}, 93$ (of vertebra), 25-27

styloid, of the fibula, $13^{8}$ of the radius, 115 of the temporal bone, $48,62,64$ of the third metacarpal bone, 122 of the ulna, 114, 115

transverse, 25, 26, 28

tympanic, anterior, 70,71 posterior, 70

unciform, of the unciform bone, 118, I2I uncinate, $78,90,94,95,99$

ungual, of the phalanges of the fingers, 122 of the toes, I4I, 145

vaginal, of the sphenoid bone, $58,59,61,90,91$ xiphoid, 4 i of the temporal bone, $64,70,71$

Processus accessorius, 27

alaris, 78,94

alveolaris (n1axillæ), $80,82,99$

- articularis inferior vertebrarum, 25-27, 29 superior ossis sacri, $30-32$ vertebrarum, 25-27, 29

clinoideus, anterior, 58-60 
Processus clinoidcus, medius, 59, 60

posterior, 58, 59

cochleariformis, $65,66,68$

condyloideus, 84,85

coracoideus, IIO, III

coronoideus mandibulæ, 84-86

costaruus, 27

ulnæ, 114

etlımoidalis, 79,90

frontalis, $80,8 \mathrm{I}$,

frontosphenoidalis, 83

intrajugularis ossis occipitalis, 56

jugularis, $54,56,89$

temporalis, 63

lacrimalis, 79,90

lateralis tali, 143 tuberis calcanei, $141, \mathrm{I} 43$

mamillaris, 27

marginalis, 83

mastoidens, $48,62,64,67,71,88$

maxillaris, 79,99

medialis tuberis calcanei, I4I, I43

nasalis ossis palati, 83,99

orbitalis, $83,90-92,98,99$

palatinus, 80-82, 90, 91, 97

paramastoideus, 88

postior tali, I41, I43

pterygoideus, 48, 58-61, 91,92

pterygospinosus [Civinini], $60,9 I$

pyraniidalis, $83,97,99$

sphenoidalis, $83,90,91$

spinosus, $25-27$

styloideus ossis netacarpalis III., 122

temporalis, $48,62,64$ radii, 115

ulnie, I I4, II 5

temporalis, 83

transversus, $25,26,28$

troclilearis, 143

tympanicus, anterior, 70,71 posterior, 70

uncinatus, $78,90,94,95,99$

vaginalis, $58,59,6 \mathrm{I}, 90$, $9 \mathrm{I}$

xiphoideus, 4 I

zygonlaticus maxillæe, 80,82 ossis frontalis, 75-77 teurporalis, $62-64,70,7$

Prominence of tle aqueduct of Fallopius, 66 of the external semicircular canal, 66,67 styloid, 64

Prominentia canalis facialis, 66 styloidea, 64 semicircularis lateralis, 66,67

Promontorium (cavi tympani), 66-68 (columnæe vertebralis), 24,124

Promontory of the tympanum, 66-68 sacral, 24, I 24

Protovertebræ, 34

Protuberance, mental, $84-86$ occipital, external, $48,55,56$ internal, $49,54,57,89$

Protuberantia mentalis, $84-86$ mentalis, $84-86$
occipitalis externa, $48,55,56$ interna, $49,54,57,89$

Pterygoid plate, external, 58, 60, 6I, 99 internal, 58,6 I

Publs, the, 124.126

Pyrantid of the ty"upanum, 66, 67, 69

Pyramis [pars petrosa] ossis temporalis, 62-64, 70, 7I

\section{R.}

Radius, 13, 106, II5, II6 development of, II7

Radix arcus vertebræ, 25,26

Ramus, inferior ossis ischii, 128 , I 30 pubis, I 28,130 of the ischinm, inferior, 128,130 mandibulæe, $84-87$
Ramus of the pubis, ascending, I 28

$$
\begin{aligned}
& \text { descending, } 128,130 \\
& \text { inferior, } 128,130
\end{aligned}
$$
superior, 128

superior ossis iscliii, 128 pubis, 128

Recess, elliptical, 69 epitympanic, $64,69,70$ splreno-ethnoidal, 90,92

Recessus ellipticus, 60

epitympanicus, $64,69,70$

splieno-eth moidalis, 90,92

Ribs, the, $36-40$ asterual, 36 , development of, 42

false, 36

floating, 36

sternal, 36

true, 36

Ridge or ridges :

of the carpus, radial, 118 ulnar, t 18

cruciform, internal, 54

gluteal, 132

for the interarticular costocentral liganent, 40

intermediate, of the crest of the ilium, 128,130

interosseous, of the fibula, 138

intertrochanteric, $\mathrm{I}_{32}, 133$ of the tibia, $136-1,38$

mylohyoid, 85

of the neck of the rib, 40

orbital, 80,98

pectoral, i1 2

postauricular, 62

superciliary, $46,48,74$

supinator (of the ulna), II4

transverse, of the sacruu, 30

of the trapeziuu, 118,121

trapezoid, 109

Ring, tynpanic, 70, 103,104

Roof of the skull, 5o of the tympanum1, 65

Rostrum, sphenoidal, 58-6i, gi

Row of teeth, 48 primitive, 6I

S.

Sacrum, the, 24, 30-33, I25, 126 development of, 35

apex of the, 30,31

Scapula, the, 106, 108 , I 10 development of, in I

Sella turcica, 60 , and footnote

Semicanalis musculi tensoris tympani, $64,66,67,70$

Septa, interalveolar, 82,84

Septum between the canal for the tensor tympani muscle and the Eustaclian canal, 64-68 canalis inusculotubarii, $64,66,67$ of the frontal siuuses, 76, 94 nasi osseum, 46, 9I -93, 96 of the mose, bony, 46, 9I-93, 96 sinumm frontalium, 76, 94 sphenoirlalium, 60, 93 sphenoidal, 60,93

Shaft of the fensur, 132, I33 of the fibula, 138 of the humerus, II 2 of the radius, 115 of the tibia, 136,137 of the ulna, I 44

Shafts of the metacarpal bones, 122 of the metatarsal bones, 145 of the phalanges of the fingers, I22 of the ribs, 40 of the toes, 145

Shoulder-girdle, I06, I08

Sinciput, 47

+ Sinus cervicalis, 202 frontalis, $76,77,90,91,94,95$ nuaxillaris, $80-82,93-95,97,99$ posterior (cavi tympani), 64, 66, 67 
Sinus spbenoidalis, $60,61,90-93$ tarsi, 140 tympani, 66, 67

Skeleton, appendicular, 105-147 axial, 23-104

extrenitatis inferioris, 105, 107, 124-147 superioris, 105, 106, 108-123

of the foot, I $40-142$ developrnent of, 146, I47

of the hatid, 118,119

hun1an, 22 development of, 123

of the lower limb, 105, 107, 124-127

$$
\text { development of, } 123
$$

development of, 146,147

trunci, 23-43

of the trunk, 23-43

of the upper limb, 105, 106, 108-123

Skull (see also "Craniunı")

cap, $5^{\circ}$

neasurements of, ror

views of :

$$
\begin{aligned}
& \text { hase, external, } 48 \\
& \text { internal, } 49 \\
& \text { front, } 46, \text { IOI } \\
& \text { roof, inner, } 50 \\
& \text { side, } 47, \text { IOI } \\
& \text { top, IOI }
\end{aligned}
$$

Sinall wing of the splienoid, $5^{8-61}$

Space, interosseous, of the forearm1, 106, 116 of the leg, 107

Spaces, intercostal, 36

Spatia intercostalia, 36

+Spatium interossenn1 antibrachii, 106, II6

Sphenoid bone, $58-60$

$$
\text { cruris, } 107
$$

Spina vel spinæ:

$$
\text { development of, } 61
$$

angularis, 58-61, 93

ethnioidalis, 59

frontalis, $74-77,90,91$

iliaca anterior inferior, 128,129

superior, $128-130$

posterior inferior, 128,129

ischiadica, 128,120

superior, 128,129

mentalis, $84,85,96$

$+\quad$ musculi recti lateralis, 58

nasalis anterior, $46,47.80,90,91,93,97$ pasterior, 90, 91, 97

palatirie, 82, 97

scapula, 110

supranieaturn, 62

trocblearis, 76,98

tympanica major, 64,7

Spine, ethmoidal, "f the sphenoid bone, 59

iliac, antsrior inferior, 128, I29 superior, 128-130

posterior inferior, 128,129

superior, 128,129

of the ischium, 128,129

for the lower head of the external rectus muscle of the eveball, 58

inental, $84,85,96$

nasal, anterior, of the superior maxillary bone, 46 , $47,90,91,93,97$ posterior, $90,91,97$

of the frontal bone, $74-77,90,91$

palatine, go, 91, 97

peroneal, of the astragalus, 143

pharyngeal, 56

pubic, I3o

of the scapula, r yo

of the sphenoid bone, 58-61, 93

suprameatal, 62

of the tibia, 136,137

trocblear, 76,98
Spine, tynipanic, anterior, 64,71

* Spines, palatine, 82, 97

posterior, 64, 70, 71

Spongy bone, sphenoidal, 58, 59, 61

Squamia frontalis, $74-77$

occipitalis, $54-57$

temporalis, $62-64,70,71$

Squamous portion of the frontal bone, 74-77 of the occipital bone, 54-57

Sternum, 41 of the temporal bone, $62-64,70,71$

developmient of, 42

Subiculuni promontorii, 67

Substance of bone, cortical, 19, 20

Substantia compacta, $11-17$, I9

corticalis, 19, 20

spongiosa, 11-17, 19

Sulcus vet sulci :

arteriæ occipitalis, 62, 71 temporalis mediæ, 62

arteriosi, 50,73 vertebralis, 29

calcanei, 143

canaliculi mastoidei, 62,65

caroticus, 58,59

carpi, II 8

chiasmatis, 59

costae, 40

ethmoidalis, 79, 91

hamuli pterygoidei, 58

in fra-orbitalis, $80,93,94,98,99$

intertubercularis, 112

lacrinialis maxillae, $80,82,91,98$ ossis lacrimalis, 79,92

lateral, 49, 54, 56, 63, 64, 73, 88, 89

longitudinal, $54,73,75,88$, S9

mallei, 70

malleolaris (tibix), 136

musculi flexoris hallucis longi (calcanei), 14I, 143 peronæi longi (calcanei), 143

(tali), I4I, 143

mylohyoideus, 85

(ossis cuboidei), 140, I41, 144

nervi petrosi superficialis majoris, 63,64

radialis, I 12

spinalis, 26

uluaris, 112

obturatorius, 128

olfactorius, 90

palatini, 82 , 97

paraglenoidalis, 128

petrosal, inferior, $56,62,63,88$ superior, 63

+ petrosquamosus, 64

petrosus inferior, 88 ossis occ?pitaiis, 56 superior, 63 temporalis, 62,63

præauricularis, 128

promontorii, 67
$+\quad$ pterygopalatinus

$+\quad$ pterygopalatinus maxillx, so

ossis palatini, 83 sphenoidalis, 58

sagittalis (ossis frontalis), 75,88 (ossis occipitalis), 54, 89 (ossis parietalis), 73

sigmoideus, $49,56,63,64,88,89$

subclavix, 40

tali, 143

transversus ossis occipitalis, $49,54,56,89$

tubæ auditiva, 48

tympanicus, $64,66,69,70$

venosus, 50

Supra-occipital bone, note to p. 57 portion of the occipital bone, 54-57, and note, p. 57

Surface, articular, of the astragalus, superior, 143 of the external inalleolus, $137,{ }_{13} 8$ 
Surface, articular, of the head of the fibula, 138 of the internal malleolus, 137 of the patella, 136 of tine radius, for the ulna, 115 of the tilsia, for the head of the fibula, 136,137

inferior or distal, 137 superior or proximal, 137

auricnlar, of the ilium, 128

of the sacrum, 31,32

of the femur, anterior, 132,133

patellar, I $32-134$

popliteal, 132

postero-external, 132, 133

of the fibula, anterior postero-internal, 132,133

external, 138

internal, 138

of the foot, dorsal, I40

of the frontal bone, anterior, 74

cerebral, 75

frontal, 74

orbital, 76

posterior, 75

temporal, 74, 77

of the great wing of the sphenoid bone, cerebral, $58,6 \mathrm{r}$

of the great wing of the sphenoid bone, orbital, 58-6I, 98

of the great wing of the sphenoid bone, splienomaxillary, 58 , 99

- of the great wing of the sphenoid hone, temporal, 58-6r, and note, p. 59

of the hand, dorsal, I 19 palmar, I 8

of the humerus, antero-external, II2 antero-internal, II2 posterior, I 12

of the nular bone, malar, 83 orbital, 83 outer, 83 temporozygonatic, 83

patellar (of the feniur), 132-1 34

of the parietal hone, cerebral, 73 external, 72 internal, 73 parietal, 72 temiporal, 47,72

of the petrous portion of the temporal bone, anterior, 65

of the petrous portion of the temporal bone, inferior, 65

of the petrous portion of the lemporal bone, posterior, 65

poplitea:, I 32

of the pubic symphysis, 128

of the radius, anterior, $114-116$

external, i14-116

posterior, $114-116$

of the sacrum, dorsal, 31,32 pelvic, 30, 32, 125 posterior, 126

of the scapular, anterior, ino posterior, 1 10

of the squamous portion of the temporal bone, cerebral, 63, 64

of the squamous portion of the temporal bone, temporal, 62,63

of the sternum, anterior, 36

of the superior maxillary bone, anterior, 80

facial, 80

nasal, 80

orbital, 80

zygomatic, 80,99

temporozygonatic, $58-6 \mathrm{r}$, and note, p. 59

of the tibia, external, $136-13^{8}$

internal, 136,138

posterior, $136-138$
Surface, of the ulna, anterior, 114,116

internal, 114

posterior, II4

of the vertical plate of the palate-bove; external, $8_{3}$ internal, 83

zygomatic, 58-6i, and note, p. 59 nasal, $8_{3}$

Sustentaculum tali, 140, 141, 143

Sutura coronalis, $46,47,49,50,88,100$ ethmoideomaxillaris, 98

frontalis, 77

fronto-etlinoidalis, 49,98

frontolacrimalis, $9 \mathrm{l}, 98$

frontomaxillaris, 46,98

incisiva, 48, 82, 97

infra-orbitalis, 80

intermaxillaris, 46

internasalis, 46,92

lacrimocouchalis, 90,95

$+\quad$ lacrimo-ethmoidalis, 91,98

lacrimomaxillaris, $9 \mathrm{I}, 98$.

lambdoidea, $47,50,89,100$

$+\quad$ mendosa, 55, 57, 104

nasofrontalis, 46, 90-92, 98

1uasomaxillaris, 46,47

occipitalis transversa, 100

occipitomastoidea, $47-49,88,89$, Iou

palatina mediana, 96,97 transve:sa, 90, 91, 96, 97

palato-ethmoidalis, og

palatomaxillaris, 98

parietomastoidea, $47,49,89$, I00

sagittalis, $50,88,100$

spheno-ethnoidalis, $49,98,99$

sphenofrontalis, 47

spheno-orbitalis, 49,98

sphenoparietalis, $46,47,88$

sphenosquan1 osa, $46-49,88$

splineozygomatica, 47,98

squamosa, $46,47,88$

squanısomastoidea, $62,70,7$

zygomaticofrontalis, $46,47,92$

zygomaticomaxillaris, 46,47

zygomaticotemporalis, 46,47

Suture, coronal, $46,47,49,50,88,100$

ethmoidomaxillary, 98

frontal, 77

fronto-ethmoidal, 49,98

frontolachrymal, 91,98

frontomalar, $46,47,92$

frontomaxillary, 46,98

frontoparietal, $46,47,49,50,88,100$

i11 fra-orbital, 80

intermaxillary, 46

interparietal, 50,88 , 100

internasal, 46, 92

lachrymo-ethmoidal, 91,98

lachrymomaxillary; 91, 98

laclirymoturbinal, 90,95

lannbdoid, $47,50,89$, 100

malomaxillary, 46,47

miendosa, $55,57,104$, and note to p. 5 ?

netopic, 77

nasofrontal, 46, 90-92, 98

nasomaxillary, 46, 67

occipital, transverse, $55,57,100,104$, and note to p. 57

occipitomastoid, $47-49,88,89,100$

occipitoparietal, $47,50,89,100$

palatine, anterior, $48,82,97$

median, 96,97

niddle, 96,97

posterior, 90, 91, 96, 97

transverse, 90, 91, 96, 97

palato-ethmoidal, 99

palatomaxillary, 98

parietomastoid, $47,49,89,100$

petrosphenoidal, 48,49

premaxillary; $48,82,97$

sagittal, 50,88 , I00 
Suture, spheno-ethmoidal, 49, 98,99 sphen ofrontal, 47

sphenonialar, 47,98

splieno-orbital, 49,98

sphenoparietal, $46,47,88$

sphenosqualnous, 46-49, 88

squamosoniastoid, $62,70,71$

squannous, $46-4^{8}$

temporomalar, 46,47

Symphysis ossium pubis, 125

$$
\text { pubic, } 125
$$

Synchondrosis epipliyseos, 20 intersplienoidalis, 6 ! intra-occipitalis, anterior, 57 posterior, 57 occipitosphenoidal, 49 spheno-occipitalis, 49 sternalis, $4 \mathrm{I}$

\section{$T$.}

Table, inner, of the bones of the skull, 19, $5^{\circ}$ of the frontal bone, 75-77

outer, of the bones of the skull, I9, 50 of the frontal bone, 75,76

Tabular portion of the occipital bone, 54-57, and note, p. 57

Talus, I7, I42, 143

Tarsus, I07, 140

Tegmen tympani, 64, 65, 69-71, 96

Tlyorax, 36, 37

Tibia, 15, 18, 107, 136,137 developinent of, 139

Tissue of bone, cancellous, II-17, I9 compact, I I-1 7, ig

Toes, skeleton of, I4O, I4I

Tooth-sockets of the lower jaw, 84

"Torus occipitalis, I00 of the upper jaw, 82 palatinus, 96

Tractus spiralis foraminulentus, 68

Trapeziun1, the, II9-I 2 I

Trochanter, great, I32-I34 major, 132-1 34 minor, 132,133 small, I 32, I 33 tertius, I 33

third, 133

Trochlea humeri, I12 phalangis manus, I2? tali, I 40, I43 pedis, 145

Tuber calcanei, I4O, 14I, I43, I47 cochleæ, 66-68

frontale, $46,74,77,104$

ischiadicum, I28-1 30

maxillare, $80-82,99$

parietale, 72,104

Tubercle of the atlas, anterior, 29

$$
\text { posterior, } 29
$$

carotid, 24

of the cervical vertebræ, anterior, 26

conord, Iog posterior, 26, 29

infraglenoid, I to

of tlie 1schium, I2S-I30

of Lisfranc, 40

mental, $84,85,96$

obturator, anterior, 128

pharyngeal, 56

$$
\text { posterior, 128, 130 }
$$

of the posterior process of the astragalus, external, 143

of tile posterior process of the astragalus, internal, I 43

of the ribs, 37,40

scalene, 40

of the spine of the tibia, inner, 137

supraglenoirl, no
Tubercle of the tibia, 136,137

of the tuberosity of the calcaneum, inner, I4I, I43

Tuberculum anterius atlantis, 29

outer, I4I, I 43

articulare, 62

vertebrarum cervicalium,, 6

caroticum, 24

costae, 37,40

intereondyloideum laterale, $\mathbf{I} 37$

jugulare, 54,56

mediale, 137

$+\quad$ laterale tali, 143

majus, II 2

mediale tali, 143

mentale, $84,85,96$

minus, II2

obturatorium anterius, 128

posterius, 128, I3o

ossis u1ultanguli majoris, I I8, I2 I navicularis mausus, I18, 120

pliaryngeum, 56

posterius atlantis, 29

pubicum, I 30 vertebrarum cervicalium, 26, 29

scaleni [Lisfranci], 40

sella, 59-6t

Tuberositas coracoidea, IOg

costie II., 40

costalis, 109

deltoidea, II 2

glutæa, I 32

iliaca, I 28, 129

infraglenoidalis, I IO

n1asseterica, 84,86

ossis cuboidei, I4I, I44

netacarpalis V., I22

metatarsalis I., I4I, I45

V., $140,141,145$

navicularis pedis, $140,14 \mathrm{I}, \mathrm{I} 44$

pterygoidea, 85

radii, II5, I16

sacralis, $3 I$

supraglenoidalis, IIo

tibixe, 136,137

ulnæ, I I4

unguicularis phalangum digitorum (manus', 122

unguicularis phalangum digitorum pedis, $14 \mathrm{I}$, 145

Tuberosity, costal, I09

of the cuboid bone, I4I, I44

of the femur, external, 132,134

internal, 132, I33

of the fifth metacarpal bone, I22

of the first metatarsal bone, I4I, I45

of the fifth inetatarsal bone, I40, I4I, 145

of the humerus, great, II 2 snall, II2

of the ilium, 128,129

masseteric, 84,86

of the navicular bone, 140, I4I, 144

of the os calcis, $140,14 \mathrm{I}, \mathrm{I} 43, \mathrm{I} 47$

of the palate-bone, $83,97,99$

pterygoid, internal, 85:

of the radius, II5, I16

of the sacrum, 31

of the scaplioid bone, II 8,120

of the superior maxillary bone, $80-84,99$

of the tibia, exterual, 136, 137 internal, I36, 137

of the trapezium, IIS, I2I

of the ulua, II4

Turbinate bone, sphenoidal, 58, 59, 6I

Tympanic plate, $62,64,65,7$ I orbital border of the, 59

ring, $70,103,104$

sinus, 66,67

spine, anterior, 64,7 I

posterior, $64,70,7 \mathrm{r}$

sulcus, $64,66,69,70$ 
Ulna, the, $13,106,114,116$ developinent of, 117

V.

Vaginal process of the teinporal bone, $64,70,71$ of the sphenoid bone, $5^{8}, 59,61,90$, 9r

Vagina prccessus styloidei, $64,70,71$

Venter of the scapula, 110

Vertebra or vertebra:

cervical, $24,26,29$
seventh,

development of, 34,55

dorsal, $24,25,28$

first, 28

eleventh, 28

twelfth, 28

lumbar, $24,27,28$

fifth, 28,33

prominens, 24

sacral, 24, 30-32

structure, I 6

thoracales, $24,25,28$

thoracalis I., 28

XI., 28

XII., 28

U.

al bone, $64,70,7$
bone, $58,59,6$

29
4,55
83
28

Vertex, 46, 47
Vesicle, optic, primary, 102 umbilical, 102

Vestibulum labyri thi, $6 \dot{5}, 68,69$

Vomer, 53, 79, 91, 94, 95

W.

Wall of the orbit, external, 98 inferior, 93,98
internal, 98 superior, 92, 98 of the tympanum, carotid, 65,66 inner, 65,66 jugular, 66 labyrinthine, 65,66 mastoid, 66

Wing of the ilium, I 30 superior (roof), 65

of the sphenoid, great, $58-6 \mathrm{I}$ small, 58-6r

Xiphisternum, 41

x.

Z.

Zygoma, 46.48, 62-64, 70, 71, 96 'Zygomatic width,' IOI 


\section{A N A T L A S}

OF

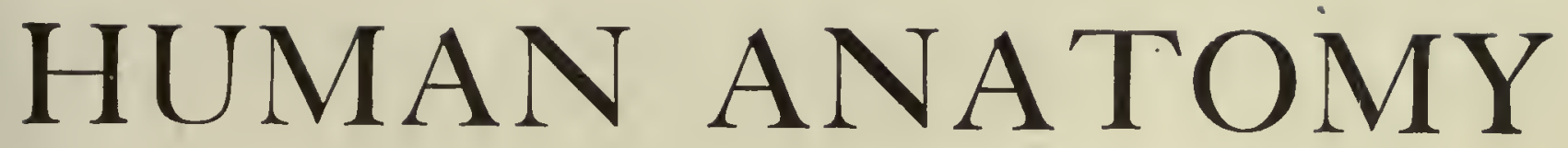

FOR STUDENTS AND PHYSICIANS

\section{BY \\ CARL TOLDT, M.D.}

ASSISTED BY

PROFESSOR ALOIS DALLA ROSA, M.D.

Goapted to Englísb and Zmerican and Fnternational Terminology

BY

M. EDEN PAUL, M.D. Brux., M.R.C.S., L.R.C.P.

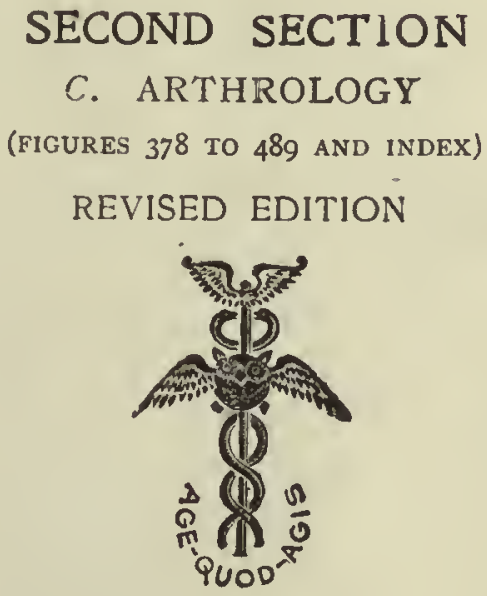

NEW YORK

REBMAN COMPAN Y

141, 143 AND 145 WEST 36TH STREET 
Copyright, 1919, by REBMAN COMPANY 


\section{SYNDESMOLOGIA}

ARTHROLOGY 

THE ARTICULATIONS IN GENERAL 


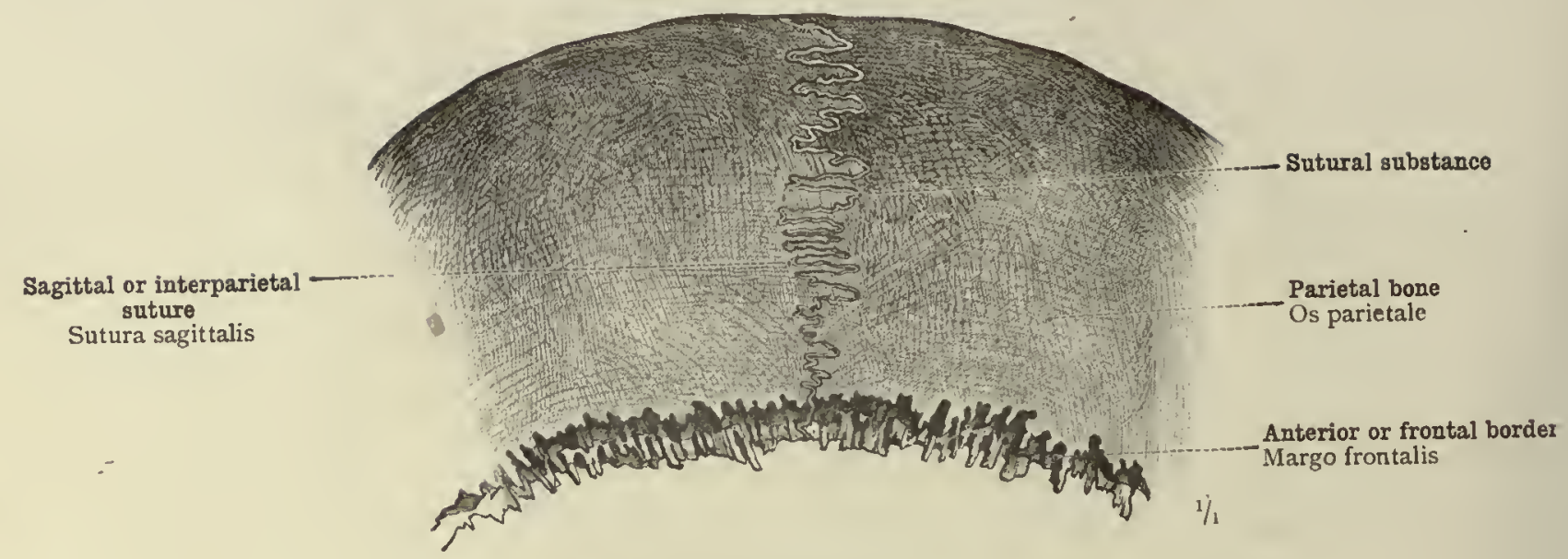

Fig. 378.-Sutura Serrata-Serrated or Dentated Suture.

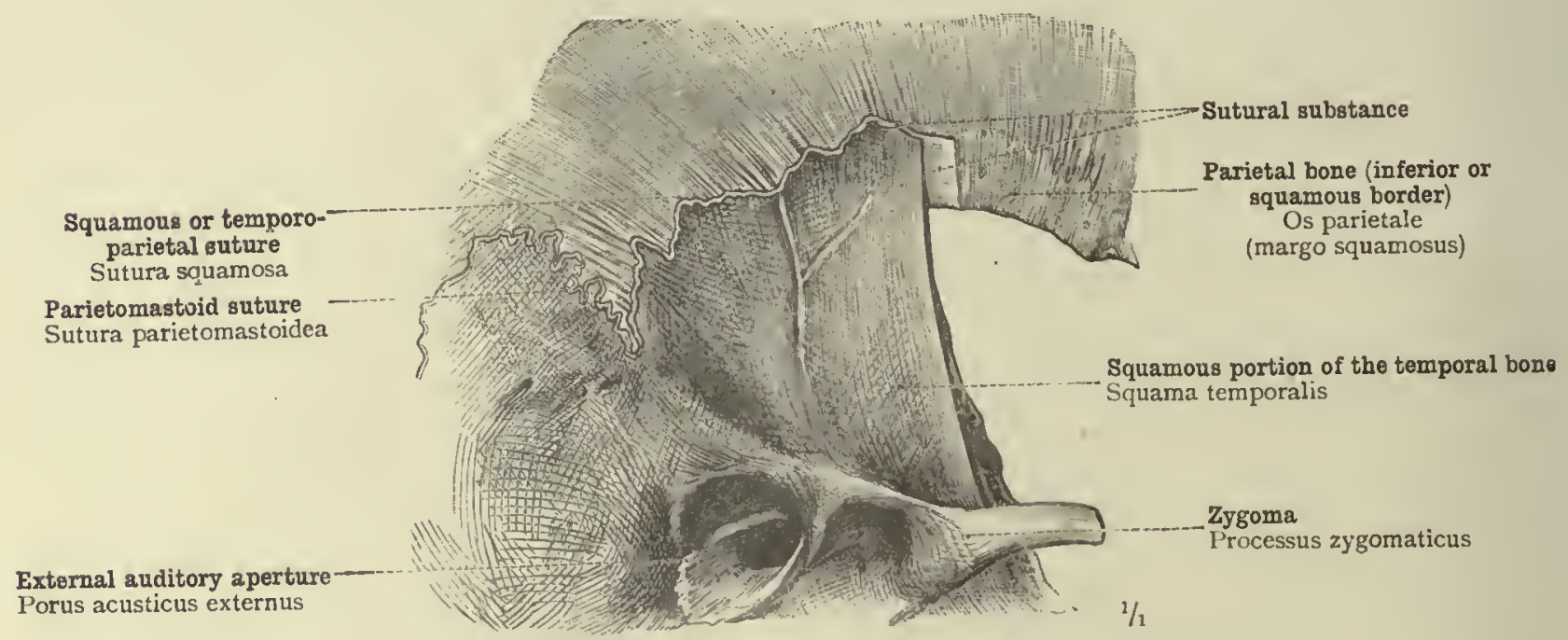

Fig. 379.-Sutura Squamosa-Squamous or Scaly Suture.

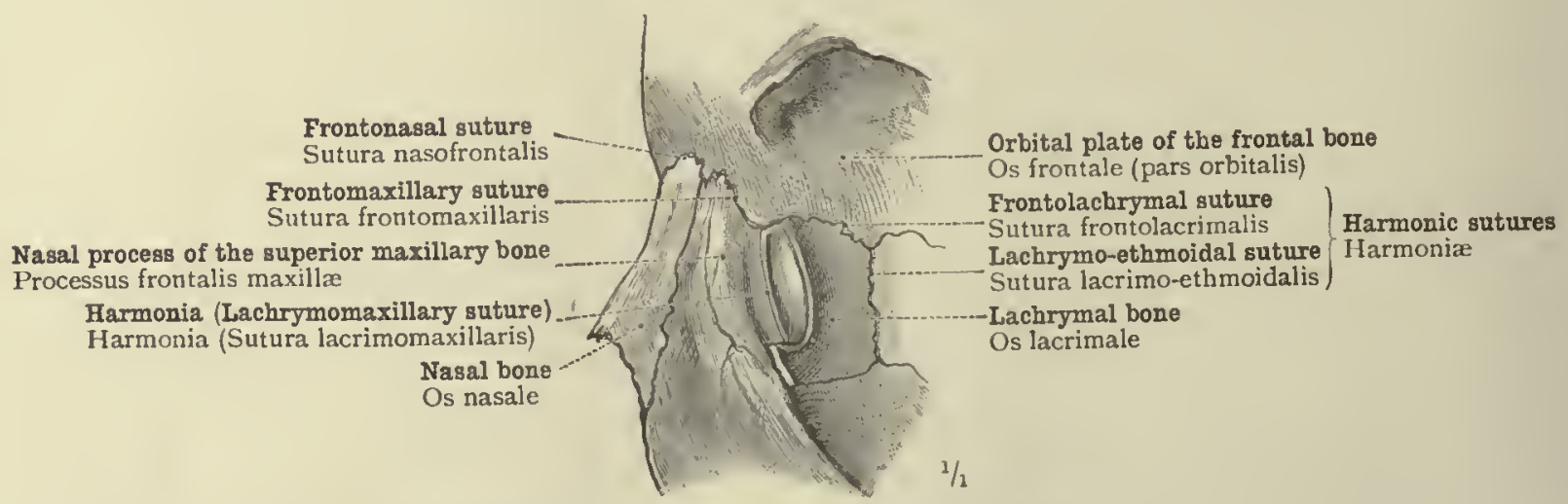

Fig. 380.-Harmonia-Harmonic Suture.

Synarthrosis, or Continuous Articulation. 


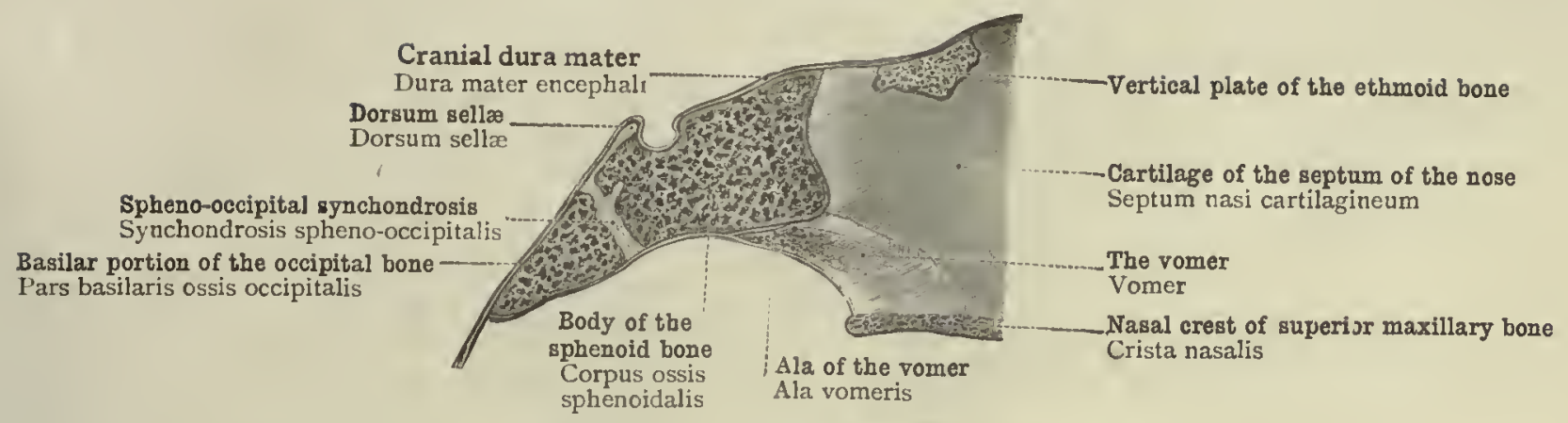

Fig. 381.-Synchondrosis. (The Spheno-occipital Synchondrosis of a Girl at the Age of Two Years; Median Sagittal Section.)

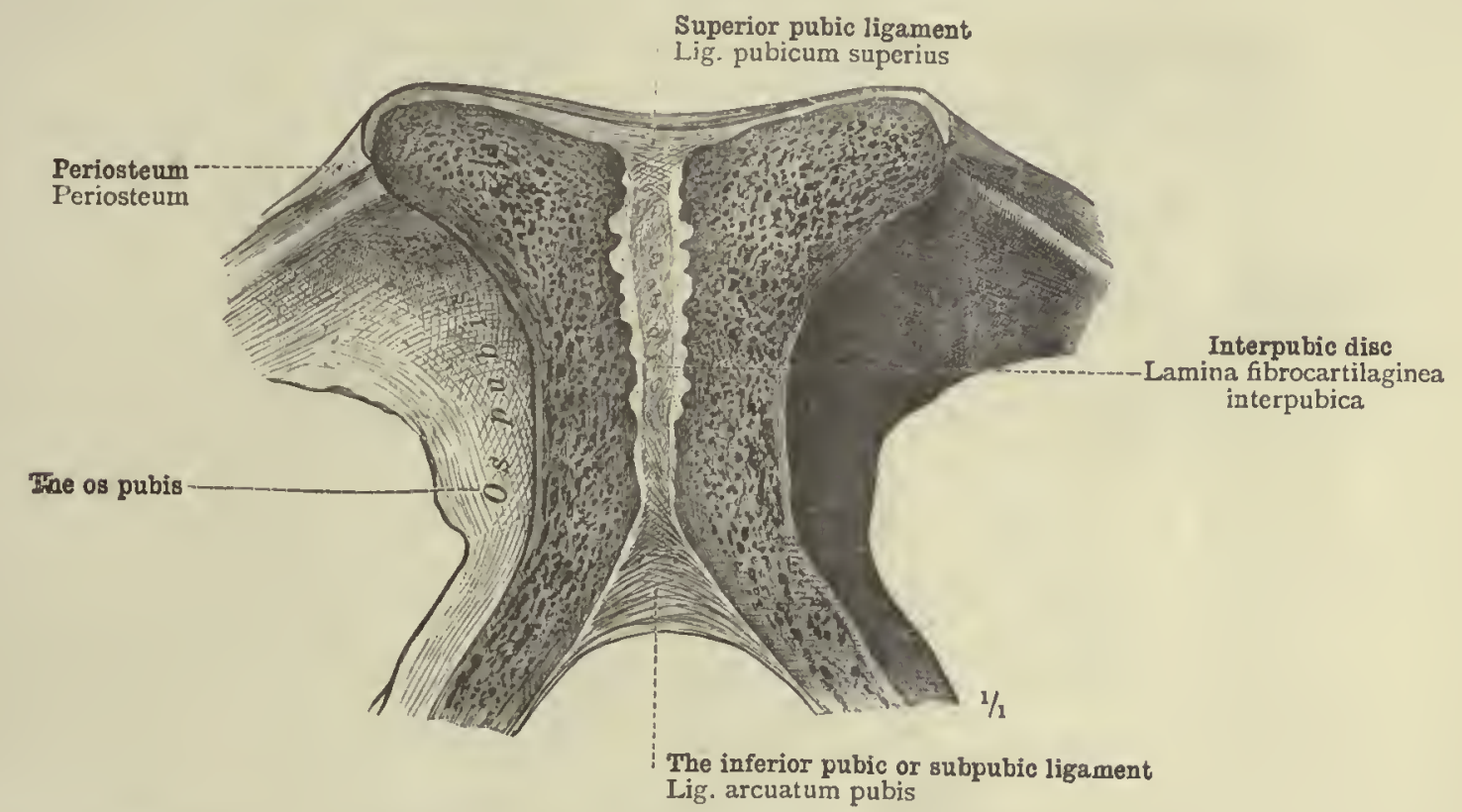

Fig. 382.-Symphysis. (The Pubic Symphysis; Frontal Section, Posterior Portion.)

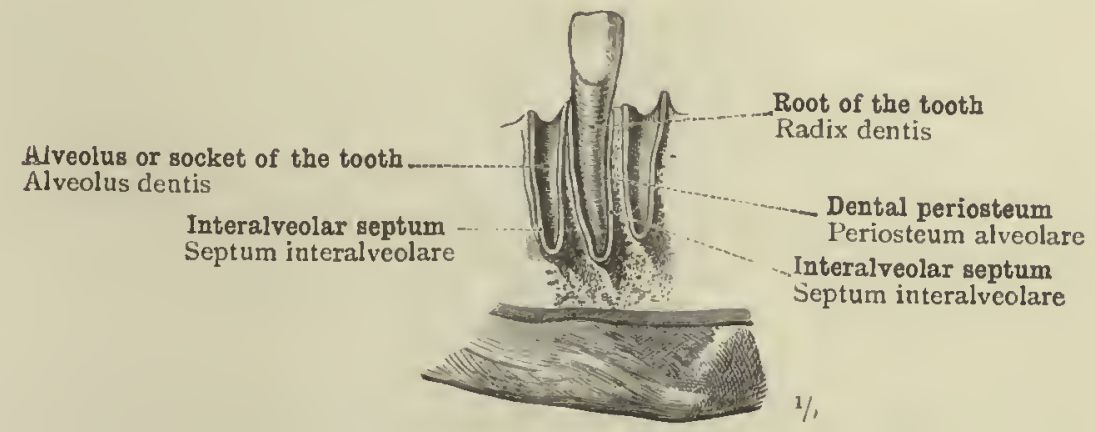

FIG. 383.-GOMPHOSIS.

Synarthrosis, or Continuous Articulation. 


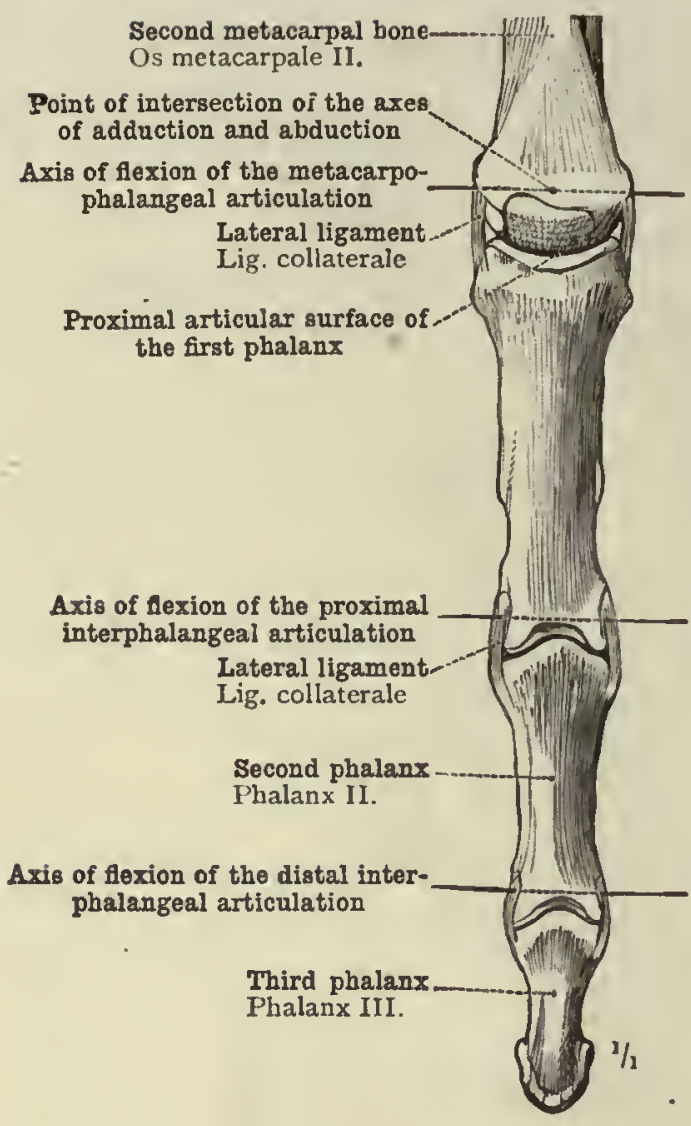

Fig. 384.-Extension. Posterior ASPECT.

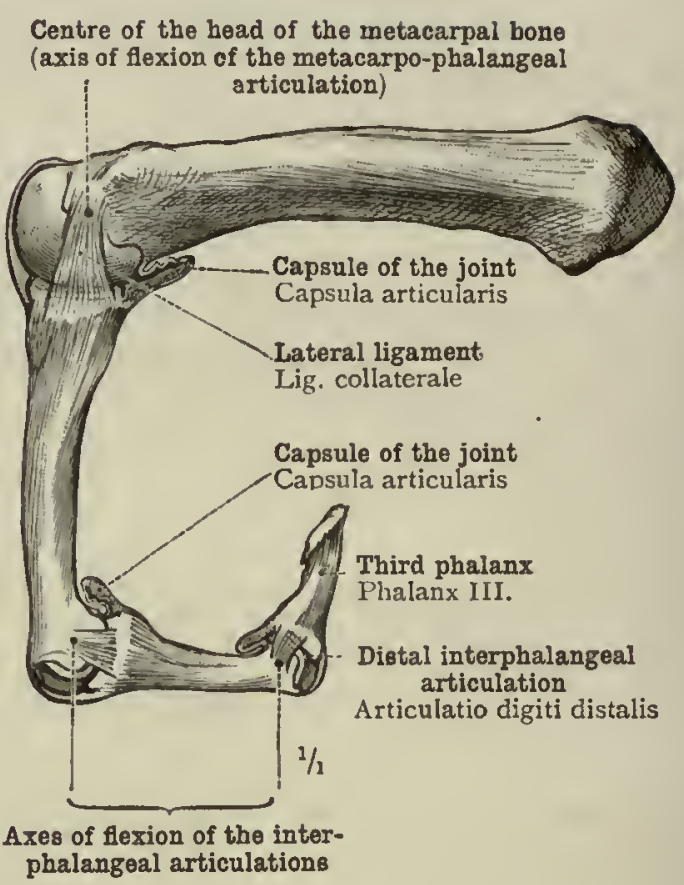

Fig. 385.-FLexion. Lateral ASPECT.

Diarthrosis (Metacarpo-phalangeal articulation).-Ginglymus, or Hinge Joint (Articulations of the Fingers).

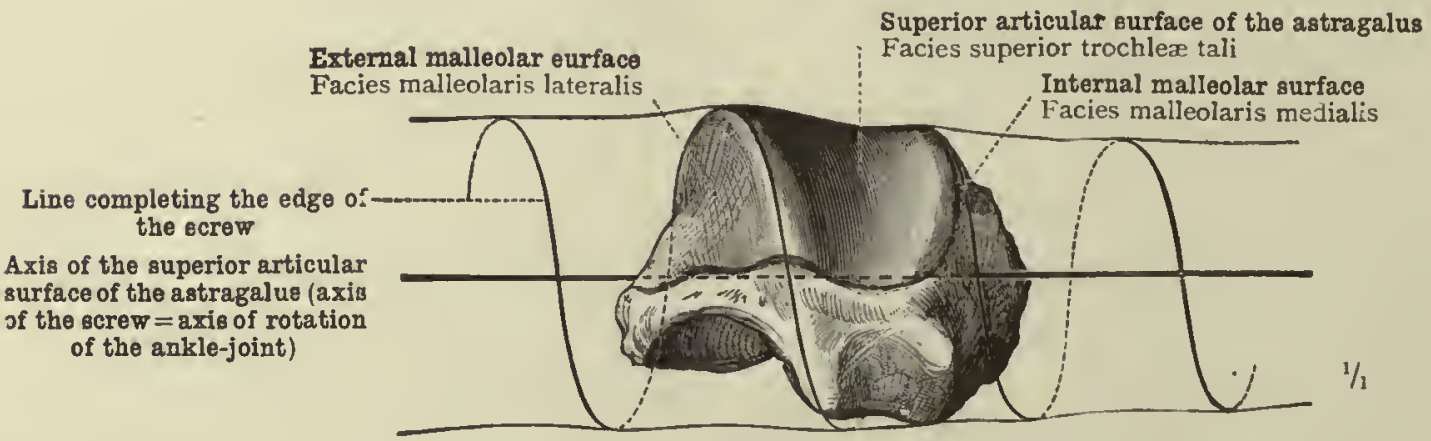

Fig. 386.-Articulatio Cochlearis, Cochleoid or Scre Ginglymus. (Superior Articular Surface of the Left Astragalus, SEen From Behind, SHowing the Screw Form of the ANKLE-JOINT.

Diarthrosis, or Discontinuous Articulation-Articulatio simplex, simple joint. 


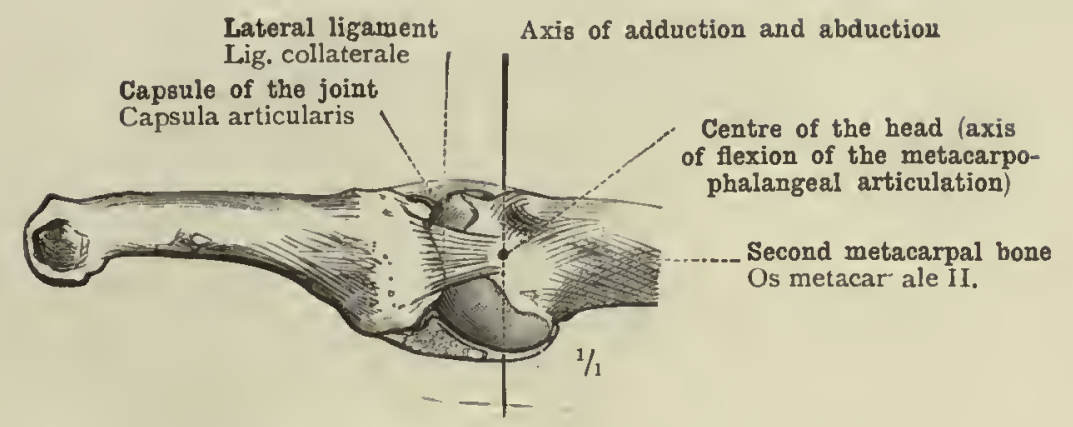

Fig. 387.-Condylarthrosis, or Condyloin Joint. (The Metacarpo-phalangeal Articulation OF THE INDEX-Finger; LATERAL VieW.)

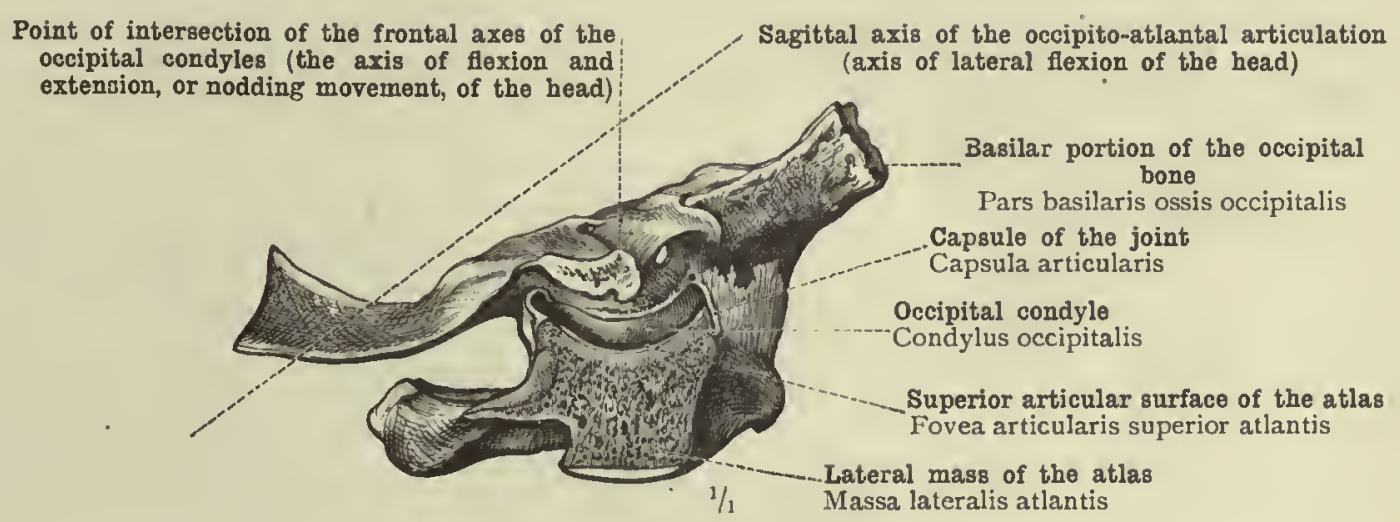

Fig. 388.-Condylarthrosis, or Condyloid Joint. (Right Occipito-atlantal Articulation; SEEN FROM THE OUTER Side.)

The outer half of the lateral mass of the atlas has been removed by a sagittal section passing through the joint.

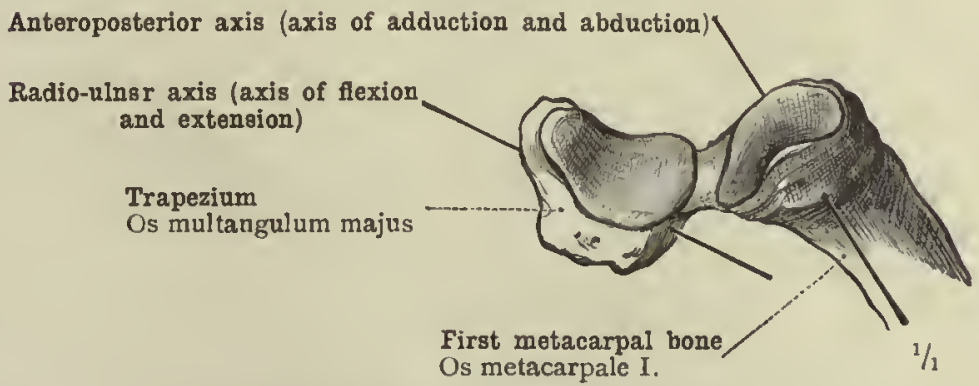

Fig. 389.-Articulatio Sellaris-Saddle Joint. (Articulatio Carpometacarpea PollicisCarpometacarpal Joint of the Thumb.)

Diarthrosis, or Discontinuous Articulation-Articulatio simplex, simple joint. 


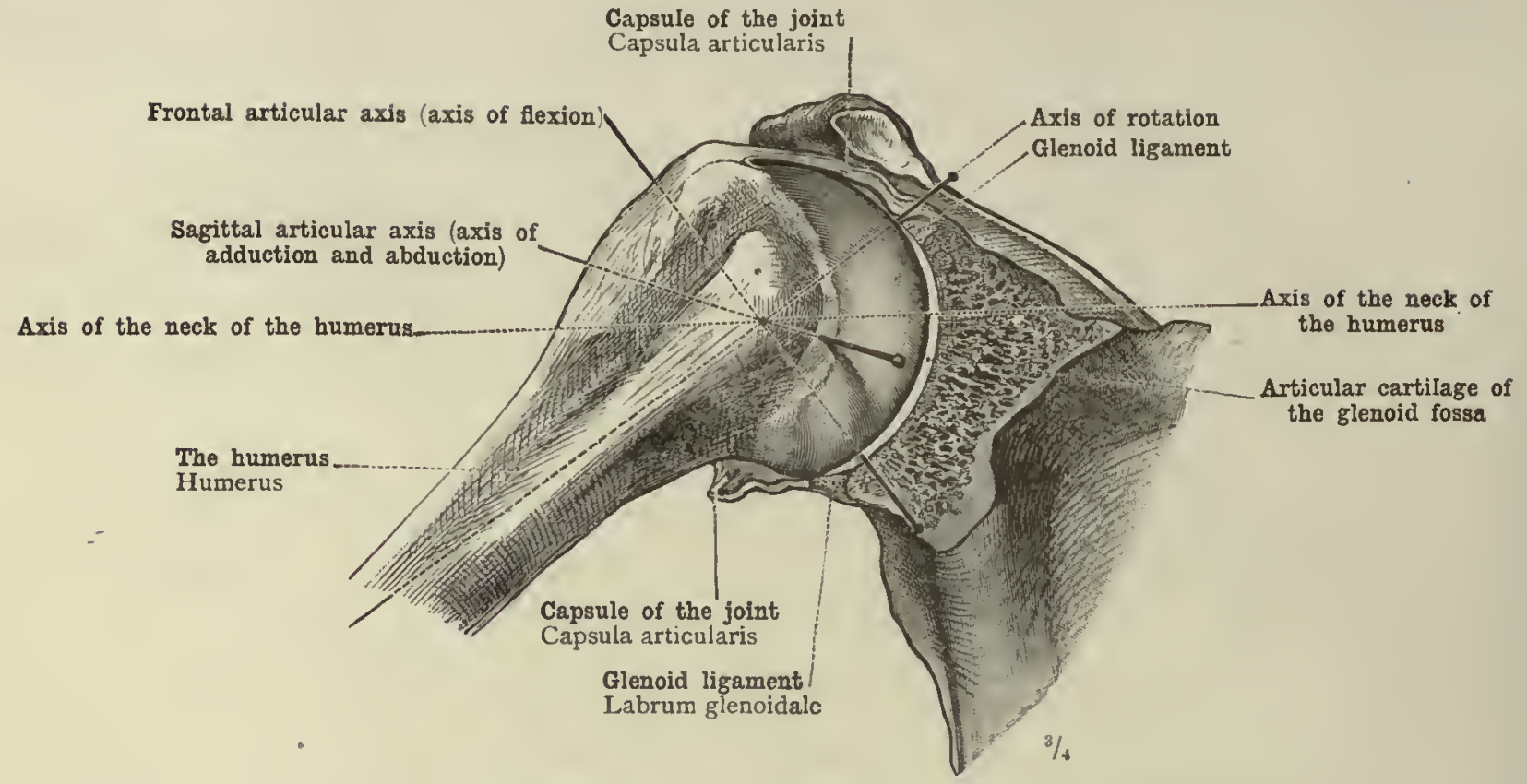

Fig. 390.-Enarthrosis, ${ }^{1}$ Or Arthrodia; Ball-and-Socket Joint. (The Right Shoulder-Joint SEEN from Before, the Anterior Half of the Glenoid Fossa and of the Capsule of THE JOINT HAVING BEEN RE.MOVED.)

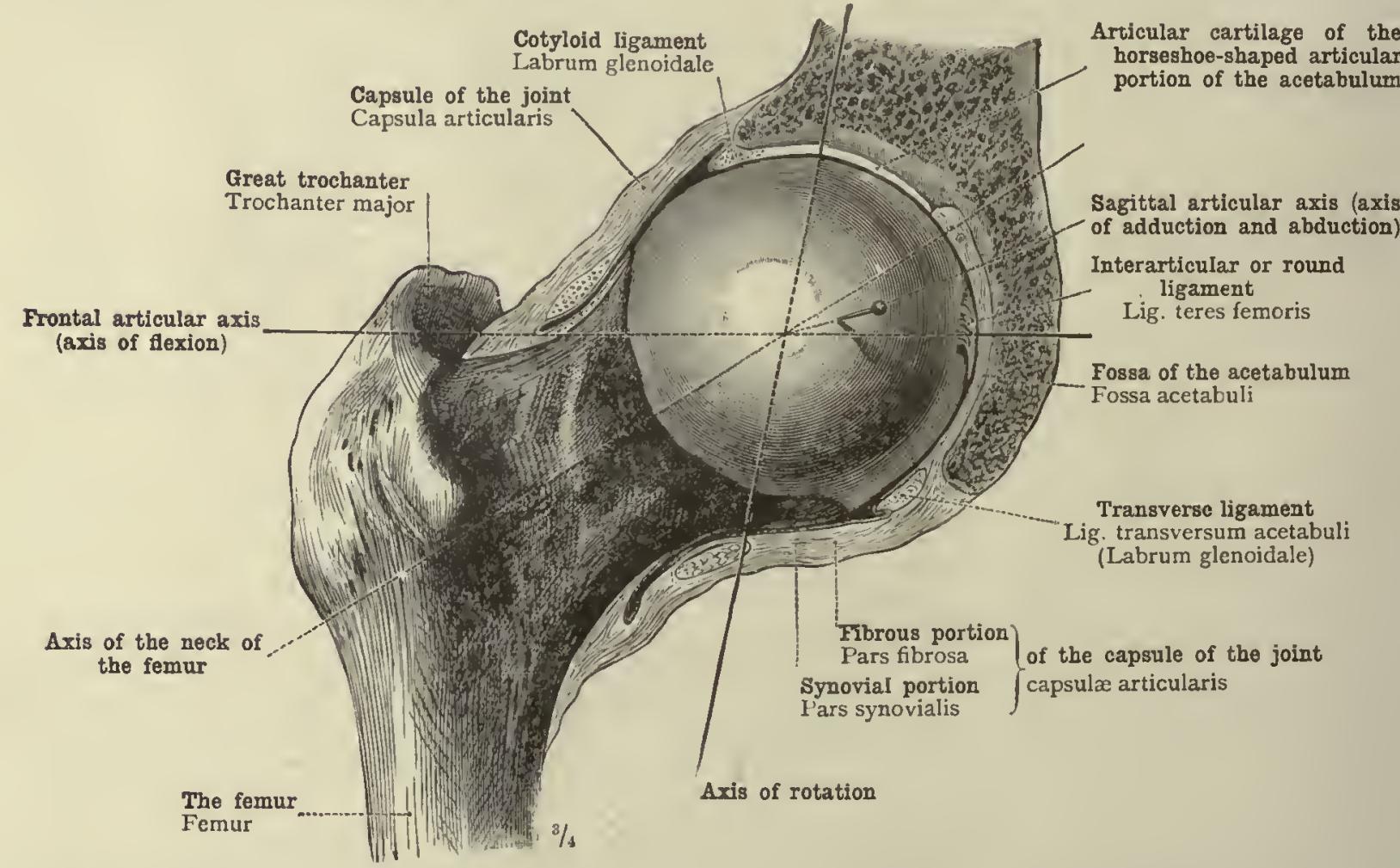

Fig. 39I.-Enarthrosis, ${ }^{1}$ OR ARThrodia; Ball-ANd-Socket Joint. (The Right Hip-Joint SEen From Before, the Anterior Half of the ACetabulum and of the Capsule of the Joint HAVING BEEN REMOVED.)

I have departed a little on this page from the author"s terminology, which differs slightly from that in use in England. Both the hip and the shoulder joint are classed by him as examples of ARTiculatio spH R. ROIDEA, Kugelgelenk-lit.. "ball joint"; one of these, the shoulder-joint. in which the concave articular surface is considerably less than a hemisphere in extent, is called by him ARTHRODIA, freies Gelenk-lit." "free joint "; while the orher, the hip.joint, in which the concave articular surface is considerably more than a hemisphere in extent, is called ENARThrosis, Nusselenk-lit., "nut joint." English anatomists do not, as a rule, draw this distinction. The movements of the hip and the shoulder joint are identical in character, and the greater extent of the rigid portion of the enveloping surface in the one case of the hip and the shoulder joint are identical in character, and the greater extent of the rigid portion of the enveloping surface in the one case
than in the other has not been considered a difference sufficiently important to warrant a separation into two classes. Hence, in England the terms ENARTHROSiS and ARTHRODIA are applied indifferently to all ball-and-socket joints. - TR.

Diarthrosis, or Discontinuous Articulation-Articulatio simplex, simple joint; articulatio sphæroidea, ${ }^{1}$ ball-and-socket joint. 


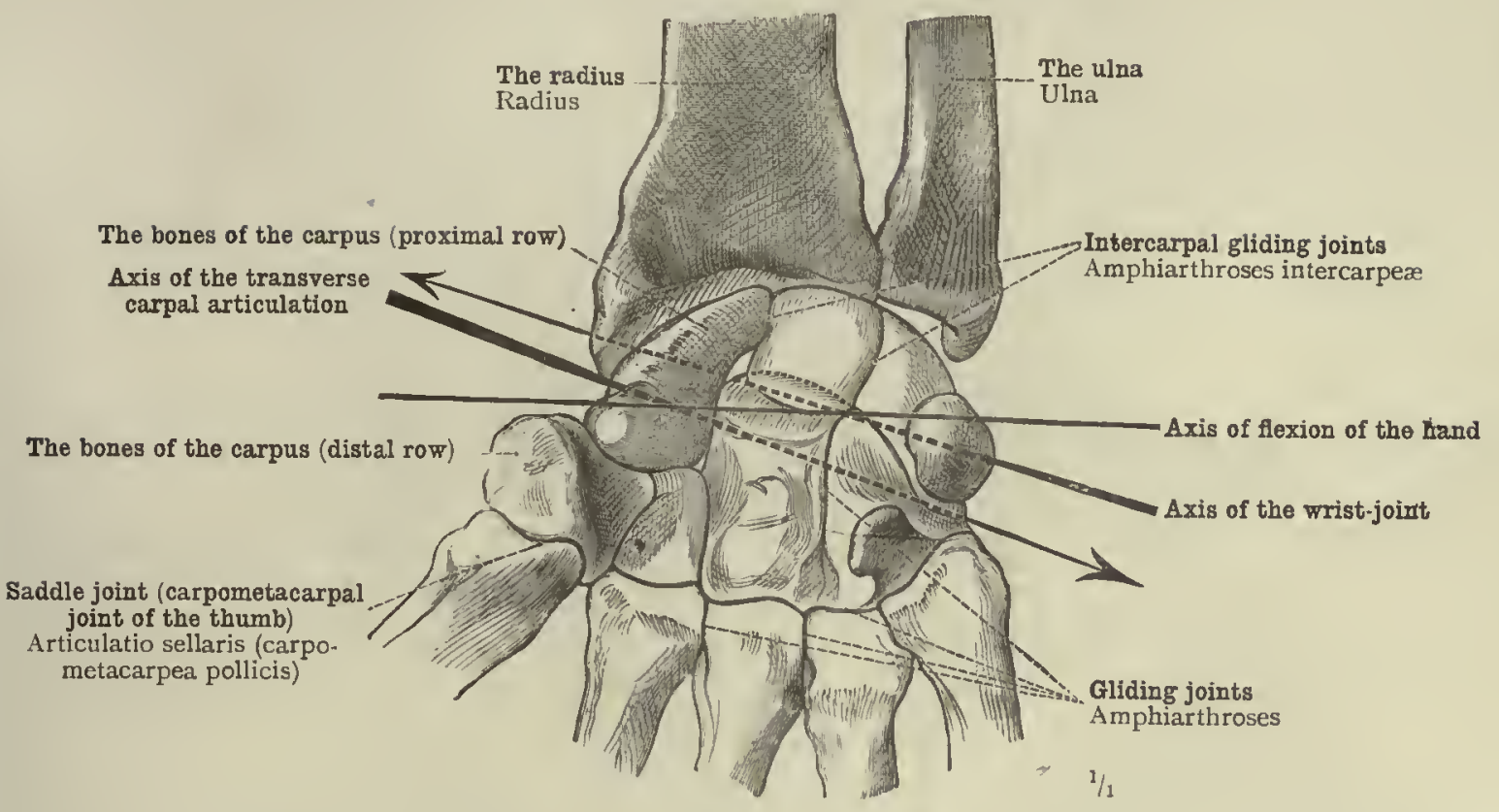

Fig. 392.-Articulatio Composita, Compound Joints (Articulations of the Hand).AMPHIARTHROSIS=ARTHRODIA OR GLIDING JOINT, AS SEEN IN THE INTERCARPAL, CARPOMETACARPAL, AND INTERMETACARPAL JOINT.

The arrows show the dorsal emergence of the axes of the wrist joint and of the transverse carpal articulation respectively.

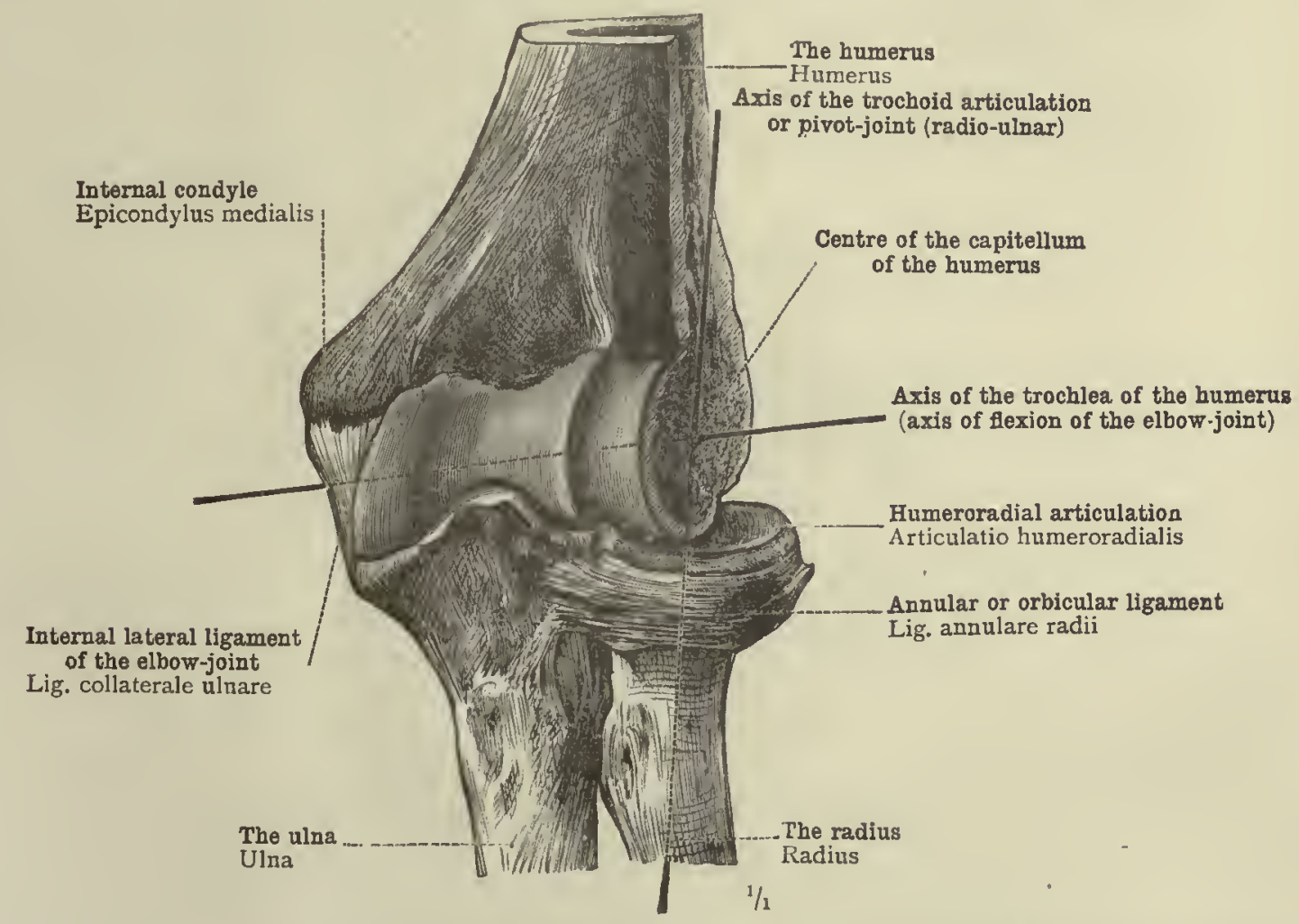

Fig. 393.-Articulatio Trochoidea, Trochoid or Pivot Joint.-Ginglymus, Hinge Joint. (PAlmar Aspect of the Elbow-Joint.)

The radial half of the capitellum of the humerus has been removed by a sagittal section passing through its centre of curvature.

Diarthrosis, or Discontinuous Articulation.

Amphiarthrosis, arthrodia or gliding joint-Articulatio composita, compound joint. 


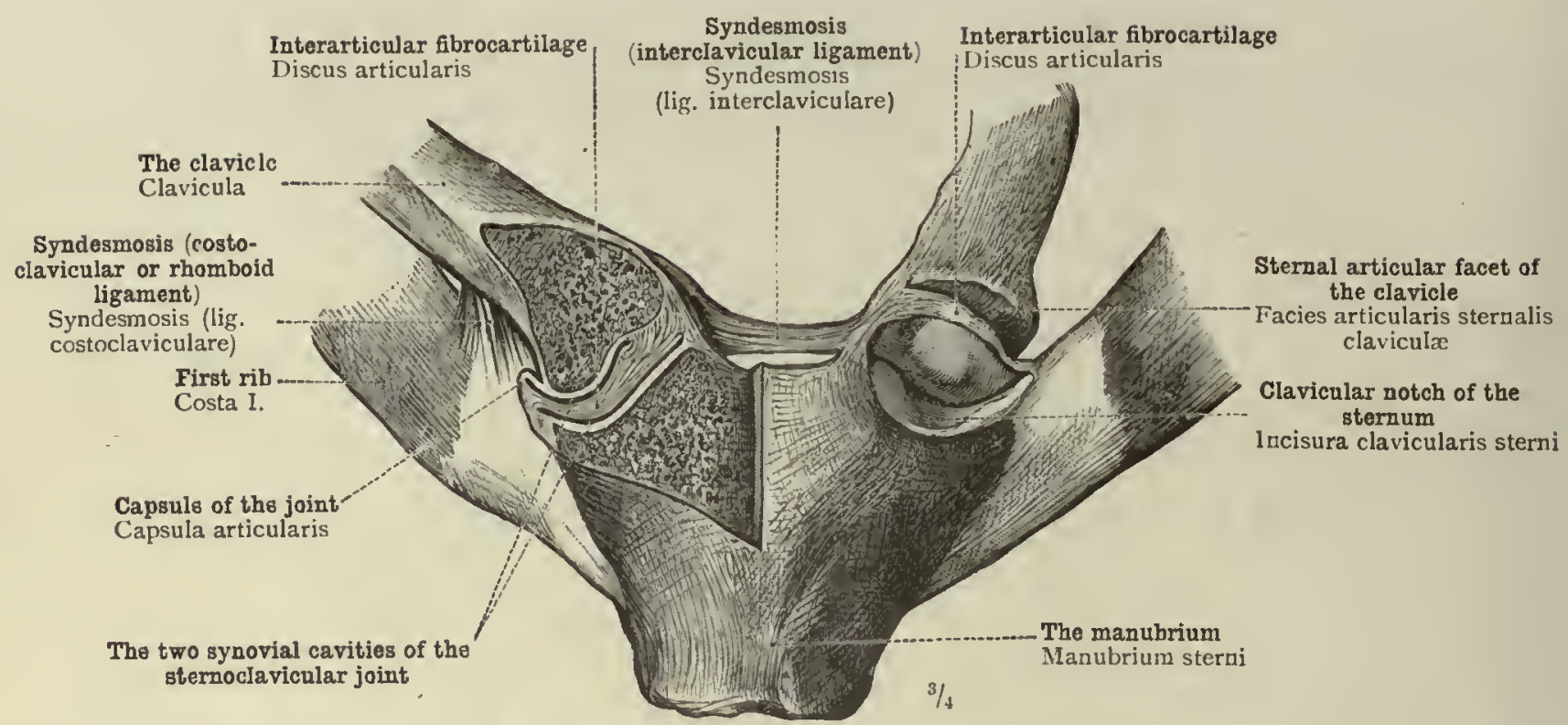

Fig. 394.-Syndesmosis.-Interarticular Fibrocartilage. (The Sternoclavicular Articulation, Anterior Aspect.)

The right articulation is divided through the middle by a frontal secti $n$; in the left, ne front portion of the capsule has been removed, and the clavicle has been drawn backwards.

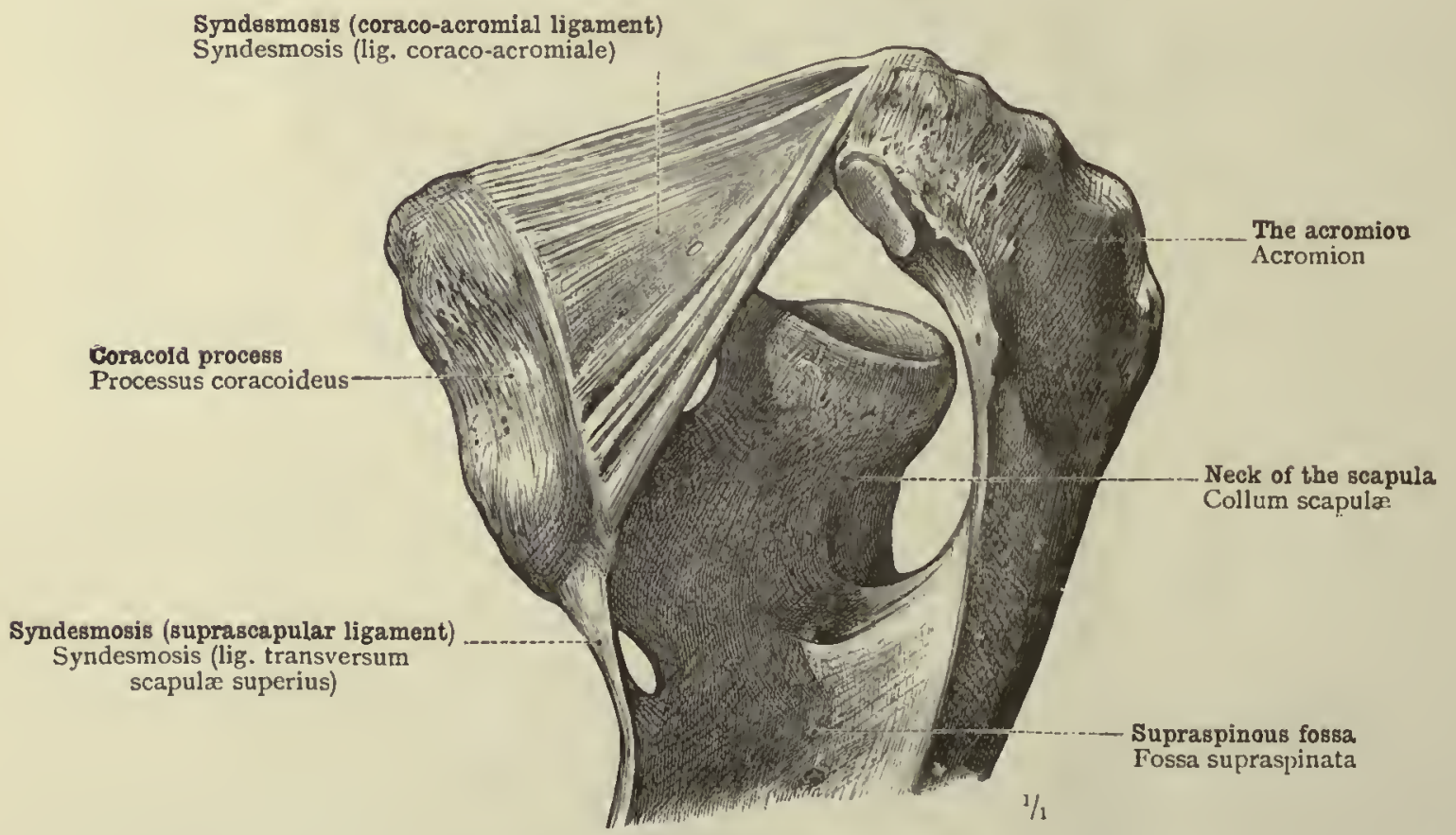

Fig. 395.-Syndesmoses Scapule, Proper Ligaments of the Scapula; seen from Above.

Syndesmosis, fibrous or gamentous union-Discus articularis, interarticular fibrocartilage. 


\section{JUNCTURÆ OSSIUM TRUNCI}

\section{THE ARTICULATIONS OF THE TRUNK}




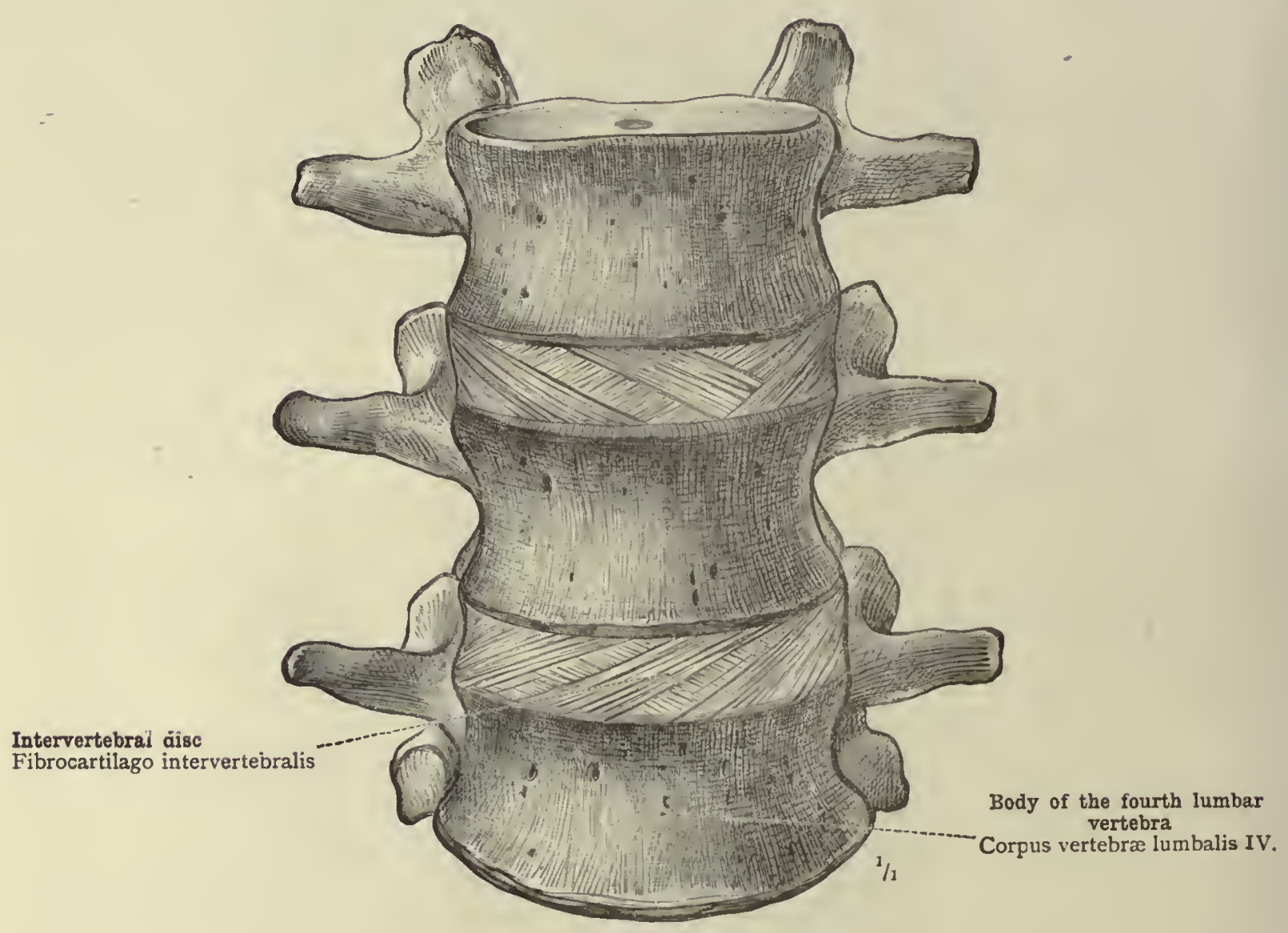

Fig. 396.-Fibrocartilagines Intervertebrales, Intervertebral Discs. (Second, Third, and Fourth Lumbar Vertebre; seen from Before.)

Ligamenta columnæ vertebralis-The ligaments of the vertebral column. 


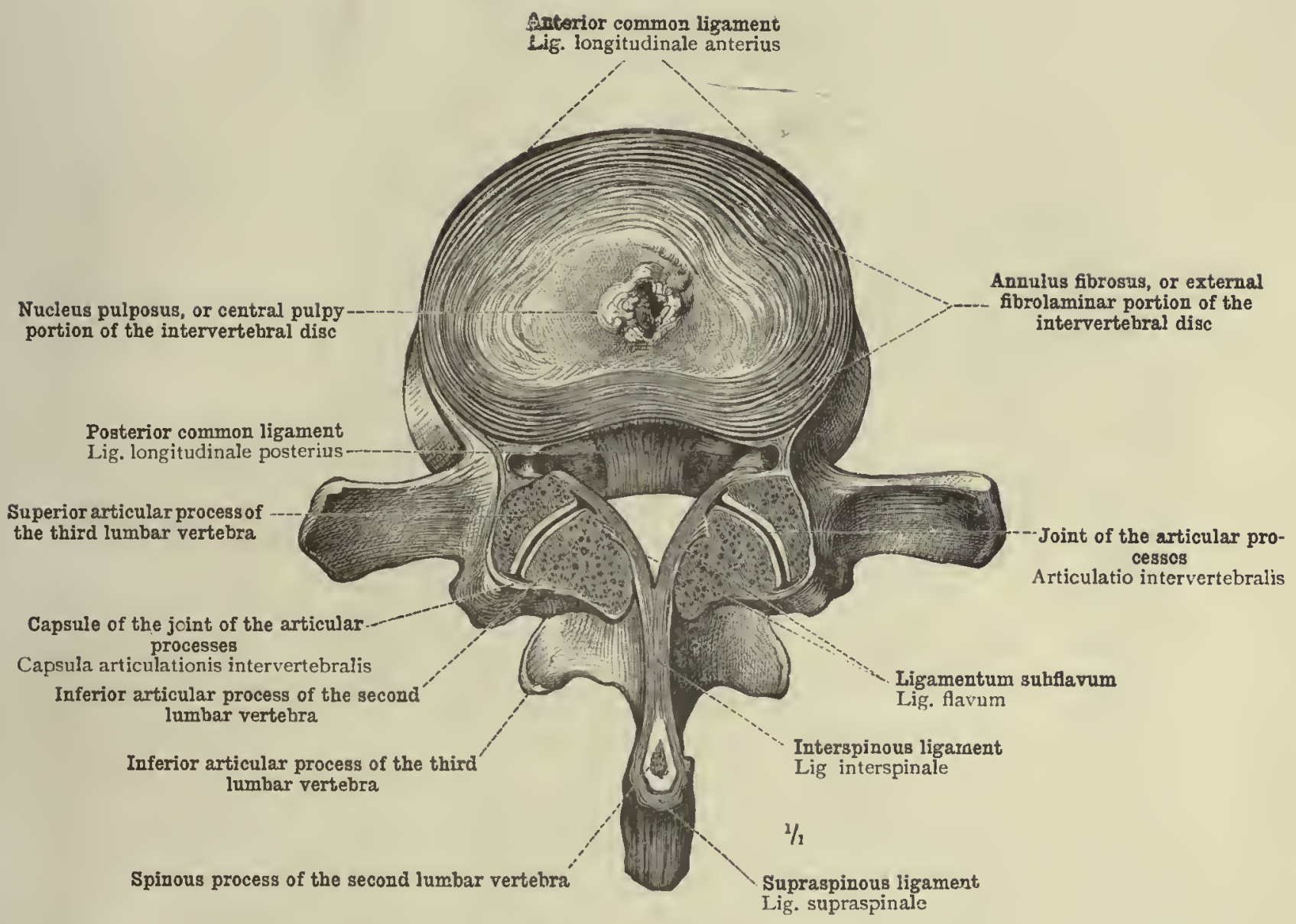

Fig. 397.-Intervertebral. Orsc between the Second Lumbar Vertebra and the Third. (Lower Half of a Horizontal Section.) 


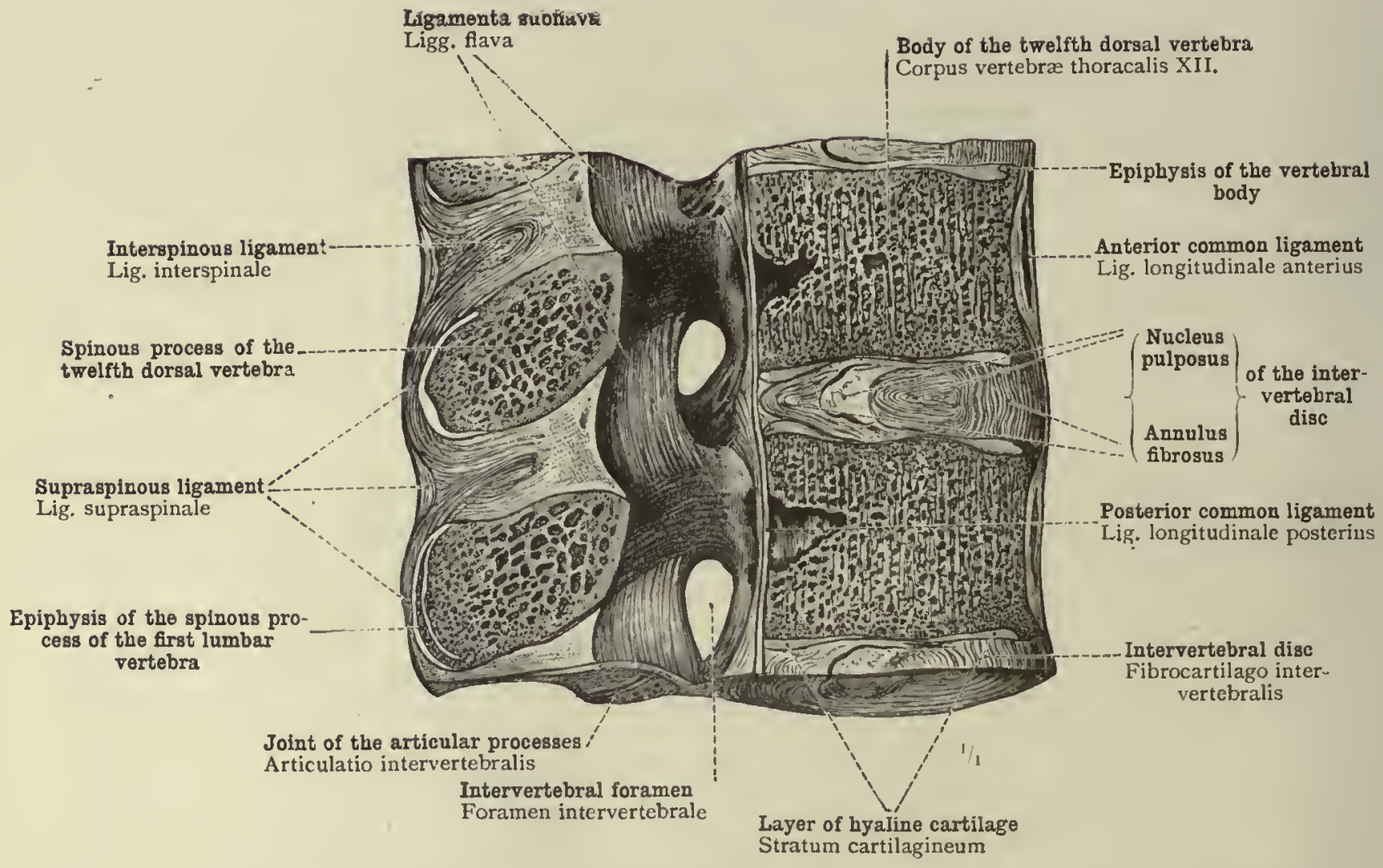

Fig. 398.-Fibrocartilagines Intervertebrales, Intervertebral Discs. Ligamenta Flava, or Subflava. Ligamenta Interspinalia, Interspinous Ligaments. Ligamentum Supraspinale, Supraspinous Ligament. (Median Section through the Twelfth Dorsal and the First Lumbar Vertebre, Left Half.?

Ligamenta columnæ vertebralis - The ligaments of the vertebral column. 


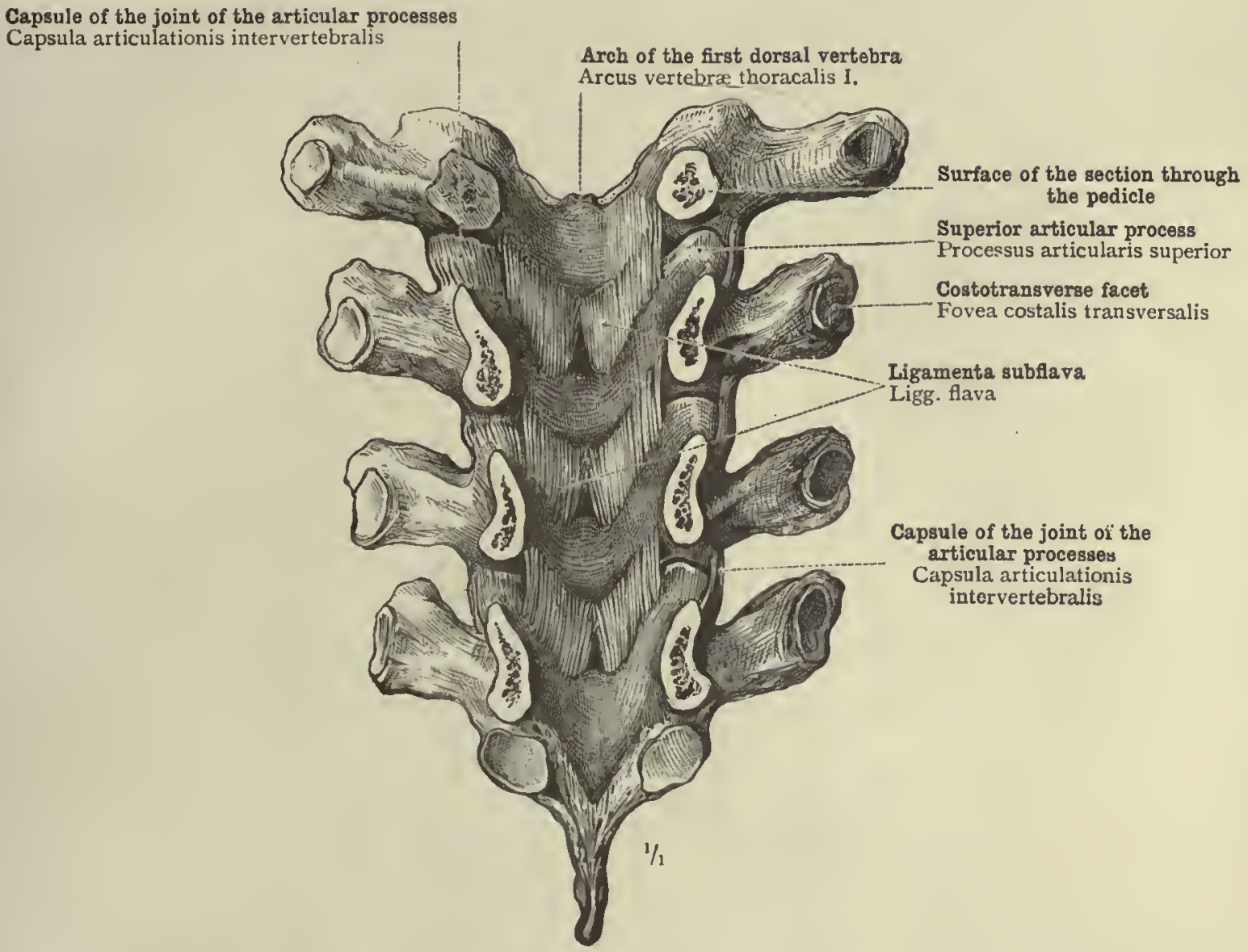

Fig. 399.-Ligamenta Flava, Ligamenta Subflava. Articulationes Intervertebrales, Intervertebral ARticulations. OF these LATTER the Rigit ARE UNOPENED, the Left opened. (The Arches of the First Four Dorsal Vertebra, separated from the Bodies by a Frontal Section. Seen from Before.)

Ligamenta columnæ vertebralis-The ligaments of the vertebral column. 
Anterior occipito-atlantal ligament Membrana atlanto-occipitalis anterior

First cervica! vertebra Vertebra cervicalis I.

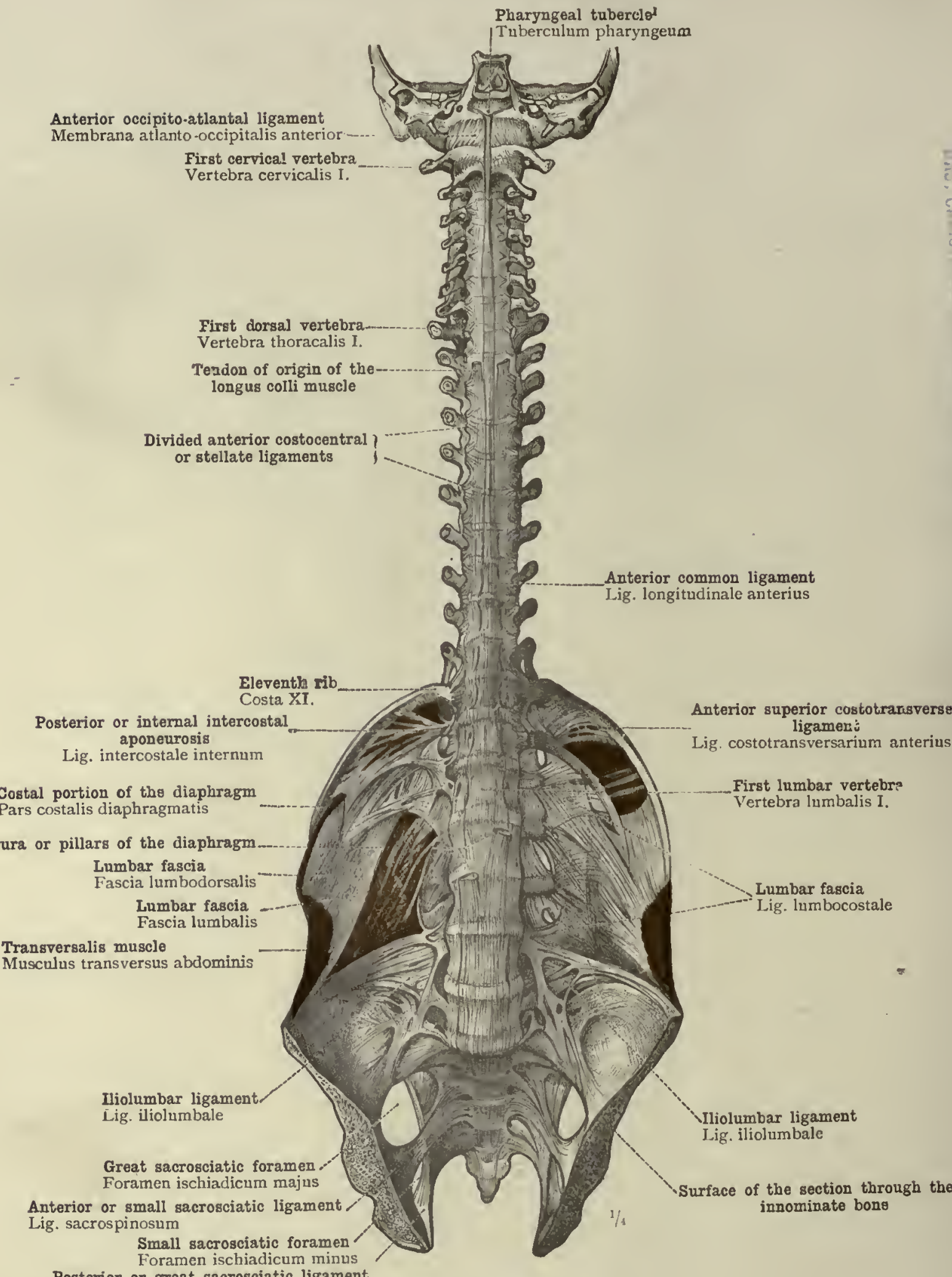

Posterior or great sacrosciatic ligament

Lig. sacrotuberosum

1 U.S. : Pharyngeal spine.

Fig. 400.-Ligamentum Longitudinale Anterius, the Anterior Common Ligament. Ligamentum Lumbocostale, Lumbocostal Ligament. (The Ventral Aspect of the Vertebral Column, the Anterior Half of the Base of the Skull and the Anterior Half of the Pelvis having beEN Removed.)

Ligamenta columnæ vertebralis-The ligaments of the vertebral column. 
Basi-occipital and basi-

Corpus ossis basilaris

Anterior arch of the atlas Arcus anterior atlantis

Odontoid process Dens epistrophei
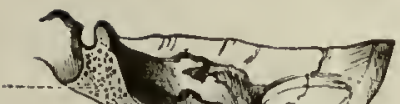

Spinal canal

Canalis vertebralis

First dorsal vertebra

Vertebra thoracalis I.
External occipital protuberance

Protuberantia occipitalis externa

Ligamentum nuchæ

Spinous process of the seventh cervical vertebra Processus spinosus vertebræ prominentis

Supraspinous ligament ilig. supraspinale

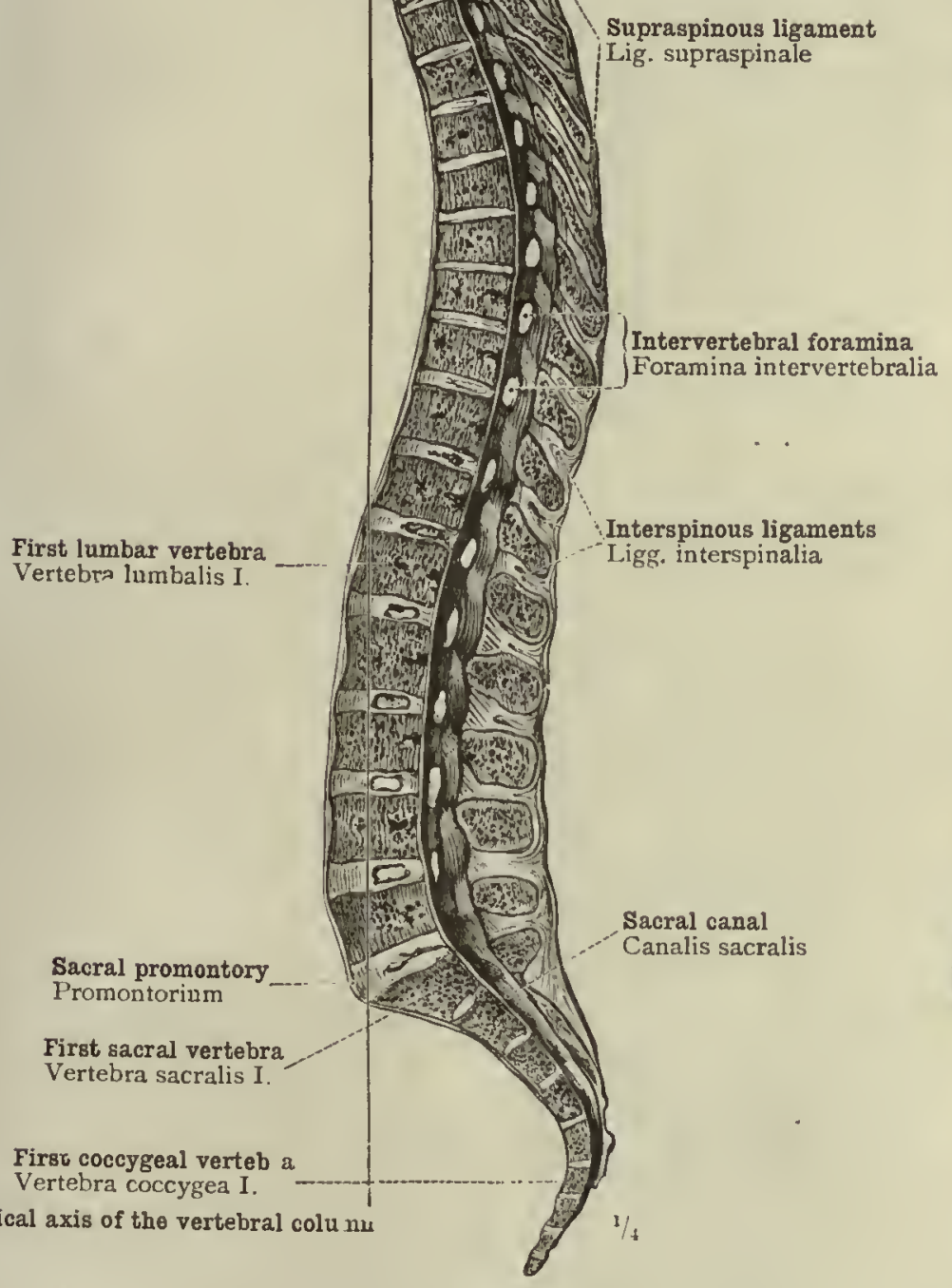

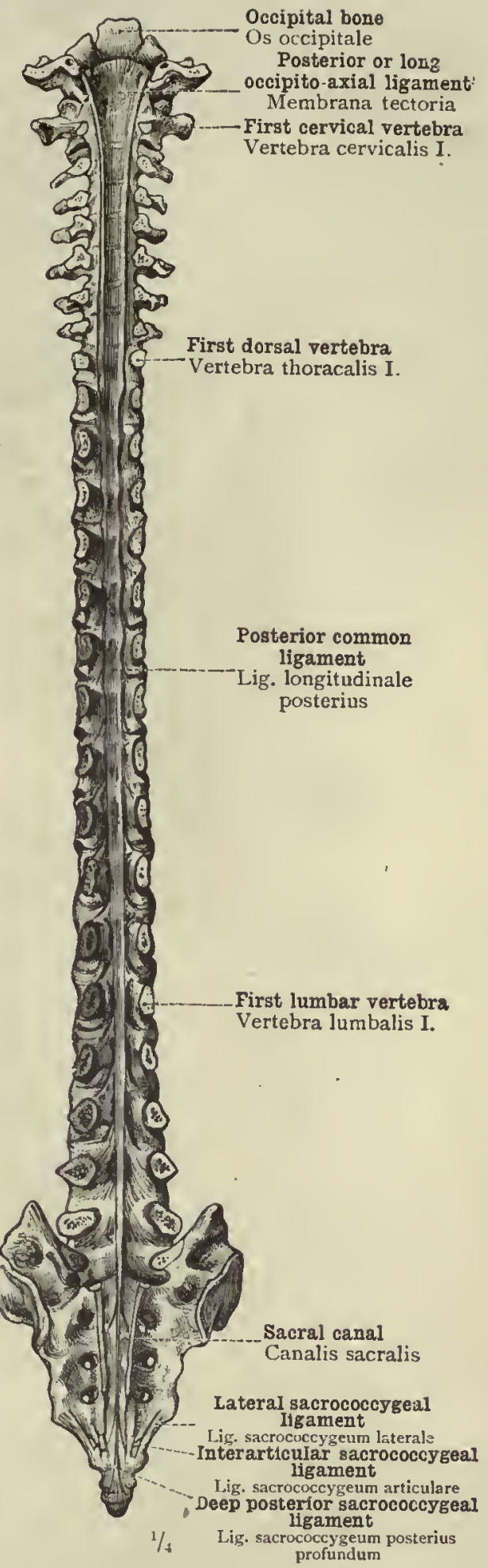

Fig. 402.-Posterior Common Ligament AND its Relation with the Posterior OccipitoAXIAL AND THE DEeP POSTERIOR SACROCOCCYGEal. Ligaments. (The Vertebral Columin twith the Spinal Canal opened by the Removal of the Neural Arghes; SEEN FROM BEHIND.)

1 Macalister calls this ligament ligamentum latum axiale, the broad axial ligament.-Tr.

Ligamenta columnæ vertebralis-The ligaments of the vertebral column. 


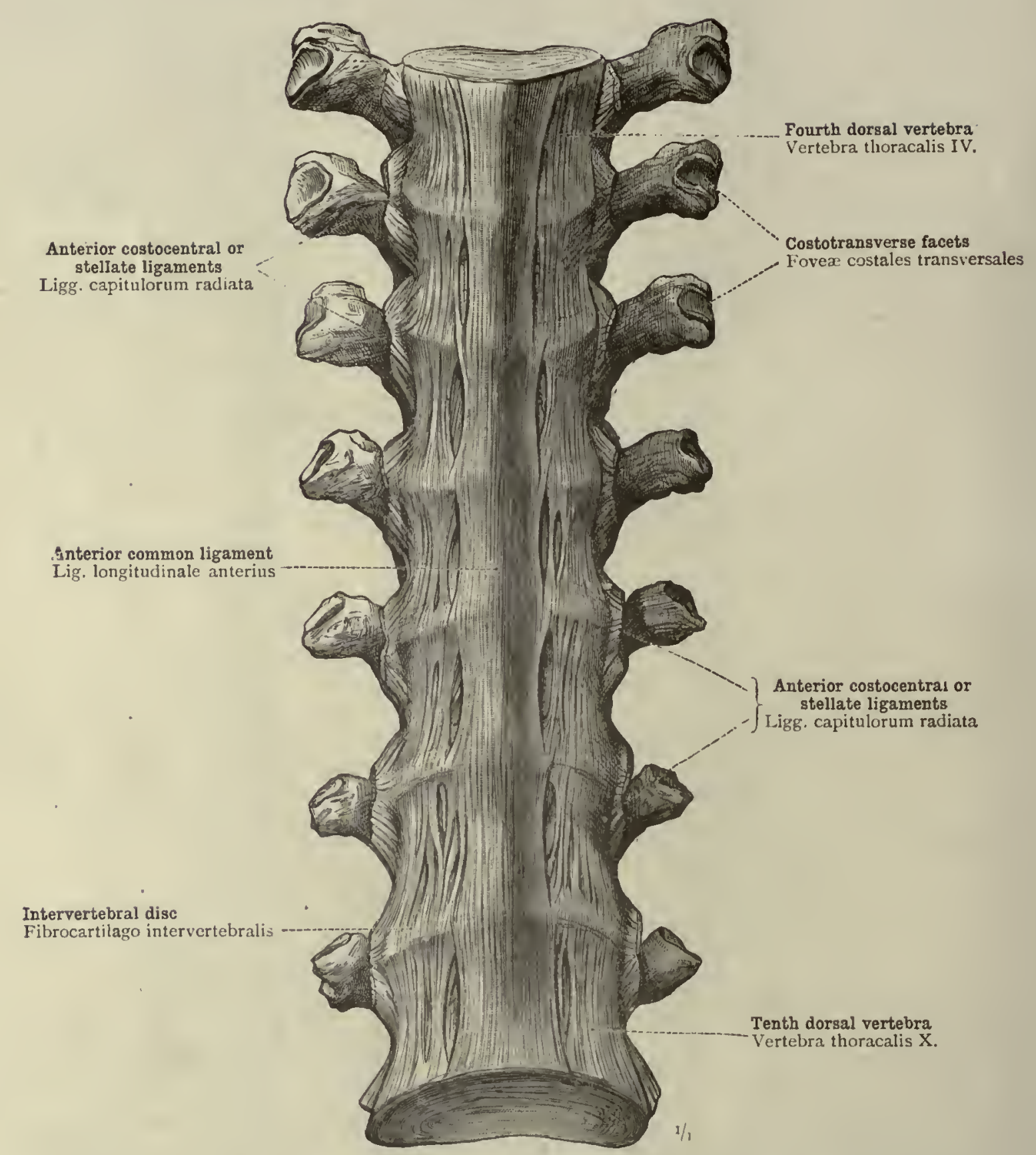

Fig. 403.-Ligamentum Longitudinali: Anterius, the Anterior Common Ligament of the Vertebrai Columa. (The Fourth to the Tenth Dorsal Vertebra:; SEEN FROM BEFORE.)

Ligamenta columnæ vertebralis-The ligaments of the vertebral column. 


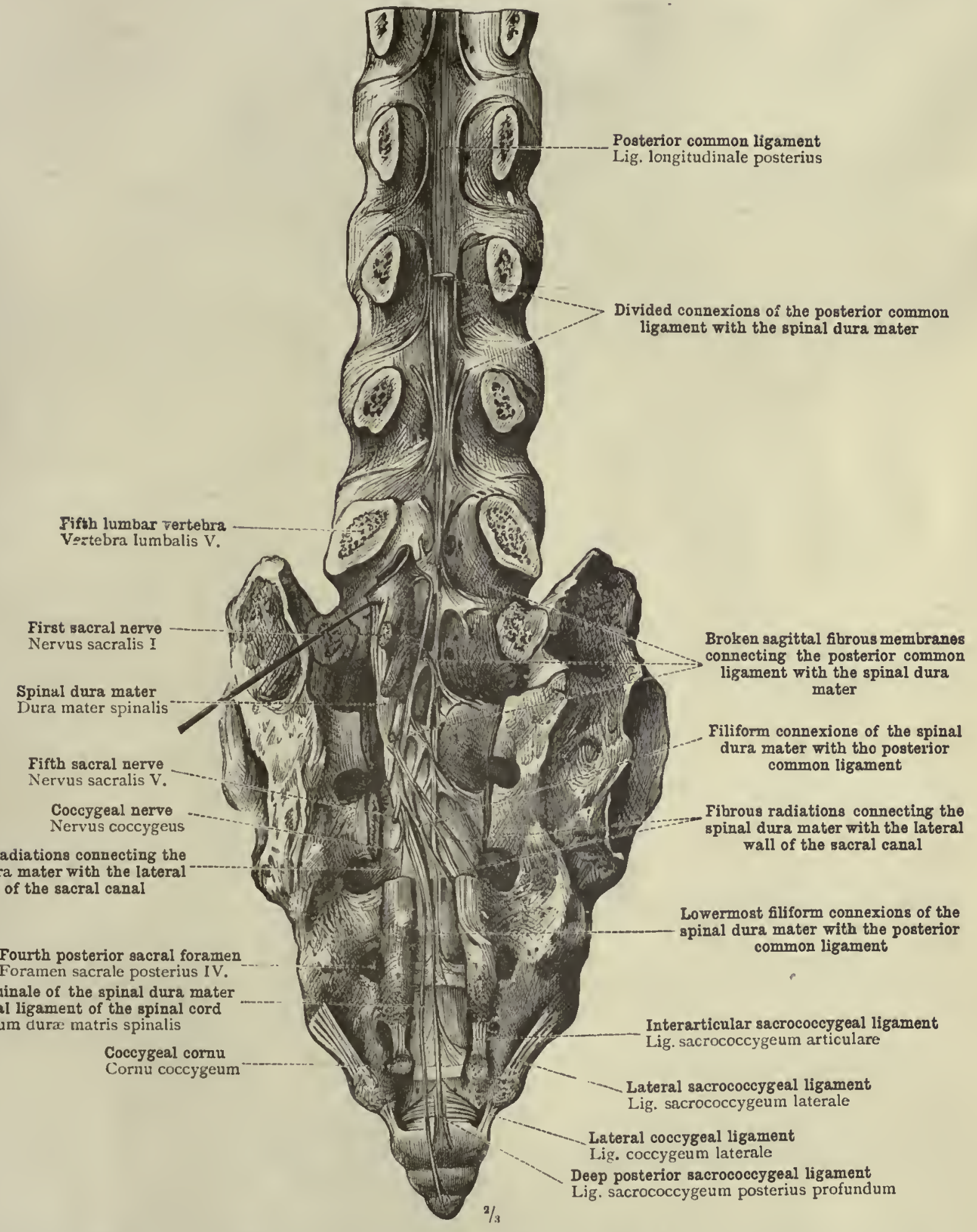

Filiform radiations connecting the spinal dura mater with the lateral wall of the sacral canal

Fourth posterior sacral foramen or central ligament of the spinal cord Filum durx matris spinalis

rarticular sacro Lig. sacrococcygeum articulare

Lateral sacrococcygeal ligament Lig. sacrococcygeum laterale

teral coccygeal ligament

posterior sacrococcygeal ligament

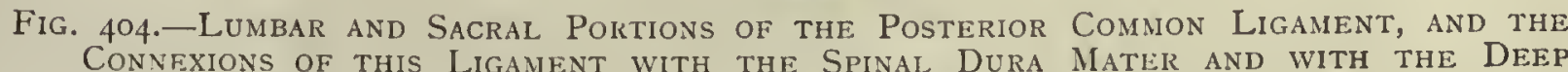
Posterior Sacrococcygeal Ligament. (The Sacrum and the Lumbar Portion of the Vertebral Column with the Spinal Canal laid open from Behind.)

The sacral portion of the dura mater has been drawn to the left side.

Ligamenta columnæ vertebralis-The ligaments of the vertebral column. 


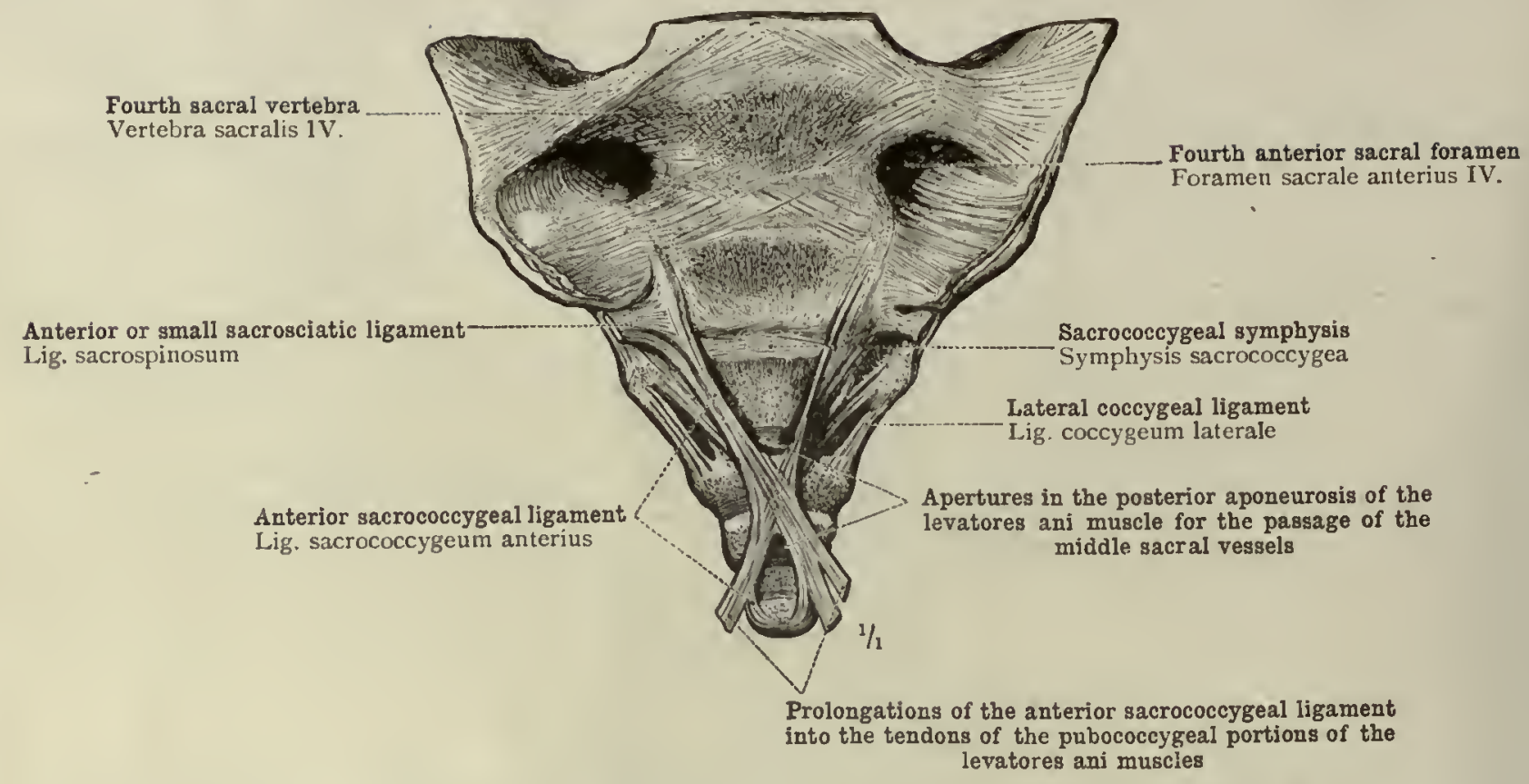

Fig. 405.-The Ligaments connecting the Anterior Surfaces of the Sacrum and Coccyx : the ANTerior and the Lateral Sacrococcygeal Ligaments.

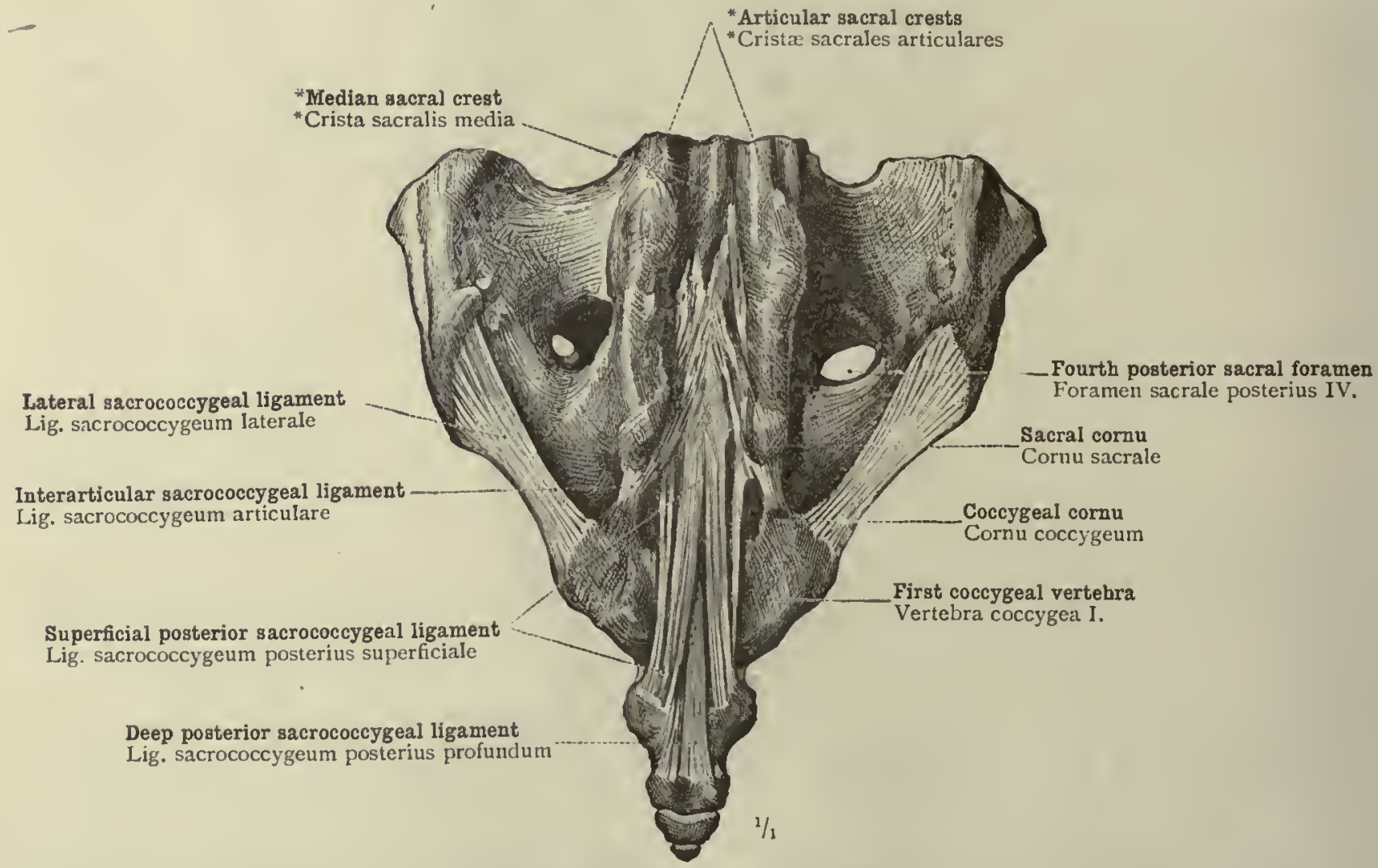

Fig, 406.-Tile Ligaments connecting the Posterior Surfaces of the Sacrum and Coccyx: the Superficial and Diel' Posterior Sacrococcyglial Ligaments, and the Interarticular and Lateral Sacrococcygeal Ligaments.

The Coccix with the Two Last Sacral Vertebre.

Ligamenta columnæ vertebralis-The ligaments of the vertebral column. 


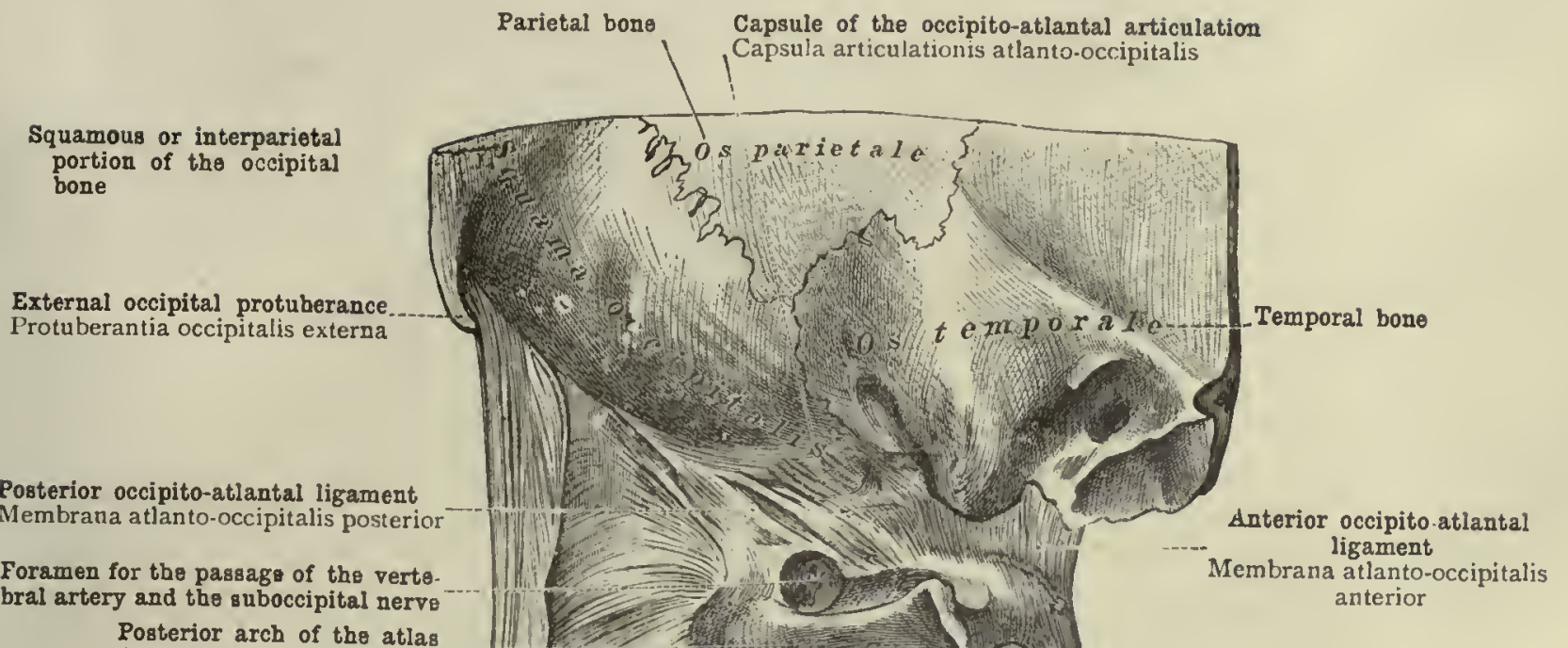

Posterior arch of the atlas Arcus posterior atlantis

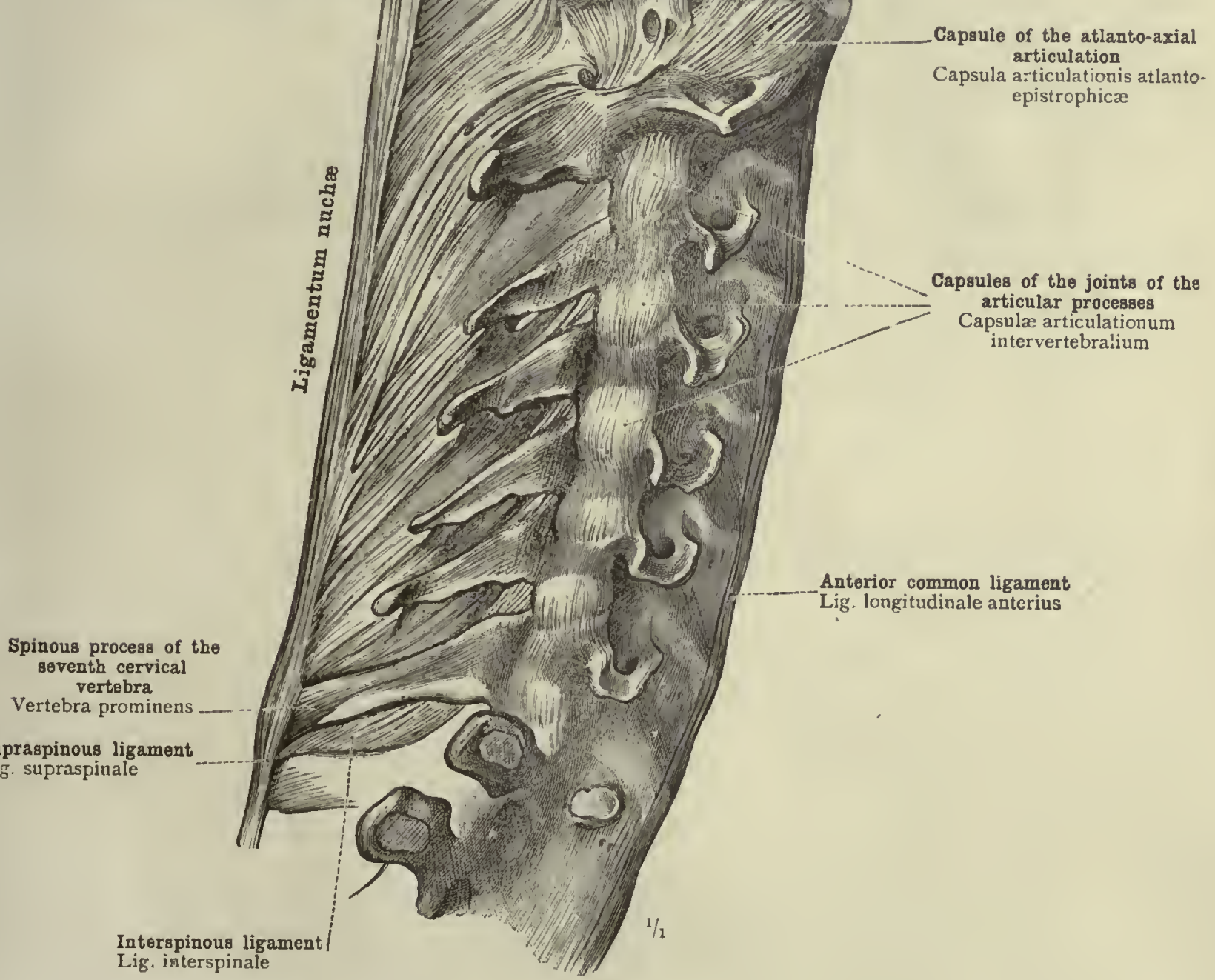

Fig. 407.-I.igamentum Nucha. (The Cervical Portion of the Vertebral Column and the Posterior Portion of the Cranium; seen from the Right Side.)

Ligamenta columnæ vertebralis-The ligaments of the vertebral column. 


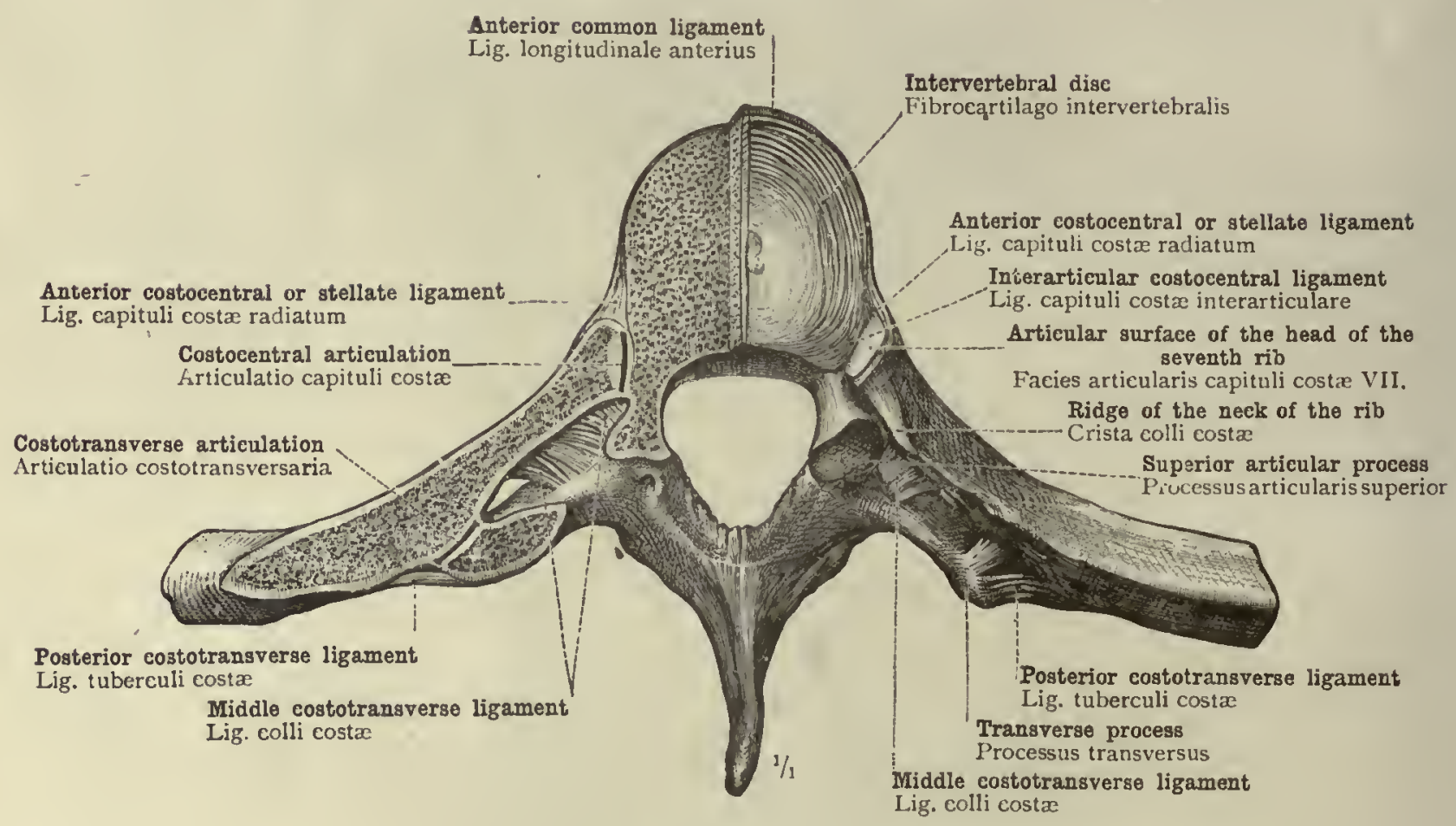

Fig. 408.-Articulationes Capitulorum et Costotransversaria, the Costocentral and Costotransverse Articulations: Ligamentum Capituli Coste Interarticulare, the Interarticular Costocentral Liganent; Ligamentum Colli Costa et Ligamentum Tuberculi Coste, the Middle and Posterior Costotransverse Ligaments. (The Seventil Dorsal Vertebra with the Vertebral Extremities of the Seventh Pair of RiBS; SEEN FROM ABOVE.)

On the left side the costocentral and costotransverse articulations have been opened by a horizontal section through the rib and the vertebral body; on the right side the section passes through the intervertebral disc on a plane just above the attachnent of the interarticular costocentral ligament to the ridge between the two articular facets on the vertebral extrenity of the rib. 


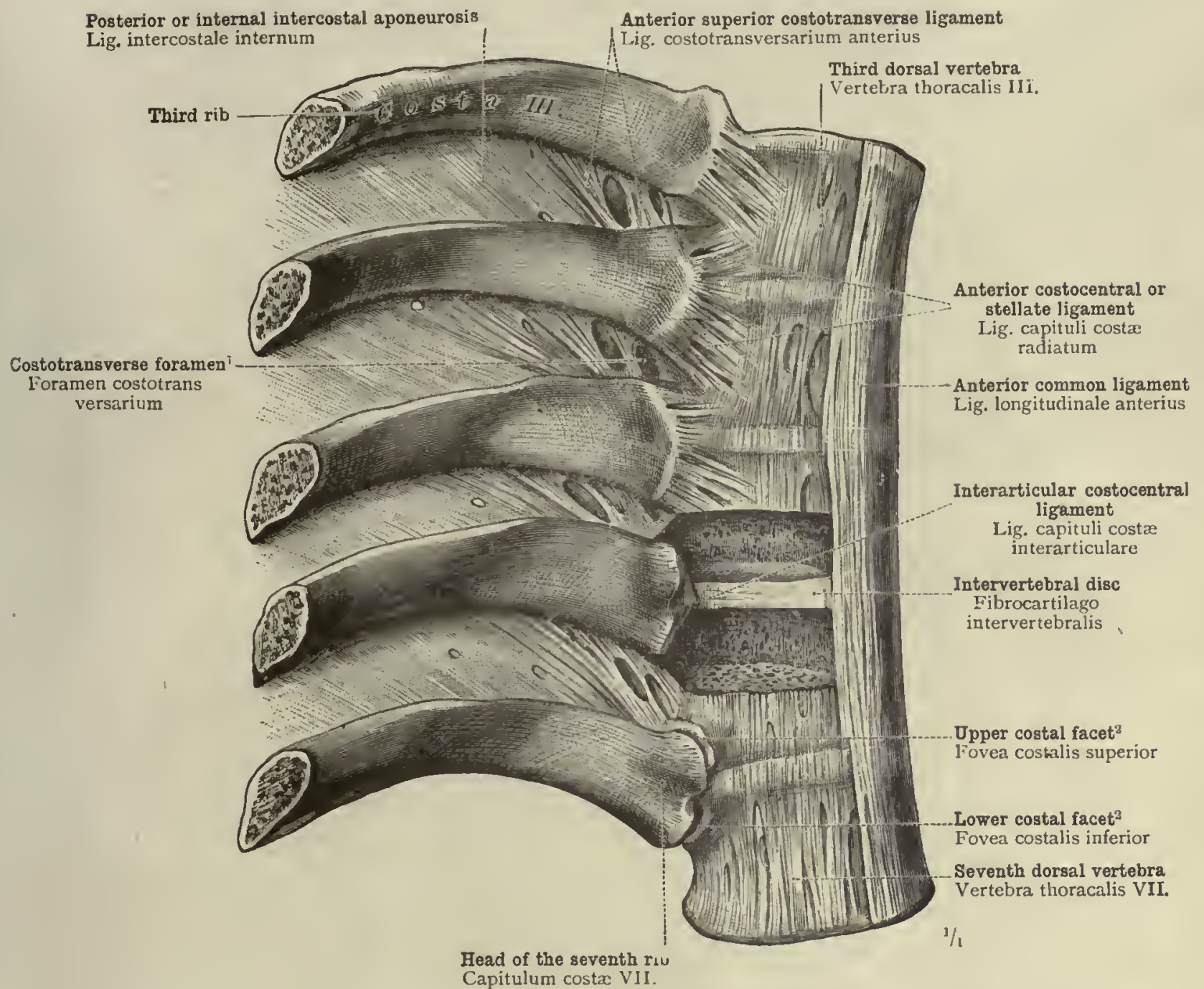

1 This term, costotransverse foramen, is also used by English anatomists to denote the foramina in the transverse processes of the cervical vertebrx for the transmission of the vertebral artery. - TR.

2 These are upper and lower costal facets respectively in relation to the articular surface of the bead of the rib : but, strictly speaking, what is here called "upper costal facet" is the lower costal facet of the sixth dorsal vertebra; while what is here called "lower costal facet" is the upper costal facet of the seventh dorsal vertebra. - TR.

Fig. fog.-Costocentral and Costotransverse Articulations: Anterior Costocentral or Stellate Ligament; Interarticular Costocentral Ligament; Anterior Superior Costotransverse Ligament; and Costotransverse Foranina. Posterior or Internal Intercostal Aponeuroses. (The Third to the Seventh Dorsal Vertebre with the Vertebral Extremities of the Third to the Seventh Right Ribs; seen from the RIGHT AND FROM BEFORE.)

The third, fourth, and fifth costocentral articulations are unopened; the sixth and the seventh have been opened from before. In the sixth articulation, by the partial removal of the bodies of the fifth and sixth dorsal vertebra, the upper and lower surfaces of the intervertebral disc have been exposed, and the attachment of the disc to the ridge between the two articular facets on the head of the rib has been demonstrated.

\section{Articulationes costovertebrales-Costovertebral articulations.}




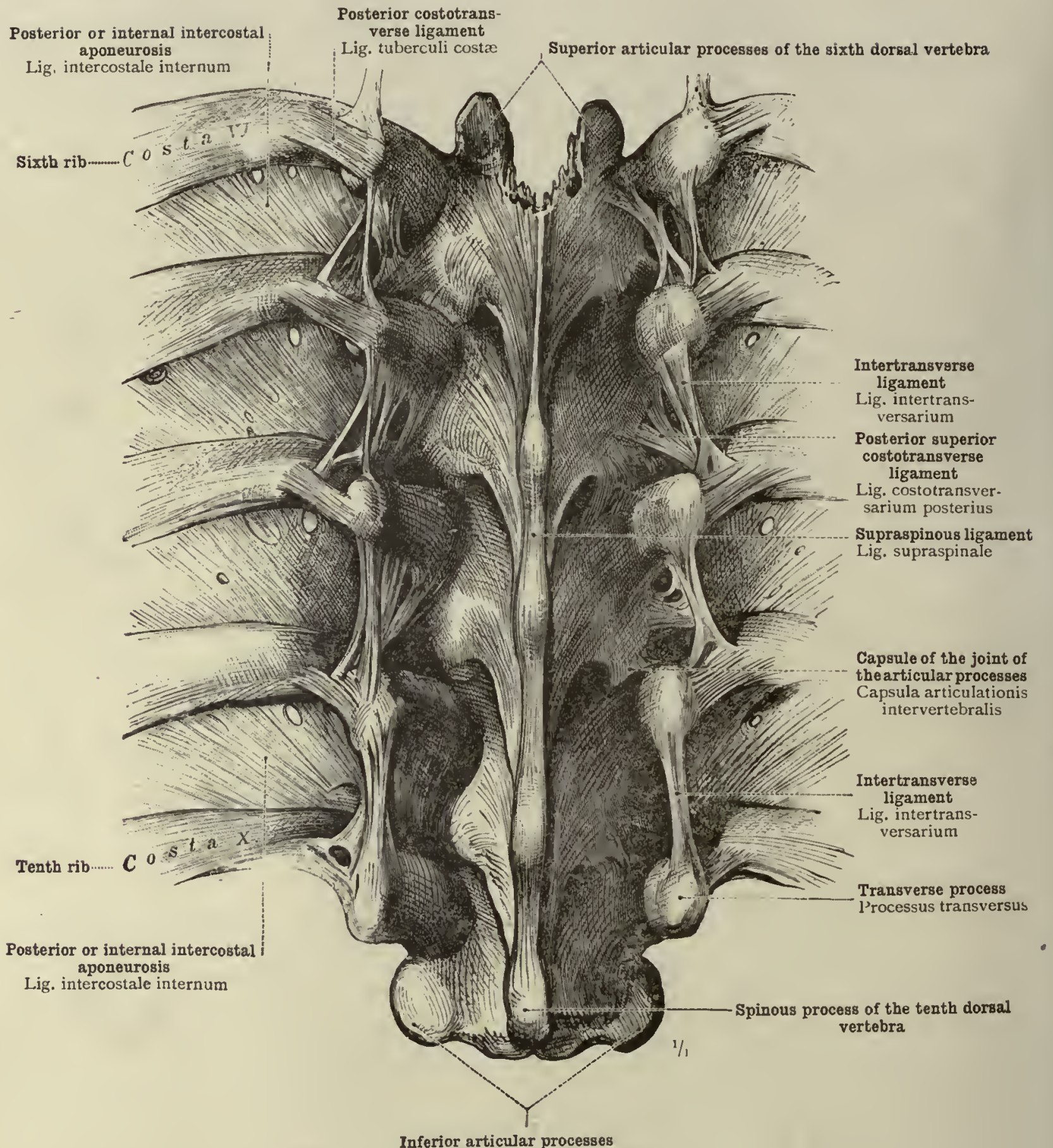

Inferior articular processes

Processus articulares inferiores

Fig. 4IO.-The Ligaments connecting the Dorsal Vertebra with the Ribs posteriorly: Posterior and Posterior Superior Costotransverse Ligaments; Intertransverse Ligaments; Posterior or Internal intercostal Aponeuroses; Supraspinous Ligament. (Sixth to Tenth Dorsal Vertebres With the Vertebral Extremities of the Sixth to Tenth Ribs.) 
Third cervical vertebra Vertebra cervicalis III.

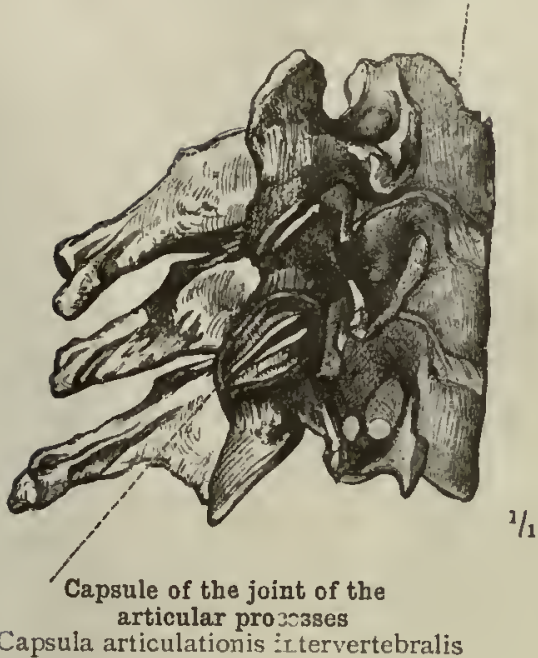

Fig. 4I.-Third, Fourth, AND Fifth Cervical Vertesres SEEN FROM THE Right EDE.

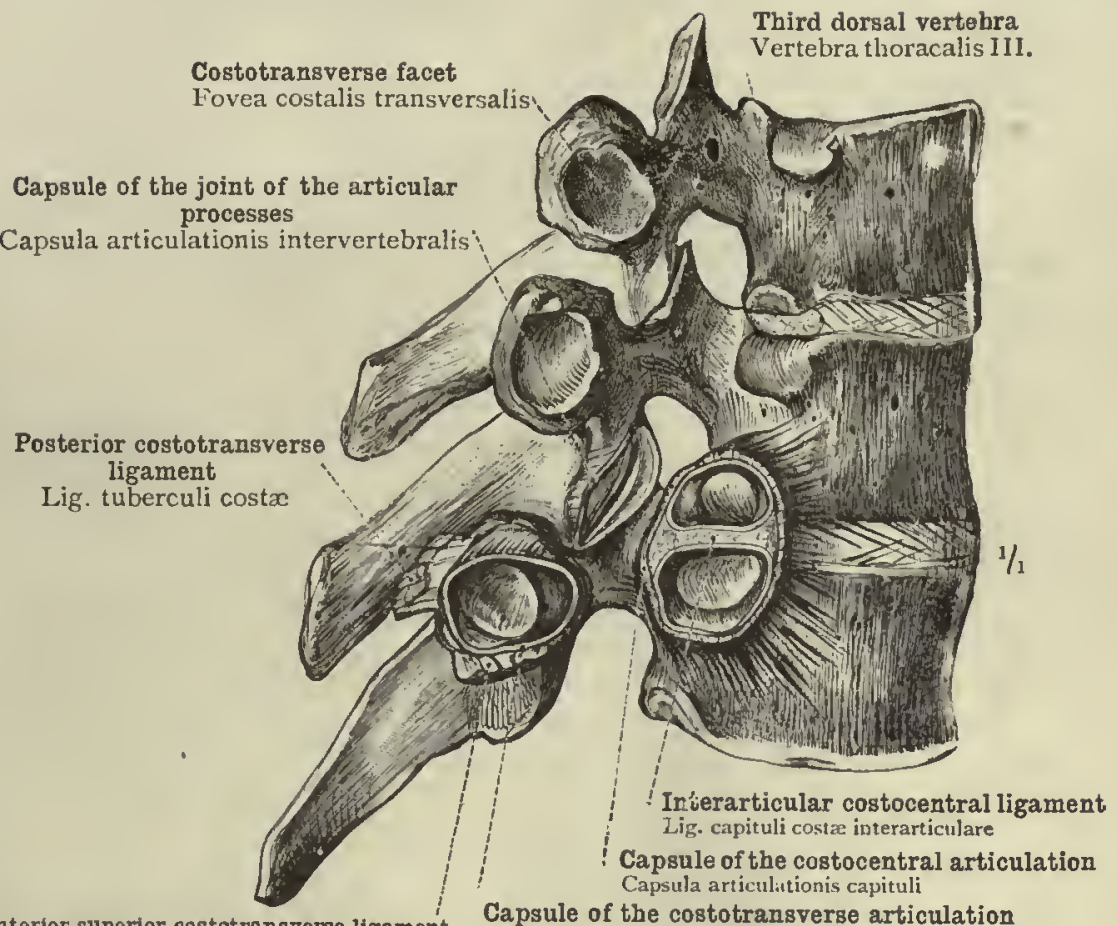

Anterior superior cestetransverse ligament Lig. costotransversarium anterius
Capsule of the costotransverse articulation Capsula articulationis costotransversaria

Fig. 4I2.-Third, Fourth, and Fifth Dorsal Vertebre SEEN FROM THE Right SIDE.

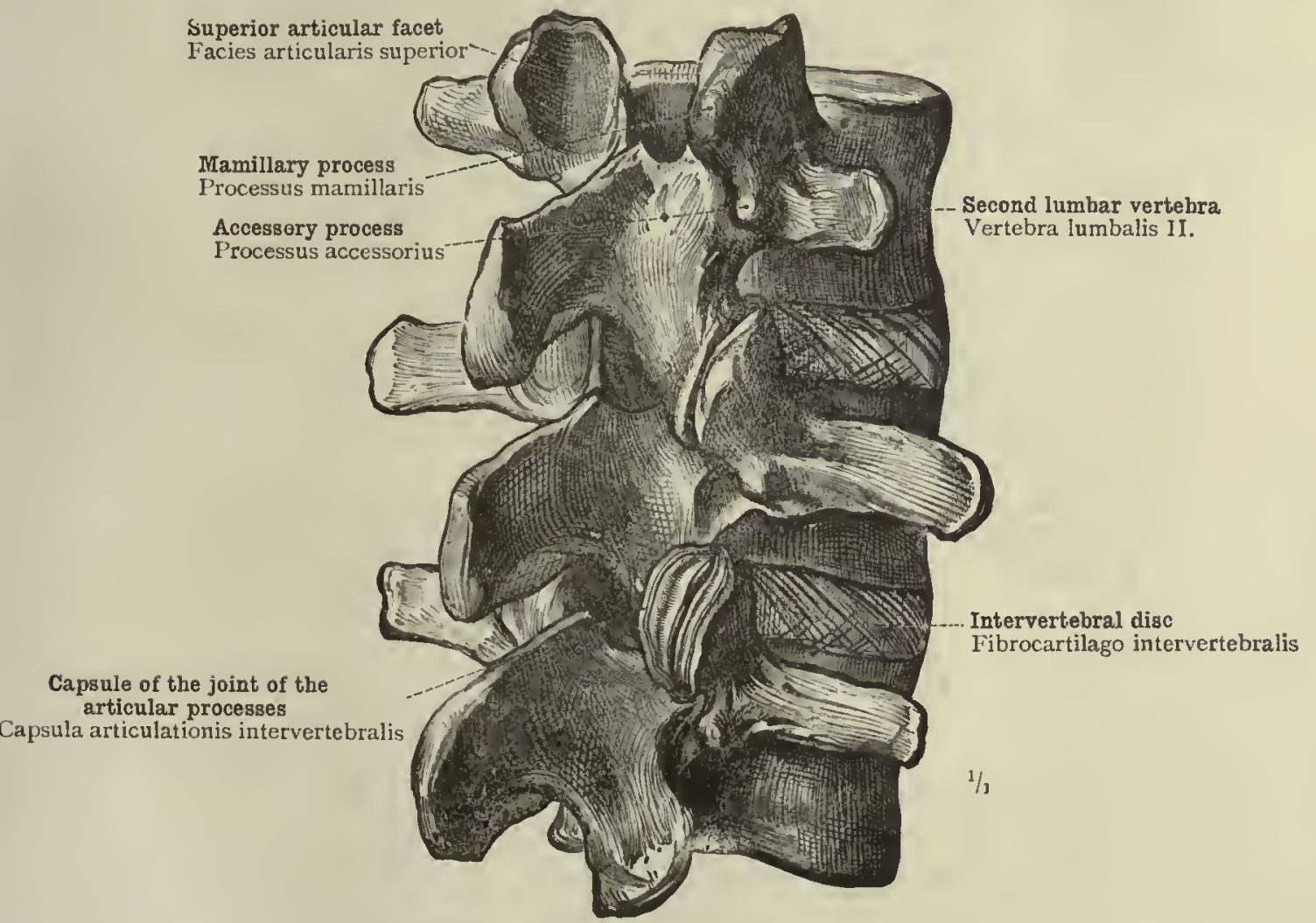

Fig. 413.-Second, Third, and Fourth Lumbar Vertebre seEn From the Right and FROM BEHIND.

The Direction of the Articular Surfaces and the Connexions of the Capsules of tile Joints of the Articular Processes in the Cervical, Dorjal, and Lumbar VERTEBRA RESPECTIVELY. 


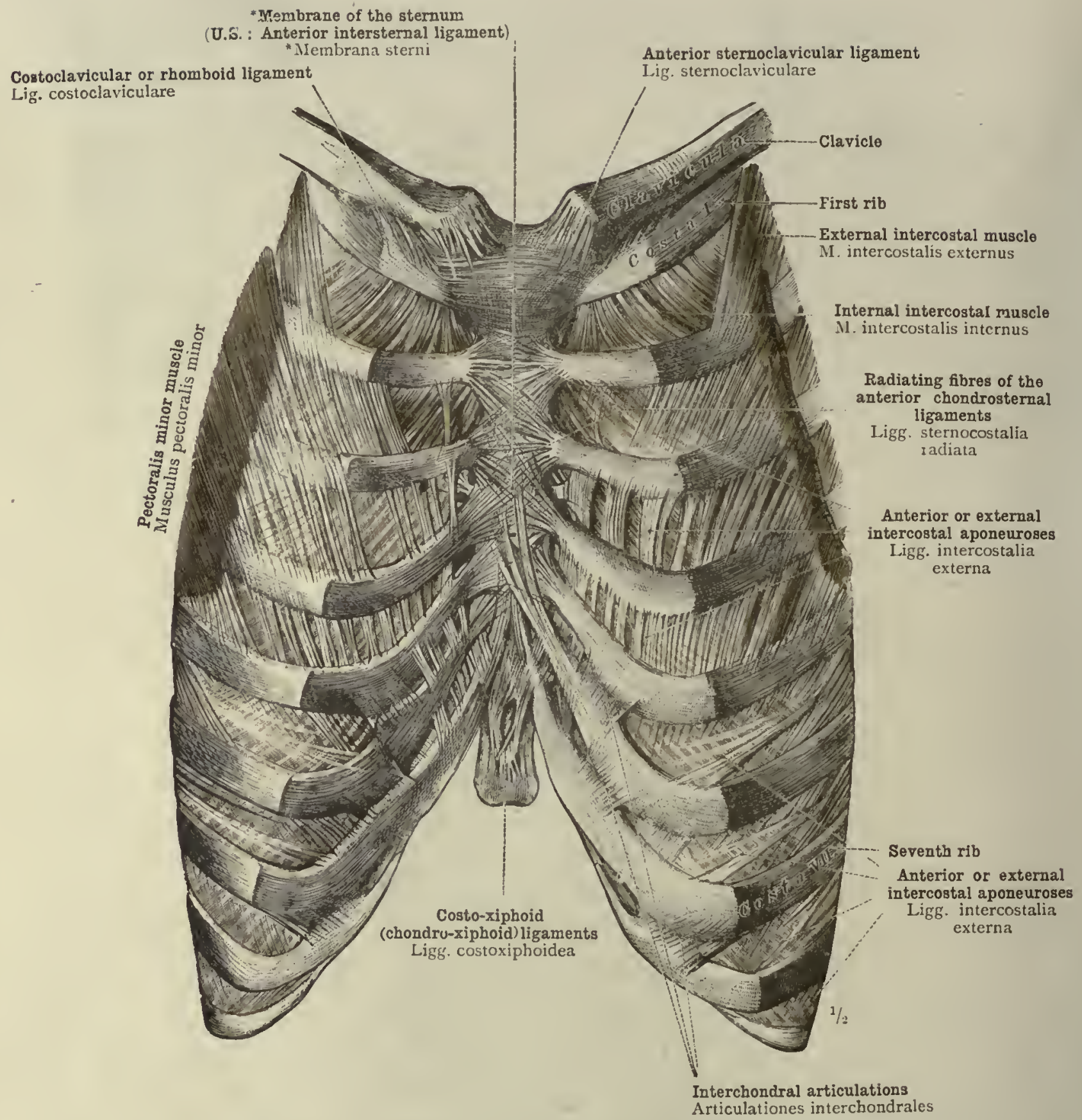

Fig. 4i4.- *Membrane of the Sternum. Anterior Chondrosternal Ligaments, Costoxipioid Ligaments, and Anterior or External Intercostal Aponeuroses. The Relation of these Latter to the External Intercostal Muscles and to the. Pectoralis Minor Muscle. (Anterior Wall of the Thorax seen from Before.) 


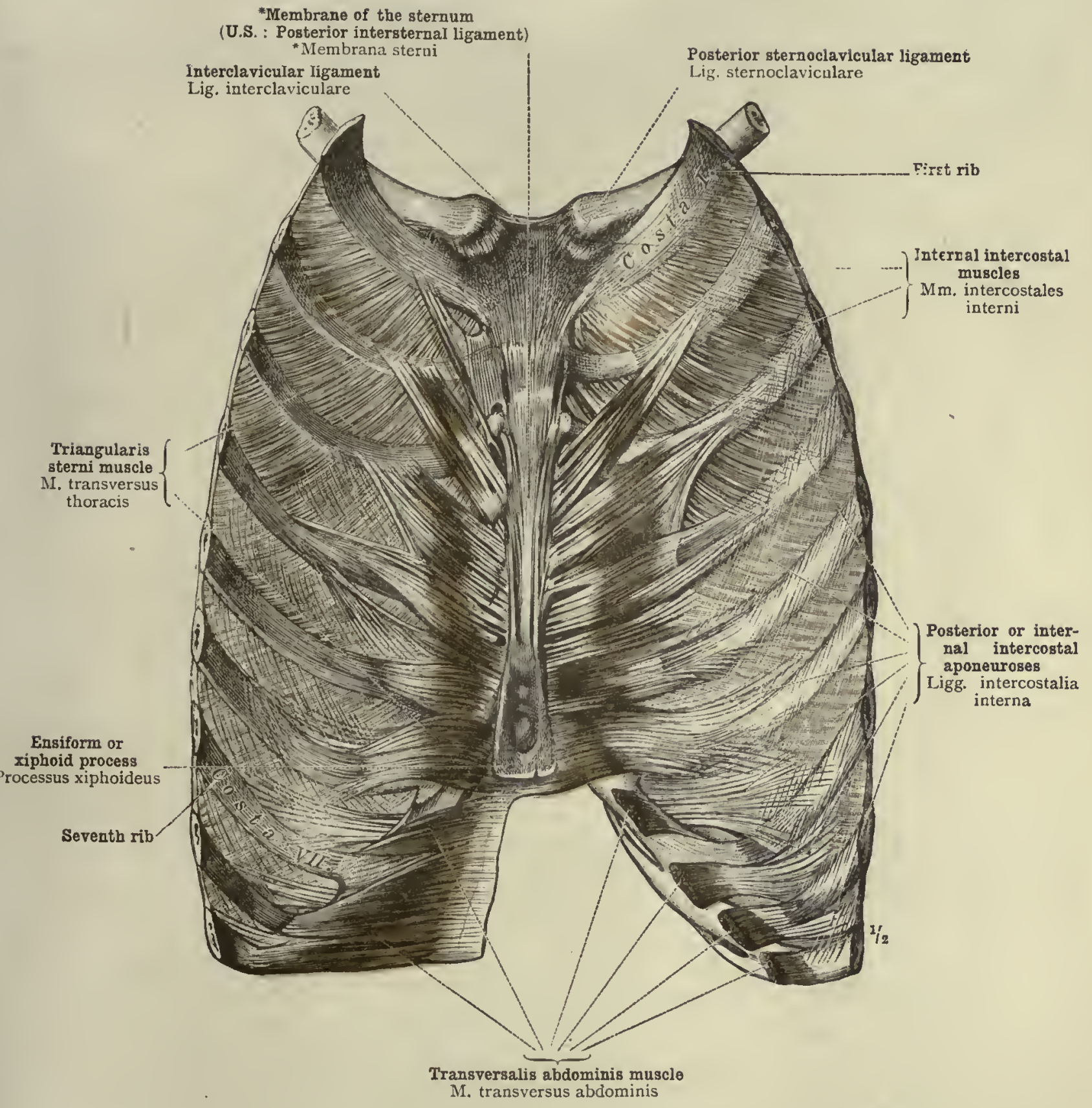

Fig. 4I5.-Posterior or Internal Intercostal Aponeuroses, and their Relation to the Triangularis Sterni and Transversalis Abdominis Muscles. Sternoclavicular Articulation. (Anterior Wall of the Thorax seen from Behind.) 


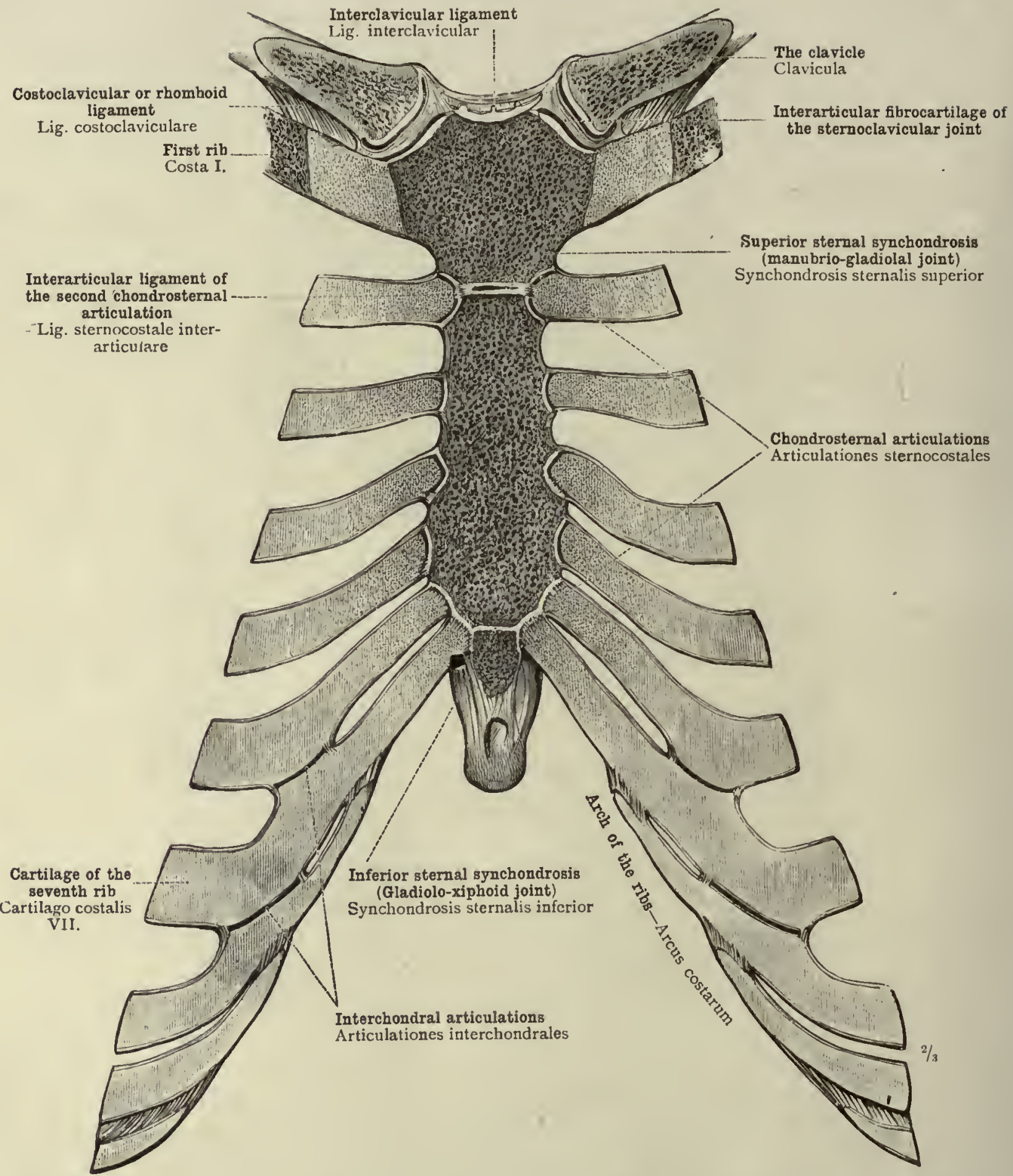

Fig. 4i6.-Chondrosternal Articulations. Interchondral Articulations. Intersti Rnal Synchondroses. Sternoclavicular articuration. (Posterior half of a Frontal Section through the Sternum, the Cartilages of the Ribs, and the Sternal. Extremities of the Clavicles.) 


\section{ARTICULATIONES \\ ET LIGAMENTA CAPITIS}

THE ARTICULATIONS

AND LIGAMENTS OF THE HEAD 


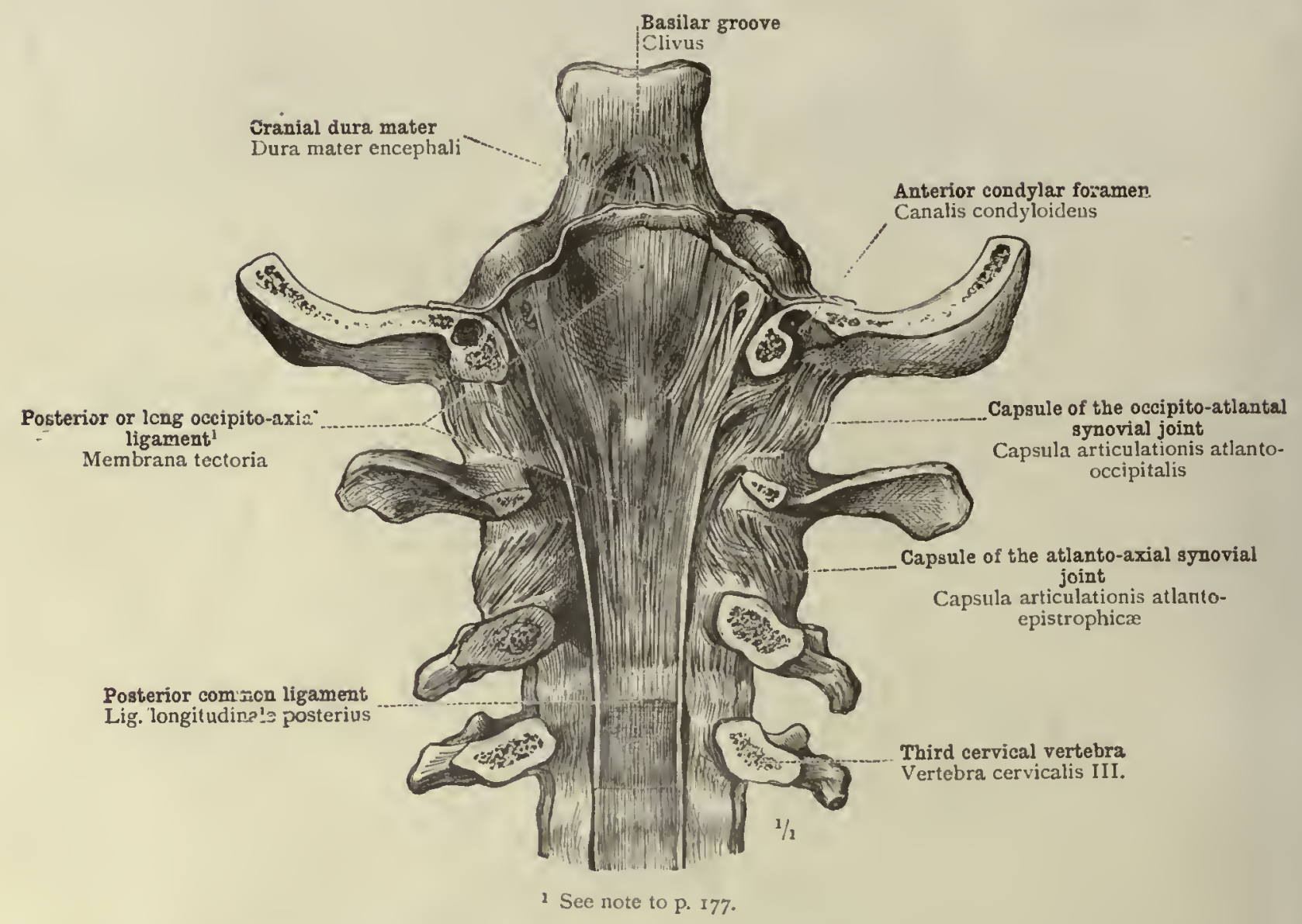

Fig. 4I7.-Posterior Occipito-Axial Liganent. Occipito-atlantal and Atlanto-axial Synovial Joints. (The Three Uppermost Cervical Vertebre and tile Occipital BONE SEEN FROM BEHIND.)

By a frontal section behind the occipital condyles, the squamous portion of the occipital bone and the neural arches have been removed. The dura mater has bcen cut transwersely in the basilar groove, and turned upwards

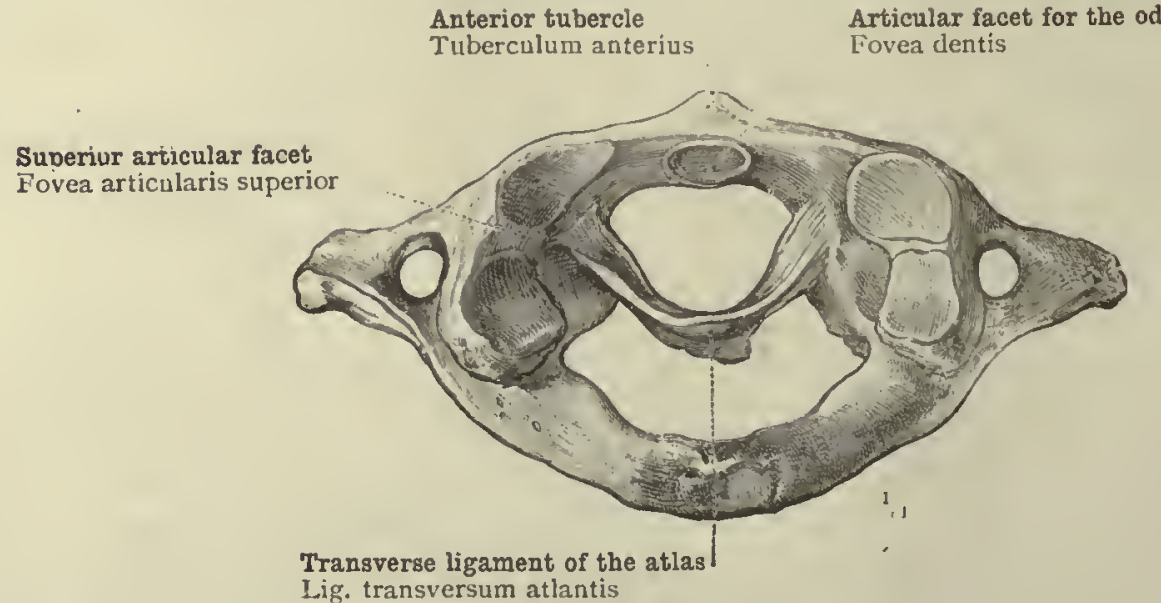

Fig. 4i8.-Transverse Ligament of the Atlas. (The Atlis seen from Above.) 


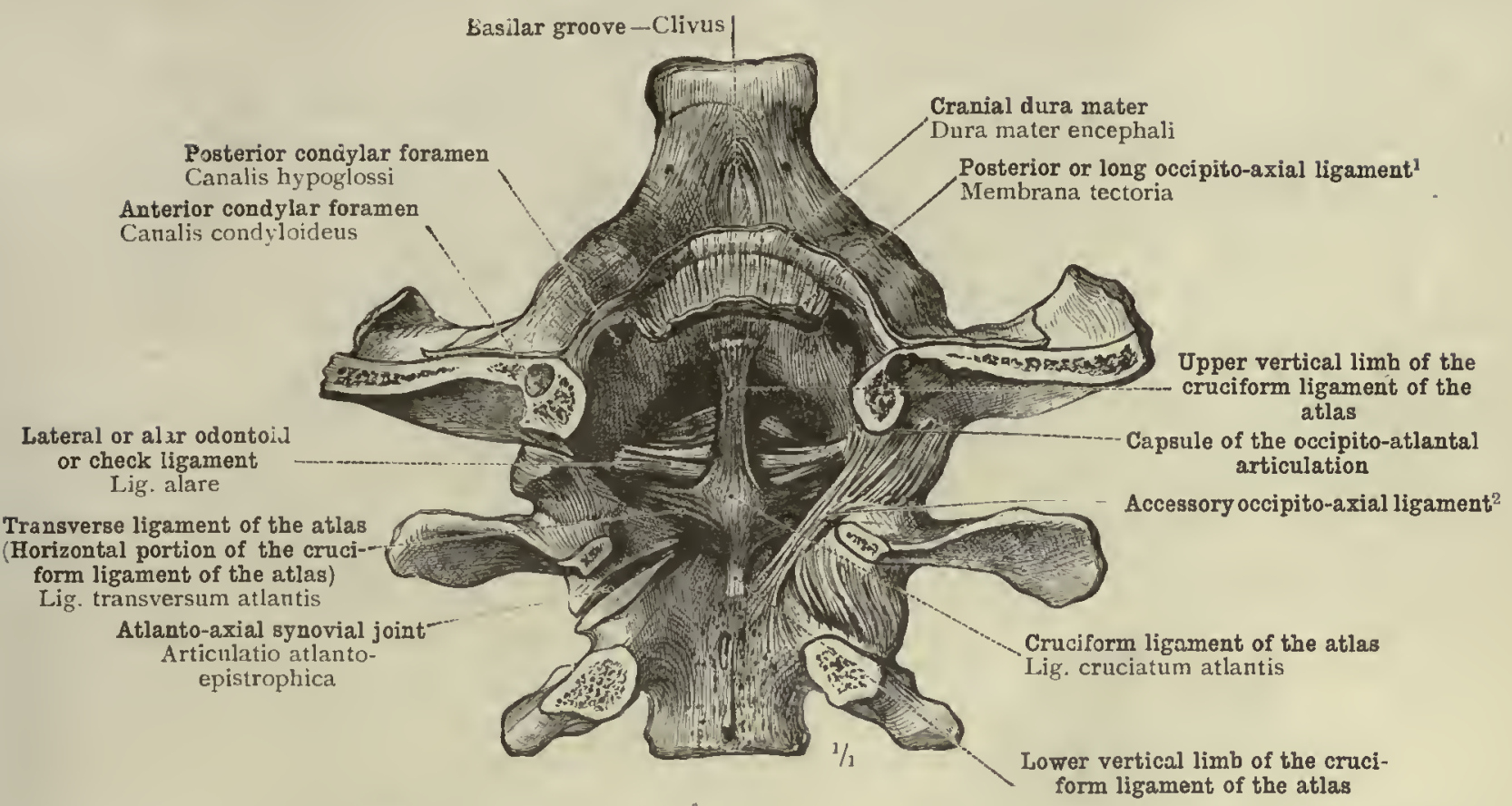

Fig. 4i9.-Cruciform Ligament of the Atlas; Lateral or Alar Odontoid or Check Ligaments Occipito-atlantal and Atlanto-axial Synovial Joints, the Right closed, the Left open.

The cranial clura mater and the posterior or long occipito-axial ligament ${ }^{1}$ have been cut transversely

See note to p. 177 .

in the basilar groove and turned upwards.

2 Accessory occipito-axinl ligament. This ligament is not mentioned by the author, though it is well shown in Fig. 4 rg. The accessory ligament is a bundle of filures strengthening the capsule of the occipito-atlantal joint at its postero-internal angle. 11 runs downwards and inwards from the back of the occipital condyle to the body of the axis near the base of the odontoid process.-Tik.

Basilar groove-Clivus !

Jccipito-atlantal synovial joint Canalis hypoglossi

Articulatio atlanto-occipitalis

Transverse ligament of the atlas

Lig. transversum atlantis
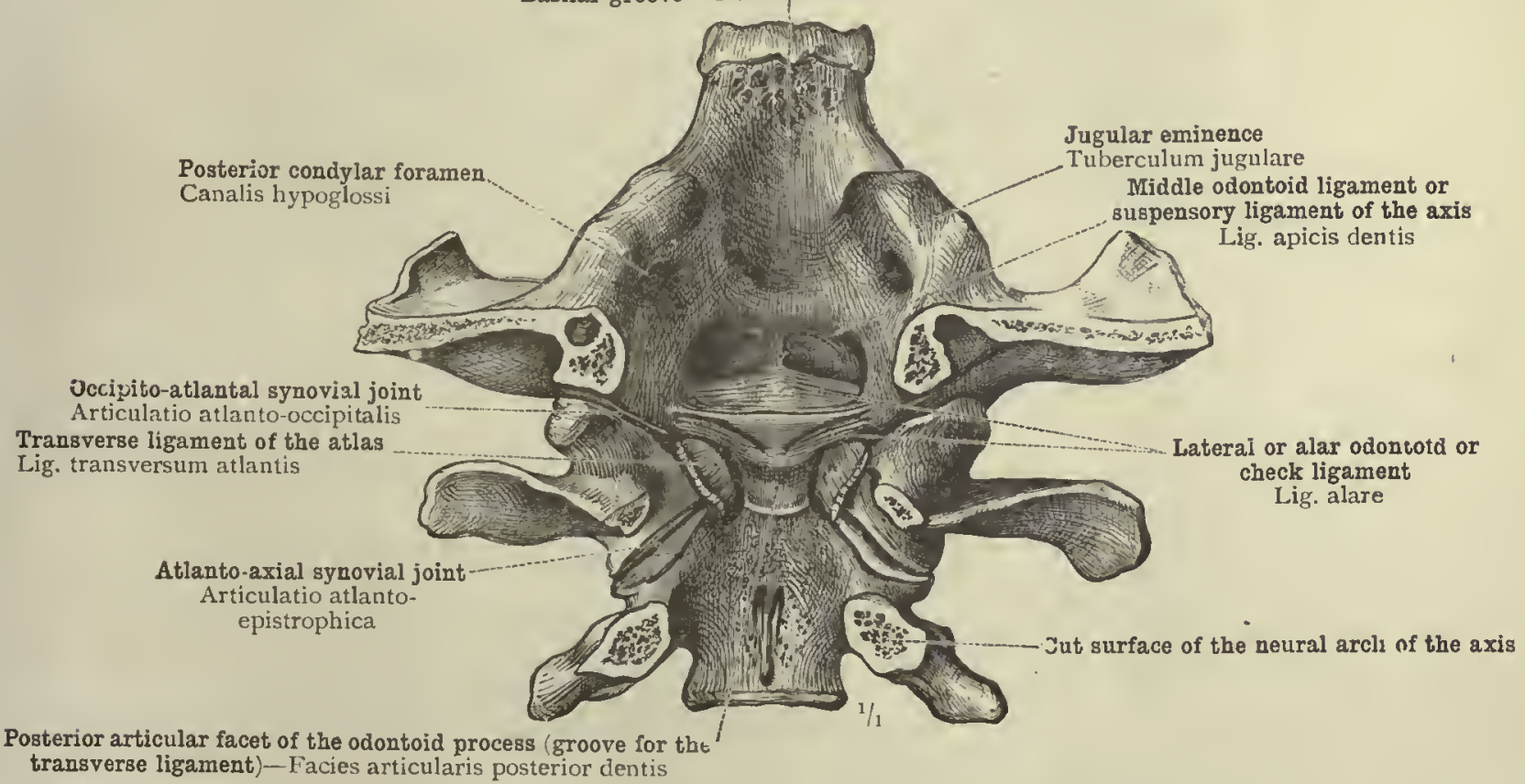

transverse ligament)-Facies articularis posterior dentis

Fig. 420.-Lateral or Alar Odontoid or Check Liganents. Middle Odontoid Ligament or Suspensory Liganent of the Axis.

The transverse ligament of the atlas has been divided in the middle and the parts have been turned outwards; the dura matcr and the posterior or long occipito-axial ligament have been entirely removed.

The Atlas and the Axis with the Anterior Portion of the Occipital Bone seen from Beinind,

a Section having been made similar to that in the Preparation shown in Fig. 4 I4.

Articulationes atlanto-occipitalis et atlanto-epistrophica-Occipito-atlantal and atlanto-axial articulations. 


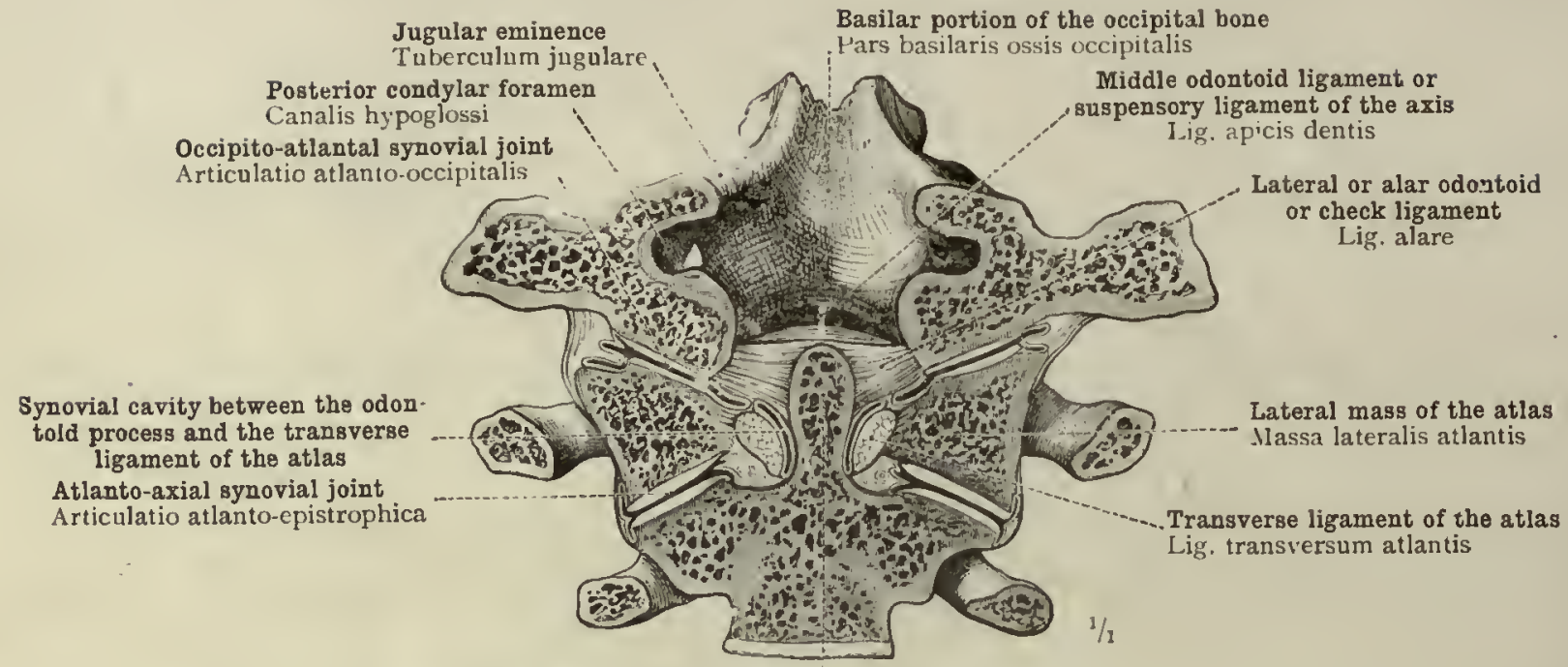

Odontoid process-Deis CFistrophei

Fig. 421.-Occipito-atlantal and tetlanto-axial Articulations in Frontal Section. Lateral or Alar Odontoid or Check Ligaments and Midule Odontoid Ligament or SUSPENSORY LigaMent OF THE AXIS.

The section passes through the middle of the fosterior condylar frramina; and divides the summit of the antero-pcsterior curve of the occipital condyles.

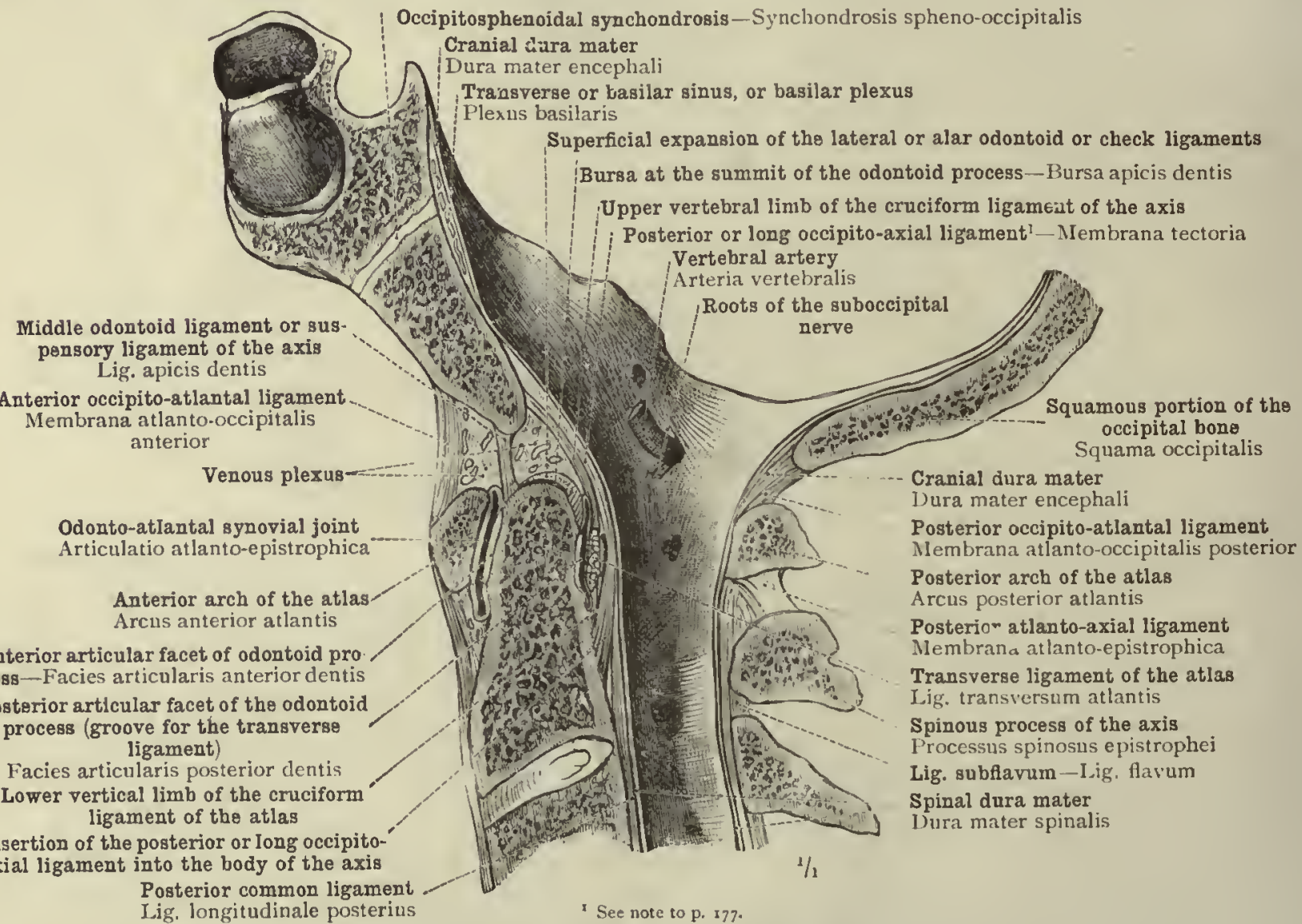

Fig. 422.-Articulations and I-igaments of the Odontoil Process. Stratiform Arrangement of the Cruciform Ligament of the Atlas, tile Posterior or Long Occipitoaxial Ligamient, and the Dura Mater. Spheno-occipital Srnchondrosis. (Mideian Section thlough the Posterior Portion of the base of thli Cranium and the Three Uppermost Cervical. Verteibre.)

Articulationes atlanto-occipitalis et atlanto-epistrophica-Occipito-atlantal and atlanto-axial articulations. 


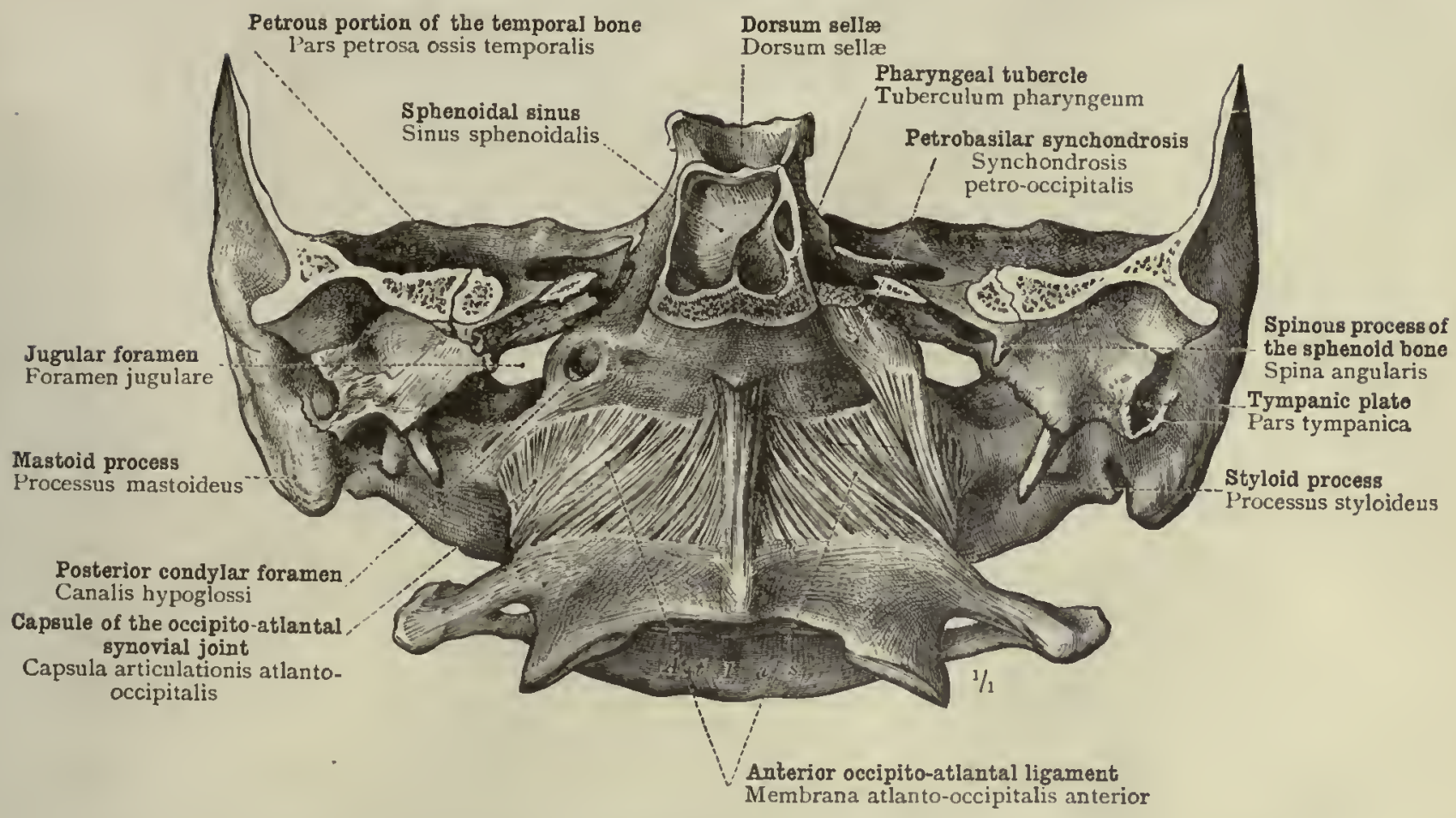

Fig. 423.-Antep or Occipito-atlantal Ligament and Petrobasilar Synchondrosis. (The Atlas with the Posterior Portion of the Base of the Skull, seen from Before.)

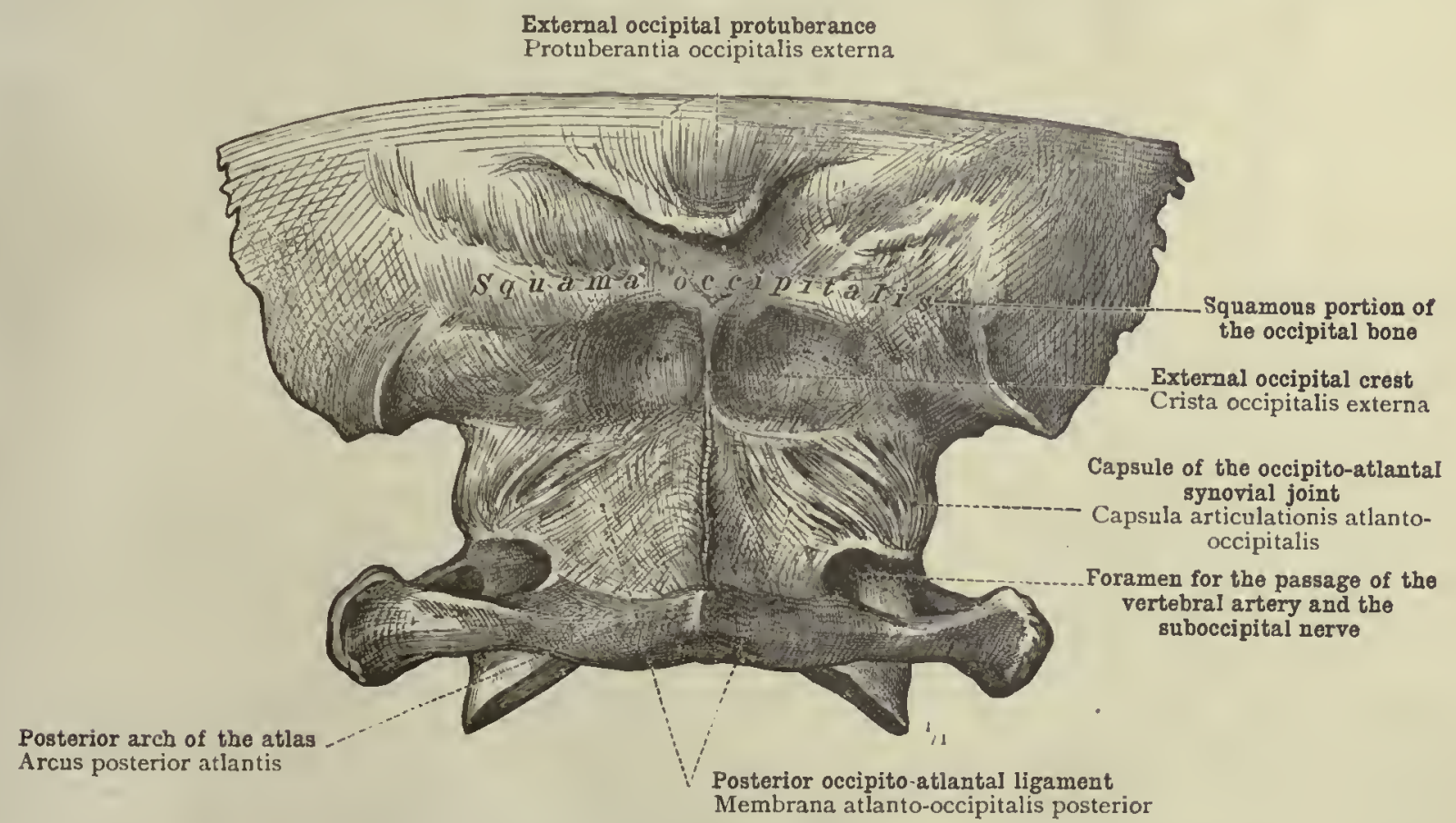

Fig. 424.-Posterior Occipito-Atlantal Ligament. (The Atlas witil the Occipital Bone, SEEN FROM BEHIND.)

Articulatio atlanto-occipitalis-Occipito-atlantal articulation. 


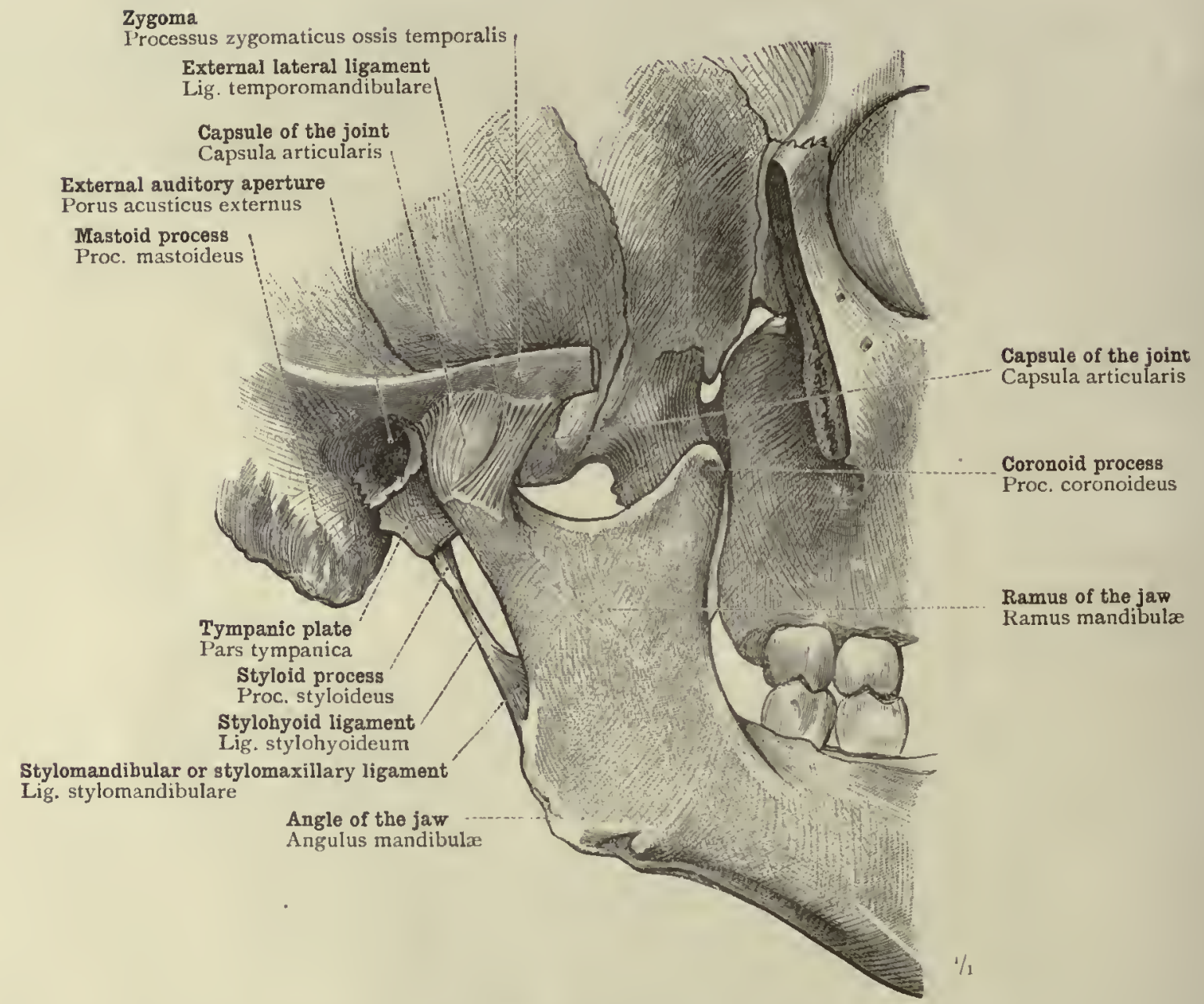

Fig. 425--Articulatio Mandibularis, Temporomandibular or Temporomaxillary Articulation: Ligamenta Temporomandibulare et Stylomandibulare, External Lateral and StyloMandibular or Stylomaxillary Ligaments. Ligamentum Stylohyoideum, Stylohyoid) Ligament. (Right Temporomandibular or Temioromaxillaky Articulation, seen from TIIE OUTER SIDE.) 


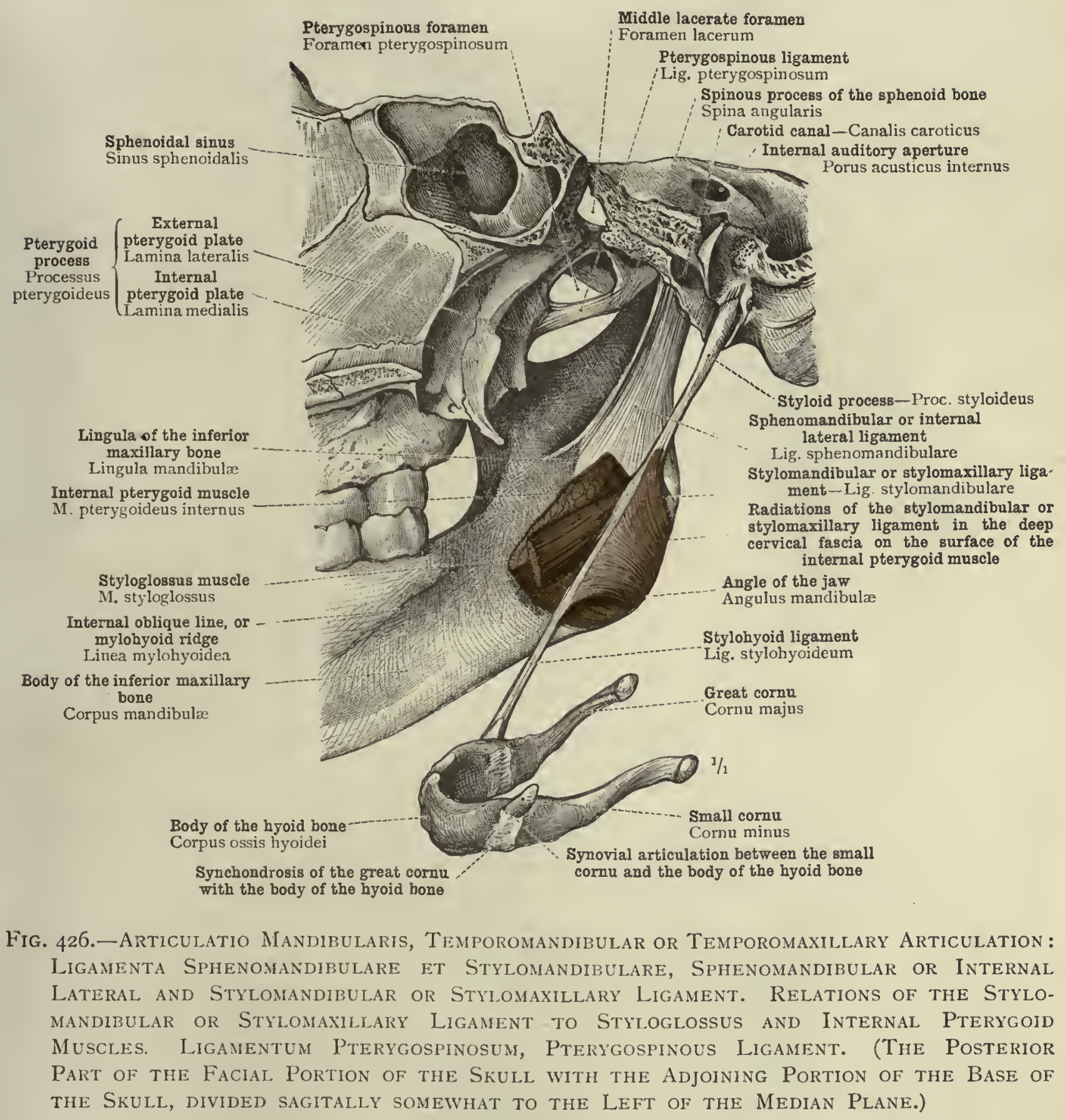

The basilar and condylar portions of the occipital bone have been removed.

Articulatio mandibularis-Temporomandibular or temporomaxillary articulation. 
Infratemporal crest-Crista infratemporalis Capsule of the joint Capsula articularis

Articular eminence-Tuberculum articnlare Articular portion of the glenold fossa Fovea articularis fosse manibularis Interarticular disc or meniscus Discus articularis

External auditury meatus-Meatus acusticus externus : Mastoid cells Cellulæ mastoideæ

Pars tympanica

Capsule of the joint

Capsula articularis

Condyle of the inferior maxillary bone, Capitulum mandibulx

Neck of the inferior maxillary bone, Collum mandibula Styloid process
Processus styloideus

Stylomandibular or stylomaxillary ligament/ Lig. stylomandibulare Ramus of the inferior maxillary bone Ramus mardibule
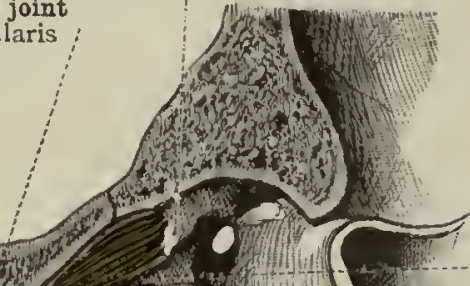

Superior head ) of the external Inferior head $\} \begin{gathered}\text { pterygoid } \\ \text { muscle }\end{gathered}$

Coronoid process

Proc. coronoideus

Sigmoid notch

Incisura mandibula

Body of the inferior maxillary bone Corpus mandibulæ

Fig. 427.-Articulatio Mandibularis, Temporomandibular or Temporomaxillar: Articulation: Discus Articularis. Interarticular Disc or Miniscus, and Ligamentum Stylomandibulare, Stylomandibular or Stylomaxillary Ligamint. Relations ol the Superior Head of tite External Pterygoid Muscle to the Anterior Wall of the Capsular Ligament and to

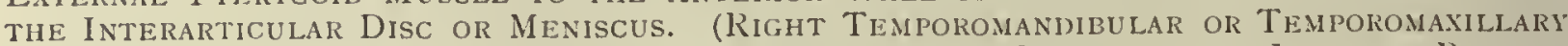
Articulation, divided in a Plane nearly approaching the Sagittal; tile Internal Portion BEING FIGURED.)

The section runs somewhat obliquely forwards and inwards.

External pterygold plate Yterygospinous ligament Lig. pterygospinosum

Fibrocartilage of the foramen lacerum medium

Fibrocartilago basalis Petrosphenoidal synchondrosis Synchondrosis spheno etrosa

Spinous process of the sphenoid hone Spina angularis

Petrous portion of the temporal bone Pyramis Carotid canal Canalis caroticus Jugular or posterior lacerate foramen Foramen jugulare

Jugular process Processus jugularis
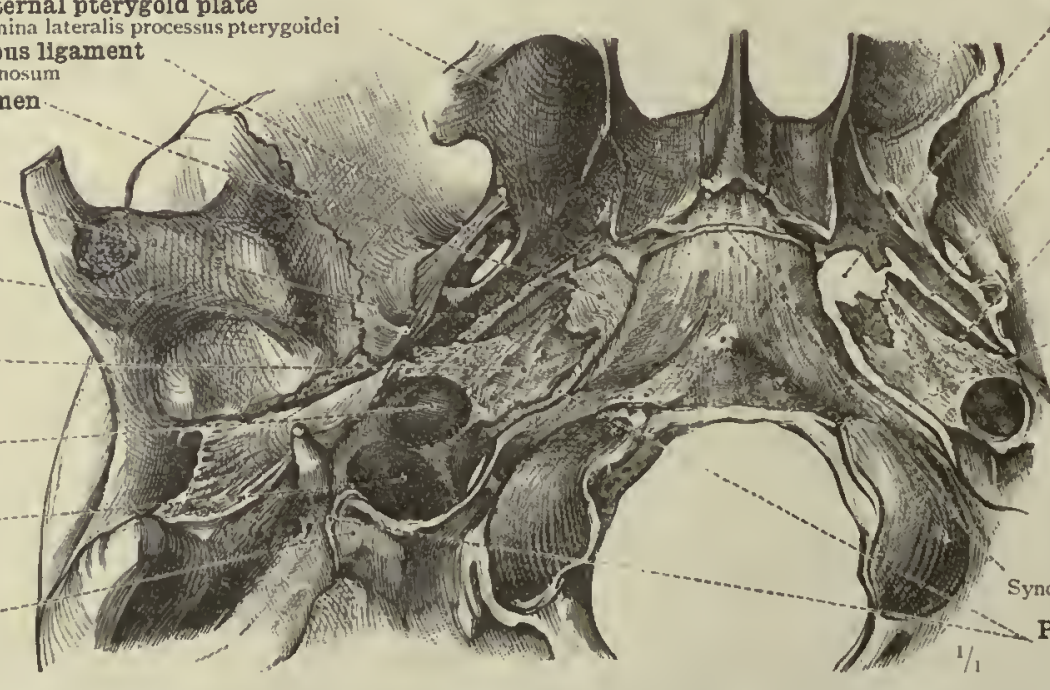

Middle lacerate foramen Foramen lacerum

Petrosphenoidal fissure lissura splienopetrosa

Petrous portion of the temporal bone l'yramis

Petrobasilar fissure Fissura petro.occipitalis

Fig. 428.-Fibrocartilago Basalis; Fibrocartilage of the Foramen Lacerum Medium: Synchondroses Sphenopetrosa, Petro-occipitalis, et Spheno-occipitalis; Petrosphenoidal, Petrobasilar, and Occipitosphenoidal Sýnchondroses: Ligamentum Pterygospinosum; Pterggospinous Ligament. (The Middle Portion of tile Base of the Skull, seen from BELOW.)

Articulatio mandibularis, temporomandibular or temporomaxillary articulation-Synchondroses et ligamenta baseos cranii, synchondroses and ligaments of the base of the skull. 


\section{JUNCTURÆ OSSIUM EXTREMITATUM, \\ SUPERIORIS ET INFERIORIS}

THE ARTICULATIONS

OF THE SUPERIOR AND INFERIOR EXTREMITIES 


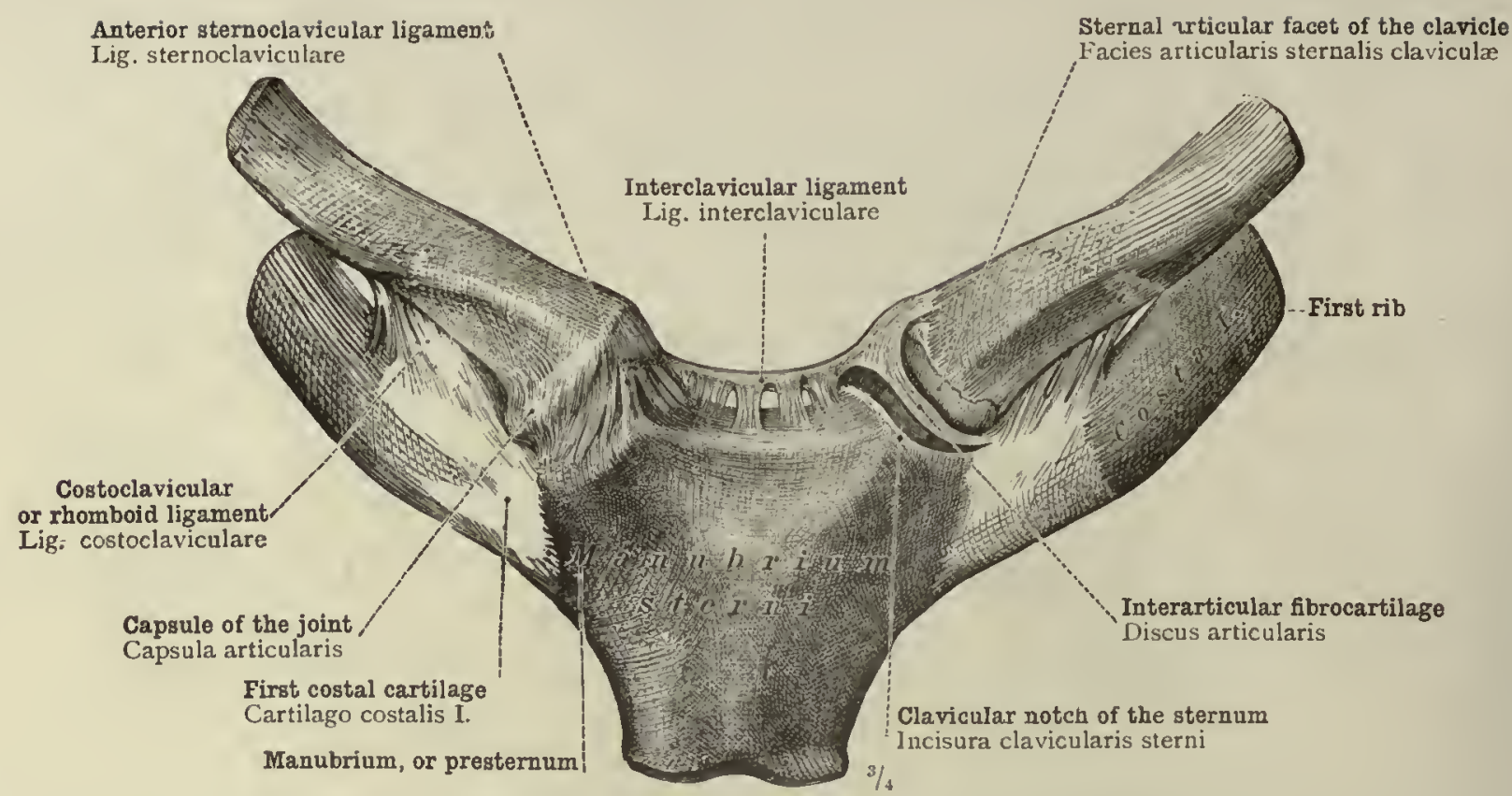

Fig. 429.-Articulatio Sternoclavicularis, Sternoclaviculak Articulation : Capsula Articularis, Capsule of the Joint; Discus Articulaisis, Interarticular FibroCARTILAge; Ligamenta Interclaviculare ET Costoclaviculare, InTERClavicular and Costoclavicular or Rhomboid Liganents.

The left sternoclavicular articulation has been opened by the removal of the anterior wall of the capsular ligament.

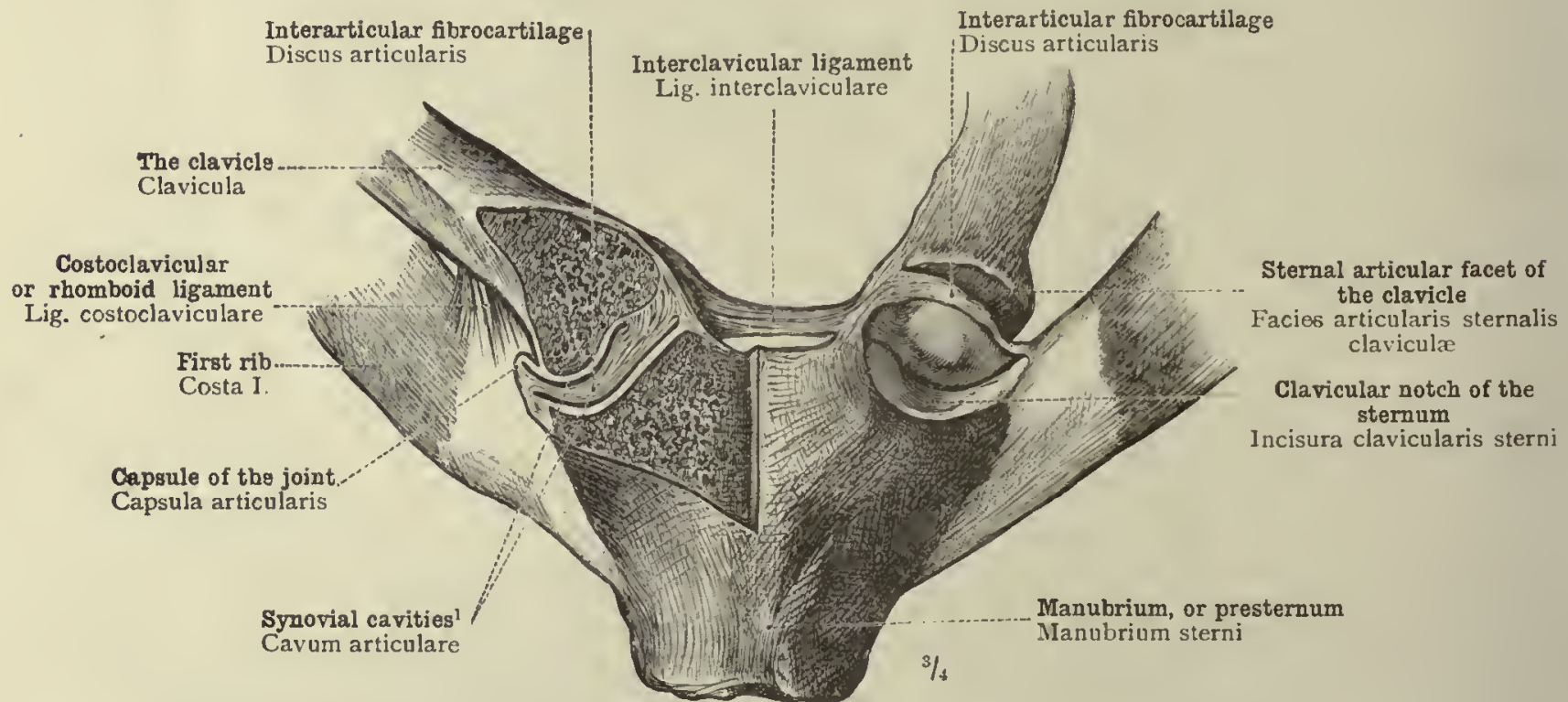

1 The interarticular fibrocartilage is occasionally defective in the centre, and in rare cases even entirely wanting ; there is then only one synovial cavity. - TR.

Fig. 430.-Articulatio Sternoclavicularis, Sternoclaviculak Articulation: Discus et Capsula articularis, Interarticular Fibrocartilage and Capsular Ligament; Cavum Articulare, Synovial Cavity or Cavities; Liganenta interclaviculare et Costoclaviculare, Interclavicular and Costoclavicular or Rhomboid Ligaments.

The right sternoclavicular articulation has been divided by a frontal section; in the left, the capsule has been removed and the clavicle has been drawn backwards.

Sternoclavicular articulation, seen from Before.

Articulationes et ligamenta cinguli extremitatis superioris-Articulations and ligaments of the shoulder-girdle. 


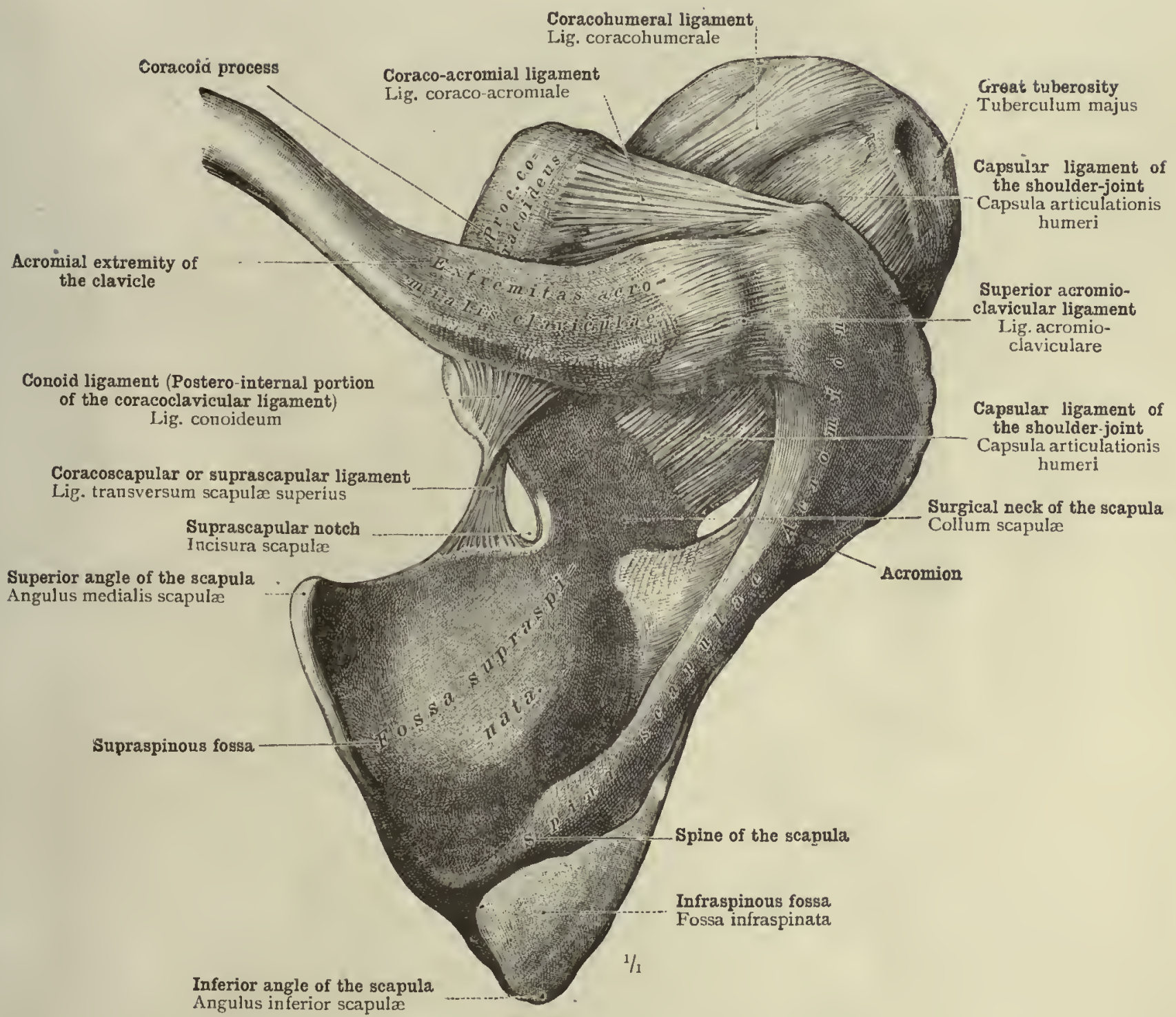

Fig. 431.--Ligamenta Acromioclaviculare et Coracoclaviculare, Superior Acromioclavicular Ligament and Coracoclavicular I.igament (Conoid Portion); Ligamenta Coraco-acromiale et Transversum Scapule Superius, Coraco-acromial and Suprascapular Ligaments. (The Right Scapula with the Acromial Hat.f of the Clavicle and the Shoulder-Joint, SEEN FROM ABOVE.)

Articulationes et ligamenta cinguli extremitatis superioris-Articulations and ligaments of the shoulder-girdle. 


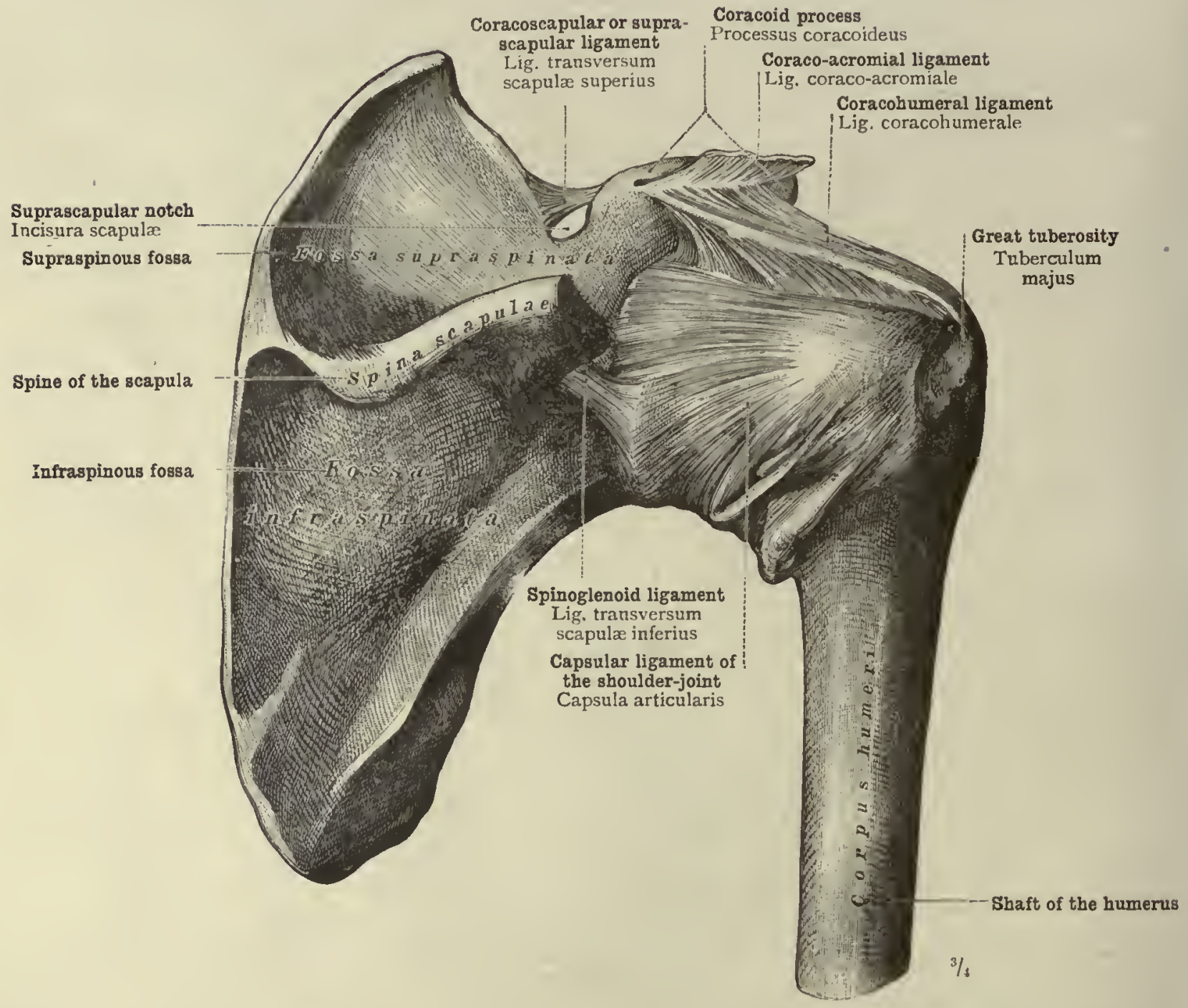

Fiz. 432.-Articulatio Humeri, Shoulder-Joint: Capsula Articularis, Capsular Ligament; Ligamentum Coracohumerale, Coracohumeral Ligament; Ligamentum Transversum Scapula Superius et Ligamentum Transversum Scapule Inferius, Coracoscapular or Suprascapular Ligament and Spinoglenoid Ligament. (The Right Shoulder-Joint, seen FROM BEHIND.)

The acromion has been sawn off, and the coracoid extremity of the coraco-acromial ligament has been turned upwards. 


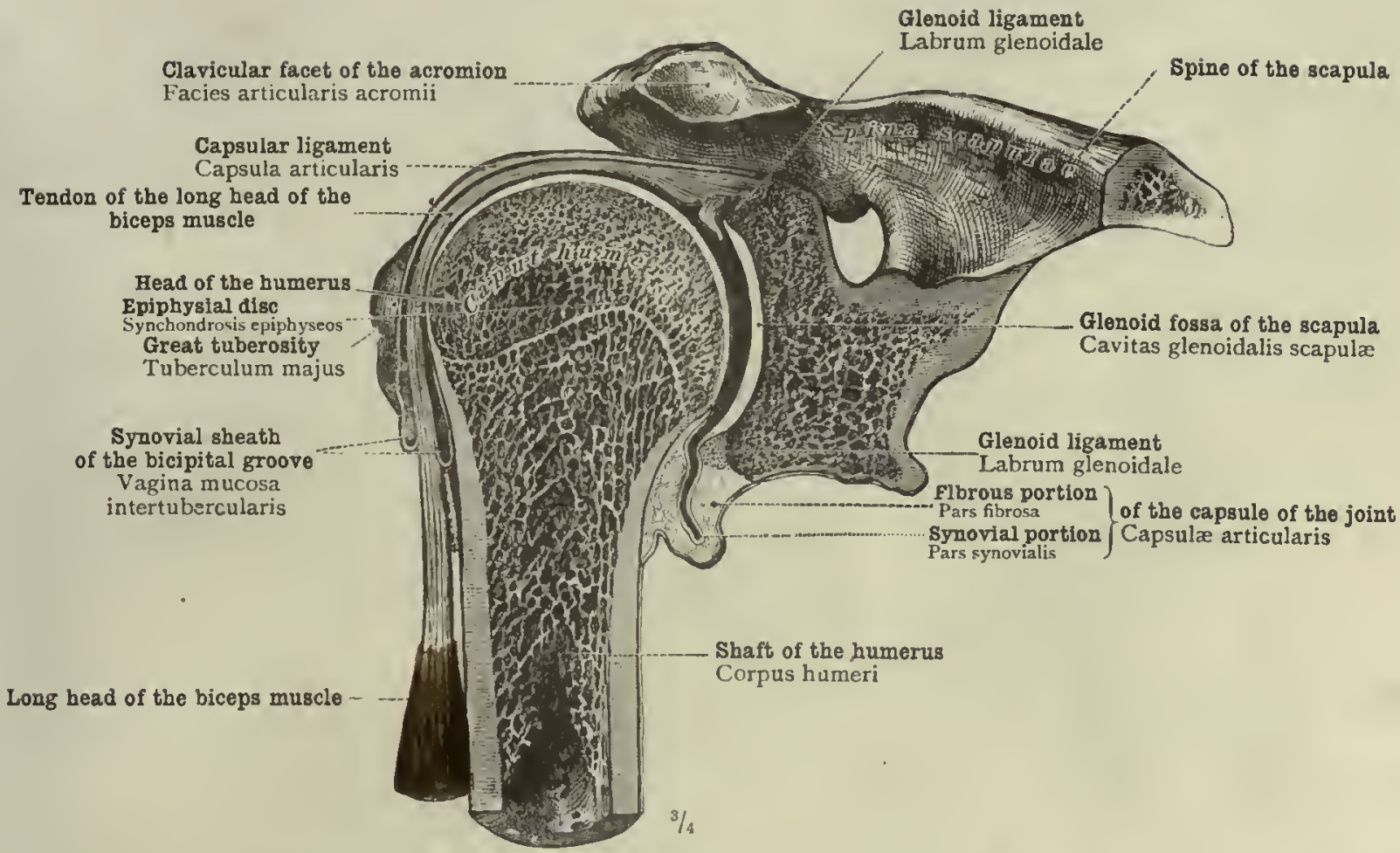

Fig. 433.-Articulatio Humeri, Shoulder-Joint : Labrum Glenoidale, Glenoid Ligament ; Relations of the Tendon of the Long Head of the Biceps Muscle and of the Epiphysial Disc to the Synovial Cavity of the Articulation. (The Right Shoulder. Jolnt in Frontal Section; Posterior Half.)

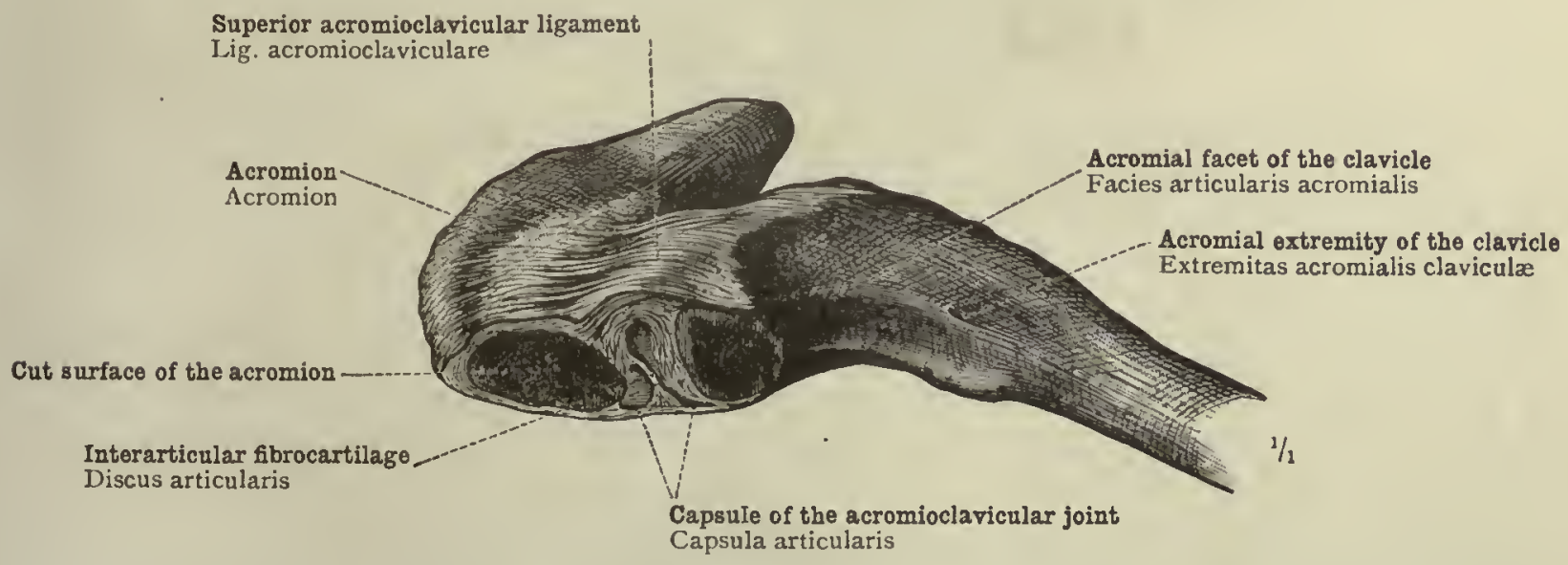

Fig. 434.-Articulatio Acromioclavicularis, Acromioclavicular Joint : Discus Articularis, Interarticular Fibrocartilage; Ligamentum Acromioclaviculare, Superior Acromioclavicular Ligament. (The Right acromioclavicular articulation in Frontal Section; Posterior Portion.)

Articulatio humeri-Shoulder-joint. Articulatio acromioclavicularis-Acromioclavicular articulation. 


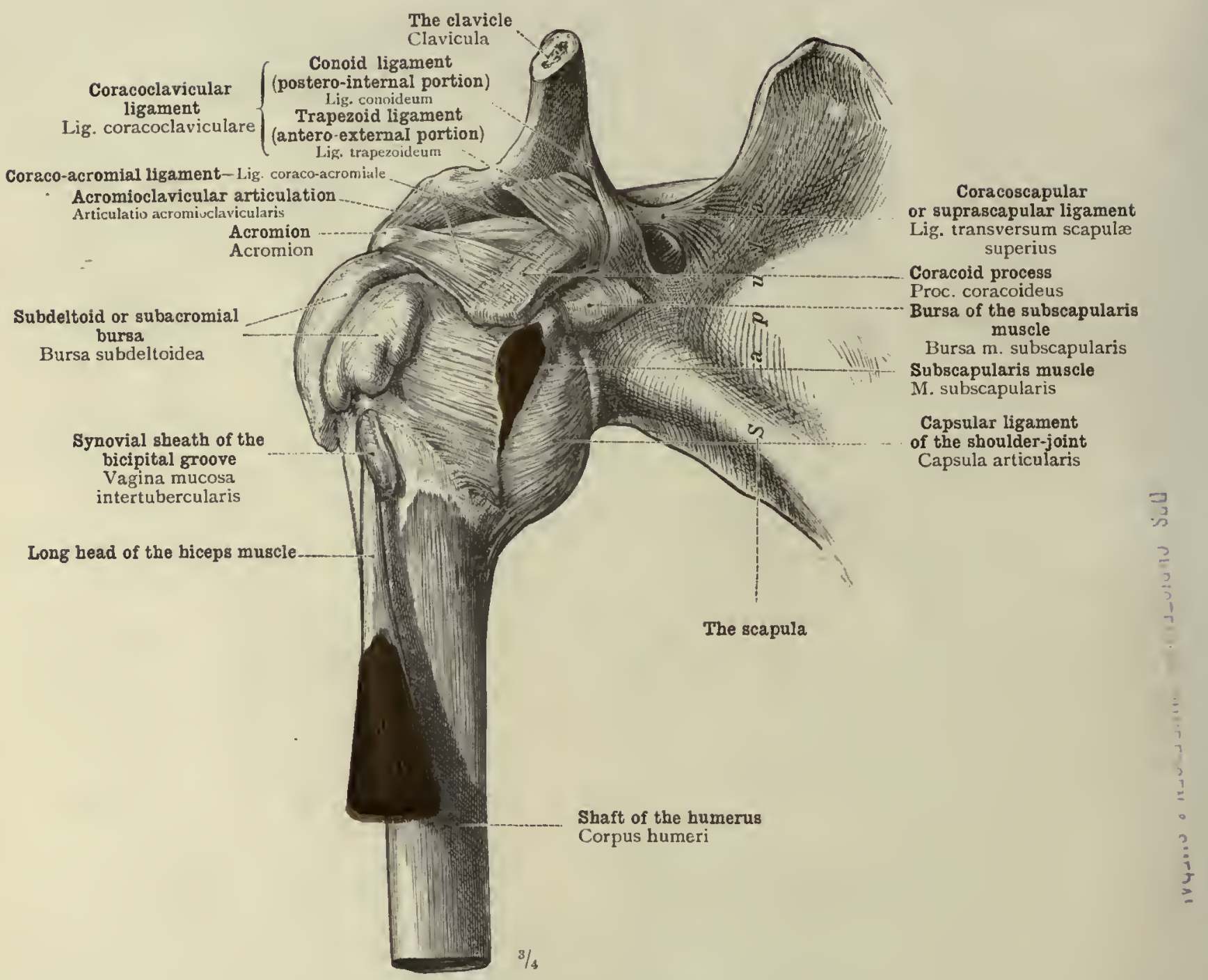

Fig. 435.-Articulationes Humeri et Acromioclavicularis, the Shoulder-Joint and the Sternoclavicular Articulation: Bursa Musculi Subscapularis et Bursa Subdeltoidea, Bursa of the Subscapularis Muscle and Subdeltoid or Subacromial Bursa; Vagina Muscosa Intertubercularis, Synovial Sheath of the Bicipital Gronve; Ligamenta Coracoclaviculare, Coraco-acromiale, et Transversum Scapulate Superius; the Coracoclavicular (Conoid and Trapezoid), Coraco-acromial, and Coracoscapular or Suprascapular ligament. (Right Shoulder-Joint, injected with Tallow; the Acromial Extremity of the Clavicle has beEn draivn upwards. Seen FROM BEFORE.) 


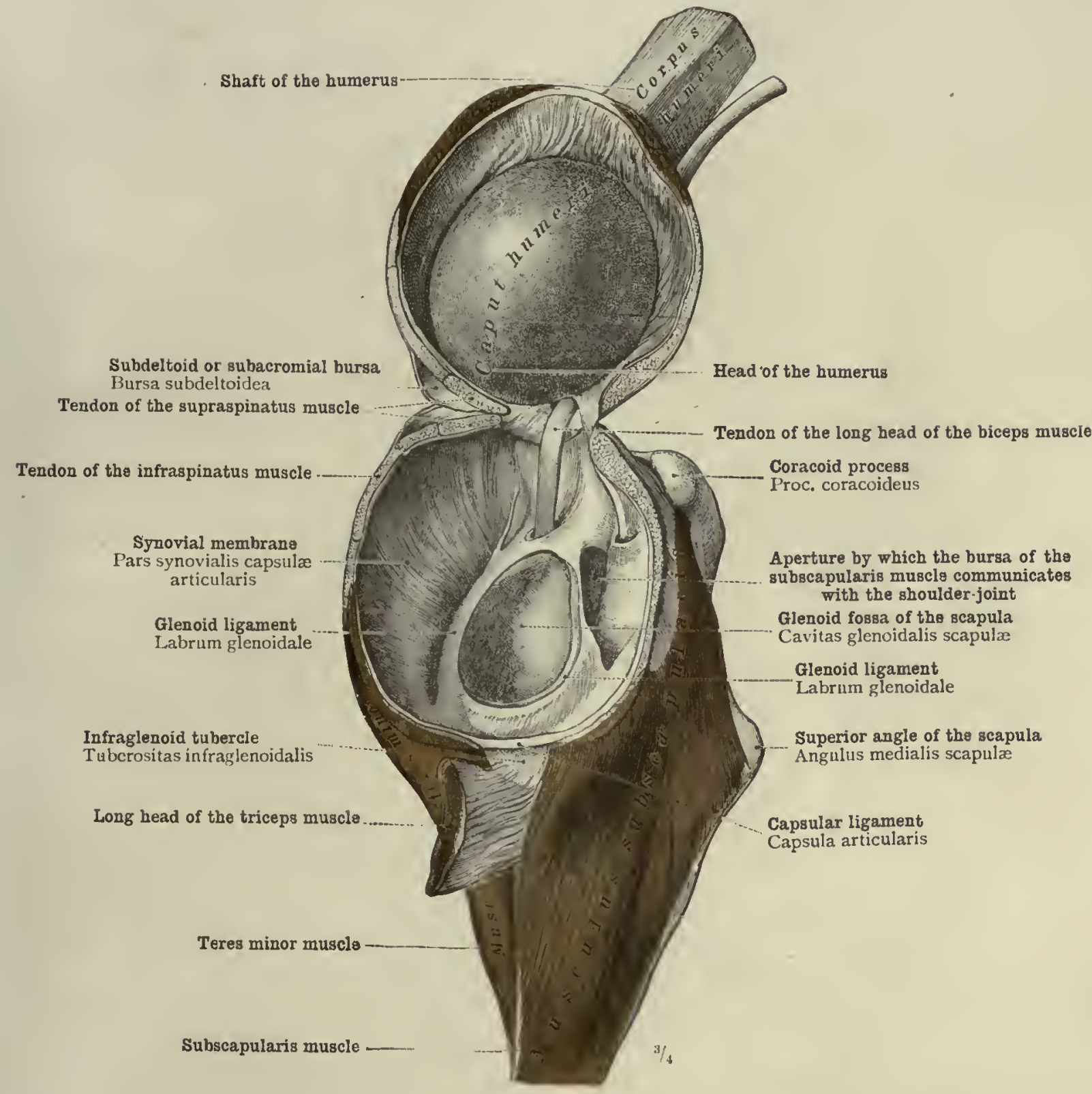

Fig. 436.-Articulatio Humeri, Shoulder-Joint: Intracapsular Portion of the Tendon of the Long Head of the Biceps Muscle; Labrum Glenoidale, Glenoid Liganent; Aperture of Communication of the Bursa of the Subscapularis Muscle with the Shoulder-Joint; Relations of the Tendons of the Scapular Muscles with the Capsule of the Shoulder-Joint. (Right Shoulder-Joint from the Outer Side)

After tallow had been injected into the joint and allowed to harden. the capsular ligament and the surrounding scapular muscles wcre divided by a circular incision midway between their attach. ments to the scapula and the humerus, a strip of the capsulc, however, being left undivided, where the tendon of the long head of the biceps muscle passes through the joint. The humerus with the distal half of the capsule has been turned upwards. 


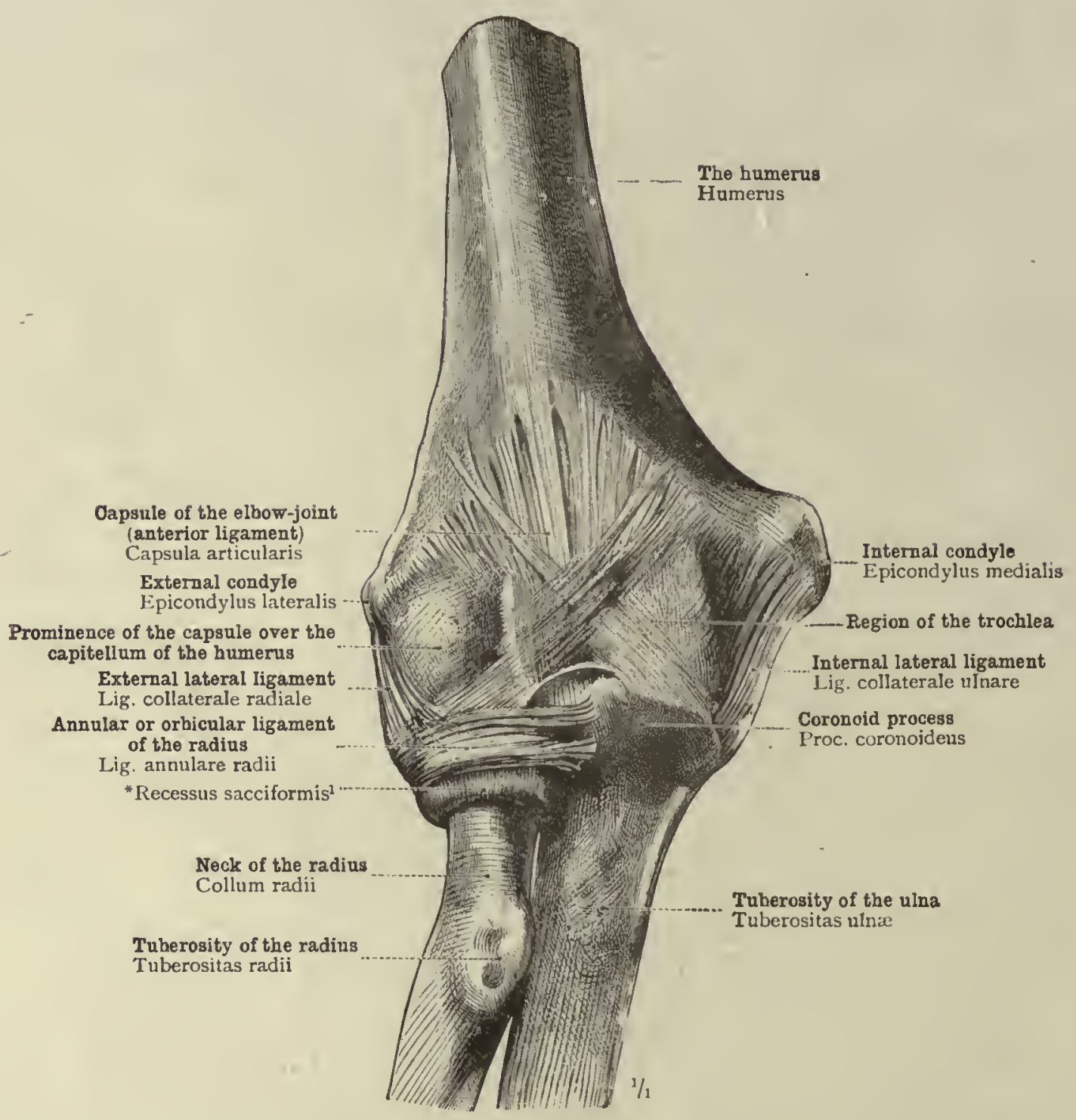

1 Projection of the synovial membrane of the elbow-joint, which membrane, after rassing downwards between the vertical articular surface of the head of the radius and the inner surface of the orbicular ligamenc, forms a circular pouch or sac below tbis ligament around the neck of the radius.- $T$ r.

Fig. 437.-Articulatio Cubiti, Elbow-Joint : Capsula Articulairis, Capsule of the Joint; Ligamenta Collateralia, Lateral Liganents; Ligamentum Annulare Radii, Annular or Orbicular Ligament of the Radius; *Recessus Sacciformis (sce notcabove). (Right Elbow-Joint, unopened; Anterior or PAlmar Aspect.)

The * recessus sacciformis has been injected with tallow. 


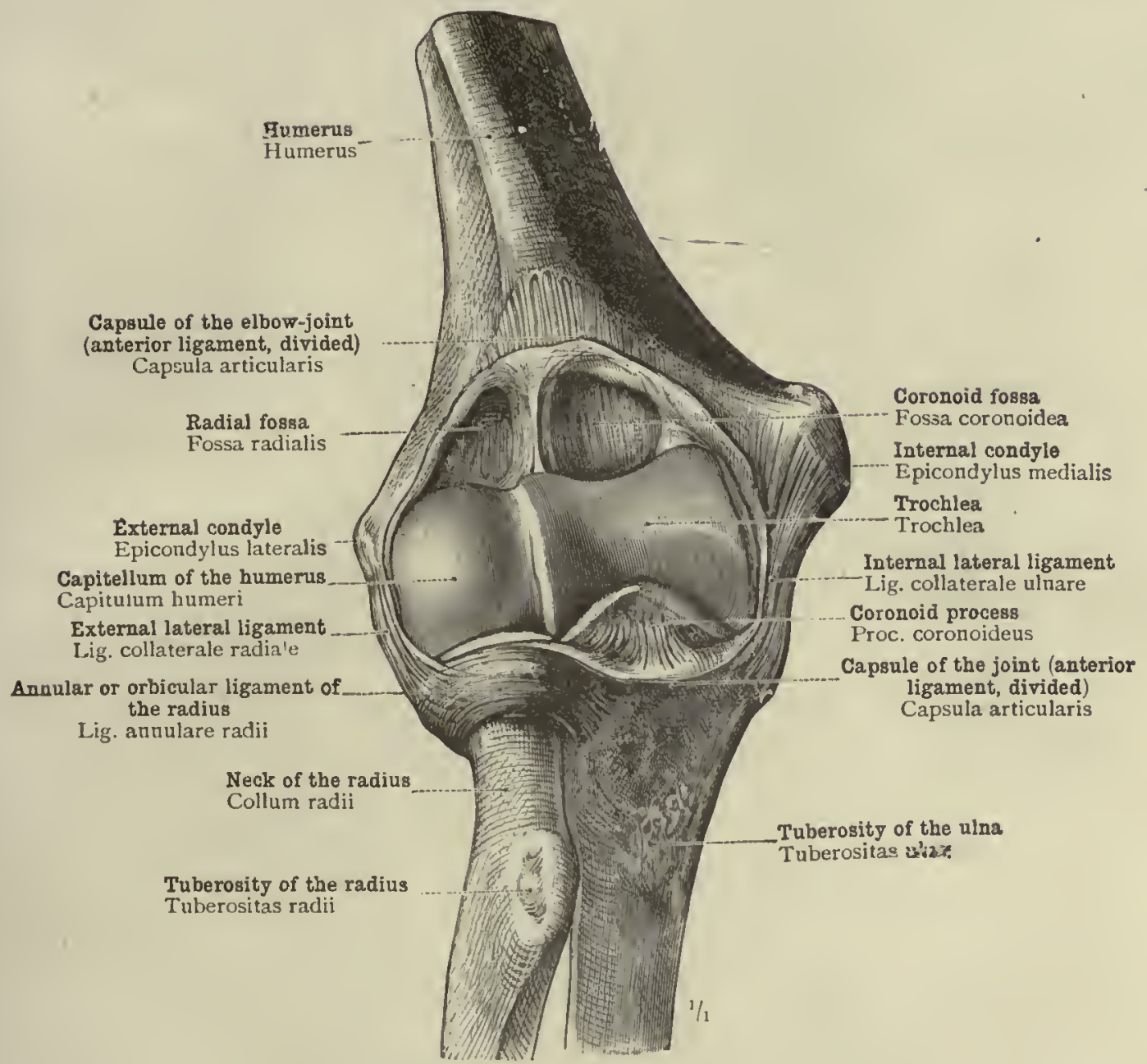

Fig. 438.-Articulatio Cubiti, Elbow-Joint; Attachment of the Capsule to the Anteriok Surfaces of the Humerus and the Ulna (Anterior Liganent); Ligamenta Collateralia, Lateiral Ligaments; Ligamentum Annulare Radit, Annular or Orbicular Ligament of the Radius. (Rigirs Elbow-Joint; Anterior or Palmar Aspect.)

The capsule has been divided above and below, close to its attachment to the bones, and between the lateral ligaments (i.e., the greater portion of the anterior ligament has been removed); the cut ends of the anterior ligament have been folded back against the bones. The ${ }^{*}$ recessus sacciformis - see note on previous page-has bean removod. 


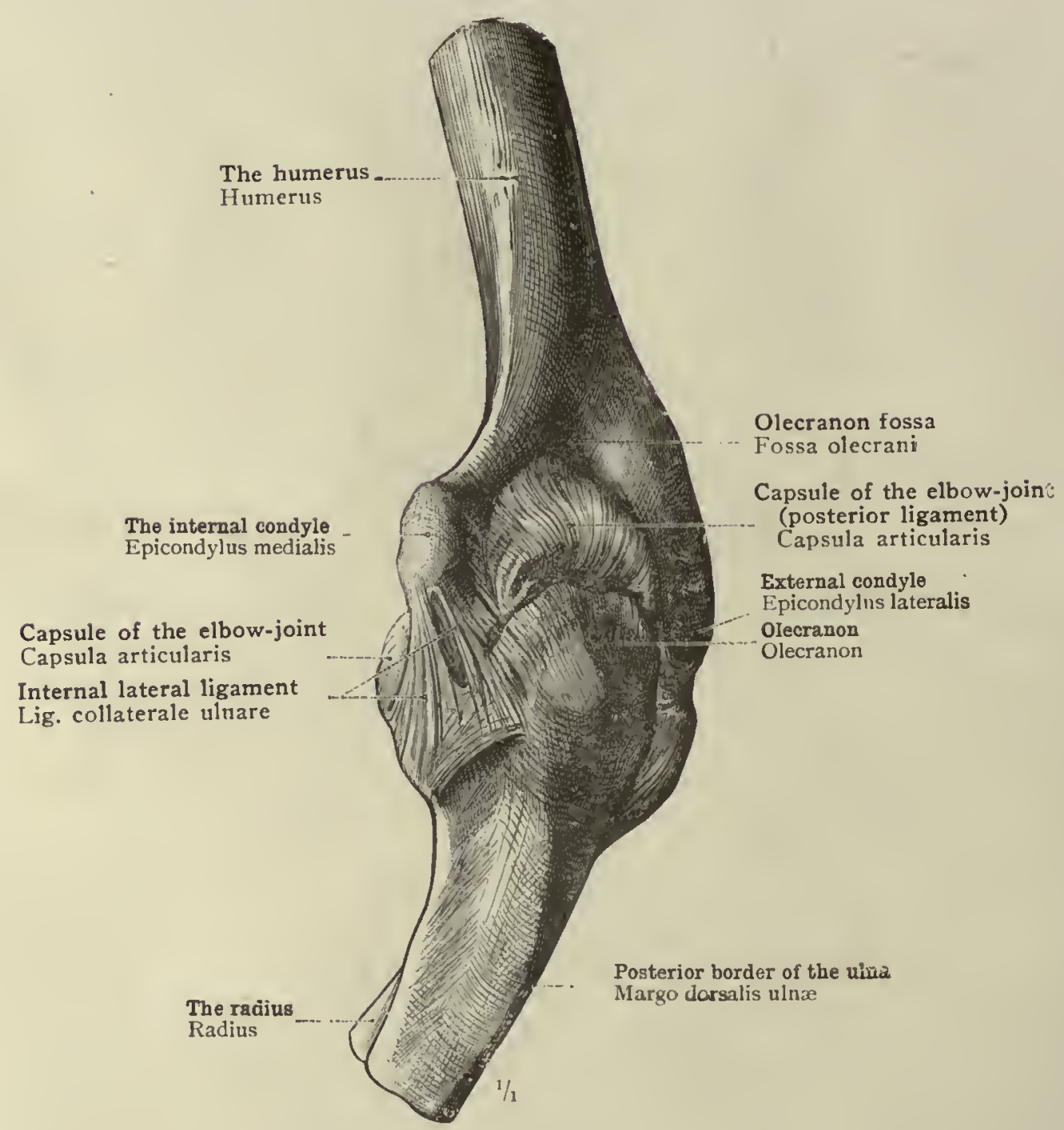

Fig. 439--Articulatio Cubiti, Elbow-Joint : Capsula Articularis, Capsulfe of the Joint; Ligamentum Collaterale Ulnare, Intermal. Lateral Ligament. (Right Elboiv-Joint; Postero-internal Aspect.) 


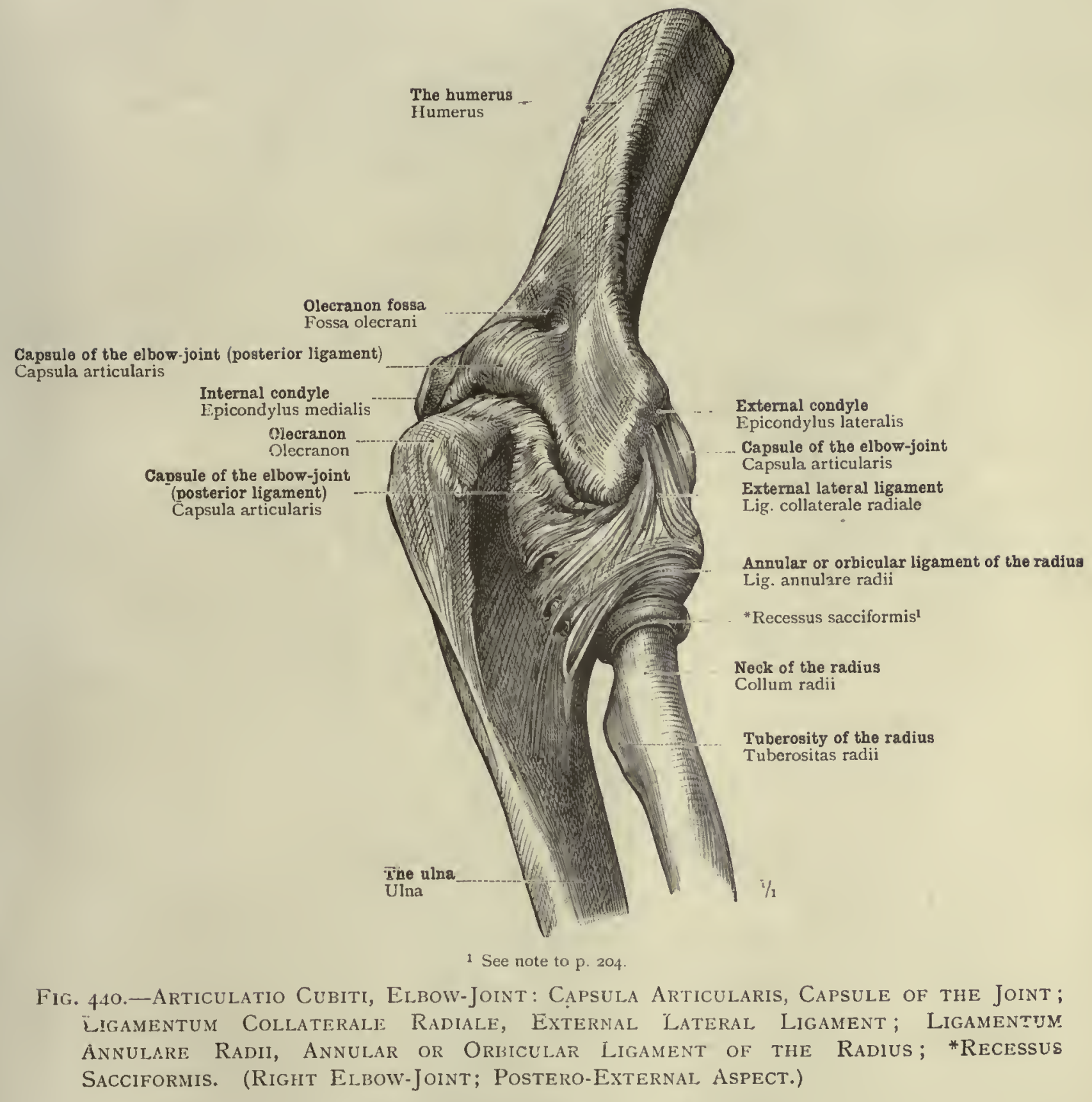

The * recessus sacciformis has bcen injected with tallow. 


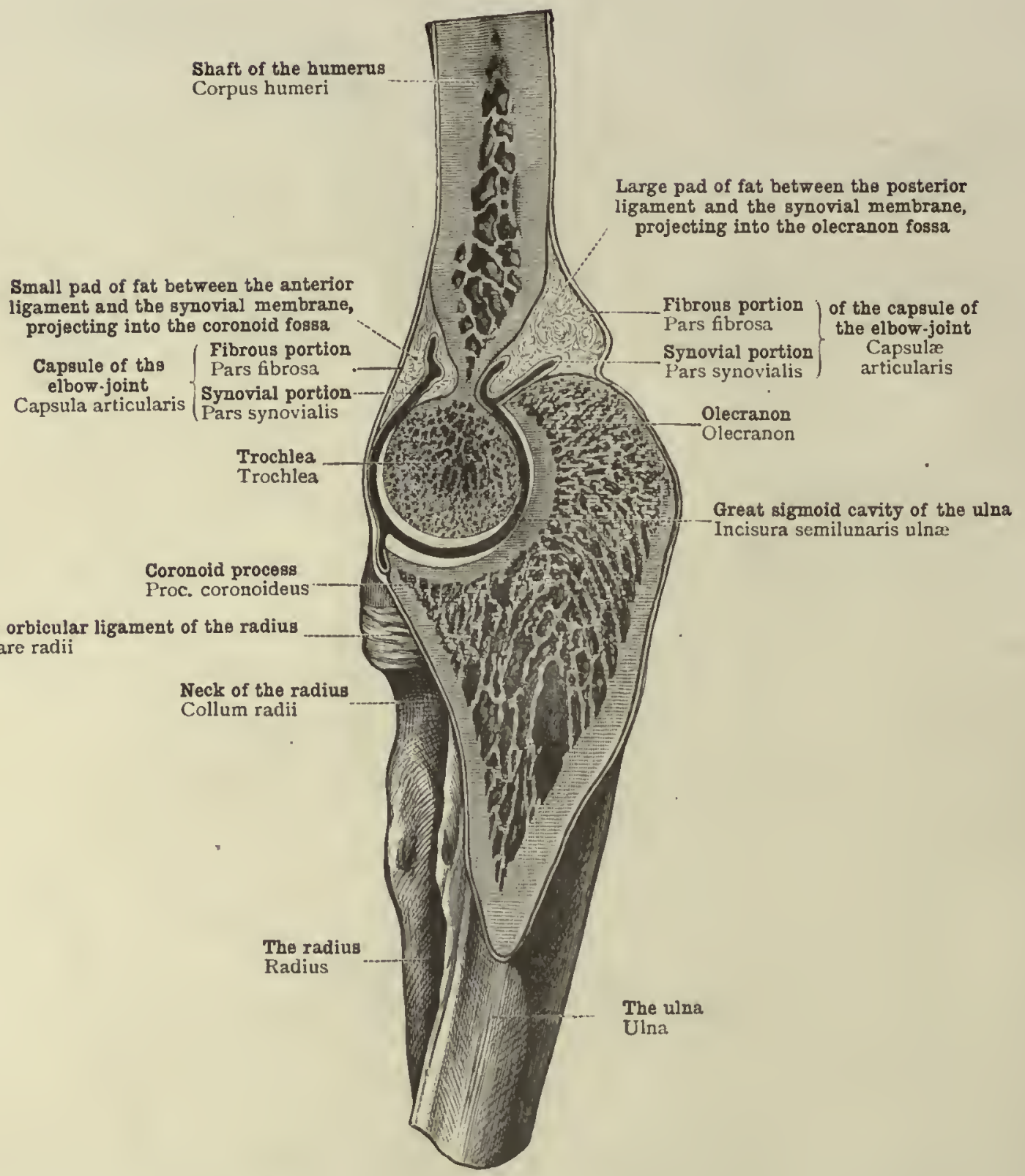

Fig. 44I.-Articulatio Humero-ulnaris, Humero-ulnar Articulation. (Sagittal Section of the Right Elbow-Joint ; the Radial Half is figured.)

The section passes through the trochlea and the great sigmoid cavity of the ulna, in a plane vertical to the axis of the trochlea. 


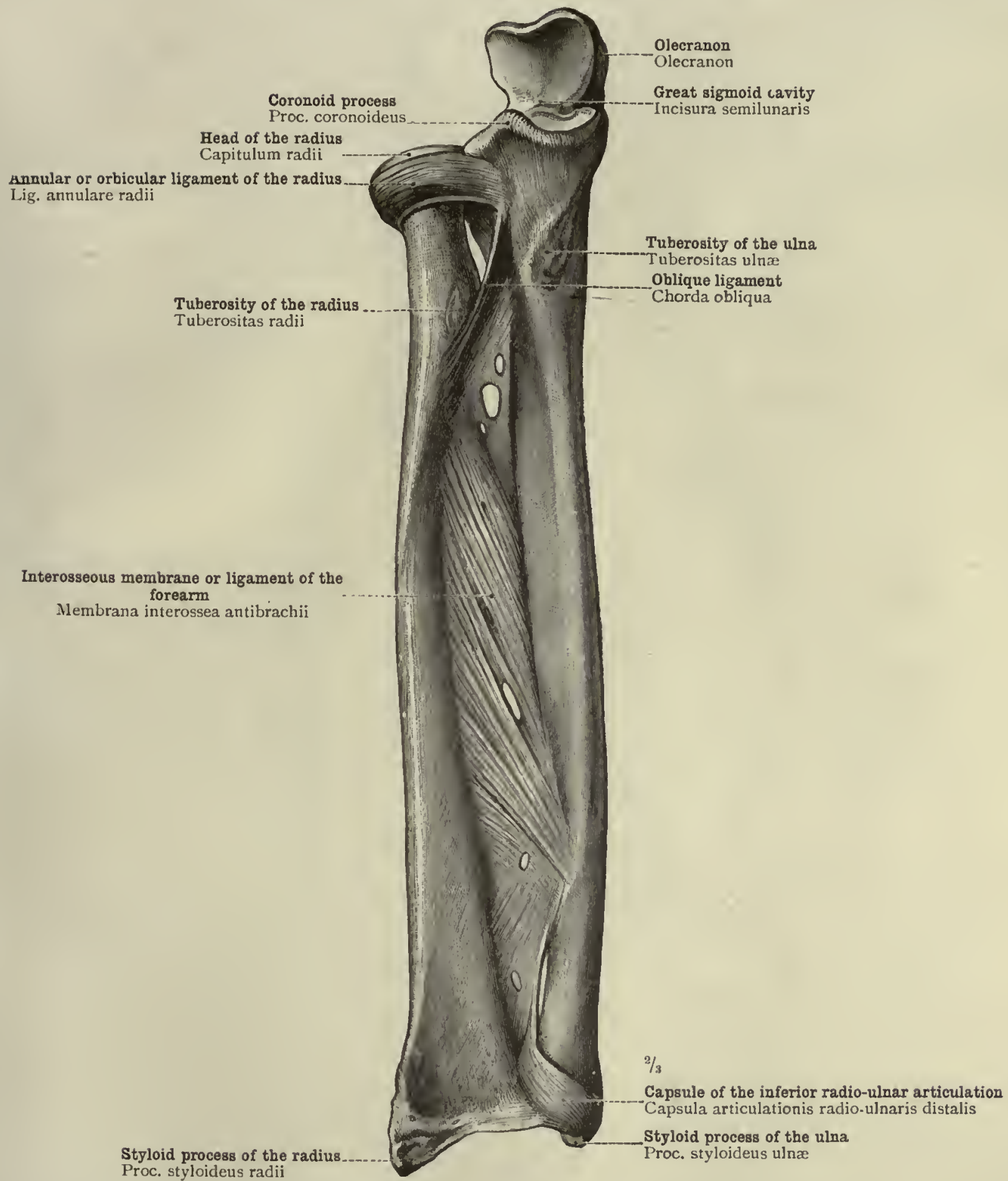

Fig. 442.-Articulationes Radio-ulnares, Proximalis et Distalis; Radio-ulnar articulations, Suplerior and Inferior: Ligamentum annulare Radit, Annular or Oribicular Ligament of the Radius; Membrana Interossea Antibrachil, Interosseous Membrane or Ligament of the Forearm. (The Bones of the Right Forearm with the Radio-ulnar Ligaments; Anterior or Palmar Aspect.) 
Interosseous membrane or ligament of the forearm

Membrana interossea antibrachii

\section{Capsule of the inferior radio-ulnar} articulation

Capsula articulationis radio ulnaris distalis. Styloid process of the ulna Proc. styloideus uln $x$

Internal lateral ligament of the wrist-joint Lig. collaterale carpi uluare

Pyramidal or cuneiform bone-Os triquetrum Posterior or dorsal ligament of the transverse carpal articulation-Lig. intercarpenm dorsale Unciform bone Os hamatum

Posterior or dorsal carpometacarpal ligament Lig. carpometacarpeum dorsale

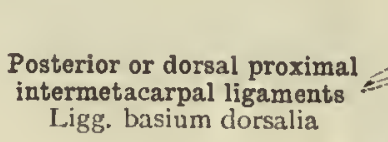

Capsule of the metacarpo-phalangeal articulation of the little finger Capsula articulationis metacarpophalangeæ digiti $\mathrm{V}$

Lateral ligaments of the metacarpophalangeal articulation of the middle finger

Ligamenta collateralia articulationis metacarpo-phalangex digiti III.

Capsule of the proximal interphalangeal articulation of the little finger Capsula articulationis proximalis digiti $\mathrm{V}$.

Capsule of the distal interphalangeal articulation of the little finger Capsula articulationis distalis digiti $\mathrm{V}$

Lateral ligaments of the interphsiangeal articulations of the mlddle finger Ligg. collateralia articulationum digiti III.
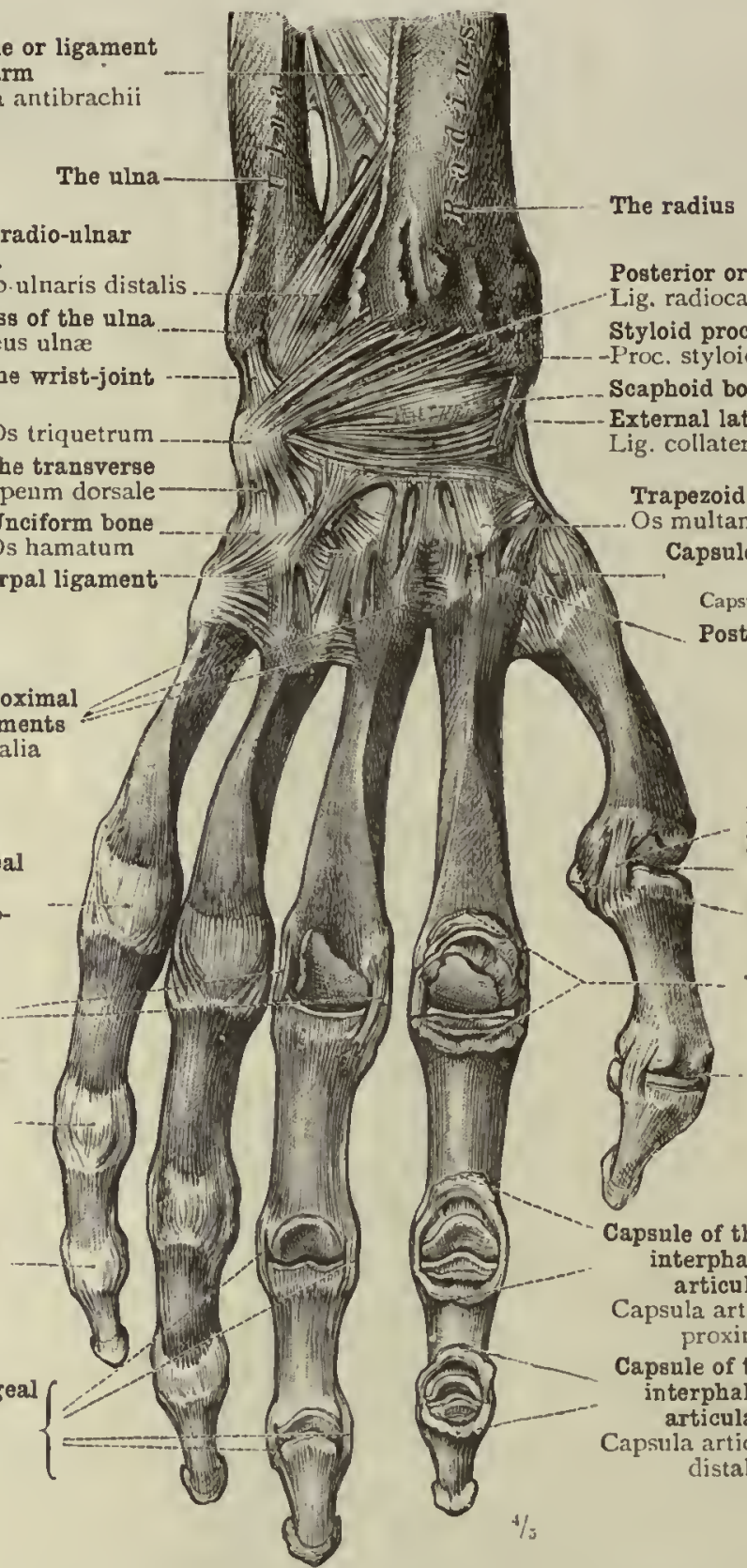

Posterior or dorsal ligament of the wrist.joint - Lig. radiocarpeum dorsale Styloid process of the radius -Proc. styloideus radii Scaphoid bone-Os naviculare - External lateral ligament of the wrist-joint Lig. collaterale carpi radiale

Trapezoid hone

. Os multangulum minus

Capsule of the carpometacarpal joint of the thumb

Capsula articulationis carponetacarpere pullicis

Posterior or dorsal car pometacarpal ligament

Lig. carpometacarpeum dorsale

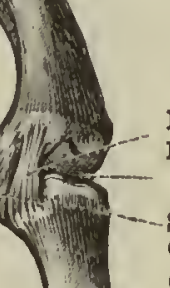

Lateral ligament-Iig. collaterale Metacarpo-phalangeal articulation Articulatio metacal po-phalangea pollicis Sesamoid bone Os sesamoldeum Capsule of metacarpo-phalangeal articulaticn of the index finger Capsula articulationis metacarpophalangex digiti $1 \mathrm{I}$.

Interphalangeal articulation of the thumb Articulatio pollicis

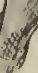

Capsule of the proximal interphalangeal articulation

Capsula articulation is proximalis

Capsule of the distal interphalangeal articulation Capsula articulationis
distalis

Fig. 443.-The Posterior or Dorsal Ligaments ol the Wrist and Hand: Ligamenta Collateralia Carpi, lateral Liganents of the IVrist and tue Carpus; Superficial Posterior or Dorsal Ligaments of Carpus and Metacarpus. The Capsules and the Lateral Ligaments of the Metacarpo-phalangeal and Interphalangeal AkticuLATIONS.

In the articulations of the index finger the posterior wall of the capsule has been divided transversely across the middle of the joint, and the ends have becn turned upwards and downwards; in the articulations of the thumb and the middle finger the capsule has been divided only between the lateral ligaments, leaving these intact; in the articulations of the ring and little fingers the rapsule has not becn opened.

Articulationes manus et digitorum-Articulations of the hand and fingers. 


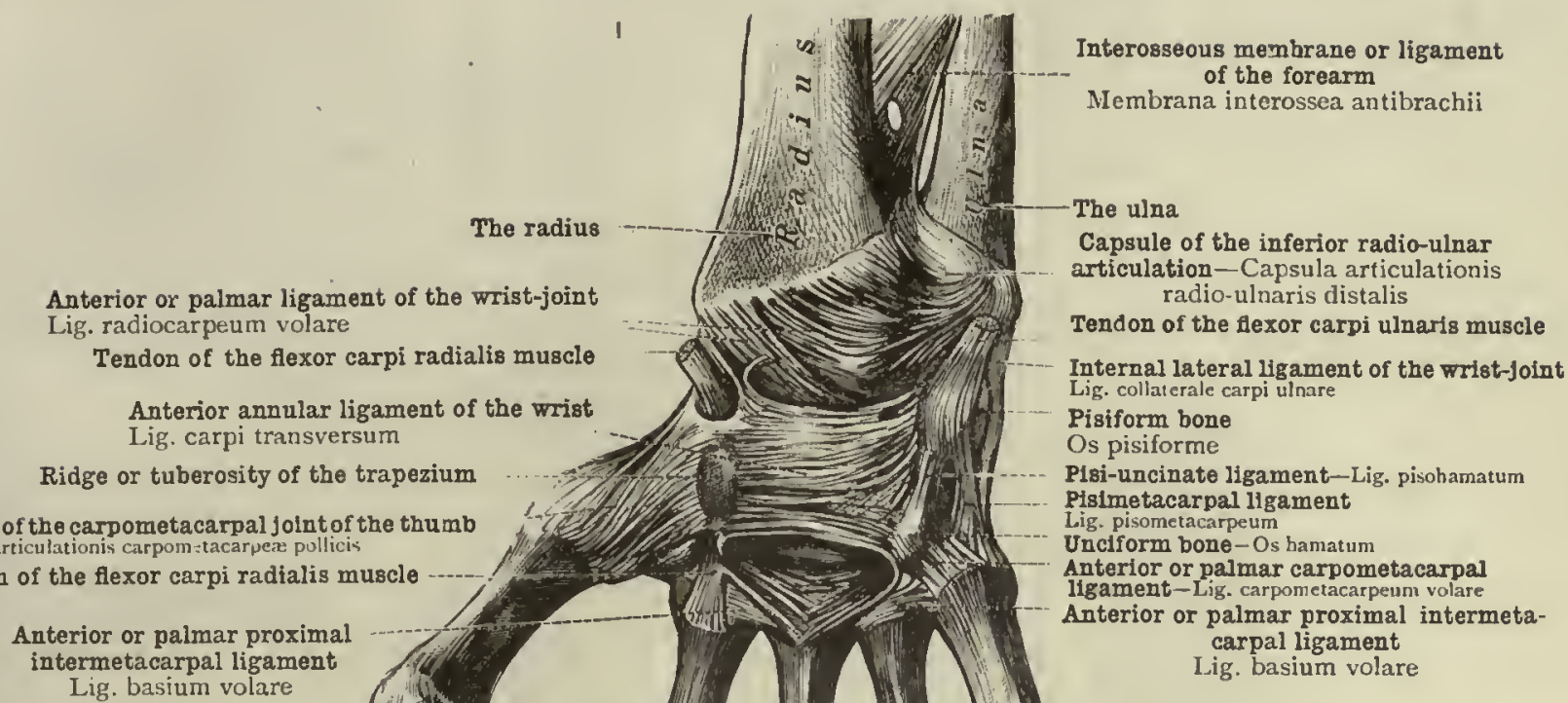

Capsule of the carpometacarpal joint of the thumb Capsula articulationis carpom:tacarpea pullicis

Tendon of the flexor carpi radialis muscle Lig. basium volare

Interphalangeal articulation. of the thumb Articulatio pollicis

Anterior or palmar metacarpophalangeal ligaments ${ }^{1}$ Ligg. accessoria volaria

Proximal interphalangeal articulation of the index finger Articulatio proximalis digiti 11

Lateral ligaments) Ligg. collateralia $\}$

Distal interphalangeal articulation of the index finger Articulatio distalis digiti II.

Capsule of the distal interphalangeal if articulation of the middle finger Capsula articulationis distalis digiti III.

\section{Capsule of the metacarpo-phalangeal articulation of the little finger Capsula articulationis metacarpo-phalangex digiti $\mathrm{V}$.}

Sesamoid bone

Os sesamoideum

Transverse metacarpal ligament (Anterior or palmar distal intermetacarpal ligaments)

Ligg. capitulorum transversa

Internal lateral ligaments of the interphalangeal articulations of the little finger

Ligg. collateralia ulnaria articulationum digiti $\mathrm{V}$.

\footnotetext{
I These are fibrous plates rather than ligaments properly so called, and, being thickened into fibrocartilage at each side along their attach. ments to the lateral metacarpo-phalangeal ligaments, they are grooved on the palmar surfaces for the flexor tendon. Macalister calls then glenoid ligaments. It is in the lateral fibrocartilaginous portinns of these plates that the sesamoid bones of the metacarpo-phalangeal joint of the thutah, aud occasionally of some of the other fingers, are developed. $-T_{R}$.
}

F1G. 444.-ThE ANTERIOR OR PALMAR LigaMents OF THE IVRIST AND HAND: THE SUPERFICIAL LIGAMENTS OF THE CARPUS AND THE METACARPUS; 'THE CAPSUlfS AND LIGAMENTS OF THF METACARPO-PHALANGEAL AND THE INTERPHALANGEAL ARTICUIATIONS. LiganeNTUM CARPI TRANSVERSUM, ANTERIOR ANNULAR LIGAMENT OF THE IVRIST: CANALIS CARPI, CANAL OF THE CARPUS BENEATH THE ANTERIOR ANNULAR l.igaMeNT (FOR THE TRANSMISSION OF THE FLEXOR TFNDONS). Relations OF THE TENDONS OF THE Flexor Carpi Ulnaris aNd Flfyor Carpi Ranialis Muscle to the ANTeriuR or Palmar Carpal and. Metacarpal Ligaments. Ligamenta ACCessoria Volaria, ANTerior or Palmar MetacarpoPHALANGeal Liganen's; LigaMfNTa Capitulorum Transversa, Transverse MetaCarpal Ligament (Anterior or Palmar Distal Intermetacakpal Ligaments). Ossa Sesamoidea, Sesamoid Bones.

In the interphalangeal articulations of the index finger the antcrior portions of the capsules between the lateral ligaments have heen entirely cut away: in those of the middle finger the capsules have been divided transversely across the niddle of the joint and the divided halves of the anterior ligament turned upwards and downwards; in the interphalangeal articulation of the thum', the anterior portion of the capsule has been divided along its attachment to the distal phatanx and the lateral liganents, and, logether with the sesamoid bones embedded in it on each side, has been turned upwards; in the remaining joints the capsule has been left intacl.

\section{Articulationes manus et digitorum-Articulations of the hand and fingers.}




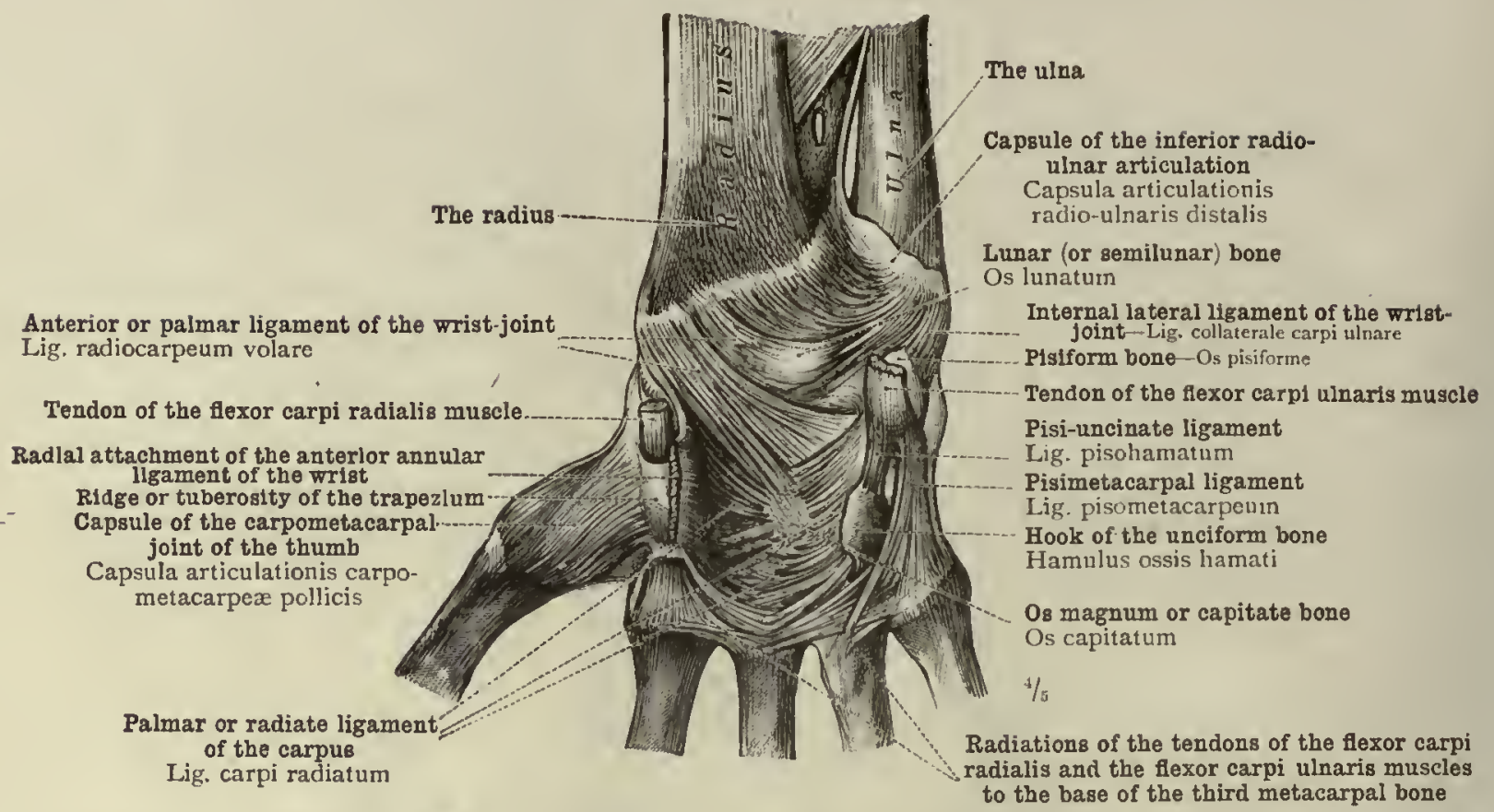

Fig. 445.-The ANterior or Palmar ligaients of the Right Carpus, shown by the ReMovat, of the ANTERIOR ANNULAR LIGAMLNT OF THE IVRIST: LIGAMENTUM RADIOCARPEUM VOLARE, ANTERIOK OR PALMAR LIGAMENT OF THE IWRIST-JOIN'; LIganeNTUM CARPI RAdiatum, ANTERIOR OR RADIATE LIGAMENT OF THE CARPUS.

The radius Capsule of the inferior radio-ulnar articulation Sigmoid cavity of the radius.
Incisura ulnaris

Lunar (or semilunar) bone Os lunatum

Anterior ligament of the wrist-joint Lig. radiocarpeum volare

Scaphoid bone-Os naviculare

Tuberosity of the scaphoid bone Tuberculum ossis navicularis External lateral ligament of the transverse carpal articulation $(I)$

Groove of the trapezium

Capsule of carpometacarpal joint of thumb(z). Os magnum, or capltate bone (3)

Palmar or radlat 3 Ilgament of carpus (4)

Carpometacarpal articulation of the thumb

Articulatio carpometacarpea pollicis

Anterior or palmar carpometacarpal ligaments

Ligg. carpometacarpea volaria

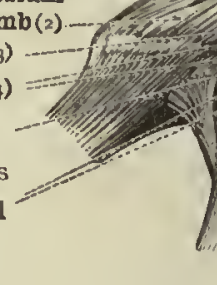

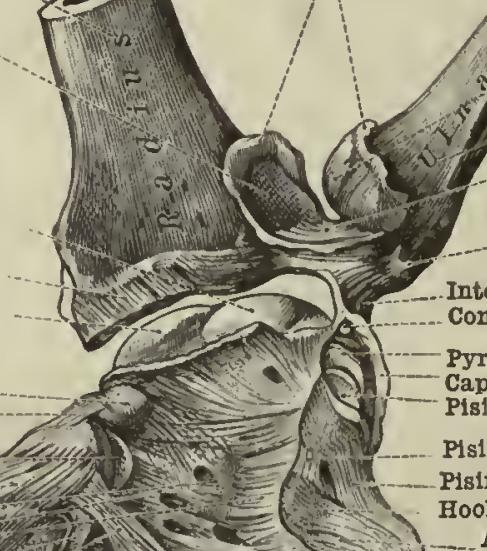

Hook of the unciform bonePrac. styloideus ulna Istform bone-Os pisiforme Anterior or palmar carpometacarpal ligament

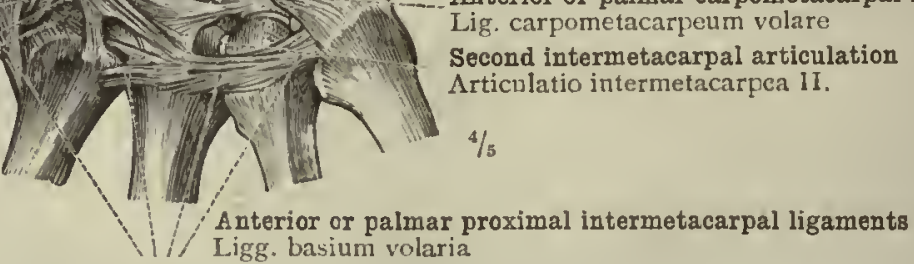

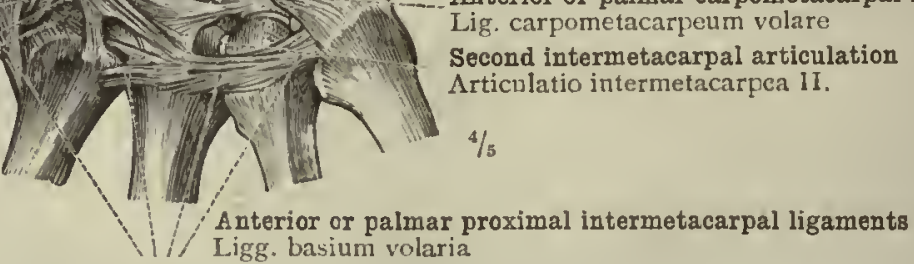

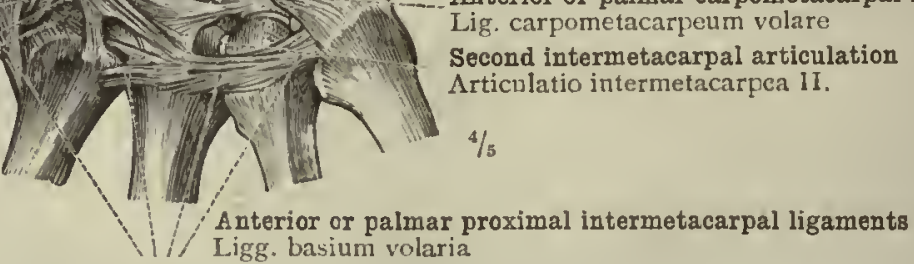

Styloid process of the ulna

nternal lateral ligament of the wrist-joint ( 5$)$ the pisipyramidal ar ticulation midal or cunelform bone - Os iriquetrum apsule of the plsipyramidal articulation (6)

st-uncinate ligament-I,ig. pisohamnım -Lancinate ligament-1,ig. pisohamnion Anterior or palmar prosium volaria

(x) Lig. intercarpeum volare. [Connecting the tuberosities of the scaphoid bone and the trapezium, - TR.]
(2) Capsula articulationis carpo.
(3) Os capitatum
(4) Lig. carpi radjatum
(5) Lig. collaterale carpi ulnare
(6) Capsula articulationis ossis metacarpex pollicis
ALAR T.IGAMIENTS

4. 446. -THE ANTERIOR OR PALMAR I.IGAMENTS OF THE INTERCARPAL (TRANSVERSE CARPAL) AND CARPO-

METACARPAL ARTICULATIONS, AFTER THE ANTERIOR ANNULAR LIGAMFNT OF THE WRIST AND THE

TENDONS OF THE FlexoR CARPI RADIALIS AND FlEXOR CARPI ULNARIS HAVE BEEN ENTIRELY REMIOVED.

The radiocarpal and distal radio.ulnar articulations have been opened, the triangular fibrocartilage and the internal lateral ligament of the wrist-joint being left intact; the bones of the forearm have been separated from one another and from the carpus; the pisipyramidal articulation, the carpometacarpal articulations of the thumb and the ring finger, and the second intermetacarpal articulation, have been partially opened. 


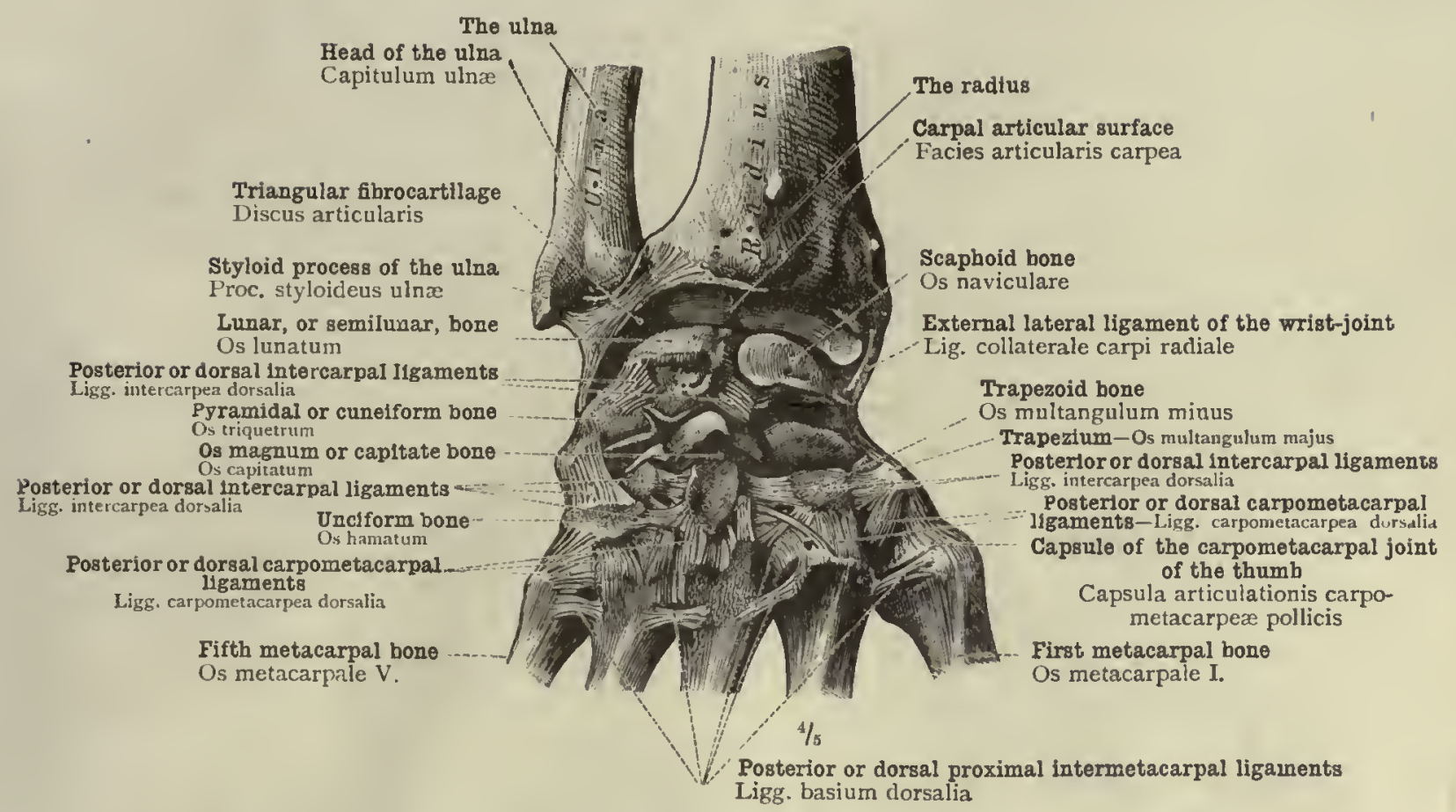

Fig. 447.-Tie Short Posterior or Dorsal Ligaments of the Transverse Carpal Articulation, and of the Carpometacarpal and Intermetacarpal Articulations. (Tile Right Carpus with the Distal Extremities of the Bones of the Forearm and the Proximal Extremities of the Metacarpal Bones.)

The distal radio-ulnar articulation and the radiocarpal and transverse carpal articulations have been opened by the removal of the posterior ligaments, and the bones of the forearm have been drawn a little upwards and away from the carpus.

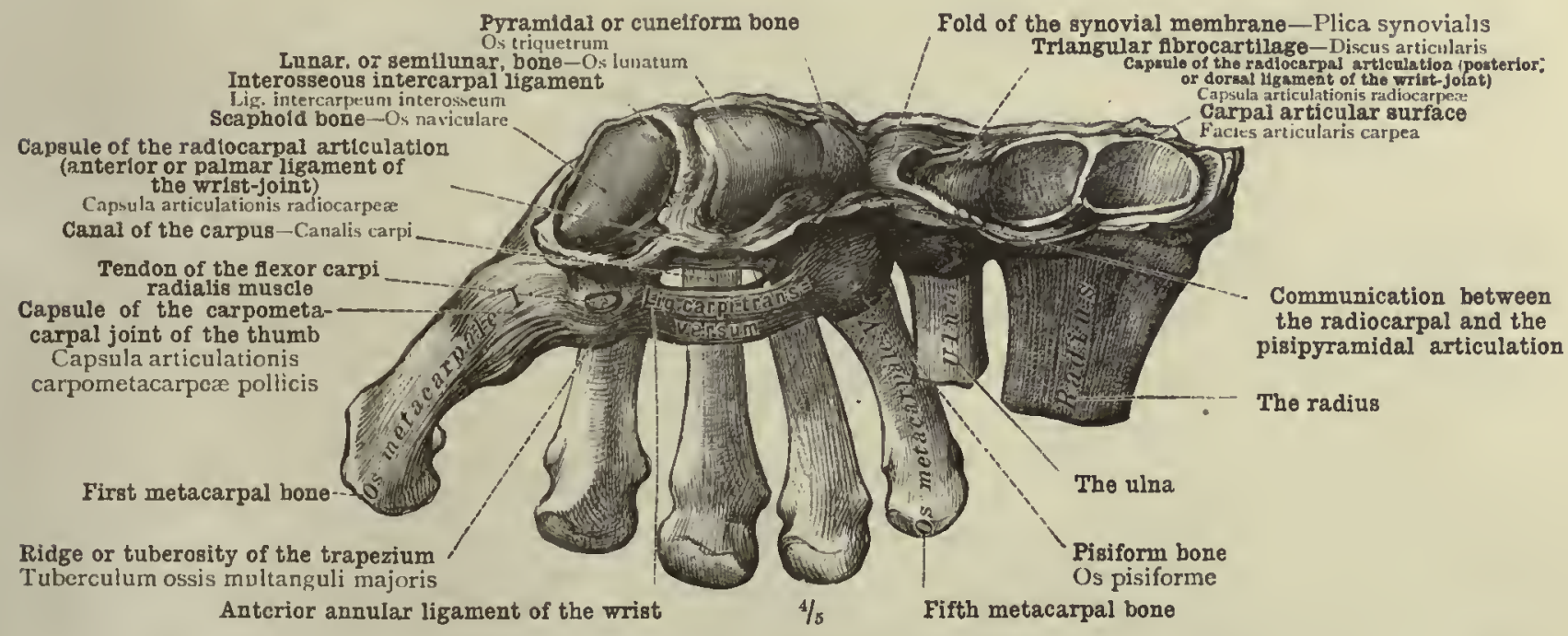

Fig. 448.-The Articular Surfaces and the Attachments of the Capsule of tile Radiocarpal articulation or Wrist-Joint; Canalis Carpi, the Canal of the Carpus. (The Right Cakpus with the Metacarpal Bones; Antero-superior Aspect.)

The distal extremities of the bones of the forearm have been turned to the ulnar side, after division of the capsule of the wrist-joint with the exception of the internal lateral ligament. 


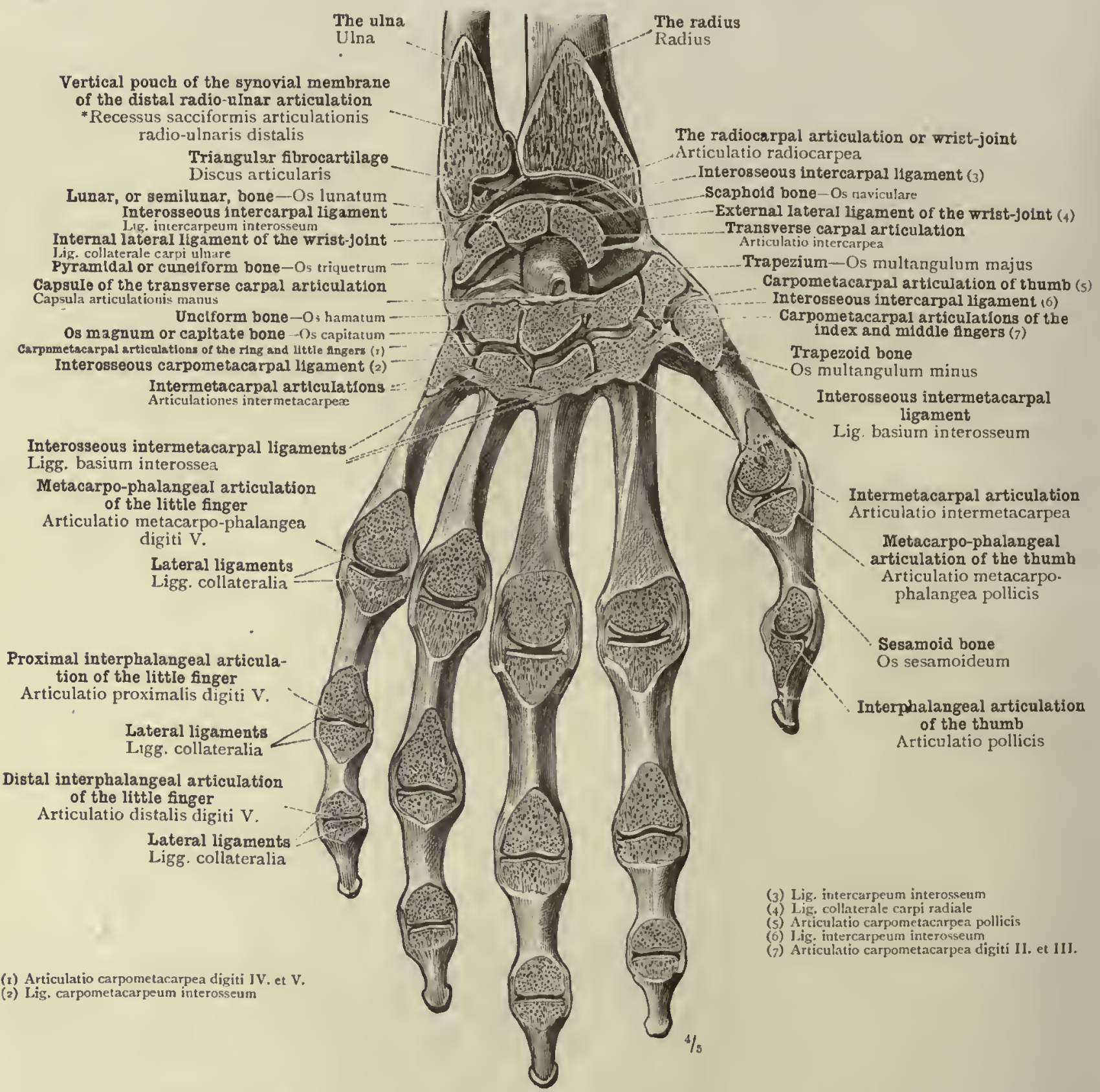

Fig. 449.-Articulatio Radio-ulnaris Distalis, Distal Radio-vlnar Articulation. Articulatio Manus, Articulations of the Hand: Articulationes Radiocarpea et Intercarpea, Radiocarpal Articulation or Wrist-Joint and Transverse Carpal Articulation. Articulationes Carpometacarper, Carpometacarpal Articulations; Articulationes InterMETACarpeæ, Intermetacarpal Articulations. Articulationes Metacarpo-phalange $A$, Metacarpo-phalangeal Articulations; Articulationes Digitorum Manus, Interphalangeal Articulations of the Fingers. (The Skeleton of the Right Hand with the Distal Extremities of the Bones of the Forearm; Posterior or Dorsal Aspect.)

The articulations are all opened by a section in the frontal plane: and whereas in the fingers this plane passes through the joints from side to side, dividing the lateral ligaments; in the thumb, owing to the op rosition of this member, the plane of section passes through the joints in a dorsopalmar direction, and divides the dorsal and palmar ligaments.

Articulationes manus et digitorum-Articulations of the hand and fingers. 


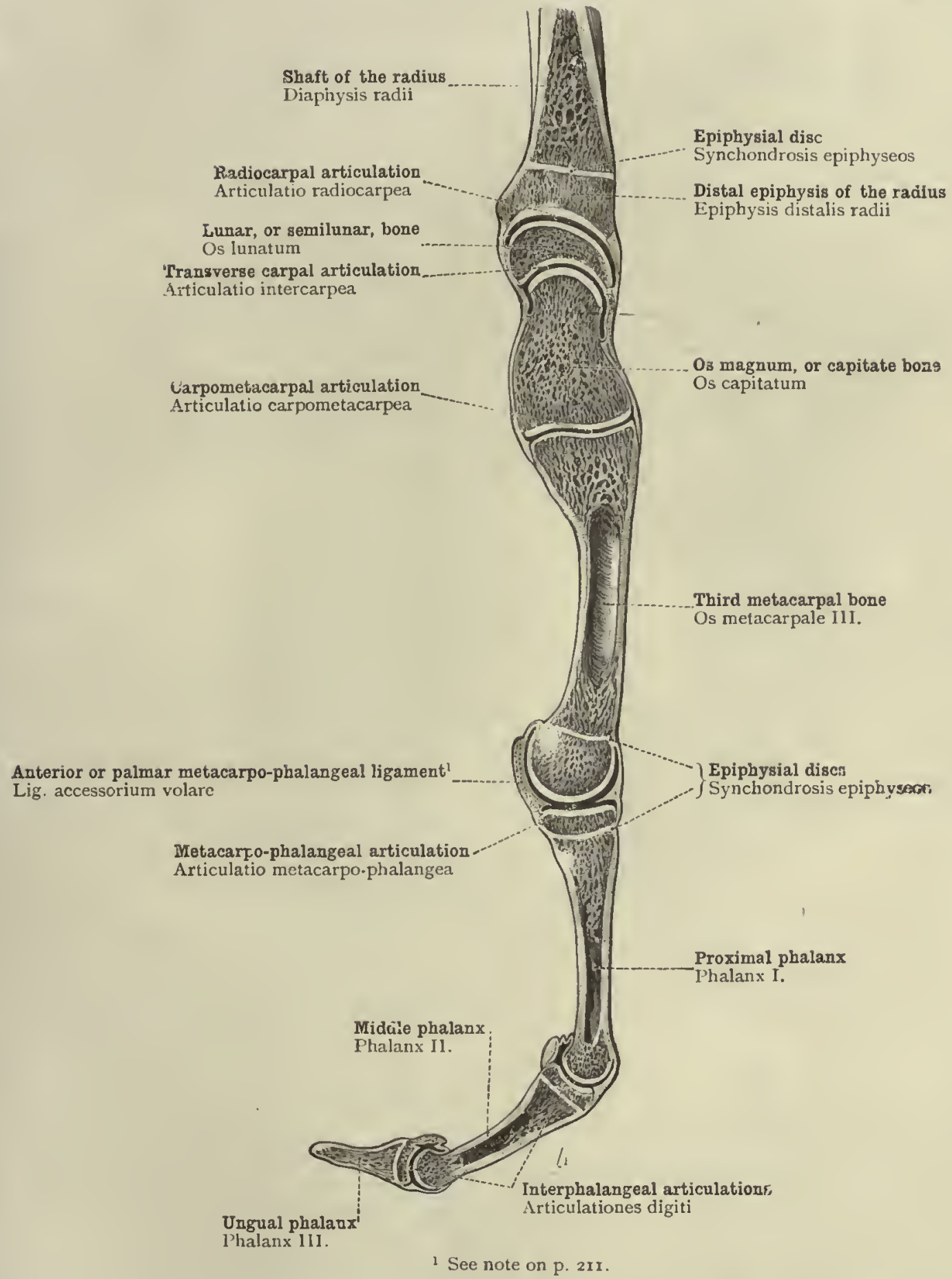

Fig. 450.- The Articulations of the Hand, seen in Sagittal or Dorsopaimar section, Showing tijeir Relations to tile Epiphysial Discs. (The Radial Portion of the Divided Right Hand of a Youth aged Seventeen Years.)

The section traverses the distal extremity of the radius, the carpus, and the metacarpal bone an phalangres of the middle finger.

Articulationes manus et digitorum-Articulations of the hand and fingers. 


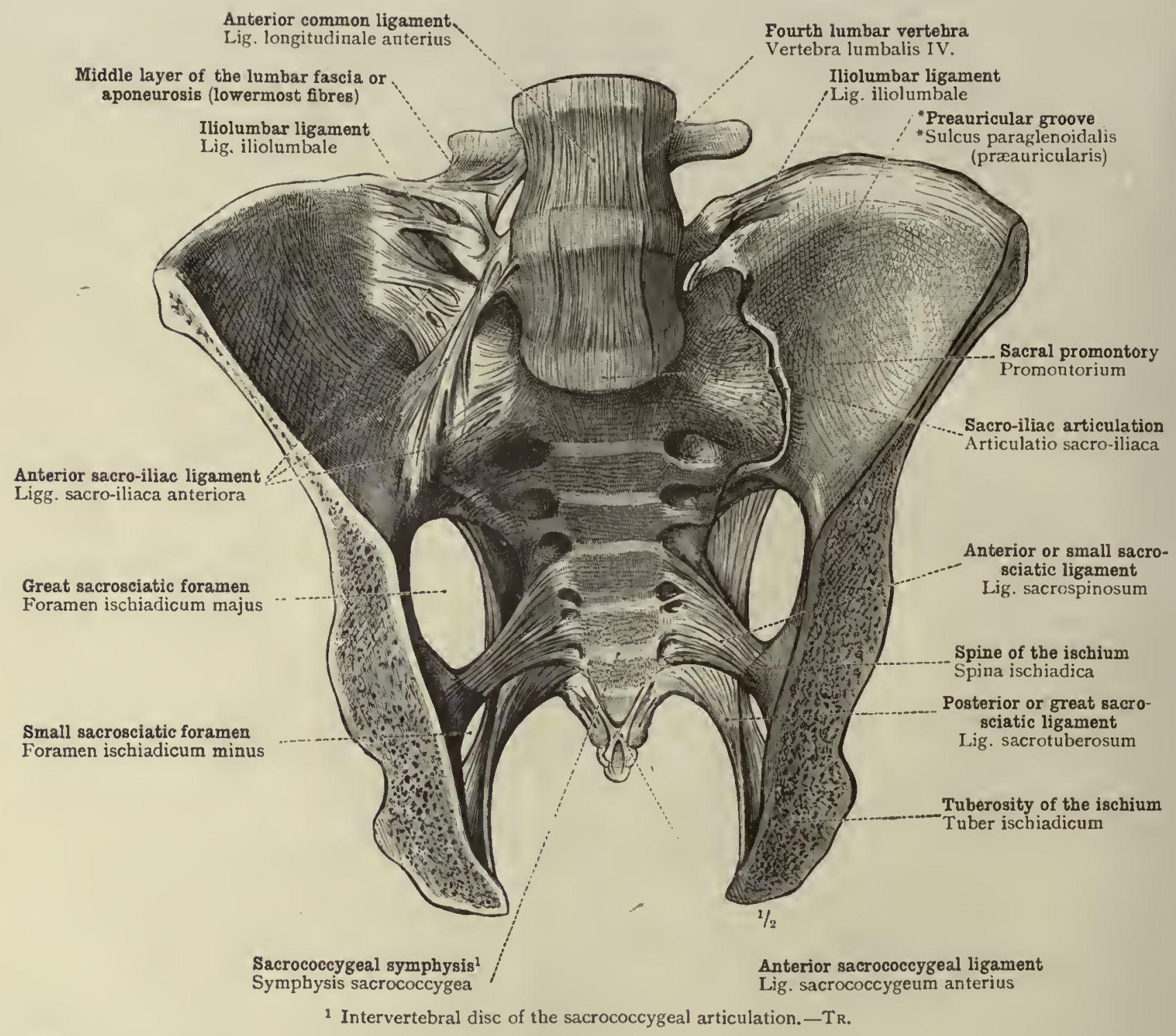

Fig. 451.-Articulatio Sacro-iliaca, Sacro-iliac Articulation: Ligamenta Sacro-iliaca Anteriora, ANterior SaCro-iliac Ligament; Ligamentum Iliolumbale, Iliolumbar Ligament. Ligamenta Sacrospinosum et Sacrotuberosum, Small or Anterior and Great or Posterior Sacrosciatic Ligaments. Foramina Ischiadica Majus et Minus, Great and Small Sacrosciatic Foramina. (The Pelvis with the Fourth and Fifth Lumbar Vertebrai, in Frontal Section; Posterior Half, seen from Before.)

The ligaments of the right sacro-iliac articulation are intact; those of the left articulation have been removed.

Articulationes et ligamenta cinguli extremitatis interioris-Articulations and ligaments of the pe vic girdle, 


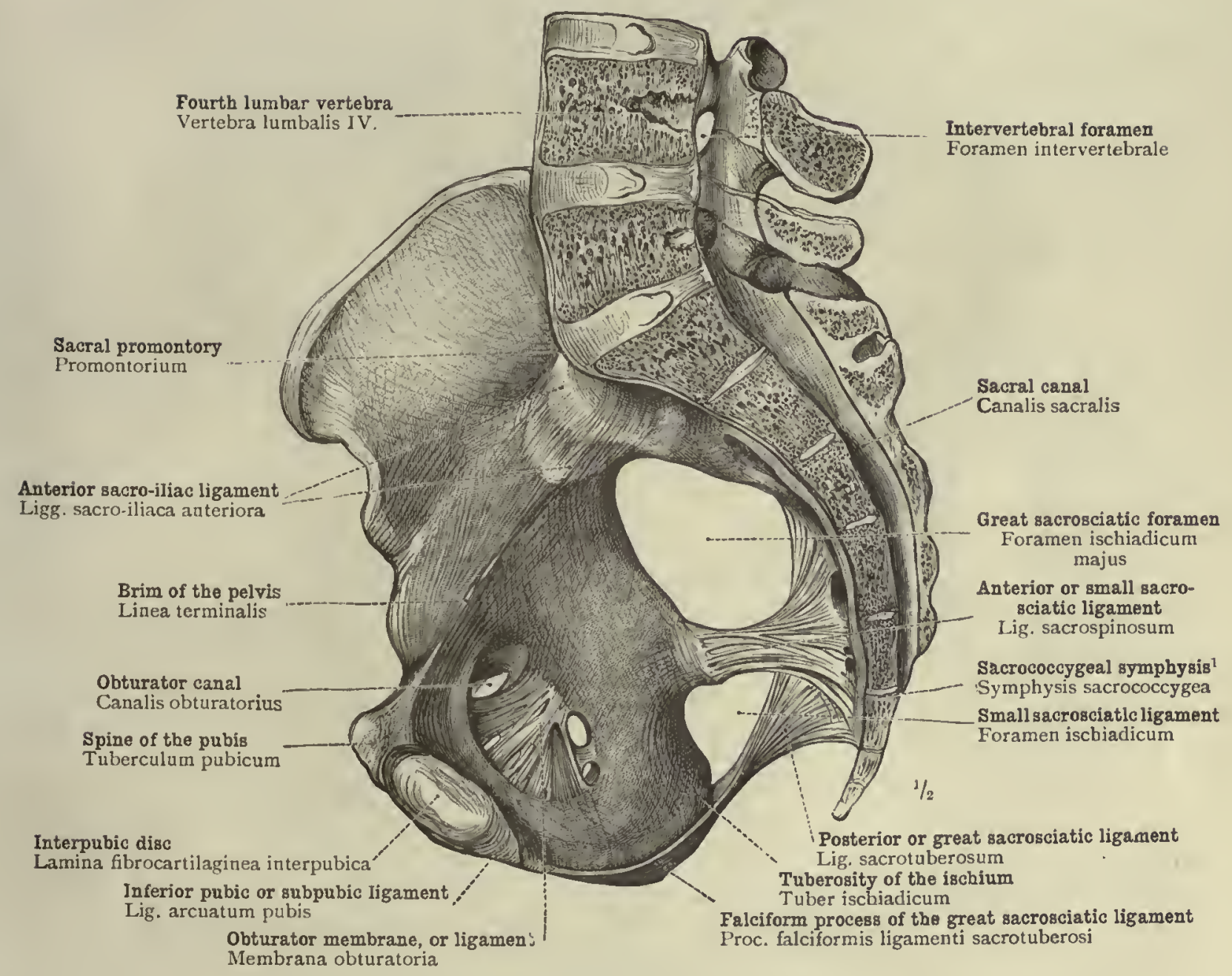

1 See note on p. 216.

Fig. 452.-Ligamenta Sacrotuberosum et Sacrospinosum, Posterior or Great and Anterior or Small Sacrosciatic Ligaments; Foramina Ischiadica, Sacrosciatic Foramina. membrana Obturatoria, Obturator Membrane or ligament; Canalis Obturatorius, Obturator Canal. Articulatio Sacro-iliaca, Sacro-iliac Articulation. (The Right Half of a Pelvis divided in the Median Plane; seen from the Ixner SIDE.)

Articulationes et ligamenta cinguli extremitatis inferioris-Articulations and ligaments of the pelvic girdle. 


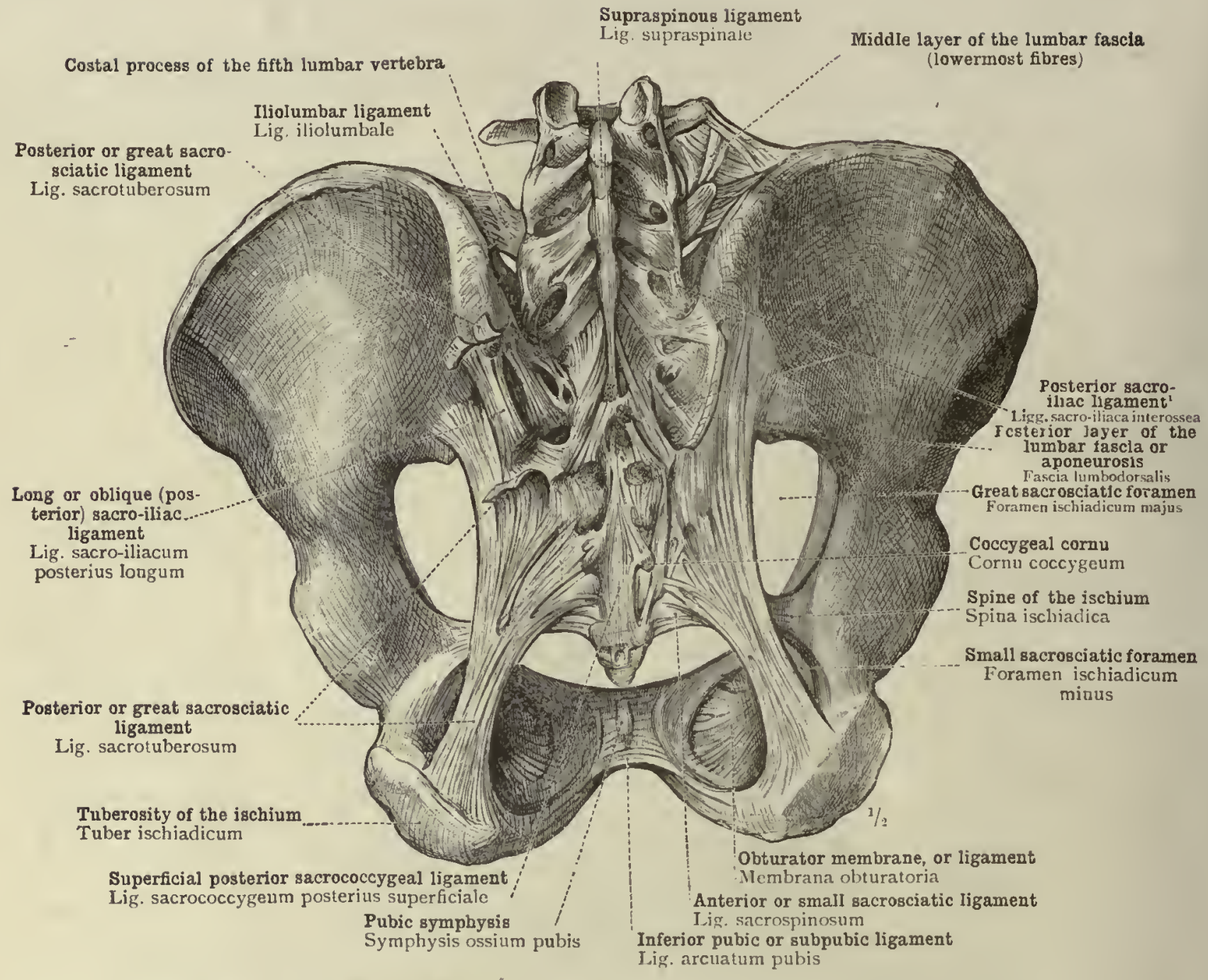

\footnotetext{
I Macalister and some other Engli-h anatomists agree with Toldt in naning this ligament the interossnous sarro-iliac ligament. That osseous fine fibres are occasionally found connecting corresponding parts of the auricular surfaces of the sacrum and the iliun. Trume
}

Fig. 453.-Posterior Liganents of the Pelvig Girdle: Ligamentum Sacrotuberosum, Posterior or Great Sacrosciatic Ligament, and its Relation to tile Posterior Layer of the Lumbar Aponeurosis. Foramina isciiladica, Sacrosciatic fioramina. Ligamentum Sacro-iliacum Posterius Longum, Long or Obligue (Posteiror) Sacroiliac Ligament; Ligamenta Sacro-iliac Interossea, Posterior Saciro-iliac Ligament (see note above); Ligamentum Iliolumbale, Jliolumbar Ligament. (Tile Pelvis witu tile Fourth and Fifth Lumbar Verteisa:; SEen from Beilind.)

On the right side, the posterior layer of the lumbar aponeurosis has been divided close to its continuation into the posterior or great sacrosciatic ligament, and turned outwards ; on the left side, this superficial portion of the posterior or great sacrosciatic li'ament has been cut across, and the divided ends have been turned upwards and downwards. The lowermost fibres of the middle layer of the lumbar aponeurosis have on the right side been left intact, but on the left side entirely removed.

Articulationes et ligamenta cinguli extremitatis inferioris-Articulations and ligaments of the pelvic girdle. 


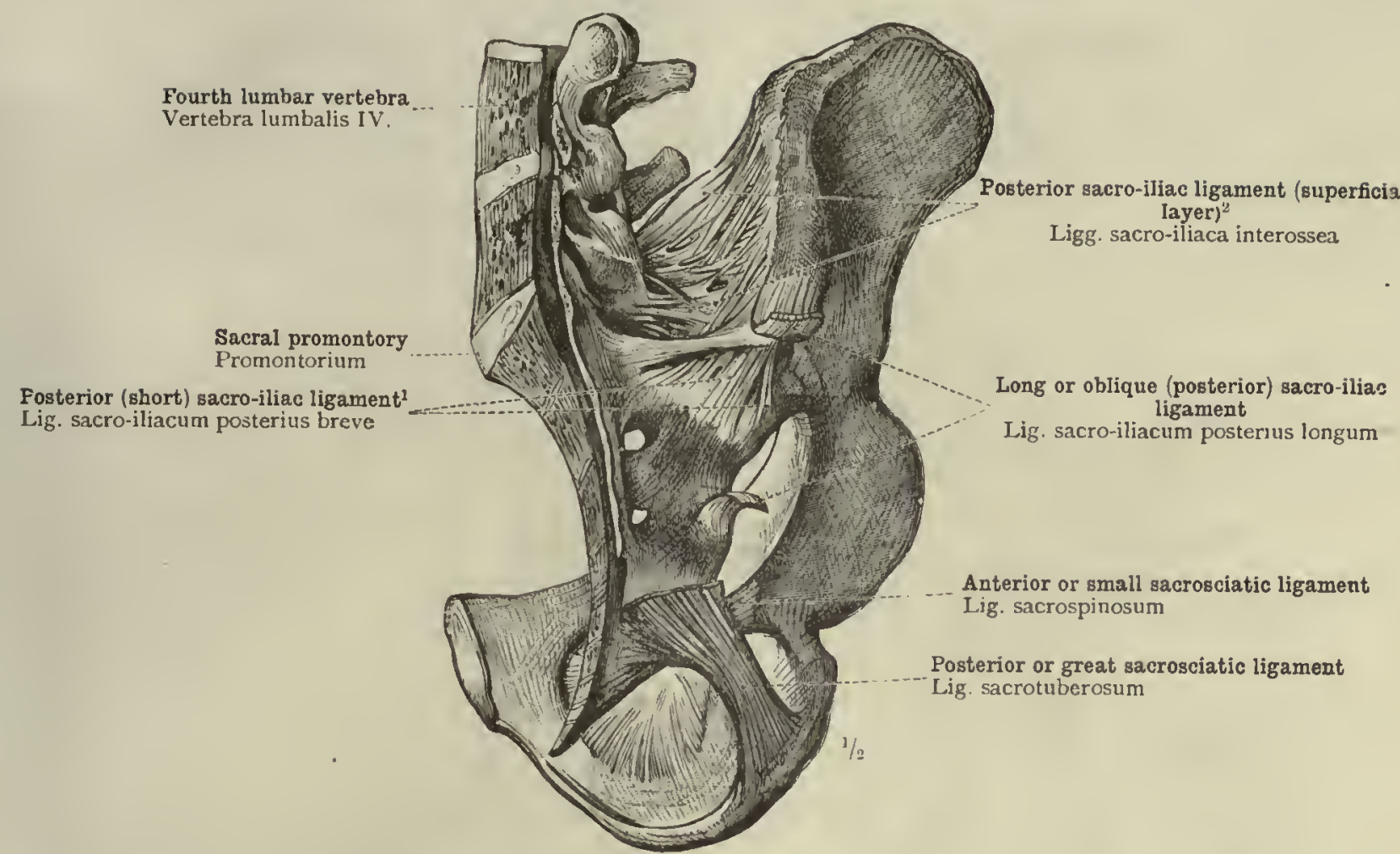

Fig. 454.-Deep Posterior Ligaments of the Sacro-iliac Articulation: Ligamenta Sacroiliaca Interossea, Posterior Sacro-iliac Ligaments ; Ligamentum Sacro-iliacum Posterius Breve, Posterior (Short) Sacro-iliac Jigament. (The Right Half of a Pelvis divided in the Median Plane; Postero-internal Aspect.)

The upper portion of the posterior or grent sacrosciatic ligament has been removed; the long or oblique (posterior) sacro-iliac ligament has been divided transversely in the middle, and the ends have been turned upwards and downwards.

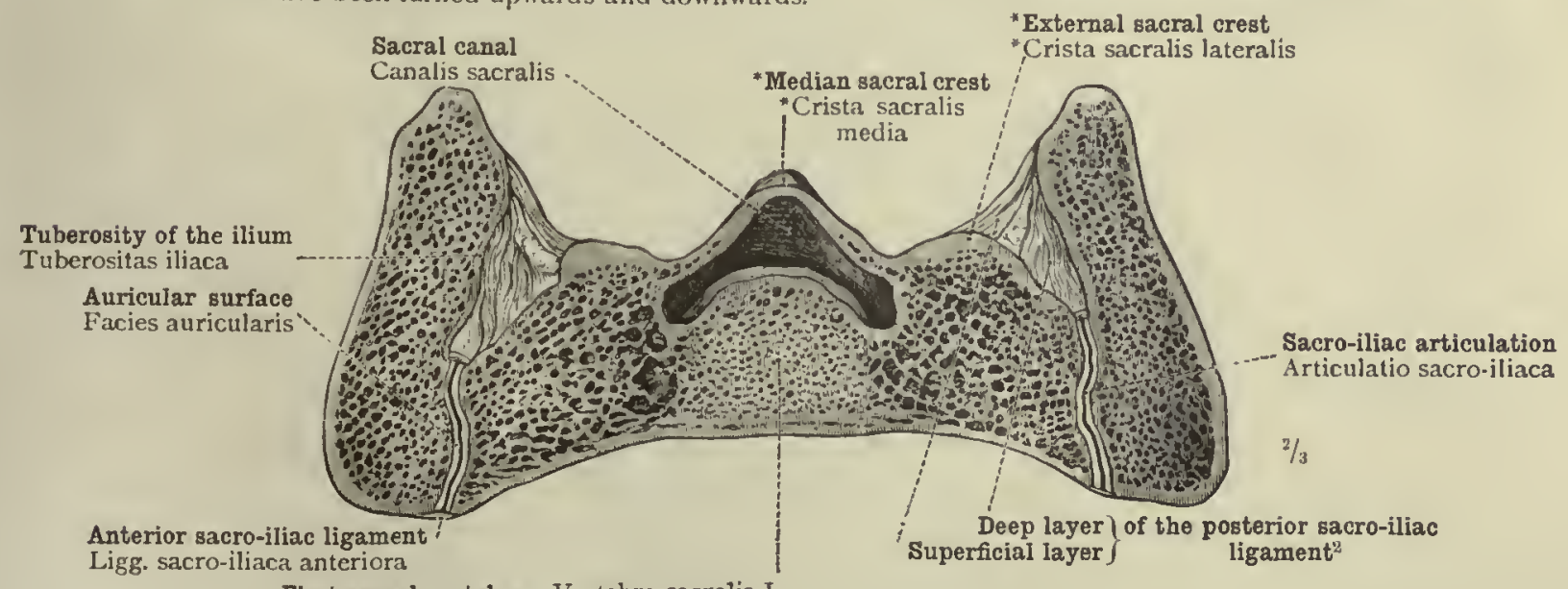

First sacral vertebra-Vertebra sacralis $\mathrm{I}$.

Fig. 455.- Horizontal Section througi the Sacro-iliac Articulation; Upper Surface of Lower Segment: Superficial and Deep Layers of the Posterior Sacro-iliac Ligament.

The section was made in a plane at right angles to the long axis of the pelvis, and passes through the middle of the body of the first sacral vertebra.

1 This forms part of the fosterior sacro-iliac ligament of English anatomists. See note on p. 218. Tr. ${ }^{2}$ See note on p. 218.

Articulationes et ligamenta cinguli extremitatis inferioris-Articulations and ligaments of the pelvic girdle. 


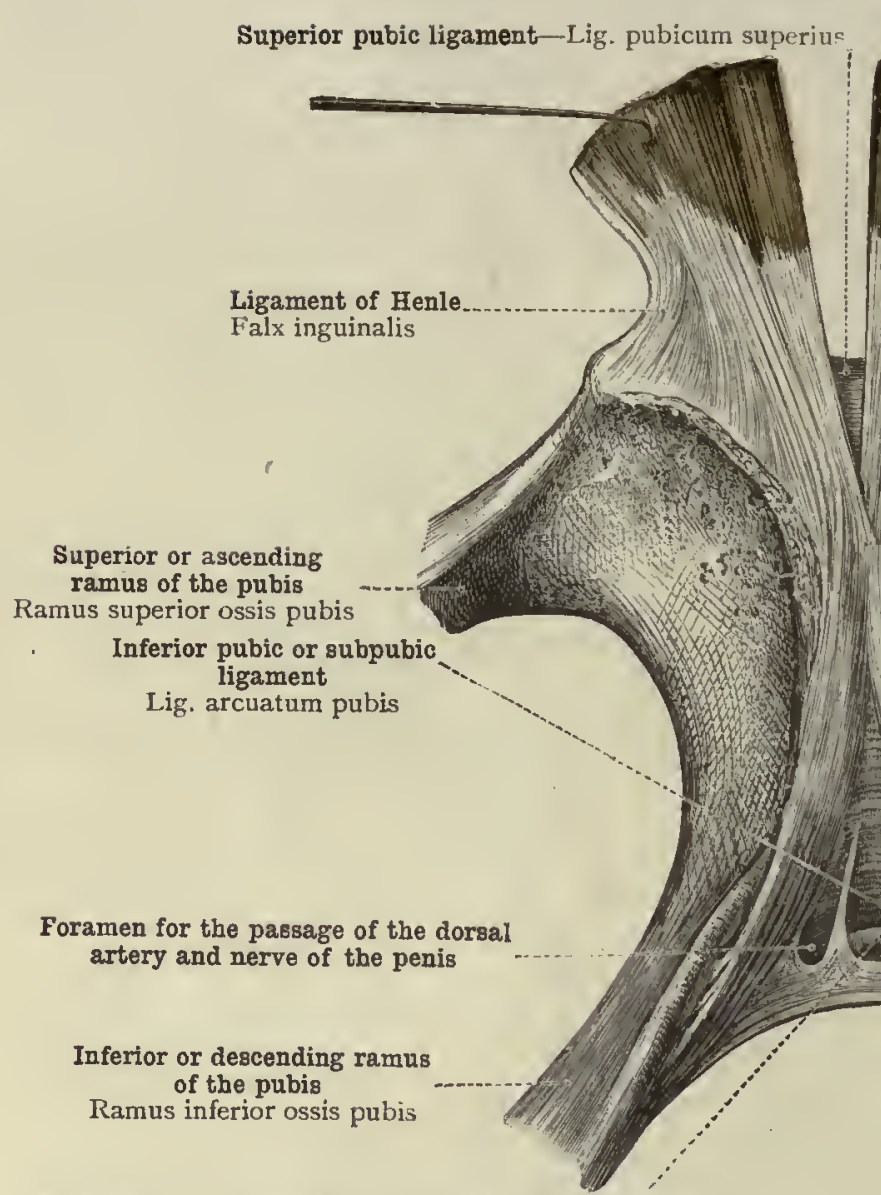

Foramen for the passage of the dorsal vein of the penis

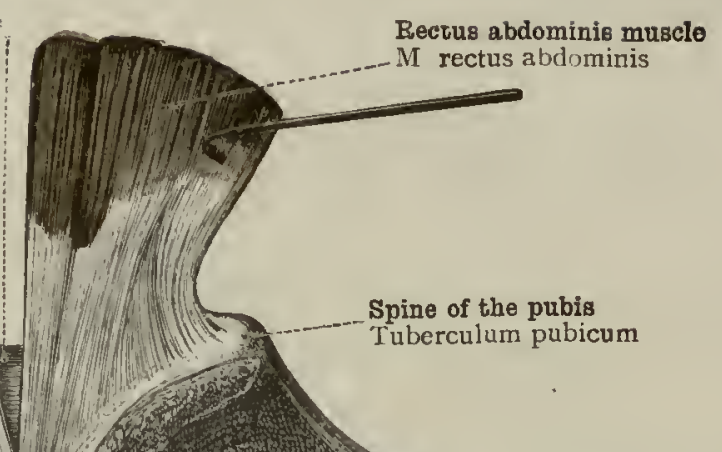

Rectus abdominis muscle

Interlacing of the fibres of the tendons of origin of the rectus abdominis muscles ${ }^{1}$

Fig. 456.-Symphysis Ossium Pubis, Pubic Symphysis: Ligamentum Pubicus Superius, Superior Pubic Ligament; Ligamentum Arcuatum Pubis, Inferior Pubic or Subpubic Ligament; Ligamentum Transversum Pelvis, Transverse Ligament of the Pelvis. The Origin of the Tendons of the Rectus Abdominis Muscles from the Pubis, and the Relation of these Tendons to the Pubic Symphysis. (The Anterior Aspect of the Pubic Symphysis.) The lower extremities of the rectus abdominis muscles have been pulled a little apart.

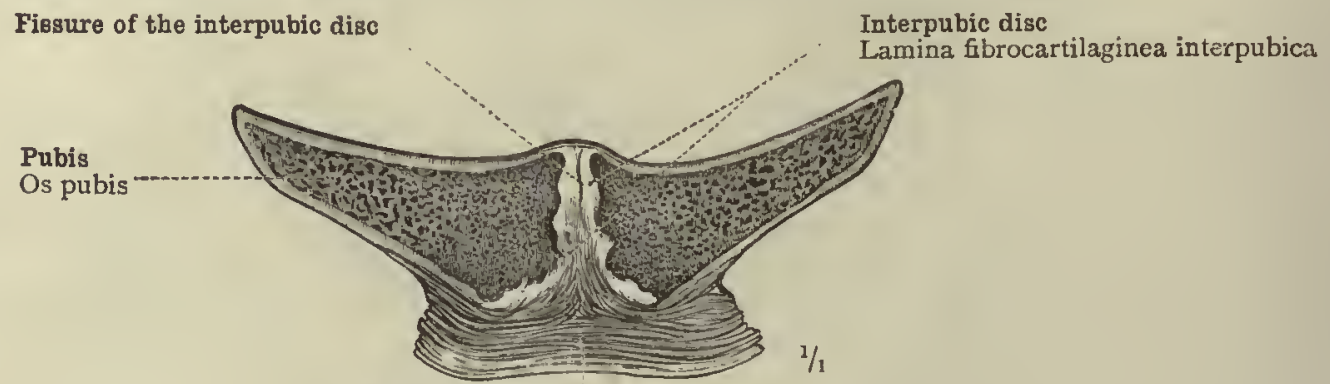

Interlacing tendons

The anterior pubic tigament is not mentioned by the author. It consists of two parts, a superficial and a deep. The deep past, which is not shown in any of the figures, is made up of fibres passing transvernely from bone to bone in front of the interpubic disc; the fibres nf the superficial part are oblique, interlace freely, and are mainly derived from the tendons of the external oblique and rectus muscles of the abdomen, as well as from those of the superficial adductors of the thigh. These interlacing tendinous fibres of the superficial part of the anterior puhic ligament are shown in both the figures on this page. - Tr.

2 This ligament is a portion of the deep perineal fascia or triangulat ligament of the urethra. The name of transverse ligament of the pelvis, which is rarely used in England, was given to it by Henle. - TR.

Fig. 457--Horizontal Section through the Pubic Symphysis of a Nulliparous IVoman aged Twenty-One Years; Upper Surface of Lower Segment: Lamina Fibrocartilaginea Interpubica; Interpubic Disc; Fissure in the Interpubic Disc. Re-Inforcement of the Interpubic Articulation by The Interlacing on its Anterior Surface of the Fibres of the Tendons of Origin of the Rectus Abdominis Muscles and the Tendons of Insertion of the External Oblidue Muscles.

The plane of section lies in the upper half of the symplysis. 
Superior pubic ligament-Iig. pubicum superius!

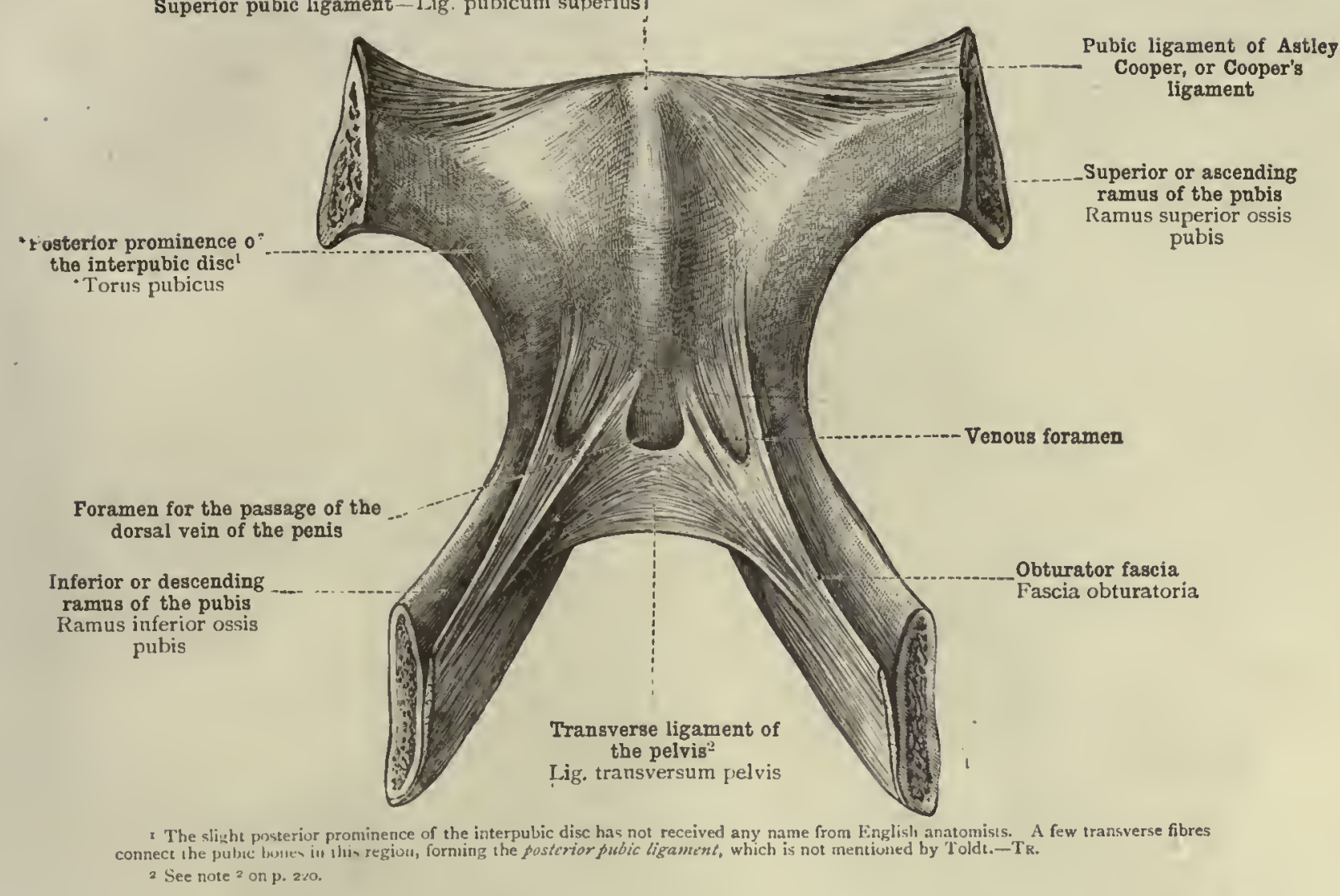

Fig. 458.-Symphysis Ossium Pubis, Pubic Srmphysis: Torus Pubicus, Posterior Prominence of the Interpuizic Disc; Ligamentum Transversum Pelyis, Transverse Ligament of the Pelvis (see note 2 aboie), with the Venous Foramina; Connexions of the Transverse Ligament of the Pelvis with the Obturator fascia. (Tile Pubic Symphysis seen from Behind.)

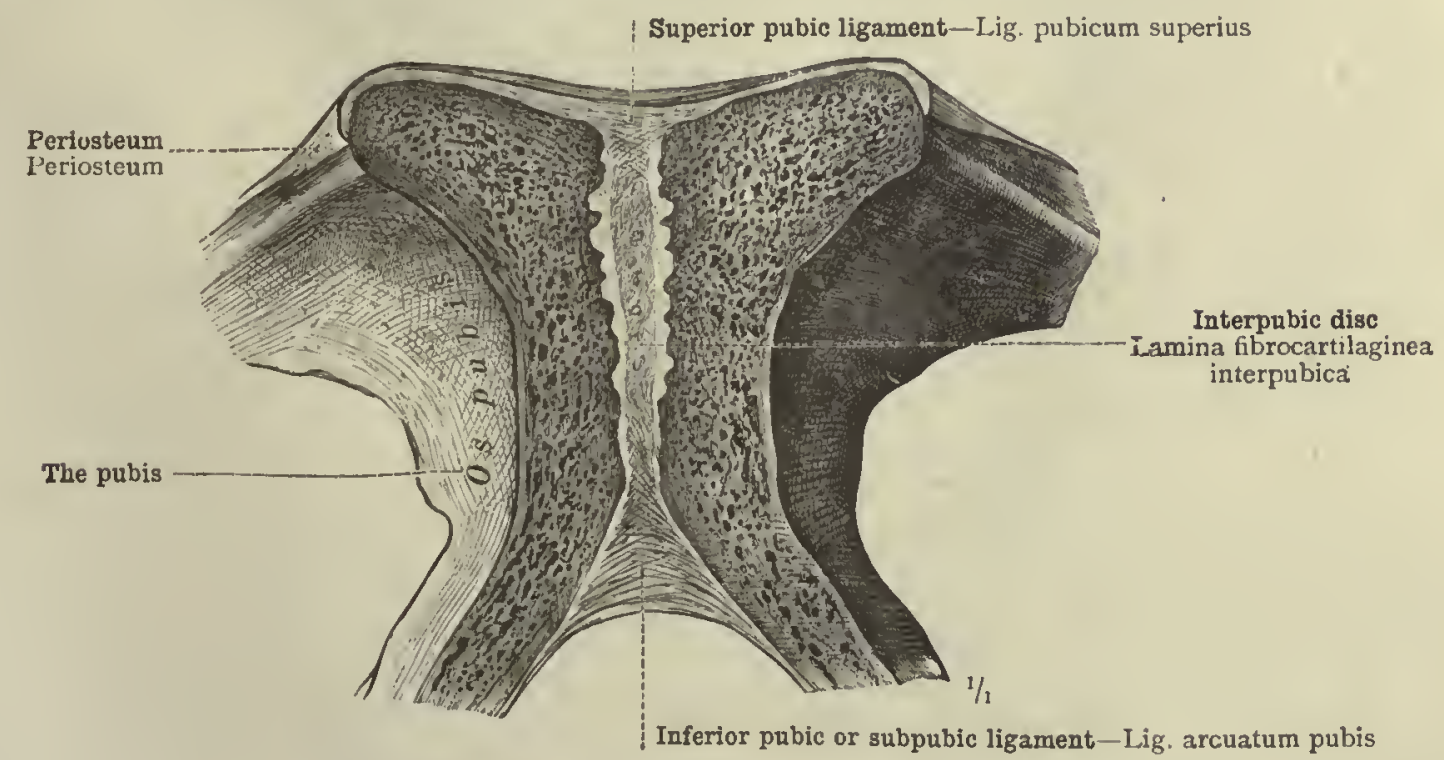

Fig. 459.--Symphysis Ossium Pubis, Pubic Symphysis: Lamina Fibrocartilaginea Interpubica, Interpuid Disc; Liganentum Pubicum Superius, Superior Pubic Ligament; Ligamentum Arcuatum Puis, Inferior Pubic or Subpubic Ligament. (Thi, Pubic Symphysis in Frontal Section; Anterior Surface of Posterior Segment.) 


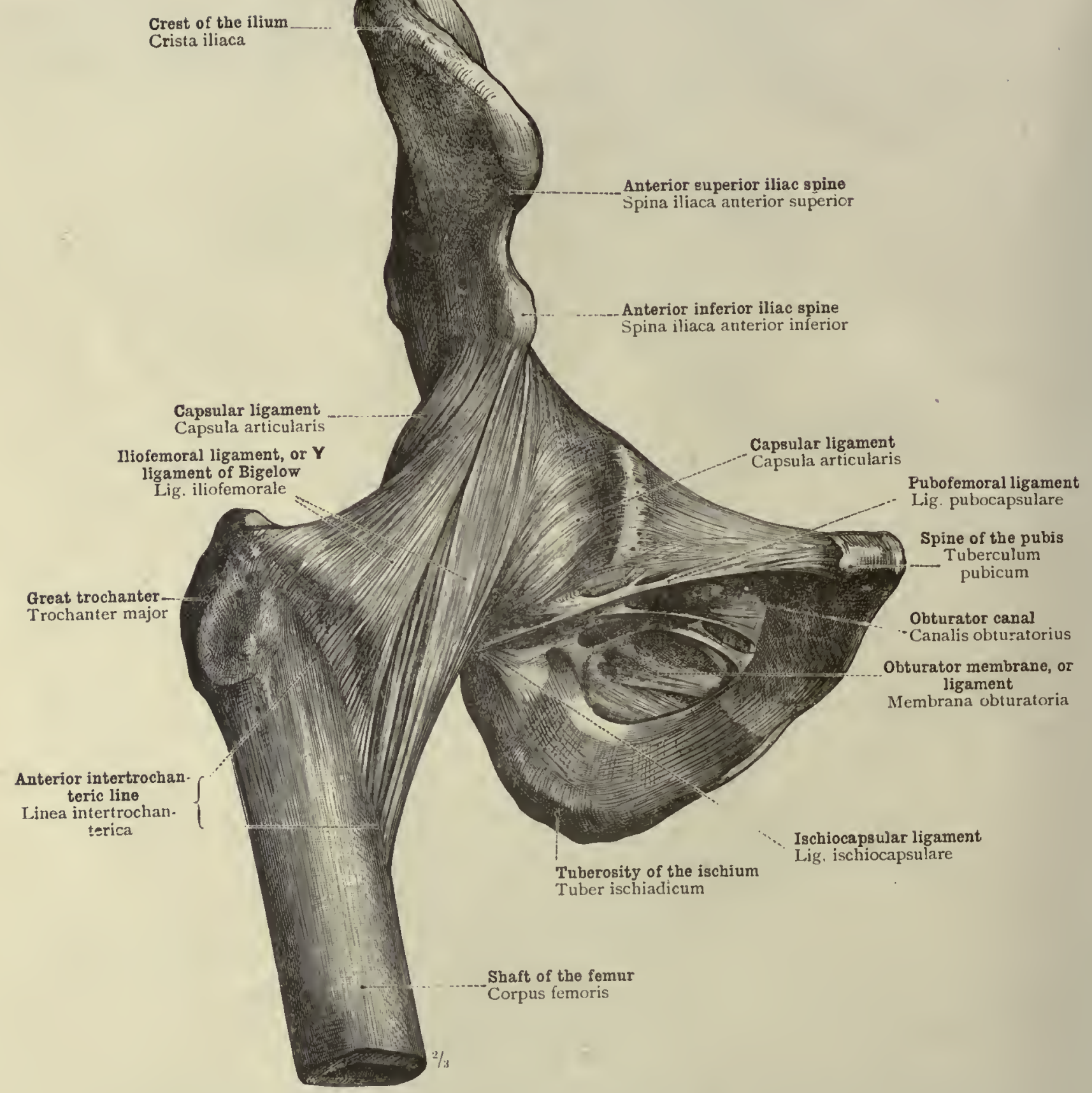

rig. 46o.-Articulatio Coxa, tile Hip-Joint: Ligamentum Iliofemorale, Iliofemoral. Ligament, or $Y$ Ligament of Bigelow; Ligamentum Pubocapsulare, Pubofenoral Ligament, and its Relations to the Obturator Membrane. (The Right Hip-joint, SEEN FROM BEFORE.) 


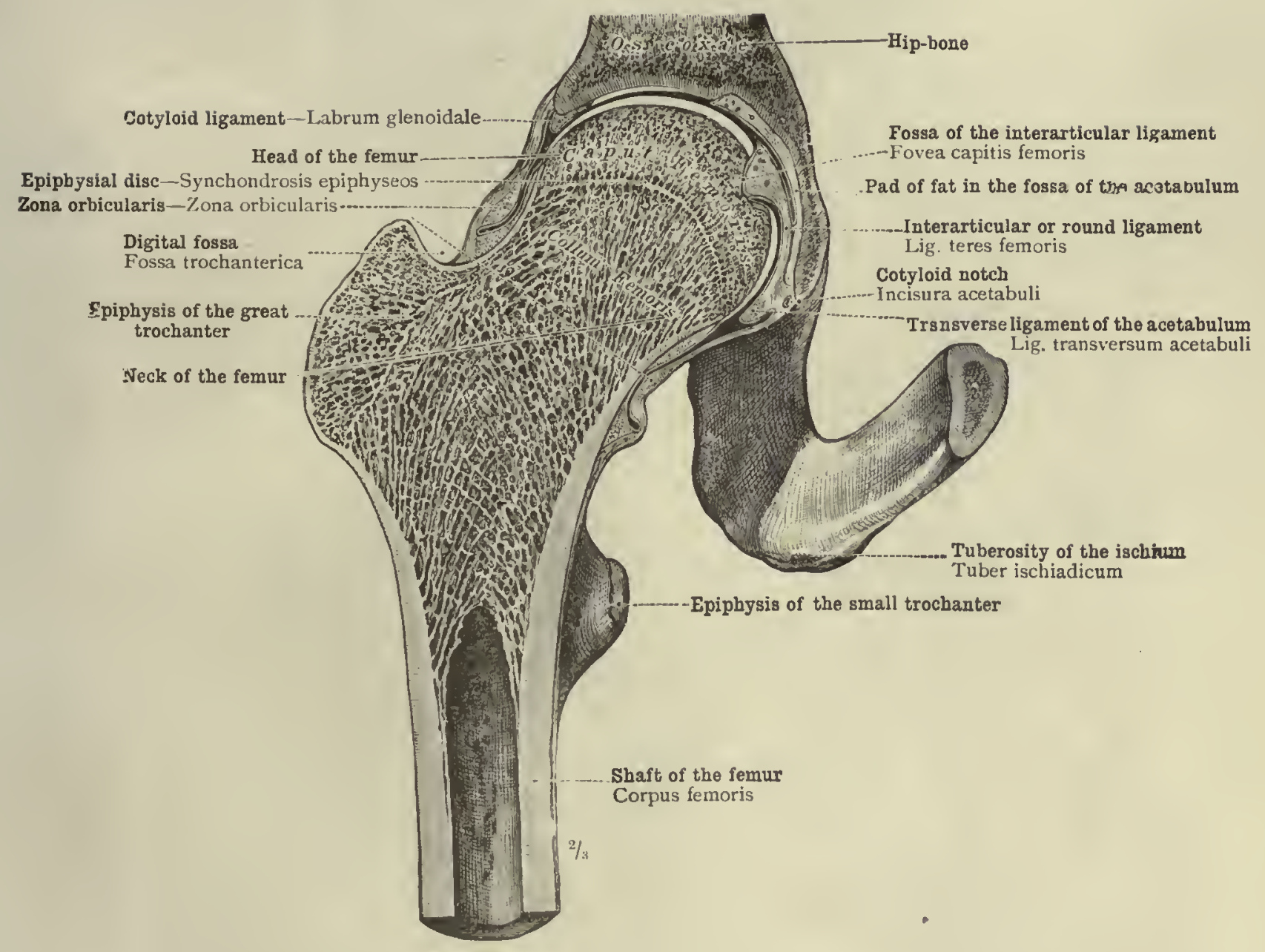

Fig. 461.-Articulatio Coxe, tile Hip-Jornt: Capsula Articularis, Capsular liganent; Zona Oribicularis, the Circularly Disposed fibres of the Capsular ligament, Forming a Band Round the NeCK of tile FEMUR, Which is MOST distinct Behind and Below. Relation of tife Epiphysial Disc of the Head of the Femur to the Hipjolnt. ('The Right Hip-Joint in Frontal Section; Anterior Surface of Posterior SEGMENT.)

The section pisses through the middle of the cotyiord notch and of the fossa of the interarticular higament. 


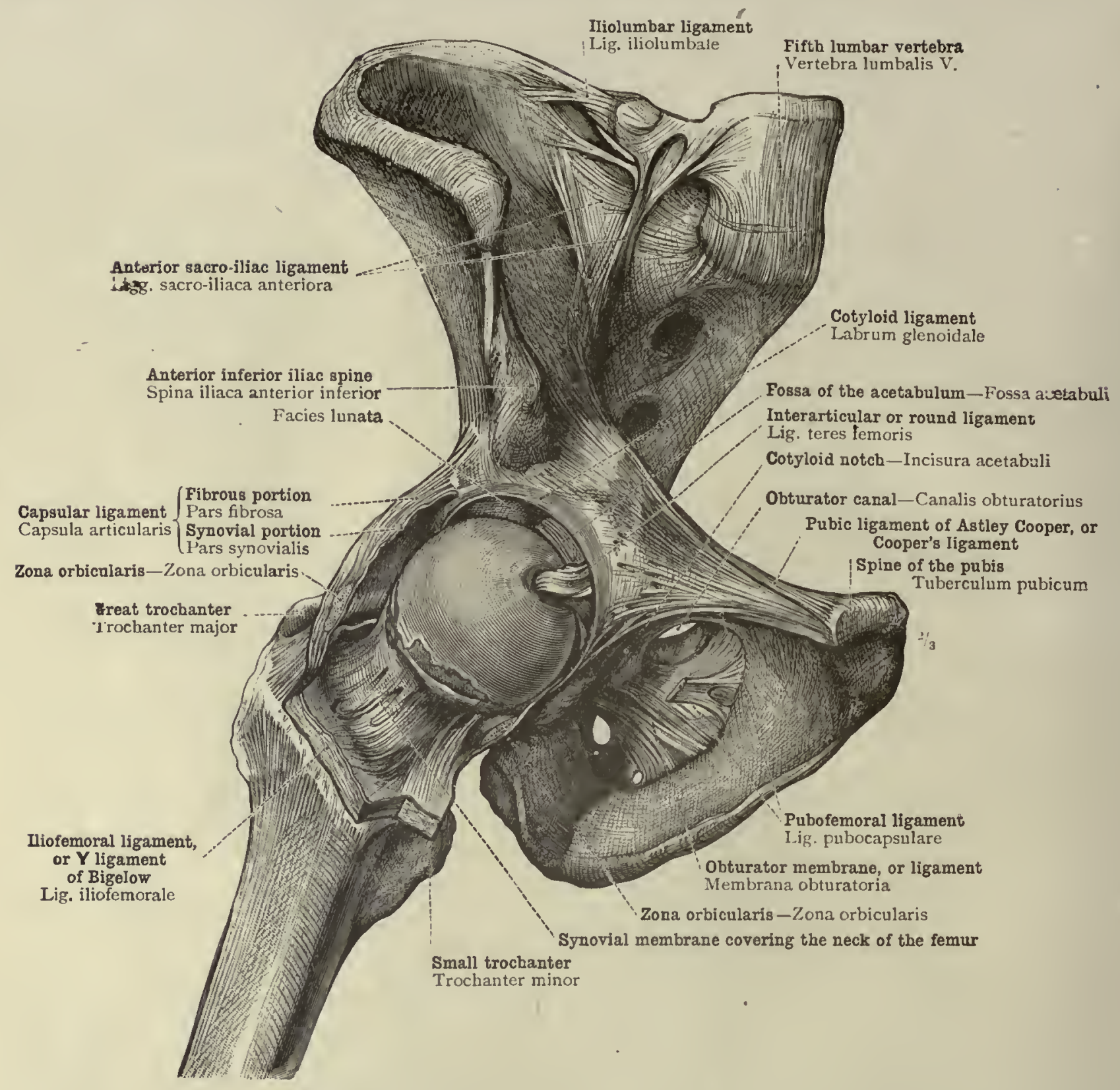

Fig. 462.-Articulatio Coxæ, the Hip-Joint; Ligamentum Teres Femoris, Interarticular or Round Ligament of the Hip-Joint ${ }^{1}$; Labrum Glenoidale, Cotyloid Ligament; Capsula Articularis, Capsular Ligament of the Hip-Joint; Reflection of the Synovial Membrane of the Hip-Toint From the Inner Surface of the Capsulak Ligament on to the Neck of the FEMUR; Z̈ONa Üribicularis, Circular Band of the Capsular Ligament round the Neck of the Femur. ${ }^{2}$ (The Right Hip-Joint seen FROM BEFORE.)

The anterior wall of the capsular ligament has been removed, except for a narrow band at its distal attachment, which has been turned outwards. The head of the f $\mathrm{tmur}$ has been slightly withdrawn from its socket in a downward and outward direction.

1 Perbaps most frequently known in England by its Latin name, liganentum teres.

2 Also frequently known in England by its Latin name, zona orbiculuris. 


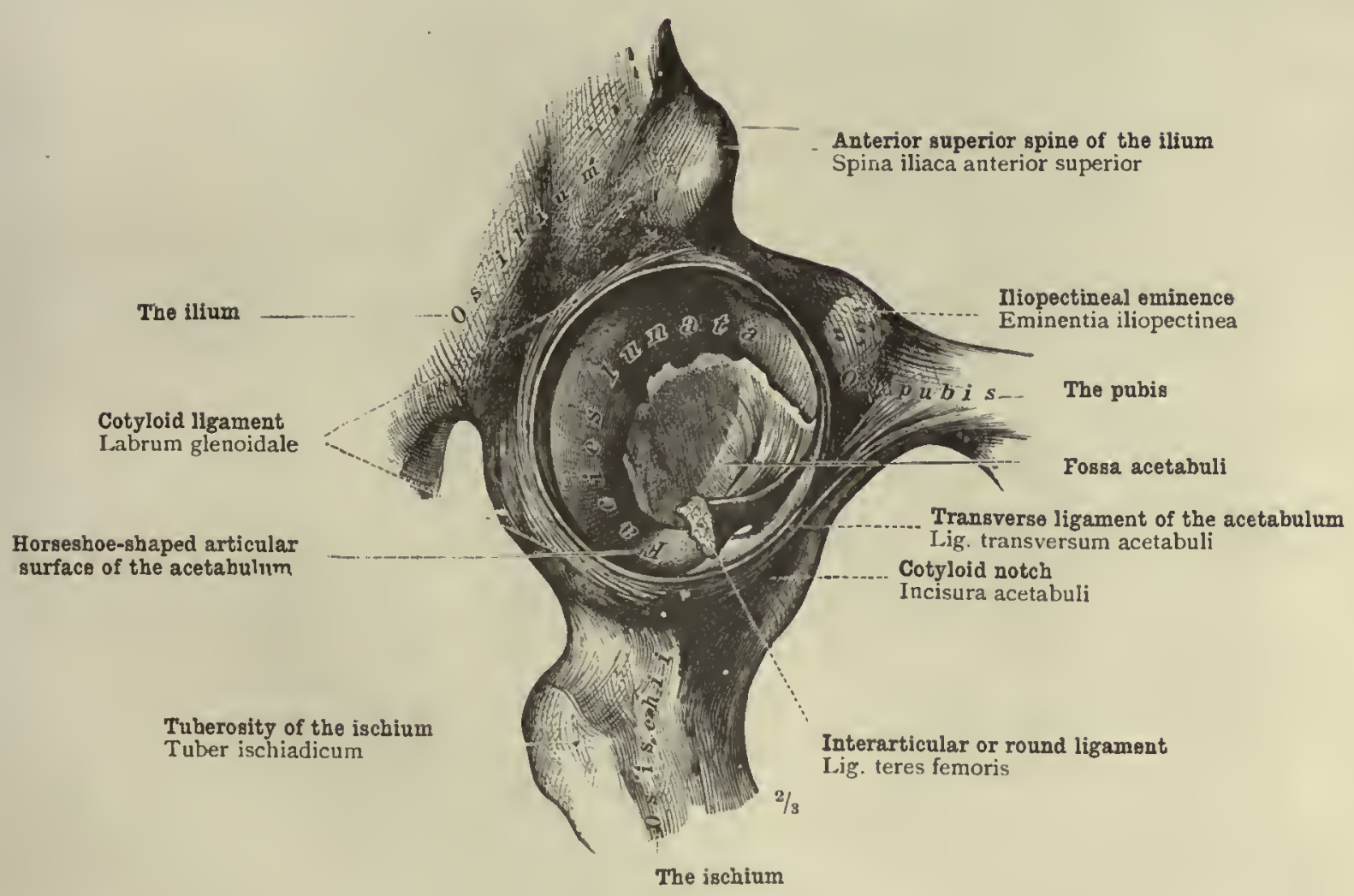

Fig. 463.-Articulatio Cox.e, the Hip-Jolnt: the Acetabulum; Labrum Glenoidale et Ligamentum Transversum Acetabuli, the Cotyloid Ligament and the Transverse Ligament of the Acetabulum. Ligamentum Teres Femoris, the Interarticular or Round Liganent. (View of the Interior of the Socket of the Right Hip-Joint.)

The interarticular or round ligament has been divided close to its attachment to the head of the femur. 


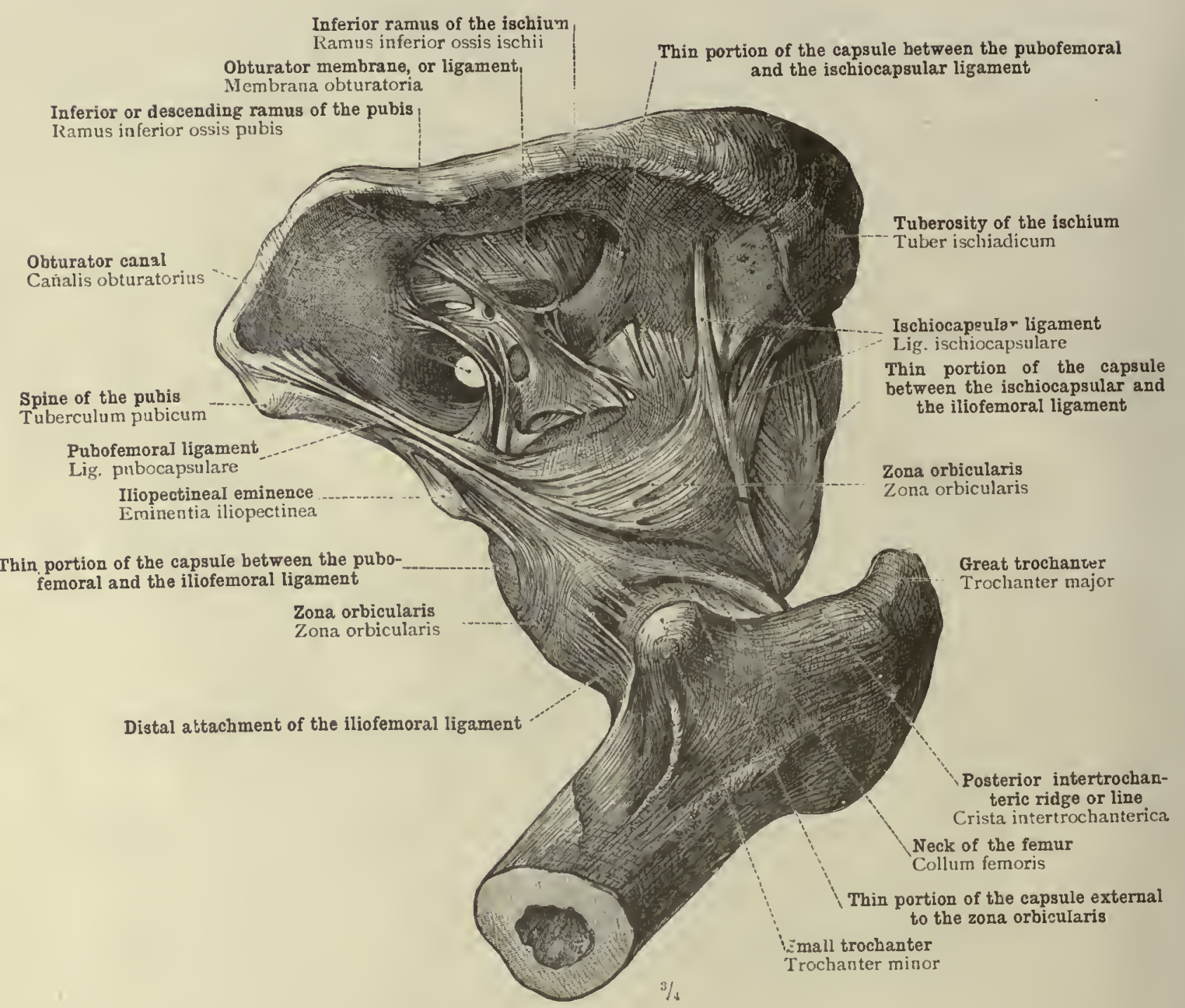

Fig. 464.-Articulatio Coxe, the Hip-joint: Capsula Articularis, the Capsular LigaMent; Zona Orbicularis (sec $p$. 223), and its Relations to the Pubofemoral and Ischiocapsular Ligaments. Membrana Obturatoria et Canalis Obturatorius, Obturator Membrane or Ligament and Obturator Canal. (The Postero-internal Side of THE Right Hip-JoInt SEEN FROM Below.)

The articular cavity has been injected with tallow. 


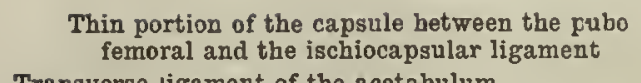

Transverse ligament of the acetabulum Lig. transversum acetabuli

Fossa acetabuli-Fossa acetabuli :

Interarticular or round ligament-Lig. teres femoris?

Horseshoe-shaped articularsurface of

the acetabulum-Facies lunata

Spine of the ischium

Soina ischiadica

Sciatic, or small sciatic, notch

Incisura ischiadica minor

Tuberosity of the ischium Tuber ischiadicum

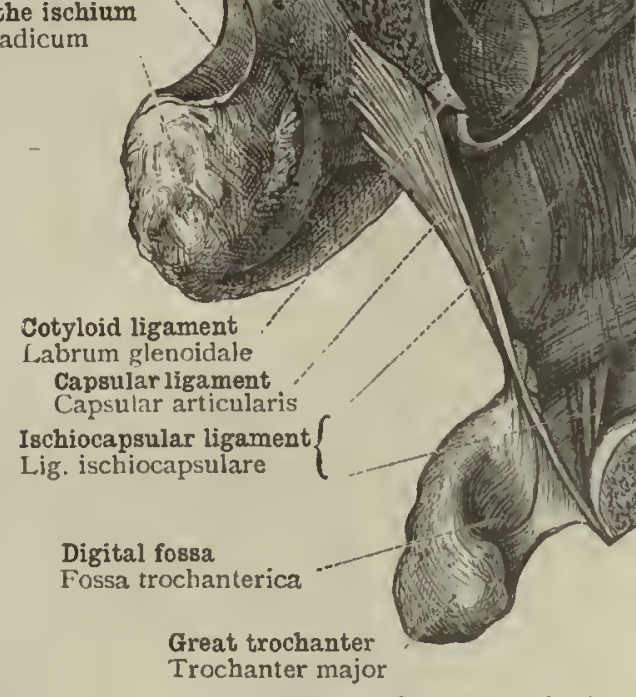

Capsular articularis

schiocapsular ligament Lig. ischiocapsulare

Digital fossa

Great trochanter
Cnt surface of the neck of the femur

Horseshoe-shaped articular surface of the acetabulum surface of the acetabuly
Facies lunata
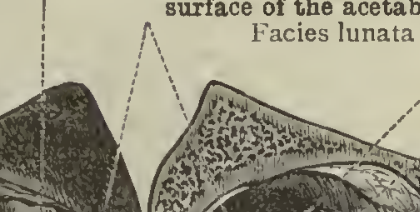

Pubofemoral Ligament-Lig. pubocapsulare Thin portion of the capsule communicatlon between the synovial cavity the Lllopsoss musclo oral ligament $-\mathrm{Lig}$. ilio illofemoral fenorale
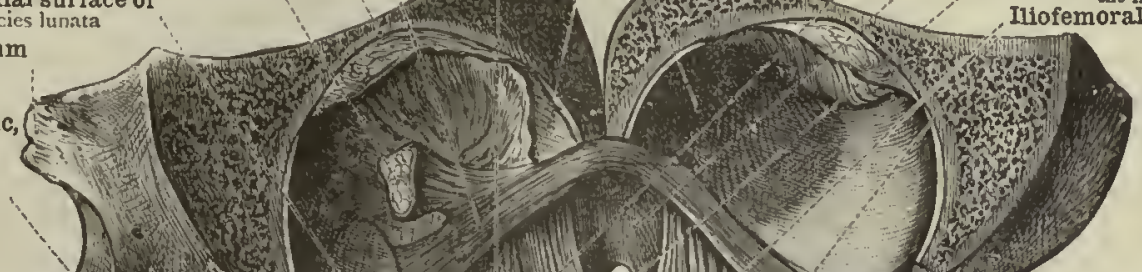

Cotyloid ligament

Labrum glenoidale

Thin portion of the capsule hetween the iliofemoral and the ischiocapsular ligament

Zona orbicularis Zona orbicularis

Capsular ligament Capsula articularis
Great trochanter

Trochanter major

$3 / 4$

Femoral attachment of the iliofemoral ligament

Thin portion of the capsule external to the zona orbicularis

Fig. 465.-Articulatio Coxæ, the Hip-Joint: Zona Orbicularis (see p. 223), and its Relations to the Iliofemoral, PUbofemoral, and Ischiocapsular Ligaments; the Thin Portions of the Capsule, and the Communication between the Synovial Cavity and the Bursa beneath the Tendon of the Illopsoas Muscle; the Acetaiblum, with the Transverse Liganent of the Acetabulum, and the InterARTICULAR OR ROUND LigaMENT.

After the capsule of the right hip-joint had been prepared from without, the joint was fully flexed; the capsule was then divided by a section in the direction of a line passing from the middle of the upper border of the great trochanter to the inner border of the iliopectineal eminence; the ilium was cut away except for that portion of the bone which contributes to the formation of the acetabulum, and the neck of the femur was sawn across just internal to the distal attachment of the capsule; the interarticular ligament was divided close to the head of the femur, and this latter, together with the intracapsular portion of the neck, was removed; the acetabulum and the renaining proximal portion of the femur were divided in two by a continuation of the section already made through the upper wall of the capsule ; the two halves of the acetabulum and the head and neck of the femur were then opened out till the cut surfaces met at a very obtuse angle ; so that the capsule and the cotyloicl ligament were fully exposed from within. The synovial membrane was clissected off, and the inner surface of the capsule cleaned from fat and cellular tissue. 


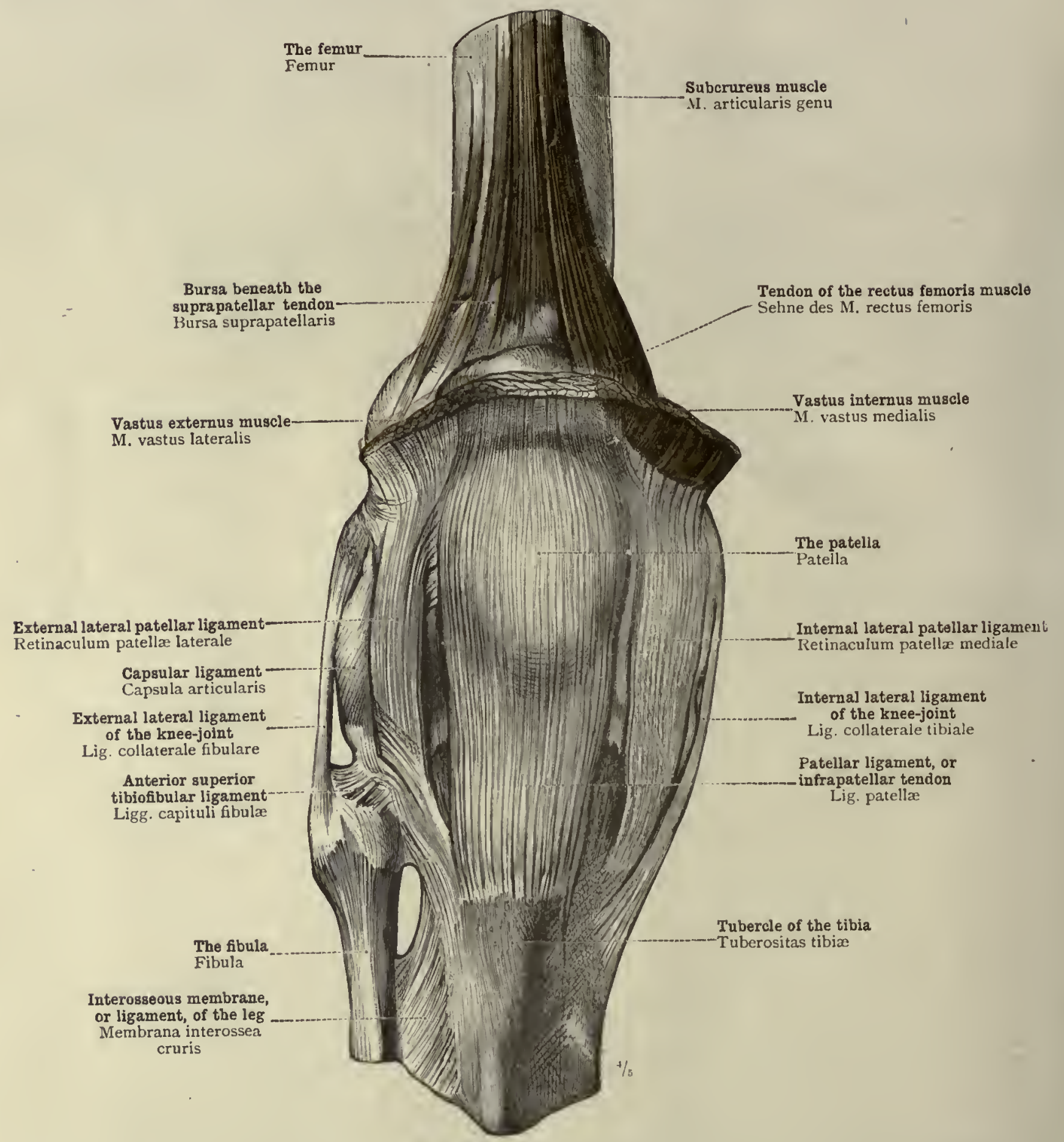

Fig. 466.-Articulatio Genu, the Kinee-joint : Ligamentum Patelle, Patellar Ligament, or Infrapatellar Tendon; Retinacula Patella, Lateral Patellar Ligaments; Ligamenta Collateralia, Lateral Ligaments of the KNeE-Joint. Bursa Suprapatellaris, the Bursa beneath the Suprapatellar Tendon; the Relation of the unusually Large Subcrureus Muscle to the Capsule of the Knee-Joint. Articulatio Tibiofibularis, Superior Tibiofibular Articulation: Ligamenta Capituli Fibule, ANterior Superior Tibiofibular Ligament. (The Right Knee-joint irom Before.)

The synovial cavity has been injected with tallow. 


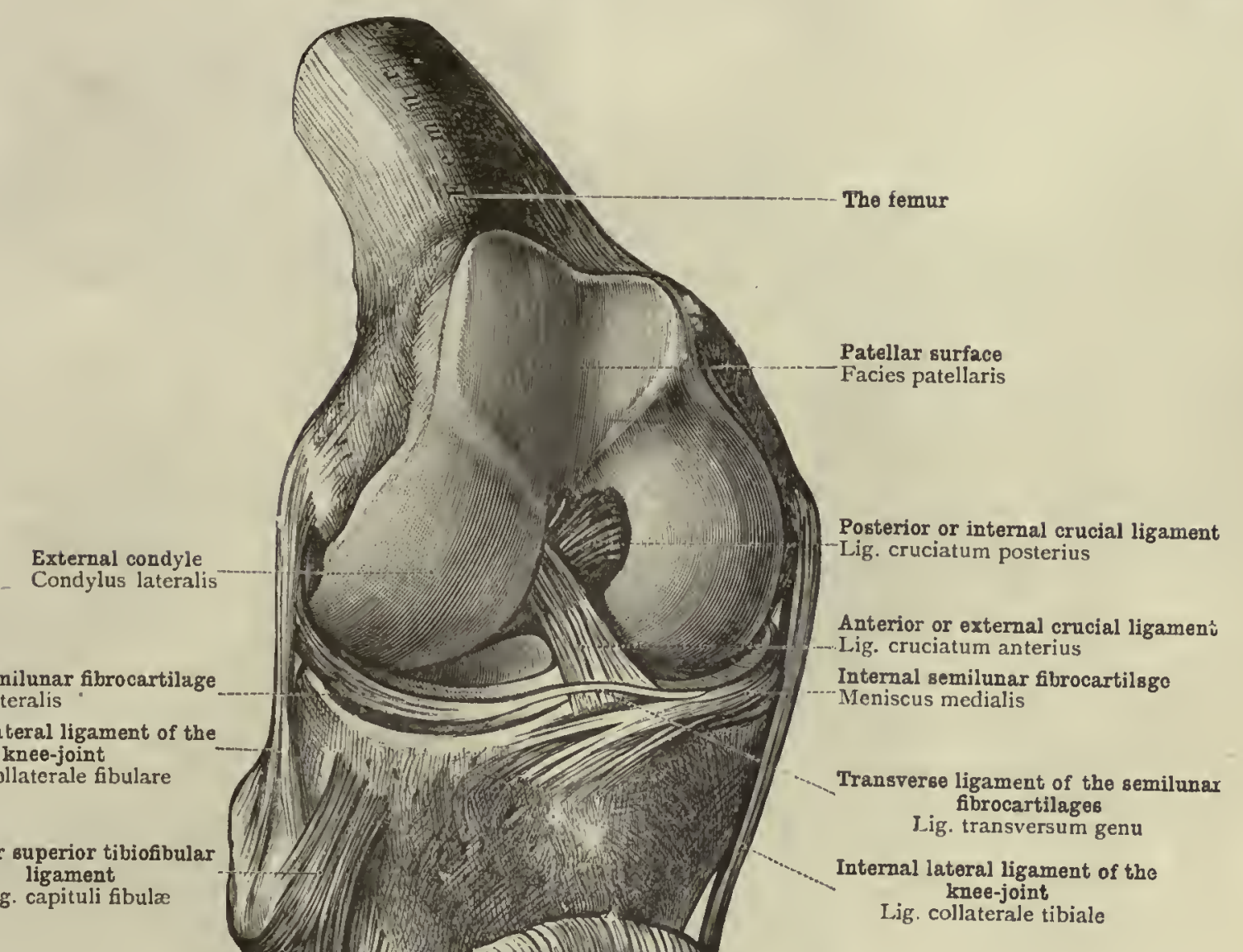
External semilunar fibrocartilage
Meniscus lateralis

External lateral ligament of the Lig. collaterale fibulare

Anterior superior tibiofibular Ligg. capituli fibulx

Interosseous membrane, or ligament, of the leg Membrana interossea cruris

The fibula Fibula

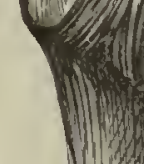

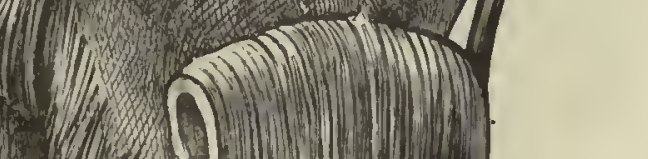

Patellar ligament, or infrapatellar tendon Lig. pateliæ

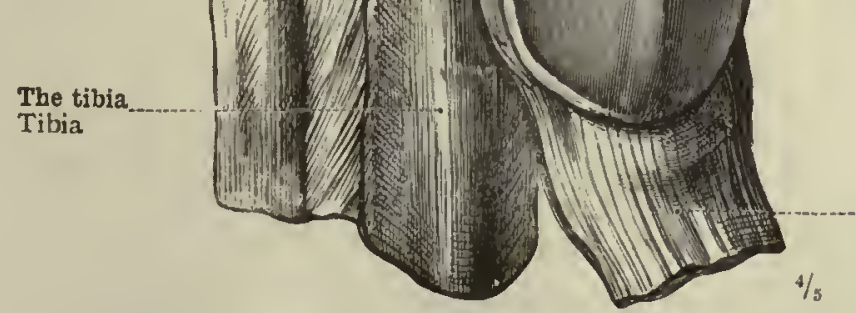

Articular surface of the patella

Facies articularis patellæ

Suprapatellar tendon, or common tendon of the quadriceps extensor cruris muscle

Fig. 467--Articulatio Genu, the Knee-Joint: Ligamenta Collateralia, lateral LigaMents of the KNeE-Joint; Ligamenta Cruciata, Crucial Ligaments; Ligamentum Patella, Patellar Ligament, or Infrapatellar Tendon. Articulatio Tibiofibularis, Superior Tibiofibular Articulation: Ligamenta Capituli Fibule, Anterior Superior Tibiofibular Ligament. (The Right Knee-Joint seen from Before and Without.)

The capsular ligament has been removed from the front of the joint between the two lateral ligaments, and the patellar ligament has been turned downwards. 


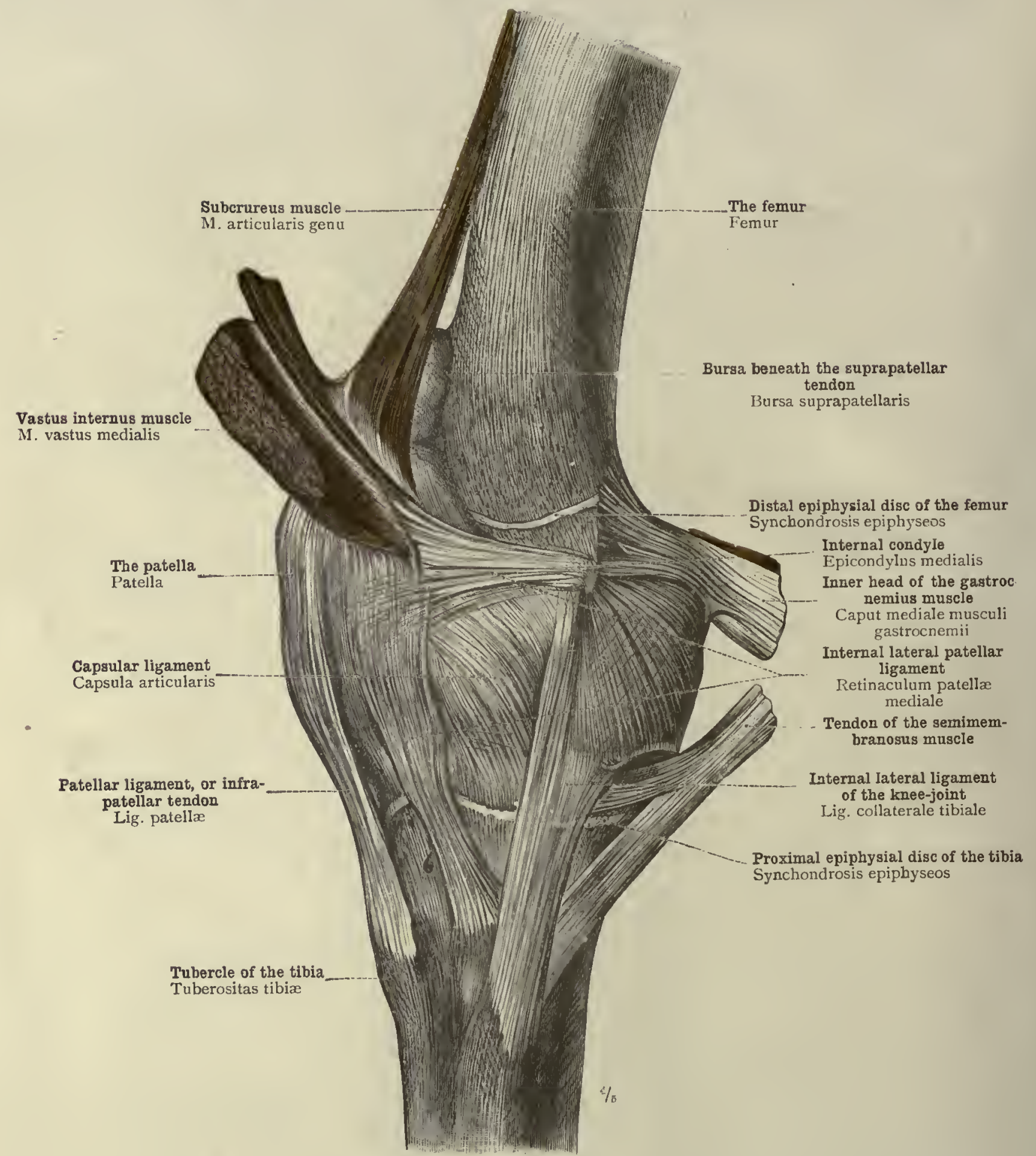

Fig. 468.-Articulatio Genu, the Knee-Joint: Capsula Articularis, Capsular Ligament, and the Relations of the Subcrureus Muscle to this Liganent; Bursa Suprapatellaris, the Bursa beneath the Suprapatellar Tendon. Ligamentum Collaterale Tibia, Internal Lateral Ligament of the Knee-Joint; Liganentum Patella et Retinaculum Patelle Mediale, Patellar Ligament, or Infrapatellar Tendon, and Internal Lateral Patellar Ligament. Relations of the Epiphysial Discs to the ARTICULATION.

The same preparation as that of Fig. 466, seen from within. 


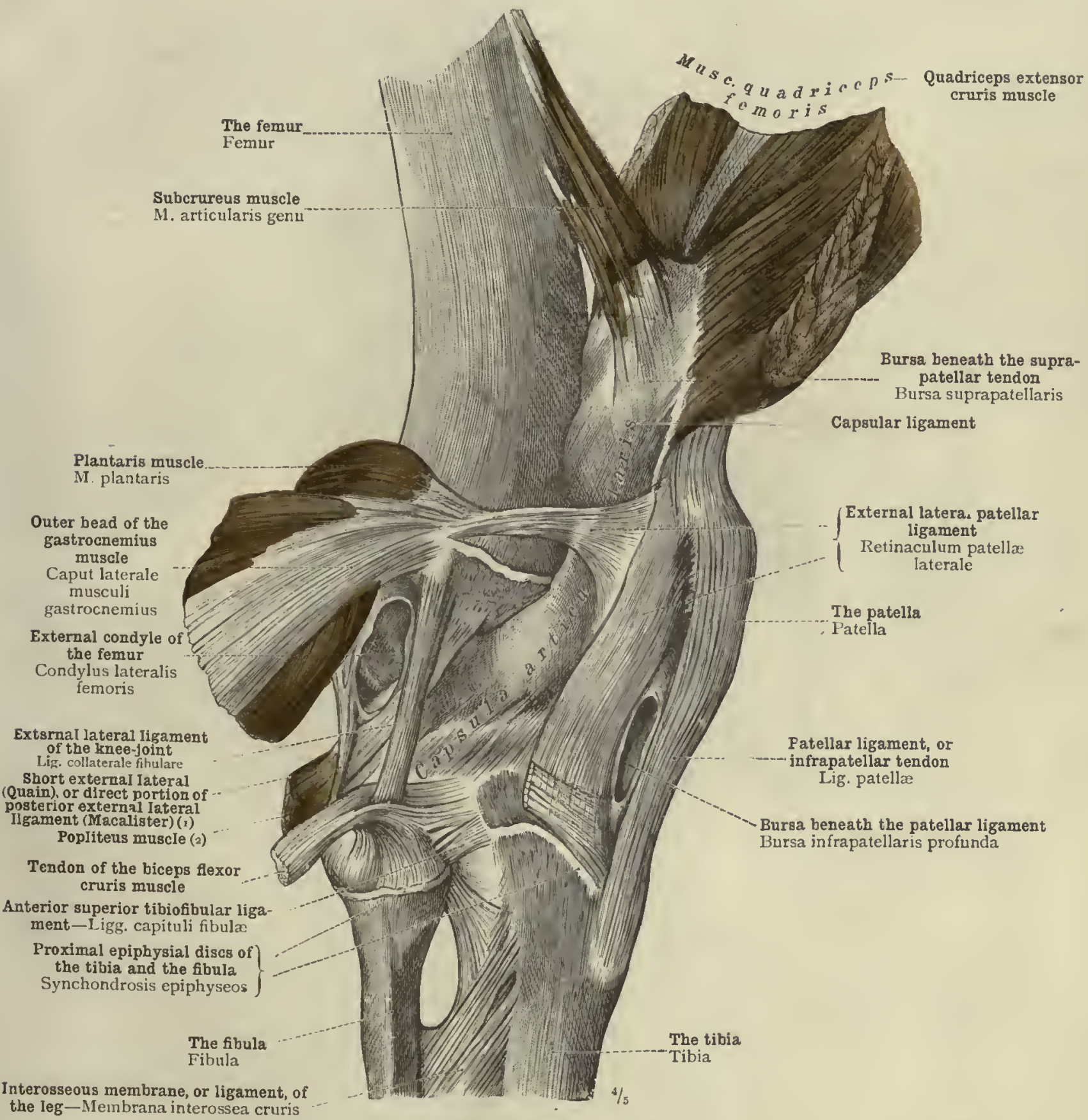

the leg-Membrana interossea cruris

(s) Retinaculum ligamenti arcuati

(2) M, popliteus

Fig. 469.-Articulatio Genu, the Knee-Joint: Capsula Articularis, Capsular ligament; Bursa Suprapatellaris, and the Relations of the Quadriceps Extensor Cruris Muscle to the Same. Ligamentum Collaterale Fibulare, External lateral Ligament of the Knee-Joint. Ligamentum Patella et Retinaculum Patelle Laterale, Patellar Ligament, or Infrapatellar Tendon, and External Lateral Patellar liganent; the Relations of the Latter to the Plantaris Muscle and to the Outer Head of the Gastrocnemius Muscle. Bursa Infrapatellaris Profunda, Bursa ibeneath the Patellar Ligament. Articulatio Tibiofibularis, Superior Tibiofibular Articulation. Ligamenta Capituli Fibule, Anterior Superior Tibiofibular Ligament. Relations of the Epiphysial Discs to Both the JoInts.

The same preparation as that of Figs. 466 and 468 , secn from the outer side. The synovial cavity of the knee-joint has been opened behind the external lateral ligament of the knee-joint, and the bursa beneath the patellar ligament has also been opened. 


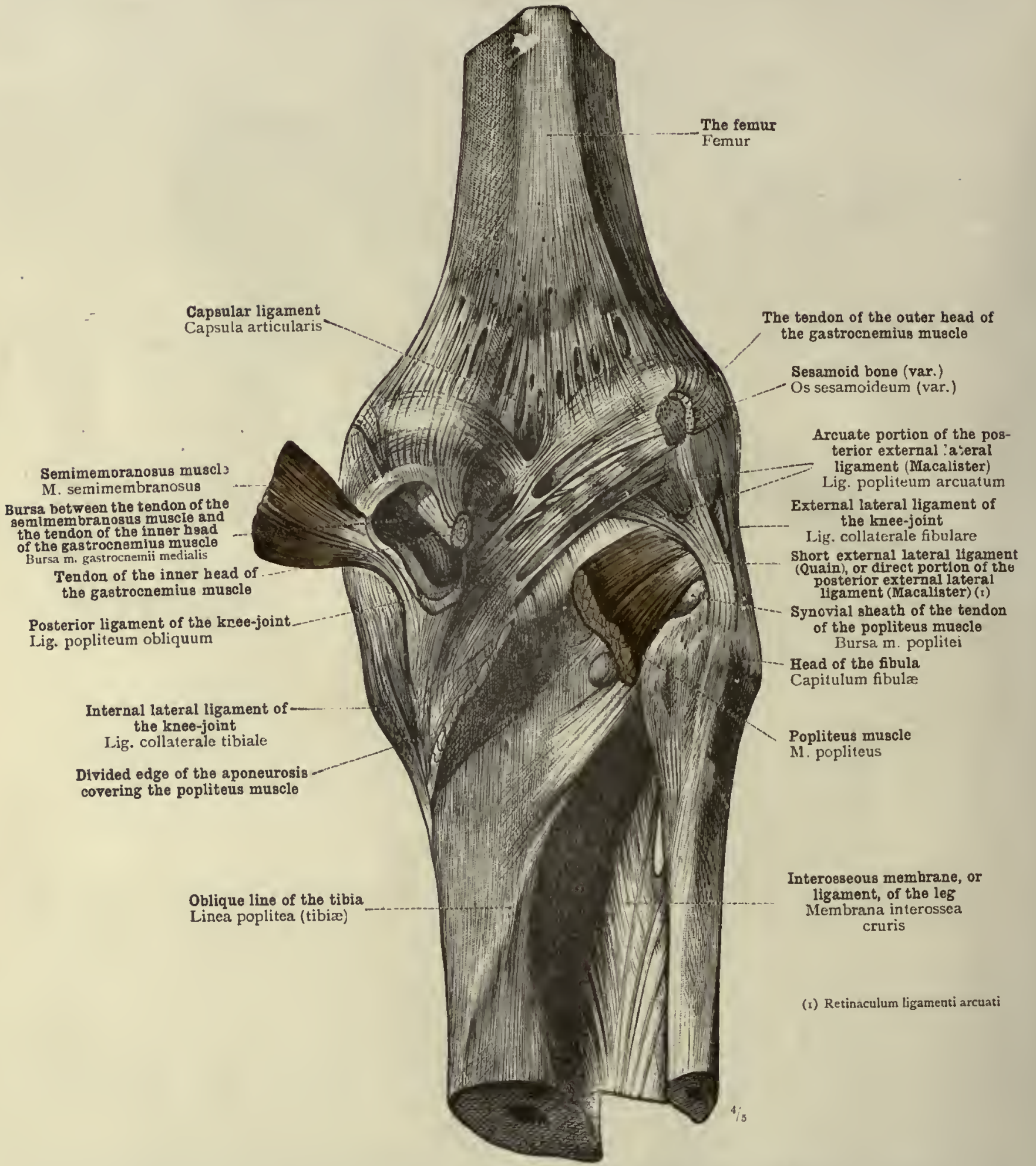

Fig. 470.-Articulatio Genu, the Knee-Joint : Capsula Articularis, Capsular Ligament ; Ligamentua Popli-

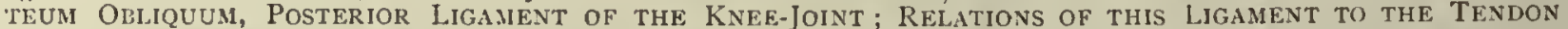

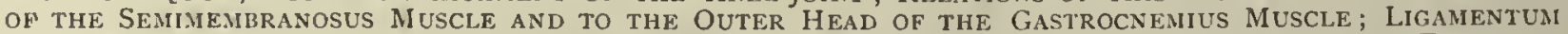
Popliteum Arcuatum et Retinaculum Ligamenti Arcuati, ArCuate Portion of the Posterior External

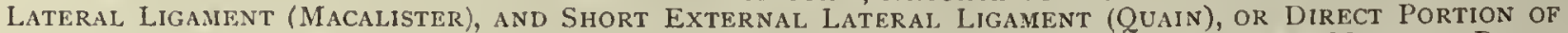
the Posterior External Lateral Ligament (Macalister). Bursa Musculi Gastrocnemit Menialis, Bursa

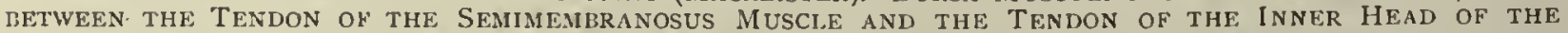
GASTROCNEMIUS MUSCle, COMMUNICATING WITH THE KNEE. JOINT AND HAVING A COMMON CAVITV WITH THE Bursa between the Tendon of the Semimembranosus Muscle and the KNEe-Joint. Bursa Musculi Poplitei, Synovial Sheath of the Tendon of the Popliteus Muscle. (The Right Knee-Joint, seen from BEHIND.) 


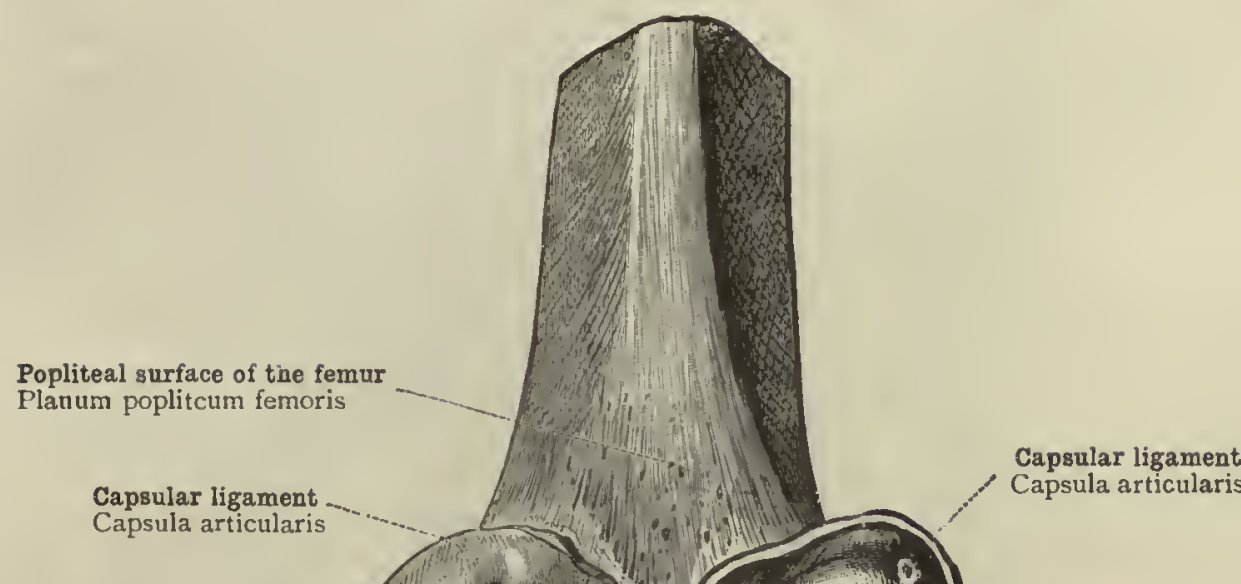

Internal condyle of the femur Condylus medialis femoris Posterior or ascending band of the external semilunar fibrocartilage (Ellis), or ligament of Wrisberg (Macalister)

Lig. menisci lateralis (Roberti) Internal lateral ligament of the kneo-joint

Lig. collaterale tibiale

Internal semilunar fbrocartilage

Meniscus medialis

Posterior border of the superior articular surface of the tibia Margo infraglenoidalis tibix Capsular ligament

Capsular ligament
Capsula articularis

Posterior or internal crucial ligament Lig. cruciatum posterius

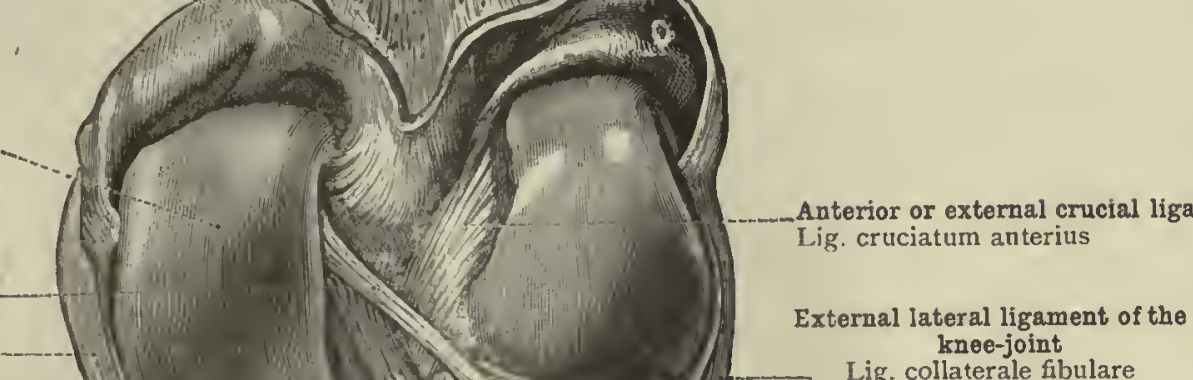

knee-joint Lig. collaterale fibulare External semilunar fibrocartilago Meniscus lateralis

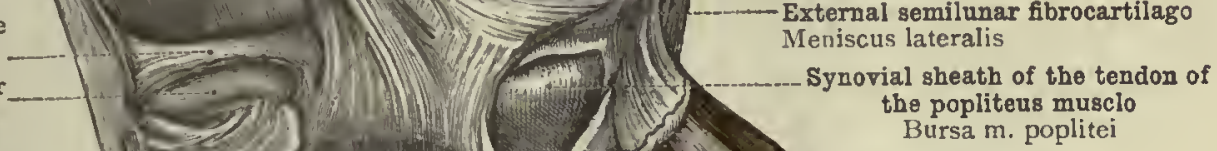

.

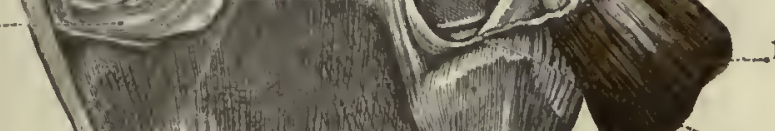

Popliteus muscle

M. popliteus

Communicarion between the synovial cavity of the superior tibiofibular articulation and the synovial sheath of the tendon of the popliteus muscie

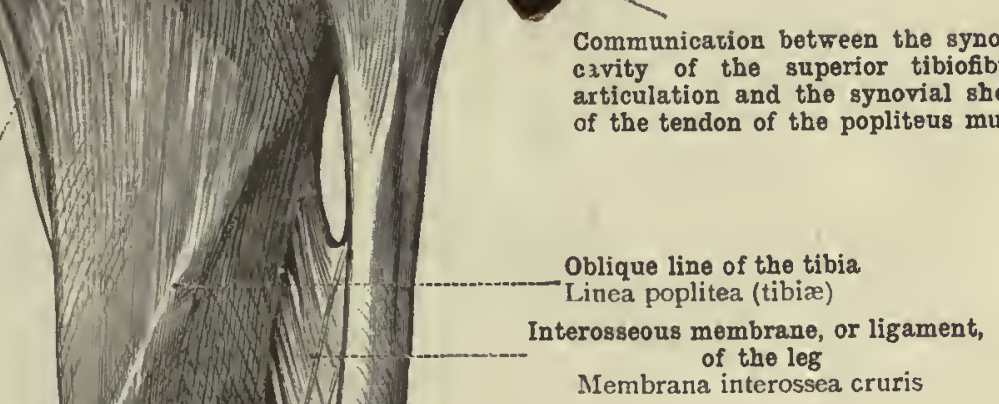

The fibula

Fibula

Fig. 471.-Articulatio Genu, the KneE-Joint: Ligamenta Cruciata, Crucial Ligaments, and Ligamentum Menisci Lateralis, Posterior or Ascending Band of the External Semilunar Fibrocartilage (Ellis)

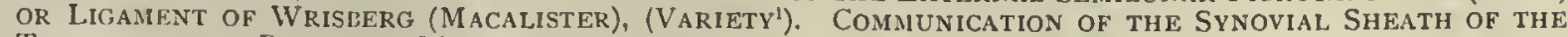
Tendon of the Popliteus Muscle with the Synovial Cavities of the KNeE-Joint and of the Superior Tibiofibular ARticulation. (The Right KNeE-Joint, SEen From Behind.)

The posterior portion of the capsular ligament, between the external and internal lateral ligaments, has been removed, except for a strip left above close to the femoral attachment, which has been turned upwards; the synovial sheath of the tendon of the popliteus muscle has been opened at its inner side, and its posterior wall has been iurned outwards with the tendon and the proximal portion of the popliteus miscle.

* Though this band is called a variety by Toldt, it is, in fact, usually present, but its situation varies; inasmuch as it passes, sometimes behind (as her-), and sometimes before, and sometimes as a double band behind and before, the posterior or internal crucial ligament. Its strength and thickness varies much, but it is seldom entirely wanting. - TR. 
Bursa beneath the suprapatellar tendon

Bursa suprapatellaris
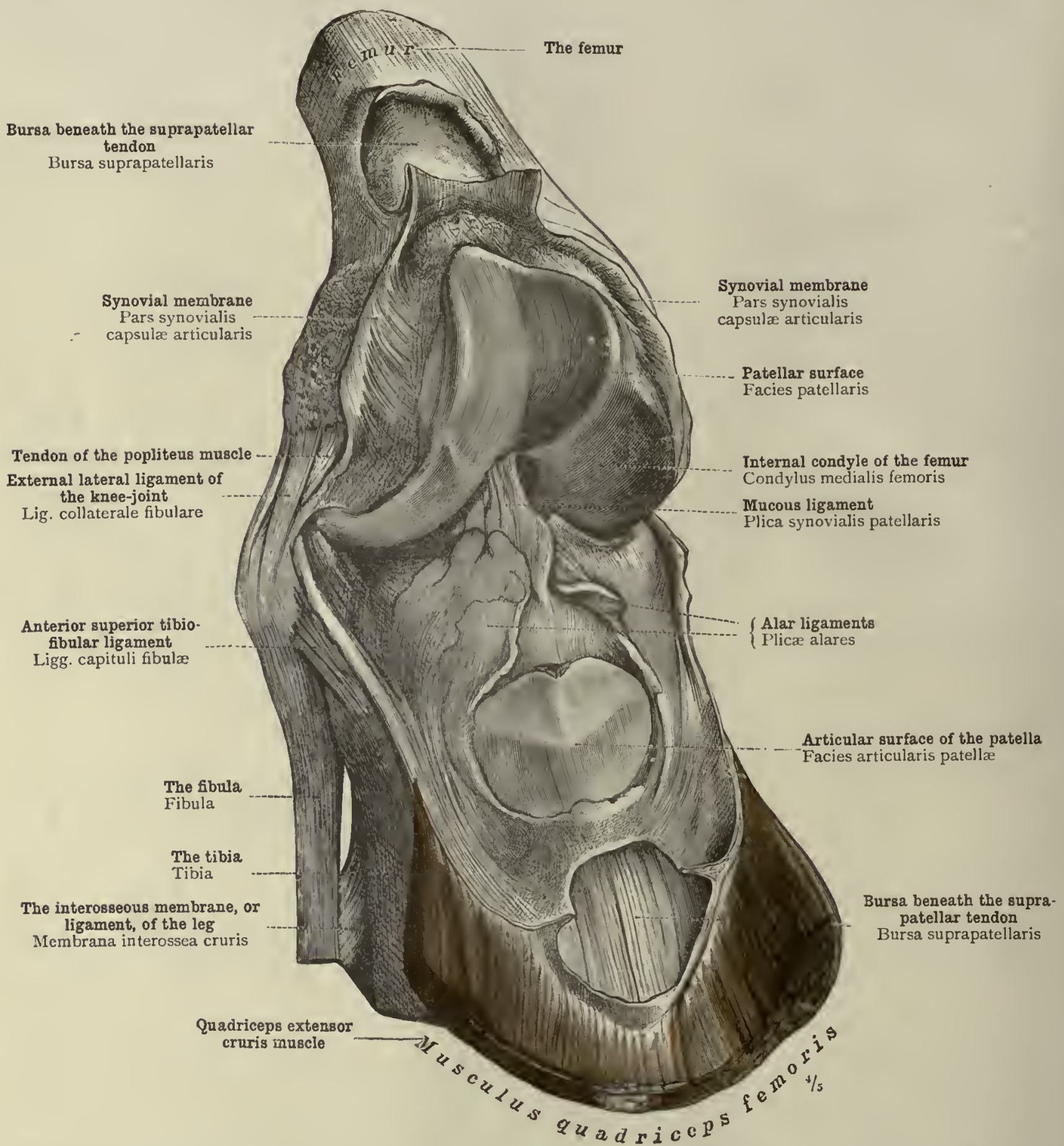

Fig. 472.-Articulatio Genu, the Knee-Joint: Pars Synovialis Capsule Articularis, Synovial Membrane of the Knee-Joint; Plica Synovialis Patellaris, Mucous Ligament; Plica Alares, Alar Ligaments; Bursa Suprapatellaris, Bursa beneath the Suprapatellar Tendon. (The Right Knee-Joint, seen FROM BEFORE AND IVITHOUT.)

The joint was first injected, and the injected nuaterial allowed to solidify; the capsule of the joint was then prepared from without, the quadriceps extensor cruris muscle being left intact; subsequently the joint was opened by a section passing through the quadriceps muscle and the upper part of the front of the capsule from one lateral ligament to the other close to the attachment of the capsule to the femur, and the anterior wall of the joint together with the distal portion of the quadriceps extensor nuuscle was turned down. The quadriceps was divided at a soniewhit bigher level than the capsule, and the bursa beneath the suprapatellar tendon divided is the frontal plane, to show the communication of this bursa with the joint. 


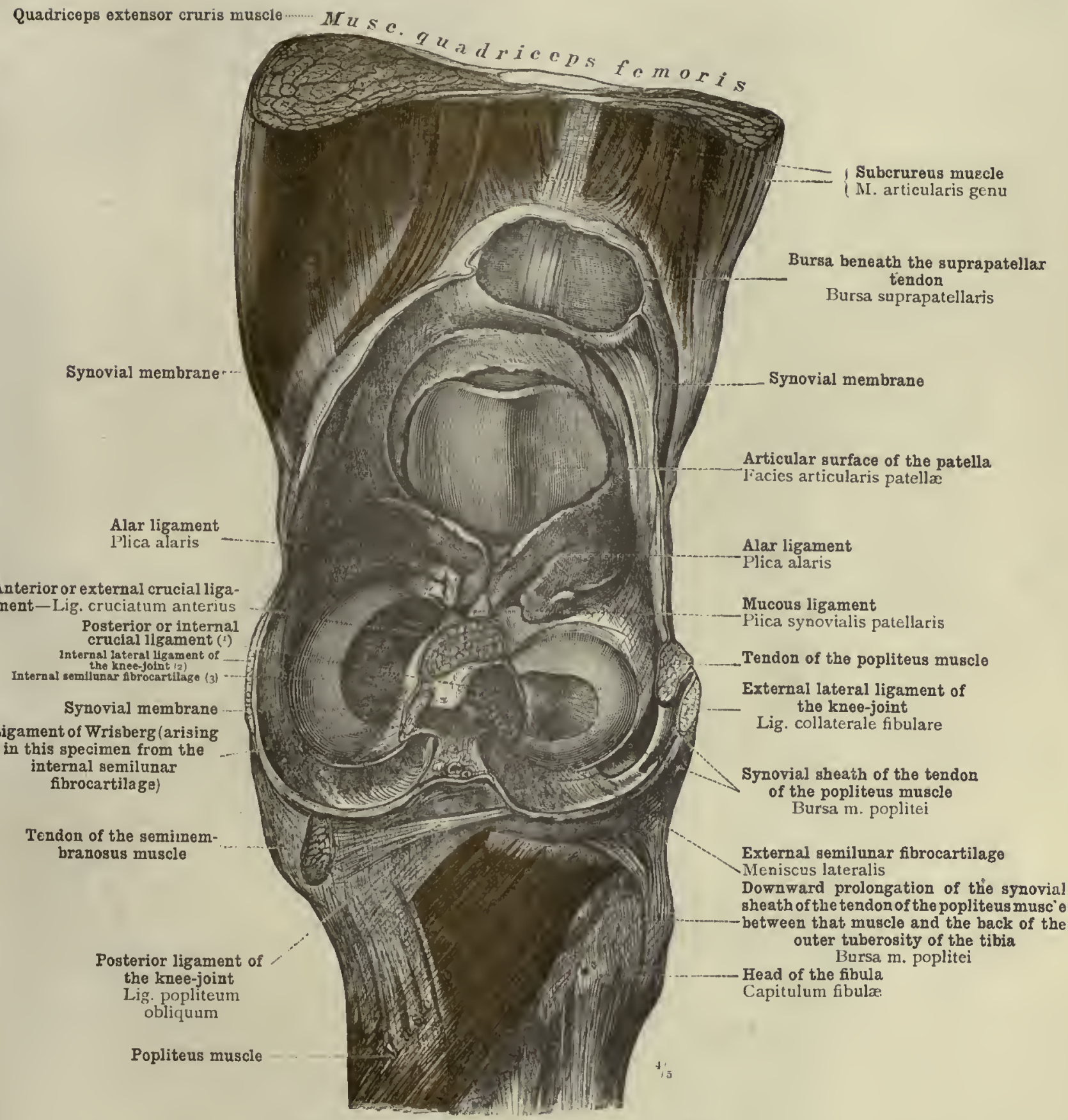

(1) Lig. cruciatum po teriu

(2) Lig. collaterale tibiale

(3) Meniscus medialis

Fig. 473.-Articulatio Genu, the Knee-Joint: The Semilunar Fibrocartilages, the Alar Ligaments, and the Mucous Ligament; the Insertion into the Synovial Membrane of the Subcrureus Muscle; the Extension of the Symovial Membrane of the KneE-Jont to form the Synovial Sheath of the Tendon of the Popliteus Muscle and the Bursa between that Muscle and the Posterior Surface of the Outer Tuberosity of the Tibia, and the Relation of the Synovial Sheath of the Tendon to the External Lateral Ligament of the Knee-Joint. (The Proximal Extremities of the Bones of the Leg with the Anterior IVall of the Capsule of the Knee-joint seen fron Behind.)

After the joint had been injected, and the injected material allowed to solidify, the capsule of the joint was prepared from without, the quadriceps extensor cruris muscle being left intact; the lateral ligaments and the tendon of the popliteus nuscle were then divided, and the capsule was opened behind and on eather side at a higher level than the senilunar carrilages, and was divided in front along the line of jts reflection on to the anteriur surface of the femur; after division of the crucial lizani nts, the femur wis removed.

\section{Articulatio genu-The knee-joint.}




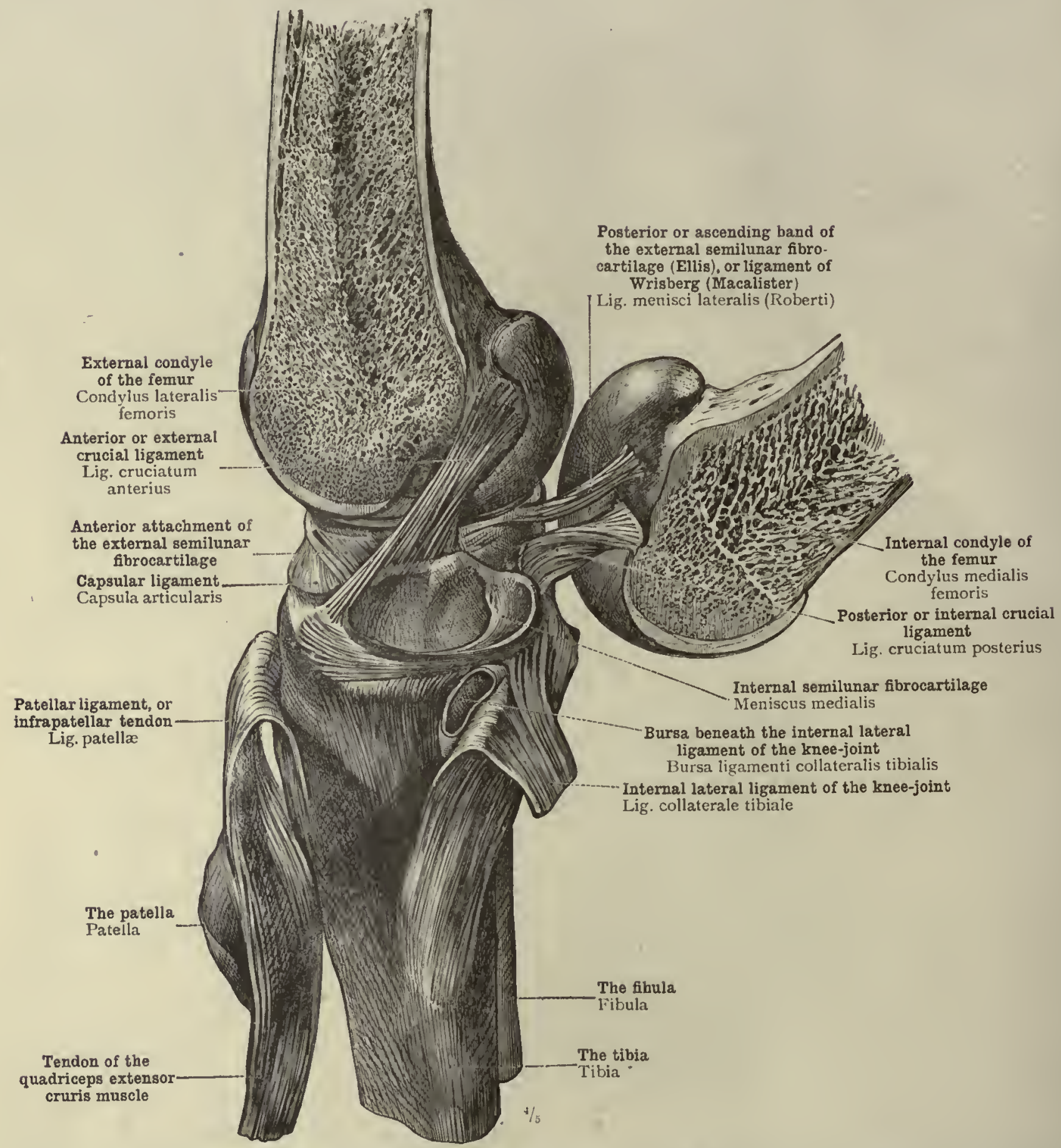

Fig. 474.-Articulatio Genu, the Knee-joint : Crucial Ligaments and Ligament of Wrisberg; Bursa beneath the Internal Lateral Liganent of the KneE-Joint. (The Right KineeJOINT SEEN FROM THE INNER SIDE.)

The capsule was removed, the patellar ligament and the internal lateral ligamient were turned down. wards: the femur was divided sagittally through the middle of the intercondylar fossa, and the external condyle placed in the position it occupies during exten-ion of the knee-joint, while the internal condyle was turned backwards and rotated on its median axis to the extent of $180^{\circ}$. 
Transverse ligament of the semilunar fibrocartilages

Lig. transversum genu
Anterior attachment of the internal semilunar fibrocartilage

External tubercle of the spine of the tibia

Tuberculum intercondyloideum laterale

Capsular ligamer $\tau$ Capsula articularis

External semilunar fibrocartilage Meniscus lateralis

Synovial sheath of the tendon of the popliteus muscle

Bursa m. poplitei

Anterior superior tibiofibular. ligament

Ligg. capituli fibula

Styloid process of the fibula Apex capituli fibulx

commulcation between the synovial cartity of the superlor tiblofibular articulatlon and the eynovial the ath of the tendon of the popltte us muscle.

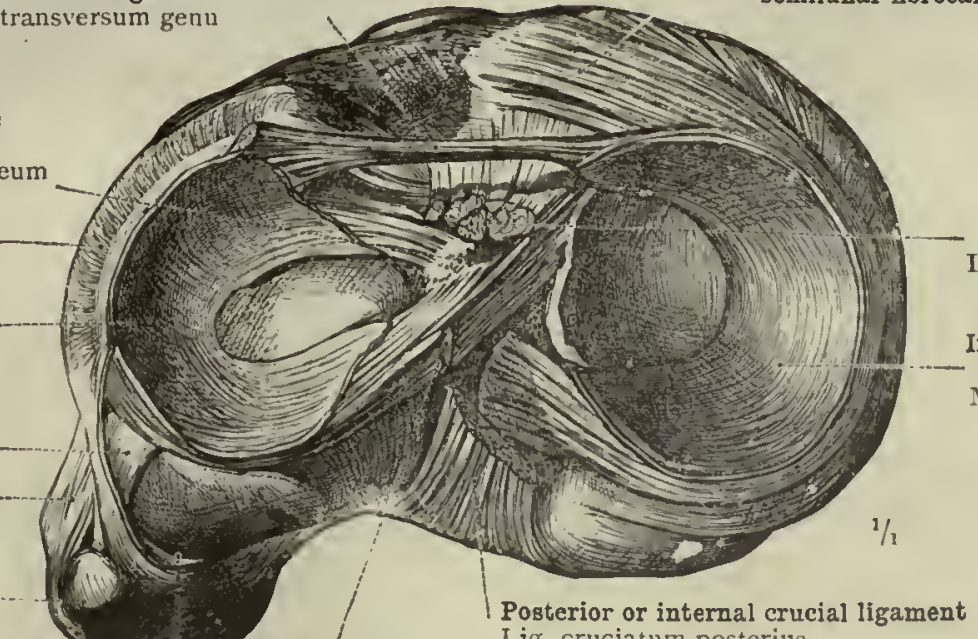

Lig. cruciatum posterius

Ligament of Wrisherg

Lig. menisci lateralis (Roberti)

1 See note to p. 233.

Fig. 475.-The Distal. Articular Surfaces of the KneE-Joint: The Interarticular Semilunar Fibrocartilages, and the Extension of the Anterior Extremities of these in the Transverse Ligament of the Semilunar Fibrocartilages. The Communication between the Superior Tibiofibular Articulation and the Synovial Sheath of the Tendon of the Popliteus Muscle. (The Proximal Extremity of the Left Tibia with the Semilunir Fibrocartilages and the Head of the Fibula, seen from Above.)

The capsule was divided above (proximal to) the semilunar fibrocartilages, the crucial ligaments were cut across, and the femur was removel.

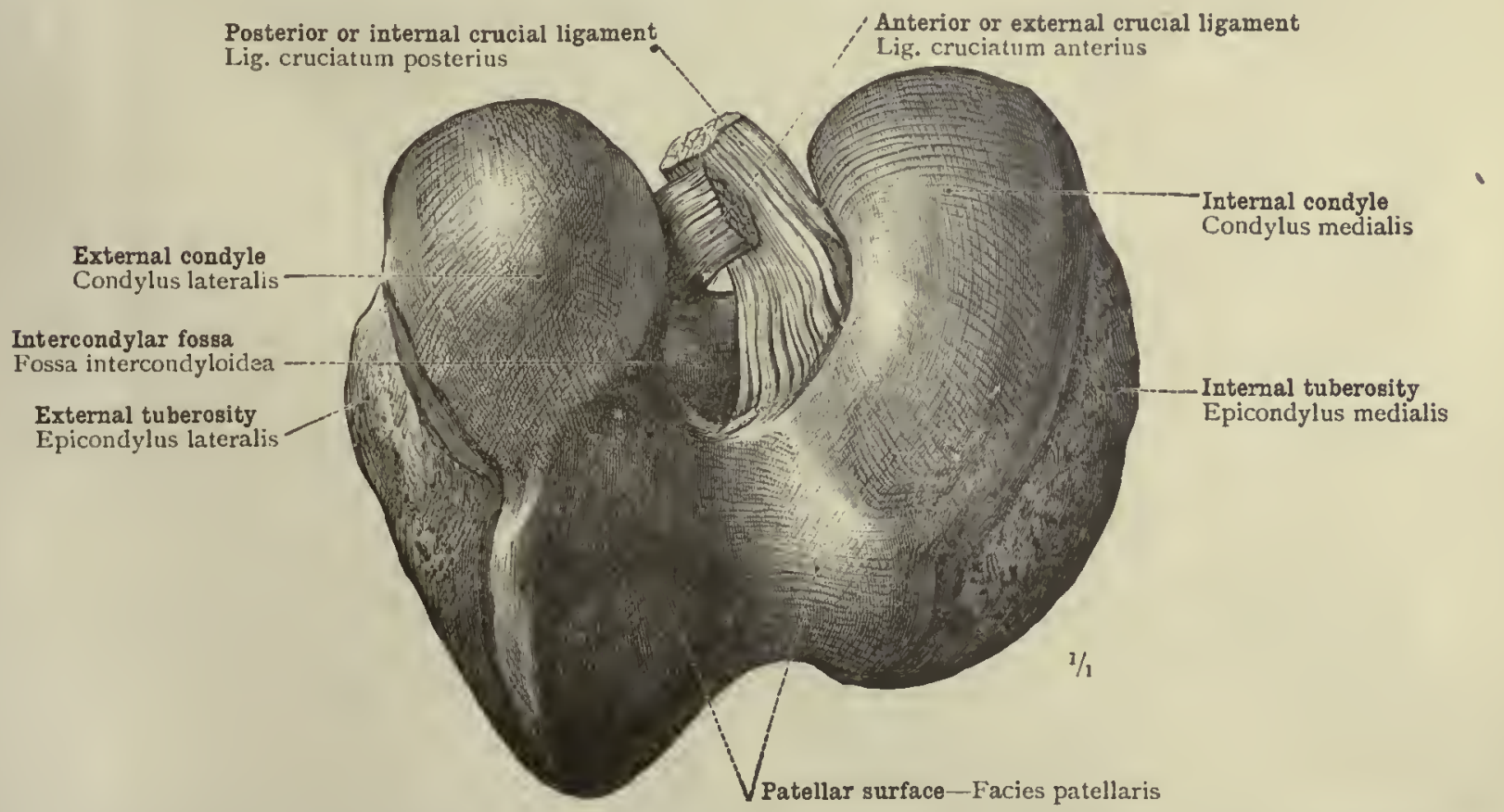

Fig. 476.-The Proximal Articular Surfaces of the KneE-Jornt, and the Femoral Attachments of the Crucial Liganents.

The distal extremity of the femur removed from the preparation shown in Fig. 475, seen from below. 
Anterior superior tibiofibular ligament Ligg. capituli fibulæ

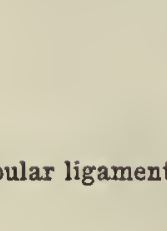

Extermal surface Facies lateralis

Interosseous membrane, or ligament, of the leg. Membrana interossea cruris

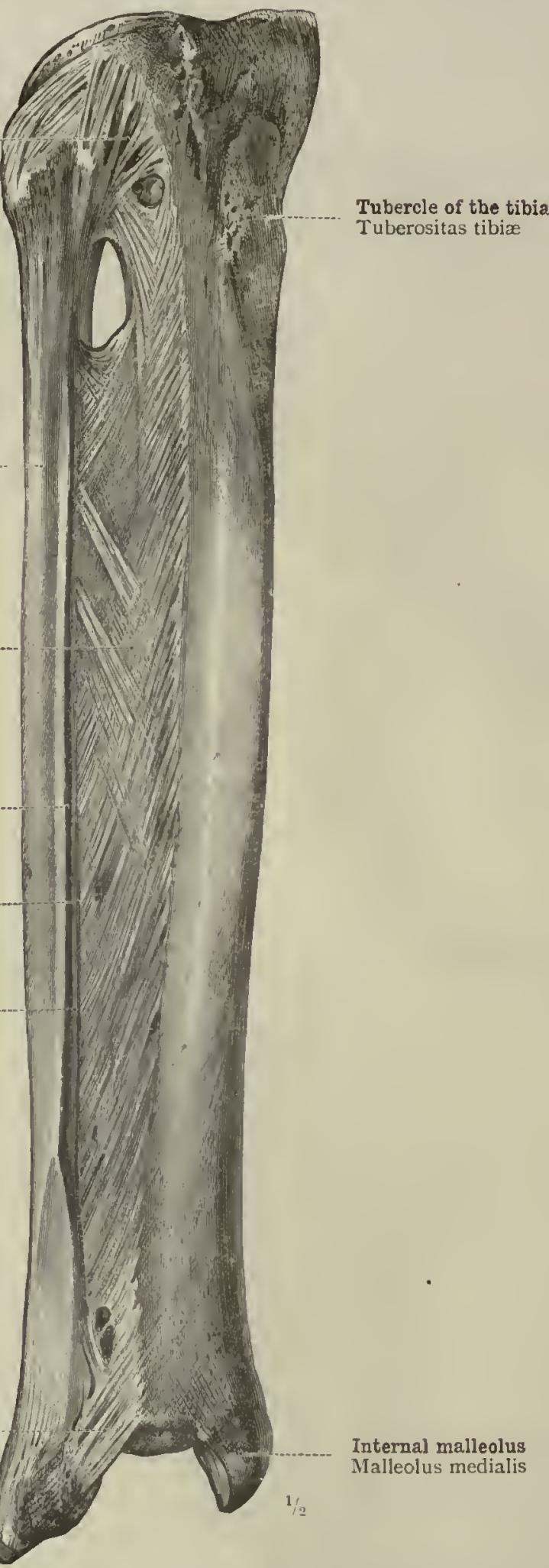

Fig. 477.-Articulatio Tibiofibularis et Syndesmosis Tibiofibularis, the Tibiofibular Articulations. The Interosseous Membrane, or Ligament, of the RigitT Leg; the Anterior Superior and ANterior Inferior Tibiofibular Ligaments. (Seen from Before.) 


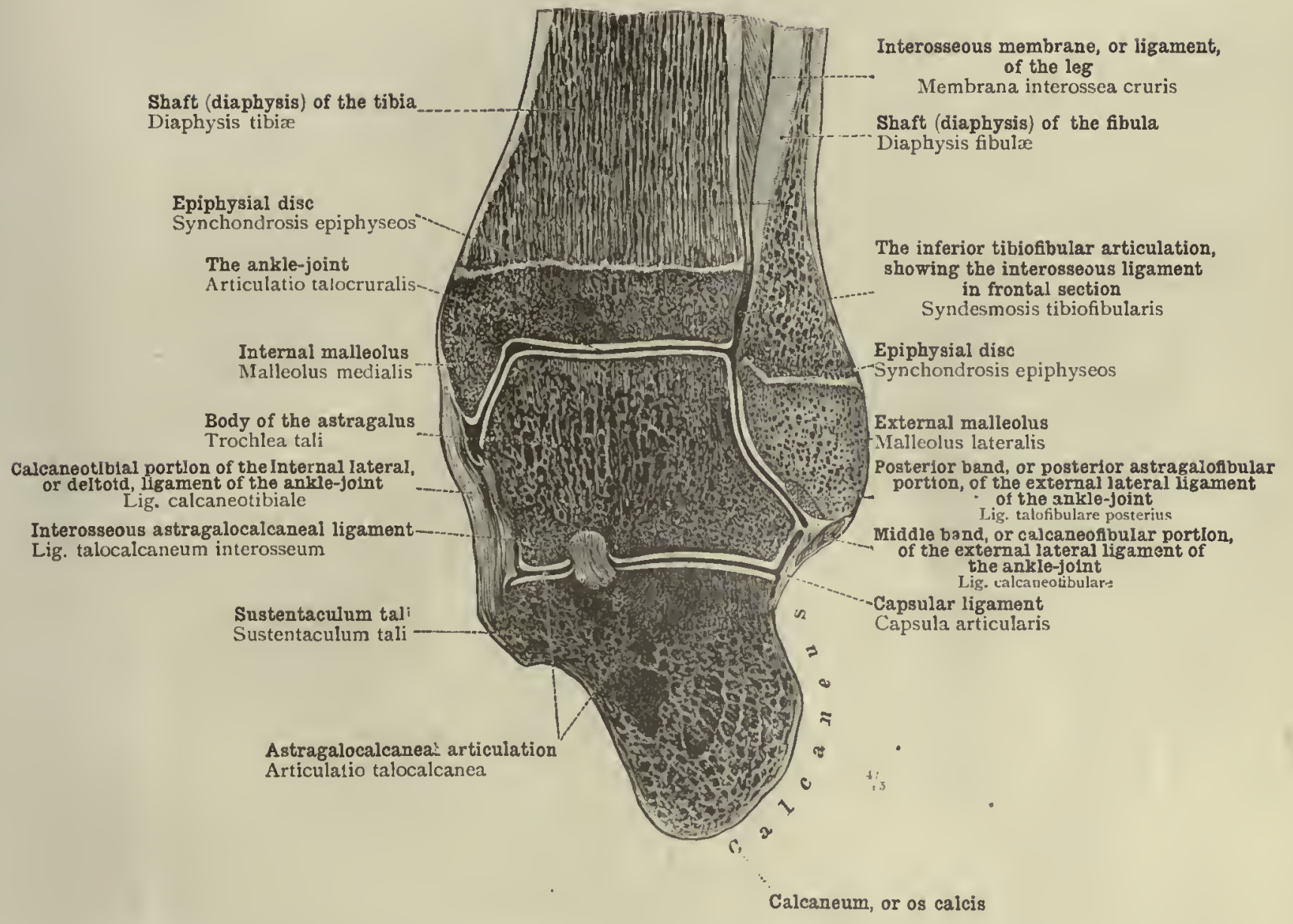

Fig. 478.-Articulationes Talocruralis et Talocalcanea, the Ankle-Joint and the Astragalocalcaneal Articulation; Syndesmosis Tibiofibularis, Inferior Tibiofibular Articulation, showing the Interosseous Ligament. The Relations of the Distal Epiphysial Discs of the Tibia and the Fibula to the Ankle-Joint. (The AnkleJoint and the Astragalocalcaneal Articulation of the Right Leg, divided in a Vertical Plane closely approximating the Frontal Plane; Posterior Surface of the Anterior Segment.)

The plane of section passes through the lowermost parts of the lateral portions of the superior articular surface of the astragalus.

Articulationes pedis-The articulations of the foot. 


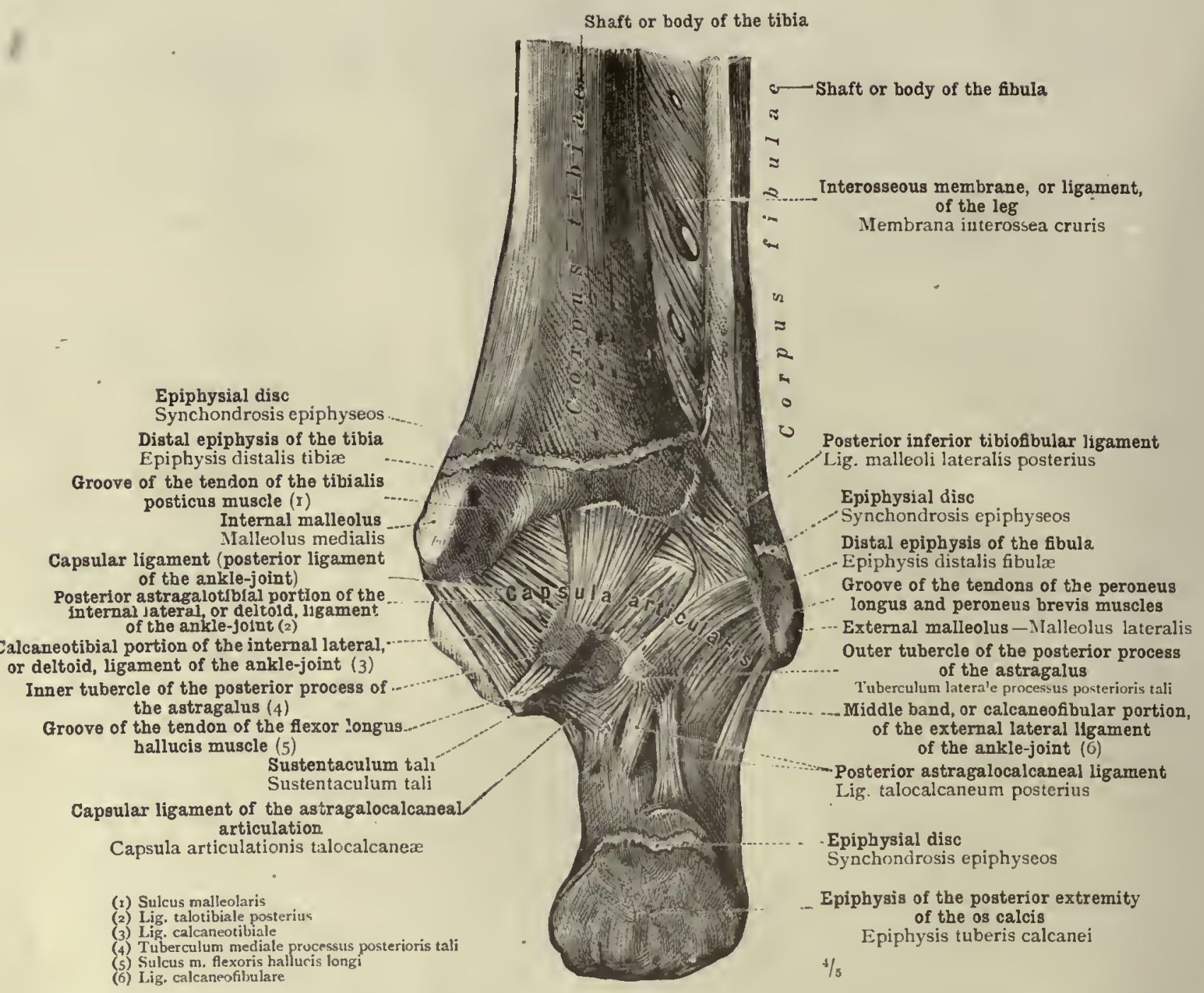

Fig. 479.- -The Capsular Ligaments and the Super ricial Posterior Ligaments of the Ankle-Joint and of the Astragalocalcaneal Articulation. The Relations of the Distal Epiphysial. Discs of the Tibia and Fibula tu the Ankle-Joint. The Posterior Portions of the Lateral Ligaments of the Ankle-Joint: Ligamentum Talotibiale Posterius, the Posterior Astragalotibial Portion of the Internal Lateral, or Deltoid, Ligament of the Ankle-Joint; Ligamentum Calcaneotibiale, the Calcaneotibial Portion of the Internal Lateral, or Deltoid, Ligament of the Ankle-Joint; Ligamentum Calcaneofibulare, the Middle Band, or Calcaneofibular Portion, of the External. Lateral Ligament of the Ankle-Joint. Ligamentum Talocalcaneum Posterius, the Posterior Astragalocalcaneal Liganent.-Sindesmosis Tibiofibularis: Ligamentum Malleoli Lateralis Posterius, the Posterior Inferior Tibiofibular Ligament. (The Anile-Joint and the Astragalocalcaneal. Articulation of the RIGHT LEG, SEEN FROM BEHIND.) 


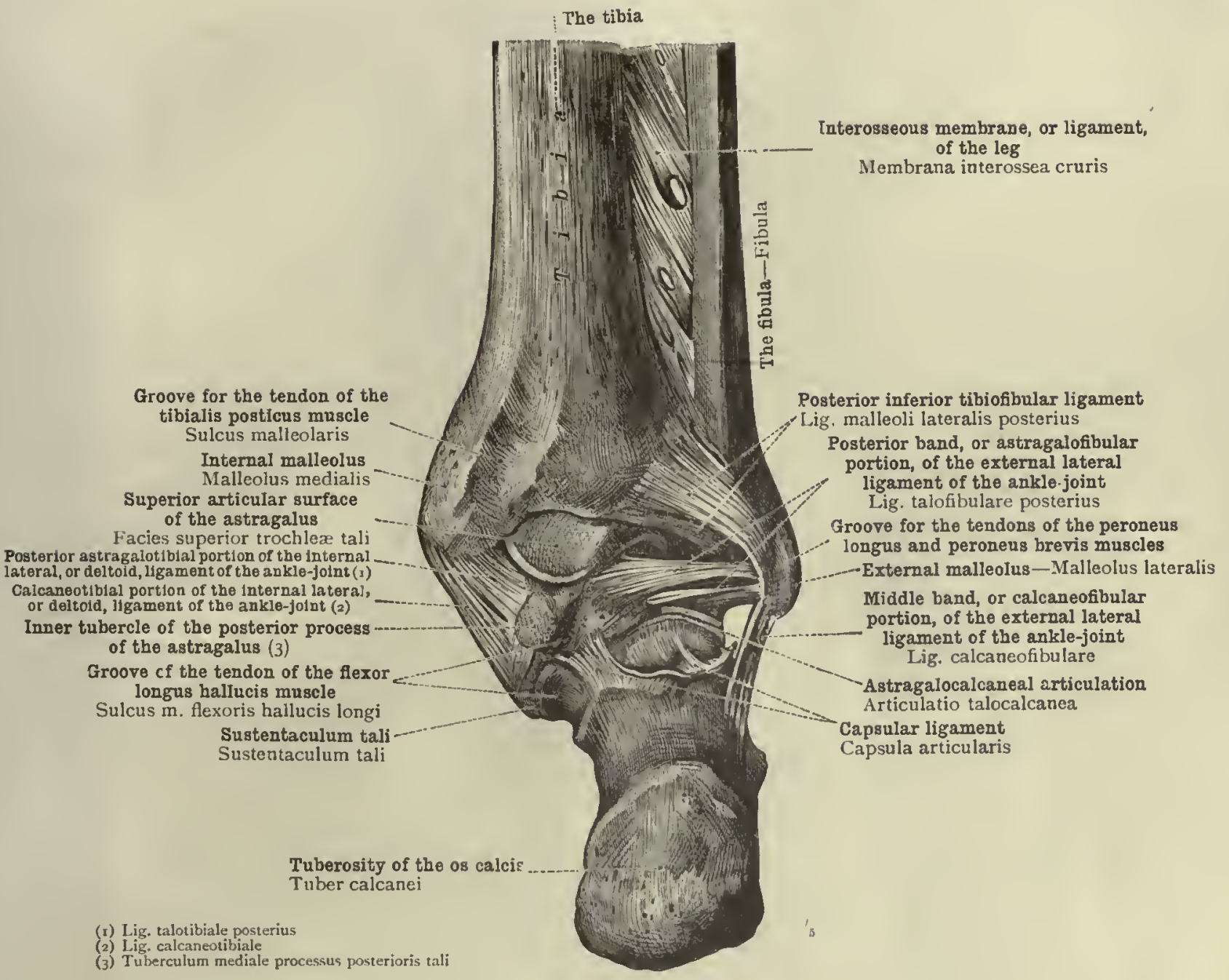

Fig. 480.-Articulationes Talocruralis et Talocalcanea, the Ankle-Joint and the Astragalocalcaneal Articulation; Syndesmosis Tibiofibularis, the Inferior Tibiofibular Articulation: Ligamentum Malleoli Lateralis Posterius, the Posterior Inferior 'Tibiofibular ligament. The Posterior Portions of the lateral Ligaments: Ligamentum Talotibiale Posterius, the Posterior Astragalotibial Portion of the Internal Lateral, or Deltoid, Ligament of the Ankle-Joint; Ligamentum Calcaneotibiale, the Calcaneotibial Portion of the Internal Lateral, or Deltoid, Ligament of the Ankle-Joint; Ligamentum Talofibulare Posterius, the Posterior Band, ok Astragalofibular Portion, of the External lateral Ligament of the Ankle-Joint; Ligamentum Calcaneofibulare, tile Middle Band, or Calcaneofibular Portion, of the External Lateral Ligament of the Ankle-Joint. (The Ankle-Joint and the Astragalocalcaneal. Articulation of the Right Leg, seen from Behind.)

The thin posterior portion of the capsule of the ankle-joint has been removed The posterior portion of the capsule of the astragalocalcaneal articulation has been separated from its attachment to the astragalus external to its attachment to the posterior process of that bone, and turned backwards on to the us calcis. 


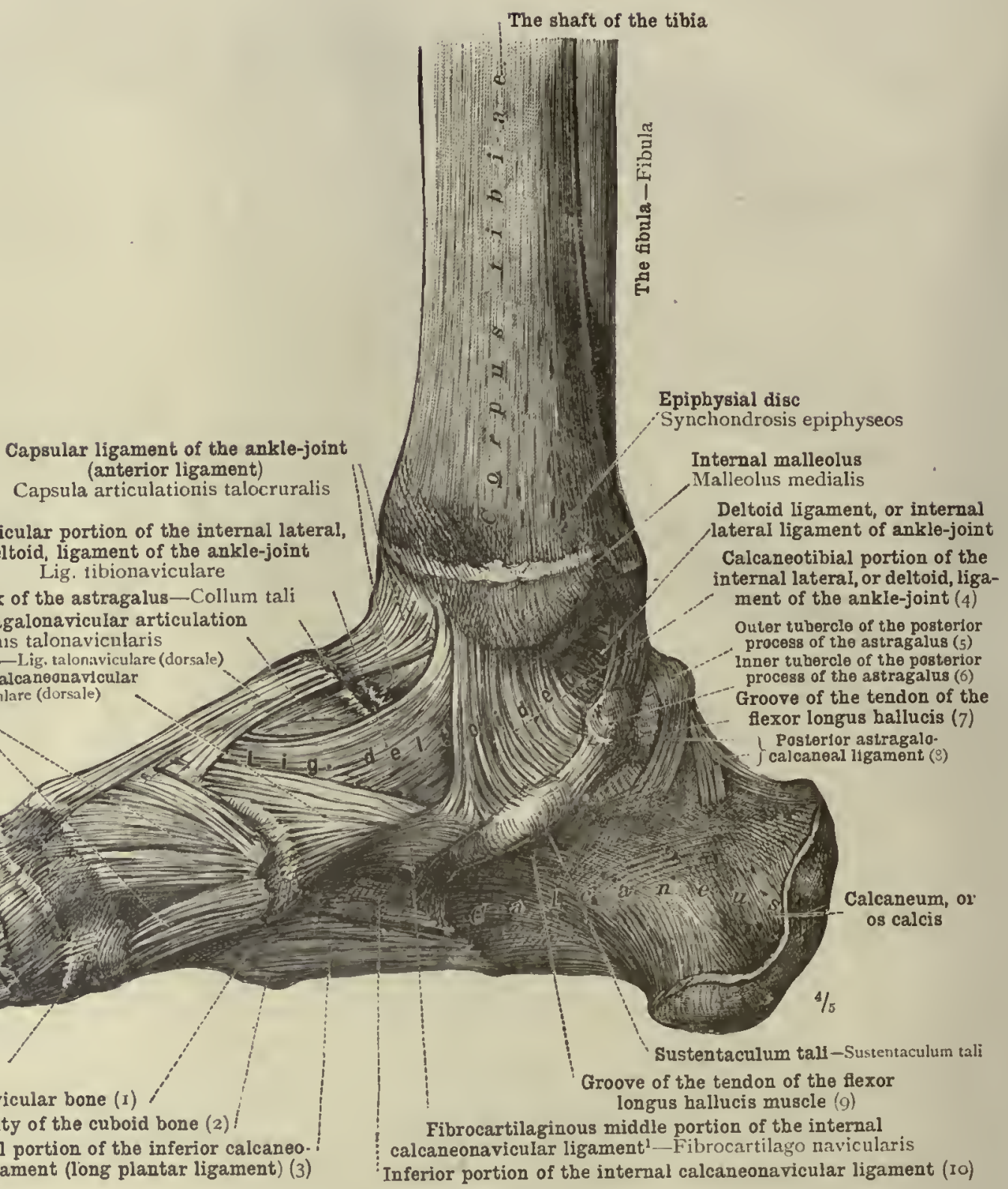

Tibionavicular portion of the internal lateral, or deltoid, ligament of the ankle-joint

Neck of the astragalus-Collum tali

Capsule of the astragalonavicular articulation

Capsula articulations talonavicularis

Astragalonavicular ligament-Lig. talonsviculare (dorsale)

Superior portion of the internal calcaneonavicular

Igament-Lig, calcaneona viculare (dorsale)

Dorsal naviculocuneiform

ligaments

Ligg. navicularicunei-

formia dorsalia

Dorsal tarsometatarsal ligament

Lig. tarsometa-

tarseum

corsale

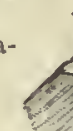

Internal or first cuneiform

bone-Os cuneiforme I.

Tuberosity of the navicular bone (I)

Tuberosity of the cuboid bone (2)

Superficial portion of the inferior calcaneo.? cuboid ligament (long plantar ligament) (3)

calcaneonavicular ligament ${ }^{1}$ - Fibrocartilago naviculari

Inferior portion of the intermal calcaneonavicular ligament (Io)

(1) Tuberositas ossis navicularis

(1) Tuberositas ossis navicularis

(3) ligerositas ossis cuboidei

(4) lig. calcancotibiale
(5) Tuberculum laterale processus

(5) Tuberculum laterateris iali

(6) Tuberculum inediale processus posterioris tali

1 See note 10 p. 2.48 .
(7) Sulcus m. fiexnrit hallucis longi

(8) Lig. talocalcaneum pocterius

(9) Sulcus m. texwris hall neis longi

Fig. 48i. - The Superficial Internal Liganents of the Ankle-Joint and of the Astragalocalcaneal. Articulation, and the Rlilation of the Distal Epiphysial Disc of the Tibia to the Ankle-Joint. (The Right Tarsus, with the Adjoining Portions of the Tibia and Fibula and of the First Metatarsal Bone; seen from the InNer Side.) 


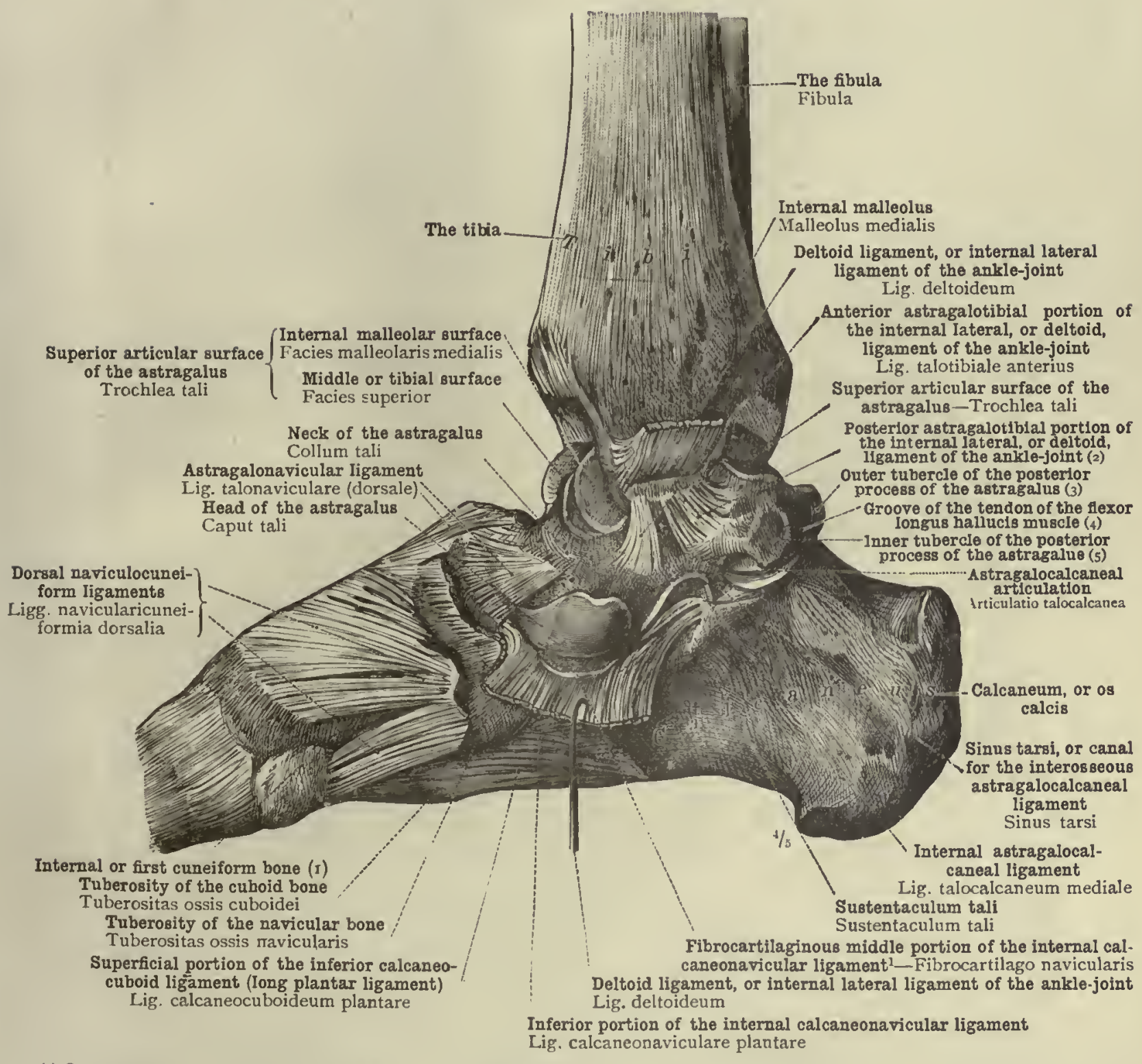
(I) Os cuneiforme I.
(2) Lig. talotibiale posterius
(3) Tuberculum laterale (4) Sulcus $m$. flexoris hallucis longi
See note ${ }^{1}$ to p. 248 .
(s) Tuberculum mediale

Fig. 482.-The Deep Internal Liganents of the Ankle-Joint and of the Astragalocalcaneal Articulation. (The Right Tarsus, ivith the adjoining Portions of the Tibia and Fibula and of the First Metatarsal Bone; seen from the Inner Side.)

The deltoid ligament (internal lateral ligament of the ankle-joint) has been cut across the middle, and the divided ends have been turned up and down. The capsular ligaments of the ankle-joint and of the astragalocalcaneal articulation have been removed, except for the decper special bands. 


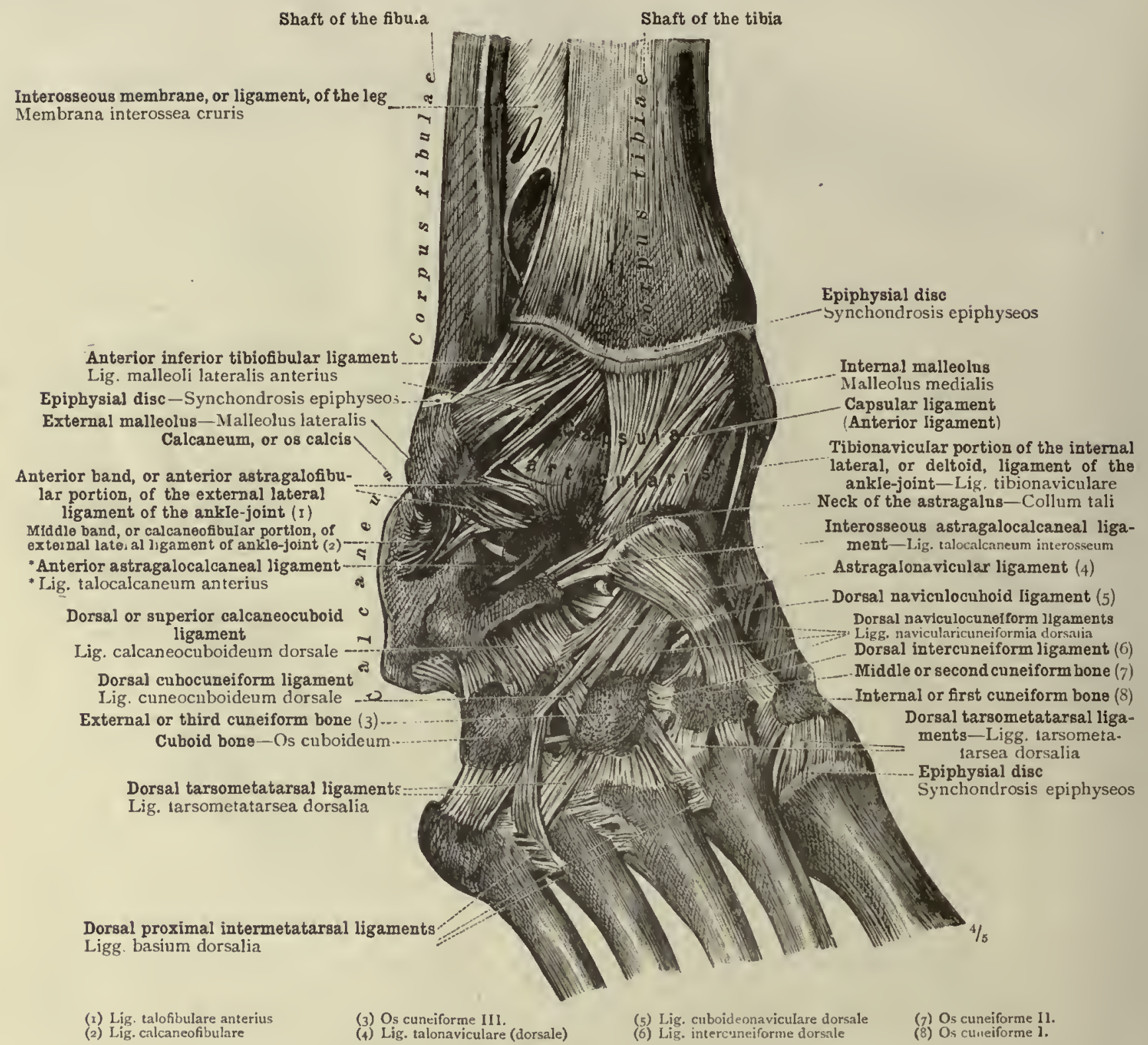

Fig. 483-Articulatio Talocruralis, the Ankle-Joint; Syndesmosis Tibiofibularis, the Inferior Tibiofibular articulation. The Relations of the Distal Epiphysial. Discs of the Tibia and Fibula to the Ankle-Joint. Articulationlis Intertarsere et Tarsometatarsea, the Intertarsal and Tarsometatarsal Articulations; Articulationes Intermetatarsea, the Internetatarsal Articulations. Ligamenta Tarsi Dorsalia et Tarsometatarsea Dorsalia et Ligamenta Basium Dorsalia; the Dorsal Ligaments of the Tarsus, the Dorsal Tarsometatarsal Ligaments, and the Dorsal Proximal Intermetatarsal Ligaments. (The Right Tarsus with the adjoining Portions of the Tibia and Fibula and of the Metatarsus; Dorso-external Aspect.)

The joints are unopened "except for the astragalocal raneal, astragalonavicular, and naviculocuneiform articulations, which have been partly opened. 


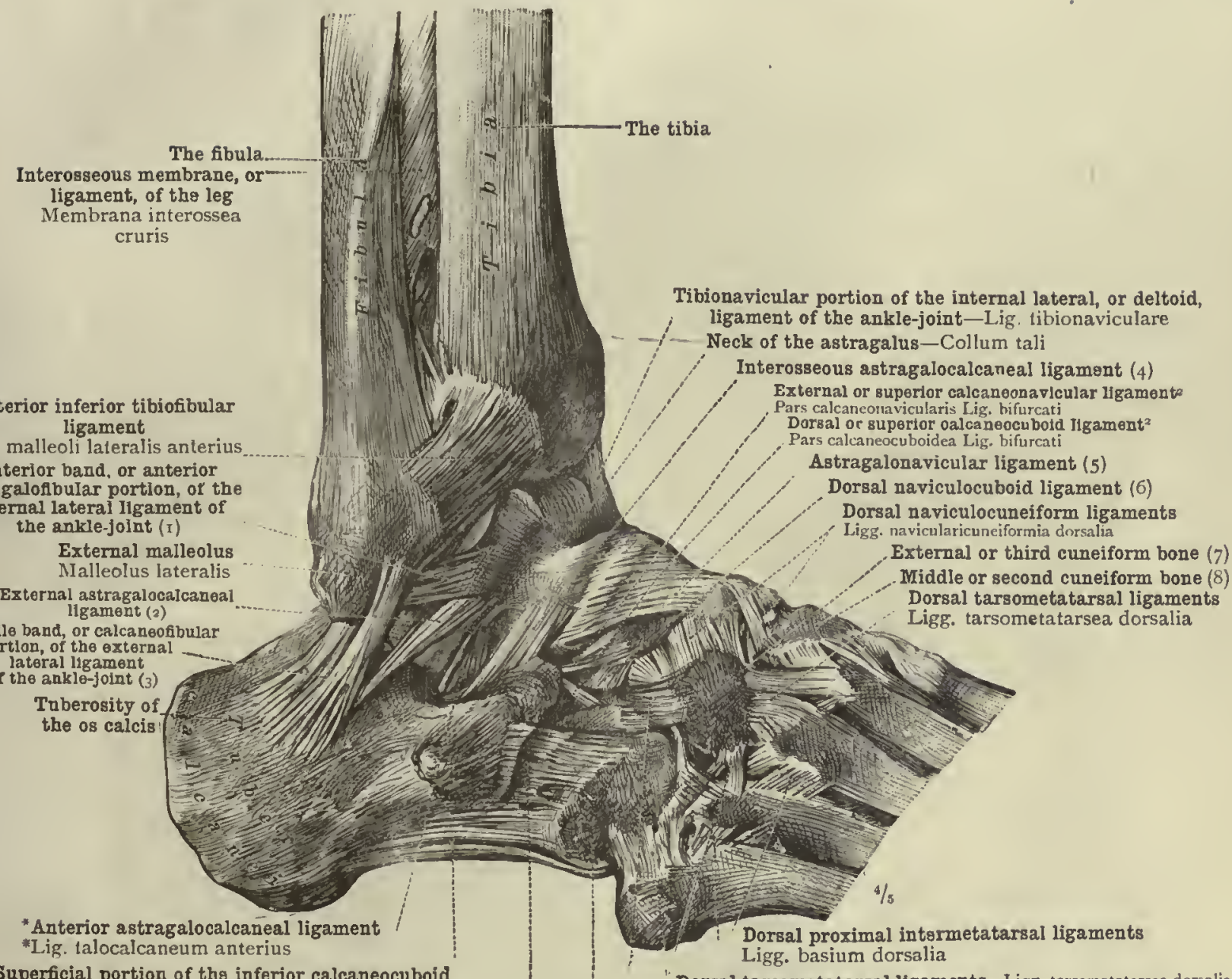

Superficial portion of ths inferior calcaneocuboid ligament (long plantar ligament) Lig. planiare longum

Dorsal or superior calcaneocuboid ligament²

Lig. calcaneocuboideum dorsale

Dorsal tarsomstatarsal ligaments-l.igg. tarsometatarsea dorsalia Dorsal cubocuneiform ligament-Lig. cuneocuboideum dorsale Cuboid bone

Os cuboideum
(2) Lig. talofibulare anterius
(3) Lig. calcaneofibulare
(5) Lig. talonaviculare (dorsale)
(6) Lig. cuboideonaviculare dorsale
(9) Os cuneiforme III.

I The strongest part of this ligament is situate external, and not superior, to the calcaneocuboid articulation; it would tberefore be more aopropriately named the extermal calcaneocuhnit ligament.--TR.

2 In the English nomenclature these are regarded as two distinct ligaments, not, as by Toldt, as two parts of a single ligament.-TR.

Fig. 484.-Articulationes Talocruralis et Talocalcanea, the Ankle-Joint and the Astragalocalcaneal Articulation; Ligamentum Malleoli Lateralis Anterius, Anterior Inferior Tibiofibular Liganent. The Anterior and Middle Bands of the External Lateral Liganent of the Ankle-Joint (Ligamentum Talofibulare Anterius et Ligamentum Calcaneofibulare): Ligamenta Talocalcanea, Laterale. "Anterius, et Interosseum: the External, *ANTERIOR, ANd Interosseous Astragalocalcaneal LigaMents.ARticulationes INTERTARse E ET Tarsometatarse Articulations; Articulationes Intermetatarsee, the Intermetatarsal Articulations: Ligamenta Tarsi Dorsalia, Ligamenta Tarsonetatarse $x$ Dorsalia, et Ligamenta Basium Dorsalia, the Deeper Dorsal Tarsal and Tarsometatarsal Ligaments, and the Dorsal Proximal Intermetatarsal Ligaments. (The Right Tarsus, with the Adjoining Portions of the Tibia and Fibula and of the Metatarsal. Bones; Dorso-external Aspect.)

The anterior ligament of the ankle-joint and the lateral portion of the capsule of the astragalocalcaneal articulation have been removed. 


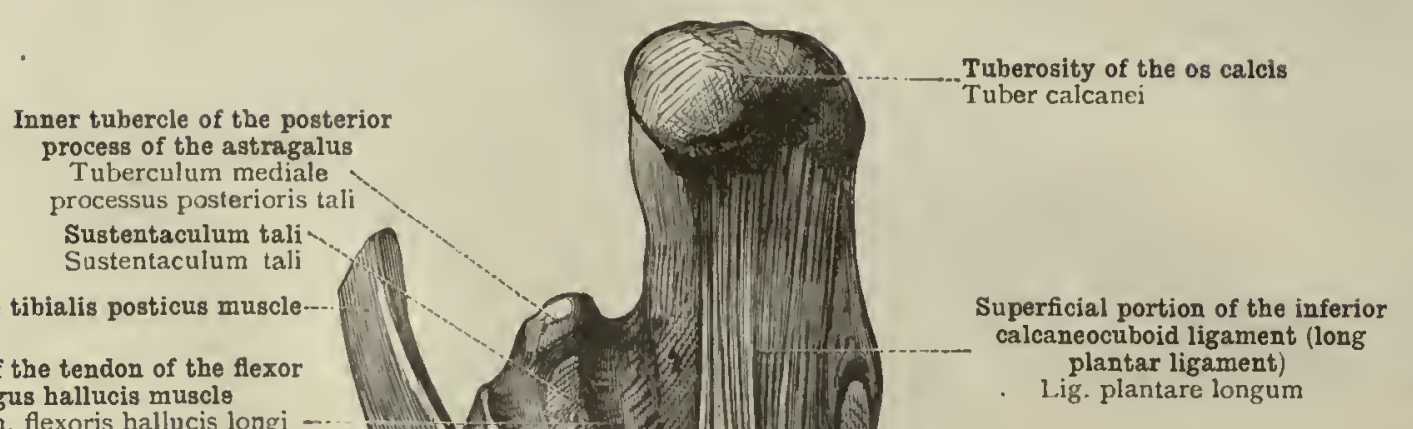

Tendon of the tibialis posticus muscle

Groove of the tendon of the flexor longus hallucis muscls Sulcus $\mathrm{m}$. flexoris hallucis longi -..

Groove of the tendon of the flexor. longus digitorum pedis muscls Sulcus $\mathrm{m}$. flexoris digitorum longi -Inferior portion of the internal calcaneonavicular ligament ( 1 ) Deep portion of the interior calcaneccubold ligament (short plantar ligament) (2) Plantar naviculocubold ligament (3)-

Tendon of the tibialis posticus muscle:

Plantar cubocuneiform ligament (4) External or third cuneiform bone (5) Tendon of tho tibialis anticus muscle Plantar cubocuneiform ligament (6) Internal or first cuneiform bons (7)

Plantar tarsometatarsal ligaments $($. Ligg. tarsometatarsea plantaria

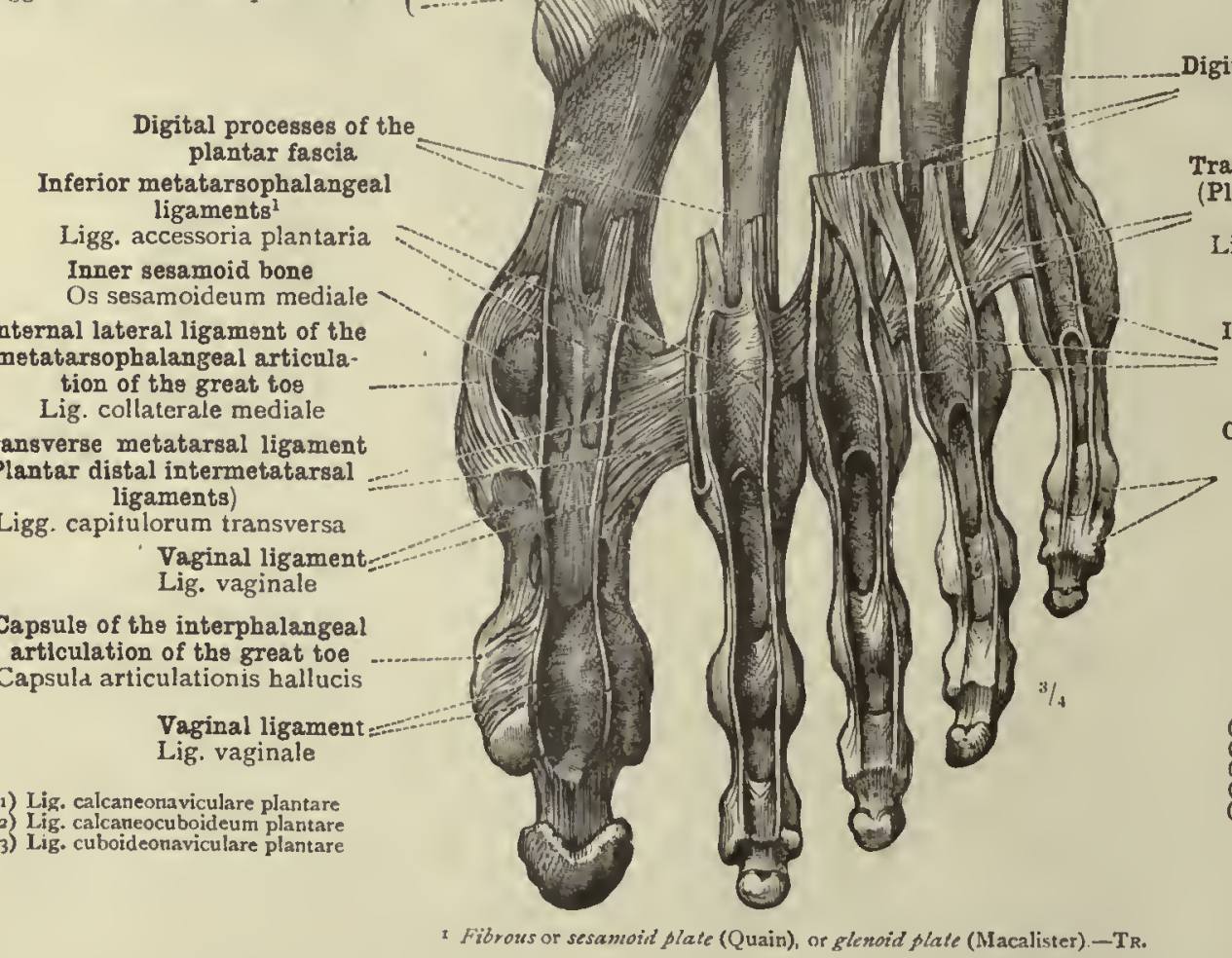

Plantar tarsometatarsal ligaments - Ligg. tarsometatarsea planiaria ..-Tendon of the peroneus longus muscle Tuberosity of the fifth metatarsal bone (8)

Distal radiations of the long plantar -ligament, divided and turned forwards Plantar proximal intermotatarsal ligaments

Ligg, basium plantaria

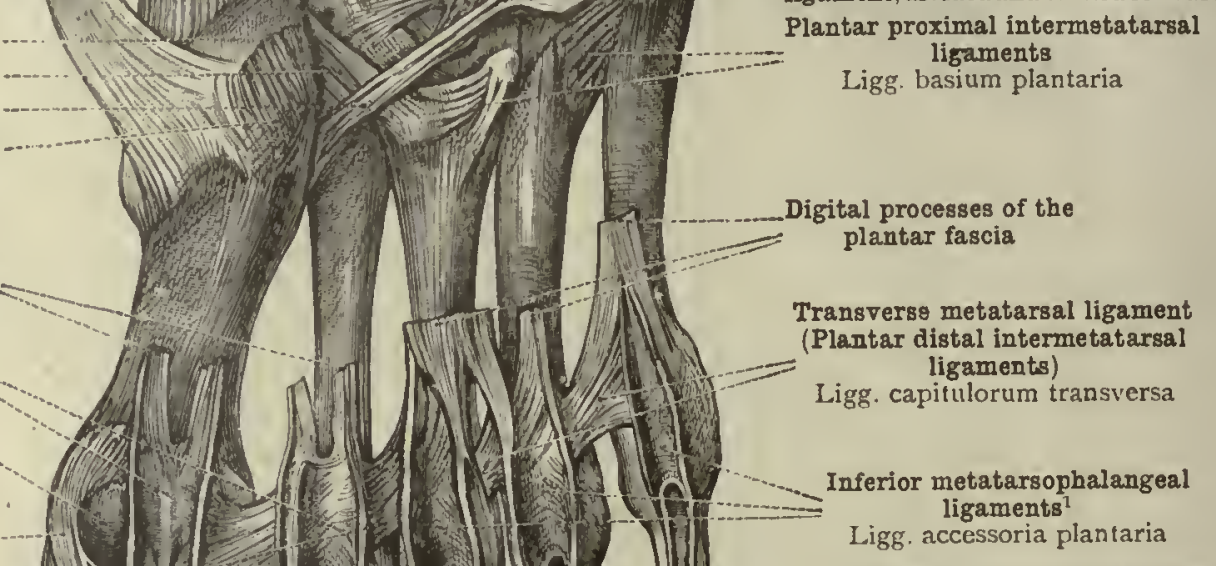

Transverse metatarsal ligamen (Plantar distal intermetatarsal

Ligg. capifulorum transversa Vaginal ligament Lig. vaginale

Capsule of the interphalangeal articulation of the great toe
Capsuld articulationis hallucis Vaginal ligam
Lig. vaginale

(1) Lig. calcaneonaviculare plantare (2) Lig. calcaneocuboideum plantare
(3) Lig. cuboideonaviculare plantare

1 Fibrous or sesamoin plate (Quain), or glenoid plate (Macalister).- $T_{R}$.

Capsules of the interphalangeal articulations of the little toe Capsula articulationum digiti $\mathrm{V}$.

(4) Lig. cuneocuboideum plantare (5) Os cunciforme III.

(6) Lig. cuneocuboideum plantare

(8) Tuberositas ossis metatarsalis $V$.

Fig. 485.-The Superficial Ligaments of the Plantar Surface of the Right Foot and the Relations of the Tendons of the Tibialis Anticus and Posticus and of the Peroneus Longus Muscles to these Ligaments. Ligamenta Tarsi et Tarsometatarsed, the Tarsal and the Tarsonetatarsal Ligaments: Ligamenta Basium Plantaria, Ligamenta Capitulorum Transversa, et Ligamenta Accessoria Plantaria; the Plantar Proximal Intermetatarsal Ligaments, the Transverse Metatarsal Liganent, and the Inferior Metatarsophalangeal Ligaments (see note above); the Relations of these Ligaments to the Digital Processes of tile Plantar Fascia.

Articulationes pedis-The articulations of the foot. 


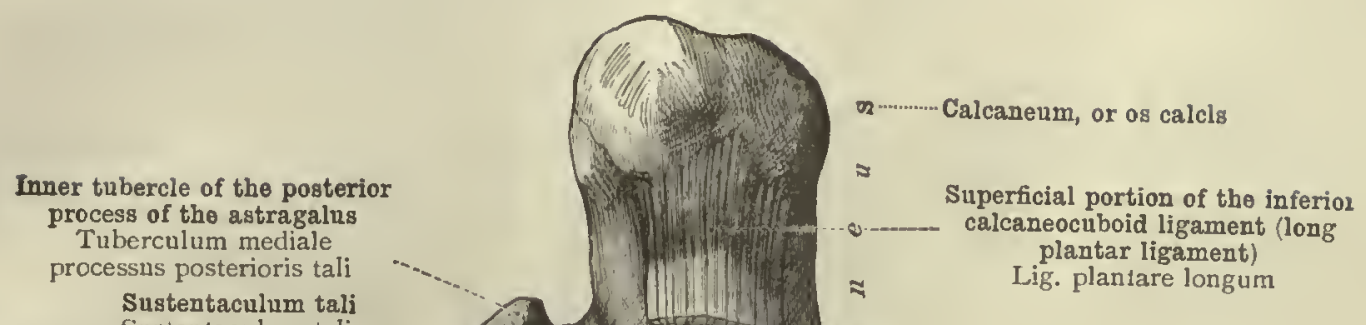

Groove of the tendon of the flexor longus hallucis Sulcus $\mathrm{m}$. flexoris hallucis longi

Groove of the tendon of the flexor longus digitorum

pedis-Snlcus $m$. flexoris digitorum longi

Middle fihrocartlaginous portion of the internal calcannonavicular ligament
(Groove of the tendou of the tibla lis postion tendon of the tiblabis posticus muscle) (1) Inferior portion of the internal calcaneonavicular ligament

Lig. calcaneonaviculare plantare

Tuberosity of the navicular bone

Tuberositas ossis navicularis

Plantar naviculocuboid ligament

Ligg. cuboideonavicularia plantaria

Plantar naviculocuneiform ligaments

Ligg. navicularicuneiformia plantaria

Plantar cubocunelform ligament Lig. cuneocuhoideum plantare

External or third cunolform bone

Os euneiforme 111 .

Internal or first cuneiform bone Os cunciforme I.

Capsule of the first tarsometatarsal articulation (2)

Plantar tarsometatarsal

ligaments
Ligg. tarsometatarsea plantaria

Inferior metatarsophalangea Ligg. accessoria plantaria

Capsule of the metatarsophalangeal articulation of the great toe Capsula articulationis metatarsophalangex I.

Capsule of the interphalangeal articulation of the great toe Capsula articulationis hallucis

(i) Fibrocartilago navicularis (see note $I$ to p. 248$)$ (Sulcus musculi tibialis pesterioris)
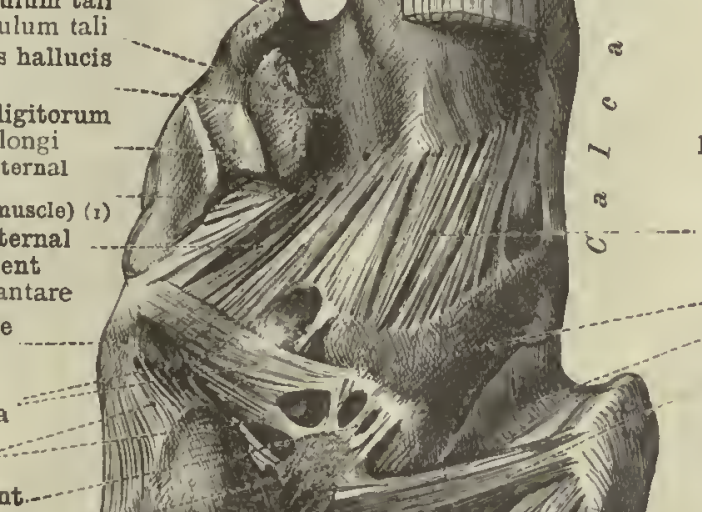

Deep portion of the inferior

calcaneocuboid ligament

(short plantar ligament)

Lig. calcaneocuboideum plantare

Tuberosity of the cuboid bone

Tuberositas ossis cuboidei

Plantar tarsometatarsal ligaments

Ligg. tarsometatarsea plantaria

Plantar proximal intermetatarsal ligament

Lig. basium plantare

Plantar tarsometatarsal ligaments

Ligg. tarsometatarsea plantaria

Plantar proximal intermetatarsal ligament

Lig. basium plantare
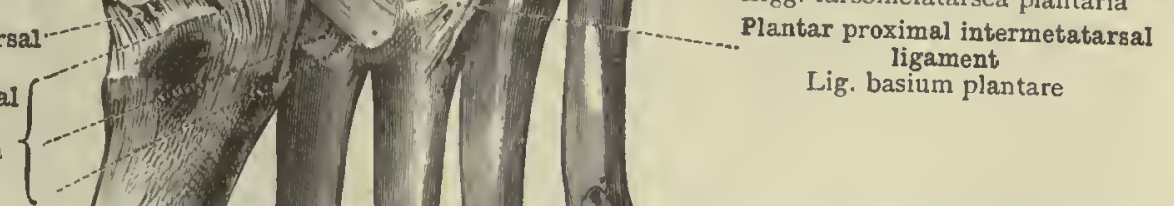

(2) Capsula articulationis tarsometatarsea: 1.

Fig. 485.-The Deep Ligaments of the Sole of the Foot and the Sesamoid Bones of the Metatarsophalangeal Articulation of the Great ToE.

In the preparation shown in Fig. 485 the tendons of the muscles were removed, also the long plantar ligament except for its posterior extremity, and the transverse metatarsal ligament and the interphalangeal of the plantar fascia were cut away. Some of the metatarsophalangeal and interphalangeal articulations have been opened; others have been left intact. 


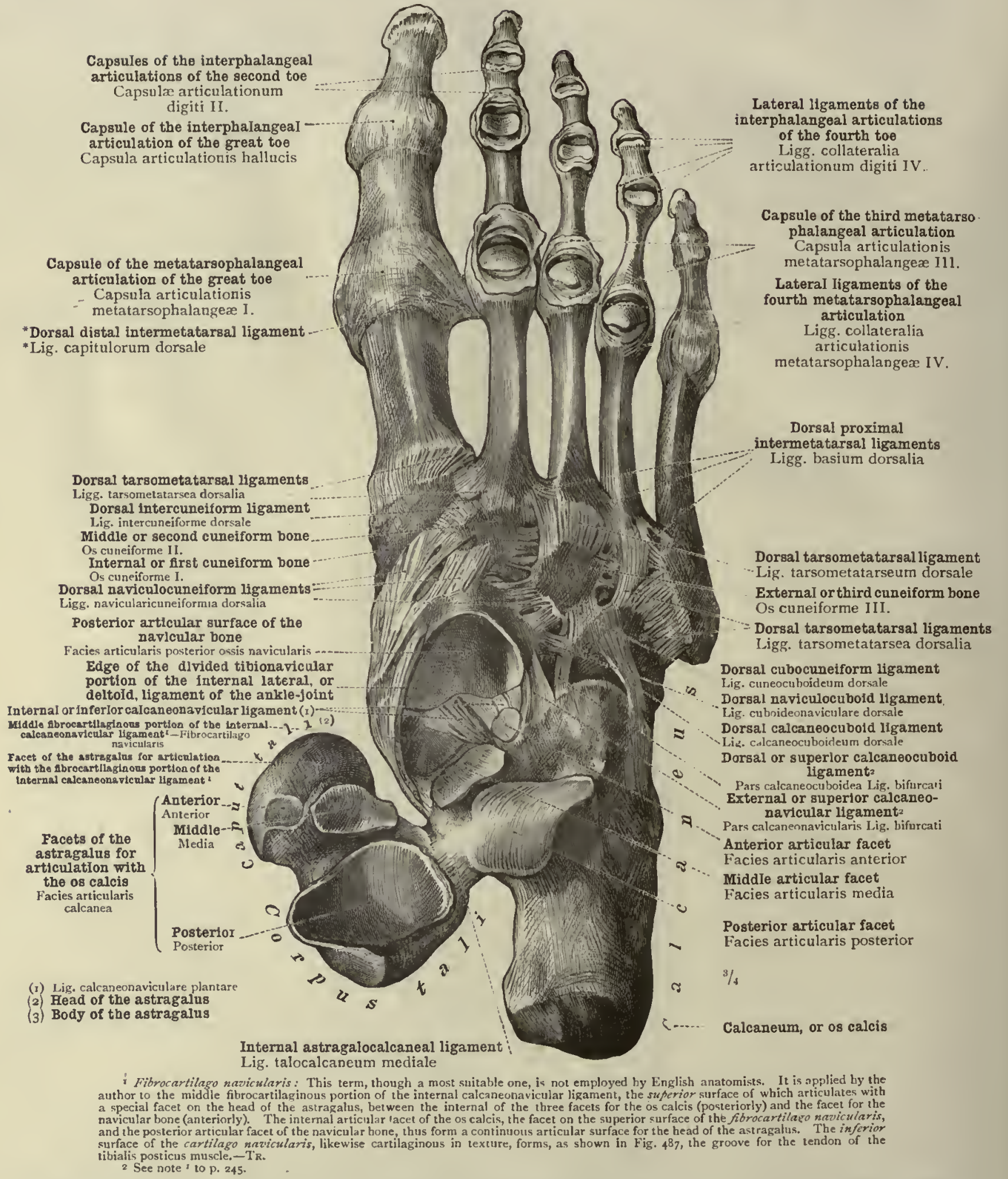

Fig. 487. - The ARticular Surfaces of the Astragalocalcaneonavicular Articulation, The Deep ligaments OF THE DORSUM OF THE FOOT, THE METATARSOPHalangeal aND INTERPHALANGEal ARTICULATIONS OF THE TOES. (THE RIGHT FOOT SEEN FROM THE DORSAL Side.)

The capsule of the astragalocalcaneal articulation was removed, with the exception of the internal astragalocalcaneal ligament; the capsule of the astragalonavicular articulation was also removed with the exception of its internal and plantar walls ; and, after removing the interosseous astragalocalcaneal ligament, the astragalus was rotated inwards (on the internal astragalocalcaneal ligament as a hinge), until its inferior surface looked directly upwards. 


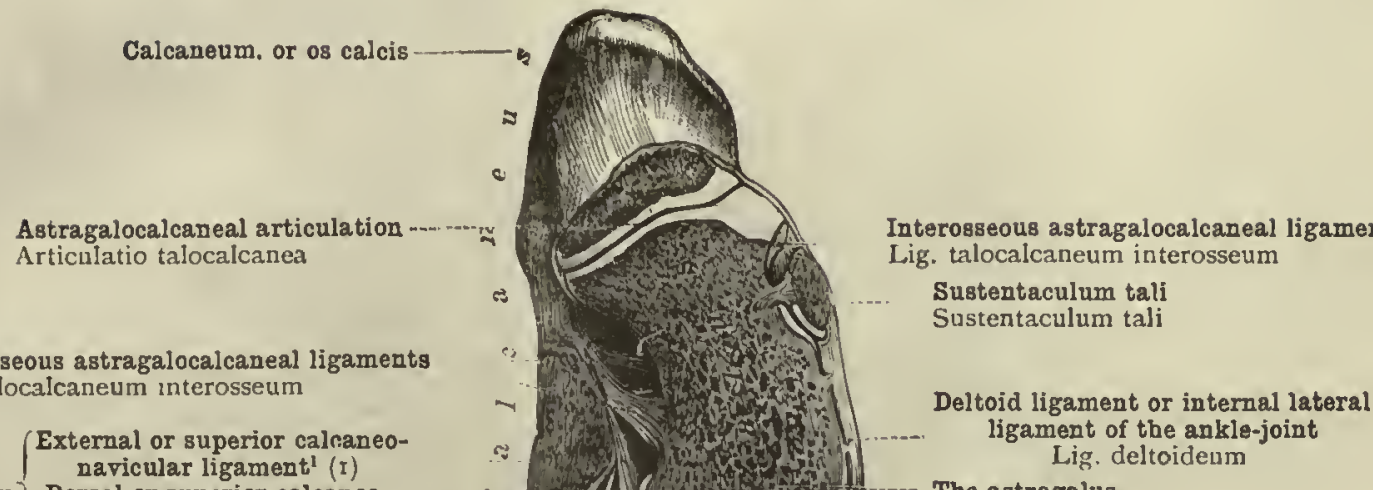

Interosseous astragalocalcaneal ligaments

Lig. talocalcaneum interosseum

Lig. $\quad \begin{gathered}\text { External or superior calcaneo } \\ \text { navicular ligament }\end{gathered}$ bifurcatum Dorsal or superior calcaneocuboid ligament ${ }^{1}(2)$

The navicular boze

The cuboid bone-Os cuboideum

The three cuneiform bones

Interosseous cubocuneiform ligament

Lig. cuneocuboideum interosseum

Interosseous intercuneiform ligament

Lig. in tercuneiforme interosseum Dorsal proximal intermetatarsal ligaments
Lig. basium dorsalia

Metatarsophalangeal articulation Articulatio metatarsophalangea

Interphalangeal synchondrosis (var.) Synchondrosis interphalangea (var.)

Interphalangeal articulations of the fourth toe Articulationes digiti IV.

(1) Pars calcaneonavicularis

(2) Pars calcaneocuboidea

- See note I to p. 245

2 Known also ai the me fin'arsal or mid-tarsal joint. It is through this joint (the two parts of which are, however, entirely separate articulations) that the font is divided in Chopart's amputation.

3 It is through the tarsometatarsal articulations that the foo is divided in Lisfranc's amputation.
Astragalonavicular Transverse tarsal articulation (3) articulation ${ }^{2}$

Calcaneocuboid (Articulatio tarsi trans. articulation (4) versa (Choparti)

Naviculocuneiform articulation

Articulatio cuneonavicularis

Tarsometatarsal articulation ${ }^{3}$

Articulatio tarsometatarsea (Lisfrauc1)

Epiphysial disc

Sy uchondrosis epiphyseos

Epiphysial disc

Synchondrosis epipnyseos

Epiphysial disc

Synchondrosis epiphyseos

$3 / 4$

(3) Articulatio talonavicularis
(4) Articulatio calcaneocuboidea

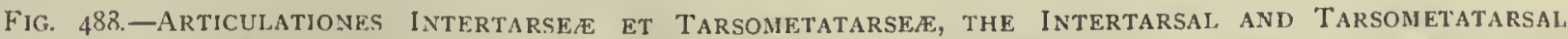
ARticulations, SHOWing CHOPART'S (MEDIOTARSAL) LiNE, aNd Lisfranc's OR Hey's TARSOMETATARSAL

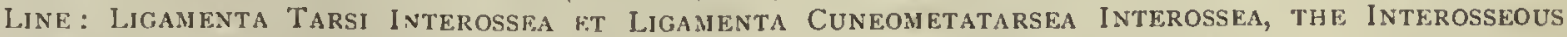
LIGAMENTS OF THE TARSUS, AND THE INTEROSSEOUS METATARSOCUNEIFORM LIGAMENTS. ARTICULATIONIS INTERMHTATARSFA, THE INTERMITATARSAL ARTICULATIONS. ARTICULATIONES METATARSOPHALANGEA, the Metatarsophilangeal. Articulations, Articulationes Digitorum Pedis, the Interphalangeal Articulations of the Tors. The Relations of the EPiphysial Discs of the Metatarsal Bones and of the Phalanges of the TOes to the Respectiye articulations. (Horizontal Section through the Articulations of THE Right foot of a Youth Aged Seventefa Years. Superior Surface of the LOWER SEGMENT.) 


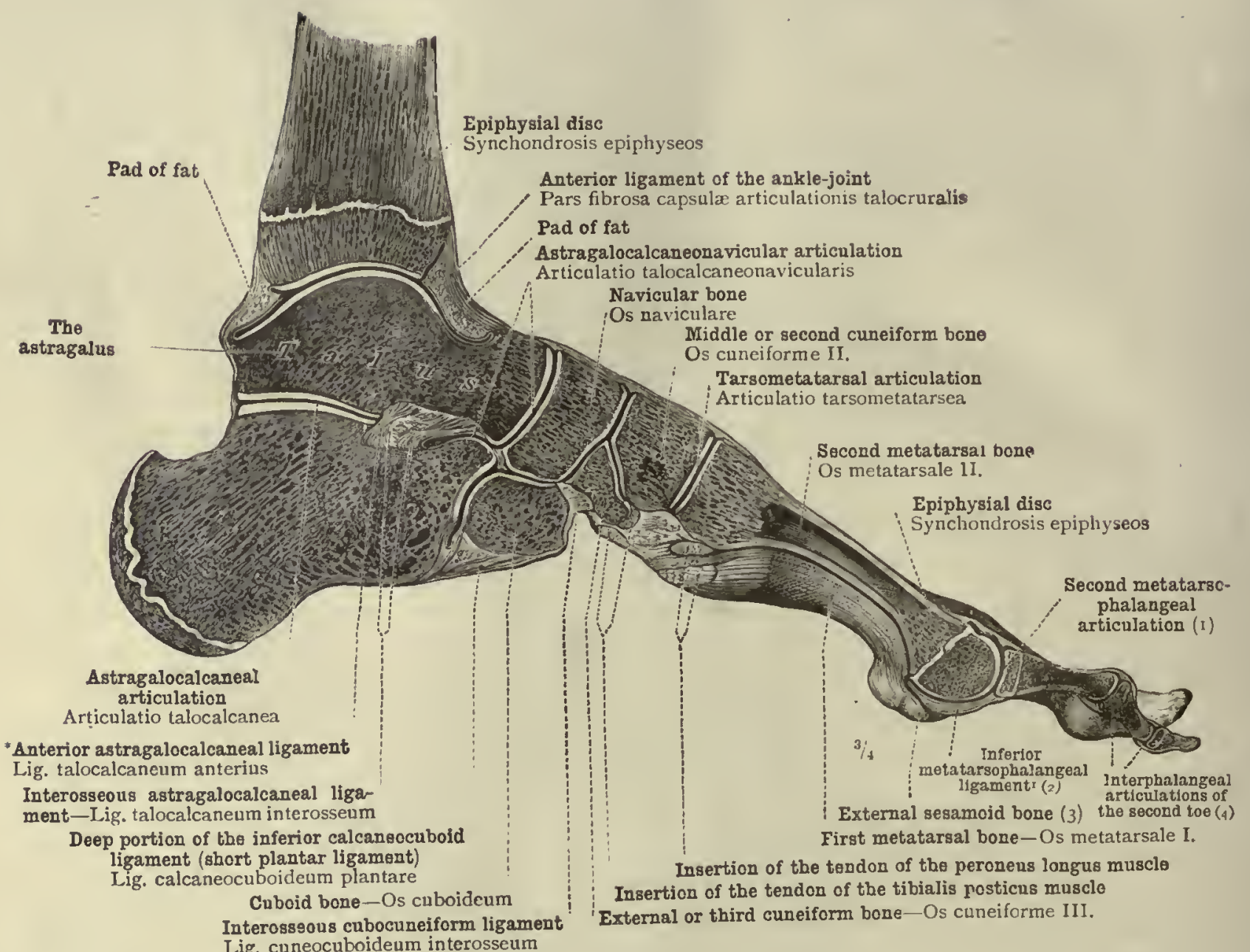
Lig. cuneocuboideum interosseum

(r) Articulatio metatarsophalangea II.

(2) Lig. accessorium plantare

(3) Os sesamoideum laterale

(4) Articulationes digiti II.

1 See note to p. 246.

Fig. 489.-The Articulations of the Right Foot of a Youth aged Seventeen Years, SeEn in Sagittal Section, and showing the Relations of these Articulations to THE EPIPHysial Discs.

The section passes through the distal extrenity of the tibia, the astragalus, the os calcis, the middle cuneiform bone, the second metatarsal bone, and the phalanges of the second toe. 


\section{N I) E X}

\section{TO THE ARTHROLOGY}

Certain names in this Index have an asterisk (*) prefixed; these, as more fully explained in the Translator's Preface, being terms that form part of the English nomenclature used in this work, hut which are not commonly employed by English anatomists. To other names a dagger ( $t$ ) is prefixed; these are English nomenclature used in this work, hut which are not commonly employed by English anatomists. To other nanies a dagger
Latun nanes used by the author in the original work, but not included in the official nomenclature of the "Anatomische Gesellschaft."

\section{A.}

ACETABULUM, the, 225, 227 transverse ligament of the, $168,223,225,227$

† Anpliarthroses 1 ntercarpex, I69

Amphiarthrosis, 169

Ankle-joint, the, 239, 24I, 243, 245

Annulus fibrosus (fibrocartilaginis intervertebralis), 173,174

Aponeurosis (see also "Fascia"): intercostal, anterior or external, 186 posterior or internal, $176,183,184$, 187

lumbar, see "Fascia, lumbar"

plantar, 246

Arthrodia, 168

plantaris, 246

Articular facet of the clavicle, sternal, 198

surface of the carpus, radial, 213

Articulatio vel articulationes :

acronioclavicularis, 201, 202

atlanto-epistrophica, 190-192

atlanto-occipitalis, $167,190-193$

calcaneocuboidea, 249

capitulorum (costaru111), 182-184, 185

carponetacarpea, I67, 212-2I5

cochlearis, $\mathrm{I} 66$ pollicis, $167,212-214$

composita, 169

costotransversariæ, 182

costovertebrales, $182-184$

coxæ, I68, 222-227

cubiti, 169, 204-208

cunleonavicularis, 244,249

diǵitorunı (manus), I66, 210, 211, 214, 215

ellipsoidea, 167 pedis, 249,250

et ligamenta capitis, 190-196

cinguli extremitatis inferioris, 216219 cinguli extremitatis superioris,

genu, 228-237 198, 199

hallucis, 246-248

humieri, I68, 200-203

humeroradialis, 169

humero.ulnaris, 208

intercarpea, $169,212-215$

interchondrales, 186,188

internnetacarpeæ, $169,212-214$

intermetatarsex, 244, 245, 249

intertarsere, $244,245,249$

intervertebrales, $173-175,185$

miandibularis, 194-196

manus, $169,210-214$

inetacarpophalangex, I66, 167, $210,211,214,215$

metacarpoplalangea pollicis, 210,214

metatarsophalangex, 249,250

ossis pisiform11s, 212

pedis, 239,250

pollicis, $210,211,214$

radiocarpea, $169,212-215$

radio-ulnaris distalis, 209-214

proximalis, 169,209
Articulatio vel articulationes:

sacro-iliaca, 216, 217,219

sellaris, 167,169

simplex, 166-168

sphæroidea, 168

sternoclavicularis, $170,185-187,198$

sternocostales, 186-188

talocalcanea, 239, 241, 244, 245, 249, 250

talocalcaneonavicularis, 250 ; articular surfaces of, 248

talocruralis, 239, 241, 243-245

talonavicularis, 244,249

tarsi transversa (Choparti), 249

tarsometatarseæ, $244,245,249,250$

tibiofibularis, 228, 229, 231, 233, 238

troclsoidea, 169

Articulation or articulations (see also "Joint"): acromio-clavicular, 201, 202

and ligaments of the head, 190-196 of the pelvic girdle, 216-219 of the shoulder-girdle, 195-199

astragalocalcaneal, 239, 241, 244, 245, 249, 250 astragalocalcaneonavicular, 250; articular surfaces of, 248

astragalonavicular, 244, 249

atlanto-axial, 190-192

calcaneocuboid, 249

carpal, transverse, 169, 212-215

carpometacarpal, $167,212-215$

chondrosternal, I86-188

of the thumb, I16, 212-214

continuous, 164,165

costocentral, $182-185$

costotransverse, 182

discontinuous, 166.169

of the fingers, $166,210,211,214,215$

of the foot, 239,250

of the great toe, 246.248

of the hand, $169,210-214$

of the hip, 168, 222-227

hnmeroradial, 169

humero-ulnar, 208

intercarpal, I69, 212-2I5

interchondral, 186,188

intermetacarpal, 169, 212-114

intermetatarsal, 244, 245, 249

interphalangeal, of the fingers, $166,210,211$, 214,215

of the thumb, 210, 2II; 214

intertarsal, $244,245,249$

of the toes, 249,250

intervertebral, $173-175,185$

of the knee, 228-237

of the lower extrenity;, 216-250

niediotarsal (Chopart's), 249

metacarpophalangeal, I66, 167, 210, 21 I, 214, 215

of the thumb, 210, 2I4

metatarsoplialangeal, 249,250

naviculocuneiform, 244,249

occipito-atlantal, 167, 190-193

pisipyranidal, 212 
Articulation or articulations:

radiocarpal, $169,212-215$

radio-ulnar, distal, 209-214 proxinial, 169, 209

sacrococcygeal, 180, 216, 217

sacro-iliac, $216,217,219$

of the shoulder, I68, 200-203

sternoclavicular, $170,185-187,198$

tarsometatarsal, 244, 245, 249, 250

teniporomandihular, 194-196

temporomaxillary, 194-198

of the thutilb, 210, 211,214

tibiofibular, in ferior, $238-24 \mathrm{t}, 244,245$ superior, 228, 229, 231, 233, 238

of the trunk, 171-187

of the upper extrenity, 198-215

\section{B.}

Bicipital groove, synovial sheath of the, 201,202

Bigelow, Y liganient of, 222, 224, 226, 227

Bones, sesamoid, of the foot, $246,247,25^{\circ}$

of the inand, $210,211,214$

of the knee, 232 , and note, p. 211

Bursa beneath the internal lateral ligament of the kneejoint, 236

beneath the patellar ligament, 231

beneath the suprapatellar tendon, 228, 230, 231, 234, 235

between the tendon of the semimembranosus muscle and the knee-joint, 232

between the tenclon of the semimembranosus muscle and the tendon of the inner head of the gastrocnenius muscle, 232

iliopectineal, 227

of the odontoid process, 192

of the subscapularis muscle, 202, 203

subacromial, 202, 203

subdeltoid, 202, 203

of the tendon of the popliteus muscle, 232, 233, 235, 237

†Bursa apicis dentis (epistrophei), 192

iliopectinea, 227

infrapatellaris profunda, 231

ligamenti collateralis tibialis, 236

musculi gastrocneniii medialis, 232

poplitei, 232, 233, 235, 237

semimemibranosi, 232

subscapularis, 202, 203

subdeltoidea, 202, 203

suprapatellaris, 228, 230, 231, 234, 235

\section{c.}

Canal of the carpus, 211, 213

neural, I77

obturator, $217,222,224,226$

Canalis carpi, 211,213

obturatorius, 217, 222, 224, 226

vertebralis, 177

Capsula vel capsulæ:

articularis, $166-168,170$

pars fibrosa, 168

synovialis, 168

articulationis acromioclavicularis, 201

atlanto-epistrophicæe, 181,190

atlanto-occipitalis, 167, 181, 190, 193

capituli, 185

carponetacarpere pollicis, $210-213$

costotransversarize, 185

coxæ, 168, 222, 223, 226, 227 pars fibrosa, 224

cubiti, 204-207 synovialis, 224

pars fibrosa, 208 synovialis, 208

genu, 228, 230-233, 236, 237 pars synovialis, 234,235

hallucis, $246-248$
Capsula val capsulæ:

articulationis huneri, 199, 200, 203

mandibularis, 194,196

pars fibrosa, 201 synovialis, 201, 203

IIlanus, 214

ossis pisiformis, 212

radiocarpece, 213

radio-ulnaris distalis, $209 \cdot 212$

sternoclavicularis, 198

talocalcaner, 239-241

talocruralis, 240-242

talonavicularis, 242

pars fibrosa, 250

articulationum digitorum (111anus), 166, 210,211 pedis, $246-248$

intervertehralium, $173,175,181,154$, 185

metacarpophalaugearum, 166, 167, 210,211

metatarsoplialangearum, 247,248

tarsonetatarsearum, 247

Capsule or capsules (see also "Ligament, capsular"):

of the acromioclavicular joint, 201

of the articulations of the great toe, $246-248$

of the astragaionavicular articulation, 242

atlanto-axial, $18 \mathrm{r}, 190$

of tlie carponetacarpal joint of the thunb, $210-213$

of the costocentral articulations, 185

of the costotransverse articulations, 185

of the hip.joint, fibrous portion, 168 synovial portion, 168

of the interplialangeal articulations of the fingers, $166,210,211$

of the interplialangeal articulations of the toes, $246-248$

of the inferior radio-ulnar articulation, $209-212$

of the joints of the articular processes of the vertebra, $173,175,181,184,185$

of the inetacarpophalangeal articulations, 166,167 , $210, ' 211$

of the metatarsophalangeal articulations, 247,248

occipito-atlantal, 167, 18 $1,190,193$

of the pisipyramidal articulation, 212

of the radiocarpal articulation, 213

of the sternoclavicular joint, 198

of the tarsonietatarsal articulations, 247

of the transverse carpal articulation, 214

of the wrist-joint, 213

Cartilage, articular, 168

hyaline, of the vertebral bodies, 174

Cartilago articularis, 168

Cavitas glenoidalis scapulæ, 201, 203

Cavity, sigmoid, of the radius, 212

synovial, 170 great, of the ulna, 208,209

Cavum articulare, 170

Chorda obliqua, 209

Communication hetween the radiocarpal and the pisipyranidal articulation, 212,213

Communication between the wrist-joint and the pisipyranuidal articulation, 212,213

Cond ylarthrosis, 167

Condyles of tlie femur, 237

Condyli femoris, 237

Continuous articulation, 164,165

Cooper's ligament, 22!, 224

Cotyloid notcli, 223-225

\section{D.}

Diarthrosis, 166-169

Discontinuous articulation, 166-169

Disc or dises, epiphysial:

of the femur, distal, 230

proximal, 223

of the fibula, distal, $239,240,244$

proximal, 231

of the humerus, proxinal, 201

of the nietatarsal bones, 249,250

of the os calcis, 240 
Disc or dises, epiphysial :

of the phalanges of the fiugers, 215 of the middle finger, 215 of the toes, 249

of the radius, distal, 215

of the third metacarpal bone (distal extremity), 215 of the tibia, distal, 239, 240, 242, 244, 250 proximal, 230,231

Disc, interpubic, 21 7, 220, 221

Discs, intervertebral, $172-174,177,178,182,183,185$ of the sacrococcygeal articulation,

Discus articularis, 170

$$
216,217,180
$$

articulationis acromioclavicularis, 201

mandibularis, 196

radio-ulnaris distalis, $212-214$

sternoclavicularis, 160,188 , I98

Dura mater encephali, 165, 190, 192 spinalis, 179

E.

Elbow-joint, 169, 204-208

Enarthrosis, 168

\section{F.}

Facies articularis acromii, 20r

$$
\begin{gathered}
\text { calcanea (tali) anterior, } 248 \\
\text { media, } 248 \\
\text { posterior, } 248 \\
\text { (calcanei) anterior, } 248 \\
\text { media, } 248 \\
\text { posterior, } 248
\end{gathered}
$$

capituli costæe, 182

carpea (radii), 213

(dentis epistrophei) anterior, 192

fossæe mandibularis, 196 posterior, 192

patellæ, 229, 234, 235

posterior (ossis navicularis pedis), 248

sternalis (claviculae), 198

auricularis (ossis ilium), 219

lunata (acetabuli), 168, 224, 225, 227

patellaris (femoris), 229, 234, 237

Falciform process of the great sacrosciatic ligament, 217

Falx inguinalis, 220

† Fascia lumbalis, 176

lutubar, 176, 216, 218

lumbodorsalis, 176,218

obturator, 221

perineal, deep, 220, 221 , and note, p. 221

plantar, 246

triangular, 220

Fibrocartilage, interarticular, 170

$$
\begin{aligned}
& \text { of the acromioclavicular } \\
& \text { joint, 20r } \\
& \text { of the inferior radio-ulnar } \\
& \text { articulation, 212-214 } \\
& \text { of the sternoclavicular joint, } \\
& 170,188 \text {, I98 } \\
& \text { of the temporomandibular } \\
& \text { articulation, } 196
\end{aligned}
$$

triangular, 212-214

Fibrocartilages, senilunar, 229, 233, 235-237

$$
\text { posterior or ascending band of }
$$
the external, $233,235-237$

transverse ligament of the, 229 , 237

Fibrocartilaginous midclle portion of the internal calcaneonavicular liganent, $242,243,247,248$, and note, p. 248

Fibrocartilago basalis, 196

Fibrocartilagines intervertebrales, $172.174,177,178,182$, 183,185

Fibrocartilago navicularis, 242, 243,247, 248, and note, p. 248

Filum terminale, 179

Fissure of the interpubic disc, 220

Fold of the synovial niembrane of the wrist.joint, 213

Foramen iscliatlicum majus, 176, 216-218 11111us, $176,216-218$
Foramen, sacrosciatic, great, 176, 216-218 sinall, $176,216.218$

Fossa, glenoid, of the scapula, 201, 203 of the interarticular ligament, 223

Fovea articularis superior (atlantis), 167, 190 capitis femoris, 223 dentis, 190

Fovere costales (corporum vertel)rarum), 183 transversales, $175,178,185$

Ginglymus, cochleoid, 166 screw, 166

Gliding joints, 169

Gomphosis, 165 intercarpal, 169

*Groove, preauricular, 216

Harmonia, 164

G.

Hip-joint, 168, 222-227

H.

I.

Incisura clavicularis (sterni), 198

scapulæ, 199, 200

semilunaris (ulnæ), 208, 209

ulnaris (radii), 212

Interlacing tendons in front of the pubic symphysis, see

"Ligament, pubic, anterior"

Interpubic disc, $217,220,22 \mathrm{I}$

Intervertebral discs, see "Discs, intervertebral"

J.

Joint or joints, see also "Articulation" :

ball-and-socket, 168

compound, 169

condyloid, 167

elbow, 169, 204-208

hinge, 166,169

knee, 228-237

mediotarsal, 249

pivot, 169

saddle, 167,169

simple, $166-168$

trochoid, 169

Juncturæ ossium extrenitatis inferioris, 216-250 trunci, 17I-187

superioris, $198-215$

K.

Knee-joint, 228-237

L.

Labrum glenoidale, 168

articulationis coxæ, 223-225, 227 humeri, 201, 203

Lanina fibrocartilaginea interpubica, 21 7, 220, 221

Ligament or ligaments: acronioclavicular, superior, 199, 201 alar, 234, 235

of the ankle-joint:

anterior, 242, 244, 250

astragalofibular, anterior, 244,245

posterior,
astragalonavicular, $242-245$ posterior, $239,24 \mathrm{r}$

astragalotibial, anterior, 243 posterior, $240,241,243$

calcaneofibular, 239-24I, 244, 245

calcaneotibial, 239-242

capsular, $240,242,250$

deltoid, $239-245,248,249$

lateral, external, 239-24I, 244, 245

posterior, 240

internal, 239-245, 248, 249

tibionavicular, $242,244,245,248$

annular, of radius, $169,204,205,207-209$ 
Ligament or ligaments :

astragalocalcaneal, *anterior, $244,245,250$

capsular, 239-24I

external, 245

internal, 243,248

interosseous, 239, 244, 245 , 249,250

posterior, 240, 242

of the atlas, cruciform, 19I, I92

transverse, $190-19^{2}$

of the base of the skull, 196

of Bigelow, 222, 224, 226, 227

calcaneocuboid, dorsal, 244, 245, 248

inferior, $242,243,245-247,250$

plantar, 242, 243, 245-247, 250

calcaneonavicular, internal:

superior, $244,245,248$

inferior portion, $242,243,246,248$

middle portion, $242,243,247,248$, and note p. 248

superior portion, 242

capsular, I66-I68, I70 (see also "Capsule or capsules")

of the elbow-joint, 204-208

of the hip-joint, fibrous portion, 224 synovial portion, 224

of the shoulder-joint, 199, 200, 203

of the temporomandibular articulation, I94, 196

of the temporomaxillary articulation, I94, 196

of the carpus, annular, anterior, 2 I I-2I3

palnar, 2 I 2

carpometacarpal, $210-214$

$$
\begin{aligned}
& \text { anterior, } 2 \mathrm{I} \text { I, } 2 \mathrm{I} 2 \\
& \text { dorsal, 2I0, } 213 \\
& \text { interosseons, } 2 \mathrm{I} 4 \\
& \text { palmar, 2I I, } 2 \mathrm{I} 2 \\
& \text { posterior, } 2 \mathrm{IO}, 2 \mathrm{I} 3
\end{aligned}
$$

central, of the spinal cord, I79

coccygeal, lateral, i 79, I8o

conoid, I99, 202

Cooper's, 221, 224

coraco-acrollial, I70, 199, 200, 202

coracoclavicular, 199,202

coracohumeral, 199, 200

coracoscapular, I70, 199, 200, 202

costoclavícular, $186,188,198$

costocentral, anterior, $176,178,182,183$

interarticular, $182,183,185$

stellate, I76, I $78,182,183$

costotransverse, anterior superior, 176,183 midelle, 182 posterior, I $82,184,185$ posterior superior, 184

cotyloid, 223-225, 227

crucial, 229, 233, 235-237

of the knee, 229, 233, 235-237

cruciform, of the atlas, 19I, I 92

cubocuneiform, dorsal, 244, 245, 248 interosseous, 249, 250 plantar, 246, 247

of the elbow-joint, anterior, 204, 205 capsular, 204-208 external lateral, 204, 205, 207 internal lateral, 204-206

glenoid, I68 posterior, 206, 207

of the hip-joint :

capsular, I68, 222, 223, 226, 227

cotyloid, 223-225, 227

iliofemoral, 222, 224, 226, 227

interarticular, $169,223-225,227$

ischiocapsular, 222, 226, 227

pubofemoral, 222, 224, 226, 227

round, $169,223-225,227$

teres, $169,223-225,227$

traisverse, of acetabulum, 168, 223, 225, 227
Ligament or ligaments:

of the hip-joint :

Y, of Bigelow, 222, 224, 226, 227

zona orbicularis, $223,224,226,227$

iliofemoral, 222, 224, 226, 227

iliolumbar, I $76,216,218,224$

interarticular, of the lip-joint, 169, 223-225, 227

interclavicular, 157,158 , 198

intercuneiform, dorsal, $244,24 \mathrm{~S}$

interosseous, 249

intermetacarpal, distal, anterior, 2 I I

palmar, 2 I I

proximal, anterior, 2II, 212

dorsal, 2 IO, 2 I 3

interosseous, 214

palmar, 2II, 212

intermetatarsal, distal, dorsal, 248 posterior, 210,213 vlantar, 246

proximal, dorsal, 244, 245, 248, 249

plantar, 246, 247

interosseons, of the forearn1, 209

of the leg, 228, 229, 231-235, 238-24I

interspinous, $163,174,177,18$ I

intertransverse, 184

ischiocapsular, 222, 226, 227

of the knee-joint, 228-237

alar, 234, 235

capsular, 228, 230-233, 236, 237

crucial, anterior or external 229, 233 , 235-237

internal or posterior, 229, 233, 235-237

Jateral, external, 228, 229, 23 I-235

posterior, 23I, 232 arcuate portion of the, 232

direct portion of

short, 23I, 232 the, 231, 232

internal, 228-230, $232,233,235,236$

mucous, 234, 235

patellar, 228-23I, 236

lateral, external, 228,231

internal, 228,230

posterior, 232, 235

semilunar fibrocartilages :

external, $229,233, \mathbf{2 3 5 - 2 3 7}$ posterior or ascending band of the, 233 . 235-237

internal, 229, 233, 235.237 transverse ligament of the, 229 , 237

Wrisberg's, 233, 235-237

lateral, of the finger-joints, I66, 2IO, 2I I, 2 I 4 of the metacarpophalangeal articulation of the thumb, 210

of the nietacarpophalangeal articulations, $166,167,210,214$

of the nietatarsoplialangeal articulations, 266-268

of the toe-joints, 247,248

metacarpal, transverse, 211

metacarpoplialangeal, anterior, 2I I, 215 glenoid, 211,215

metatarsal, traissverse, 246 palınar, 2II, 2 I 5

tuetatarsocuneiform, interosseous, 249

metatarsoplialangeal, 246, 247

nincous, 234, 235

inferior, 250 , and note, p. 246

naviculocuboid, dorsal, $244,245,248$

plantar, 246,247

naviculocuneiform, dorsal, 242-245, 248

oblique radio-ulnar, 209 plantar, 247

obturator, II 7,2 I8, 222, 224, 226 
Ligament or liganents:

occipito-atlantal, anterior, 176, I81, 192, 193 posterior, $181,192,193$

occipito-axial, posterior or long, $177,190-192$

odontoid, alar, 191, 192

clieck, I9I, IO2

Jateral, I9I, I92

t11iddle, I91, 192

suspensory, 191, 192

orbicular, of the radius, $169,204,205,207-209$

patellar, $228-231,236$ lateral, external, 228, 23 I

internal, 228, 231

of the pelvis, transverse, 220, 22I, and note, p. 22 I

pisintetacarpal, 2II, 212

pisi-uncinate, 211,212

plantar, long, $242,243,245,246,24 \%$ short, 247,250

pterygospinons, 195,196

pubic, anterior, note, p. 220

of Astley Cooper, 221, 224

inferior, 2I 7, 21S, 220, 221

posterior, note, p. 22 I

subpubic, 217, 21 8, 220, 22 I

superior, 220, 221

puivofen10ral, 222, 224, 226, 227

rhomboid, 186,188 , 198

round, of the lip-joint, I69, 223-225, 227

sacrococcygeal, anterior, 18o, 216

interarticular, $177,179,180$

lateral, 177,179 , I8o

posterior, deep, 177, I 79, I8o superficial, I80, 218

sacio-iliac, anterior, $216,217,219,244$

interosseous, note, p. 218

long, $2 \mathrm{LS}$

oblique, 218

posterior, 218,219

sacrosciatic, anterior, 176, 180, 216-219

great, $176,216-219$

posterior, $176,216,219$

s111all, 176, 180, 216-219

splenontundibular, 195

splienomaxillary, i95

of the spine, I72-I8I

"tinoglenoid, 200

sternoclavicular, $186,187,198$

sty'lohyoid, I94, 195

sty"lonandibular, I95

stylo:l1axillary, 195

subflava, $173-175,192$

supraseapular, 170, 199, 200, 202

supraspinous, $173,174,177,181,184,218$

tarsometatarsal, dorsal, 242, 244, 245, 248

interosseous, 249

of the tarsus, dorsal, 244,245 plantar, 246, 247

interosseous, 249

plantar, 246

temporomandibular, 19.4

temporonaxillary, Ig4

tibiofibular, anterior inferior, $238,244,245$ superior, $228,229,23 \mathrm{~J}, 234$, 237,238

posterior inferior, 240,241

transverse, of the acetabulum, 168, 223, 225, 227

of the atlas, 190-192

of the transverse carpal articulation, 2 J0.2 4

anterior, 212

dorsal, $2 \mathrm{IO}, 213$

interosseous, 21 3, 214

palunar, 212

posterior, 210,213

trapezoid, 202

iriangular, of the uretlira, 220, 221, and note, p. 221

vaginal; of the toes, 246

of the vertebral columu, $172-181$
Ligament or ligaments:

of the vertebral column, anterior common, ${ }^{73}$, I $74,176,178,181-183$, 216

posterior contmion, I73, $174,177,179,190,192$

of the wrist-joint, anterior, 211,212 aniular, 21 I-213

dorsal, 2 Io

lateral, exterual, 210, 213,214 internal, $210-212,214$

palniar, 211,212

posterior, 2 to

Ligamentum vel liganienta :

accessoria plantaria, 246, 247, 250

volaria, 211,215

acrouloclaviculare, 199,201

alaria, 19I, I92

anunlare radii, $169,204,205,207-209$

apicis dentis, 191, 192

arcuatum pubis, $217,218,220,221$

basinm (ossium netaearpalium) dorsalia, 210 , 213

(osium netacarpalium) interossea, 214 volaria, I2 I, 2 I2

(ossinm metatarsalium) dorsalia, 244 , $245,248,249$

(ossiun1 metatarsalium) plantaria, 246, 247

bifurcatum, $245,248,249$

calcaneocuboideum dorsale, $244,245,248$

plantare, $242,243,246$, 247,250

calcaneofibulare, 239-241, 244, 245

calcaneonaviculare dorsale, 242

calcaneotibiale, 239-242

plantare, $242,243,246.248$

capituli costa interarticulare, $182,183,185$ radiatum, $176,178,182,183$

fibule, $228,229,23 \mathrm{I}, 234,237,238$

caysitulorum (ossiun metacarpalium) trans. versa, 211

(ossium metatarsalium) dorsale, $24^{8}$

carpi radiatum, 2 I2

trans. versa, 246

transversu111, 21 1-213

carpometacarpea dorsalia, 210, 213

interossea, 214

volaria, 2 II, 212

coccygenm laterale, I79, ISo

collaterale carpi radiale, 210, 213, 214 uliare, 2 I0-212, 214

fibulare, 228, 229, 23I-235

radiale, $204,205,207$

tibiale, $228-230,232,233,235,236$ ulnare, $204-206$

collateralia articulationum digitorum(manus), $166,210,211,214$

articulationum digitorum pedis, 247,248

articulationis metacarpo. phalangere pollicis, 210

articulationun netacarpophalangearum, 166, 167, 210, 214

artieulationum inetatarsoplial: 1

colli costa, 182 gearuin, $246 \cdot 248$

columna vertebralis, I72-I8I

conoideum, 199, 202

coraco-acroniale, 170, 199, 200, 202

coracoclaviculare, 202

coracoliumerale, J99, 200

costoclaviculare, IS6, 188,198

costotransversarinm anterins, I 76, 183

costoxiphoidea, IS6

posterius, 181

cruciatum anterius, 229, 233, 235-237 atlantis, I9I, 192 
Ligamentum vel ligamenta:

cruciatun1 posterius, 229, 233, 235-237

cruciata (gellu), 229, 233

cuboideonaviculare dorsale, $244,245,2.48$ plantare, 246,247

cuneocuboideun clorsale, $244,245,248$ interosseum, 249. 250 plantare, 246,247

cuneometatarsen interossea, 249

deltoideum, 242, 243, 249

flava, $173-175,192$

iliofenorale, 222, 224, 226, 227

iliolumbale, $176,216,21 \mathrm{~S}, 224$

intercarpea dorsalia, 210,213

interossea, 213, 214

volaria, 212

interclaviculare, $187,188,198$

intercostalia externa, 186 interna, $176,183,184,187$ jutercuneifornia dorsalia, 244,248
interossea, 249

interspinalia, $163,174,177,181$

intertransversaria, 184

ischiocapsulare, 222, 226, 227

longitudinale anterius, $173,174,176,178$, $181-183,216$ posterit1s, $173,174,177,179,190$, 192

luubocostale, I76, 216, 218

malleoli lateralis anterius, 238, 244, 245 posterins, 240, $24 \mathrm{I}$

menisci lateralis (Roberti), 233, 235-237

navicularicuneiformia dorsalia, $2.42-245,24 \mathrm{~S}$

nuchre, $177,18 \mathrm{r}$ plantaria, 247

patella, 228.231, 236

pisohaniatum, $21 \mathrm{t}, 212$

pisometacarpeum, 211, 212

plantare longuw1, 245-247

popliteum arcuatum, 232 obliquum, 232, 23.5

pterygospinosun1, 195, 196

pubicum superius, 220, 221

pubocapsulare, $222,224,226,227$

radiocarpeutu dorsale, 210

$$
\text { volare, } 211,212
$$

sacrococcygeun anterius, ISo, 216 articulare, $177,179,180$ laterale, $177,179,180$

posterius profundum, 177 , 179, I 80 superficiale, 180 , 181

sacro-iliaca anteriora, 216, 217, 219, 224 interossea, 218, 219

sacro-iliacum posterius breve, 219

sacrospinosum, I76, I $80,216-219$

longum, 218,219

sacrotuberosum, I 76, 216-219

sphenomandibulare, 195

sternoclaviculare, I86, 187,198

sternocostale interarticulare, 188

sternocostalia radiata, 186

stylohyoideum, 194, 195

stylomandibulare, 194-196

supraspinale, 173,174, 177, 181, 184, 218

talocalcaneum anterius, 244, 245, 250

interosseun, 239, 244, 245, 249, 250

laterale, 245

mediale, 243,248

posterius, 240,242

talofibulare anterius, 244,245

posterius, 239,24 I

talonaviculare (dorsale), 242-245

tarsi dorsalia, 244, 245

interossea, 249

plantaria, 246

tarsometatarsea dorsalia, 242, 244, 245, 248

interossea, 249
I,igamentum vel ligamenta :

tarsouletatarsea plantaria, 246, 247

temporoniandibulare, 194

teres femoris, $169,223-225,227$

tibionaviculare, $242,244,245,248$

transversum acetabuli, $168,223,225,227$ atlantis, $190-192$ genu, 229, 237

pelvis, 220, 22I

scapula inferius, 200

superius, 170, 199, 200,

trapezoideum, 202

202

Line, Chopart's, 249

costr, 182, 184, I85

Hey's, 249

Lisfranc's, 249

unediotarsal, 249

M.

† Membrana atlanto-epistrophica, 192

atlanto-occipitalis anterior, 176, 181, 192, 193

interossea antibrachii, 209 posterior, 181, 192, 193 cruris, 238

obturatoria, II $7,218,222,224, .26$

sterni, 186, 187

tectoria, 177, 190-192

Nembrane, intercostal, see "Apoueurosis"

interosseous, of the forearm, 209

of the leg, 228, 229, 231-235, 238$24 \mathrm{I}$

obturator, $117,218,222,224,226$

synovial, of the hip-joint, 223-22.5; 227 ; its reflection on the neck of tne femur, 224

Meniscus lateralis, 229, 233, 235-237 of the knee-joint, 234, 235

inedialis, $229,233,235-237$

MI usculus articularis genu, 228, 230, 231, 235

N.

Notcli, clavicular, of the stermun, ig8 cotyloid, 223-225

suprascapular, 199, 200

Nucleus pulposus of the intervertebral dises, $: 3,174$

\section{O.}

Olsturator canal, 21 7, 222, 224, 226

fascia, 221

ligament, $I I 7,218,222,224,226$

nembrane, i1 $7,218,222,224,226$

Ossa sesamoidea lianus, $210,211,214$

pedis, $246,247,250$

Os sesamoideum articulationis genu (var.), 232

\section{P.}

Parl of fat of the fossa acetabuli, 223

l'eriosteum, dental, 165

l'late, fibrous, 246, 247, 250, and notes, pp. 211 and 246 glenoich, 246, 247, 250, and notes, pp. 21 I and 246 sesamoid, $246,247,250$, and notes, pp. 2 I I and 246

I'lica alares, 234,235

liica syllovialis (articulationis radiocarper), 213 patellaris, 234, 235

loucl of synovial membraue, circular, of the proxinal radiouluar articulation, 204, 207, and note, p. 204

vertical, of the distal rarlioulnar articulation, 214

Process, falciform, of the great sacrosciatic ligament, 217

Prccessuts falciformis, 217

Proninence of the pubic symplyysis, posterior, 22 I

Proninontorinin, 177, 216, 21 7, 219

1'romontory of the sacrim, 177, 216, 217, 219

l'ubic sympliysis, 218, 220, 22 ! 
R.

* Recess, sacciforn, of the distal radio-ulnar articulation, 214 of the proximal radio-uluar articulation, 204. 207, and note, p. 204

Recessus sacciformis (articulationis radio-ulnaris distalis) 214 (articulationis radio-ulnaris proxi

Reticaculun liganenti nialis), 204, 207 patelle laterale, 228,231 , mediale, 22S, 330

\section{$\mathrm{S}$.}

Sacral promontory, 117, 216, 217, 219

Siesdnuid bones, see "Bones, sesamoid" of the foot, $2.46,2.47,250$ of the liand, 210, 2II, 214 , and note, p. 211

Sliouliler-joint, I68, 200-203

Substance, sutural; 164

Sulcus paraglenoidalis (preauricularis), 216

Sufface, articular, of tlie acetabulum; I68, 224, 225, 227 of the acronion, 201

of the astragalus for the os culcis, anterior 248

of the astragalus for the os calcis, midlde, 248

of tlie astragalus for the os calcis, posterior, 248

of the atiss, superior, 167,190

of the centra for the ribs, 183

of the lieads of the ribs, $\mathrm{IS}_{2}$

of the navicular bolle, posterior, 248

of the odontoid process, anterior, 192

of the os calcis, anterior, 248 posterior, 192 micldle, 248 posterior, 21

o: the patella, 229, 234, 235

of the transverse processes for the ribs,

$175,178,185$
of the astragalis, superior articular:

external malleolar portion, I66

internal malleolar portion, $166,-4$ ?

tibial portion, $166,241,243$

auricular, of the ilium, 219

Situra, 164

patellar, of the femur, 229, 234, 237

serrata, 164

squamosa, 164

Sutural substance, 164

Suture, rarieties of, 164

Syr11physis, 165

ossiunir pubis; $21 \$, 220,221$

sacrococcygea, ISo, 216,217

Synartlurosis, 164.165

Synchond rosis, 165
Syncliondrosis vel synchondroses:

epiplyysial, see "Disc, epiplyysial"

epiphyseos capitis feuroris, 223

li umeri, 201

capituli ossis metacarpalis III. 215

distalis femoris, 230

fibulae, 239, 240, 244

rartii, 215

tıbix, 239, 240, 242, 244 250

proxinualis fibula, 23 I

tibix, 230, 231

tuberis calcanei, 240

epiplysiuur ossium metatarsalium, 249, 250 phalangun digiti II. (manus), 215

et ligamenta baseos cranii, Ig6

digritor

petro-occipitalis, 193, I96

spheno-occipitalis, $165,192,196$

sphenopetrosa, 196

$+\quad$ sternalis, iuferior, 188

Syudesuosis, I

superior, 188

titiofibularis, 238-241, 244, 245

Synovial niembrane of the shouller-joint, 202, 203

sleath of the bicipital groove, 201, 202

of the tendon of the popliteus muscle, 232, $233,235,237$; its connmunication with tlie knee-joint and the superior tibiofrbular articulation, 233

\section{T.}

Tendon of the long heaf of the biceps muscle, 20r, 202, 203

†Torus pubicus, $22 \mathrm{I}$

Triangular fibrocartilage, $212-214$

ligament of the t1rethra, 220, 221, and note,

Troclilea tali, i66, 22r

facies malleolaris lateralis, 166

superior, '166, 241,243

Trochlear surface of the astragalns, $166,239,241$

V.

Vagina mucosa intertubercularis, 201, 202

W.

Wrist-joint, 169, 2i 2-2 5

Z.

Zowa orbicularis, $223,224,226,227$ 



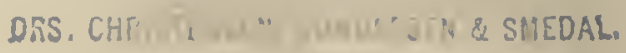

THE IIBRA!? 

